University of Louisville

ThinkIR: The University of Louisville's Institutional Repository

Electronic Theses and Dissertations

$5-2017$

\title{
Homogeneous ligand-centered hydrogen evolution and hydrogen oxidation : exploiting redox non-innocence to drive catalysis.
}

Andrew Z. Haddad

University of Louisville

Follow this and additional works at: https://ir.library.louisville.edu/etd

Part of the Analytical Chemistry Commons, Environmental Chemistry Commons, Inorganic Chemistry Commons, and the Physical Chemistry Commons

\section{Recommended Citation}

Haddad, Andrew Z., "Homogeneous ligand-centered hydrogen evolution and hydrogen oxidation : exploiting redox non-innocence to drive catalysis." (2017). Electronic Theses and Dissertations. Paper 2710.

https://doi.org/10.18297/etd/2710

This Doctoral Dissertation is brought to you for free and open access by ThinkIR: The University of Louisville's Institutional Repository. It has been accepted for inclusion in Electronic Theses and Dissertations by an authorized administrator of ThinkIR: The University of Louisville's Institutional Repository. This title appears here courtesy of the author, who has retained all other copyrights. For more information, please contact thinkir@louisville.edu. 


\title{
HOMOGENEOUS LIGAND-CENTERED HYDROGEN EVOLUTION AND HYDROGEN OXIDATION: EXPLOITING REDOX NON-INNOCENCE TO DRIVE CATALYSIS
}

\author{
By \\ Andrew Z. Haddad \\ B.A. University of Louisville 2012 \\ M.S. University of Louisville 2015
}

\begin{abstract}
A Dissertation Submitted to the Faculty of the College of Arts and Sciences of the University of Louisville in Fulfillment of the Requirements for the Degree of
\end{abstract}

Doctor of Philosophy in Chemistry

Department of Chemistry University of Louisville Louisville, KY

May 2017 
(C) 2017 by Andrew Zahi Haddad

All Rights Reserved 



\section{HOMOGENEOUS LIGAND-CENTERED ELECTROCATALYTIC HYDROGEN EVOLUTION AND HYDROGEN OXIDATION EXPLOITING REDOX NON-INNOCENCE TO DRIVE CATALYSIS}

By

Andrew Z. Haddad

B.A. University of Louisville, 2012

M.S. University of Louisville, 2014

A Dissertation Approved on

April 20, 2017

By the following Dissertation Committee

Advisor: Dr. Craig A. Grapperhaus

Dr. Robert M. Buchanan

Dr. Richard P. Baldwin

Dr. Gamini Sumanasekra 
For Mom and Yaba 


\section{ACKNOWLEDGEMENTS}

I would first like to thank Professor Craig Grapperhaus for accepting me into his group and providing me guidance over the last five years. Professor Grapperhaus has supported my growth as both a person and a scientist beyond my highest expectations, while also managing to be caring and sincere. I am very thankful for the numerous talks and conferences he has sent me to which have provided me the opportunity to grow outside of the lab by gaining exposure within the broader chemistry community. Additionally, he has provided countless opportunities for me to learn the intricacies of working in academia, and how to think pragmatically. Not only has he been a tremendous mentor to me, but he also gave me the opportunity to pursue my $\mathrm{PhD}$, and for this I will forever be indebted. Professor Grapperhaus is one of the best at his profession that I know, and I so grateful that I've had an opportunity to learn as much as I have from him.

I would like to thank Professor Robert Buchanan for his support and advice over the last five years. I have learned so much from you and have enjoyed some of the most rewarding scientific discussions, in addition to enjoying the many emails, text messages, and general correspondence about research. Your unmatched knowledge of bio-inorganic chemistry and synthetic methods has been one of the most helpful things during the last five years. I also appreciate all the countless times you assisted me in the preparation of manuscripts and your guidance in helping me develop into a proper scientific writer. Most importantly, you showed me how to enjoy research and how to make it into

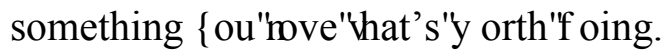


I am extremely grateful to my computational collaborators, Professor Pawel Kozlowski and Brady Garabato. Professor Kozlowski shaped my entire understanding of computational chemistry, and we have enjoyed many fulfilling discussions over the last few years. Without your guidance, I would not have been able to achieve the level of theoretical understanding I currently have. I also owe much to Brady Garabato, who not only served as a sort of computational guide, but is one of my dearest friends. I want to thank you for the incredible support and patience you provided me; I could not have accomplished much of the theoretical work without your insight. You also provided me an outlet outside of lab, where we had fantastic safaris, great scientific debates, as well as thought provoking discussions on life and our future ambitions.

I would also like to thank Dr. Mark Mashuta, who solved many crystal structures for me and provided me with many ideas for growing crystals. Furthermore, I would like to him for welcoming me to his fantastic football tailgates, which provided a great getaway from lab over the last five years.

I would to thank Rajat Chauhan and Davinder Kumar who took me into the Grapperhaus Lab my first year and taught me almost everything I know about electrochemistry and Schlenk line synthesis. Often times, during the first few years when our group was very small, it would just be the three of us in the lab. Those times were incredibly influential, and that is when and where I learned the type of work ethic you need to complete a $\mathrm{PhD}$, as well as how to maintain a lab. I also enjoyed the many discussions we had about world events and history of civilizations. I also would like to thank all of the other members of Grapperhaus Group, past and present. I am grateful for 
their support and friendship over the years, in addition to making my work possible, as all science is built upon the work of those that came before.

I would also like to thank my undergraduate research mentor, Professor Mark Noble. Working in your lab as an undergraduate provided an excellent knowledge base and skill set, which was incredibly helpful while completing my $\mathrm{PhD}$.

I would like to thank Professor Richard Baldwin and Professor Gamini Sumanasekra for serving on my dissertation committee. I would also like to thank Professor Baldwin for being a reliable source of knowledge on all things electrochemistry, and for talking me through various parts of my work and for providing me with insight into certain experimental designs.

Finally, I would like to thank my parents, Zahi and Deborah, and my older brother, David. You all have been the biggest influences on my life and without you I certainly would not be where I am today. I owe so much to you for making every dream I have ever had possible, and proving me with endless, loving support. 


\title{
ABSTRACT \\ HOMOGENEOUS LIGAND-CENTERED HYDROGEN EVOLUTION AND HYDROGEN OXIDATION:
}

\section{EXPLOITING REDOX NON-INNOCENCE TO DRIVE CATALYSIS}

\author{
Andrew Z. Haddad
}

April 20, 2017

Hydrogen is a promising carbon-free fuel / energy carrier and is an essential building block for many industrial and agricultural processes. Rising energy demands have ignited interest in the development of carbon-free and carbon neutral energy sources. In this context, hydrogen is an attractive candidate-being energy-dense, carbon-free-and easily accessible through a two-electron reduction of water. Accordingly, many electrochemical homogeneous catalyst systems have been studied, with a focus on understanding the mechanism of hydrogen evolution proceeding through metal-hydride intermediates. However, there has been a renaissance in hydrogen evolution reaction (HER) catalyst design, with many groups implicating ligand redox non-innocence as a crucial driving force for catalysis rather than metal-hydride formation. In this dissertation, using characterization techniques including, cyclic voltammetry, controlled potential coulometry, UV-visible spectroscopy, ${ }^{1} \mathrm{H}$ NMR, cyclic voltammetry modeling, x-ray crystallography, kinetic isotope effect studies, and density functional theory, we investigate ligand-centered electrocatalysts, which function without 
the generation of metal-hydride intermediates, for the production and oxidation of dihydrogen.

Chapter three expands upon the previous work in the Grapperhaus Lab, and focus on $\operatorname{ReL}_{3}$ ( $\mathrm{L}=$ diphenylphosphinobenzenethiolate). $\mathrm{ReL}_{3}$ reduces acids to $\mathrm{H}_{2}$ in dichloromethane with an overpotential of $0.708 \mathrm{~V}$ and a turnover frequency (TOF) of 32 $\mathrm{s}^{-1}$, and also oxidizes $\mathrm{H}_{2}$ in the presence of base with an overpotential of $0.970 \mathrm{~V}$ and a TOF of $4 \mathrm{~s}^{-1}$. The mechanism is supported by kinetic isotope effect (KIE) studies and density functional theory calculations (DFT). Chapters four and five will build on Chapter three, aiming to develop sustainable approaches for ligand-centered catalysis. The non-transition metal complex, $\mathrm{ZnL}^{1}$, the metal-free complex, $\mathrm{H}_{2} \mathrm{~L}^{1}$, and the transition metal complex, $\mathrm{CuL}^{1}\left(\mathrm{~L}^{1}=\right.$ diacetyl-bis(N4-methyl-3-thiosemicarbazonato)), function as electrocatalysts for hydrogen evolution $\left(\mathrm{ZnL}^{1}, \mathrm{H}_{2} \mathrm{~L}^{1}\right.$ and $\left.\mathrm{CuL}^{1}\right)$ and hydrogen oxidation ( $\mathrm{ZnL}^{1}$ and $\mathrm{H}_{2} \mathrm{~L}^{1}$ ). $\mathrm{H}_{2} \mathrm{~L}^{1}$ and $\mathrm{ZnL}^{1}$ display TOF's of $1,320 \mathrm{~s}^{-1}$ and $1,170 \mathrm{~s}^{-1}$ at overpotentials of 1.43 and $0.756 \mathrm{~V}$, respectively, while the $\mathrm{CuL}^{1}$ complex demonstrates a TOF of $10,000 \mathrm{~s}^{-1} \cdot \mathrm{H}_{2} \mathrm{~L}^{1}$ and $\mathrm{ZnL}^{1}$ also display TOF values for $\mathrm{H}_{2}$ oxidation of $32 \mathrm{~s}^{-1}$ and $72 \mathrm{~s}^{-1}$ at overpotentials of 0.328 and $0.315 \mathrm{~V}$, respectively. Mechanisms for the HER were modeled using digital simulations and are further supported by DFT calculations.

$$
\mathrm{ReL}_{3}, \mathrm{ZnL}{ }^{1}, \mathrm{H}_{2} \mathrm{~L}^{1} \text {, and } \mathrm{CuL}^{1} \text { represent a fundamentally new class of }
$$
electrocatalysts. Contrary to traditional molecular electrocatalysts that employ a metalhydride as the key mechanistic intermediate, this approach facilitates $\mathrm{H}_{2}$ evolution through ligand-centered proton and electron-transfer events resulting in the evolution of $\mathrm{H}_{2}$ through either ligand-centered $\mathrm{H}^{\bullet}$ radical coupling or ligand-centered hydride proton coupling. 


\section{TABLE OF CONTENTS}

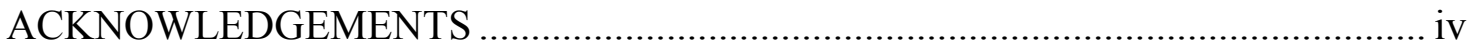

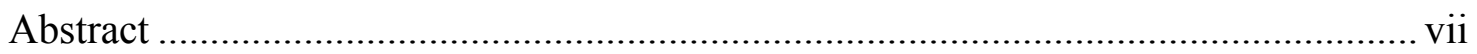

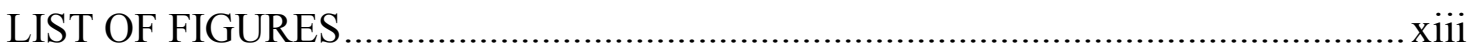

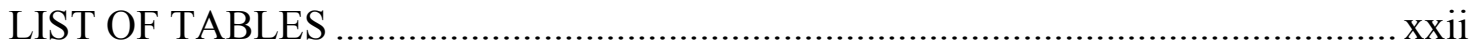

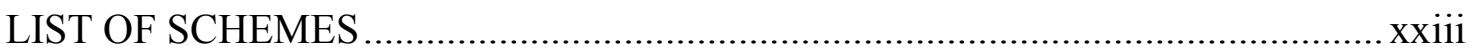

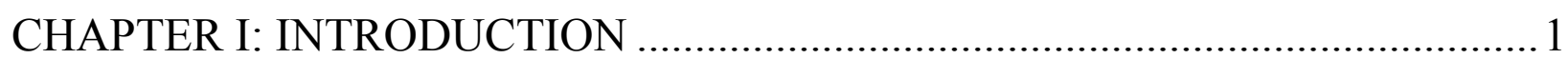

1.1. Hydrogen: Importance and Background ...................................................... 2

1.2. Hydrogenase and Biomimetic Hydrogenase Complexes ..................................... 3

1.3. Mechanistic Features of $\mathrm{H}_{2}$ Evolution and Oxidation........................................ 9

1.4. Ligand-Centered HER Electrocatalysts ........................................................... 10

CHAPTER II: EXPERIMENTAL DETAILS ........................................................ 14

2.1. Materials and Physical Methods ...................................................................... 15

2.2. Crystallographic Details ............................................................................ 15

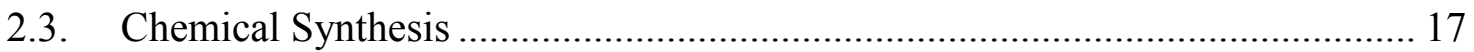

2.4. Electrochemical Methods ......................................................................... 19

2.5. Overpotential Determination and Calculations ................................................ 23

2.6. $\mathrm{ReL}_{3}$ : Determination and Calculation of Third-Order Rate Constant, $k$, from Pseudo First-Order Rate Constant $k_{o b s}$, and estimation of Turnover Frequency (TOF) for $\mathrm{H}_{2}$ Evolution and Oxidation ............................................................................ 25

2.7. $\mathrm{ZnL}^{1}$ and $\mathrm{H}_{2} \mathrm{~L}$ : Determination and Calculation of TOF for $\mathrm{H}_{2}$ Evolution and

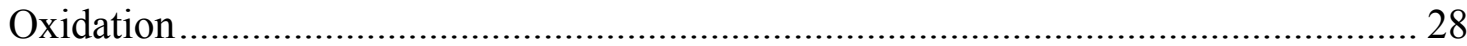

2.8. $\mathrm{CuL}^{1}$ : Determination and Calculation of TOF for $\mathrm{H}_{2}$ Evolution ....................... 29

2.9. $\mathrm{ReL}_{3}$ : Quantification of $\mathrm{H}_{2}$ from Controlled Potential Coulometry (CPC) and Calculation of Turnover Number and Faradaic Efficiency ............................................ 30

2.10. $\mathrm{ZnL}^{1}$ : Quantification of $\mathrm{H}_{2}$ from $\mathrm{CPC}$ and Turnover Number and Faradaic Efficiency Calculations …………………………………………………………..... 32

2.11. $\mathrm{CuL}^{1}$ : Quantification of $\mathrm{H}_{2}$ from Controlled Potential Coulometry and Turnover Number and Faradaic Efficiency Calculations.............................................. 33

2.12. Determination and Calculation of Diffusion Coefficients, $\mathrm{D}_{0}$, for $\mathrm{ZnL}^{1}$ and

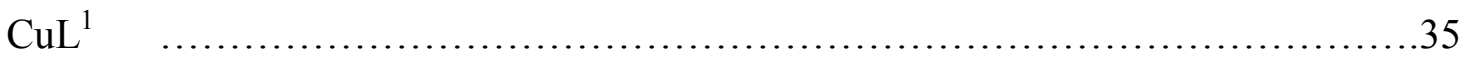

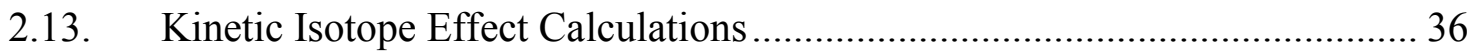




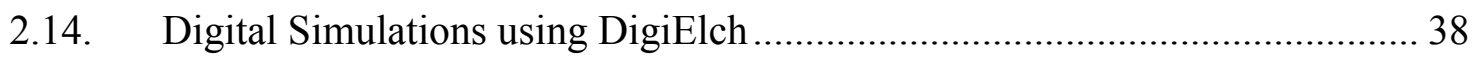

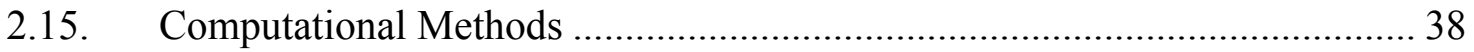

CHAPTER III: LIGAND-CENTERED ELECTROCATALYTIC HYDROGEN EVOLUTION AND HYDROGEN OXIDATION

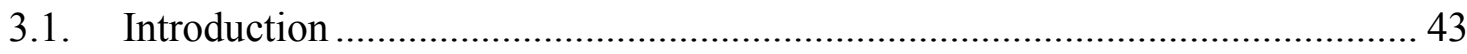

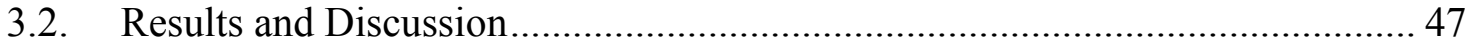

3.2.1. Cyclic Voltammetry HER and HOR Studies and X-ray Crystallography...... 47

3.2.2. Controlled Potential Coulometry and Gas Product Analysis ......................... 54

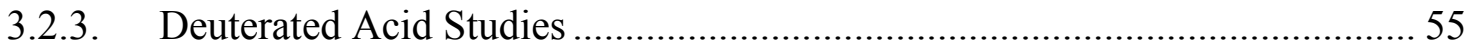

3.2.4. Mechanism Discussion and Theoretical Insight ............................................ 56

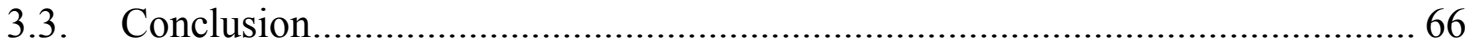

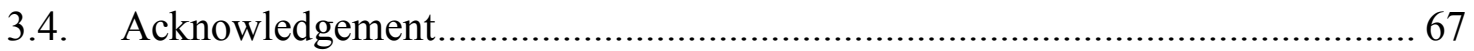

CHAPTER IV: SUSTAINABLE METAL ALTERNATIVES FOR LIGAND-CENTERED $\mathrm{H}_{2}$ EVOLUTION AND HYDROGEN OXIDATION .....68

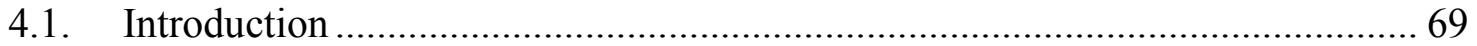

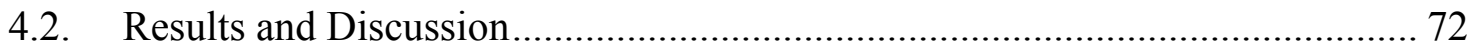

4.2.1. $\quad \mathrm{ZnL}^{1}$ Cyclic Voltammetry Characterization................................................ 72

4.2.2. $\mathrm{ZnL}^{1}$ Cyclic Voltammetry Hydrogen Evolution and Hydrogen Oxidation

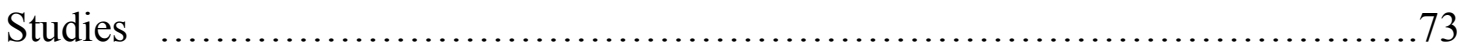

4.2.3. $\mathrm{H}_{2} \mathrm{~L}^{1}$ Cyclic Voltammetry Hydrogen Evolution and Hydrogen Oxidation

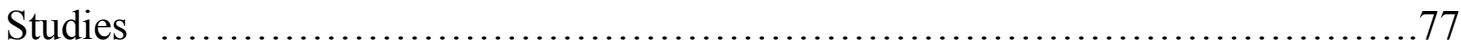

4.2.4. $\mathrm{ZnL}^{1}$ Extended Stability and Gas Identification: Controlled Potential

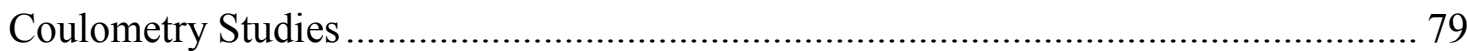

4.2.5. $\mathrm{ZnL}^{1}$ Mechanism Evaluation: Digital Simulations, Isotope Effect Studies ... 81

4.2.6. $\quad \mathrm{ZnL}^{1}$ Density Functional Theory Study........................................................ 83

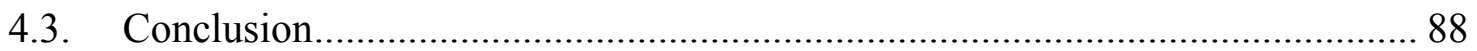

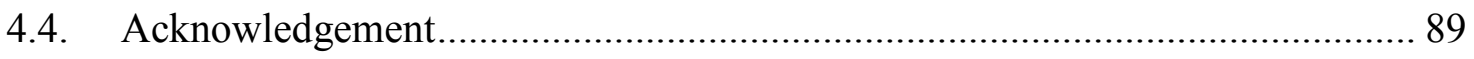

CHAPTER V: TRANSITION METAL ASSISTED LIGAND-CENTERED $\mathrm{H}_{2}$ EVOLUTION.

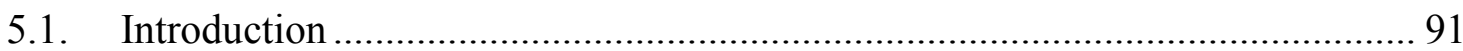

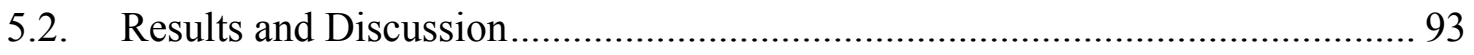

5.2.1. CuL $^{1}$ Cyclic Voltammetry HER Studies ........................................................ 93 
5.2.2. $\mathrm{CuL}^{1}$ Extended Stability: Controlled Potential Coulometry and Gas

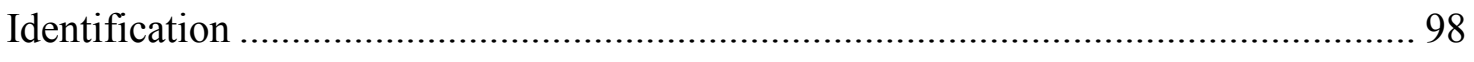

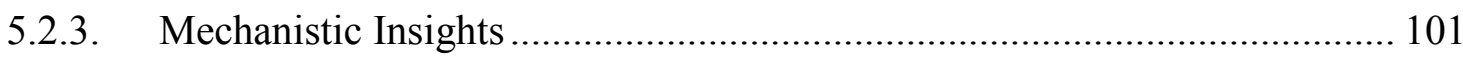

5.2.4. $\quad \mathrm{CuL}^{1}$ Density Functional Theory Study ........................................................ 104

5.2.5. Overview of $\mathrm{CuL}^{1}$ and Comparison with $\mathrm{ZnL}^{1}, \mathrm{H}_{2} \mathrm{~L}^{1}$ and Other HER

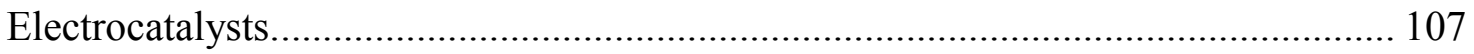

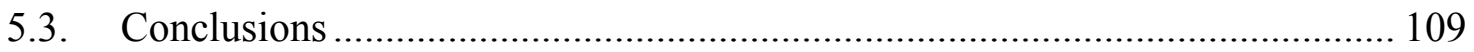

5.4. Acknowledgement .................................................................................. 110

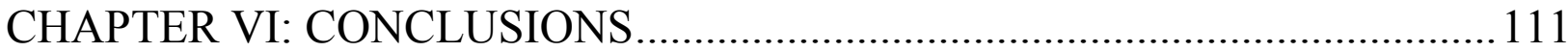

6.1. Ligand-Centered Electrocatalytic Hydrogen Evolution and Hydrogen Oxidation 112

6.2. Sustainable Metal Alternatives for Ligand-Centered $\mathrm{H}_{2}$ Evolution Oxidation 114

6.3. Transition Metal Assisted Ligand-Centered $\mathrm{H}_{2}$ Evolution ............................ 117

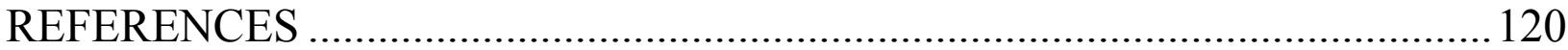

APPENDIX A: CYCLIC VOLTAMMETRY SIMULATION

PARAMETER TABLES AND DIGIELCH GUIDE ......................................... 128

APPENDIX B: EXPERIMENTAL AND SIMULATED CYCLIC

VOLTAMMOGRAMS

APPENDIX C: ADDITIONAL ELECTROCHEMICAL AND UV-VIS

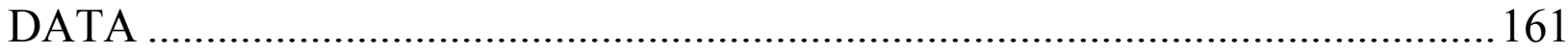

APPENDIX D: ADDITIONAL DFT STRUCTURES AND ALL

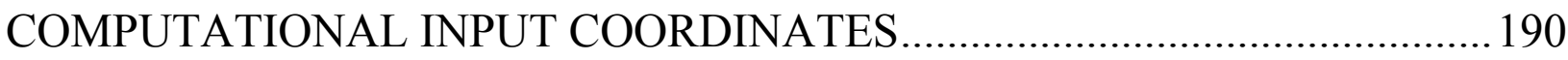

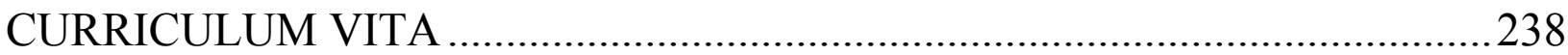




\section{LIST OF FIGURES}

Figure 1. Percent of global hydrogen use by industry. ${ }^{17}$

Figure 2. (Top) Structures of the $[\mathrm{NiFe}]$ hydrogenase ${ }^{22}$ and of the $[\mathrm{FeFe}]$ hydrogenase from Dd. ${ }^{23}$ (Bottom) the chemical structures of the active sites of the two types of hydrogenases are given; the arrows indicate the open metal coordination sites.

Figure 3. Postulated catalytic mechanism for reversible $\mathrm{H}^{+}$reduction by [FeFe]hydrogenases, the location of the proton in the $\mathrm{H}_{\text {red }}$ and $\mathrm{H}_{\text {sred }}$ state is undetermined, adapted from reference $53 .^{40}$.

Figure 4. Synthetic scheme for the preparation of $\left[(\mu-\mathrm{SEt})_{2} \mathrm{Fe}(\mathrm{CO})_{6}\right](\mathrm{left})$, and precursor diiron hexacarbonyl complex (middle) used in route to the first true [FeFe] hydrogenase

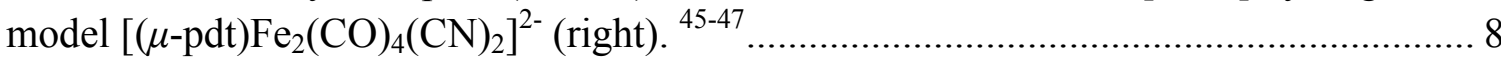

Figure 5. Illustration of two potential routes for $\mathrm{H}_{2}$ evolution following either a homolytic or heterolytic pathway.

Figure 6. Illustration showing the four traditional reaction pathways observed with redox non-innocent ligands in catalysis $(\mathrm{S}=$ substrate)....

Figure 7. Double slope plot for evaluation of the third-order rate constant, $k$.

Figure 8. Cyclic Voltammogram (CV) of $0.3 \mathrm{mM} \mathrm{ReL}_{3}$ in $0.1 \mathrm{M} \mathrm{Bu}_{4} \mathrm{NPF}_{6} \mathrm{CH}_{2} \mathrm{Cl}_{2}$ solutions.

Figure 9. (A) Calculated "p-type" lone-pair orientation of $\left[\mathrm{M}(\mathrm{SP})_{3}\right]^{\mathrm{n}}$ enforced by meridional PS chelates. (B) Proposed interactions of $\left[\mathrm{M}(\mathrm{SP})_{3}\right]^{\mathrm{n}}$ frontier orbitals with LUMO (top) and HOMO (bottom) of $\mathrm{C}_{2} \mathrm{H}_{4}$. (C) HOMO/LUMO symmetries of $\mathrm{H}_{2} \ldots \ldots . .46$ Figure 10. $\mathrm{CV}$ of $\mathrm{ReL}_{3}$ with excess $\mathrm{CH}_{3} \mathrm{CO}_{2} \mathrm{H}$ added in $0.1 \mathrm{M} \mathrm{Bu}_{4} \mathrm{NPF}_{6} \mathrm{CH}_{2} \mathrm{Cl}_{2}$ solution.

Figure 11. (Left) Labeled ORTEP ${ }^{162}$ of $\left[\mathrm{Re}(\mathrm{LH}) \mathrm{L}_{2}\right]^{+}$from $\left[\mathrm{Re}(\mathrm{LH}) \mathrm{L}_{2}\right] \mathrm{PF}_{6}$. (Right) Labeled ORTEP ${ }^{162}$ of $\left[\operatorname{Re}(\mathrm{LH}) \mathrm{L}_{2}\right]^{+}$from $\left[\operatorname{Re}(\mathrm{LH}) \mathrm{L}_{2}\right] \mathrm{O}_{3} \mathrm{SCF}_{3}$. 48

Figure 12. Cyclic Voltammograms of $0.3 \mathrm{mM} \mathrm{ReL}_{3}$ in $0.1 \mathrm{M} \mathrm{Bu}_{4} \mathrm{NPF}_{6} \mathrm{CH}_{2} \mathrm{Cl}_{2}$ solution showing $\mathrm{H}_{2}$ evolution upon successive additions of $\mathrm{CH}_{3} \mathrm{CO}_{2} \mathrm{H}$. Inset: Plot of catalytic current vs $\mathrm{CH}_{3} \mathrm{CO}_{2} \mathrm{H}$ concentration, showing acid saturation above $0.4 \mathrm{M} \mathrm{CH}_{3} \mathrm{CO}_{2} \mathrm{H}$... 50 Figure 13. Open circuit potential for the reduction of protons to acetic to $\mathrm{H}_{2}$ with $0.4 \mathrm{M}$ $\mathrm{CH}_{3} \mathrm{COOH}$ added to $0.1 \mathrm{M} \mathrm{Bu}_{4} \mathrm{NPF}_{6} \mathrm{CH}_{2} \mathrm{Cl}_{2}$ solution.

Figure 14. Peak Current vs. $\left[\mathrm{ReL}_{3}\right]$ using weak acid $\left(\mathrm{CH}_{3} \mathrm{CO}_{2} \mathrm{H}\right)$ at $(\mathrm{A}) 0.2$, (B) 0.5, (C) 1 $\mathrm{V} / \mathrm{s}$, and using strong acid $\left(\mathrm{H}_{2} \mathrm{SO}_{4}\right)$ at (D) $0.2(\mathrm{E}) 0.5,(\mathrm{~F}) 1.0 \mathrm{~V} / \mathrm{s}$

Figure 15. $\mathrm{CV}$ showing $\mathrm{H}_{2}$ oxidation upon successive additions of triethylamine to 0.3 $\mathrm{mM} \mathrm{ReL}_{3}$ in $0.1 \mathrm{M} \mathrm{Bu}_{4} \mathrm{NPF}_{6} \mathrm{CH}_{2} \mathrm{Cl}_{2}$ solution under 1 atm of $\mathrm{H}_{2}$ gas. 53 
Figure 16. Plot of charge vs time recorded during the controlled potential coulometry of $0.3 \mathrm{mM} \mathrm{ReL}_{3}$ for 1.5 hours (blue) and 6 hours (red) in the presence of $\mathrm{CH}_{3} \mathrm{CO}_{2} \mathrm{H}$. Inset: Gas chromatography thermal conductivity (GC-TCD) readout of headspace analysis during electrolysis.

Figure 17. Bond lengths $(\AA)$ and angles $\left(^{\circ}\right)$ for $\operatorname{ReL}_{3}$ from $S=0$ and $S=1$ DFT optimizations (M06/LANL2DZ) and the experimental (Exp.) x-ray crystal structure. ${ }^{157}$ $\Delta \mathrm{G}$ indicates relative zero-point free energy ( $\mathrm{kcal} / \mathrm{mole}$ ) values of the $\mathrm{S}=0$ and $\mathrm{S}=1$ electronic states.

Figure 18. Bond lengths $(\AA)$ and angles $\left(^{\circ}\right)$ for $\left[\operatorname{Re}(\mathrm{LH}) \mathrm{L}_{2}\right]^{+}$from $\mathrm{S}=0$ and $\mathrm{S}=1 \mathrm{DFT}$ optimizations (B3LYP/LANL2DZ) and the experimental (Exp.) x-ray crystal structure. ${ }^{9}$ $\Delta \mathrm{G}$ indicates relative zero-point free energy ( $\mathrm{kcal} / \mathrm{mole}$ ) values of the $\mathrm{S}=0$ and $\mathrm{S}=1$ electronic states.

Figure 19. Bond lengths $(\AA)$, bond angles $\left(^{\circ}\right)$, and spin-density percentage contributions for the $\mathrm{S}=1 / 2$ DFT optimizations (M06/LANL2DZ) of (A) $\left[\mathrm{ReL}_{3}\right]^{-}$, (B) $\left[\operatorname{Re}(\mathrm{LH}) \mathrm{L}_{2}\right]^{0}$, and $(\mathrm{C})\left[\mathrm{Re}(\mathrm{LH})_{2} \mathrm{~L}\right]^{+}$.

Figure 20. Bond lengths $(\AA)$ and angles $\left(^{\circ}\right)$ for optimizations (M06/LANL2DZ) of (A) $\left[\operatorname{Re}(\mathrm{LH})_{2} \mathrm{~L}\right]^{0}(\mathrm{~S}=0)$ DFT and (B) $\left[\mathrm{HRe}(\mathrm{LH}) \mathrm{L}_{2}\right]^{0}(\mathrm{~S}=1)$. and (c) $\left[\operatorname{Re}(\mathrm{LH})_{2} \mathrm{~L}\right]^{+} . \Delta \mathrm{G}$ indicates relative zero-point free energy (kcal / mole) values of the $\mathrm{S}=0$ and $\mathrm{S}=1$ electronic states (see appendix for analysis of the singlet $\left[\mathrm{HRe}(\mathrm{LH}) \mathrm{L}_{2}\right]^{0}$ species). .... 63

Figure 21. Transition states and energy profile for HER through Re-dithiol and Rehydride pathways. (A) Representation of TS-[Re( $\left.\mathrm{LH})_{2} \mathrm{~L}\right]$ showing lengthening of two S$\mathrm{H}$ bonds associated with $\mathrm{H}_{2}$ evolution. (B) Representation of TS-[HRe(LH) $\left.\mathrm{L}_{2}\right]$ showing $\mathrm{H}_{2}$ evolution from Re-H and S-H. (C) Comparison of relative energies (ZPE corrected) for Re-dithiol and Re-hydride HER pathways using M06/LANL2DZ.

Figure 22. (A) Transition state geometry of $\left[\operatorname{Re}(\mathrm{LH}) \mathrm{L}_{2}\right]$ along the HER pathway, shown with active $\mathrm{S}-\mathrm{H}$ bond dissociations and $\mathrm{Re}$ atom associated with the imaginary frequency, $i 1113 \mathrm{~cm}^{-1}$. (B) Transition State Analysis of $\mathrm{H}_{2}$ Evolving Complex [Re( $\left.\left.\mathrm{LH}\right)_{2} \mathrm{~L}\right]$. Internal reaction coordinates (IRC) moving through the TS for $\left[\mathrm{Re}(\mathrm{LH})_{2} \mathrm{~L}\right]$ associated with the imaginary frequency $11113 \mathrm{~cm}^{-1}$. (C) Charge densities of sulfur and hydrogen atoms near $\mathrm{H}_{2}$ evolution for $\left[\mathrm{Re}(\mathrm{LH})_{2} \mathrm{~L}\right]$ along the HER pathway with respect to IRC, associated with the imaginary frequency $i 1113 \mathrm{~cm}^{-1}, \mathrm{~S} 3$ / S4 (cyan, magenta) and H5 / H105 (blue, purple). Transition State $\mathrm{S}-\mathrm{H}$ bond lengths $=1.524 \AA$ and $1.532 \AA$. (D) Charge densities of the Rhenium atom near $\mathrm{H}_{2}$ evolution with respect to IRC, associated with the imaginary frequency i1 $113 \mathrm{~cm}^{-1}$, Re1 (red).

Figure 23. (A) Cyclic voltammogram of $\mathrm{ZnL}^{1}$ in $0.1 \mathrm{M} \mathrm{Bu}_{4} \mathrm{NPF}_{6}$ methanol solution (B) Blow up of cathodic region of cyclic voltammogram of $\mathrm{ZnL}^{1}$ in $0.1 \mathrm{M} \mathrm{Bu}_{4} \mathrm{NPF}_{6}$ methanol solution. (C) Cyclic voltammogram of $\mathrm{ZnL}^{1}$ in $0.1 \mathrm{M} \mathrm{Bu}_{4} \mathrm{NPF}_{6}$ acetonitrile solution..... 72 Figure 24. (A) Cyclic voltammogram of $\mathrm{ZnL}^{1}$ in $0.1 \mathrm{M} \mathrm{Bu}_{4} \mathrm{NPF}_{6}$ methanol solution scanned at 0.1 (black), 0.2 (dark blue), 0.3 (purple), 0.4 (blue), 0.5 (green), 0.6 (light 
green). 0.7 (yellow), 0.8 (orange), 0.9 (red) and, 1.0 (black) V/s. (B) Cottrell plot of the peak current plotted against the square root of the scan rate.

Figure 25. (A) Cyclic voltammograms of $3 \mathrm{mM} \mathrm{ZnL}^{1}$ in methanol with no added acid (black), $6 \mathrm{mM} \mathrm{CH}_{3} \mathrm{COOH}$ (blue), $9 \mathrm{mM} \mathrm{CH}_{3} \mathrm{COOH}$ (purple), and $12 \mathrm{mM} \mathrm{CH}_{3} \mathrm{COOH}$ (red). Data collected at a scan rate of $0.5 \mathrm{~V} / \mathrm{s}$ in the presence of $0.1 \mathrm{M} \mathrm{Bu}_{4} \mathrm{NPF}_{6}$ as supporting electrolyte. (B) Plot of $\mathrm{i}_{\text {cat }}$ Vs $\left[\mathrm{CH}_{3} \mathrm{COOH}\right]$ for $3 \mathrm{mM} \mathrm{ZnL}^{1}$ (red) at scan rates of $0.2(\boldsymbol{\Delta}), 0.3(\bullet), 0.4(\mathbf{\bullet})$, and $0.5(\bullet) \mathrm{V} / \mathrm{s}$. 73

Figure 26. (A) Cyclic voltammograms of $3 \mathrm{mM} \mathrm{ZnL}^{1}$ in ACN with no added acid (black), $2.4 \mathrm{mM} \mathrm{CH}_{3} \mathrm{COOH}$ (dark blue), $4.8 \mathrm{mM} \mathrm{CH}_{3} \mathrm{COOH}$ (blue), $7.2 \mathrm{mM} \mathrm{CH}_{3} \mathrm{COOH}$ (light blue), $9.6 \mathrm{mM} \mathrm{CH}_{3} \mathrm{COOH}$ (green), $12.0 \mathrm{mM} \mathrm{CH}_{3} \mathrm{COOH}$ (light green), $14.4 \mathrm{mM}$ $\mathrm{CH}_{3} \mathrm{COOH}$ (yellow), $16.8 \mathrm{mM} \mathrm{CH}_{3} \mathrm{COOH}$ (orange), $19.2 \mathrm{mM} \mathrm{CH}_{3} \mathrm{COOH}$ (red), and 21.6 $\mathrm{mM} \mathrm{CH}_{3} \mathrm{COOH}$ (dark red). Data collected at a scan rate of $0.5 \mathrm{~V} / \mathrm{s}$ in the presence of 0.1 $\mathrm{M} \mathrm{Bu}_{4} \mathrm{NPF}_{6}$ as supporting electrolyte. (B) Plot of $\mathrm{i}_{\text {cat }} \mathrm{vs}\left[\mathrm{CH}_{3} \mathrm{COOH}\right]$ for $3 \mathrm{mM} \mathrm{ZnL}^{1}$ (red) at scan rates of $0.2(\diamond) \mathrm{V} / \mathrm{s}$.

Figure 27. (A) Cyclic voltammograms of $0.3 \mathrm{mM} \mathrm{ZnL}$ in methanol under $1 \mathrm{~atm} . \mathrm{H}_{2}$ with no added base (black), $3 \mathrm{mM}\left(\mathrm{CH}_{3} \mathrm{CH}_{2}\right)_{3} \mathrm{~N}$ (dark blue), $6 \mathrm{mM}\left(\mathrm{CH}_{3} \mathrm{CH}_{2}\right)_{3} \mathrm{~N}$ (light blue), $12 \mathrm{mM}\left(\mathrm{CH}_{3} \mathrm{CH}_{2}\right)_{3} \mathrm{~N}$ (light purple), $21 \mathrm{mM}\left(\mathrm{CH}_{3} \mathrm{CH}_{2}\right)_{3} \mathrm{~N}$ (dark purple), and $30 \mathrm{mM}$ $\left(\mathrm{CH}_{3} \mathrm{CH}_{2}\right)_{3} \mathrm{~N}$ (red). Data collected at a scan rate of $0.5 \mathrm{~V} / \mathrm{s}$ in the presence of $0.1 \mathrm{M}$ $\mathrm{Bu}_{4} \mathrm{NPF}_{6}$ as supporting electrolyte. (B) Plot of $\mathrm{i}_{\text {cat }} / \mathrm{i}_{\mathrm{p}}$ vs $\left[\left(\mathrm{CH}_{3} \mathrm{CH}_{2}\right)_{3} \mathrm{~N}\right]$ for $0.3 \mathrm{mM} \mathrm{ZnL}$

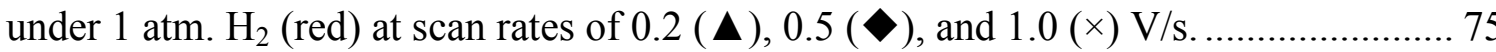

Figure 28. (A) Cyclic Voltammograms of $1.0 \mathrm{mM}$ (black), $1.5 \mathrm{mM}$ (blue), $2.0 \mathrm{mM}$ (light blue), $2.5 \mathrm{mM}$ (magenta), $3.0 \mathrm{mM}$ (red) $\mathrm{ZnL}^{1}$ with $12 \mathrm{mM} \mathrm{CH}_{3} \mathrm{COOH}$ in $0.1 \mathrm{M}$ $\mathrm{Bu}_{4} \mathrm{NPF}_{6}$ methanol solution. (B) Plot of peak current versus $\left[\mathrm{ZnL}^{1}\right]^{2}$.

Figure 29. (A) Cyclic Voltammogram of $\mathrm{H}_{2} \mathrm{~L}^{1}$ in $0.1 \mathrm{M} \mathrm{Bu}_{4} \mathrm{NPF}_{6}$ solution collected at $0.5 \mathrm{~V} / \mathrm{s}$. (B) Blow up showing cathodic scan only of $\mathrm{H}_{2} \mathrm{~L}^{1}$.

Figure 30. (A) Cyclic voltammograms of $3 \mathrm{mM} \mathrm{H}_{2} \mathrm{~L}^{1}$ with no added acid (black), $3 \mathrm{mM}$ $\mathrm{CH}_{3} \mathrm{COOH}$ (blue), $5.8 \mathrm{mM} \mathrm{CH}_{3} \mathrm{COOH}$ (purple), and $7 \mathrm{mM} \mathrm{CH}_{3} \mathrm{COOH}$ (light purple), 8.2 $\mathrm{mM} \mathrm{CH}_{3} \mathrm{COOH}$ (pink) and, $9.8 \mathrm{mM} \mathrm{CH}_{3} \mathrm{COOH}$ (red). Data collected at a scan rate of $0.5 \mathrm{~V} / \mathrm{s}$ in the presence of $0.1 \mathrm{M} \mathrm{Bu}_{4} \mathrm{NPF}_{6}$ as supporting electrolyte. (B) Plot of $\mathrm{i}_{\text {cat }} \mathrm{Vs}$ $\left[\mathrm{CH}_{3} \mathrm{COOH}\right]$ for $3 \mathrm{mM} \mathrm{H}_{2} \mathrm{~L}^{1}$ (blue) at scan rates of $0.2(\boldsymbol{\Delta}), 0.5(\bullet)$, and $1.0(\times) \mathrm{V} / \mathrm{s}$. . 78 Figure 31. (A) Cyclic voltammograms of $0.3 \mathrm{mM} \mathrm{H}_{2} \mathrm{~L}$ in methanol under $1 \mathrm{~atm} . \mathrm{H}_{2}$ with no added base (black), $0.75 \mathrm{mM}\left(\mathrm{CH}_{3} \mathrm{CH}_{2}\right)_{3} \mathrm{~N}$ (blue), $1.5 \mathrm{mM}\left(\mathrm{CH}_{3} \mathrm{CH}_{2}\right)_{3} \mathrm{~N}$ (cyan), $3 \mathrm{mM}$ $\left(\mathrm{CH}_{3} \mathrm{CH}_{2}\right)_{3} \mathrm{~N}$ (light blue), $6 \mathrm{mM}\left(\mathrm{CH}_{3} \mathrm{CH}_{2}\right)_{3} \mathrm{~N}$ (light purple), $9 \mathrm{mM}\left(\mathrm{CH}_{3} \mathrm{CH}_{2}\right)_{3} \mathrm{~N}$ (purple), $12 \mathrm{mM}\left(\mathrm{CH}_{3} \mathrm{CH}_{2}\right)_{3} \mathrm{~N}$ (pink), $15 \mathrm{mM}\left(\mathrm{CH}_{3} \mathrm{CH}_{2}\right)_{3} \mathrm{~N}$ (rose), $18 \mathrm{mM}\left(\mathrm{CH}_{3} \mathrm{CH}_{2}\right)_{3} \mathrm{~N}$ (red) and, $21 \mathrm{mM}\left(\mathrm{CH}_{3} \mathrm{CH}_{2}\right)_{3} \mathrm{~N}$ (dark red). (B) Plot of $\mathrm{i}_{\text {cat }} / \mathrm{i}_{\mathrm{p}}$ vs $\left[\left(\mathrm{CH}_{3} \mathrm{CH}_{2}\right)_{3} \mathrm{~N}\right]$ for $0.3 \mathrm{mM} \mathrm{ZnL}$

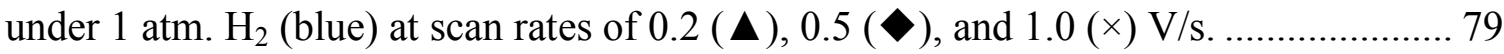
Figure 32. (A) Plot of charge vs time recorded during bulk electrolysis of $0.1 \mathrm{mM} \mathrm{ZnL}^{1}$ and $12 \mathrm{mM} \mathrm{CH}_{3} \mathrm{COOH}$ in methanol with $0.1 \mathrm{M} \mathrm{Bu}_{4} \mathrm{NPF}_{6}$ as supporting electrolyte. (B) Headspace readout of GC-TCD showing $\mathrm{H}_{2}$ as gaseous product at times 30, 60, 90, 120, and 150 minutes during electrolysis. 
Figure 33. (A) UV spectra recorded every 15 minutes during the electrolysis of $1 \mathrm{mM}$ $\mathrm{ZnL}^{1}$ under applied potential of $-1.7 \mathrm{~V}$ in $0.1 \mathrm{M} \mathrm{Bu}_{4} \mathrm{NPF}_{6}$ methanol solution. (B) $\mathrm{CV}$ of $\mathrm{ZnL}$ after electrolysis in $0.1 \mathrm{M} \mathrm{Bu}_{4} \mathrm{NPF}_{6}$ methanol solution with $12 \mathrm{mM}$ acetic acid added. $v=0.2 \mathrm{~V} / \mathrm{s}$ vs $\mathrm{Fc}^{+} / \mathrm{Fc}$.

Figure 34. Comparisons of experimental (solid) and simulated (dotted) cyclic voltammograms for $3 \mathrm{mM} \mathrm{ZnL}^{1}$ and $12 \mathrm{mM} \mathrm{CH}_{3} \mathrm{COOH}$ in methanol with $0.1 \mathrm{M} \mathrm{Bu}_{4} \mathrm{NPF}_{6}$ as supporting electrolyte at scan rates of 0.3 (blue), 0.4 (purple), and 0.5 (red) $\mathrm{V} / \mathrm{s}$....... 82 Figure 35. Concurrent catalytic pathways for hydrogen evolution through homocoupling of neutral $\mathrm{Zn}(\mathrm{HL} \bullet$ ) radicals (red arrows) and heterocoupling of a neutral $\mathrm{Zn}(\mathrm{HL} \bullet$ ) and cationic $\left[\mathrm{Zn}\left(\mathrm{H}_{2} \mathrm{~L} \bullet\right)\right]^{+}$radicals (blue arrows).

Figure 36. Optimized Structure of $[\mathrm{ZnLH}]^{+}$with protonation on the hydrazino nitrogen, B97-D/6-311G(d) 83

Figure 37. DFT optimized structures showing energetic stability of protonated species, $\left[\mathrm{ZnL}{ }^{1} \mathrm{H}\right]^{+}$. 84

Figure 38. Energy profile along with spin densities of species involved in catalyzed $\mathrm{H}_{2}$ evolution. Spin-density profiles for (A) $\mathrm{Zn}(\mathrm{HL} \bullet)$ and (B) $[\mathrm{Zn}(\mathrm{H} 2 \mathrm{~L} \bullet)]+$. (C) Relative energies (ZPE corrected) for $\mathrm{H}_{2}$ evolution through the heterocoupling of $\mathrm{Zn}(\mathrm{HL} \bullet$ ) and $\left[\mathrm{Zn}(\mathrm{H} 2 \mathrm{~L} \bullet]^{+}\right.$using the B97-D/6-311G(d) level of theory. (D) Structure of the singlet $\left[\mathrm{Zn}_{2}\left(\mathrm{H}_{3} \mathrm{~L} \cdot{ }_{2}\right)\right]^{+}$transition state through the heterocoupling pathway. Analysis of the eigenvector associated with the imaginary frequency $i 1572 \mathrm{~cm}^{-1}$, and the charge densities of atoms for $\mathrm{H}_{2}$ evolution with respect to intrinsic reaction coordinate. 84

Figure 39. (Upper) Transition state geometry of $\left[\mathrm{Zn}_{2} \mathrm{H}_{3} \mathrm{~L}_{2}{ }_{2}\right]^{+}$along the HER pathway, shown with active $\mathrm{N}-\mathrm{H}$ bond lengths associated with the imaginary frequency $i 1572 \mathrm{~cm}^{-1}$ , and equilibrium bond lengths in parentheses. (Lower) Charge densities of atoms near $\mathrm{H}_{2}$

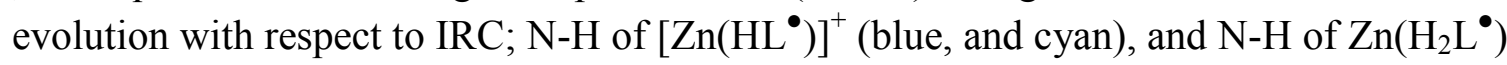
(magenta, purple). 86

Figure 40. $\mathrm{CVs}_{\text {s }}$ of $\mathrm{CuL}^{1}$ in $0.1 \mathrm{M} \mathrm{Bu}_{4} \mathrm{NPF}_{6}$ acetonitrile solution at scan rates of 0.1 (black), 0.2 (blue), 0.3 (light blue), 0.4 (green), 0.5 (light green), 0.6 (purple), 0.7 (yellow), 0.8 (orange), 0.9 (red) and 1.0 (black) V/s. CuL ${ }^{1}$. Inset: Cottrell plot of peak current vs square root of scan rate.

Figure 41. (A) $\mathrm{CV}_{\mathrm{s}}$ of $0.6 \mathrm{mM} \mathrm{CuL}^{1}$ (black) in $0.1 \mathrm{M} \mathrm{Bu}_{4} \mathrm{NPF}_{6}$ acetonitrile with 0.0244 (purple), 0.0448 (light purple), 0.0896 (light blue), 0.134 (pink), 0.179 (yellow), 0.244 (light green) and 0.269 (red) $\mathrm{M} \mathrm{CH}_{3} \mathrm{COOH}$, Inset. Blow up of $\mathrm{CV}$ showing shift of $\mathrm{Cu}^{\mathrm{II} / \mathrm{I}}$ reduction event. (B) Plot of $i_{c a t} / i_{p}$ vs $\left[\mathrm{CH}_{3} \mathrm{COOH}\right]$ for $0.60 \mathrm{mM} \mathrm{CuL}^{1}$ (blue) at scan rates of $0.20(\mathrm{X}), 0.50(\bullet)$ and $1.00(*) \mathrm{V} / \mathrm{s}(\mathrm{C})$ Catalytic Tafel Plot of $\mathrm{CuL}^{1}$ (blue) with comparison of performance for hydrogen evolution with those of others reported in literature. Blue $\diamond: \mathrm{Co}^{\mathrm{II}}(\mathrm{dmgH})_{2} \mathrm{py}$; green $\bullet$ : $\left[\mathrm{Ni}\left(\mathrm{P}_{2}{ }^{\mathrm{Ph}} \mathrm{N}^{\mathrm{Ph}}\right)_{2}\right]^{2+}$; red $\mathbf{m}$ : $\mathrm{NiL}^{2}$; magenta $\boldsymbol{\Delta}$ : $\mathrm{ZnL}{ }^{1}$; purple X: $\mathrm{H}_{2} \mathrm{~L}^{1}$. ${ }^{197}$

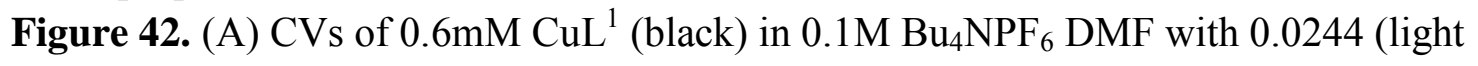
purple), 0.0448 (purple), 0.0896 (blue), 0.157 (green), 0.202 (light green), 0.246 (yellow), 
0.269 (orange). And 0.292 (red) $\mathrm{M} \mathrm{CH}_{3} \mathrm{COOH}$. (B) Plot of $i_{c a t} / i_{p}$ vs $\left[\mathrm{CH}_{3} \mathrm{COOH}\right]$ concentration. 96

Figure 43. (A) Bulk electrolysis showing plot of charge versus time of $0.6 \mathrm{mM} \mathrm{CuL}^{1}$ in $0.1 \mathrm{M} \mathrm{Bu}_{4} \mathrm{NPF}_{6}$ acetonitrile (pink and orange) and in $0.1 \mathrm{M} \mathrm{Bu}_{4} \mathrm{NPF}_{6} \mathrm{DMF}$ (red and blue) with $0.292 \mathrm{M} \mathrm{CH}_{3} \mathrm{COOH}$ added. Blank acetonitrile (green). (B) GC-TCD headspace readout of $\mathrm{H}_{2}$ from electrolysis. (C) Summary of CPE results. 98

Figure 44. Dip test post electrolysis in acetonitrile: After electrolysis working electrode was rinsed with water and immersed in a fresh solution of $0.1 \mathrm{M} \mathrm{Bu}_{4} \mathrm{NPF}_{6}$ acetonitrile solution and a CV was recorded (blue). $0.269 \mathrm{M}$ acetic acid was then added and a CV was obtained (red)

Figure 45. (A) CVs of $0.6 \mathrm{mM} \mathrm{CuL}^{1}$ in $0.1 \mathrm{M} \mathrm{Bu}_{4} \mathrm{NPF}_{6}$ acetonitrile solution with 0.269 $\mathrm{M}$ acetic acid, from 0-100\% D-acetic acid use. (B) Plot of \%D-Acetic acid use vs KIE.

Figure 46. UV-Visible spectrum of $\mathrm{CuL}^{1}$ titrated with acetic acid; 0.022 (dark red), 0.044 (red), 0.056 (light red), 0.067 (orange), 0.089 (light orange), 0.112 (yellow), 0.134 (light green), 0.157 (green), 0.202 (sky blue), 0.244 (blue), 0.269 (magenta), 0.292 (light blue), 0.337 (purple), and 0.382 (black) M. 102

Figure 47. (A) Cyclic Voltammograms run in $0.1 \mathrm{M} \mathrm{Bu}_{4} \mathrm{NPF}_{6}$ acetonitrile solution with $0.269 \mathrm{M}$ acetic acid added run with 0.1 (light blue), 0.2 (green), 0.3 (light green), 0.4 (yellow), 0.5 (orange), 0.6 (red), and 0.7 (dark red) $\mathrm{mM} \mathrm{CuL}^{1}$. (B) Plot of peak current versus catalyst concentration showing linear dependence and $1^{\text {st }}$ order relationship.... 104 Figure 48. (A) Energetic stability of protonated species, $\left[\mathrm{CuL}^{1} \mathrm{H}\right]^{+}$. (B) Energetic

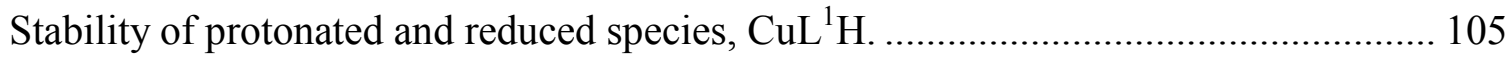

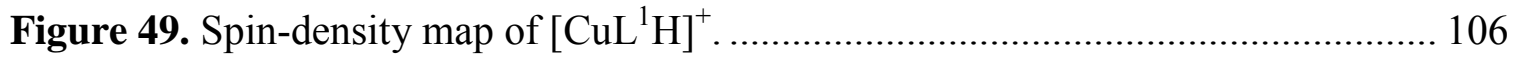

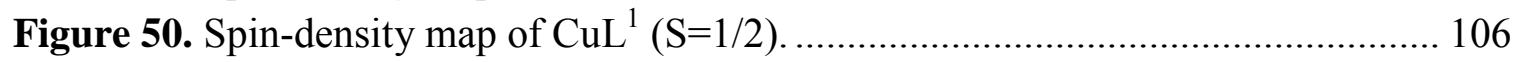

Figure A51. Screenshot of a .use file used for import into DigiElch........................... 133

Figure A52. (Left) Screenshot showing how to import files to DigiElch using import icon. (Right) Sample .use files to import.

Figure A53. Screenshot of simulation parameters. Setting under Model parameters, 2D Simulation and FEM-Simulation do not need to be changed at all .............................. 136

Figure A54. Screenshot of the chemical reactions tab................................................ 137

Figure A55. Screenshot of popup window obtained by double clicking on charge transfer

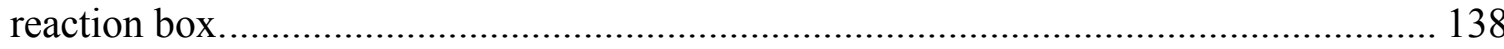

Figure B56. ZnL HER CV Simulations of experimental data; $12 \mathrm{mM}$ [acid]; $v=0.2-0.5$ $\mathrm{V} / \mathrm{s} \mathrm{vs} \mathrm{Fc}^{+} / \mathrm{Fc}$. Fit with mechanism parameters from Table A4. 141

Figure B57. Comparison of experimental (black solid) and simulated (green dotted) cyclic voltammograms; $\mathrm{ZnL}^{1}$ HER. $12 \mathrm{mM}$ [acid]; $\mathrm{v}=0.2 \mathrm{~V} / \mathrm{s} \mathrm{vs} \mathrm{Fc}^{+} / \mathrm{Fc}$. Fit with mechanism parameters from Table A4. 
Figure B58. Comparison of experimental (black solid) and simulated (green dotted) cyclic voltammograms; $\mathrm{ZnL}^{1}$ HER. $12 \mathrm{mM}$ [acid]; v $=0.3 \mathrm{~V} / \mathrm{s} \mathrm{vs} \mathrm{Fc}^{+} / \mathrm{Fc}$. Fit with mechanism parameters from Table A4.

Figure B59. Comparison of experimental (black solid) and simulated (green dotted) cyclic voltammograms; ZnL ${ }^{1}$ HER. $12 \mathrm{mM}$ [acid]; v = 0.4 V/s vs Fc $/ \mathrm{Fc}$. Fit with mechanism parameters from Table A4.

Figure B60. Comparison of experimental (black solid) and simulated (green dotted) cyclic voltammograms; $\mathrm{ZnL}^{1}$ HER. $12 \mathrm{mM}$ [acid]; v $=0.5 \mathrm{~V} / \mathrm{s} \mathrm{vs} \mathrm{Fc}^{+} / \mathrm{Fc}$. Fit with mechanism parameters from Table A4. 145

Figure B61. ZnL HER CV Simulations of experimental data; $12 \mathrm{mM}$ [acid]; v = $1.0-5.0$ $\mathrm{V} / \mathrm{s}$ vs $\mathrm{Fc}^{+} / \mathrm{Fc}$. Fit with mechanism parameters from Table A5. 146 Figure B62. Comparison of experimental (black solid) and simulated (red dotted) cyclic voltammograms; $\mathrm{ZnL}^{1}$ HER. $12 \mathrm{mM}$ [acid]; v $=1.0 \mathrm{~V} / \mathrm{s}$ vs $\mathrm{Fc}^{+} / \mathrm{Fc}$. Fit with mechanism parameters from Table A5.

Figure B63. Comparison of experimental (black solid) and simulated (red dotted) cyclic voltammograms; $\mathrm{ZnL}^{1}$ HER. $12 \mathrm{mM}$ [acid]; v = $1.5 \mathrm{~V} / \mathrm{s}$ vs $\mathrm{Fc}^{+} / \mathrm{Fc}$. Fit with mechanism parameters from Table A5.

Figure B64. Comparison of experimental (black solid) and simulated (red dotted) cyclic voltammograms; $\mathrm{ZnL}^{1}$ HER. $12 \mathrm{mM}$ [acid]; v = 2.0 V/s vs Fc $/ \mathrm{Fc}$. Fit with mechanism parameters from Table A5.

Figure B65. Comparison of experimental (black solid) and simulated (red dotted) cyclic voltammograms; $\mathrm{ZnL}^{1} \mathrm{HER} .12 \mathrm{mM}$ [acid]; v = $2.5 \mathrm{~V} / \mathrm{s}$ vs $\mathrm{Fc}^{+} / \mathrm{Fc}$. Fit with mechanism parameters from Table A5.

Figure B66. Comparison of experimental (black solid) and simulated (red dotted) cyclic voltammograms; $\mathrm{ZnL}^{1}$ HER. $12 \mathrm{mM}$ [acid]; v = 3.0 V/s vs Fc ${ }^{+} / \mathrm{Fc}$. Fit with mechanism parameters from Table A5.

Figure B67. Comparison of experimental (black solid) and simulated (red dotted) cyclic voltammograms; $\mathrm{ZnL}^{1}$ HER. $12 \mathrm{mM}$ [acid]; v = 3.5 V/s vs $\mathrm{Fc}^{+} / \mathrm{Fc}$. Fit with mechanism parameters from Table A5.

Figure B68. Comparison of experimental (black solid) and simulated (red dotted) cyclic voltammograms; $\mathrm{ZnL}^{1}$ HER. $12 \mathrm{mM}$ [acid]; v = 4.0 V/s vs $\mathrm{Fc}^{+} / \mathrm{Fc}$. Fit with mechanism parameters from Table A5. .

Figure B69. Comparison of experimental (black solid) and simulated (red dotted) cyclic voltammograms; $\mathrm{ZnL}^{1}$ HER. $12 \mathrm{mM}$ [acid]; v $=4.5 \mathrm{~V} / \mathrm{s}$ vs $\mathrm{Fc}^{+} / \mathrm{Fc}$. Fit with mechanism parameters from Table A5.

Figure B70. Comparison of experimental (black solid) and simulated (red dotted) cyclic voltammograms; $\mathrm{ZnL}^{1}$ HER. $12 \mathrm{mM}$ [acid]; v = 5.0 V/s vs Fc ${ }^{+} / \mathrm{Fc}$. Fit with mechanism parameters from Table A5.

Figure B71. $\mathrm{ZnL}^{1} \mathrm{HER}$. ZnL HER CV Simulations of experimental data; $6 \mathrm{mM}$ [acid]; v $=0.2-0.5 \mathrm{~V} / \mathrm{s} \mathrm{vs} \mathrm{Fc}^{+} / \mathrm{Fc}$. Fit with mechanism parameters from Table A6. 156 
Figure B72. Comparison of experimental (black solid) and simulated (green dotted) cyclic voltammograms; ZnL ${ }^{1}$ HER. $6 \mathrm{mM}$ [acid]; v = $0.2 \mathrm{~V} / \mathrm{s} \mathrm{vs} \mathrm{Fc}^{+} / \mathrm{Fc}$. Fit with mechanism parameters from Table A6.

Figure B73. Comparison of experimental (black solid) and simulated (green dotted) cyclic voltammograms; $\mathrm{ZnL}^{1}$ HER. $6 \mathrm{mM}$ [acid]; $v=0.3 \mathrm{~V} / \mathrm{s} \mathrm{vs} \mathrm{Fc}^{+} / \mathrm{Fc}$. Fit with mechanism parameters from Table A6.

Figure B74. Comparison of experimental (black solid) and simulated (green dotted) cyclic voltammograms; $\mathrm{ZnL}^{1}$ HER. $6 \mathrm{mM}$ [acid]; v $=0.4 \mathrm{~V} / \mathrm{s} \mathrm{vs} \mathrm{Fc}^{+} / \mathrm{Fc}$. Fit with mechanism parameters from Table A6.

Figure B75. Comparison of experimental (black solid) and simulated (green dotted) cyclic voltammograms; $\mathrm{ZnL}^{1}$ HER. $6 \mathrm{mM}$ [acid]; $v=0.5 \mathrm{~V} / \mathrm{s} \mathrm{vs} \mathrm{Fc}^{+} / \mathrm{Fc}$. Fit with mechanism parameters from Table A6.

Figure C76. $\mathrm{ZnL}^{1} \mathrm{HER}$ cyclic voltammograms in $0.1 \mathrm{M} \mathrm{Bu}_{4} \mathrm{NPF}_{6}$ methanol solution with increasing concentrations of $\mathrm{CH}_{3} \mathrm{COOH}$ added; $v=0.2 \mathrm{~V} / \mathrm{s}$.

Figure C77. Plot of $\mathrm{CH}_{3} \mathrm{COOH}$ concentration versus catalytic current for $\mathrm{ZnL}^{1}$ in $0.1 \mathrm{M}$ $\mathrm{Bu}_{4} \mathrm{NPF}_{6}$ methanol solution; $v=0.2 \mathrm{~V} / \mathrm{s}$.

Figure C78. $\mathrm{ZnL}^{1} \mathrm{HER}$ cyclic voltammograms in $0.1 \mathrm{M} \mathrm{Bu}_{4} \mathrm{NPF}_{6}$ methanol solution with increasing concentrations of $\mathrm{CH}_{3} \mathrm{COOH}$ added; $v=0.3 \mathrm{~V} / \mathrm{s}$.

Figure C79. Plot of $\mathrm{CH}_{3} \mathrm{COOH}$ concentration versus catalytic current for $\mathrm{ZnL}^{1}$ in $0.1 \mathrm{M}$ $\mathrm{Bu}_{4} \mathrm{NPF}_{6}$ methanol solution; $v=0.3 \mathrm{~V} / \mathrm{s}$. 165

Figure C80. $\mathrm{ZnL}^{1} \mathrm{HER}$ cyclic voltammograms in $0.1 \mathrm{M} \mathrm{Bu}_{4} \mathrm{NPF}_{6}$ methanol solution with increasing concentrations of $\mathrm{CH}_{3} \mathrm{COOH}$ added; $v=0.4 \mathrm{~V} / \mathrm{s}$.

Figure C81. Plot of $\mathrm{CH}_{3} \mathrm{COOH}$ concentration versus catalytic current for $\mathrm{ZnL}^{1}$ in $0.1 \mathrm{M}$ $\mathrm{Bu}_{4} \mathrm{NPF}_{6}$ methanol solution; $\mathrm{v}=0.4 \mathrm{~V} / \mathrm{s}$.

Figure C82. $\mathrm{ZnL}^{1} \mathrm{HER}$ cyclic voltammograms in $0.1 \mathrm{M} \mathrm{Bu}_{4} \mathrm{NPF}_{6}$ methanol solution with increasing concentrations of $\mathrm{CH}_{3} \mathrm{COOH}$ added; $v=0.5 \mathrm{~V} / \mathrm{s}$.

Figure C83. Plot of $\mathrm{CH}_{3} \mathrm{COOH}$ concentration versus catalytic current for $\mathrm{ZnL}^{1}$ in $0.1 \mathrm{M}$ $\mathrm{Bu}_{4} \mathrm{NPF}_{6}$ methanol solution; $\mathrm{v}=0.5 \mathrm{~V} / \mathrm{s}$.

Figure C84. $\mathrm{ZnL}^{1} \mathrm{HOR}$ cyclic voltammograms in $0.1 \mathrm{M} \mathrm{Bu}_{4} \mathrm{NPF}_{6}$ methanol solution, under an $\mathrm{H}_{2}$ atmosphere, with increasing concentrations of $\left(\mathrm{CH}_{2} \mathrm{CH}_{3}\right)_{3} \mathrm{~N}$ added; $v=0.2$ $\mathrm{V} / \mathrm{s}$.

Figure C85. $\mathrm{ZnL}^{1} \mathrm{HOR}$ cyclic voltammograms in $0.1 \mathrm{M} \mathrm{Bu}_{4} \mathrm{NPF}_{6}$ methanol solution, under an $\mathrm{H}_{2}$ atmosphere, with increasing concentrations of $\left(\mathrm{CH}_{2} \mathrm{CH}_{3}\right)_{3} \mathrm{~N}$ added; $v=0.5$ $\mathrm{V} / \mathrm{s}$. 171

Figure C86. $\mathrm{ZnL}^{1} \mathrm{HOR}$ cyclic voltammograms in $0.1 \mathrm{M} \mathrm{Bu}_{4} \mathrm{NPF}_{6}$ methanol solution, under an $\mathrm{H}_{2}$ atmosphere, with increasing concentrations of $\left(\mathrm{CH}_{2} \mathrm{CH}_{3}\right)_{3} \mathrm{~N}$ added; $v=1.0$ $\mathrm{V} / \mathrm{s}$.

Figure C87. $\mathrm{H}_{2} \mathrm{~L}^{1}$ HER cyclic voltammograms in $0.1 \mathrm{M} \mathrm{Bu}_{4} \mathrm{NPF}_{6}$ methanol solution with increasing concentrations of $\mathrm{CH}_{3} \mathrm{COOH}$ added ; $v=0.5 \mathrm{~V} / \mathrm{s}$. 
Figure C88. $\mathrm{H}_{2} \mathrm{~L}^{1}$ HER cyclic voltammograms in $0.1 \mathrm{M} \mathrm{Bu}_{4} \mathrm{NPF}_{6}$ methanol solution with increasing concentrations of $\mathrm{CH}_{3} \mathrm{COOH}$ added; $v=1.0 \mathrm{~V} / \mathrm{s}$. 174

Figure C89. Cyclic Voltammogram of $\mathrm{H}_{2} \mathrm{~L}^{1}$ in $0.1 \mathrm{M} \mathrm{Bu}_{4} \mathrm{NPF}_{6}$ methanol solution; $v=$ $0.2 \mathrm{~V} / \mathrm{s}$. 175

Figure C90. $\mathrm{H}_{2} \mathrm{~L}^{1} \mathrm{HOR}$ cyclic voltammograms in $0.1 \mathrm{M} \mathrm{Bu}_{4} \mathrm{NPF}_{6}$ methanol solution, under an $\mathrm{H}_{2}$ atmosphere, with increasing concentrations of $\left(\mathrm{CH}_{2} \mathrm{CH}_{3}\right)_{3} \mathrm{~N}$ added; $v=0.2$ V/s. 175

Figure C91. $\mathrm{H}_{2} \mathrm{~L}^{1} \mathrm{HOR}$ cyclic voltammograms in $0.1 \mathrm{M} \mathrm{Bu}_{4} \mathrm{NPF}_{6}$ methanol solution, under an $\mathrm{H}_{2}$ atmosphere, with increasing concentrations of $\left(\mathrm{CH}_{2} \mathrm{CH}_{3}\right)_{3} \mathrm{~N}$ added; $v=0.5$ $\mathrm{V} / \mathrm{s}$

Figure C92. $\mathrm{H}_{2} \mathrm{~L}^{1} \mathrm{HOR}$ cyclic voltammograms in $0.1 \mathrm{M} \mathrm{Bu}_{4} \mathrm{NPF}_{6}$ methanol solution, under an $\mathrm{H}_{2}$ atmosphere, with increasing concentrations of $\left(\mathrm{CH}_{2} \mathrm{CH}_{3}\right)_{3} \mathrm{~N}$ added; $v=1.0$ $\mathrm{V} / \mathrm{s}$.

Figure C93. $\mathrm{CuL}^{1} \mathrm{HER}$ cyclic voltammograms in $0.1 \mathrm{M} \mathrm{Bu}_{4} \mathrm{NPF}_{6}$ acetonitrile solution with increasing concentrations of $\mathrm{CH}_{3} \mathrm{COOH}$ added; $v=0.2 \mathrm{~V} / \mathrm{s}$. 178

Figure C94. $\mathrm{CuL}^{1} \mathrm{HER}$ cyclic voltammograms in $0.1 \mathrm{M} \mathrm{Bu}_{4} \mathrm{NPF}_{6}$ acetonitrile solution with increasing concentrations of $\mathrm{CH}_{3} \mathrm{COOH}$ added; $v=0.5 \mathrm{~V} / \mathrm{s}$. 179

Figure C95. $\mathrm{CuL}^{1} \mathrm{HER}$ cyclic voltammograms in $0.1 \mathrm{M} \mathrm{Bu}_{4} \mathrm{NPF}_{6}$ acetonitrile solution with increasing concentrations of $\mathrm{CH}_{3} \mathrm{COOH}$ added; $v=1.0 \mathrm{~V} / \mathrm{s}$. 180

Figure C96. 0.6 $\mathrm{mM} \mathrm{CuL}^{1}$ in $0.1 \mathrm{M} \mathrm{Bu}_{4} \mathrm{NPF}_{6}$ DMF; HER CVs scanned at $0.5 \mathrm{~V} / \mathrm{s} \ldots . .181$

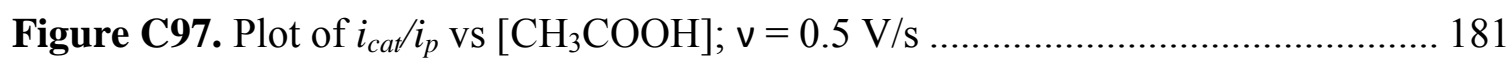

Figure C98. $0.6 \mathrm{mM} \mathrm{CuL}^{1}$ in $0.1 \mathrm{M} \mathrm{Bu}_{4} \mathrm{NPF}_{6}$ DMF; HER CVs scanned at $1.0 \mathrm{~V} / \mathrm{s} . . . .182$

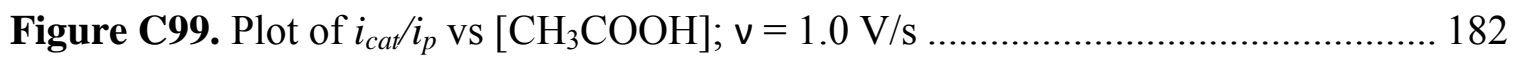
Figure C100. Scan Rate Dependence: CVs of $0.6 \mathrm{mM} \mathrm{CuL}^{1}$ in $0.1 \mathrm{M} \mathrm{Bu}_{4} \mathrm{NPF}_{6} \mathrm{DMF}$

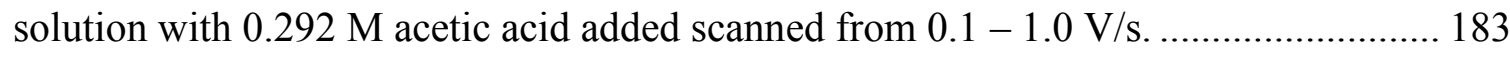

Figure C101. Plot of scan rate vs TOF for $\mathrm{CuL}^{1}$ in DMF. ....................................... 183

Figure C102. Plot of scan rate vs catalytic current for $\mathrm{CuL}^{1}$ in $\mathrm{DMF}$........................... 184

Figure C103. $\mathrm{CVs}$ run in $0.1 \mathrm{M} \mathrm{Bu}_{4} \mathrm{NPF}_{6}$ acetonitrile solutions, showing blank acetonitrile (blue), with $0.0672 \mathrm{M}$ acetic acid added (black dashed), and with $0.0672 \mathrm{M}$ acetic acid and $0.6 \mathrm{mM} \mathrm{CuL}^{1}$ (red)

Figure 104. CVs run in $0.1 \mathrm{M} \mathrm{Bu}_{4} \mathrm{NPF}_{6} \mathrm{DMF}$ solutions, showing blank DMF (blue), with $0.0224 \mathrm{M}$ acetic acid added (black dashed), and with $0.0224 \mathrm{M}$ acetic acid and 0.6 $\mathrm{mM} \mathrm{CuL}{ }^{1}$ (red).

Figure C105. CVs run in $0.1 \mathrm{M} \mathrm{Bu}_{4} \mathrm{NPF}_{6} \mathrm{DMF}$ solutions with $0.292 \mathrm{M}$ acetic acid (blue) and upon addition of $0.6 \mathrm{mM} \mathrm{CuL}^{1}$ (purple).

Figure C106. OCP measurement for $\mathrm{ZnL}^{1} \mathrm{HER} \quad 0.1 \mathrm{M} \mathrm{Bu}_{4} \mathrm{NPF}_{6}$ methanol solution with $12 \mathrm{mM}$ acetic acid added. 186

Figure C107. OCP measurement for $\mathrm{ZnL}^{1} \mathrm{HOR} 0.1 \mathrm{M} \mathrm{Bu}_{4} \mathrm{NPF}_{6}$ methanol solution with $30 \mathrm{mM}$ triethylamine added. 186 
Figure C108. OCP measurement for $\mathrm{H}_{2} \mathrm{~L}^{1} \mathrm{HER} \quad 0.1 \mathrm{M} \mathrm{Bu}_{4} \mathrm{NPF}_{6}$ methanol solution with $10 \mathrm{mM}$ acetic acid added. .

Figure C109. OCP measurement for $\mathrm{H}_{2} \mathrm{~L}^{1} \mathrm{HOR} \quad 0.1 \mathrm{M} \mathrm{Bu}_{4} \mathrm{NPF}_{6}$ methanol solution with

$10 \mathrm{mM}$ acetic acid added. 187

Figure C110. OCP measurement for $\mathrm{ZnL}^{1} \mathrm{HER}$ in Acetonitrile 0.1 $\mathrm{M} \mathrm{Bu}_{4} \mathrm{NPF}_{6}$ acetonitrile solution with $21 \mathrm{mM}$ acetic acid added. 188

Figure C111. OCP measurement for $\mathrm{CuL}^{1} \mathrm{HER} 0.1 \mathrm{M} \mathrm{Bu}_{4} \mathrm{NPF}_{6}$ acetonitrile solution with $0.269 \mathrm{M}$ acetic acid added 188

Figure C112. OCP measurement for $\mathrm{CuL}^{1} \mathrm{HER} 0.1 \mathrm{M} \mathrm{Bu}_{4} \mathrm{NPF}_{6} \mathrm{DMF}_{\text {solution with }}$ $0.292 \mathrm{M}$ acetic acid added. 189

Figure C113. UV-Vis absorbance's measured during titration of $\mathrm{ReL}_{3}$ with increasing equivalents of $\mathrm{HCl}$. 189

Figure D114. DFT (M06 / LANL2DZ) optimized geometric parameters with bond lengths $(\AA)$ and angles $\left({ }^{\circ}\right)$ for $\left[\mathrm{HRe}(\mathrm{LH}) \mathrm{L}_{2}\right]^{0}$ with free energy energies (kcal / mole) of singlet $(\mathrm{S}=0)$ and triplet $(\mathrm{S}=1)$ electronic states. 191 


\section{LIST OF TABLES}

Table 1. Comparison of selected bond distances and bond angles between $\mathrm{ReL}_{3}$, $\left[\operatorname{Re}(\mathrm{LH}) \mathrm{L}_{2}\right] \mathrm{PF}_{6},\left[\mathrm{Re}(\mathrm{LH}) \mathrm{L}_{2}\right] \mathrm{O}_{3} \mathrm{SCF}_{3}$ and, $\left[\mathrm{ReL}_{3} \cdot \mathrm{C}_{2} \mathrm{H}_{4}\right]\left[\mathrm{PF}_{6}\right]_{2}{ }^{\mathrm{a}}$

Table 2. Bond length comparison of calculated HER intermediates ............................... 87

Table 3. Bond angle comparison of calculated HER intermediates................................ 88

Table A4. $\mathrm{ZnL}^{1}$ Optimized parameters of data fitting, $12 \mathrm{mM}$ [acid]; $v=0.2-0.5 \mathrm{~V} / \mathrm{s}$ vs $\mathrm{Fc}^{+} / \mathrm{Fc}$ 129

Table A5. $\mathrm{Znl}^{1}$ Optimized parameters of data fitting, $12 \mathrm{mM}$ [acid]; $v=1.0-5.0 \mathrm{~V} / \mathrm{s}$ vs $\mathrm{Fc}^{+} / \mathrm{Fc}$ 130

Table A6. $\mathrm{ZnL}^{1}$ Optimized parameters of data fitting, $6 \mathrm{mM}$ [acid]; $v=0.2-0.5 \mathrm{~V} / \mathrm{s}$ vs $\mathrm{Fc}^{+} / \mathrm{Fc}$ 131

Table D8. Computational input coordinates for $\mathrm{ZnL}^{1}$ and related compounds. 192

Table D9. Computational input coordinates for $\mathrm{ReL}_{3}$ and related compounds. 203

Table D10. Computational input coordinates for $\mathrm{CuL}^{1}$ and related compounds. 233 


\section{LIST OF SCHEMES}

Scheme 1. Stick representation of $\operatorname{ReL}_{3}(\mathrm{~L}=$ diphenylphosphinobenzenethiolate)......... 45 Scheme 2. Proposed Mechanism for Electrocatalytic $\mathrm{H}_{2}$ evolution and oxidation by $\mathrm{ReL}_{3}$.

Scheme 3. Proposed Mechanism of $\mathrm{H}_{2}$ Evolution by $\mathrm{ReL}_{3}$.

Scheme 4. Comparison of first and second generation Ligand-Centered HER

Electrocatalysts. 69

Scheme 5. Representation of $\mathrm{ZnL}^{1}$ and $\mathrm{H}_{2} \mathrm{~L}^{1}$.

Scheme 6. Selected ligand-centered HER/HOR electrocatalysts, taken from references 71,99 and $100 .^{71,99,100}$ 71

Scheme 7. Representation of thiosemicarbazone based electrocatalysts. ....................... 93

Scheme 8. Comparison of thiosemicarbazone HER electrocatalysts. 107

Scheme 9. $\mathrm{ReL}_{3} \mathrm{HER}$ mechanism 112

Scheme 10. Representation of homolytic S-H bond cleavage leading to $\mathrm{H}_{2}$ evolution via radical coupling and calculated transition state for $\mathrm{H}_{2}$ evolution. 113

Scheme 11. Proposed mechanism for $\mathrm{H}_{2}$ evolution by $\mathrm{ZnL}^{1}$.....

Scheme 12. Mechanism for $\mathrm{H}_{2}$ evolution for $\mathrm{ZnL}^{1}$ showing evolution through heterolytic $\mathrm{N}-\mathrm{H}$ bond cleavage resulting in deprotonation of neighboring hydrogen and (right) the calculated transition state for $\mathrm{H}_{2}$ evolution. 


\section{CHAPTER I: INTRODUCTION}




\subsection{Hydrogen: Importance and Background}

Energy is an essential requirement for the development of any society, and therefore should be a key consideration in discussions of sustainable development. Yet, reliable and practical renewable energy sources remain a paramount challenge as we continue into the $21^{\text {st }}$ century. ${ }^{1}$ Current energy needs are largely met by fossil fuels, but these sources are non-renewable and their use releases billions of tons of the greenhouse gas $\mathrm{CO}_{2}$ annually. ${ }^{2,3}$ Long range predictions suggest a tripling of global energy needs by 2100, while also suggesting depletion of all fossil fuel reserves other than coal by $2042 .{ }^{4}$ Clearly, the current energy use is unsustainable, and researchers are going to great lengths to develop renewable resources capable of meeting energy demands. ${ }^{2,3,5}$

In this context, hydrogen can be viewed as being a promising alternative carbonfree fuel/energy carrier, in addition to currently being an essential building block for industrial and agricultural processes. Estimates suggest that a hydrogen based economy would require as much as 150 million tons of $\mathrm{H}_{2}$ annually, demonstrating the need for efficient electrolytic and/or photochemical catalysts that generate $\mathrm{H}_{2}$ from carbon-free sources. ${ }^{6}$ As such, the development of both heterogeneous and homogeneous catalysts for hydrogen evolution reactions (HER) from water/acid for $\mathrm{H}_{2}$ production and hydrogen

oxidation reactions(HOR) for $\mathrm{H}_{2}$ utilization have received significant attention. ${ }^{7-14}$

Not only is hydrogen an attractive energy carrier candidate, but there is also a great demand for hydrogen in other industrial sectors. Industrial production of ammonia via the Haber-Bosch process currently accounts for $54 \%$ of all hydrogen use; coming in a close second is the chemical industry/refineries, accounting for a substantial $35 \%$ of its use (Figure 1). Even more, 95\% of industrial $\mathrm{H}_{2}$ production derives from fossil-fuel 
cracking, which is environmentally unsustainable due to the aforementioned perpetual increases in atmospheric $\mathrm{CO}_{2}$ levels and continual lowering of global carbon reserves, ${ }^{5,15,16}$ further indicating the need to develop alternative, carbon neutral methods for hydrogen production. ${ }^{17}$

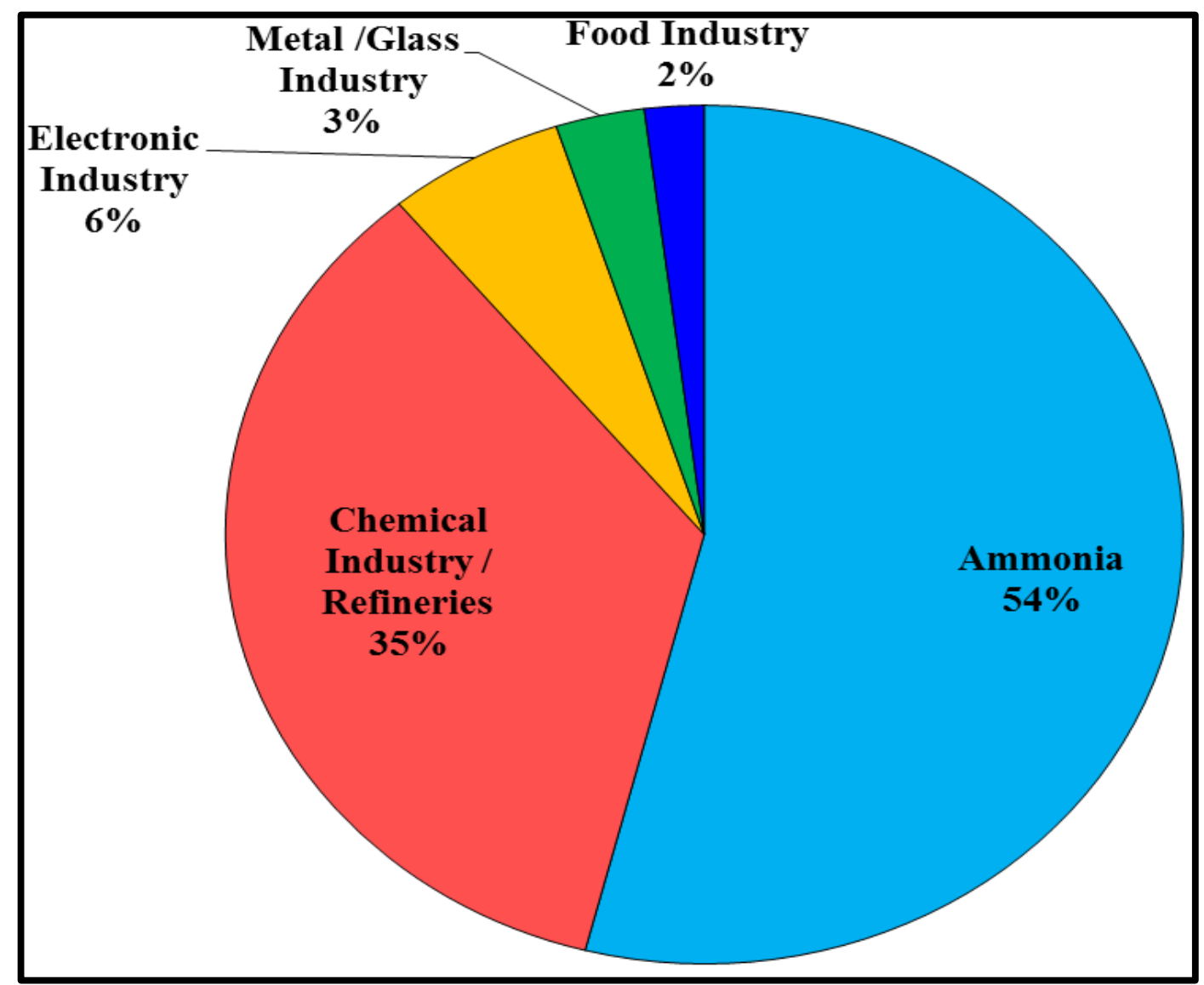

Figure 1. Percent of global hydrogen use by industry. ${ }^{17}$

\subsection{Hydrogenase and Biomimetic Hydrogenase Complexes}

Hydrogenases are a diverse group of metalloenzymes that catalyze one of the simplest molecular reactions, the oxidation of dihydrogen to protons and electrons and the reverse reaction, the formation of $\mathrm{H}_{2} \cdot{ }^{18,19}$ The term hydrogenase was first suggested by Stephenson and Strickland in $1931^{20,21}$ when observing activity in anaerobically grown Escherichia Coli cells which mediated the reversible reduction of dyes with $\mathrm{H}_{2}$. The 
observation that the dye reduction was reversibly inhibited by $\mathrm{CO}$ indicated the involvement of a transition metal in $\mathrm{H}_{2}$ activation. The hydrogenase reaction takes place at either an iron or nickel center, which utilize specific ligands to increase the acidity of $\mathrm{H}_{2}$ leading to a heterolytic splitting of the molecule. This process is strongly accelerated by the presence of a nearby base. The reverse reaction, the evolution of $\mathrm{H}_{2}$, involves the respective coupling of $\mathrm{H}^{+}$and $\mathrm{H}^{-}$ions.

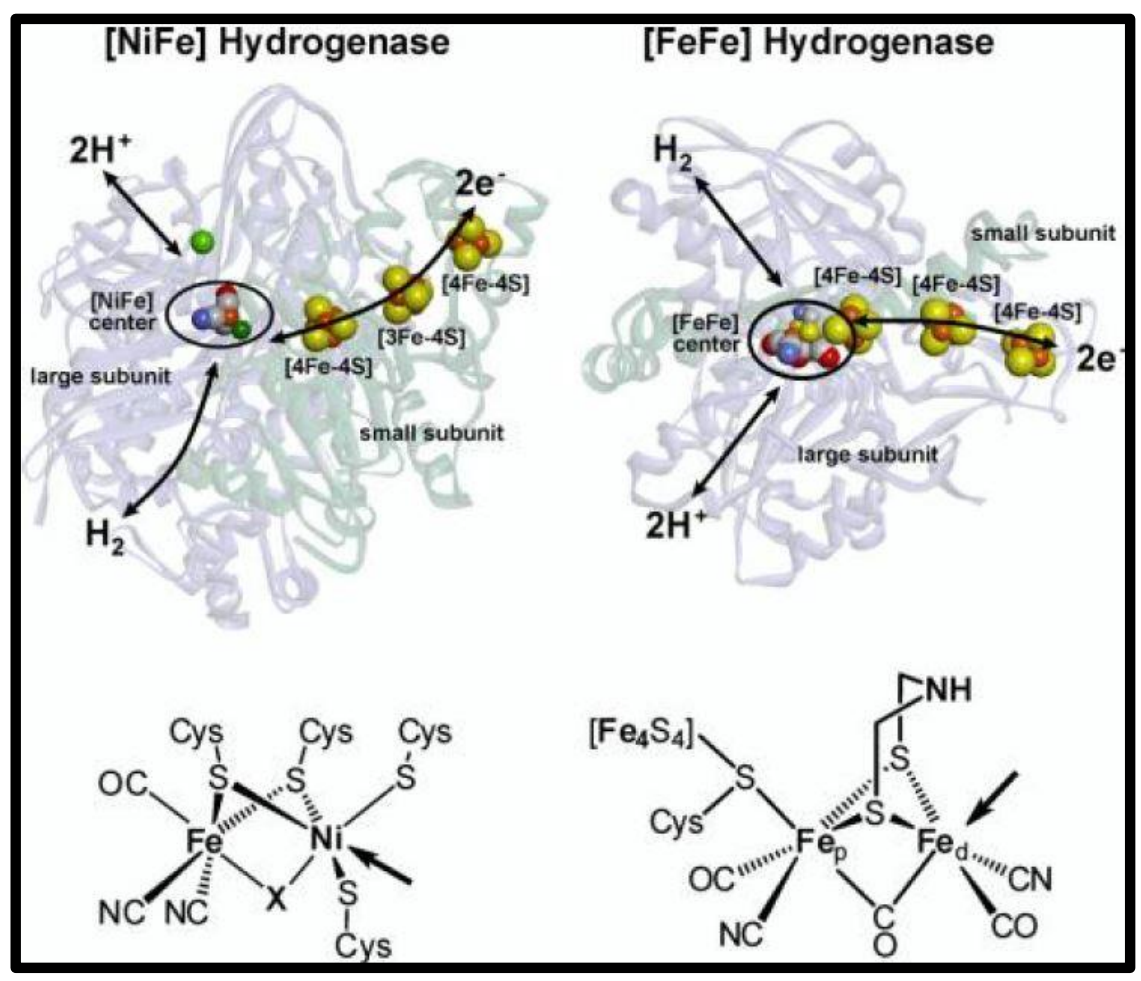

Figure 2. (Top) Structures of the $[\mathrm{NiFe}]$ hydrogenase ${ }^{22}$ and of the $[\mathrm{FeFe}]$ hydrogenase from $\mathrm{Dd} .^{23}$ (Bottom) the chemical structures of the active sites of the two types of hydrogenases are given; the arrows indicate the open metal coordination sites.

Hydrogenases are widespread in nature, occurring in bacteria, archaea, and some eukarya. $18,19,24,25$ They can be divided into three groups, according to the metal ion composition of their active sites, as either $[\mathrm{NiFe}],[\mathrm{FeFe}]$, or $[\mathrm{Fe}]$ hydrogenase, with $\mathrm{H}_{2}$ evolution favored in [FeFe]-hydrogenase, and $\mathrm{H}_{2}$-oxidation preferential at $[\mathrm{NiFe}]-$ 
hydrogenase. ${ }^{26-30} \mathrm{~A}$ characteristic feature of two of the classes, $[\mathrm{NiFe}]$ and $[\mathrm{FeFe}]$ hydrogenases, is that the iron atoms are ligated by small inorganic ligands such as $\mathrm{CO}$ and $\mathrm{CN}^{-}$, which were first detected by FTIR spectroscopy. ${ }^{31-33}$ They also exhibit sulfur bridged bimetallic centers, with an open coordination site on one of the metal centers (Figure 2). The third class, $[\mathrm{Fe}]$ hydrogenase, contains only a single iron atom ${ }^{34-37}$ with CO ligands on the iron center, in addition to its cofactor.

A combination of crystallographic and spectroscopic data has provided a clear view of the enzymatic mechanism for the [FeFe] hydrogenase (Figure 3). The initial state of hydrogenase is a dianion, termed $\mathrm{H}_{\mathrm{ox}}$. In this state, the proximal iron site $\left(\mathrm{Fe}_{\mathrm{p}}\right)$ is $\mathrm{Fe}(\mathrm{I})$ and is in an octahedral coordination environment, containing two thiolate bridging ligands with a pendant amine, two CO ligands with one terminal and one bridging, a terminal $\mathrm{CN}^{-}$ligand and a thiolate which is associated with $\left[\mathrm{Fe}_{4} \mathrm{~S}_{4}\right]$ cluster. The distal iron, $\left(\mathrm{Fe}_{\mathrm{d}}\right)$ is five coordinate with a free coordination site and is $\mathrm{Fe}(\mathrm{II}) .{ }^{38}$ Upon oneelectron reduction and protonation, the Fe(II) center is reduced to $\mathrm{Fe}(\mathrm{I})$ giving the $\mathrm{H}_{\text {red }}$ state. Here, the cubane subcluster is still in the oxidized state, while the di-iron sub cluster is still in the $\mathrm{Fe}(\mathrm{I}) / \mathrm{Fe}(\mathrm{I})$ state, with $\mathrm{Fe}_{\mathrm{p}}$ in a square pyramidal geometry bearing a free coordination site. It is important to point out that the location of the added proton has not been determined, but it is thought to be either on the right five-coordinate iron center or on one of the bridging sulfurs. ${ }^{39}$ The formation of $\mathrm{H}_{\mathrm{red}}$ from $\mathrm{H}_{\mathrm{ox}}$ is additionally described as a proton-coupled electron transfer process. Very recently a third paramagnetic redox state, $\mathrm{H}_{\text {sred }}$ (super-reduced), has been experimentally observed and characterized by EPR and FTIR spectroscopy. ${ }^{40} \mathrm{H}_{\text {sred }}$ contains one more electron than $\mathrm{H}_{\text {red, }}$ which is located on the $[4 \mathrm{Fe}-4 \mathrm{~S}]$ cluster, and is characterized by a $\mathrm{Fe}(\mathrm{I}) / \mathrm{Fe}(\mathrm{I}) /[4 \mathrm{Fe}-$ 
$4 \mathrm{~S}]^{+}$configuration. It is suggested that $\mathrm{H}_{\text {sred }}$ forms part of the catalytic cycle as an additional intermediate. ${ }^{40,41}$ It was then proposed, on this basis, that $\mathrm{H}_{2}$ oxidation, catalyzed by $[\mathrm{FeFe}]$-hydrogenases, proceeds via initial binding of $\mathrm{H}_{2}$ to the exchangeable/free coordination site of $\mathrm{H}_{\mathrm{ox}}$, followed by heterolytic cleavage of the $\mathrm{H}-\mathrm{H}$ bond assisted by the bridgehead amine function, and finally transfer of two individual electrons from the Fe-bound hydride to the $[4 \mathrm{Fe}-4 \mathrm{~S}]$ cluster and the $\mathrm{Fe}_{\mathrm{p}}$ of the $[\mathrm{FeFe}]$ subsite. Ejection of the protons and the electrons from $\mathrm{H}_{\text {sred }}$ regenerates $\mathrm{H}_{\mathrm{ox}}$ to complete the catalytic cycle. Each step is reversible, and proton reduction to $\mathrm{H}_{2}$ is proposed to use the same catalytic steps and intermediates, but in the opposite direction. The structure for [NiFe] hydrogenase was first structurally characterized by the Fontecilla-Camp Group in 1995..$^{33,42}$ Several $\mathrm{H}_{2}$ uptake mechanisms have been proposed for [NiFe] hydrogenases, but a consensus has yet to be reached. ${ }^{43}$ 


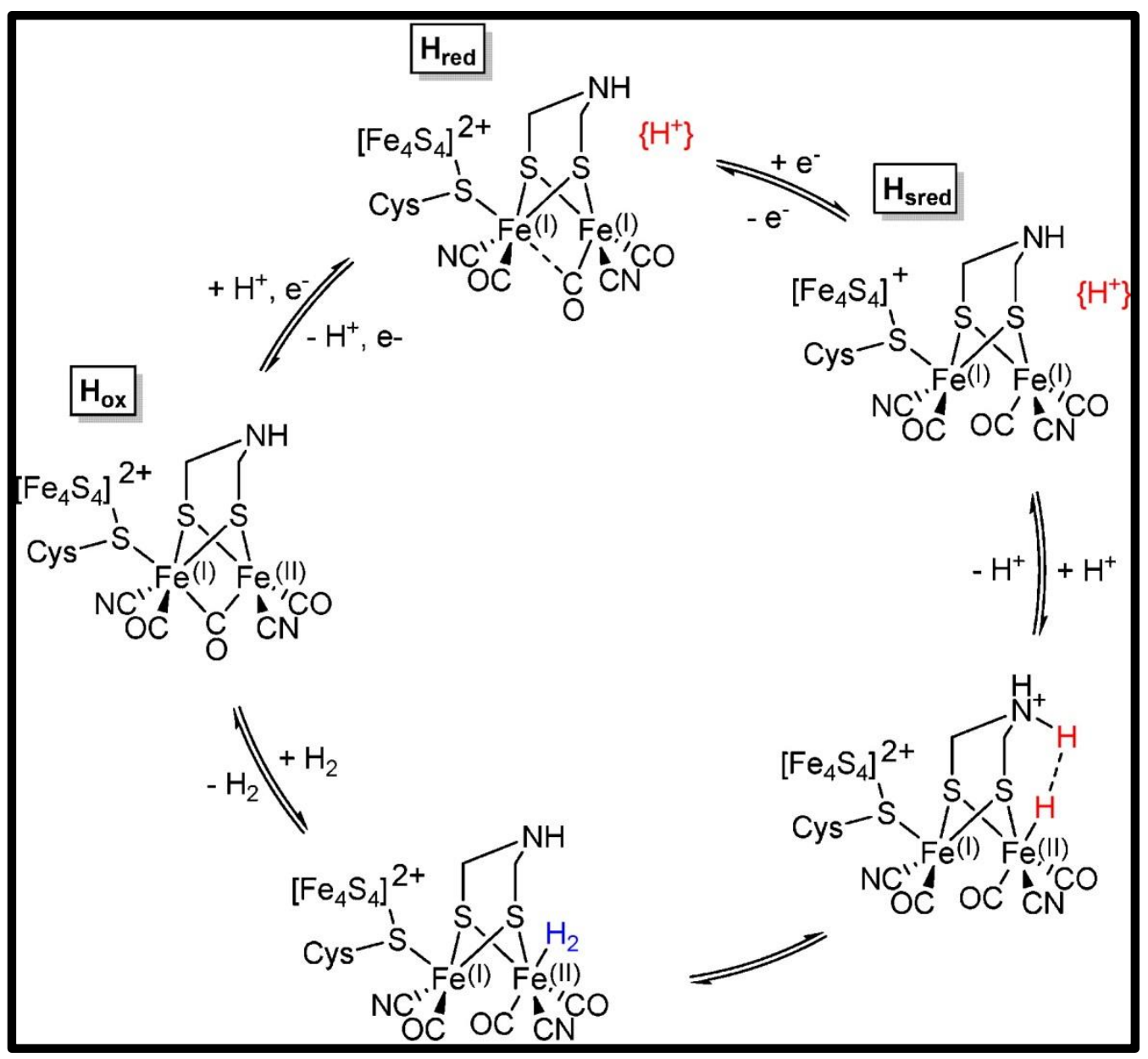

Figure 3. Postulated catalytic mechanism for reversible $\mathrm{H}^{+}$reduction by $[\mathrm{FeFe}]$-hydrogenases, the location of the proton in the $\mathrm{H}_{\text {red }}$ and $\mathrm{H}_{\text {sred }}$ state is undetermined, adapted from reference $53 .{ }^{40}$

To provide further insight into the active sight and reaction mechanism of [FeFe] and $[\mathrm{NiFe}]$ hydrogenase synthetic inorganic chemists began to make model complexes of hydrogenase in order to mimic its bifunctional behavior and high activity for $\mathrm{H}_{2}$ evolution and oxidation. A number of biomimetic hydrogenase models have been explored. Interestingly_prior to the structural elements of [FeFe] hydrogenases active site being known-in 1929 Reihlen et al. reported the preparation of analogous dithiolate-bridged hexacarbonyl di-iron complexes, $\left[(\mu \text {-SEt })_{2} \mathrm{Fe}(\mathrm{CO})_{6}\right]$ (Figure 4). ${ }^{44}$ 


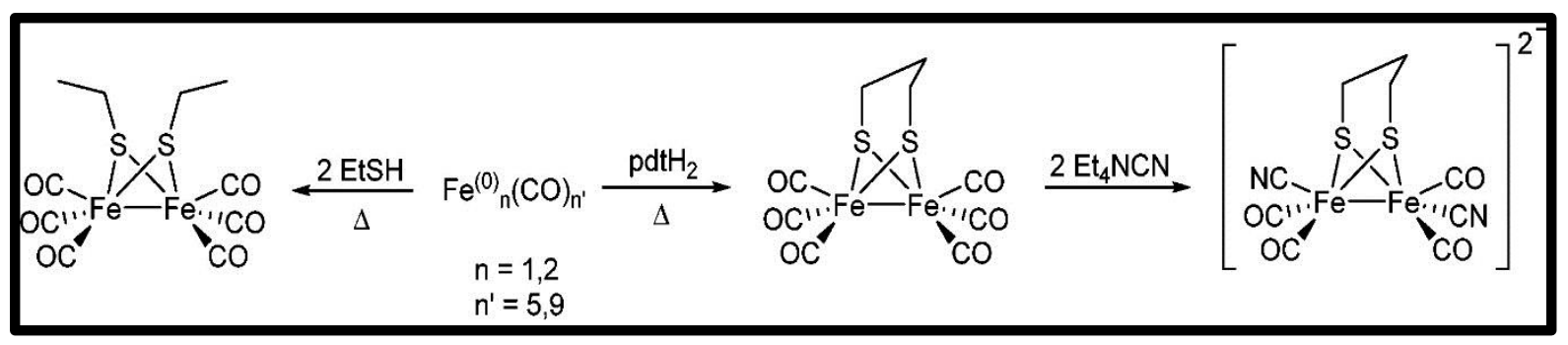

Figure 4. Synthetic scheme for the preparation of $\left[(\mu-\mathrm{SEt})_{2} \mathrm{Fe}(\mathrm{CO})_{6}\right]$ (left), and precursor diiron hexacarbonyl complex (middle) used in route to the first true [FeFe] hydrogenase model $[(\mu$ pdt) $\left.\mathrm{Fe}_{2}(\mathrm{CO})_{4}(\mathrm{CN})_{2}\right]^{2-}$ (right). ${ }^{45-47}$

The structural characterization of the H-cluster in $1998-1999$ by Peters et $a l,{ }^{23,48}$ served as an inspiration to many groups who desired to create synthetic hydrogenase analogues. Three groups, Pickett, Rauchfuss, and Darensbourg, replaced two CO groups with two $\mathrm{CN}$ ligands in order to generate the water soluble dianion, [( $\mu$ pdt)Fe $\left.{ }_{2}(\mathrm{CO})_{4}(\mathrm{CN})_{2}\right]^{2-}$ (Figure 4). ${ }^{45-47}$ These first-generation [FeFe] hydrogenase mimics initiated further synthetic inorganic chemistry research. Currently, there are over 300 model systems reported. ${ }^{39,49}$

Interest in $[\mathrm{FeFe}]$ hydrogenase has continued to the present day, with close to 100 new papers in the last five years. ${ }^{50-58}$ Much of this second-generation work has been directed to the bridging group ligands, to overcome limitations such as large overpotential requirements. Strategies included using higher group chalcogens such as selenide to replace the bridging dithiolates ${ }^{59}$, inclusion of a suitably substituted aromatic dithiolate bridgehead, ${ }^{60}$ substitution of the $\mathrm{CN}$ ligands to phosphines, ${ }^{39}$ and addition of benzene rings bearing strong electron withdrawing groups like chloride. ${ }^{60,61}$ These approaches led to moderate success, reducing overpotentials by roughly $150 \mathrm{mV}$, although at the expense of catalytic efficiency in terms of turnover frequencies. 


\subsection{Mechanistic Features of $\mathbf{H}_{2}$ Evolution and Oxidation}

The investigation into the production or oxidation of $\mathrm{H}_{2}$, as discussed above, has long been a fundamental interest of energy research. In addition to better understanding hydrogenase, research in this area does have a double incentive - that is to understand completely, whether the reaction follows a homolytic or a heterolytic pathway (Figure 5). This has been a long held question ${ }^{62,63}$ and continues to be a hotly debated issue. ${ }^{10,13,64-90}$

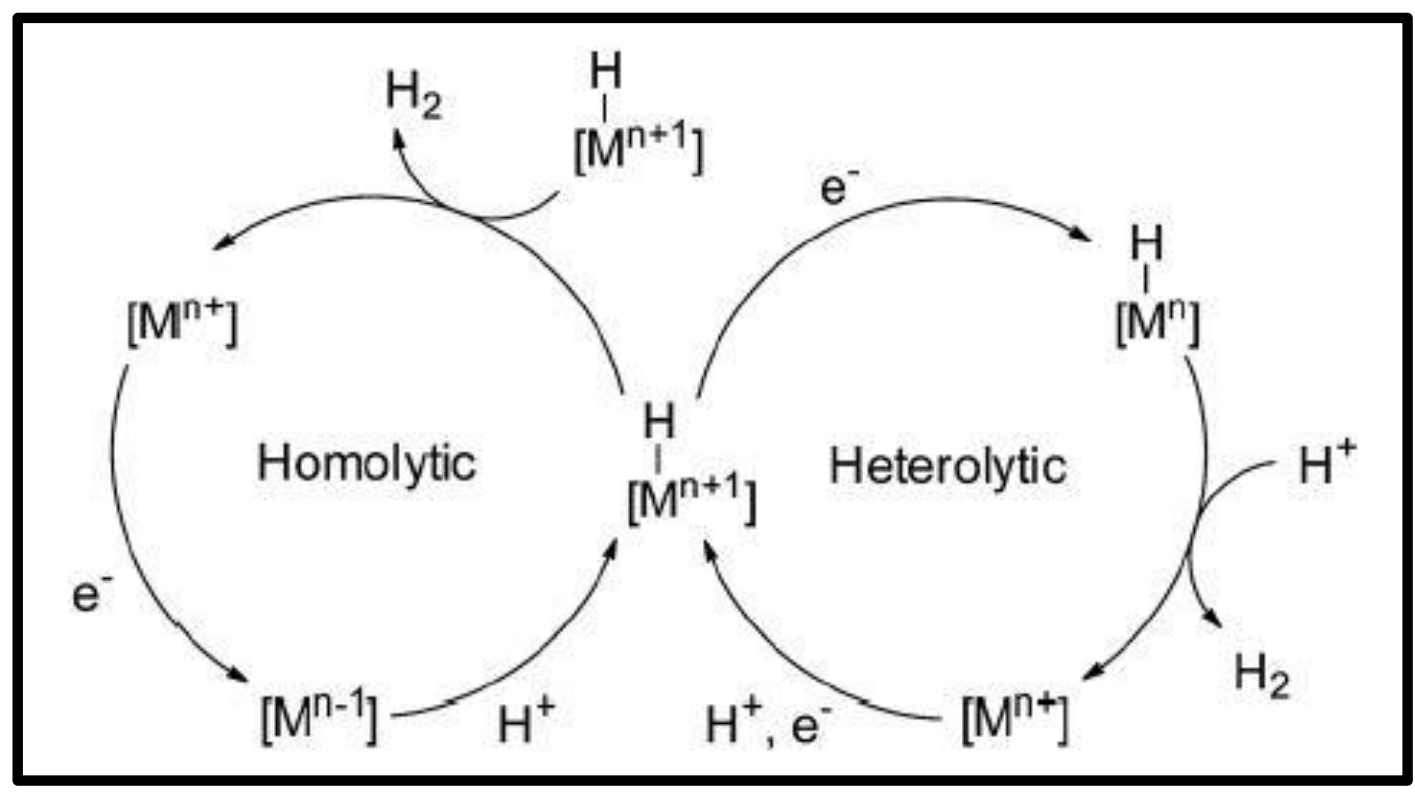

Figure 5. Illustration of two potential routes for $\mathrm{H}_{2}$ evolution following either a homolytic or heterolytic pathway.

One common and well-studied class of $\mathrm{H}_{2}$ evolution catalysts is the cobaloxime family of complexes. Initial reports by both Peters et al. ${ }^{10}$ and Dempsey et al. ${ }^{91}$ suggested a homolytic pathway involving a bi-molecular mechanism, where homolytic bond cleavage of two $\mathrm{Co}^{\mathrm{I}}-\mathrm{H}$ species results in the evolution of hydrogen. ${ }^{10,64,91}$ However, further research by Muckerman $e t a l^{72}$ and Fontecave $e t a l^{73,74}$ tend to favor a heterolytic pathway, which was further supported by an array of computational reports that also favor the heterolytic pathway. ${ }^{72,92}$ Recently, even more light has been shed onto the 
mechanism of $\mathrm{H}_{2}$ evolution with these complexes with Artero et al. suggesting in situ formation of catalytic nanoparticles as the active species for catalysis. ${ }^{93}$ Dubois and Bullock have extensively evaluated the reactivity of nickel and iron bis(diamine) complexes. ${ }^{14,94}$ The complexes mimic nature by employing a pendant amine as a proton relay group, in order to lower overpotential and increase turnover frequency and achieve some of the fastest reported homogeneous HER TOFs. Furthermore, Eisenberg and Holland reported a series of metal-dithiolene complexes with the highest TOFs and lowest overpotentials of synthetic transition metal-sulfur electrocatalysts under homogeneous conditions. ${ }^{7,11,95}$ Each of these systems are thought to follow a metalhydride pathway and it is widely regarded that transition metals capable of forming metal-hydride intermediates are essential to the HER mechanism. Naturally, most HER electrocatalysts reported to date closely follow the archetypal mechanism of ligand protonation, metal reduction, proton to hydride migration, and subsequent chemical/electrochemical steps leading to $\mathrm{H}_{2}$ release. ${ }^{94}$

While the metal-hydride approach has led to significant advances, catalyst candidates that fall into this paradigm are limited to economically viable first-row transition metals complexes capable of stabilizing hydrides. Moreover, few complexes of this type are reported to catalyze both HERs and HORs. ${ }^{13}$ This has led to a renaissance in hydrogen evolution or oxidation electrocatalyst design and thought, stimulating researchers to probe ligand-centered homolytic routes for catalysis.

\subsection{Ligand-Centered HER Electrocatalysts}

Classical behavior of transition complexes which involve a redox process encompasses oxidation or reduction of the metal, leaving the ligand unaffected. However, ligands can 
also participate in the redox process. In these cases, the ligand is referred to as being redox non-innocent or redox active. ${ }^{96,97}$ These types of ligands and their metal complexes have attracted substantial attention over the past decade and longer, since they offer a unique opportunity to modify the reactivity of transition metal complexes. Within traditional redox non-innocence, four different strategies can

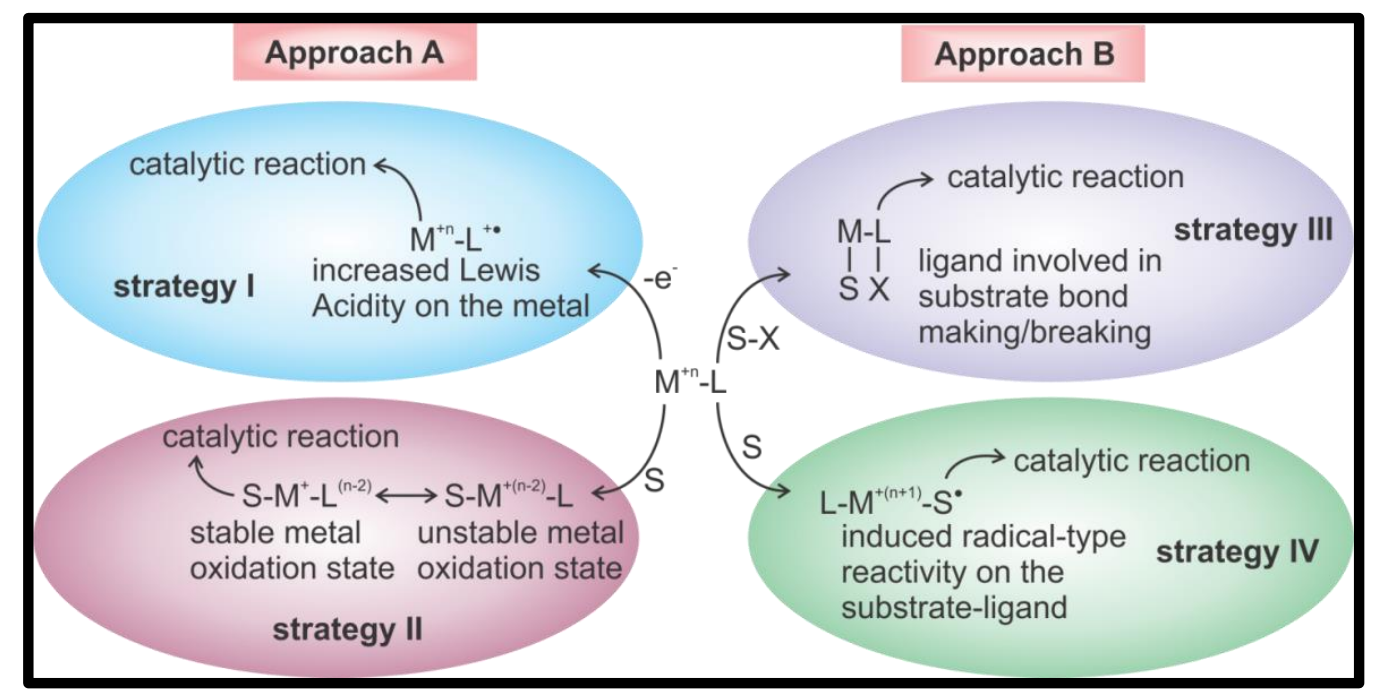

Figure 6. Illustration showing the four traditional reaction pathways observed with redox noninnocent ligands in catalysis $(\mathrm{S}=$ substrate).

be employed. The first is the modification of the Lewis acidity of the metal via reduction/oxidation of the ligand. Doing so strongly influences the substrate affinity and lowers reaction barriers for subsequent reaction steps. The second approach involves exploiting an electron-reservoir in the redox active ligand. This allows the metal to work with the ligand and store extra reducing or oxidizing equivalents on the ligand in elementary steps, avoiding uncommon oxidation states of the metal. The third strategy essentially forces/generates a reactive ligand-radical. These reactive ligand radicals can then actively participate in the making and breaking of chemical bonds during catalysis, 
allowing reactions to be performed that are difficult to achieve otherwise. The final strategy is similar to the third, but uses radical-type activation of the substrates or modification of the substrate reactivity in cases where the substrate itself acts as a redox non-innocent ligand, as demonstrated previously in the Grapperhaus group. ${ }^{98}$ In general terms, a redox active non-innocent ligand can either participate in the catalytic cycle by (A) accepting/releasing electrons (strategies I and II) or by (B) forming/breaking chemical bonds of the substrate (strategies III and IV) (Figure 6).

The first non-transition metal homogeneous HER catalyst reported was an aluminum-bis(imino)pyridine complex by Thompson et al. that evolved $\mathrm{H}_{2}$ with a TOF of $3.3 \mathrm{hr}^{-1}$ at an overpotential of $0.5 \mathrm{~V}$, via ligand-centered reduction and protonation. ${ }^{99}$ As shown later in Chapter three, Haddad et al. reported a rhenium dithiolate complex as the first reversible, ligand-centered catalyst for both HER and HOR, which proceeds through a radical coupling mechanism. ${ }^{77}$ Subsequently, Solis et al. reported a nickel phlorin intermediate with a hydridic $\mathrm{C}-\mathrm{H}$ bond that reacts with an external acid to produce $\mathrm{H}_{2}$ in a purely ligand-centered process. ${ }^{71}$ Following these reports, Zarkadoulas et $a l$. reported DFT computations that suggested Ni-dithiolene HER catalysts may proceed via metal-hydrides or a ligand-centered mechanism. ${ }^{89}$

Recently, we reported the first examples of HER/HOR activity with the noninnocent bis(thiosemicarbazone) ligand framework, Chapter four. ${ }^{76}$ The zinc complex of diacetyl-bis(N-4-methyl-3-thiosemicarbazone), $\mathrm{ZnL}^{1}$, catalyzes HER with a maximum TOF of $1170 \mathrm{~s}^{-1}$, and the HOR in the presence of triethylamine with a maximum TOF of $72 \mathrm{~s}^{-1}$. Unlike many prior homogeneous catalysts that rely on oxidation state changes of transition metals associated with the generation of a metal-hydride intermediate, the non- 
transition metal $\mathrm{Zn}(\mathrm{II})$ is redox inactive, requiring redox processes to be mediated by the ligand. Results of that work indicate a ligand-centered process involving a binuclear transition state with evolution of $\mathrm{H}_{2}$ via ligand hydride-proton coupling. Notably, the free ligand $\mathrm{H}_{2} \mathrm{~L}^{1}$ also demonstrates similar HER activity. In addition to homogeneous catalysis, transition metal-free HER electrocatalysts have been reported in heterogeneous systems, based on $\mathrm{N}$-doped graphene $(\mathrm{NG})$ with graphitic-carbon nitride $\left(\mathrm{G}-\mathrm{C}_{3} \mathrm{~N}_{4}\right),{ }^{100}$ as well as metal-free and zinc-phthalocyanines. ${ }^{101-106}$ Furthermore, a heterogeneous metalfree frustrated Lewis pair ${ }^{107} \mathrm{HOR}$ electrocatalyst has been reported and is proposed to operate via a hydride intermediate, similar to $\mathrm{Ni}{ }^{13,108}$ and $\mathrm{Fe}{ }^{86,109}$ homogeneous HOR catalysts.

Clearly, the use of redox non-innocent ligands provides a variety of new and versatile tools that can be used to control reactivity of transition metal complexes. The principal of non-innocent ligands are rapidly being applied to HER and HOR electrocatalysis, leading to the pursuit of new catalysts for small molecule activation where reactivity occurs exclusively on the ligand. This type of reactivity leads to mechanisms for hydrogen evolution or oxidation in which the $\mathrm{H}-\mathrm{H}$ bond is either split or formed in either a ligand-centered homolytic fashion through the coupling of two $\mathrm{H}^{\bullet}$ radicals, or in a ligand-centered heterolytic fashion via recombination of $\mathrm{H}^{+}$and $\mathrm{H}^{-}$. The study of these two types of ligand-centered catalysis for HER and HOR will be presented in the following chapters of this dissertation. 


\section{CHAPTER II: EXPERIMENTAL DETAILS}




\subsection{Materials and Physical Methods}

All chemicals were purchased from commercial sources (Aldrich, VWR Chemicals, TCI, Acros, Alfa Aesar) and used without purification unless noted otherwise stated. $\mathrm{AgPF}_{6}$ was obtained from Aldrich and stored in an argon filled dry box. The ligand, LH, and the $\mathrm{ReL}_{3}$ and $\left[\mathrm{ReL}_{3} \cdot \mathrm{C}_{2} \mathrm{H}_{4}\right]\left[\mathrm{PF}_{6}\right]_{2}$ metal complexes were synthesized by the modification as described below. ${ }^{110}$ The $\mathrm{H}_{2} \mathrm{~L}$ ligand and the $\mathrm{CuL}^{1}$ and $\mathrm{ZnL}^{1}$ and metal complex were made according to published literature methods ${ }^{111,112}$ as described below. All solvents were purified with an MBraun solvent purification system or prepared (methanol) utilizing standard methods and were freshly distilled immediately before use. ${ }^{113}$ All reactions were performed under anaerobic conditions via standard Schlenk line techniques unless otherwise noted. X-ray crystallography was conducted by Dr. Mark Mashuta at the University of Louisville's X-ray diffraction. X-ray crystallographic data were collected on a Brucker SMART APEX CCD diffractometer. CCDC-1403507 and 1410091 contains the supplementary crystallographic data for this dissertation. Data can be obtained free of charge from The Cambridge Crystallographic Data Centerviawww.ccdc.cam.ac.uk/data_request.cif.

\subsection{Crystallographic Details}

A purple prism $0.27 \times 0.27 \times 0.12 \mathrm{~mm}^{3}$ crystal of $\left[\operatorname{Re}(\mathrm{LH}) \mathrm{L}_{2}\right] \mathrm{PF}_{6}$ was mounted on a glass fiber for collection of x-ray data on an Agilent Technologies Gemini CCD diffractometer. The CrysAlis PRO (CCD)5 software package (v 1.171.36.28) was used to acquire a total of 562 thirty-second frame $\omega$-scan exposures of data at $100.0(1) \mathrm{K}$ to a $2 \Theta \max =56.20^{\circ}$ using monochromated MoK $\alpha$ radiation $(0.71073 \AA)$ from a sealed tube. Frame data were processed using CrysAlis PRO (RED)5 (v 1.171.34.36) to determine final unit cell 
parameters: $a=9.59553(9) \AA, b=33.0018(3) \AA, c=15.41951(15) \AA, \alpha=90^{\circ}, \beta=$ $97.5416(10)^{\circ}, \gamma=90^{\circ}, \mathrm{V}=4840.66(8) \AA 3, D_{\text {calc }}=1.663 \mathrm{Mg} / \mathrm{m}^{3}, \mathrm{Z}=4$ to produce raw $\mathrm{hkl}$ data that were then corrected for absorption (transmission min. $/$ max. $=0.743 / 1.00 ; \mu=$ $2.834 \mathrm{~mm}-1)$ using SCALE3 ABSPACK. The structure was solved by Patterson methods in the space group P $2{ }_{1} / \mathrm{c}$ using SHELXS-907 and refined by least squares methods on F2 using SHELXL-977 incorporated into the SHELXTL8 (v 6.14) suite of programs. All non-hydrogen atoms were refined anisotropically. The $\mathrm{H}$ atom bonded to S3 was located in difference maps; its geometric parameters were refined with $\mathrm{U}(\mathrm{H})=1.2 \mathrm{x}$ Ueq (attached S atom). Phenyl hydrogen atoms were placed in their geometrically generated positions and refined as a riding model that were included as fixed contributions with $\mathrm{U}(\mathrm{H})=1.2 \times$ Ueq (attached $\mathrm{C}$ atom). For 13,986 unique reflections (R(int) 0.0281 ) the final anisotropic full matrix least-squares refinement on F2 for 598 variables converged at $\mathrm{R}_{1}=0.033$ and $\mathrm{wR}_{2}=0.078$ with a GOF of 1.09 .

\section{Preparation of $\left[\operatorname{Re}(\mathrm{LH}) \mathrm{L}_{2}\right] \mathrm{PF}_{6}$ Crystal:}

$\left[\mathrm{Re}(\mathrm{LH}) \mathrm{L}_{2}\right] \mathrm{PF}_{6}$ crystals were prepared as follows: A $7.5 \mathrm{mg}$ sample of $\left[\mathrm{ReL}_{3} \cdot \mathrm{C}_{2} \mathrm{H}_{4}\right]\left[\mathrm{PF}_{6}\right]_{2}$ was placed in a test tube and $1 \mathrm{~mL}$ of dry methanol was added via syringe to yield a burgundy red solution. The sample was sealed with a rubber stopper secured with copper wire. After thirteen days, dark purple crystals of $\left[\mathrm{Re}(\mathrm{LH}) \mathrm{L}_{2}\right] \mathrm{PF}_{6}$ were obtained. Crystallographic data can be obtained free of charge from The Cambridge Crystallographic Data Center (CCDC 1403507).

\section{Preparation of $\left[\operatorname{Re}(\mathrm{LH}) \mathrm{L}_{2}\right] \mathrm{O}_{3} \mathrm{SCF}_{3}$ Crystal:}

$\left[\mathrm{Re}(\mathrm{LH}) \mathrm{L}_{2}\right] \mathrm{O}_{3} \mathrm{SCF}_{3}$ crystals were prepared as follows: A $3 \mathrm{mM}$ solution of $\mathrm{ReL}_{3}$ in dry degassed chlorobenzene was sealed in a vacuum/flame dried test tube and under a 
hydrogen atmosphere with $7 \mu \mathrm{L}$ of triflic acid. The solution was carefully layered with dry, degassed cyclohexane. After ten days dark purple crystals of $\left[\mathrm{Re}(\mathrm{LH}) \mathrm{L}_{2}\right] \mathrm{O}_{3} \mathrm{SCF}_{3}$ were obtained. Crystallographic data can be obtained free of charge from The Cambridge Crystallographic Data Center (CCDC 1410091).

\subsection{Chemical Synthesis}

(2-diphenylphosphinobenzenethiol), (LH): Benzenethiol (6.6 mL, $7 \mathrm{~g}, 0.064 \mathrm{~mol})$ was added dropwise slowly to n-butyllithium solvent (57 mL, $0.142 \mathrm{~mol}$ ) and $\mathrm{N}, \mathrm{N}, \mathrm{N}$ ', N'tetramethylethylenediamine $(22 \mathrm{~mL}, 0.14 \mathrm{~mol})$ in $100 \mathrm{~mL}(0.142 \mathrm{~mol})$ in cyclohexane at room temperature under nitrogen atmosphere. The reaction mixture was heated to $70^{\circ} \mathrm{C}$ for four hours under reflux, it was filtered and then the precipitate was washed with hexane $(100 \mathrm{~mL})$. Tetrahydrofuran $(100 \mathrm{~mL})$ in acetone dry ice bath at $-78^{\circ} \mathrm{C}$ dissolved the resultant lithium precipitate (lithium 2-lithiobenzenethiolate).

Chlorodiphenylphosphine $(8.41 \mathrm{~mL}, 0.045 \mathrm{~mol})$ was then added dropwise to the THF solution in at $0^{\circ} \mathrm{C}$ over 2 hours. The mixture was stirred for 24 hours at room temperature. The reaction mixture, diphenylphosphine 2-lithiobenzenethiolate, was quenched with aqueous hydrochloric acid $(30 \mathrm{~mL} \mathrm{HCl}$ and $170 \mathrm{~mL}$ distilled water) and dried in vacuo. Distilled water $(150 \mathrm{~mL})$ and $300 \mathrm{~mL}$ diethyl ether was then added. The water layer was extracted with ether (3X). The ether layer was then dried with $\mathrm{MgSO}_{4}$ and then the ether was using an external trap to give the indicated products (2diphenylphosphinobenzenethiol). Yield: 1.208 g. ${ }^{1} \mathrm{H}$ NMR $\left(\mathrm{CD}_{2} \mathrm{Cl}_{2}\right)$ : $(\mathrm{ppm})=7.3-6.7$ $(14 \mathrm{H}, \mathrm{m}), 4.00(1 \mathrm{H}, \mathrm{SH}) .{ }^{31} \mathrm{P} \mathrm{NMR}\left(\mathrm{CD}_{2} \mathrm{CI}_{2}\right)(\mathrm{ppm})=-11.73$.

[tris(2-diphenylphosphinobenzenethiolato)rhenium(III)], $\quad\left(\mathbf{R e L}_{3}\right): \quad 0.11 \mathrm{~g} \quad(0.036$ mmol) LH (2-diphenylphosphinobenzenethiol) in $0.7 \mathrm{~mL}$ triethylamine was added to 0.1 
g $(0.12 \mathrm{mmol})\left[\mathrm{ReOCl}_{3}\left(\mathrm{PPh}_{3}\right)_{2}\right]$ in methanol $(25 \mathrm{~mL})$. The mixture was heated and stirred under reflux for 30 minutes. The precipitate was filtered under gravity. The burgundy product was washed with ethanol and diethyl ether and dried in vacuo. Yield: $75 \%$ (0.096 g, $0.09 \mathrm{mmol})$. The square wave voltammetry showed events at $427 \mathrm{mV}$, $357 \mathrm{mV}$ and $-1600 \mathrm{mV} \mathrm{vs} \mathrm{Fc}^{+} / \mathrm{Fc}$.

([ethane-1,2-diylbis((thio-2,l-phenylene)diphenylphosphine)]-(2diphenylphosphinobenzenethiolato)rhenium(III)) hexafluorophosphate, ( $\left.\left[\operatorname{ReL}_{3}{ }^{\bullet} \mathbf{C}_{2} \mathbf{H}_{4}\right]\left[\mathbf{P F}_{6}\right]_{2}\right)$ : To a burgundy solution of $\mathrm{ReL}_{3}(30 \mathrm{mg}, 28 \mu \mathrm{mol})$ in $\mathrm{C}_{6} \mathrm{H}_{5} \mathrm{Cl}$ (5 $\mathrm{mL})$ was added $\mathrm{AgPF}_{6}(14 \mathrm{mg}, 56 \mu \mathrm{mol})$. The resulting solution was bubbled with ethylene during which an orange color developed. The mixture was then filtered through cotton wool to remove $\mathrm{Ag}(\mathrm{s})$. Within 10 minutes a fine orange microcrystalline product precipitates. The $\mathrm{C}_{6} \mathrm{H}_{5} \mathrm{Cl}$ was removed via cannula and the product dissolved in a mixture of $\mathrm{CH}_{2} \mathrm{CI}_{2}(1.0 \mathrm{~mL})$ and $\mathrm{C}_{6} \mathrm{H}_{5} \mathrm{Cl}(0.6 \mathrm{~mL})$ under an ethylene atmosphere. Slow evaporation of the solvent yields $\mathrm{x}$-ray quality needles.

Diacetyl-bis(N4-methyl-3-thiosemicarbazone), $\quad\left(\mathbf{H}_{2} \mathbf{L}^{\mathbf{1}}\right)$ : 4-methylthiosemicarbazide $(2.40 \mathrm{~g}, 22.8 \mathrm{mmol})$ was dissolved in ethanol $(50 \mathrm{~mL})$ and butane-2,3-dione $(1.0 \mathrm{~mL}, 11.4$ mmol) and concentrated $\mathrm{H}_{2} \mathrm{SO}_{4}$ (5 drops) were added. The reaction stirred at room temperature for 16 hours. The white precipitate was filtered, rinsed with ethanol and diethyl ether. (93.0\%). ${ }^{1} \mathrm{H}-\mathrm{NMR}\left(\mathrm{DMSO}_{-} \mathrm{d}_{6}\right) \delta 10.23(\mathrm{~s}, 2 \mathrm{H}) \mathrm{NH}, 8.38(\mathrm{~m}, 2 \mathrm{H}) \mathrm{NHCH}_{3}$, $3.02(\mathrm{~d}, 6 \mathrm{H}, \mathrm{J}=4.5 \mathrm{~Hz}) \mathrm{NHCH}_{3}, 2.20(\mathrm{~s}, 6 \mathrm{H}) 2 \times \mathrm{CH}_{3}$.

Diacetyl-bis(N4-methyl-3-thiosemicarbazonato) zinc(II), (ZnLL $\left.{ }^{\mathbf{1}}\right): \mathrm{H}_{2} \mathrm{~L}^{1}(1.50 \mathrm{~g}, 5.8$ mmol) was suspended in methanol $(50 \mathrm{~mL})$ and $\mathrm{Zn}(\mathrm{OAc})_{2} 2 \mathrm{H}_{2} \mathrm{O}(1.39 \mathrm{~g}, 6.3 \mathrm{mmol})$ was added. The reaction stirred at reflux for 4 hours. The yellow precipitate was filtered, 
rinsed with methanol and diethyl ether. ${ }^{1} \mathrm{H}$ NMR $\left(\mathrm{DMSO}-\mathrm{d}_{6}\right): \delta / \mathrm{ppm} 7.21(2 \mathrm{H}$, br s, $\left.\mathrm{CH}_{3} \mathrm{NH}\right) ; 2.83$ and $2.81\left(6 \mathrm{H}\right.$, two overlapping singlets, $\left.\mathrm{CH}_{3} \mathrm{NH}\right) ; 2.20\left(6 \mathrm{H}, \mathrm{s}, \mathrm{CH}_{3} \mathrm{C}=\mathrm{N}\right)$.

Diacetyl-bis(N4-methyl-3-thiosemicarbazonato) copper(II), (CuL $\left.{ }^{\mathbf{1}}\right): \mathrm{H}_{2} \mathrm{~L}^{1}(0.50 \mathrm{~g}, 1.9$ mmol) was suspended in methanol $(25 \mathrm{~mL})$ and $\mathrm{Cu}(\mathrm{OAc})_{2} \cdot \mathrm{H}_{2} \mathrm{O}(0.42 \mathrm{~g}, 2.09 \mathrm{mmol})$ was added. The reaction was stirred at reflux for four hours, and the red-brown precipitate was filtered, and rinsed with methanol and diethyl ether.

Diacetyl-bis(N4-methyl-3-thiosemicarbazonato)

Copper(I),

Bis(cyclopentadienyl)cobalt(III), $\left[\left(\mathbf{C u L}^{\mathbf{1}}\right]^{-}\right.$: In a the glove box, $6 \mu$ moles $(2 \mathrm{mg})$ of $\mathrm{CuL}^{1}$ was dissolved in $2 \mathrm{~mL}$ DMSO- $\mathrm{d}_{6}$ and stirred. To this was added 1 equivalent of cobaltocene $(6 \mu$ moles $/ 1 \mathrm{mg})$ and stirred for 15 minutes. Upon addition of cobaltocene, the solution color changes from red to purple. ${ }^{1} \mathrm{H}$ NMR (DMSO- $\left.\mathrm{d}_{6}\right): \delta / \mathrm{ppm} 7.94(1 \mathrm{H}, \mathrm{s}$, $\left.\mathrm{CH}_{3} \mathrm{NH}\right) ; 2.86\left(3 \mathrm{H}, \mathrm{CH}_{3} \mathrm{NH}\right) ; 2.72\left(3 \mathrm{H}, \mathrm{s}, \mathrm{CH}_{3} \mathrm{C}=\mathrm{N}\right)$.

\subsection{Electrochemical Methods}

Cyclic voltammetry is a technique involving sweeping the electrode potential between limits $\mathrm{E}_{\text {initial }}$ and $\mathrm{E}_{\text {final }}$ at a predetermined sweep rate or scan rate, v. Once the electrode potential reaches $\mathrm{E}_{\text {final, }}$, it is switched and returned to $\mathrm{E}_{\text {initial. }}{ }^{114,115}$ The observed peaks in cyclic voltammetry are the result of oxidation or reduction at the electrode surface, which is known as the Nernstian diffusion layer process. As the reduction potential $\left(\mathrm{E}_{\mathrm{pc}}\right)$ is reached for a system, current is produced by the reduction of the analyte.

All cyclic voltammetry (CV) and controlled potential coulometry (CPC) measurements for experiments with $\mathrm{ReL}_{3}$ were recorded using a Par 273 potentiostat, while all cyclic voltammetry (CV) and controlled potential coulometry (CPC) measurements for experiments with $\mathrm{H}_{2} \mathrm{~L}^{1}, \mathrm{ZnL}^{1}$, and $\mathrm{CuL}^{1}$ were recorded using a Gamry 
Interface potentiostat/galvanostat. All CV experiments were performed using a glassy carbon working electrode $\left(6.5 \mathrm{~mm}\right.$ diameter, surface area $\left.=0.07 \mathrm{~cm}^{2}\right)$, a platinum wire counter electrode, and $\mathrm{Ag} / \mathrm{AgCl}$ reference electrode. Potentials are reported versus ferrocenium/ferrocene $\left(\mathrm{Fc}^{+} / \mathrm{Fc}\right)$, which was measured as an internal reference for each sample. The working electrode was polished with alumina slurry prior to use. Working and counter electrodes were both cleaned before use by sonication in water, methanol, isopropanol, acetone and experimental solvent (dichloromethane/methanol/acetonitrile). All electrochemical experiments were conducted under a $\mathrm{N}_{2}$ atmosphere (except for $\mathrm{H}_{2}$ oxidation studies). CV measurements were conducted using a three-neck electrochemical cell that was washed and dried in oven over night before use.

CPC measurements with $\mathrm{ReL}_{3}$ were conducted using a custom cell described previously ${ }^{116}$ with a volume of $\sim 10 \mathrm{~mL}$, which was washed and dried in oven over night before use. The working compartment was fitted with a glassy carbon working electrode (surface area $=0.07 \mathrm{~cm}^{2}$ ) and an $\mathrm{Ag} / \mathrm{AgCl}$ reference electrode. The auxiliary compartment was fitted with a Pt wire counter electrode. The working compartment was filled with $10 \mathrm{~mL}$ of $0.05 \mathrm{M}$ acetic acid in a $0.1 \mathrm{M} \mathrm{Bu}_{4} \mathrm{NPF}_{6}$ dichloromethane solution, while the auxiliary compartment was filled with $2 \mathrm{~mL}$ of $0.1 \mathrm{M} \quad \mathrm{Bu}_{4} \mathrm{NPF}_{6}$ dichloromethane solution. Solution diffusion across the glass frit was slow under static pressure. Both compartments were purged for 15 min with $\mathrm{N}_{2}$. A control (blank) CPC study over 6 hours resulted in a total charge accumulation of $614 \mu \mathrm{C}$. Electrolysis was then measured with the addition of the $0.3 \mathrm{mM} \mathrm{ReL}_{3}$. Electrolysis was conducted for 6 hours and the headspace samples were subjected to gas chromatographic analysis. A Gow-Mac series 400 GC-TCD with molecular sieve column was used for product 
detection. The column was heated to $130{ }^{\circ} \mathrm{C}$ under $\mathrm{N}_{2}$ gas flow with $250 \mu \mathrm{L}$ injection samples injected onto the column. The integrated area of the $\mathrm{H}_{2}$ peak was then compared to the calibration curve made in order to calculate the moles of $\mathrm{H}_{2}$ generated.

$\mathrm{CPC}$ measurements for experiments with $\mathrm{ZnL}^{1}$ and $\mathrm{CuL}^{1}$ were conducted using a two-compartment glass electrolysis cell with working and auxiliary compartments separated by a frit, with a volume of $10 \mathrm{~mL}$ in each, washed and dried the night before use. The working compartment was fitted with a glassy carbon working electrode and an $\mathrm{Ag} / \mathrm{AgCl}$ reference electrode. The auxiliary compartment was fitted with a $\mathrm{Pt}$ wire counter electrode.

For CPC experiments with $\mathrm{ZnL}^{1}$ the working compartment contained $12 \mathrm{mM}$ acetic acid added to a $0.1 \mathrm{M} \mathrm{Bu}_{4} \mathrm{NPF}_{6}$ methanol solution, while the auxiliary compartment was filled with $0.1 \mathrm{M} \mathrm{Bu}_{4} \mathrm{NPF}_{6}$ methanol solution. Both compartments were purged for 15 min with $\mathrm{N}_{2}$. A control (blank) CPC study was conducted and subtracted from experimental results. Electrolysis was then measured with the addition of the $0.1 \mathrm{mM} \mathrm{ZnL}$, and run for 2.5 hours. Headspace samples were extracted and subjected to gas chromatographic analysis every 30 minutes. A Gow-Mac series 400 GC-TCD with molecular sieve column was used for product detection. The column was heated to 130 ${ }^{\circ} \mathrm{C}$ under $\mathrm{N}_{2}$ gas flow with $250 \mu \mathrm{L}$ injection samples injected onto the column. The integrated area of the $\mathrm{H}_{2}$ peak was then compared to the pre-made $\mathrm{H}_{2}$ calibration curve in order to calculate the volume and moles of $\mathrm{H}_{2}$ generated.

For CPC experiments with $\mathrm{CuL}^{1}$ the working compartment contained $0.226 \mathrm{M}$ acetic acid added to a $0.1 \mathrm{M} \mathrm{Bu}_{4} \mathrm{NPF}_{6}$ acetonitrile / dimethylformamide (DMF) solution, while the auxiliary compartment was filled with $0.1 \mathrm{M} \mathrm{Bu}_{4} \mathrm{NPF}_{6}$ acetonitrile / DMF 
solution. Both compartments were purged for $15 \mathrm{~min}$ with $\mathrm{N}_{2}$ prior to electrolysis. A control (blank) CPC study was conducted and subtracted from experimental results. Electrolysis was then measured with the addition of the $0.6 \mathrm{mM} \mathrm{CuL}^{1}$ and conducted various time intervals, then subjected to GC-TCD analysis at the end of the electrolysis in the same manner as described above.

Blank and control experiments were performed for $\mathrm{ReL}_{3}, \mathrm{CuL}^{1}, \mathrm{ZnL}^{1}$ and $\mathrm{H}_{2} \mathrm{~L}^{1}$ HER CV studies. Blank runs consisted of $0.1 \mathrm{M} \mathrm{Bu}_{4} \mathrm{NPF}_{6}$ methanol, dichloromethane, or acetonitrile, depending on experiment, which had been purged with $\mathrm{N}_{2}$ gas for 10 minutes. Control CVs run in $0.1 \mathrm{M} \mathrm{Bu}_{4} \mathrm{NPF}_{6}$ methanol, dichloromethane, or acetonitrile with acetic acid showed minimal currents when compared to currents observed after addition of either $\mathrm{CuL}^{1}, \mathrm{ZnL}^{1}$ or $\mathrm{H}_{2} \mathrm{~L}^{1}$ electrocatalysts.

Blank and control experiments were performed for $\mathrm{ReL}_{3}, \mathrm{ZnL}^{1}$ and $\mathrm{H}_{2} \mathrm{~L}^{1} \mathrm{HOR}$ $\mathrm{CV}$ studies. Blank runs consisted of $0.1 \mathrm{M} \mathrm{Bu}_{4} \mathrm{NPF}_{6}$ methanol or dichloromethane solutions, which had been purged with $\mathrm{N}_{2}$ gas for 10 minutes. Control CVs in the absence of catalyst were performed. CVs were run under an $\mathrm{H}_{2}$ atmosphere in solutions of $0.1 \mathrm{M}$ $\mathrm{Bu}_{4} \mathrm{NPF}_{6}$ methanol with increasing concentrations of triethylamine, added until reaching base saturated concentrations. The current observed was significantly lower when compared to the current observed after the addition of the $\mathrm{ReL}_{3}, \mathrm{ZnL}^{1}$ or $\mathrm{H}_{2} \mathrm{~L}^{1}$ electrocatalysts. Additionally control experiments were performed with $\mathrm{ReL}_{3}, \mathrm{ZnL}^{1}$ or $\mathrm{H}_{2} \mathrm{~L}^{1}$ in $0.1 \mathrm{M} \mathrm{Bu}_{4} \mathrm{NPF}_{6}$ methanol solutions under an $\mathrm{N}_{2}$ atmosphere. Application of an $\mathrm{N}_{2}$ atmosphere resulted in no catalytic currents. After introduction of an $\mathrm{H}_{2}$ atmosphere and purging the solution with $\mathrm{H}_{2}$ for 15 minutes, catalytic current was observed. 
Post electrolysis dip tests experiments were performed on the working electrode after electrolysis in $0.1 \mathrm{M} \mathrm{Bu}_{4} \mathrm{NPF}_{6}$ acetonitrile / DMF solutions with $0.6 \mathrm{mM} \mathrm{CuL}^{1}$ with $0.292 \mathrm{M}$ acetic acid added. After completion of electrolysis, the working electrode was taken from the solution and rinsed with DI water. In both DMF and acetonitrile solvents, a thin film was persisted, coving the working electrode surface. This film-covered electrode was then immersed into a fresh solution of $0.1 \mathrm{M} \mathrm{Bu}_{4} \mathrm{NPF}_{6}$ acetonitrile / DMF solution and $\mathrm{CVs}$ were recorded. Both $\mathrm{CVs}$ showed irreversible reductions and irreversible oxidations. Upon addition of $0.292 \mathrm{M}$ acetic acid, an increase of catalytic current was observed at $-1.7 \mathrm{~V}$ vs $\mathrm{Fc}^{+} / \mathrm{Fc}$, consistent with data observed from homogeneous $\mathrm{CV}$ experiments, and also implying that the film is an active catalyst for HER either acting dependently, independently, or in conjunction with homogenous catalysis. Efforts are currently underway to better understand this development.

\subsection{Overpotential Determination and Calculations}

Overpotential can be defined as the difference between the thermodynamic and equilibrium potentials for a given reaction and the potential at which the reaction occurs under a set of specific conditions. In the case of $\mathrm{H}_{2}$ evolution or oxidation, when either the equilibrium potential for the standard state $\mathrm{H}^{+} / \mathrm{H}_{2}$ couple $\left(\mathrm{E}_{\mathrm{H}}^{\circ}\right)$ is not known for some particular solvent or a reliable pKa scale is unavailable, the direct measurement of the equilibrium potential for the reduction of protons $\left(\mathrm{E}_{\mathrm{H}+}\right)$ can be accomplished through an open circuit potential (OCP) measurements, as described by Bullock, Appel and Helm. ${ }^{117}$ Using this method this method provides an accurate determination of the equilibrium potential for the $\mathrm{H}^{+} / \mathrm{H}_{2}$ couple under a wide range of acids and bases, as well as solvents or mixtures of solvents. For example, recent reports using this method have 
appeared in the literature for the determination of $\mathrm{E}_{\mathrm{H}^{+}}$of protic ionic liquids ${ }^{118}$ and various acid base pairs in acetonitrile and/or water. ${ }^{87}$ The accurate determination of overpotential requires an estimation of $\mathrm{E}_{\mathrm{cat} / 2}$ and $\mathrm{E}_{\mathrm{H}+}$, each of which can change, depending on the reaction conditions. The value for the potential for catalysis should be related to the catalytic current, and therefore, we use $\mathrm{E}_{\mathrm{cat} / 2}$. This combined with a value for $\mathrm{E}_{\mathrm{H}+}$, obtained through OCP measurements allows for calculation of the overpotential ( $)$ for proton reduction or $\mathrm{H}_{2}$ oxidation under specific experimental conditions. This can be estimated as: $\eta=\left|\left(E_{O C P}-E_{c a t / 2}\right)\right|$, where $E_{O C P}$ is the measured open circuit potential measured under catalytic conditions specific for each reaction, and $\mathrm{E}_{\mathrm{cat} / 2}$ is the potential at one-half the maximum of the catalytic current measured for the catalyzed reduction of protons or oxidation of $\mathrm{H}_{2}$. (see appendix for OCP plots)

Overpotential Calculation: $\operatorname{ReL}_{3}$ HER:

$$
\begin{gathered}
\eta=\text { Overpotential }=\left|\left(\mathrm{E}_{\mathrm{BH}+(\mathrm{OCP})}\right)-\left(\mathrm{E}_{\mathrm{cat} / 2}\right)\right| \\
\eta=|[-0.222 \mathrm{~V}-(-0.930 \mathrm{~V})]| \\
\eta=0.708 \mathrm{~V} \mathrm{vs} \mathrm{Fc}^{+} / \mathrm{Fc}
\end{gathered}
$$

\section{Overpotential Calculation; $\operatorname{ReL}_{3}$ HOR:}

$$
\begin{array}{r}
\eta=\text { Overpotential }=\left|\left(\mathrm{E}_{\mathrm{BH}+(\mathrm{OCP})}\right)-\left(\mathrm{E}_{\mathrm{cat} / 2}\right)\right| \\
\eta=|[-1.18-(0.210)]| \\
\eta=0.970 \mathrm{~V} \mathrm{vs} \mathrm{Fc} / \mathrm{Fc}
\end{array}
$$

\section{Overpotential calculation; $\mathrm{ZnL}^{1}$ HER:}

$$
\begin{array}{r}
\eta=\text { Overpotential }=\left|\left(\mathrm{E}_{\mathrm{BH}+(\mathrm{OCP})}\right)-\left(\mathrm{E}_{\mathrm{cat} / 2}\right)\right| \\
\eta=|[-0.924-(-1.68)]| \\
\eta=0.756 \mathrm{~V} \mathrm{vs} \mathrm{Fc} / \mathrm{Fc}
\end{array}
$$


Overpotential calculation; $\mathrm{ZnL}^{1}$ HOR:

$$
\begin{gathered}
\eta=\text { Overpotential }=\left|\left(\mathrm{E}_{\mathrm{BH}+(\mathrm{OCP})}\right)-\left(\mathrm{E}_{\mathrm{cat} / 2}\right)\right| \\
\eta=|(0.190-0.505)| \\
\eta=0.315 \mathrm{~V} \mathrm{vs} \mathrm{Fc}^{+} / \mathrm{Fc}
\end{gathered}
$$

Overpotential calculation; $\mathrm{H}_{2} \mathrm{~L}^{1}$ HER:

$$
\begin{gathered}
\eta=\text { Overpotential }=\left|\left(\mathrm{E}_{\mathrm{BH}+(\mathrm{OCP})}\right)-\left(\mathrm{E}_{\mathrm{cat} / 2}\right)\right| \\
\eta=|[-0.37-(-1.80)]| \\
\eta=1.43 \mathrm{~V} \mathrm{vs} \mathrm{Fc} / \mathrm{Fc}^{0}
\end{gathered}
$$

Overpotential calculation; $\mathrm{H}_{2} \mathrm{~L}^{1}$ HOR:

$$
\begin{gathered}
\eta=\text { Overpotential }=\left|\left(\mathrm{E}_{\mathrm{BH}+(\mathrm{OCP})}\right)-\left(\mathrm{E}_{\mathrm{cat} / 2}\right)\right| \\
\eta=|(0.177-0.505)| \\
\eta=0.328 \mathrm{~V} \mathrm{vs} \mathrm{Fc}^{+} / \mathrm{Fc}
\end{gathered}
$$

Overpotential Calculation; $\mathrm{CuL}^{1}$ HER

$$
\begin{gathered}
\eta=\text { Overpotential }=\left|\left(\mathrm{E}_{\mathrm{BH}+(\mathrm{OCP})}\right)-\left(\mathrm{E}_{\mathrm{cat} / 2}\right)\right| \\
\eta=|[-0.50-(-2.20 \mathrm{~V})]| \\
\eta=1.7 \mathrm{~V} \mathrm{vs} \mathrm{Fc} / \mathrm{Fc}^{0}
\end{gathered}
$$

\subsection{ReL $L_{3}$ : Determination and Calculation of Third-Order Rate Constant, $k$, from Pseudo First-Order Rate Constant $k_{o b s}$, and estimation of Turnover Frequency (TOF) for $\mathrm{H}_{2}$ Evolution and Oxidation}

Calculations were performed using the method described by Dubois et al. ${ }^{84} \mathrm{~A}$ summary of the methods with respect to our specific data is provided below. Equation 1 details the relationship between the catalytic current $i_{c}$, the catalyst concentration [cat], and the acid concentration $\left[\mathrm{H}^{+}\right]$for a catalytic reaction that is second-order in acid, and first-order in catalyst. The terms $n, F, A$, and $D$, are the normal electrochemical terms related to the 
number of electrons transferred, Faraday's constant, area of the electrode, and diffusion constant, respectively.

$i_{\text {cat }}=n F A[$ cat $] \sqrt{D k\left[H^{+}\right]^{2}}$

Equation 2 (Randle-Sevcik eq.) ${ }^{114}$ provides the relationship between the peak current $i_{p}$, catalyst concentration, and scan rate $(v)$ in the absence of acid. The factor of 0.4463 is related to the diffusion equations, ${ }^{114} R$ is the gas constant, and T is temperature in $\mathrm{K}$. The other terms are the same as in equation 1.

$i_{p}=0.4463 F A[c a t] \sqrt{\frac{F v D}{R T}}$

Thus, the ratio of $i_{c a t} / i_{p}$ (equation 3 ) is obtained from equations S1 and S2

$\frac{i_{c a t}}{i_{p}}=\frac{n}{0.4463} \sqrt{\frac{R T k\left[H^{+}\right]^{2}}{F v}}$

Under pseudo first-order conditions where $k_{o b s}=k\left[H^{+}\right]^{2}$, equation 3 simplifies to $4 .^{79,119}$

$\frac{i_{c a t}}{i_{p}}=\frac{n}{0.4463} \sqrt{\frac{R T k_{o b s}}{F v}}$

It should be noted that from equations 3 and 4 that the ratio of $i_{c a t} / i_{p}$ should be directly proportional to the acid concentration at lower acid concentrations and independent of acid concentrations under pseudo first-order conditions as shown in our experimental results.

Equation 4 can be rewritten to solve for $k_{o b s}$ under scan rate independent conditions. Using numerical values of constants at $298 \mathrm{~K}$, equation 5 is obtained.

$k_{o b s}=v * 1.94\left(\frac{i_{c a t}}{i_{p}}\right)^{2}$

At a scan rate of $0.2 \mathrm{~V}$, our currents of $149 \mu \mathrm{A}$ and $17 \mu \mathrm{A}$ for $i_{c a t}$ and $i_{p}$ yield $k_{o b s}=29.8$ $\mathrm{S}^{-1}$. 
From equation 3 , a straight line in a plot of $i_{c a t} / i_{p}$ versus $\left[\mathrm{H}^{+}\right]$in the acid-dependent region is indicative of a second-order dependence on acid concentration. As shown in later in chapter 3 for scan rates of $0.2,0.5$, and $1.0 \mathrm{~V} / \mathrm{s}$, respectively, our data is consistent with this interpretation.

Further, the third-order order rate constant, $k$, can be obtained from the scan rate dependence of the slopes of the current vs $\left[\mathrm{H}^{+}\right]$plots in order to provide a double slope plot for which the slope can be used to solve for $k$, described by equations 6 and 7 .

$$
\begin{aligned}
& \frac{i_{c a t}}{i_{p}}=\frac{n}{0.4463} \sqrt{\frac{R T k}{F v}}\left[H^{+}\right]^{2} \\
& \text { slope }=\frac{n}{0.4463} \sqrt{\frac{R T k}{F v}}
\end{aligned}
$$

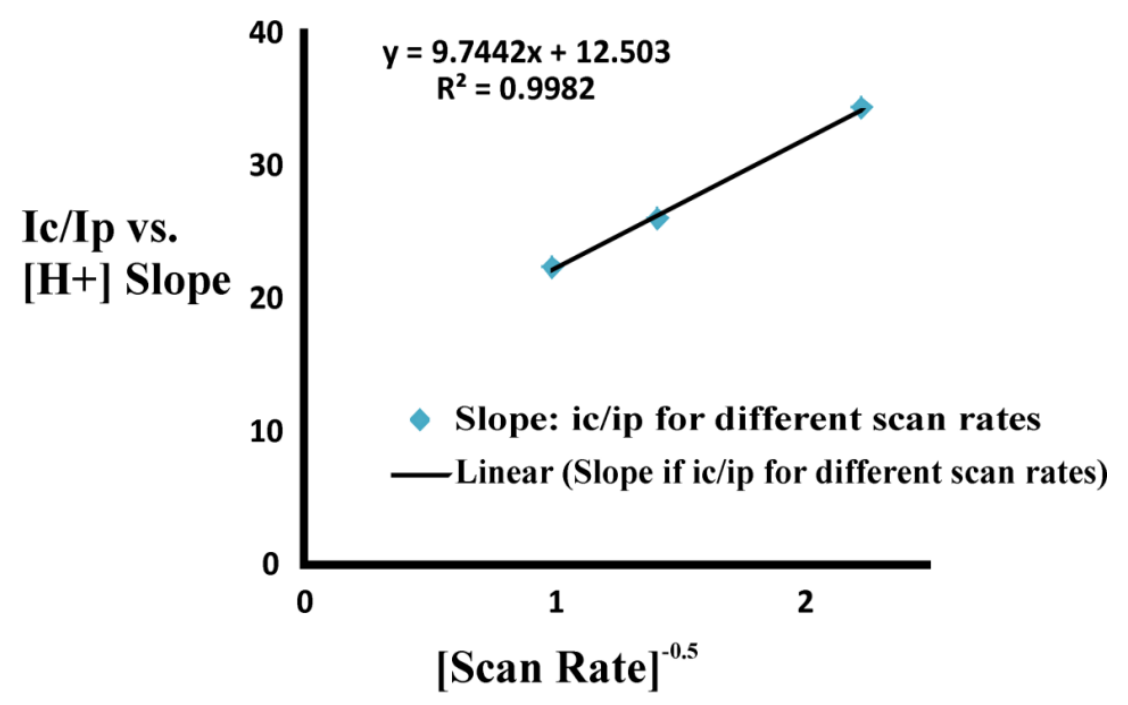

Figure 7. Double slope plot for evaluation of the third order rate constant, $k$.

A plot of slopes from Figures S7 - S9 versus $\sqrt{\frac{1}{v}}$ yields a linear relationship (Figure 7).

The slope of this line (the double slope) allows quantification of the third order rate constant $k$ using equation 8 at $298 \mathrm{~K}$. 
double slope $=0.72 \sqrt{k}$

Using our data, $k=184 \mathrm{M}^{-2} \mathrm{~s}^{-1}$.

\section{7. $\mathrm{ZnL}^{1}$ and $\mathrm{H}_{2} \mathrm{~L}$ : Determination and Calculation of TOF for $\mathrm{H}_{2}$ Evolution and Oxidation}

As stated above equation 4 is obtained by taking the ratio for catalytic current, equation 1 , and peak current (equation 2).

$\frac{i_{c a t}}{i_{p}}=\frac{n}{0.4463} \sqrt{\frac{R T k_{o b s}}{F v}}$

Equation 4 can further be simplified to equation 5 under scan rate independent conditions, when $\mathrm{n}=1$ for bimolecular processes. An $\mathrm{n}$ value of 1 was used due to the bimolecular nature of the mechanism involving $\mathrm{ZnL}^{1}$ and $\mathrm{H}_{2} \mathrm{~L}^{1}$.

$k_{o b s}=v \times\left[\frac{\frac{i_{c a t}}{i_{p}}}{0.35}\right]^{2}$

Since no peak current for $\mathrm{ZnL}^{1}$ was observed in the absence of substrate in methanol, the experimentally determined diffusion coefficient (described below), $1.15 \times 10^{-7}$, was used to calculate the value for $i_{p}$. This gave an $i_{p}$ of $43 \mu \mathrm{A}$ when run at $5 \mathrm{~V} / \mathrm{s}$ (the scan rate in which catalytic current becomes independent of scan rate). Furthermore, the value of $i_{p}$ was confirmed through simulations using DigiElch, which agree with the calculated $i_{p}$ values. Using equation 5 , the TOF or $k_{o b s}$ can be calculated using the experimentally determined $i_{p}$ value as well as the $i_{\text {cat }}$ observed at $5 \mathrm{~V} / \mathrm{s}, 230 \mu \mathrm{A}$. This results in a TOF of $1170 \mathrm{~s}^{-1}$.

We then calculated the TOF using Eq. 10, which is Eq. 1 under pseudo first-order conditions, to compare both calculated values, which are in agreement with each other. 
$i_{c a t}=n F A[c a t] \sqrt{D k_{o b s}}$

Sample Calculations $\mathrm{ZnL}^{1}{ }^{\mathrm{TOF} / \mathrm{k}_{\mathrm{obs}}}$ :

Using Eq. 10:

$$
\begin{aligned}
i_{c a t}=230 \mu \mathrm{A} ; \mathrm{i}_{\mathrm{p}}=43 \mu \mathrm{A} ; v=5.0 \mathrm{~V} / \mathrm{s} & \\
& =k_{\text {obs }} / \mathrm{TOF}=1170 \mathrm{~s}^{-1}
\end{aligned}
$$

Using Eq. 9:

$$
\begin{gathered}
i_{c a t}=230 \mu \mathrm{A} ; \mathrm{n}=1 \text { mole } \mathrm{e}^{-} / \text {mole of } \mathrm{ZnL} ; \mathrm{F}=96485 \mathrm{C} / \mathrm{mol} \mathrm{e} ; \mathrm{A}= \\
\left.0.071 \mathrm{~cm}^{2} ; \text { [cat }\right]=3 \mathrm{E}-6 \text { moles } / \mathrm{cm}^{3} ; \mathrm{D}_{\text {cat }}=1.15 \mathrm{E}-7 \mathrm{~cm}^{2} / \mathrm{s} . \\
=k_{\text {obs }} / \mathrm{TOF}=1100 \mathrm{~s}^{-1}
\end{gathered}
$$

HOR TOF ZnL and $\mathrm{H}_{2} \mathrm{~L}$ Sample Calculation when $v=1.0 \mathrm{~V} / \mathrm{s}$ :

$Z n L^{1}$ :

$$
\mathrm{TOF}=k_{o b s}=\nu * 1.94\left(i_{c a t} / \mathrm{i}_{\mathrm{p}}\right)^{2} \text { when } i_{c a t}=-712 \mu \mathrm{A} \text { and } \mathrm{i}_{\mathrm{p}}=-117 \mu \mathrm{A} \text { at } 1.0
$$

$\mathrm{V} / \mathrm{s}$

$$
\mathrm{TOF}=72 \mathrm{~s}^{-1}
$$

$\mathrm{H}_{2} L^{1}$ :

$$
\mathrm{TOF}=k_{\text {obs }}=v * 1.94\left(i_{\text {cat }} / \mathrm{i}_{\mathrm{p}}\right)^{2} \text { when } i_{\text {cat }}=-475 \mu \mathrm{A} \text { and } \mathrm{i}_{\mathrm{p}}=-117 \mu \mathrm{A} \text { at } 1.0
$$

$\mathrm{V} / \mathrm{s}$

$$
\mathrm{TOF}=32 \mathrm{~s}^{-1}
$$

\section{8. $\mathrm{CuL}^{1}$ : Determination and Calculation of TOF for $\mathrm{H}_{2}$ Evolution}

Using equation 5 as described above we can calculate the estimated TOF for the $\mathrm{CuL}^{1}$ electrocatalyst. The $i_{p}$ of $\mathrm{Cu}^{\mathrm{II} / \mathrm{I}}$ reduction event, $14.0 \mu \mathrm{A}$, and the $i_{c a t}$ max of $2.25 \mathrm{~mA}$ correspond with a maximum $i_{c a t} / i_{p}$ value of 161 , affording a TOF of $10000 \mathrm{~s}^{-1}$ in 
acetonitrile. ${ }^{120-123}$ Following the same procedure for CVs run in DMF, we get a TOF of $5140 \mathrm{~s}^{-1}$.

\section{$\mathrm{CuL}^{1}$ HER TOF Sample Calculations}

$\underline{\mathrm{TOF}}_{\max }$ Sample Calculation for $\mathrm{CuL}^{1}$ in acetonitrile:

Using equation 5, at scan-rate independent conditions, when $v=0.2 \mathrm{v} / \mathrm{s}$ and when $i_{\text {cat }}=2250 \mu \mathrm{A}$ and $i_{p}=14 \mu \mathrm{A}$

$$
\begin{aligned}
& \frac{i_{c a t}}{i_{p}}=160.71 \\
& \mathbf{T O F}_{\max } / \boldsymbol{k}_{\text {obs }}=\mathbf{1 0 0 0 0 ~ \mathbf { s } ^ { - 1 }}
\end{aligned}
$$

$\underline{\mathrm{TOF}}_{\max }$ Sample Calculation for $\mathrm{CuL}^{1}$ in dimethylformamide:

Using equation 5 , at scan rate independent conditions, when $v=1.0 \mathrm{v} / \mathrm{s}$, and when $i_{\text {cat }}=1490 \mu \mathrm{A}$ and $i_{p}=29 \mu \mathrm{A}$

$$
\begin{aligned}
\frac{i_{c a t}}{i_{p}}= & 51.44 \\
& \mathbf{T O F}_{\max } / \boldsymbol{k}_{\text {obs }}=\mathbf{5 1 4 0 ~ \mathbf { s } ^ { - 1 }}
\end{aligned}
$$

\subsection{ReL $L_{3}$ : Quantification of $\mathrm{H}_{2}$ from Controlled Potential Coulometry} (CPC) and Calculation of Turnover Number and Faradaic Efficiency

Theoretical Moles of Hydrogen Made via Total Charge:

$$
\left(Q_{\text {net }}\right) X\left(1 \mathrm{~mol} \mathrm{e}^{-} / 96485 \mathrm{C}\right) \times\left(1 \mathrm{~mol} \mathrm{H}_{2} / 2 \mathrm{~mol} \mathrm{e}^{-}\right)=\text {liberated moles } \mathrm{H}_{2} \text {. }
$$

$$
\begin{aligned}
Q_{\text {net }}= & Q_{\text {with cat }} \mathrm{Q}_{\mathrm{w} / \mathrm{o} \mathrm{cat}}=31.2202635-0.0002635=31.22 \mathrm{C} \\
& (31.22) \times(1 \mathrm{~mol} \mathrm{e} / 96485 \mathrm{C}) \times\left(1 \mathrm{~mol} \mathrm{H}_{2} / 2 \mathrm{~mol} \mathrm{e}^{-}\right)=0.000162 \mathrm{~mol}
\end{aligned}
$$

$\mathrm{H}_{2}$

$\mathrm{TON}=\left(\mathrm{mol}\right.$ of $\mathrm{H}_{2}$ produced $/ \mathrm{mol}$ of catalyst used $)$

$$
=(0.000162 / 0.000003)=54.0
$$

\section{\% Headspace Calculation}

Assumptions

1. Henry's constant $\left(k_{H}\right)$ for hydrogen in dichloromethane is $0.00151 \mathrm{M} / \mathrm{atm}$

2. Bulk electrolysis occurs in a closed, gas tight cell. 
3. The volume of the solution is $10.0 \mathrm{~mL}$ and it remains constant.

4. The headspace above the reaction prior to bulk electrolysis is $1 \mathrm{~atm}$ of nitrogen.

5. The reaction takes place at $298 \mathrm{~K}$.

6. Ideal gas behavior

Calculation Procedure

1. Calculate moles of $\mathrm{H}_{2}$ based on total charge at $100 \%$ Faradaic efficiency.

2. Divide by the volume of the solution to obtain $\left[\mathrm{H}_{2}\right]$ in solution.

3. Convert $k_{H}$ to the dimensionless form $k_{H}^{c c}$ by multiplying by RT.
a. $\mathrm{k}_{\mathrm{H}}=\left[\mathrm{H}_{2}\right]_{\sin } / \mathrm{P}_{\mathrm{H} 2}$
b. $\mathrm{P}_{\mathrm{H} 2} / \mathrm{RT}=\mathrm{n}_{\mathrm{H} 2 \mathrm{~g}} / \mathrm{V}_{\mathrm{g}}=\left[\mathrm{H}_{2}\right]_{\mathrm{g}}$
c. multiply both sides of "a": $k H R T=R T[H 2] \sin / P H 2$
d. combine "c" and "d": $k_{H} R T=\left[H_{2}\right]_{s l n} /\left[H_{2}\right]_{g}=k_{H}{ }^{c c}$

4. Use $k_{H}^{c c}$ to calculate equilibrium $\left[\mathrm{H}_{2}\right]_{\mathrm{g}}$ assuming an initial $\left[\mathrm{H}_{2}\right]_{\mathrm{g}}=0$ and initial $\left[\mathrm{H}_{2}\right]_{\mathrm{sln}}$ from step 2 .

5. Calculate the equilibrium $P_{H 2}$ using ideal gas law and the equilibrium $\left[H_{2}\right]_{g}=n / V$.

6. Calculate the total pressure as the sum of the partial pressures of $\mathrm{N}_{2}$ and $\mathrm{H}_{2}$.

7. Calculate the $\% \mathrm{H}_{2}$ in the headspace from the values in 5 and 6 .

Sample Calculation: 6 hour electrolysis

$31.22 \mathrm{C} \times\left(\mathrm{mol} \mathrm{e}^{-}\right) /(96485 \mathrm{C}) \times\left(1 \mathrm{~mol} \mathrm{H}_{2}\right) /(2 \mathrm{~mol} \mathrm{e})=0.000162$ moles $\mathrm{H}_{2}(0.000162$ moles $\left.\mathrm{H}_{2}\right) /(0.010 \mathrm{~L})=0.0162 \mathrm{M} \mathrm{H}_{2}$

$k_{H}{ }^{c c}=(0.00151 \mathrm{M} / \mathrm{atm}) \times(0.08214 \mathrm{~L} \mathrm{~atm} / \mathrm{mol} \mathrm{K}) \times(298 \mathrm{~K})=0.03696$ 


$$
\begin{aligned}
& {\left[\mathrm{H}_{2}\right]_{\sin } \quad \rightarrow \quad\left[\mathrm{H}_{2}\right]_{\mathrm{g}}} \\
& \text { intial } \quad 0.0162 \quad 0 \\
& \text { delta } \quad-\mathrm{x} \quad+\mathrm{x} \\
& \text { final } \quad 0.0162-\mathrm{x} \quad \mathrm{x} \\
& 0.03696=(0.0162-\mathrm{x}) / \mathrm{x} \\
& 0.03696 \mathrm{x}=0.0162-\mathrm{x} \\
& 1.03696 \mathrm{x}=0.0162 \\
& \mathrm{x}=\left[\mathrm{H}_{2}\right]_{\mathrm{g}}=0.01562 \mathrm{M} \\
& P_{H 2}=n R T / N=R T\left[H_{2}\right]_{g}=(0.08214 \mathrm{~L} \mathrm{~atm} / \mathrm{mol} \mathrm{K}) \times(298 \mathrm{~K}) \times 0.01562 \mathrm{M}=0.3824 \mathrm{~atm} \\
& P_{T}=1+0.3824=1.3824 \mathrm{~atm} \\
& \% \mathrm{H}_{2}=100 \times(0.3824 / 1.3824)=27.7 \%
\end{aligned}
$$

Observed actual value is lower $21.8 \%$. This indicates either 1) some $\mathrm{H}_{2}$ escaped the cell as it was not gas tight and/or 2) Faradaic efficiency is less than $100 \%$. Results are consistent with a minimum

$$
=\text { Faradaic efficiency of } 73 \% \text {. }
$$

\subsection{0. $\mathrm{ZnL}^{1}$ : Quantification of $\mathrm{H}_{2}$ from $\mathrm{CPC}$ and Turnover Number and Faradaic Efficiency Calculations}

Theoretical Moles of Hydrogen Made via Total Charge:

$19.8 \mathrm{C} \times(1 \mathrm{~mol} \mathrm{e}-/ 96485 \mathrm{C}) \times\left(1 \mathrm{~mol} \mathrm{H}_{2} / 2 \mathrm{~mol} \mathrm{\textrm {e }}\right)=$ moles $\mathrm{H}_{2}$ theoretical

Moles $\mathrm{H}_{2}$ theoretical $=0.00011$ moles $\mathrm{H}_{2}$

Faradaic Efficiency Calculation:

To quantify $\mathrm{H}_{2}$ production, the output gas was sampled, $250 \mu \mathrm{L}$, every 30 minutes and analyzed by the GC-TCD described in electrochemical methods section. After sampling, 
the chromatographic peak area of hydrogen is obtained. The GC-TCD calibration curve was prepared by sampling known hydrogen concentrations, made with known volumes of hydrogen, from the working compartment, with a constant known $\mathrm{N}_{2}$ flow rate, and then measured by the same procedure described above. A linear relationship between the chromatographic peak areas of the hydrogen sampled and the specific amounts of hydrogen used was established, defined by $\mathrm{y}=\mathrm{mx}+\mathrm{b}$, where $\mathrm{y}$ is the peak area and $\mathrm{x}$ is the amount of hydrogen. Using this linear relationship, the amount of hydrogen produced during experimental electrolysis can be calculated from the integrated peak areas obtained.

Faradaic Efficiency $=\left(\right.$ Moles $\mathrm{H}_{2}$ Quantified / Moles of $\mathrm{H}_{2}$ Theoretical $) \times 100 \%$

Faradaic Efficiency $=(0.000093$ moles $) /(0.00011$ moles $) \times 100 \%$

Faradaic Efficiency $=85 \%$

TON Calculations:

TON $=$ Moles of $\mathrm{H}_{2}$ Produced / Moles of $\mathrm{ZnL}$ Used

TON $=\left(0.00011\right.$ moles $\mathrm{H}_{2}$ produced $) /(0.000003$ moles $\mathrm{ZnL}$ used $)$

$\mathrm{TON}=36.7$

\subsection{1. $\mathrm{CuL}^{1}$ : Quantification of $\mathrm{H}_{2}$ from Controlled Potential Coulometry and Turnover Number and Faradaic Efficiency Calculations}

Sample Calculations $\mathrm{CuL}^{1}$ Electrolysis in Acetonitrile:

Trial 1: Total charge $=\mathrm{Q}_{\text {with cat }}-\mathrm{Q}_{\text {blank }}=\mathrm{Q}_{\text {net }}$ $60.49 \mathrm{C}-0.0576 \mathrm{C}=60.43$

Theoretical Moles of Hydrogen Made via Total Charge: $\left.60.43 \mathrm{C} \mathrm{x}\left(1 \mathrm{~mol} \mathrm{e}^{-} / 96485 \mathrm{C}\right) \times\left(1 \mathrm{~mol} \mathrm{H}_{2} / 2 \mathrm{~mol} \mathrm{e}\right)^{-}\right)=$moles $\mathrm{H}_{2}$ theoretical 


\section{Moles $\mathrm{H}_{2}$ theoretical $=0.00031$ moles $\mathrm{H}_{2}$ based on charge from electrolysis}

Trial 1: $\mathrm{CuL}^{1}$ TON Calculation:

$\mathrm{TON}=$ Moles of $\mathrm{H}_{2}$ Produced $/$ Moles of $\mathrm{CuL}^{1}$ Used $\mathrm{TON}=\left(0.00031\right.$ moles $\mathrm{H}_{2}$ produced $) /\left(0.000006\right.$ moles $\mathrm{CuL}^{1}$ used)

$$
\text { TON }=\mathbf{5 1 . 7}
$$

Trial 2: Total Charge $=\mathrm{Q}_{\text {with cat }}-\mathrm{Q}_{\text {blank }}=\mathrm{Q}_{\text {net }}$ $84.74 \mathrm{C}-0.0576 \mathrm{C}=84.68$

Theoretical moles of Hydrogen made via Total Charge 84.68 C x $\left(1 \mathrm{~mol} \mathrm{e}^{-} / 96485 \mathrm{C}\right) \times\left(1 \mathrm{~mol} \mathrm{H}_{2} / 2 \mathrm{~mol} \mathrm{e}^{-}\right)=$moles $\mathrm{H}_{2}$ theoretical

Moles $\mathrm{H}_{2}$ Theoretical $=\mathbf{0 . 0 0 0 4 4}$ moles $\mathrm{H}_{2}$ based on charge from electrolysis

Trial 2: $\mathrm{CuL}^{1}$ TON Calculation:

$\mathrm{TON}=$ Moles of $\mathrm{H}_{2}$ Produced $/$ Moles of $\mathrm{CuL}^{1}$ Used TON $=\left(0.00044\right.$ moles of $\mathrm{H}_{2}$ produced $) /\left(0.000006\right.$ moles $\mathrm{CuL}^{1}$ used)

$$
\text { TON }=73.3
$$

Sample Calculations $\mathrm{CuL}^{1}$ Electrolysis in DMF

Trial 1: Total charge $=\mathrm{Q}_{\text {with cat }}-\mathrm{Q}_{\text {blank }}=\mathrm{Q}_{\text {net }}$ $67.03 \mathrm{C}-0.0682 \mathrm{C}=66.96 \mathrm{C}$

Theoretical Moles of Hydrogen made via total Charge:

$66.96 \times\left(1 \mathrm{~mol} \mathrm{e}^{-} / 96485 \mathrm{C}\right) \times\left(1 \mathrm{~mol} \mathrm{H}_{2} / 2 \mathrm{~mol} \mathrm{e}\right)=$ moles of $\mathrm{H}_{2}$ theoretical

Moles $\mathrm{H}_{2}$ Theoretical $=\mathbf{0 . 0 0 0 3 5}$ moles $\mathrm{H}_{2}$ based on charge from electrolysis

Trial 1: $\mathrm{CuL}^{1}$ TON Calculation:

TON $=$ Moles of $\mathrm{H}_{2}$ Produced $/$ Moles of $\mathrm{CuL}^{1}$ Used $\mathrm{TON}=\left(0.00035\right.$ moles of $\mathrm{H}_{2}$ produced $) /\left(0.000006\right.$ moles $\mathrm{CuL}^{1}$

used)

$$
\text { TON }=58.3
$$

Trial 2: Total Charge $=\mathrm{Q}_{\text {with cat }}-\mathrm{Q}_{\text {blank }}=\mathrm{Q}_{\text {net }}$ $85.06 \mathrm{C}-0.682 \mathrm{C}=85 \mathrm{C}$

Theoretical Moles of Hydrogen made via total Charge: $85 \times\left(1 \mathrm{~mol} \mathrm{e}^{-} / 96485 \mathrm{C}\right) \times\left(1 \mathrm{~mol} \mathrm{H}_{2} / 2 \mathrm{~mol} \mathrm{e}\right)=$ moles of $\mathrm{H}_{2}$ theoretical 


\section{Moles $\mathrm{H}_{2}$ Theoretical $=\mathbf{0 . 0 0 0 4 4}$ moles $\mathrm{H}_{2}$ based on charge from electrolysis}

Trial 2: $\mathrm{CuL}^{1} \mathrm{TON}$ Calculation:

TON $=$ Moles of $\mathrm{H}_{2}$ Produced $/$ Moles of $\mathrm{CuL}^{1}$ Used $\mathrm{TON}=\left(0.00044\right.$ moles of $\mathrm{H}_{2}$ produced $) /\left(0.000006\right.$ moles $\mathrm{CuL}^{1}$

used)

$$
\text { TON }=73.3
$$

Trial 2: $\mathrm{CuL}^{1}$ Faradaic Efficiency Calculation:

Faradaic efficiency $=\left(\right.$ moles of $\mathrm{H}_{2}$ quantified $) /\left(\right.$ moles of $\mathrm{H}_{2}$ theoretical based on charge) $\mathrm{x} 100 \%$

$=(0.00038$ moles $) /(0.00044$ moles $) \times 100 \%$

$=86 \%$ Faradaic Efficiency

Faradaic Efficiency Determination: Evolved gas from the cathode compartment displaced water in a cylinder with radius $1.12 \mathrm{~cm}$ by a height of $2.16 \mathrm{~cm}$. Using the

equation for the volume of a cylinder, $V=\Pi(r)^{2} h$, we can calculate the volume displaced. This is calculated to be $8.513 \mathrm{~mL}$. Using the conversion factor of $22.4 \mathrm{~L}$ of any ideal gas per one mole of gas allows us to quantify the number of moles of $\mathrm{H}_{2}$ evolved as $3.8 \times 10^{-4}$ moles. This value can then be compared to the theoretical number of moles of $\mathrm{H}_{2}$ evolved based on charge determined earlier, $4.4 \times 10^{-4}$. Faradaic efficiency is defined as moles of $\mathrm{H}_{2}$ quantified/moles of $\mathrm{H}_{2}$ theoretical based on charge x $100 \%$. This corresponds with a $86 \%$ Faradaic efficiency.

\subsection{Determination and Calculation of Diffusion Coefficients, $D_{0}$, for $\mathrm{ZnL}^{1}$ and $\mathrm{CuL}^{1}$}

$\mathrm{CV}$ data were collected at multiple scan rates from 0.1 to $1.0 \mathrm{~V} / \mathrm{s}$ establishing that reduction is diffusion limited. Using the Randles-Sevcik equation (Eq. 2) and plotting peak current vs the square root of the scan rate allows for accurate calculation of the diffusion coefficient, $\mathrm{D}_{0}$. 
Determination of $Z n L^{1}$ Diffusion Coefficient $\left(D_{0}\right)$ :

$$
\begin{aligned}
& \text { Slope (Figure } 24 \mathrm{~B}) \equiv 1.94 \mathrm{E}-5=0.4463 \mathrm{FA}[\mathrm{cat}]\left[\left(\mathrm{FD}_{0} / \mathrm{RT}\right)\right]^{0.5} \\
& \begin{array}{l}
\mathrm{A}=0.071 \mathrm{~cm}^{2} \\
{[\text { cat }]=3 \mathrm{E}-6 \text { moles } / \mathrm{cm}^{3}} \\
\mathrm{~F}=96485 \mathrm{C} / \text { mole } \mathrm{e}^{-} \\
\mathrm{R}=\text { ideal gas constant } \\
\mathrm{T}=298 \mathrm{~K} \\
\quad \mathrm{D}_{0}=1.15 \times 10^{-7} \mathrm{~cm}^{2} / \mathrm{s} \text { in } \mathrm{MeOH} \text { for } \mathrm{ZnL}^{1}
\end{array}
\end{aligned}
$$

Determination of $\mathrm{CuL}^{1}$ Diffusion Coefficient $\left(D_{0}\right)$ :

Slope $($ Figure 40 inset $) \equiv 3.22 \mathrm{E}-5=$

$$
\begin{aligned}
& 0.4463 \mathrm{FA}[\mathrm{cat}]\left[\left(\mathrm{FD}_{0} / \mathrm{RT}\right)\right]^{0.5} \\
& \begin{array}{l}
\mathrm{A}=0.071 \mathrm{~cm}^{2} \\
{[\mathrm{cat}]=6 \mathrm{E}-7 \text { moles } / \mathrm{cm}^{3}} \\
\mathrm{~F}=96485 \mathrm{C} / \text { mole } \mathrm{e}^{-} \\
\mathrm{R}=\text { ideal gas constant } \\
\mathrm{T}=298 \mathrm{~K} \\
\quad \mathrm{D}_{0}=2.3 \times 10^{-5} \mathrm{~cm}^{2} / \mathrm{s} \text { in acetonitrile for } \mathrm{CuL}^{1}
\end{array}
\end{aligned}
$$

\subsection{Kinetic Isotope Effect Calculations}

$\mathrm{ReL}_{3}$

Using equation (5) we can calculate $k_{o b s}$ for experiments using D-acetic acid and D-triflic acid. 
D-Acetic Acid: At a scan rate of $0.2 \mathrm{~V} / \mathrm{s}, i_{c a t}=63.17 \mathrm{uA}$ and $i_{p}=22.48 \mu \mathrm{A}$ giving a $k_{o b s}=$ 3.06

$$
\mathrm{KIE}=k_{H} / k_{D}=29.8 \mathrm{~s}^{-1} / 3.06 \mathrm{~s}^{-1}=10
$$

D-Triflic Acid: At a scan rate of $0.2 \mathrm{~V} / \mathrm{s},, i_{c a t}=115 \mathrm{uA}$ and $i_{p}=38 \mathrm{uA}$ giving a $k_{o b s}=3.55$ $\mathrm{s}^{-1}$

$$
\mathrm{KIE}=k_{H} / k_{D}=29.8 \mathrm{~s}^{-1} / 3.55 \mathrm{~s}^{-1}=9
$$

$\mathrm{ZnL} L^{1}$

Following same procedure above but instead using equation (10) we can calculate KIE for $\mathrm{ZnL}^{1}$ using D-acetic acid.

\begin{tabular}{|l|l|l|l|}
\hline Scan Rate & $k_{H}\left(\mathbf{s}^{-1}\right)$ & $k_{D}\left(\mathbf{s}^{-1}\right)$ & $k_{H} / k_{D}\left(\mathbf{s}^{-1}\right)$ \\
\hline $5 \mathrm{~V} / \mathrm{s}$ & 1170 & 975 & 1.2 \\
\hline
\end{tabular}

$\mathrm{CuL} \mathrm{L}^{1}$

Following same procedure above, using equation (5) we can calculate KIE for $\mathrm{CuL}^{1}$ using D-acetic acid. KIE studies on $\mathrm{CuL}^{1}$ were performed from $0-100 \%$ mole D-Acetic acid use. The results are summarized below.

\begin{tabular}{|r|r|r|r|}
\hline \%D-Acid & $i_{\text {cat }}(\mathrm{uA})$ & TOF $\left(\mathrm{s}^{-1}\right)$ & KIE \\
\hline 0.00 & 2250 & 10021.68 & 1 \\
\hline 20.00 & 1837 & 6680.269 & 1.500192 \\
\hline 40.00 & 1257 & 3127.852 & 3.204015 \\
\hline 60.00 & 1045 & 2161.764 & 4.635883 \\
\hline 80.00 & 910 & 1639.3 & 6.113392 \\
\hline 100.00 & 819 & 1327.833 & 7.547398 \\
\hline
\end{tabular}




\subsection{Digital Simulations using DigiElch}

Digital simulations of voltammetric data were performed using commercially available DigiElch Pro software package (v.7) ${ }^{124}$. $\mathrm{ZnL}^{1}$ models were fit using an experimentally determined $\mathrm{ZnL}^{1}$ diffusion coefficient and fitted values of $\alpha$ and $\mathrm{k}_{\mathrm{s}}$, which were based on experimental CVs of the electrocatalysts run from 0.1 to $1.0 \mathrm{~V} / \mathrm{s}$. The consistency of the mechanism over a broad set reaction conditions was confirmed through models employing multiple scan rates and acid concentrations, all which agree with experimental results (See Appendix for additional simulation data).

\subsection{Computational Methods}

\section{General Considerations}

Hybrid Hartree-Fock density functional theory (hybrid DFT) has long been of great interest for computational thermochemistry, saddle point analysis, and general computational structure optimizations. One main advantage is its low computational cost with respect to ab nito methods. Many hybrid DFT functionals have been shown to be very promising for calculation of reaction barrier heights as well as optimization of transition state geometries.

Generally speaking, hybrid DFT involves mixing various amounts of the HartreeFock (HF) nonlocal exchange operator with DFT exchange correlation functionals. A few promising hybrid DFT functionals are B3LYP $,{ }^{125} \mathrm{M} 06,{ }^{126}$ and mPW1PW91. ${ }^{127}$ These hybrid DFT methods have been shown to be effective for obtaining accurate molecular structures, vibrational frequencies, and bond energies. The most important variable that varies in these types of functionals is the fraction of the HF exchange set. For B3LYP the HF exchange set is $20 \%$, for mPW1PW91 it is $25 \%$ and for M06 it is $27 \%$. Other 
important parameters of functionals include local spin density approximation (LSDA), density-gradient expansion, constraint satisfaction, modeling the exchange-correlation hole, and empirical fits. The constraint satisfaction factor refers to having the correct limit for a uniform electron gas. The M06 family of functionals, in general, is better at improving this parameter, relative to first generation hybrid DFT functionals like B3LYP or BLYP. M06 also improves upon LSDA factor by including a spin density gradient and a spin kinetic energy density, in addition to local spin density. When using the term, local, this means that there has been replacement of a small fraction of the local densityfunctional exchange by exactly computed exchange. ${ }^{128}$ Hybrid functionals allow one to use density functional algorithms, ${ }^{129-137}$ and plane wave algorithms ${ }^{138}$ which require much less computation when compared to the best algorithms for nonlocal functionals.

$\mathrm{ReL}_{3}$

All reported calculations were performed in the gas phase using Density Functional Theory (DFT) employing the M06 exchange correlation functional ${ }^{126}$ and the LANL2DZ basis set for all atoms as implemented in the Gaussian09 suite of programs. ${ }^{139}$ LANL2DZ was chosen rather than $6-311 \mathrm{~g}(\mathrm{~d})$ due to it being a double zeta basis. Contrary to minimum basis where there are only enough functions used to contain the electrons of the neutral atoms (usually core plus valence orbitals), a double zeta (DZ) basis double the number of all basis functions. For example consider hydrogen with two 1s functions, $1 \mathrm{~s}$ and $1 s^{\prime} .1 \mathrm{~s}$ and $1 \mathrm{~s}^{\prime}$ can be thought of as inner and outer functions. The inner function has a larger zeta, $\zeta$, and is therefore tighter. The outer function has a smaller $\zeta$, and is therefore more diffuse. This enables DZ basis sets to be more computationally flexible when describing charge distribution in both parts of a molecule (the metal and the 
ligand), whereas minimum basis sets do not. Other positives of DZ basis sets include doubling the number of functions. This provides a much better description of bonding in the valence region as well as improving the description of energetically important but chemically uninteresting core electrons.

Initially, the restricted formalism using a restricted Hartree-Fock (RHF) wave function was invoked, and subsequently unrestricted calculations based on an unrestricted Hartree-Fock (UHF)-type wave function were carried out for complexes with even electron counts. Furthermore, the B3LYP functional was used to obtain broken symmetry solutions. ${ }^{125,140-143}$ Frequency calculations were performed for all optimized stationary points to ensure they were true minima. Transition states (TS) were determined using the Berny algorithm with GEDIIS, and verified by intrinsic reaction coordinate (IRC) calculations with forward and reverse step sizes of 40 . TS structures were constructed manually based on their optimized reactants and products under tight constraints, with no symmetry imposed. Chemcraft software was used for graphics visualization. ${ }^{144}$

$Z n L^{1}$

All calculations were performed in the gas phase using density functional theory (DFT) employing the B97-D exchange correlation functional, and the 6-311G(d) basis set for all atoms as implemented in the Gaussian09 suite of programs for electronic structure ${ }^{145}$ and ChemCraft was used for graphics visualization ${ }^{144}$. Transition states were determined locally using the Berny algorithm with GEDIIS, and verified by IRC calculations with forward and reverse step sizes of 40 . All optimizations were performed under tight constraints, with no symmetry imposed. Several dimeric TS structures in various 
protonation states were initially investigated by DFT using the Berny algorithm for local TS optimization in the gas phase. These structures were constructed manually based on optimized reactants and products, or by modifying previously published semicarbazide dimers. ${ }^{146}$ Dimers without ruptured $\mathrm{Zn}-\mathrm{S}$ and $\mathrm{Zn}-\mathrm{N}$ bonds were also considered, but precluded based on energetic grounds.

\section{$\mathrm{CuL} L^{1}$}

Initial calculations were performed using M06, B3LYP and B97-D. ${ }^{125,126,140-142,147}$ Based on energetic minima results, B97-D was chosen for use as functional for subsequent calculations. Optimizations were performed in the gas phase using density functional theory (DFT) employing the B97-D exchange correlation functional, and the 6-311G(d,p) basis set for all atoms as implemented in the Gaussian09 suite of programs for electronic structure ${ }^{145}$ and ChemCraft was used for graphics visualization. ${ }^{144}$ All optimizations were performed under tight constraints, with no symmetry imposed. All input coordinates are available in in the Appendix. 


\section{CHAPTER III: \\ LIGAND-CENTERED \\ ELECTROCATALYTIC HYDROGEN EVOLUTION AND HYDROGEN OXIDATION}




\subsection{Introduction}

Hydrogen serves as a promising alternative carbon-free fuel and is an essential building block for industrial and agricultural processes. Currently, 95\% of industrial $\mathrm{H}_{2}$ derives from fossil-fuel cracking, which is environmentally unsustainable due to perpetual increases in atmospheric $\mathrm{CO}_{2}$ levels and continual lowering of global carbon reserves. ${ }^{5,15,16}$ Estimates suggest a hydrogen based economy would require as much as 150 million tons of $\mathrm{H}_{2}$ annually, further demonstrating the need for efficient electrolytic and/or photochemical catalysts that generate $\mathrm{H}_{2}$ from carbon-free sources. ${ }^{6}$ As such, the development of both heterogeneous and homogeneous catalysts for hydrogen evolution reactions (HER) from water/acid for $\mathrm{H}_{2}$ production and hydrogen oxidation reaction (HOR) catalyst for $\mathrm{H}_{2}$ utilization have received significant attention. ${ }^{7-14}$ The energy stored within the $\mathrm{H}_{2}$ molecule can be recovered in a fuel cell through the catalyzed oxidation of $\mathrm{H}_{2}$ to protons (HOR); which is the reverse of a HER. The utility of $\mathrm{H}_{2}$ as an energy storage/recovery agent has been exploited since the earliest forms of life through reactivity at the transition metal-sulfur cores of hydrogenase with $\mathrm{H}_{2}$ evolution favored in [FeFe]-hydrogenase and $\mathrm{H}_{2}$-oxidation preferential at [NiFe]-hydrogenase. ${ }^{26-28}$ In spite of the efficiency of these enzymes, their translation to industrial applications has been proven difficult, underscoring the need for artificial HER and HOR electrocatalysts. Platinum is the current "gold standard" because it operates at low overpotential with high turnover frequencies; however, its scarcity and high cost severely limit wide spread use. ${ }^{26-28,109}$ Thus, a considerable effort has been directed toward earth-abundant, first-row transition metal catalysts, including the remarkable bio-inspired pendant-base bis(diamine) nickel complexes of Dubois and Bullock. ${ }^{8,14}$ Furthermore, Eisenberg and Holland reported a series of metal-dithiolene complexes with the highest TOFs and 
lowest overpotential of synthetic transition metal-sulfur electrocatalysts under homogeneous conditions. ${ }^{7,11,12}$ In addition, cobalt complexes of glyoxime ligands have been shown to be efficiently evolve $\mathrm{H}_{2}$ at low overpotential over a wide range acid/base conditions in both aqueous and non-aqueous solvents, ${ }^{148,149}$ although indicate the activity may result from nanoparticles formed during catalyst degradation. ${ }^{150}$ Each of these and related systems follows a metal-hydride pathway and it is widely regarded that transition metals capable of forming metal-hydride intermediates are essential to the HER mechanism. Naturally, most HER electrocatalysts reported to date closely follow a mechanism including ligand protonation, metal reduction, and proton to hydride migration with subsequent chemical/ electrochemical steps leading to $\mathrm{H}_{2}$ release. ${ }^{8}$

While the metal-hydride approach has resulted in significant advances, catalyst candidates are limited to economically viable first-row transition metals complexes capable of stabilizing hydrides. Moreover, despite numerous years of effort, materials based on this paradigm have not yet yielded practical systems for wide-scale application. $^{13}$ The development of new catalytic systems that function via a fundamentally different mechanism may prove valuable to overcome this current limitation. Given our laboratory’s history ${ }^{98,151-156}$ with non-innocent ligands, it seemed logical to investigate ligand-centered hydrogen evolution reactivity. 


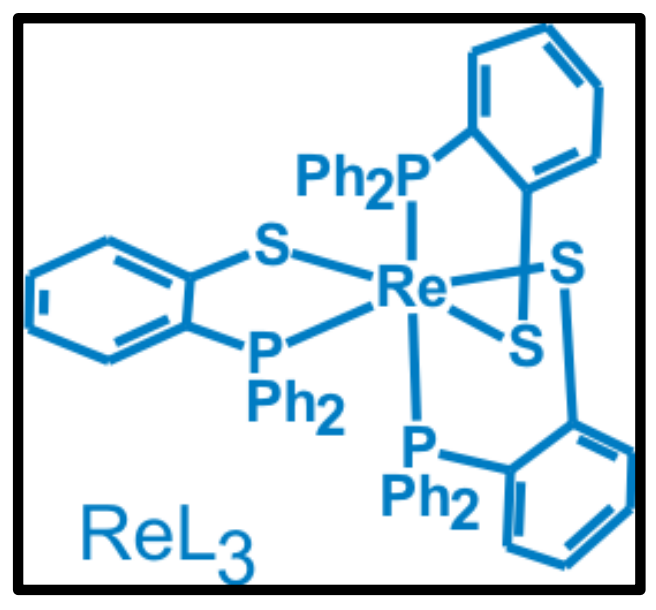

Scheme 1. Stick representation of $\operatorname{ReL}_{3}(\mathrm{~L}=$ diphenylphosphinobenzenethiolate).

The synthesis and electrochemistry of $\mathrm{ReL}_{3}$ (L = diphenylphosphinobenzenethiolate) (scheme 1), was first reported by Dilworth et al. in 1992. ${ }^{157}$ The electrochemistry of $\mathrm{ReL}_{3}$ displays a reversible $\mathrm{Re}^{\mathrm{III} / \mathrm{II}}$ reduction at $-1.50 \mathrm{~V}$ and two reversible, non-innocent oxidations at $-0.4\left(\mathrm{Re}^{\mathrm{IV} / \mathrm{III}}\right)$ and $+0.5 \mathrm{~V}\left(\mathrm{Re}^{\mathrm{V} / \mathrm{IV}}\right) \mathrm{Vs}$ $\mathrm{Fc}^{+} / \mathrm{Fc}$ (ferrocenium/ferrocene) (Figure 8). ${ }^{153}$

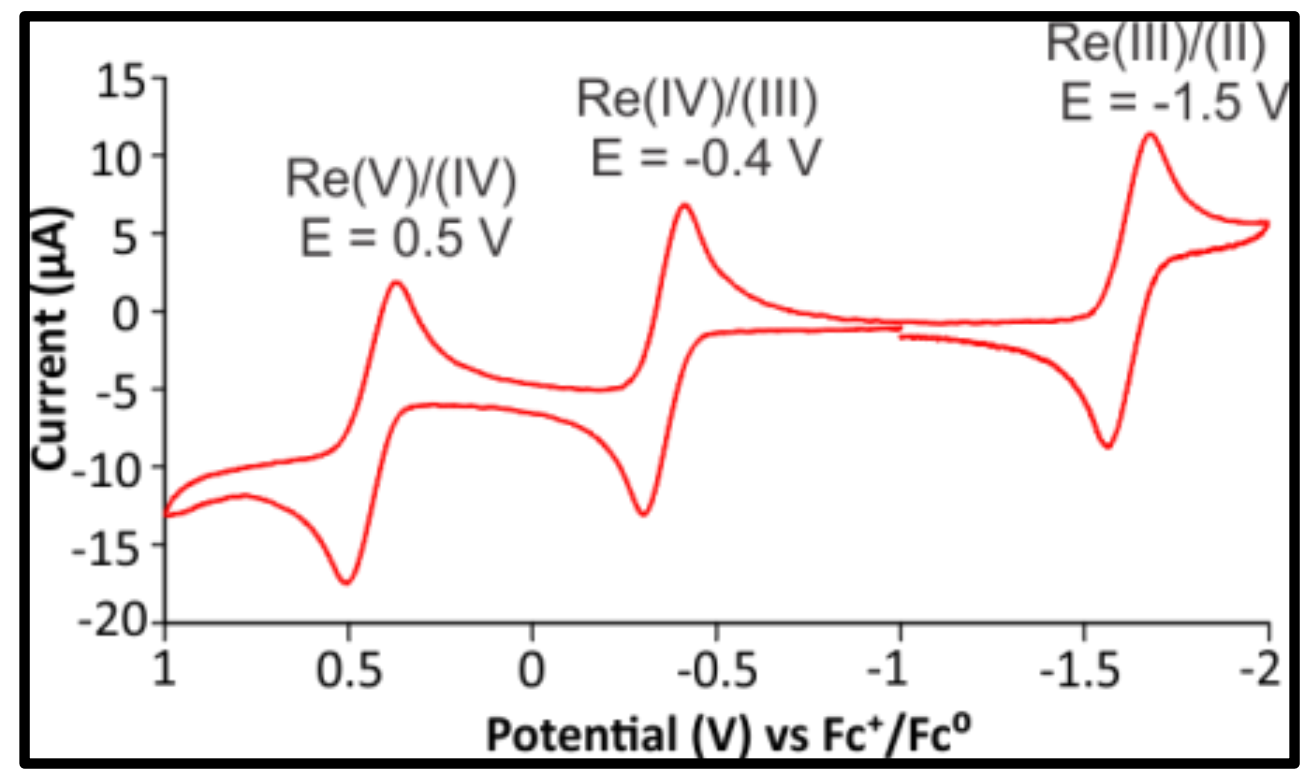

Figure 8. Cyclic Voltammogram (CV) of $0.3 \mathrm{mM} \mathrm{ReL}_{3}$ in $0.1 \mathrm{M} \mathrm{Bu}_{4} \mathrm{NPF}_{6} \mathrm{CH}_{2} \mathrm{Cl}_{2}$ solutions. 
The non-innocence of the ligands is attributed to covalent metal-sulfur interactions that result in frontier molecular orbitals with significant metal-d and sulfur-p character, as also observed previously in our laboratory with the analogous ruthenium complex, $\mathrm{RuL}_{3} .^{116,143,151,152,154,155,158,159}$ As a result, while $\left[\mathrm{ReL}_{3}\right]^{+}$contains a formal $\mathrm{Re}^{\mathrm{IV}}$, the complex has some $\mathrm{Re}^{\mathrm{III}}$-thiyl radical character and the formal $\mathrm{Re}^{\mathrm{V}}$ of $\left[\mathrm{ReL}_{3}\right]^{2+}$ has $\mathrm{Re}^{\mathrm{IV}}$-thiyl and $\mathrm{Re}^{\mathrm{III}}$-dithiyl radical character. The reactivity of this complex was previously studied for the reversible binding of ethylene. ${ }^{98,143,153,160}$

Expanding upon this previous work in the Grapperhaus Lab, and given the rich literature history of HER electrocatalysis using dithiolenes, we surmised that $\mathrm{ReL}_{3}$ could serve as an electrocatalyst for hydrogen evolution or hydrogen oxidation, dependent on the presence of acid or base and the applied potential.

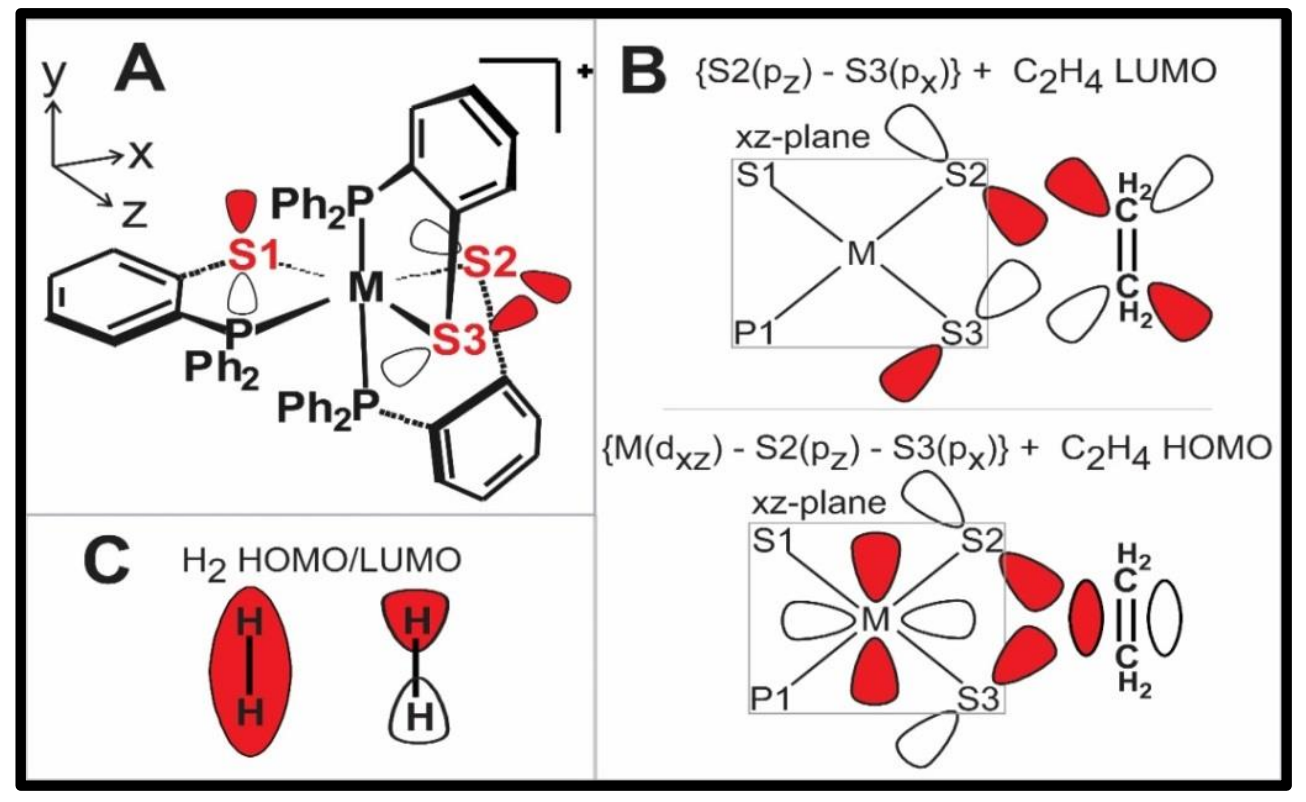

Figure 9. (A) Calculated "p-type" lone-pair orientation of $\left[\mathrm{M}(\mathrm{SP})_{3}\right]^{\mathrm{n}}$ enforced by meridional PS chelates. (B) Proposed interactions of $\left[\mathrm{M}(\mathrm{SP})_{3}\right]^{\mathrm{n}}$ frontier orbitals with LUMO (top) and HOMO (bottom) of $\mathrm{C}_{2} \mathrm{H}_{4}$. (C) HOMO/LUMO symmetries of $\mathrm{H}_{2}$. 
A combination of characteristics makes metal-thiolates an excellent HER firstsphere promoter. Employing two lone pairs, metal-thiolates will easily accept protons under even moderately acidic conditions. Dithiolenes are well-known to exhibit noninnocent redox behavior, affording ligand-centered reductions and oxidations. ${ }^{11,12,143,153,161}$ This ligand non-innocence offers extremely reactive thiyl radicals. As detailed in (Figure 9A) the facial arrangement of the PS chelates in $\left[\mathrm{ReL}_{3}\right]^{\mathrm{n}}$ enforces a symmetry preferred interligand addition route. ${ }^{143,153}$ The lone-pair p-type orbitals on S1 and S2 are coplanar, and the frontier molecular orbitals include an occupied out-of-phase combination supporting the necessary geometry needed to interact with the $\pi^{*}$-orbital of alkenes, and a vacant in-phase combination, which is anti-bonding with respect to the metal d-orbital, providing the proper symmetry to interact with the $\pi$ orbital of alkenes, or in the case of $\mathrm{H}_{2}$, the $\sigma$ orbital. ${ }^{143}$ When examining the HOMO/LUMO molecular frontier orbitals of $\mathrm{H}_{2}$ (Figure 9C) we observe the same analogous frontier orbital arrangement as that seen in the HOMO/LUMO of ethylene (Figure 9B) which suggests similar interactions with $\mathrm{H}_{2}$ and ethylene.

\subsection{Results and Discussion}

\subsubsection{Cyclic Voltammetry HER and HOR Studies and X-ray Crystallography}

Upon addition of acetic acid to $\mathrm{CH}_{2} \mathrm{Cl}_{2}$ solutions of $\mathrm{ReL}_{3}$ the cathodic current at $-1.70 \mathrm{~V}$ $\mathrm{vs}^{+} \mathrm{Fc}^{+} / \mathrm{Fc}$ increases, indicative of electrocatalytic reduction (Figure 10). Two new peaks appear $0.18 \mathrm{~V}$ and $-0.84 \mathrm{~V}$, respectively. These values are shifted by +0.52 and $+0.76 \mathrm{~V}$

relative to $\left[\mathrm{ReL}_{3}\right]^{+/ 0}$ and $\left[\mathrm{ReL}_{3}\right]^{0 /-}$, respectively, suggesting protonation of a single thiolate donor. 


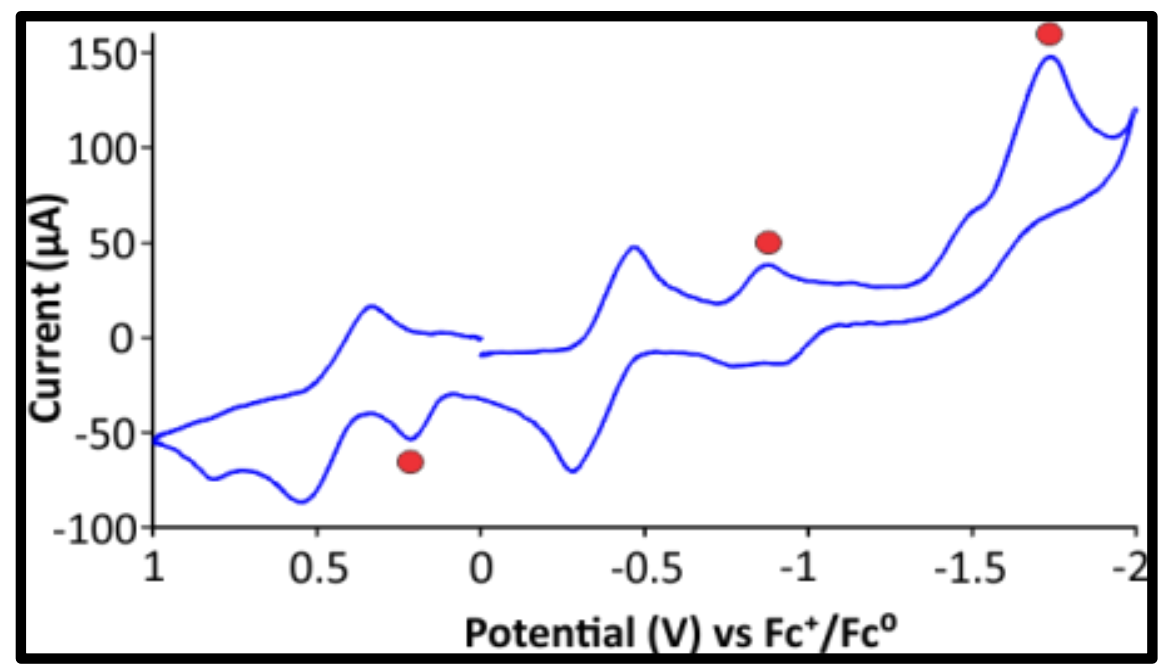

Figure 10. $\mathrm{CV}$ of $\mathrm{ReL}_{3}$ with excess $\mathrm{CH}_{3} \mathrm{CO}_{2} \mathrm{H}$ added in $0.1 \mathrm{M} \mathrm{Bu}_{4} \mathrm{NPF}_{6} \mathrm{CH}_{2} \mathrm{Cl}_{2}$ solution.

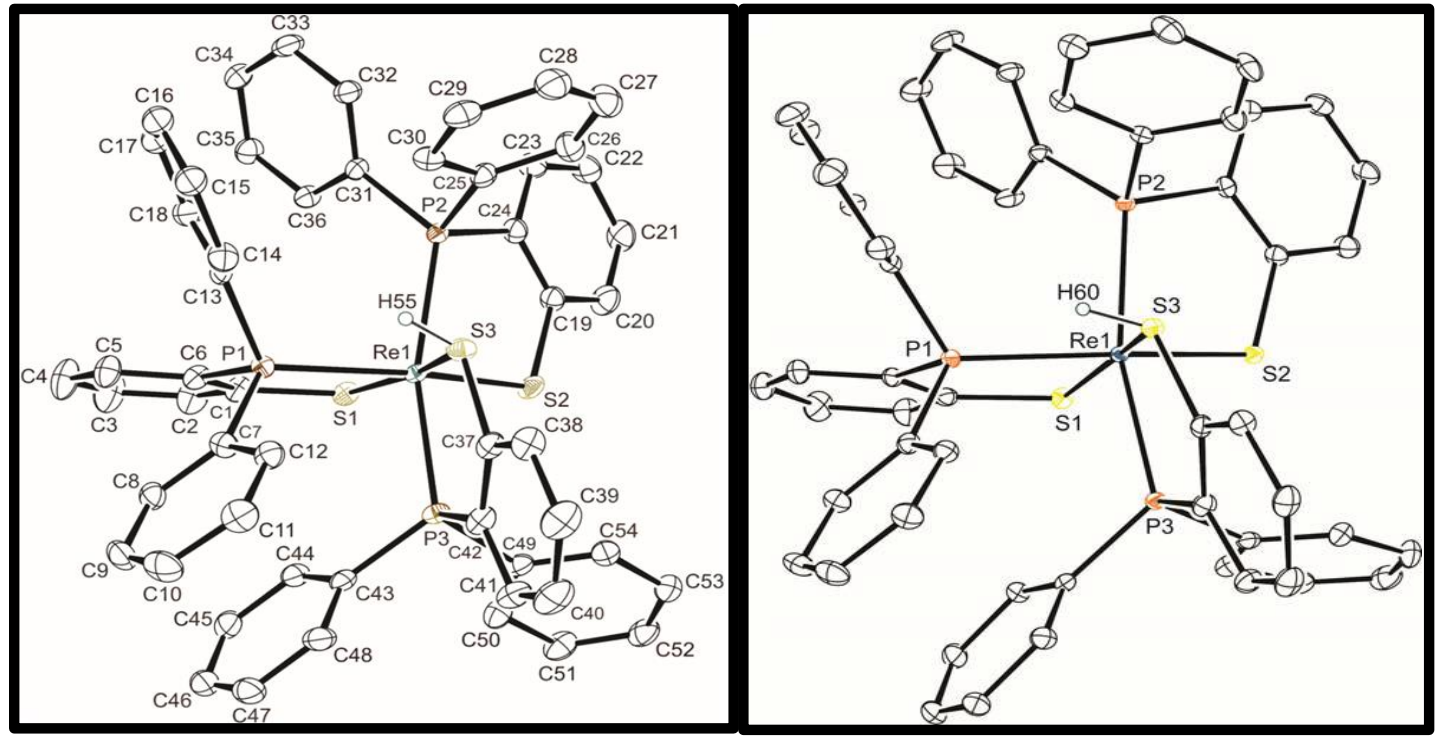

Figure 11. (Left) Labeled ORTEP ${ }^{162}$ of $\left[\mathrm{Re}(\mathrm{LH}) \mathrm{L}_{2}\right]^{+}$from $\left[\mathrm{Re}(\mathrm{LH}) \mathrm{L}_{2}\right] \mathrm{PF}_{6}$. (Right) Labeled $\mathrm{ORTEP}^{162}$ of $\left[\operatorname{Re}(\mathrm{LH}) \mathrm{L}_{2}\right]^{+}$from $\left[\operatorname{Re}(\mathrm{LH}) \mathrm{L}_{2}\right] \mathrm{O}_{3} \mathrm{SCF}_{3}$.

In order to confirm the identity of the new peaks, attempts were made to isolate and crystallize the protonated intermediate, $\left[\operatorname{Re}(\mathrm{LH}) \mathrm{L}_{2}\right]^{+}$. High quality single crystals of $\left[\operatorname{Re}(\mathrm{LH}) \mathrm{L}_{2}\right] \mathrm{PF}_{6}$, obtained as a degradation product of $\left[\mathrm{ReL}_{3} \cdot \mathrm{C}_{2} \mathrm{H}_{4}\right] \mathrm{PF}_{6}$ in methanol, reveal S3 as thiol through the location and subsequent refinement of the proton H55 (Figure 11 left). The S3-H55 bond distance is 1.077(18) $\AA$ with a Re1-S3-H55 bond 
angle of $105.8(18)^{\circ}$. The structure was confirmed by X-ray analysis of $\left[\operatorname{Re}(\mathrm{LH}) \mathrm{L}_{2}\right]^{+}$as the triflate salt prepared upon protonation of $\mathrm{ReL}_{3}$ with triflic acid (Figure 11 right). A comparison of metric parameters for $\operatorname{ReL}_{3},\left[\operatorname{Re}(\mathrm{LH}) \mathrm{L}_{2}\right]^{+}$, and $\left[\operatorname{ReL}_{3}{ }^{\circ} \mathrm{C}_{2} \mathrm{H}_{4}\right]^{2+}$ is provided in Table 1 below. ${ }^{98,157}$ The metal ligand bond distances of the $\left[\operatorname{Re}(\mathrm{LH}) \mathrm{L}_{2}\right]^{+}$cation in the structures of $\left[\operatorname{Re}(\mathrm{LH}) \mathrm{L}_{2}\right] \mathrm{PF}_{6}$ and $\left[\mathrm{Re}(\mathrm{LH}) \mathrm{L}_{2}\right] \mathrm{O}_{3} \mathrm{SCF}_{3}$ are consistent. The corresponding Ru-P bond distances differ by 0.011(1) to 0.014(1) $\AA$ while the corresponding Ru-S bond distances are statistically equivalent. The $\mathrm{S} 3-\mathrm{H}$ bond distance of $\left[\operatorname{Re}(\mathrm{LH}) \mathrm{L}_{2}\right] \mathrm{PF}_{6}$ is $0.076(26) \AA$ longer in than $\left[\mathrm{Re}(\mathrm{LH}) \mathrm{L}_{2}\right] \mathrm{O}_{3} \mathrm{SCF}_{3}$, which is a small change compared to the relative error. The Re-S bond distances in $\operatorname{ReL}_{3},\left[\operatorname{Re}(\mathrm{LH}) \mathrm{L}_{2}\right]^{+}$, and $\left[\mathrm{ReL}_{3} \cdot{ }^{\cdot} \mathrm{C}_{2} \mathrm{H}_{4}\right]^{2+}$ reveal a common trend upon sulfur-modification. Conversion of S3 from an anionic thiolate in $\mathrm{ReL}_{3}$ to a neutral thiol in $\left[\operatorname{Re}(\mathrm{LH}) \mathrm{L}_{2}\right]^{+}$increases the Re-S3 bond by $0.018(5) \AA$, whereas the bond distances to the remaining thiolates contract by $0.120(5)$ and $0.014(5) \AA$ for Re$\mathrm{S} 1$ and Re-S2, respectively. The same compensatory effect is observed, but to a larger degree, in the ethylene adduct $\left[\operatorname{ReL}_{3}{ }^{\bullet} \mathrm{C}_{2} \mathrm{H}_{4}\right]^{2+}$. Conversion of $\mathrm{S} 2$ and $\mathrm{S} 3$ from anionic thiolates to neutral thioethers increases bond distances by $0.131(6)$ and $0.163(6) \AA$, respectively. The bond distance to the sole remaining thiolate, $\mathrm{S} 1$, decreases by $0.268(6)$ Å. Addition of strong acids to solutions of $\left[\operatorname{Re}(\mathrm{LH}) \mathrm{L}_{2}\right]^{+}$results in a color change from purple to yellow-brown, although we have no yet been able to isolate $\left[\mathrm{ReL}_{3} \cdot \mathrm{H}_{2}\right]^{2+}$ or its reduced derivatives.

Table 1. Comparison of selected bond distances and bond angles between $\operatorname{ReL}_{3}$, $\left[\operatorname{Re}(\mathrm{LH}) \mathrm{L}_{2}\right] \mathrm{PF}_{6}$, $\left[\mathrm{Re}(\mathrm{LH}) \mathrm{L}_{2}\right] \mathrm{O}_{3} \mathrm{SCF}_{3}$ and, $\left[\mathrm{ReL}_{3} \cdot \mathrm{C}_{2} \mathrm{H}_{4}\right]\left[\mathrm{PF}_{6}\right]_{2}{ }^{\mathrm{a}}$

\begin{tabular}{|c|c|c|c|c|}
\hline $\begin{array}{c}\text { Bond } \\
\text { distances } \\
\left(\mathbf{A}^{\circ}\right)\end{array}$ & $\operatorname{ReL}_{3}{ }^{a}$ & {$\left[\operatorname{Re}(\mathbf{L H}) \mathrm{L}_{2}\right] \mathbf{P F}_{6}$} & {$\left[\operatorname{Re}(\mathrm{LH}) \mathrm{L}_{2}\right] \mathrm{O}_{3} \mathrm{SCF}_{3}$} & {$\left[\operatorname{ReL}_{3} \cdot \mathrm{C}_{2} \mathrm{H}_{4}\right]\left[\mathrm{PF}_{6}\right]_{2}^{b}$} \\
\hline Re-P1 & $2.473(5)$ & $2.4976(6)$ & $2.4836(8)$ & $2.420(3)$ \\
\hline Re-P2 & $2.411(5)$ & $2.4493(6)$ & $2.4480(8)$ & $2.457(3)$ \\
\hline Re-P3 & $2.391(5)$ & $2.4419(6)$ & $2.4308(8)$ & $2.467(3)$ \\
\hline
\end{tabular}




\begin{tabular}{|c|c|c|c|c|}
\hline Re-S1 & $2.477(5)$ & $2.3575(6)$ & $2.3547(8)$ & $2.209(3)$ \\
\hline Re-S2 & $2.303(5)$ & $2.2884(6)$ & $2.2855(8)$ & $2.434(3)$ \\
\hline Re-S3 & $2.269(5)$ & $2.2875(6)$ & $2.2917(7)$ & $2.432(3)$ \\
\hline S3-H55 & & $1.077(18)$ & $1.001(19)$ & $1.857(10)$ \\
\hline S2-C55 & & & & $1.831(10)$ \\
\hline S3-C56 & & & & $169.97(9)$ \\
\hline $\begin{array}{c}\text { Bond Angles } \\
\left({ }^{\circ}\right)\end{array}$ & & $168.17(2)$ & $166.53(3)$ & $174.00(9)$ \\
\hline $\begin{array}{c}\text { S(1)-Re(1)- } \\
\text { S(3) }\end{array}$ & $166.4(1)$ & $163.23(3)$ & $162.68(9)$ \\
\hline $\begin{array}{c}\text { P(1)-Re(1)- } \\
\text { S(2) }\end{array}$ & $159.6(1)$ & $162.63(2)$ & $164.85(3)$ & $84.37(10)$ \\
\hline $\begin{array}{c}\text { P(2)-Re(1)- } \\
\text { P(3) }\end{array}$ & $166.7(1)$ & $164.48(2)$ & $108.54(3)$ & $112.3(7)$ \\
\hline $\begin{array}{c}\text { S(3)-Re(1)- } \\
\text { S(2) }\end{array}$ & $113.0(2)$ & $109.95(2)$ & & \\
\hline $\begin{array}{c}\text { S(2)-C(55)- } \\
\text { ( (56) }\end{array}$ & & & & \\
\hline $\begin{array}{l}\text { a) Data from reference 149 with relabeling of atomic positions for consistency. } \\
\text { b) Data from reference 90. }\end{array}$ & & \\
\hline
\end{tabular}

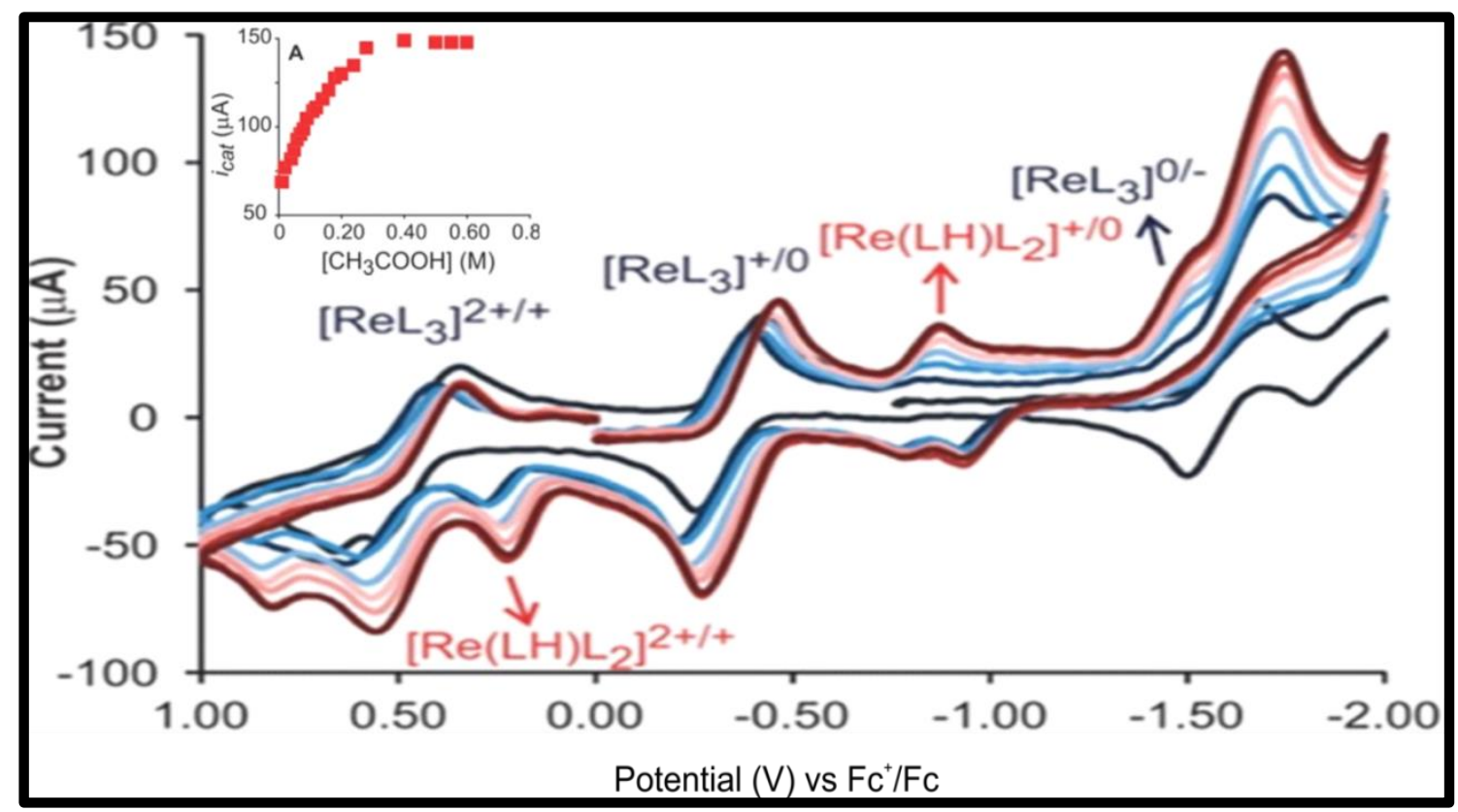

Figure 12. Cyclic Voltammograms of $0.3 \mathrm{mM} \mathrm{ReL}_{3}$ in $0.1 \mathrm{M} \mathrm{Bu}_{4} \mathrm{NPF}_{6} \mathrm{CH}_{2} \mathrm{Cl}_{2}$ solution showing $\mathrm{H}_{2}$ evolution upon successive additions of $\mathrm{CH}_{3} \mathrm{CO}_{2} \mathrm{H}$. Inset: Plot of catalytic current $\mathrm{vs}^{\mathrm{CH}_{3} \mathrm{CO}_{2} \mathrm{H}}$ concentration, showing acid saturation above $0.4 \mathrm{M} \mathrm{CH}_{3} \mathrm{CO}_{2} \mathrm{H}$. 
CVs obtained during titration of $\mathrm{CH}_{3} \mathrm{CO}_{2} \mathrm{H}$ into $0.1 \mathrm{M} \mathrm{Bu}_{4} \mathrm{NPF}_{6} \mathrm{CH}_{2} \mathrm{Cl}_{2}$ solutions of $0.3 \mathrm{mM} \mathrm{ReL}_{3}$ display a gradual growth in the intensity of the catalytic current at $-1.7 \mathrm{~V}$ vs $\mathrm{Fc}^{+} / \mathrm{Fc}$ (Figure 12) (see appendix for additional data). At low acid concentrations, the current displays a linear dependence on the acid concentration, indicating diffusion control to the electrode surface. At acid concentrations above $0.4 \mathrm{M}$, the current is acidindependent indicating the solution is acid saturated, and that $\mathrm{CV}$ response is no longer limited by diffusion (Figure 12;inset). ${ }^{121,163-165}$ Under these pseudo-first order conditions, the turnover frequency (TOF), which is also the observed rate constant, is $30 \pm 4 \mathrm{~s}^{-1}$. Hydrogen evolution using sulfuric acid as the $\mathrm{H}^{+}$source yields a statistically equivalent TOF of $32 \pm 3 \mathrm{~s}^{-1}$. The overpotential for hydrogen evolution is $0.708 \mathrm{~V}$ with either acid source, based on open circuit potential measurements (Figure 13). ${ }^{117}$

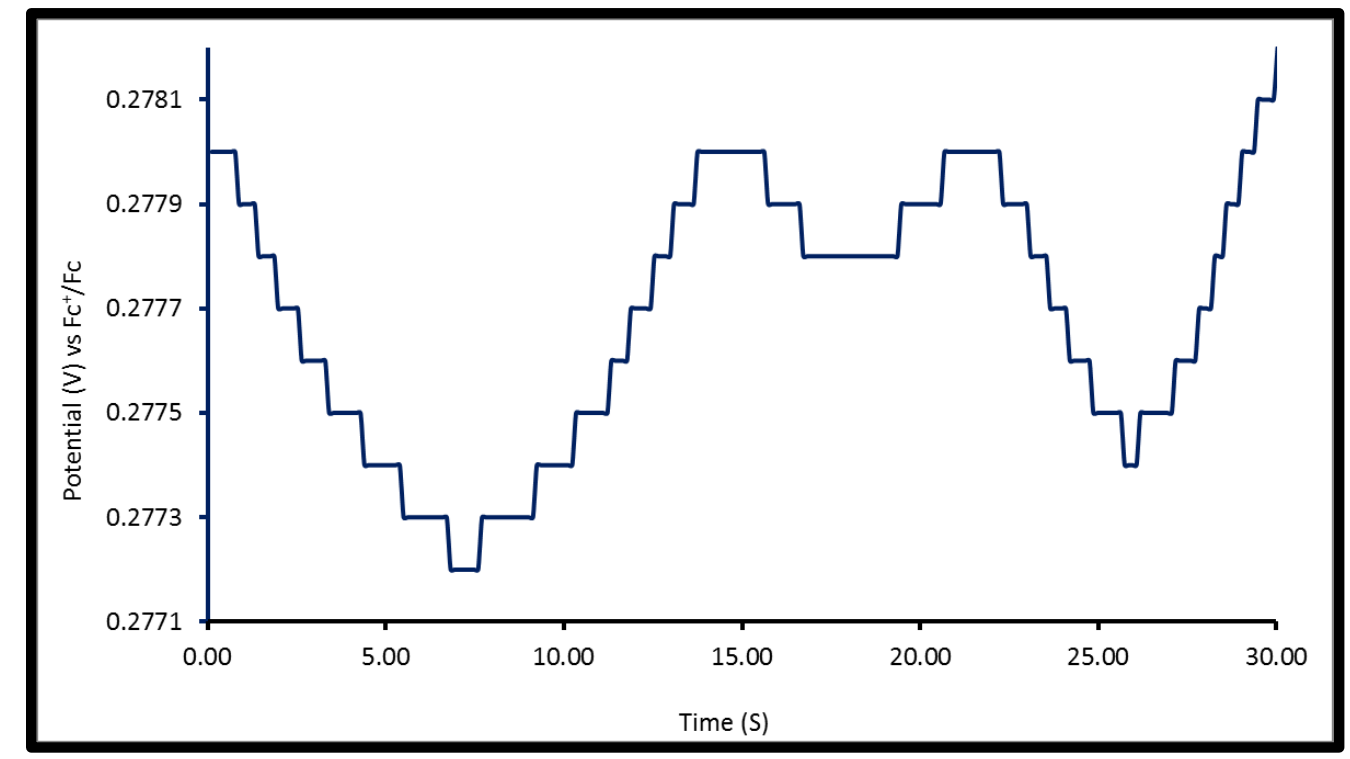

Figure 13. Open circuit potential for the reduction of protons to acetic to $\mathrm{H}_{2}$ with $0.4 \mathrm{M}$ $\mathrm{CH}_{3} \mathrm{COOH}$ added to $0.1 \mathrm{M} \mathrm{Bu}_{4} \mathrm{NPF}_{6} \mathrm{CH}_{2} \mathrm{Cl}_{2}$ solution.

A series of controls were performed to confirm that the electrocatalyst $\mathrm{ReL}_{3}$ was indeed responsible for catalysis. Acetic acid $(0.4 \mathrm{M})$ was added to a $0.1 \mathrm{M} \mathrm{Bu}_{4} \mathrm{NPF}_{6}$ 
$\mathrm{CH}_{2} \mathrm{Cl}_{2}$ solution without any added catalyst. CVs display that the reduction of acetic acid occurs with an onset potential of $-1.9 \mathrm{~V}$ vs $\mathrm{Fc}^{+} / \mathrm{Fc}$, giving values far below those observed upon the addition of $\mathrm{ReL}_{3}$. A subsequent dip-test control was performed in order to eliminate the possibility of catalyst decomposition or deposition on the electrode surface as source of possible catalysis. Prolonged reduction of $\mathrm{ReL}_{3}$ was performed by holding an applied potential of $-2.0 \mathrm{~V}$ vs $\mathrm{Fc}^{+} / \mathrm{Fc}$. The electrodes were then removed from the solutions rinsed with DI water and then immersed into a fresh solution containing no catalyst, upon which no current was observed, thus eliminating the possibility of decomposition or absorption onto the electrode surface.

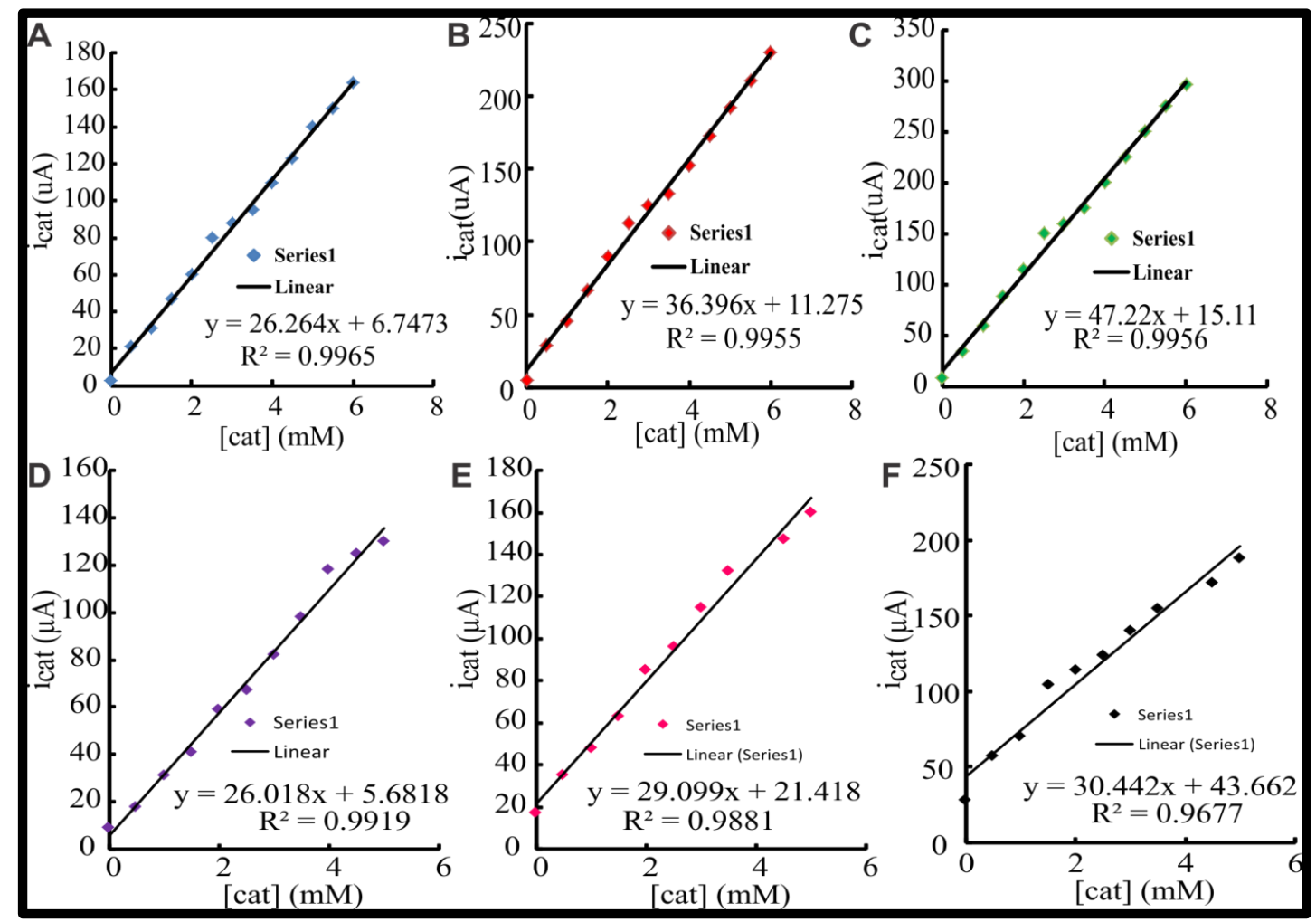

Figure 14. Peak Current vs. $\left[\mathrm{ReL}_{3}\right]$ using weak acid $\left(\mathrm{CH}_{3} \mathrm{CO}_{2} \mathrm{H}\right)$ at $(\mathrm{A}) 0.2$, (B) 0.5, (C) $1 \mathrm{~V} / \mathrm{s}$, and using strong acid $\left(\mathrm{H}_{2} \mathrm{SO}_{4}\right)$ at (D) $0.2(\mathrm{E}) 0.5,(\mathrm{~F}) 1.0 \mathrm{~V} / \mathrm{s}$.

In order to determine the order of the reaction with respect to catalyst concentration, CVs were run at scan rates of $0.2,0.5$ and $1.0 \mathrm{~V} / \mathrm{s}$ at fixed $\left[\mathrm{H}^{+}\right](20 \mathrm{mM}$ 
for both strong and weak acids) under varied concentrations of $\mathrm{ReL}_{3}$. The peak currents from each $\mathrm{CV}$ were recorded and plotted against the concentration of the $\mathrm{ReL}_{3}$ electrocatalyst. Plots for both strong and weak acids across all scan rates display a linear correlation between peak current and catalyst concentration, indicating a first-order dependence on the concentration of catalyst (Figure 14A-F). Overall, the rate law for $\mathrm{H}_{2}$ evolution is third-order with a rate constant $k=184 \mathrm{M}^{-2} \mathrm{~s}^{-1}$ (see Chapter II for more information on calculation of $k$ ).

In addition to electrocatalytic hydrogen evolution, $\mathrm{ReL}_{3}$ also catalyzes $\mathrm{H}_{2}$ oxidation. Addition of triethylamine to $\mathrm{ReL}_{3}$ under 1 atmosphere of $\mathrm{H}_{2}$ increases anodic current near the formal $\mathrm{Re}^{\mathrm{V} / \mathrm{IV}}$ couple (Figure 15). At concentrations above $0.8 \mathrm{mM}$, the catalytic current is base-independent and a TOF of $4 \pm 1 \mathrm{~s}^{-1}$ was determined at an overpotential of $970 \mathrm{mV}$ (see appendix for more information). ${ }^{86,117,166}$ Control experiments with triethylamine/ $\mathrm{H}_{2}$, but no $\mathrm{Re}_{3}$, show no significant current.

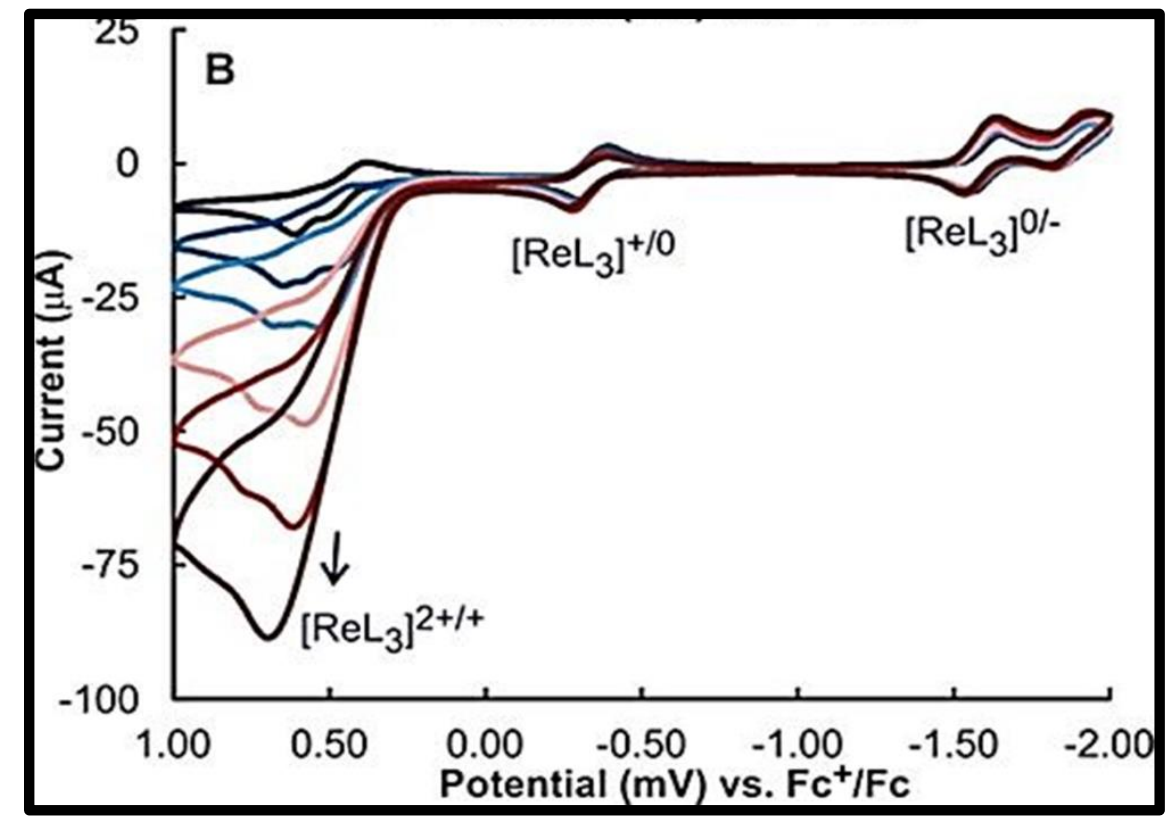

Figure 15. $\mathrm{CV}$ showing $\mathrm{H}_{2}$ oxidation upon successive additions of triethylamine to $0.3 \mathrm{mM} \mathrm{ReL}_{3}$ in $0.1 \mathrm{M} \mathrm{Bu}_{4} \mathrm{NPF}_{6} \mathrm{CH}_{2} \mathrm{Cl}_{2}$ solution under $1 \mathrm{~atm}$ of $\mathrm{H}_{2}$ gas. 


\subsubsection{Controlled Potential Coulometry and Gas Product Analysis}

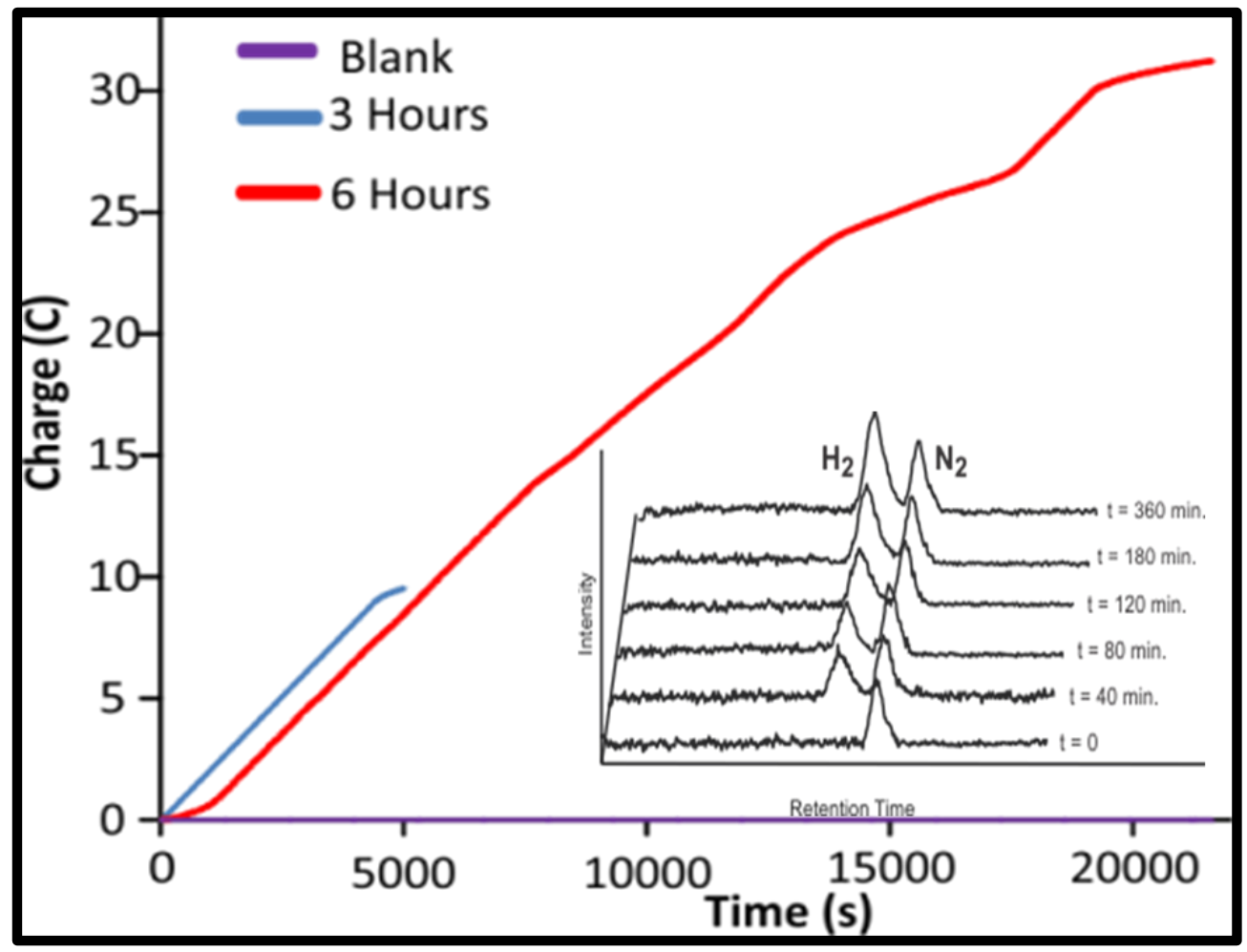

Figure 16. Plot of charge vs time recorded during the controlled potential coulometry of $0.3 \mathrm{mM}$ $\mathrm{ReL}_{3}$ for 1.5 hours (blue) and 6 hours (red) in the presence of $\mathrm{CH}_{3} \mathrm{CO}_{2} \mathrm{H}$. Inset: Gas chromatography thermal conductivity (GC-TCD) readout of headspace analysis during electrolysis.

The robustness of the catalyst was evaluated by controlled potential coulometry bulk electrolysis experiments. At an applied potential of $-1.8 \mathrm{~V} \mathrm{vs} \mathrm{Fc}^{+} / \mathrm{Fc}, \mathrm{ReL}_{3}$ catalytically evolved $\mathrm{H}_{2}$ from $0.1 \mathrm{M} \mathrm{Bu}_{4} \mathrm{NPF}_{6} \mathrm{CH}_{2} \mathrm{Cl}_{2}$ solutions containing $0.05 \mathrm{M}$ acetic acid, with turnover numbers (TON) of 13.6 and 54.0 after 1.5 and $6 \mathrm{~h}$, respectively (Figure 16). Under these conditions, the TOF remains at $\sim 9 \mathrm{~h}^{-1}$ with no significant decrease in HER activity over $6 \mathrm{~h}$. The gas evolved during electrolysis was confirmed as $\mathrm{H}_{2}$ by gas chromatography analysis of headspace (Figure 16 inset). After $6 \mathrm{~h}$, the headspace consisted of $22 \% \mathrm{H}_{2}$ indicating a minimum Faradaic efficiency of $73 \%$, although the 
actual value may be higher as some $\mathrm{H}_{2}$ escaped during electrolysis (see appendix for more information).

\subsubsection{Deuterated Acid Studies}

The $\mathrm{ReL}_{3}$ complex catalyzes $\mathrm{H}_{2}$ evolution approximately 8 times faster than it catalyzes $\mathrm{H}_{2}$ oxidation. The TOF for $\mathrm{H}_{2}$ evolution is statistically equivalent for weak and strong acids, suggesting the two pathways share a common rate-determining step (RDS). Further information into the RDS was obtained by performing catalysis using deuterated acid substrates. The $\mathrm{ReL}_{3}$ catalyst exhibits a large kinetic isotope effect (KIE) of $9 \pm 1$ for both weak and strong acids, $\mathrm{CH}_{3} \mathrm{CO}_{2} \mathrm{H} / \mathrm{CD}_{3} \mathrm{CO}_{2} \mathrm{D}$ and $\mathrm{CF}_{3} \mathrm{SO}_{3} \mathrm{H} / \mathrm{CF}_{3} \mathrm{SO}_{3} \mathrm{D}$. The similarities of the KIE values for strong and weak acids further support a common RDS, in which evolution of $\mathrm{H}_{2}$ does not involve reaction with a proton, given that $\mathrm{KIE}$ values are statistically equivalent when using strong or weak acid. The large value of the KIE further suggests the rate determining step is $\mathrm{H}_{2}$ release with significant catalyst-hydrogen bond breaking occurring at the transition state. Despite the significant number of electrocatalysts reported for HERs, relatively few studies have reported KIE data. Gray and coworkers reported an inverse KIE with values ranging from $0.54-0.57 .{ }^{167}$ A similar inverse value observed by Fukuzumi was attributed to rate-determining metal hydride formation via proton coupled electron transfer. ${ }^{168}$ The relatively high KIE values for $\mathrm{ReL}_{3}$ as compared to the inverse KIE observed for metal hydrides by Gray et al., clearly indicate a different mechanism for $\mathrm{H}_{2}$ evolution. Markedly, Fukuzumi recently reported a KIE of 40 for $\mathrm{H}_{2}$ evolution with $\left[\operatorname{Ir}^{\mathrm{III}}\left(\mathrm{Cp}^{*}\right)\left(\mathrm{H}_{2} \mathrm{O}\right)(\mathrm{bpm}) \mathrm{Ru}^{\mathrm{II}}(\mathrm{bpy})_{2}\right]-\left(\mathrm{SO}_{4}\right)_{2}\left(\mathrm{Cp}^{*}=\eta 5-\right.$ pentamethylcyclopentadienyl, bpm $=2,2$-bipyrimidine, bpy $=2,2^{\prime}$-bipyridine) attributing the unusually high KIE to large tunneling effects during catalytic $\mathrm{H}_{2}$ evolution 
reactions. ${ }^{169}$ Overall, the rate law for hydrogen evolution is third-order with a rate constant $k=184 \mathrm{M}^{-2} \mathrm{~s}^{-1}$. The rate constant is approximately 200 times lower than the corresponding value for the Mo-S dimer metal thiolate, $k=3.7 \times 10^{4} \mathrm{M}^{-2} \mathrm{~s}^{-1}$, reported by Dubois. ${ }^{79}$

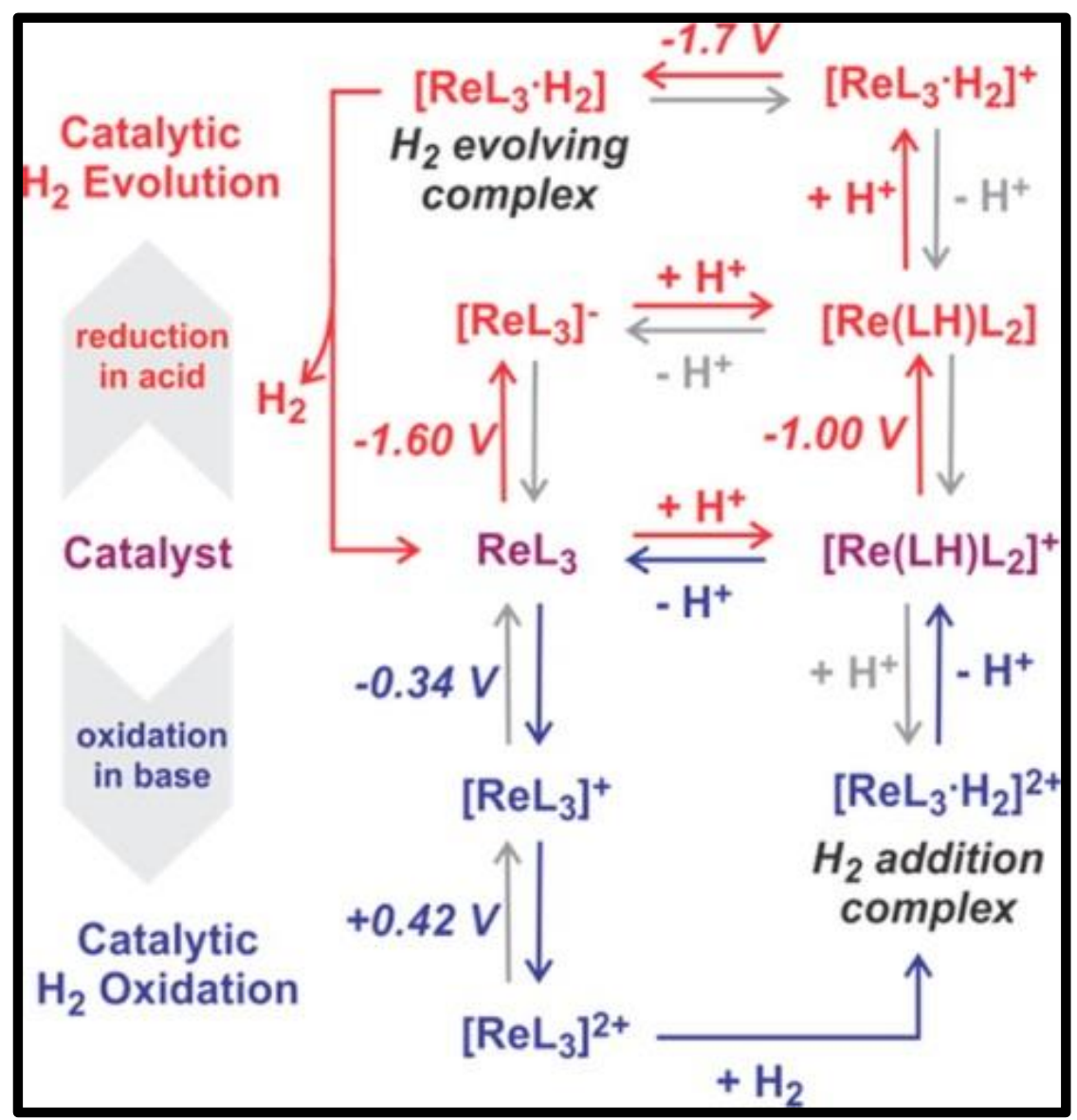

Scheme 2. Proposed Mechanism for Electrocatalytic $\mathrm{H}_{2}$ evolution and oxidation by $\mathrm{ReL}_{3}$.

\subsubsection{Mechanism Discussion and Theoretical Insight}

Based on kinetic studies and the unusually large KIE values observed with $\operatorname{ReL}_{3}$, we initially assigned the rate-determining step for $\mathrm{H}_{2}$ evolution as $\mathrm{H}_{2}$ release from the $\mathrm{H}_{2}$ evolving intermediate $\left[\mathrm{ReL}_{3} \cdot \mathrm{H}_{2}\right]$, Scheme 2 . The cyclic voltammetry studies clearly demonstrate that both electrons must be delivered prior to the $\mathrm{H}_{2}$ evolution step. We can discount a catalytic route involving a single reduction prior to $\mathrm{H}_{2}$ release (via $\left[\mathrm{ReL}_{3} \cdot \mathrm{H}_{2}\right]^{+}$) 
since this route proceeds through the monothiol complex $\left[\operatorname{Re}(\mathrm{LH}) \mathrm{L}_{2}\right]^{+}$, which is reduced at potentials significantly more positive than the catalytic event. As shown in Figure 12, under catalytic conditions the cyclic voltammogram contains redox events associated with $\left[\operatorname{Re} L_{3}\right]^{\mathrm{n}}$ and $\left[\operatorname{Re}(\mathrm{LH}) \mathrm{L}_{2}\right]^{\mathrm{n}}$, in addition to the catalytic event. Potentials associated with $\left[\operatorname{Re}(\mathrm{LH}) \mathrm{L}_{2}\right]^{2+/+}$ and $\left[\operatorname{Re}(\mathrm{LH}) \mathrm{L}_{2}\right]^{+/ 0}$ are observed at 0.18 and $-0.84 \mathrm{~V}$, respectively. These values are shifted by +0.52 and $+0.76 \mathrm{~V}$ relative to $\left[\operatorname{ReL}_{3}\right]^{+/ 0}$ and $[\operatorname{ReL} 3]^{0 /-}$, respectively, consistent with protonation of a single thiolate donor, as previously described. ${ }^{170,171}$

While reduction of $\left[\mathrm{ReL}_{3} \cdot \mathrm{H}_{2}\right]^{+}$is the final step of hydrogen evolution, hydrogen oxidation proceeds through sequential oxidations followed by $\mathrm{H}_{2}$ addition. Oxidation of $\mathrm{ReL}_{3}$ by two electrons in the presence of $\mathrm{H}_{2}$ generates the hydrogen addition complex, $\left[\mathrm{ReL}_{3} \cdot \mathrm{H}_{2}\right]^{2+}$. Stepwise deprotonation with two equivalents of triethylamine regenerates $\operatorname{ReL}_{3}$ via $\left[\operatorname{Re}(\mathrm{LH}) \mathrm{L}_{2}\right]^{+}$, Scheme 2 bottom.

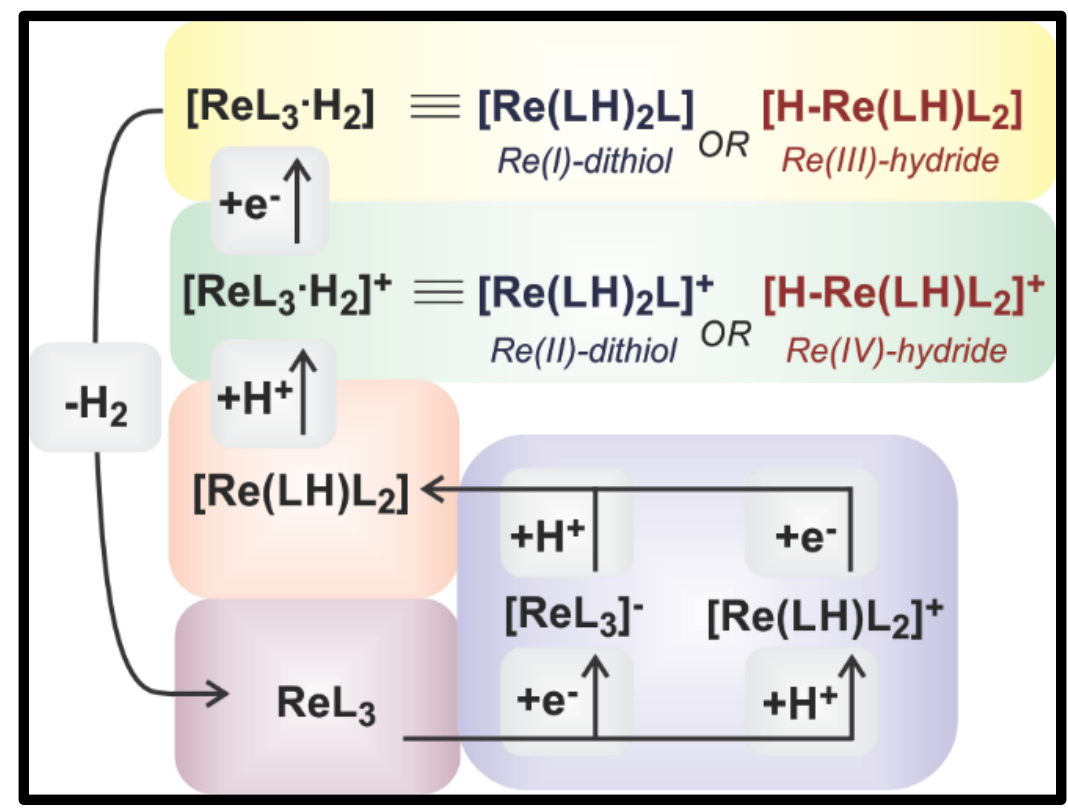

Scheme 3. Proposed Mechanism of $\mathrm{H}_{2}$ Evolution by $\mathrm{ReL}_{3}$. 
In order to elucidate the mechanism of hydrogen evolution by $\mathrm{ReL}_{3}$, DFT calculations were performed. The electronic and geometric properties of all complexes of the proposed mechanism in Scheme 3 were explored along with location of their transition states for $\mathrm{H}_{2}$ evolution pathways. Complexes with an even number of electrons $\left(\mathrm{ReL}_{3},\left[\operatorname{Re}(\mathrm{LH}) \mathrm{L}_{2}\right]^{+},\left[\mathrm{HRe}(\mathrm{LH}) \mathrm{L}_{2}\right]\right.$ and $\left.\left[\operatorname{Re}(\mathrm{LH})_{2} \mathrm{~L}\right]\right)$ were considered in both the singlet $(\mathrm{S}=0)$ and triplet $(\mathrm{S}=1)$ ground states for both closed-shell and open-shell configurations. All odd electron complexes $\left(\left[\mathrm{ReL}_{3}\right]^{-},\left[\operatorname{Re}(\mathrm{LH}) \mathrm{L}_{2}\right]^{0}\right.$, and $\left.\left[\operatorname{Re}(\mathrm{LH})_{2} \mathrm{~L}\right]^{+}\right)$ were calculated as doublets $(\mathrm{S}=1 / 2)$. Intermediates formed upon the addition of one proton were evaluated with protonation at S3, consistent with previous X-ray crystallographic studies. ${ }^{157}$ Addition of the second proton was examined for both ligandbased protonation at $\mathrm{S} 2$ and metal-based addition as the Re-hydride.

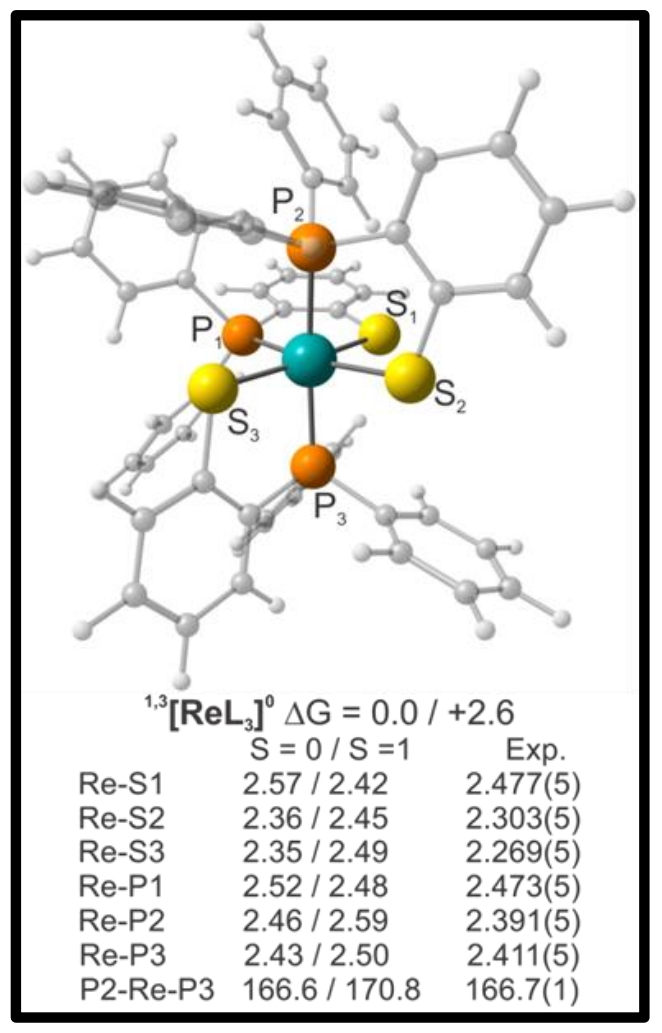

Figure 17. Bond lengths $(\AA)$ and angles $\left(^{\circ}\right)$ for $\operatorname{ReL}_{3}$ from $\mathrm{S}=0$ and $\mathrm{S}=1$ DFT optimizations (M06/LANL2DZ) and the experimental (Exp.) $\mathrm{x}$-ray crystal structure. ${ }^{157} \Delta \mathrm{G}$ indicates relative zero-point free energy ( $\mathrm{kcal} / \mathrm{mole}$ ) values of the $\mathrm{S}=0$ and $\mathrm{S}=1$ electronic states. 
The ground state of the neutral $\mathrm{ReL}_{3}$ complex is best described as a restricted singlet $\operatorname{Re}(\mathrm{III})\left(\mathrm{d}^{4}, \mathrm{~S}=0\right)$ center bound to three thiolate ligands (Figure 17). Optimized metal-ligand bond lengths for the singlet ground state are 0.02 to $0.09 \AA$ longer than experimental values, as typical for DFT calculations, while triplet state deviations from experimental bond lengths were larger. Furthermore, the neutral singlet species $(S=0)$ was favored over the triplet state $(\mathrm{S}=1)$ by $2.6 \mathrm{kcal} / \mathrm{mole}$. Due to the small difference in energy between the singlet and triplet states, attempts were made to obtain broken symmetry solution for the open-shell singlet. Calculations for the open-shell singlet were performed using the singlet geometry in combination with triplet orbitals as initial guesses. Examination of optimization steps show a decrease in the $<\mathrm{S}^{* *} 2>$ value moving from 2.0152 and collapsing to a final value of 0.00 . This result confirms the nature of the $\mathrm{ReL}_{3}$ complex as a closed-shell restricted singlet. 


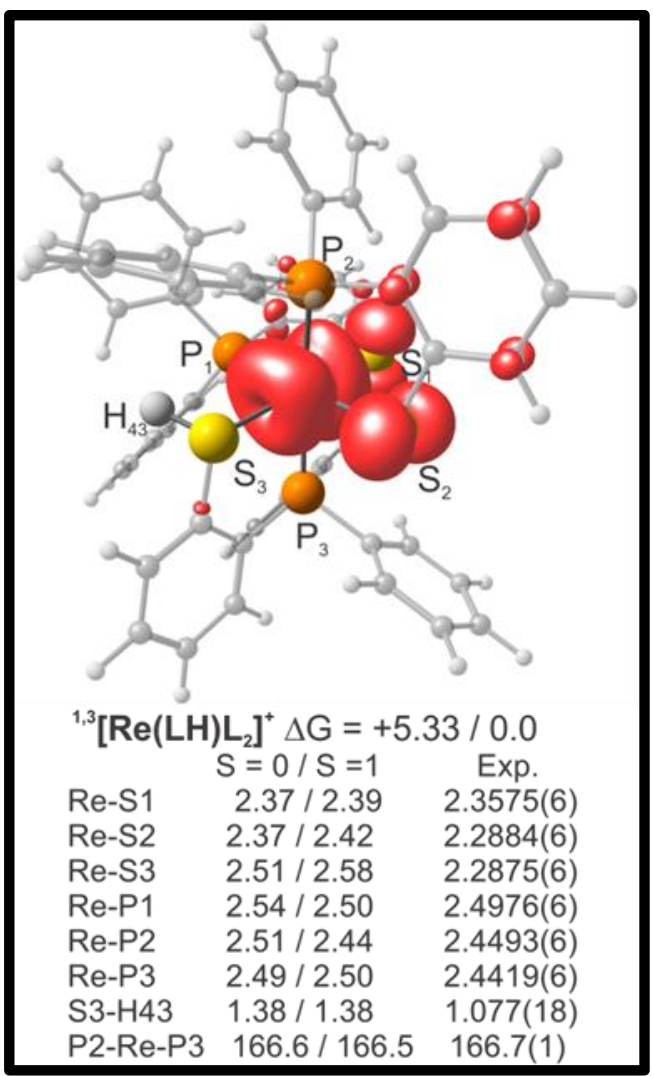

Figure 18. Bond lengths $(\AA)$ and angles $\left(^{\circ}\right)$ for $\left[\operatorname{Re}(\mathrm{LH}) \mathrm{L}_{2}\right]^{+}$from $\mathrm{S}=0$ and $\mathrm{S}=1$ DFT optimizations (B3LYP/LANL2DZ) and the experimental (Exp.) x-ray crystal structure. ${ }^{9} \Delta \mathrm{G}$ indicates relative zero-point free energy ( $\mathrm{kcal} / \mathrm{mole}$ ) values of the $\mathrm{S}=0$ and $\mathrm{S}=1$ electronic states.

The initial steps of the catalytic mechanism involve the transfer of one proton and one electron to $\mathrm{ReL}_{3}$ to yield the neutral $\left[\mathrm{Re}(\mathrm{LH}) \mathrm{L}_{2}\right]$ intermediate. Prior studies indicate that either proton or electron transfer can occur first. ${ }^{9}$ Initial protonation at S3 yields the previously isolated and characterized $\left[\mathrm{Re}(\mathrm{LH}) \mathrm{L}_{2}\right]^{+}$. The $\left[\mathrm{Re}(\mathrm{LH}) \mathrm{L}_{2}\right]^{+}$intermediate is best described as a $\operatorname{Re}(\mathrm{III})(\mathrm{S}=1)$ open-shell triplet coordinated by two non-innocent thiolate donors and one thiol donor (Figure 18). Single point energy calculations were performed as both closed-shell singlet and triplet in addition to obtaining the broken symmetry solution. Comparison of the triplet state geometric parameters reveal good agreement with the x-ray crystal structures of $\left[\operatorname{Re}(\mathrm{LH}) \mathrm{L}_{2}\right]^{+}$. The free energy of the triplet is also 
preferred energetically, lying $5.33 \mathrm{kcal} / \mathrm{mole}$ lower than the closed-shell singlet and 3.55 $\mathrm{kcal} / \mathrm{mole}$ lower than the open-shell singlet. Further examination of the $<\mathrm{S}^{* *} 2>$ values confirms an open-shell configuration of the triplet, yielding a final value of 2.0132, with the less energetically preferred open-shell singlet with an $<\mathrm{S} * * 2>$ value of 0.9516 .

For the double intermediates, $\left[\operatorname{ReL}_{3}\right]^{-},\left[\operatorname{Re}(\mathrm{LH}) \mathrm{L}_{2}\right]^{0}$ and $\left[\operatorname{Re}(\mathrm{LH})_{2} \mathrm{~L}\right]^{+}$, examination of the atomic spin densities (SD) reveals a propagation of ligand-centered radical character around the three $\mathrm{S}$ donors with each protonation step. The formal $\operatorname{Re}(\mathrm{II})$ species $\left[\mathrm{ReL}_{3}\right]^{-}$shows 6.5 and $6.4 \% \mathrm{SD}$ on the $\mathrm{S} 2$ and $\mathrm{S} 3$ donors with no significant contribution from S1 (Figure 19A). This suggests S2 and S3 have a small degree of thiyl character and can be considered "non-innocent", while S1 is best described a thiolate. Protonation of $\left[\mathrm{ReL}_{3}\right]^{-}$occurs preferentially at $\mathrm{S} 3$ yielding $\left[\operatorname{Re}(\mathrm{LH}) \mathrm{L}_{2}\right]$ resulting in a notable transfer of spin-density from S3 and Re onto S1 and S2. The S1 and S2 donors are now noninnocent with 8.6 and $9.1 \% \mathrm{SD}$, respectively, whereas $\mathrm{S} 3$ is a thiol (Figure 19B). The next step of the mechanism is the formation of $\left[\operatorname{Re}(\mathrm{LH})_{2} \mathrm{~L}\right]^{+}$upon addition of the second proton. Although this may potentially occur at sulfur yielding a $\operatorname{Re}(\mathrm{II})$-dithiol or at the metal to give a $\operatorname{Re}(\mathrm{IV})$-hydride, only the former structure could be optimized. Protonation is favored at S2 prompting a shift of SD onto S1, which now accounts for $23.1 \%$ of the unpaired SD (Figure 19C). The electronic structure of $\left[\operatorname{Re}(\mathrm{LH})_{2} \mathrm{~L}\right]^{+}$is doublet $(\mathrm{S}=1 / 2)$ with a formal $\operatorname{Re}(\mathrm{II})$ center coordinated by a non-innocent thiolate (S1) and two thiols (S2 and S3). 


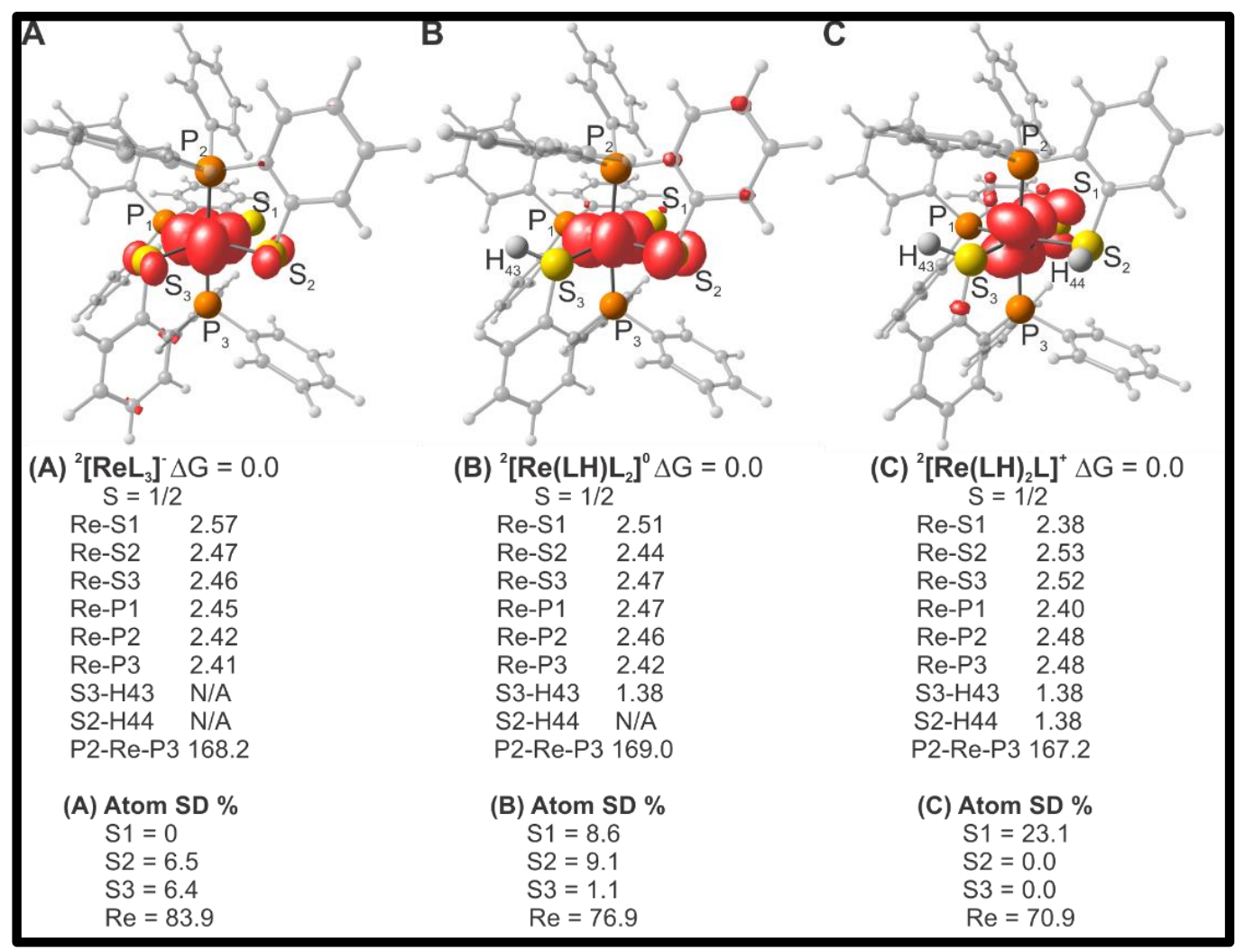

Figure 19. Bond lengths $(\AA)$, bond angles $\left(^{\circ}\right)$, and spin-density percentage contributions for the $\mathrm{S}$ $=1 / 2$ DFT optimizations (M06/LANL2DZ) of (A) $\left[\operatorname{ReL}_{3}\right]^{-},(\mathbf{B})\left[\operatorname{Re}(\mathrm{LH}) \mathrm{L}_{2}\right]^{0}$, and (C) $\left[\operatorname{Re}(\mathrm{LH})_{2} \mathrm{~L}\right]^{+}$.

Propagation of spin density as a function of protonation may be seen by analyzing the geometric parameters of the doublet intermediates. The Re-S1 bond distance decreases as a function of ligand electron density, further indicating non-innocent character. The distance drops from $2.57 \AA$ in $\left[\mathrm{ReL}_{3}\right]^{-}$to $2.51 \AA$ in $\left[\operatorname{Re}(\mathrm{LH}) \mathrm{L}_{2}\right]$ after initial protonation at $\mathrm{S} 3$, with a further decrease to $2.38 \AA$ in $\left[\mathrm{Re}(\mathrm{LH})_{2} \mathrm{~L}\right]^{+}$after the second protonation at S2. The Re-S2 bond distance decrease upon protonation at S3 is consistent with an increased SD, which further increases when S2 is protonated. The Re-S3 bond distance shows an increase with each protonation step. 


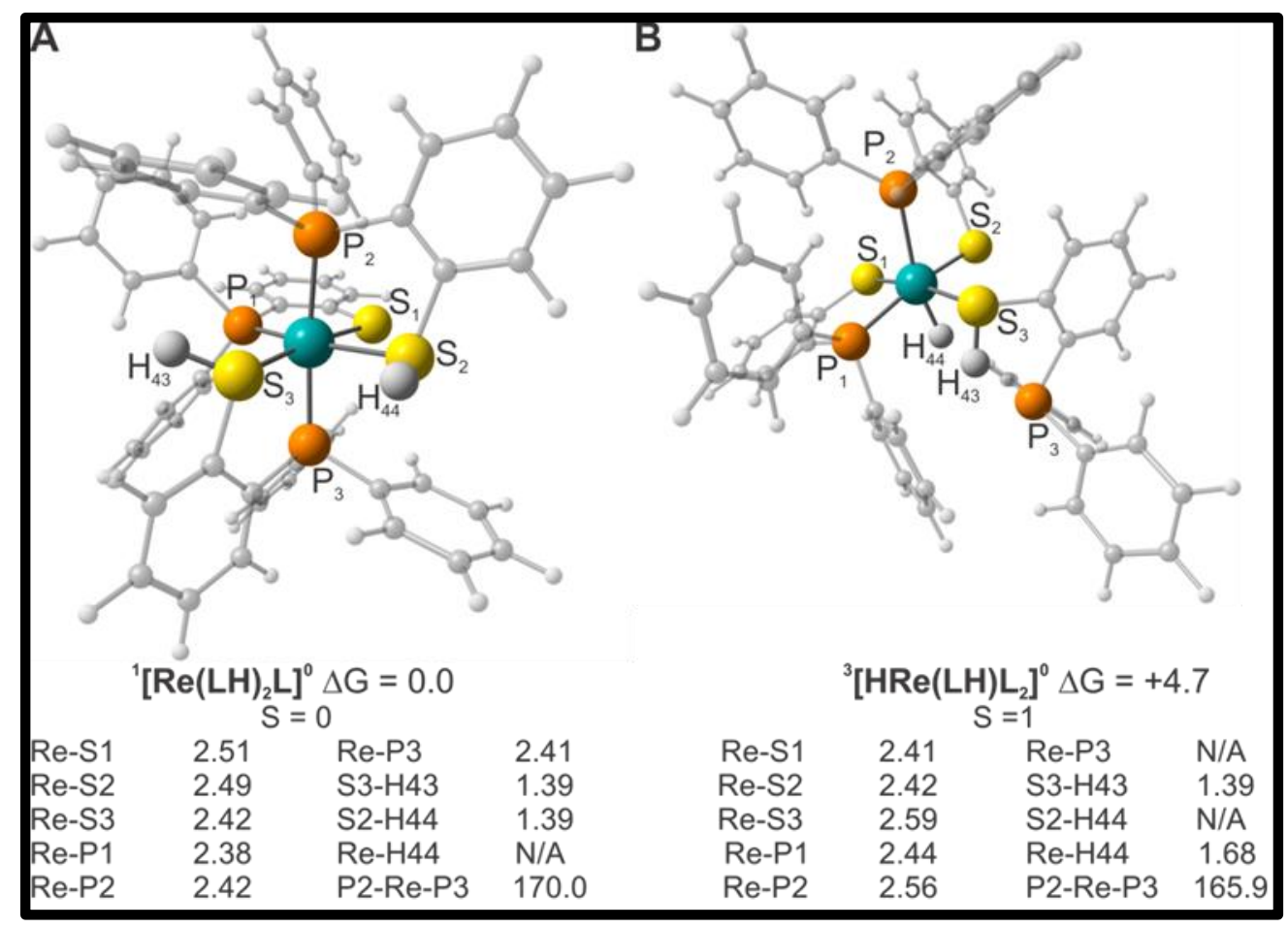

Figure 20. Bond lengths $(\AA)$ and angles $\left({ }^{\circ}\right)$ for optimizations (M06/LANL2DZ) of (A) $\left[\operatorname{Re}(\mathrm{LH})_{2} \mathrm{~L}\right]^{0}(\mathrm{~S}=0)$ DFT and $(\mathbf{B})\left[\mathrm{HRe}(\mathrm{LH}) \mathrm{L}_{2}\right]^{0}(\mathrm{~S}=1)$. and $(\mathrm{c})\left[\operatorname{Re}(\mathrm{LH})_{2} \mathrm{~L}\right]^{+} . \Delta \mathrm{G}$ indicates relative zero-point free energy (kcal / mole) values of the $\mathrm{S}=0$ and $\mathrm{S}=1$ electronic states (see appendix for analysis of the singlet $\left[\mathrm{HRe}(\mathrm{LH}) \mathrm{L}_{2}\right]^{0}$ species).

The final step of the HER mechanism is the addition of a second electron to yield the hydrogen evolving complex $\operatorname{ReL}_{3} \cdot \mathrm{H}_{2}$, which can be represented as either a $\mathrm{Re}(\mathrm{I})$ dithiol or a $\operatorname{Re}(\mathrm{III})$-hydride. The electronic and geometric parameters of the $\operatorname{Re}(\mathrm{I})$-dithiol, $\left[\operatorname{Re}(\mathrm{LH})_{2} \mathrm{~L}\right]$, were examined in the singlet $(\mathrm{S}=0)$, as well as the triplet $(\mathrm{S}=1)$ states, however with only successful optimization of the singlet electronic state. The electronic and geometric parameters of the $\operatorname{Re}(\mathrm{III})$-hydride, $\left[\mathrm{HRe}(\mathrm{LH}) \mathrm{L}_{2}\right]$, was examined as a singlet $(\mathrm{S}=0)$ and triplet $(\mathrm{S}=1)$ with the triplet being $2.03 \mathrm{kcal} / \mathrm{mole}$ lower in energy than the singlet (see Appendix for more information). The singlet $\operatorname{Re}(\mathrm{I})$-dithiol $(\mathrm{S}=0)$ configuration is favored over the triplet $\operatorname{Re}(\mathrm{III})$-hydride $(\mathrm{S}=1)$ by $4.7 \mathrm{kcal} / \mathrm{mol}$ (Figure 20). This energy gap is sufficiently small, and it should be noted that $\left[\operatorname{HRe}(\mathrm{LH}) \mathrm{L}_{2}\right]$ 
cannot completely be excluded as the $\mathrm{H}_{2}$-evolving complex based solely on single point energy calculations.

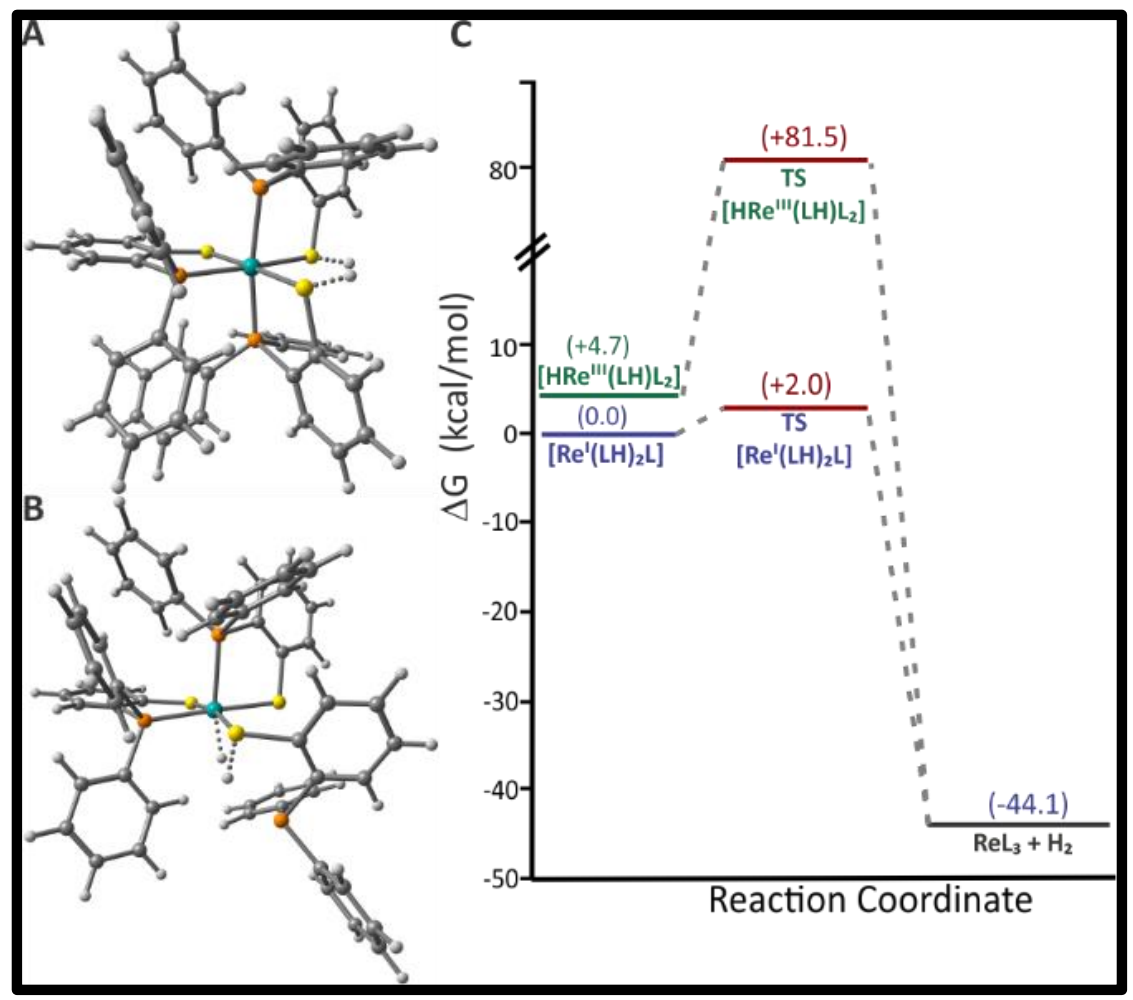

Figure 21. Transition states and energy profile for HER through Re-dithiol and Re-hydride pathways. (A) Representation of TS-[Re(LH) $\left.)_{2} \mathrm{~L}\right]$ showing lengthening of two S-H bonds associated with $\mathrm{H}_{2}$ evolution. (B) Representation of TS-[HRe(LH) $\left.\mathrm{L}_{2}\right]$ showing $\mathrm{H}_{2}$ evolution from $\mathrm{Re}-\mathrm{H}$ and S-H. (C) Comparison of relative energies (ZPE corrected) for Re-dithiol and Rehydride HER pathways using M06/LANL2DZ.

To unequivocally resolve the electronic structure of the $\mathrm{H}_{2}$-evolving complex, transition states (TS) for reaction pathways were located for both $\left[\operatorname{Re}(\mathrm{LH})_{2} \mathrm{~L}\right]$ (Figure $21 \mathrm{~A}$ ) and $\left[\mathrm{HRe}(\mathrm{LH}) \mathrm{L}_{2}\right]$ (Figure 21B). The traditional metal-hydride $\left[\mathrm{HRe}(\mathrm{LH}) \mathrm{L}_{2}\right]$ pathway proceeding through $\mathrm{TS}-\left[\mathrm{HRe}(\mathrm{LH}) \mathrm{L}_{2}\right]$ requires an insurmountable $81.5 \mathrm{kcal} /$ mole barrier. In contrast, ligand-centered $\mathrm{H}_{2}$ evolution along the $\left[\mathrm{Re}(\mathrm{LH})_{2} \mathrm{~L}\right]$ pathway proceeds through TS-[Re(LH) $\left.)_{2} \mathrm{~L}\right]$ over a modest barrier of $2 \mathrm{kcal} /$ mole (Figure $21 \mathrm{C}$ ), represented by the imaginary frequency $i 1113 \mathrm{~cm}^{-1}$. The $\mathrm{S}-\mathrm{H}$ bond lengths in TS- 
$\left[\operatorname{Re}(\mathrm{LH})_{2} \mathrm{~L}\right], 1.524$ and $1.532 \AA$, are $0.125-0.133 \AA$ longer than the respective equilibrium bond lengths, 1.399 and $1.399 \AA$ in $\left[\operatorname{Re}(\mathrm{LH})_{2} \mathrm{~L}\right]$. This may be attributed to a transfer of charge densities from the formal $\operatorname{Re}(\mathrm{I})$ to the thiol sulfurs moving forward along the intrinsic reaction coordinate (IRC), initiating the release of two $\mathrm{H}$-atoms that couple to form hydrogen (Figure 22ABCD). The IRC analysis is consistent with a ligandcentered $\mathrm{H}_{2}$ evolution pathway best described as homolytic cleavage of two ciscoordinated metal thiol S-H bonds.

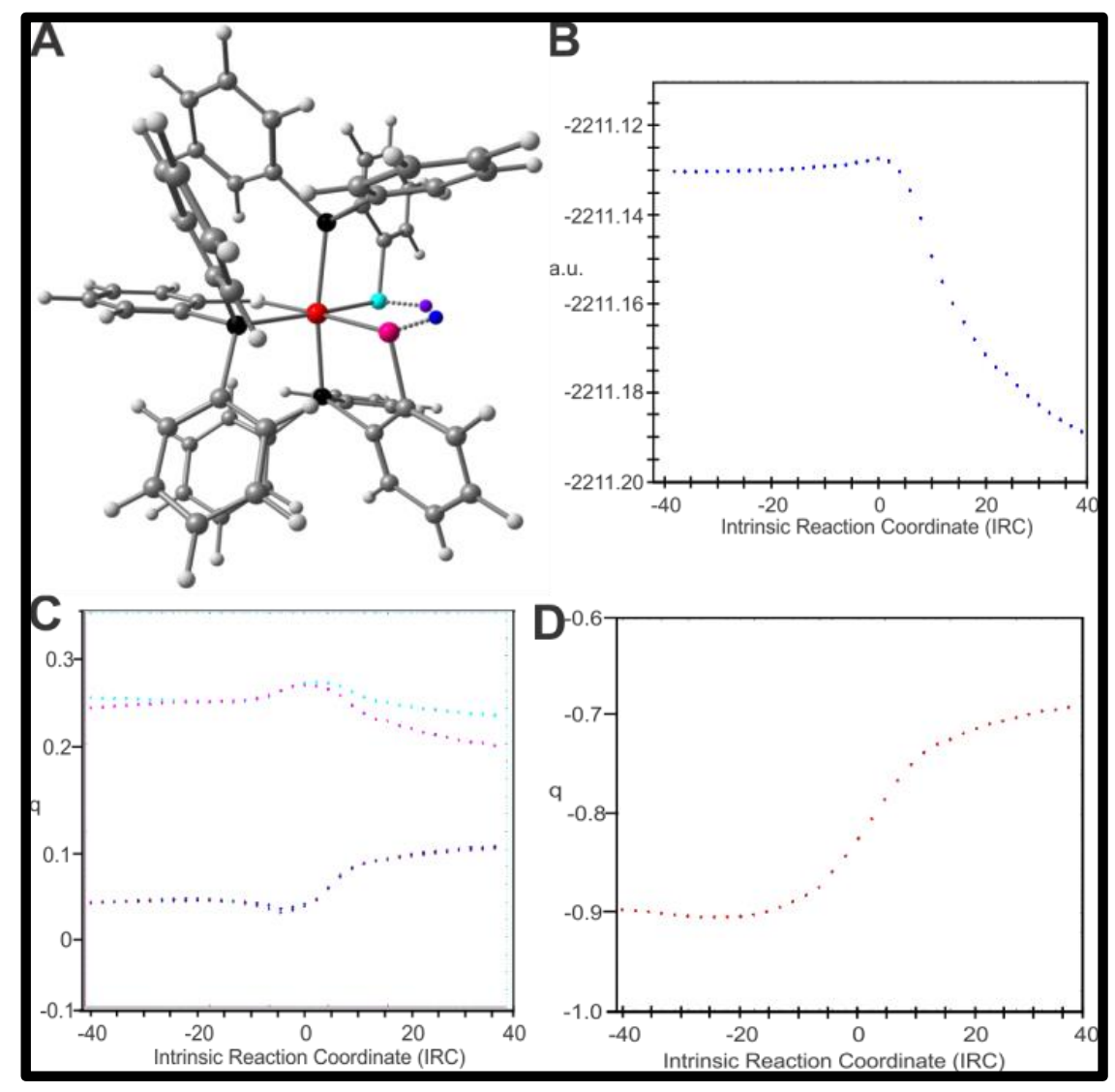

Figure 22. (A) Transition state geometry of $\left[\operatorname{Re}(\mathrm{LH}) \mathrm{L}_{2}\right]$ along the HER pathway, shown with active $\mathrm{S}-\mathrm{H}$ bond dissociations and Re atom associated with the imaginary frequency, $i 1113 \mathrm{~cm}^{-1}$. (B) Transition State Analysis of $\mathrm{H}_{2}$ Evolving Complex $\left[\mathrm{Re}(\mathrm{LH})_{2} \mathrm{~L}\right]$. Internal reaction coordinates (IRC) moving through the TS for $\left[\operatorname{Re}(\mathrm{LH})_{2} \mathrm{~L}\right]$ associated with the imaginary frequency $i 1113 \mathrm{~cm}^{-}$ ${ }^{1}$. (C) Charge densities of sulfur and hydrogen atoms near $\mathrm{H}_{2}$ evolution for $\left[\mathrm{Re}(\mathrm{LH})_{2} \mathrm{~L}\right]$ along the HER pathway with respect to IRC, associated with the imaginary frequency $i 1113 \mathrm{~cm}^{-1}, \mathrm{~S} 3 / \mathrm{S} 4$ (cyan, magenta) and H5 / H105 (blue, purple). Transition State S-H bond lengths $=1.524 \AA$ and $1.532 \AA$. (D) Charge densities of the Rhenium atom near $\mathrm{H}_{2}$ evolution with respect to IRC, associated with the imaginary frequency $11113 \mathrm{~cm}^{-1}$, Re1 (red). 


\subsection{Conclusion}

Homogeneous electrochemical studies were performed to assess $\mathrm{ReL}_{3}$ as an electrocatalyst for $\mathrm{H}_{2}$ evolution and oxidation. ${ }^{9}$ Electrochemical studies show that $\mathrm{ReL}_{3}$ reduces acid in $\mathrm{CH}_{2} \mathrm{Cl}_{2}$ to $\mathrm{H}_{2}$ with an overpotential of $0.708 \mathrm{~V}$ and a turnover frequency of $32 \pm 3 \mathrm{~s}^{-1}$ via a unimolecular mechanism. Additionally, $\mathrm{ReL}_{3}$ oxidizes $\mathrm{H}_{2}$ in the presence of base at an overpotential of $0.970 \mathrm{~V}$ with a turnover frequency of $4 \pm 1 \mathrm{~s}^{-1}$. To our knowledge this is one of four published electrocatalysts which can perform both the HER and HOR reaction. Furthermore, it was the first ligand-centered HER/HOR electrocatalyst reported. The HER mechanism is supported by DFT, including location of the transition state and intrinsic reaction coordinate analysis, identifying the $\mathrm{H}_{2}$ evolving complex as a Re-dithiol that generates $\mathrm{H}_{2}$ through a radical coupling mechanism. The process involves homolytic S-H bond cleavage with no formation of metal-hydride intermediates. The results represent the first example of a ligand-centered HER mechanism to be validated through a rigorous combination of digital simulations of voltammetric data, DFT optimizations and spin-density analyses of all catalytically relevant metal complexes, location of the transition state and analysis of intrinsic reaction coordinates by computational methods.

While unprecedented in homogeneous mononuclear systems, Yan et al. recently reported heterogeneous $\mathrm{H}_{2}$ evolution from $\mathrm{MoS}_{2}$ proposing exposed unsaturated $\mathrm{S}$ edge atoms as reaction sites. ${ }^{172}$ The unique reactivity of $\mathrm{ReL}_{3}$ could be attributed to a sterically crowded, kinetically inert, and coordinativley saturated metal center that prevents facile formation of metal hydride, which is proposed for other active metal-sulfur catalysts. While this would normally be expected to render a complex inactive, the noninnocent ligands in $\mathrm{ReL}_{3}$ are known to react with small molecule substrates in a ligand-centered 
pathway. This could explain the unusual KIE and bifunctional $\left(\mathrm{H}_{2}\right.$ evolution and $\mathrm{H}_{2}$ oxidation) activity of $\mathrm{ReL}_{3}$. Nonetheless, this work represents a valuable jumping off point into the field of strictly ligand-centered catalysis, and the lessons learned will undoubtedly be pivotal in the future design of other small molecule activation catalysts.

\subsection{Acknowledgement}

The work described in chapter 3 was supported by the National Science Foundation research grant (CHE-1361728) and a grant from the Kentucky Science and Engineering Foundation as per grant agreement no. KSEF-148-502-15-350 with the Kentucky Science and Technology Corporation. The authors are thankful to Cardinal Research Cluster at the University of Louisville for providing the computational facilities. 


\section{CHAPTER IV: SUSTAINABLE METAL ALTERNATIVES FOR LIGAND- CENTERED $\mathrm{H}_{2}$ EVOLUTION AND HYDROGEN OXIDATION}




\subsection{Introduction}

The $\mathrm{ReL}_{3}$ system described in Chapter Three opens the door to novel pathways and alternative strategies for catalytic HER development. However, the system suffers from significant limitations including: 1) incorporation of a non-sustainable, precious metal; 2) the ligand synthesis requires multiple steps that are air, moisture, and/or light sensitive performed under inert conditions; 3) catalysis is limited to halogenated organic solvents; 4) modification of the ligand structure requires an individualized approach for each new derivative; and 5) large complex size $/ 3^{\text {rd }}$ row transition metal complicates computational studies of the mechanism.

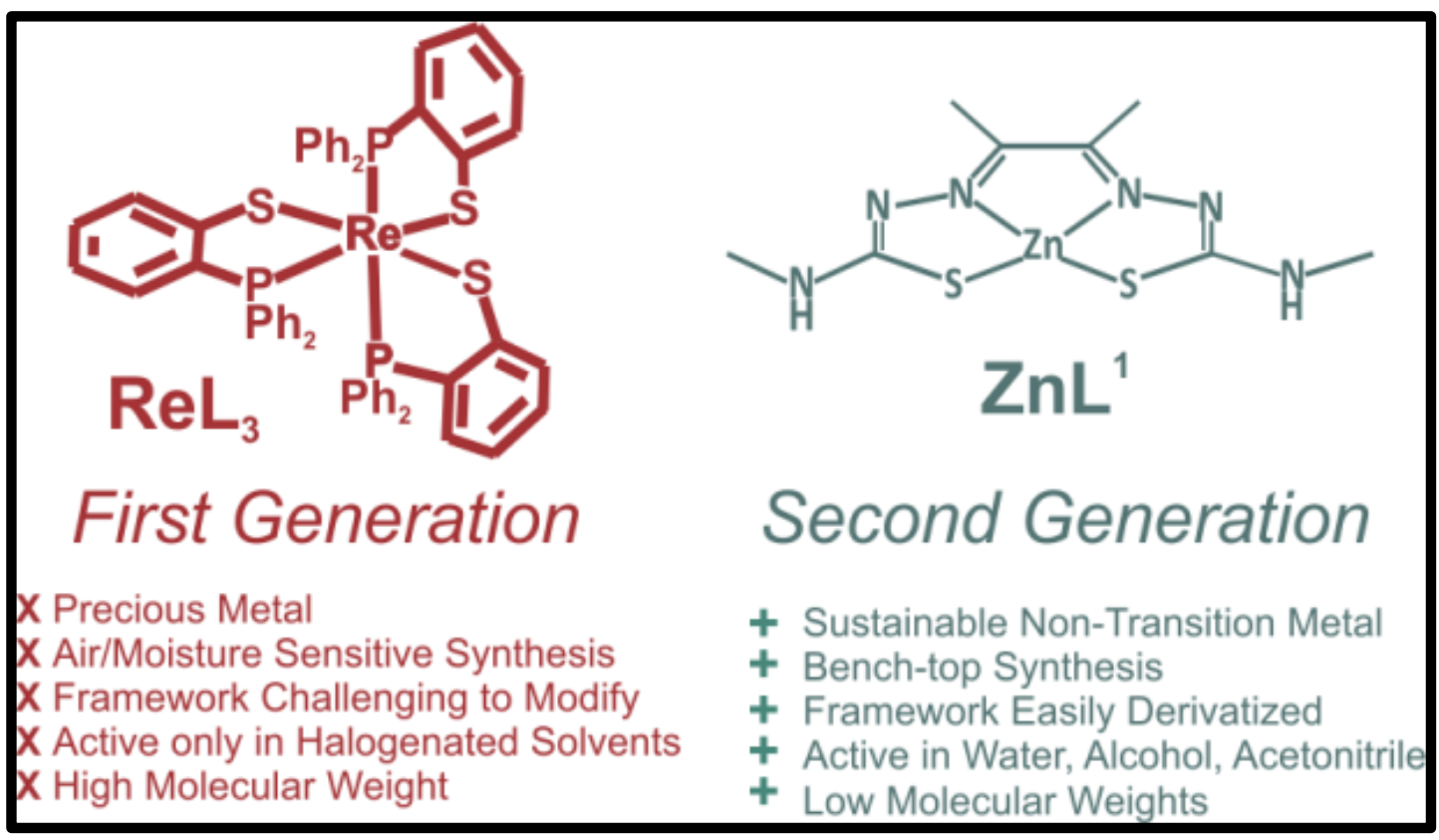

Scheme 4. Comparison of first and second generation Ligand-Centered HER Electrocatalysts.

To overcome the limitations of $\operatorname{ReL}_{3}$, we developed new catalysts based on the non-innocent bis-thiosemicarbazone ligand $\quad \mathrm{H}_{2} \mathrm{~L}^{1} \quad$ (L $=$ diacetyl-bis(N-4-methyl-3thiosemicarbazide), Scheme 4. This chapter will focus on two electrocatalysts based on 
this ligand class, encompassing the metal free ligand, $\mathrm{H}_{2} \mathrm{~L}^{1}$ and the transition metal free, $\mathrm{ZnL}^{1}$ Scheme $5 . \mathrm{H}_{2} \mathrm{~L}^{1}$ represents the first homogeneous metal-free HER catalyst, $\mathrm{ZnL}^{1}$ is the most active transition metal free HER catalyst. ${ }^{76}$ Further, these systems overcome the limitations noted above as they: 1) incorporate sustainable first-row metals; 2) the ligand syntheses require no specialized skills and can be performed on the benchtop in water and/or alcohol using inexpensive synthons; 3) catalysis occurs in water/alcohol or acetonitrile; 4) the framework is easily derivatized and very stable to hydrolysis; 5) the structures are small with metals that are well calibrated from the computational perspective.

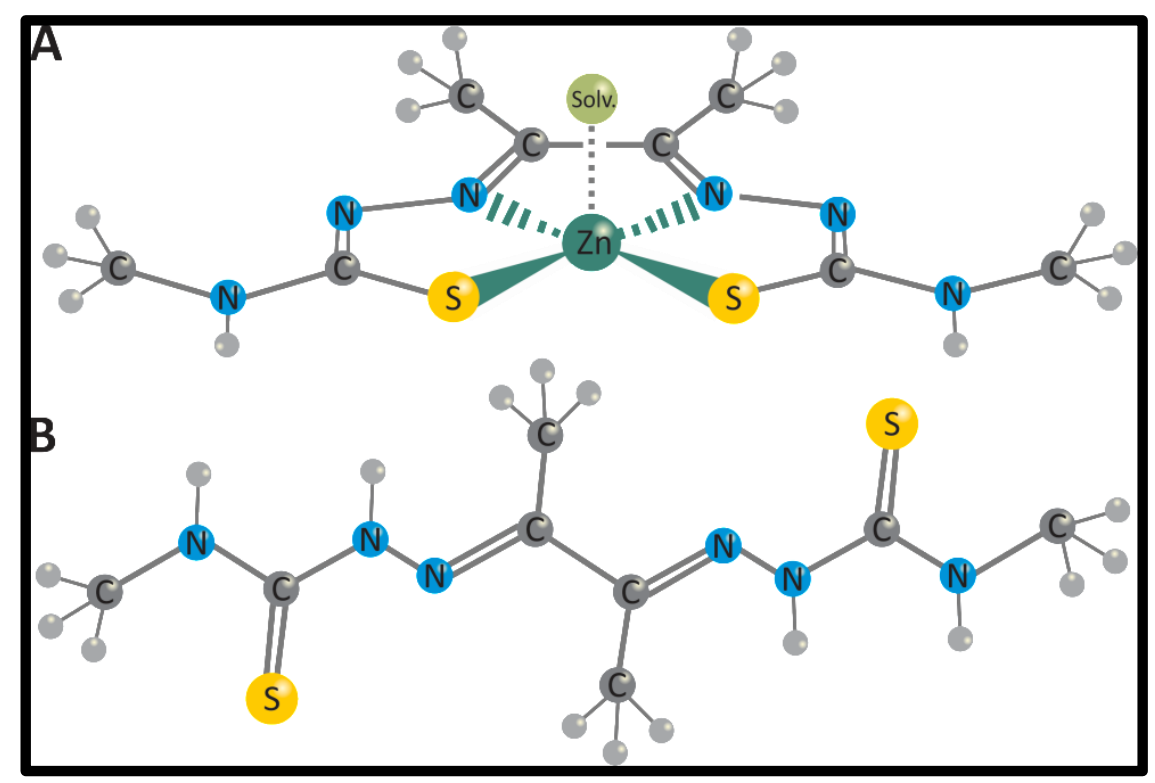

Scheme 5. Representation of $\mathrm{ZnL}^{1}$ and $\mathrm{H}_{2} \mathrm{~L}^{1}$.

Other ligand-centered processes for HER/HOR are emerging in the literature, Scheme 6. Initial reports focused on heterogeneous systems including a metal-free HER catalyst based on $\mathrm{N}$-doped graphene with graphitic-carbon nitride ${ }^{100}$ and metal-free and 
zinc-phthalocyanines. ${ }^{101,105,106}$ Notable heterogeneous HOR electrocatalysts include a metal-free frustrated Lewis pair ${ }^{107}$ that is proposed to operate through a hydride intermediate similar to homogeneous $\mathrm{Ni}$ and Fe HOR catalysts. More recently, an aluminum-bis(imino)pyridine complex was reported as a homogeneous, non-transition metal HER electrocatalyst with a TOF of $3.3 \mathrm{hr}^{-1} \cdot{ }^{99}$ Activity was attributed to a radical process involving homolytic $\mathrm{C}-\mathrm{H}$ bond cleavage. A similar mechanism was proposed for a nickel "hangman"-porphyrin complex via a Ni phorlin intermediate, although no TOF was reported. ${ }^{173}$ Recently, a heterobimetallic W-Ni complex employing a redox-active ligand was reported as a HER catalyst in acidic aqueous solutions with a cis-thiolate core proposed as the active site. ${ }^{174}$ The recent development of ligand-centered HER/HOR catalysts underscores the need for alternate approaches to the traditional metal-hydride systems. The remainder of this chapter will cover the electrochemical, computational, and mechanistic study of $\mathrm{H}_{2} \mathrm{~L}^{1}$ and $\mathrm{ZnL}^{1}$ as electrocatalysts for hydrogen evolution or hydrogen oxidation.

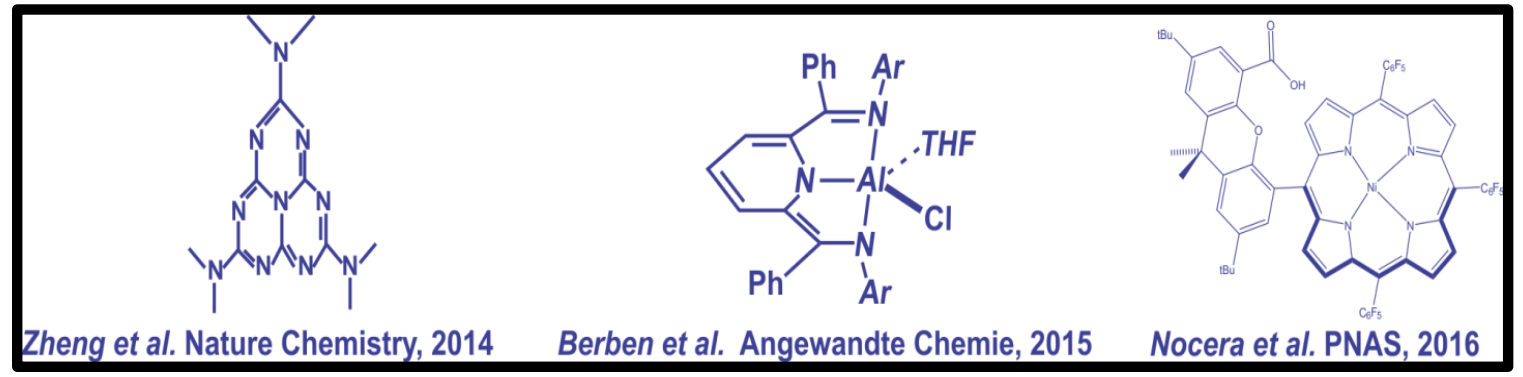

Scheme 6. Selected ligand-centered HER/HOR electrocatalysts, taken from references 71, 99 and $100 .^{71,99,100}$ 


\subsection{Results and Discussion}

\subsection{1. $\mathrm{ZnL}^{1}$ Cyclic Voltammetry Characterization}

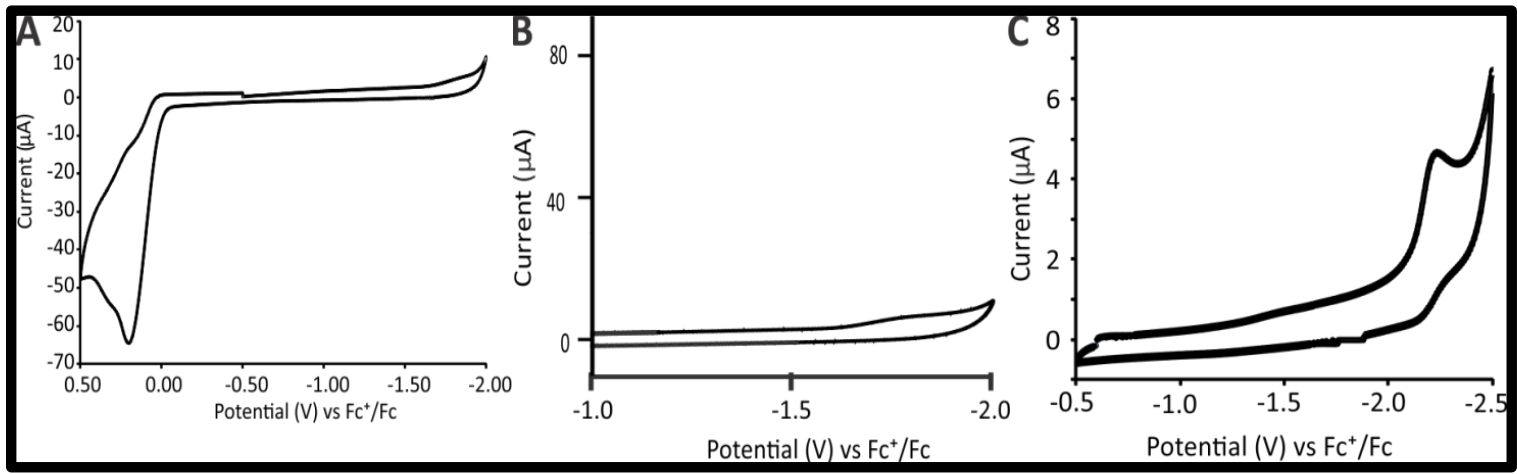

Figure 23. (A) Cyclic voltammogram of $\mathrm{ZnL}^{1}$ in $0.1 \mathrm{M} \mathrm{Bu}_{4} \mathrm{NPF}_{6}$ methanol solution (B) Blow up of cathodic region of cyclic voltammogram of $\mathrm{ZnL}^{1}$ in $0.1 \mathrm{M} \mathrm{Bu}_{4} \mathrm{NPF}_{6}$ methanol solution. (C) Cyclic voltammogram of $\mathrm{ZnL}^{1}$ in $0.1 \mathrm{M} \mathrm{Bu}_{4} \mathrm{NPF}_{6}$ acetonitrile solution.

$\mathrm{ZnL}^{1}$ was synthesized according to literature procedure reported by Holland et al. ${ }^{11,112}$ The $\mathrm{ZnL}^{1}$ complex is stable open to air and is soluble in a variety of solvents including, methanol, ethanol, acetonitrile, and dimethylformamide. $\mathrm{Zn}^{\mathrm{II}}$ complexes of tetradentate ligands that are constrained in pseudo-square planar conformations can potentially bind a fifth donor atom in the axial coordination site, as indicated in Scheme $5,{ }^{175}$ foreshadowing the ability of the $\mathrm{ZnL}^{1}$ to dimerize, making it an excellent candidate for multi-step electrocatalysis.

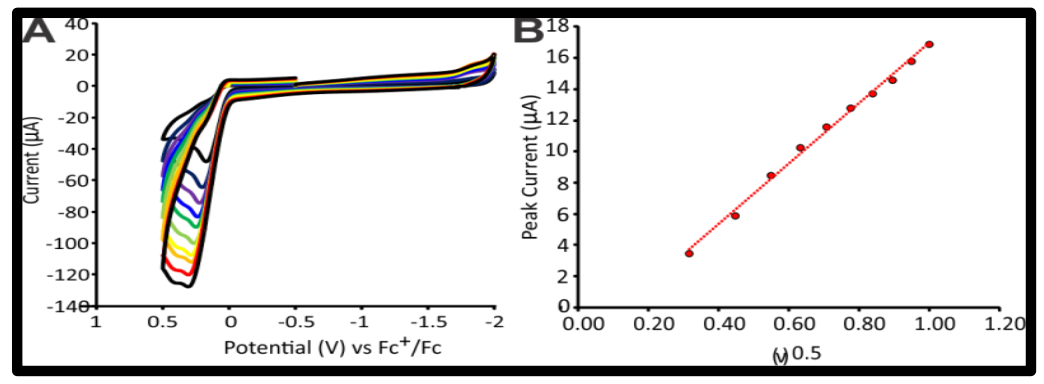

Figure 24. (A) Cyclic voltammogram of $\mathrm{ZnL}^{1}$ in $0.1 \mathrm{M} \mathrm{Bu}_{4} \mathrm{NPF}_{6}$ methanol solution scanned at 0.1 (black), 0.2 (dark blue), 0.3 (purple), 0.4 (blue), 0.5 (green), 0.6 (light green). 0.7 (yellow), 
0.8 (orange), 0.9 (red) and, 1.0 (black) V/s. (B) Cottrell plot of the peak current plotted against the square root of the scan rate.

$\mathrm{CVs}$ of $\mathrm{ZnL}^{1}$ were initially run in methanol and acetonitrile. In $0.1 \mathrm{M} \mathrm{Bu}_{4} \mathrm{NPF}_{6}$ methanol solution an irreversible oxidation observed with onset potentials near and $0.3 \mathrm{~V}$ vs $\mathrm{Fc}^{+} / \mathrm{Fc}$ (Figure 23A). In methanol sweeping in the cathodic direction was limited by solvent reduction of methanol, resulting in no observed reductions (Figure 23B). However cathodic sweeps in acetonitrile show an irreversible reduction at $-2.3 \mathrm{~V}$ vs $\mathrm{Fc}^{+} / \mathrm{Fc}$ (Figure 23C). Subsequent $\mathrm{CV}$ studies without substrate were run from 0.1 to 1.0 V/s (Figure 24A) Cottrell plots were constructed by plotting the peak current from each against the square root of the scan rate in order to yield a linear relationship with a slope of $1.94 \times 10^{-5}$ ( Figure 24B). This was then used in conjunction with the Randles-Sevcik equation in order to calculate a diffusion coefficient of $1.15 \times 10^{-7} \mathrm{~cm}^{2} / \mathrm{s}$.

\subsection{2. $\mathrm{ZnL}^{1}$ Cyclic Voltammetry Hydrogen Evolution and Hydrogen Oxidation Studies}

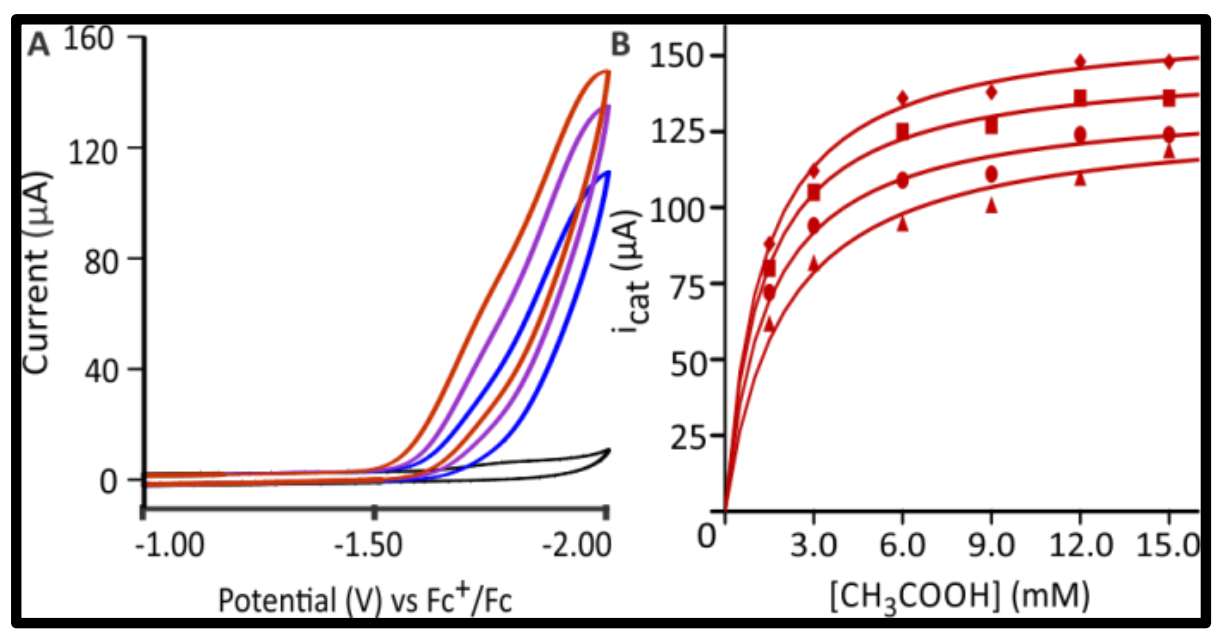

Figure 25. (A) Cyclic voltammograms of $3 \mathrm{mM} \mathrm{ZnL}^{1}$ in methanol with no added acid (black), 6 $\mathrm{mM} \mathrm{CH} 3 \mathrm{COOH}$ (blue), $9 \mathrm{mM} \mathrm{CH} \mathrm{COOH}_{3} \mathrm{Cpurple}$ ), and $12 \mathrm{mM} \mathrm{CH}_{3} \mathrm{COOH}$ (red). Data collected at a scan rate of $0.5 \mathrm{~V} / \mathrm{s}$ in the presence of $0.1 \mathrm{M} \mathrm{Bu}_{4} \mathrm{NPF}_{6}$ as supporting electrolyte. (B) Plot of 
$\mathrm{i}_{\text {cat }}$ vs $\left[\mathrm{CH}_{3} \mathrm{COOH}\right]$ for $3 \mathrm{mM} \mathrm{ZnL}^{1}(\mathrm{red})$ at scan rates of $0.2(\boldsymbol{\Delta}), 0.3(\bullet), 0.4(\boldsymbol{\bullet})$, and $0.5(\bullet)$ $\mathrm{V} / \mathrm{s}$.

Solutions of $\mathrm{ZnL}^{1}$ in methanol display catalytic hydrogen evolution upon reduction in the presence of acetic acid. The cathodic current intensity at $-1.7 \mathrm{~V}$ increases with increasing acid concentration indicative of an electrocatalytic process (Figure 25A). The current plateaus at $12.0 \mathrm{mM}$ acetic acid, indicating acid saturation and signifying that $\mathrm{CV}$ response is no longer limited by diffusion of the substrate to the electrode surface (Figure 25B) ${ }^{121,163-165}$, with a maximum TOF of $1170 \mathrm{~s}^{-1}$ at overpotential of $756 \mathrm{mV}$ (see appendix for more information). ${ }^{121,176,177}$ The new reduction event observed during catalysis at $-1.5 \mathrm{~V}$ in methanol signifies that the HER undergoes an initial protonation prior to reduction, effectively pushing the first reduction to more anodic potentials than that observed in the absence of acid.

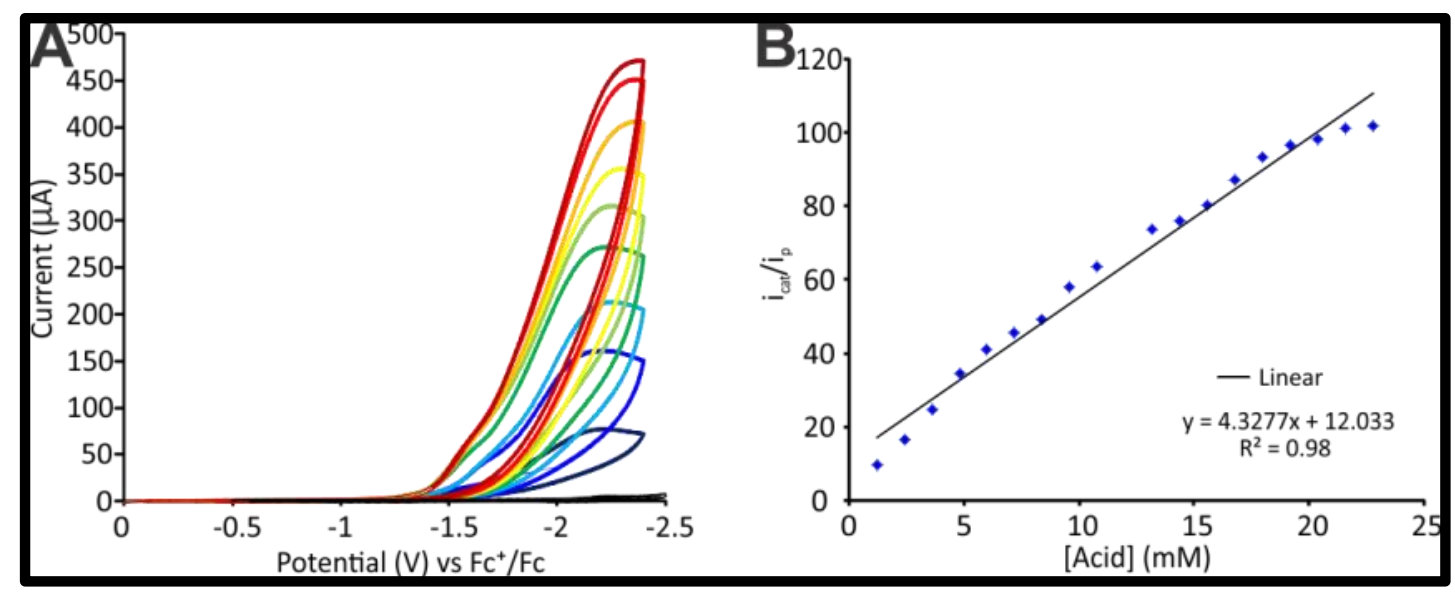

Figure 26. (A) Cyclic voltammograms of $3 \mathrm{mM} \mathrm{ZnL}^{1}$ in $\mathrm{ACN}$ with no added acid (black), 2.4 $\mathrm{mM} \mathrm{CH}{ }_{3} \mathrm{COOH}$ (dark blue), $4.8 \mathrm{mM} \mathrm{CH}_{3} \mathrm{COOH}$ (blue), $7.2 \mathrm{mM} \mathrm{CH}_{3} \mathrm{COOH}$ (light blue), $9.6 \mathrm{mM}$ $\mathrm{CH}_{3} \mathrm{COOH}$ (green), $12.0 \mathrm{mM} \mathrm{CH} \mathrm{CHOH}_{3} \mathrm{COO}$ (light green), $14.4 \mathrm{mM} \mathrm{CH} \mathrm{CHOOH}_{3} \mathrm{Cyellow}$ ), $16.8 \mathrm{mM}$ $\mathrm{CH}_{3} \mathrm{COOH}$ (orange), $19.2 \mathrm{mM} \mathrm{CH} \mathrm{CH}_{3} \mathrm{COOH}$ (red), and $21.6 \mathrm{mM} \mathrm{CH}_{3} \mathrm{COOH}$ (dark red). Data collected at a scan rate of $0.5 \mathrm{~V} / \mathrm{s}$ in the presence of $0.1 \mathrm{M} \mathrm{Bu}_{4} \mathrm{NPF}_{6}$ as supporting electrolyte. (B) Plot of $\mathrm{i}_{\text {cat }} \mathrm{vs}\left[\mathrm{CH}_{3} \mathrm{COOH}\right]$ for $3 \mathrm{mM} \mathrm{ZnL}^{1}$ (red) at scan rates of $0.2(\diamond) \mathrm{V} / \mathrm{s}$. 
In acetonitrile, addition of acetic acid results in catalytic current at $-2.3 \mathrm{~V}$ (Figure $26 \mathrm{~A})$, which is within the range of reduction potentials previously reported for similar thiosemicarbazones. ${ }^{178}$ The catalytic current becomes independent of acid concentration at $23 \mathrm{mM}$ (Figure 26B), yielding a higher TOF value of $11700 \mathrm{~s}^{-1}$ than that observed in methanol, but with a larger overpotential of $1.07 \mathrm{~V}$ (see appendix for more information). The lower overpotential in methanol is consistent with outer-coordination sphere proton shuttling, ${ }^{179}$ which facilitates ligand protonation prior to electrochemical reduction, as previously suggested for thiosemicarbazone complexes. ${ }^{180}$

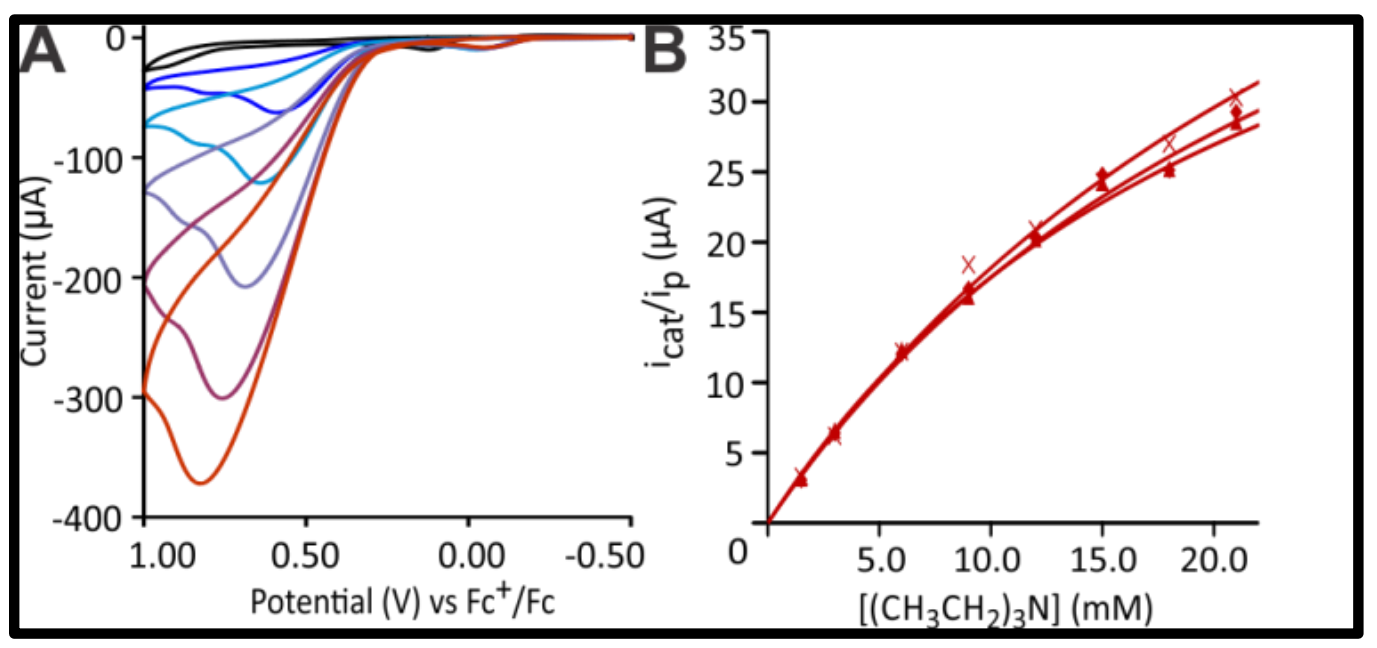

Figure 27. (A) Cyclic voltammograms of $0.3 \mathrm{mM} \mathrm{ZnL}$ in methanol under $1 \mathrm{~atm} . \mathrm{H}_{2}$ with no added base (black), $3 \mathrm{mM}\left(\mathrm{CH}_{3} \mathrm{CH}_{2}\right)_{3} \mathrm{~N}$ (dark blue), $6 \mathrm{mM}\left(\mathrm{CH}_{3} \mathrm{CH}_{2}\right)_{3} \mathrm{~N}$ (light blue), $12 \mathrm{mM}$ $\left(\mathrm{CH}_{3} \mathrm{CH}_{2}\right)_{3} \mathrm{~N}$ (light purple), $21 \mathrm{mM}\left(\mathrm{CH}_{3} \mathrm{CH}_{2}\right)_{3} \mathrm{~N}$ (dark purple), and $30 \mathrm{mM}\left(\mathrm{CH}_{3} \mathrm{CH}_{2}\right)_{3} \mathrm{~N}$ (red). Data collected at a scan rate of $0.5 \mathrm{~V} / \mathrm{s}$ in the presence of $0.1 \mathrm{M} \mathrm{Bu}_{4} \mathrm{NPF}_{6}$ as supporting electrolyte. (B) Plot of $\mathrm{i}_{\text {cat }} / \mathrm{i}_{\mathrm{p}}$ vs $\left[\left(\mathrm{CH}_{3} \mathrm{CH}_{2}\right)_{3} \mathrm{~N}\right]$ for $0.3 \mathrm{mM} \mathrm{ZnL}$ under $1 \mathrm{~atm} . \mathrm{H}_{2}$ (red) at scan rates of $0.2(\boldsymbol{\Delta}), 0.5(\diamond)$, and $1.0(\times) \mathrm{V} / \mathrm{s}$.

As well as electrocatalytic HER, $\mathrm{ZnL}^{1}$ also catalyzes HOR. Introduction of triethylamine to methanol solutions of $\mathrm{ZnL}^{1}$ under $1 \mathrm{~atm}$ of $\mathrm{H}_{2}$ results in an increase in anodic current near the irreversible oxidation wave of $\mathrm{ZnL}^{1}$.(Figures 27A). The catalytic current intensity shows saturation behavior (Figure 27B) with near saturation at a base 
concentration of $30 \mathrm{mM}$, indicating that catalysis is no longer limited by diffusion of the substrate to the electrode surface, yielding a TOF of $72 \mathrm{~s}^{-1}$ with an overpotential of 0.31 $\mathrm{V}$ (see appendix for more information). The HER and HOR TOF values of $\mathrm{ZnL}^{1}$ is substantially higher than those of other proposed ligand-centered catalysts, suggesting that $\mathrm{H}_{2} \mathrm{~L}^{1}$ itself may also demonstrate catalytic activity.

In order to determine the reaction order with respect to the catalyst for the HER, $\mathrm{CVs}$ were run at a fixed acid concentration of $12 \mathrm{mM}$ with increasing concentration of $\mathrm{ZnL}^{1}$ (Figure 28A). The peak current was measured at each catalyst concentration. Rather than yielding a linear first-order relationship, a second-order dependence was observed. A plot of the peak current versus the squared catalyst concentration yielded a linear dependence confirming the second-order dependence on $\mathrm{ZnL}^{1}$, although above concentrations of $2.0 \mathrm{mM}$ the plot deviates from a second-order to first-order dependence (Figure 28B).

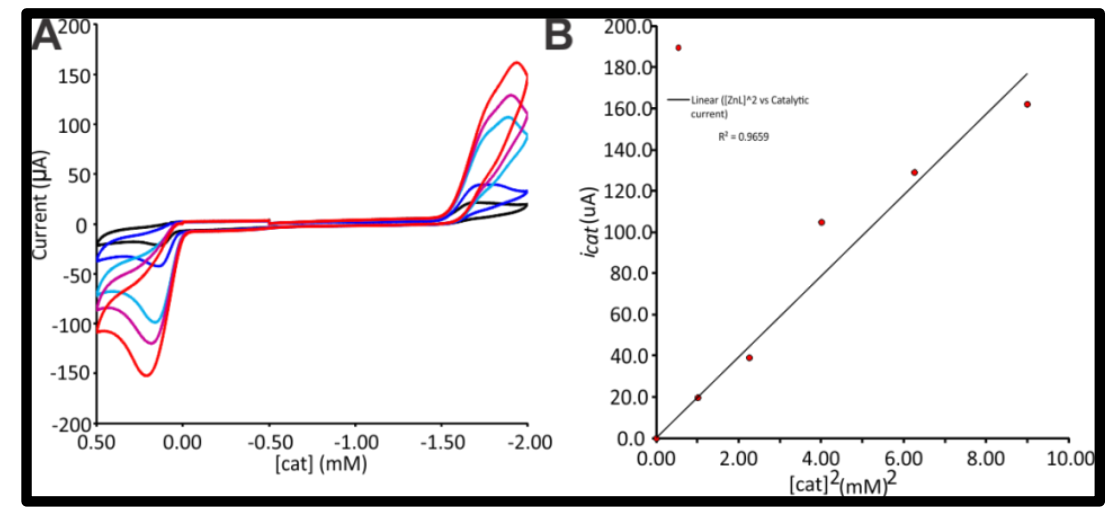

Figure 28. (A) Cyclic Voltammograms of $1.0 \mathrm{mM}$ (black), $1.5 \mathrm{mM}$ (blue), $2.0 \mathrm{mM}$ (light blue), $2.5 \mathrm{mM}$ (magenta), $3.0 \mathrm{mM}$ (red) $\mathrm{ZnL}^{1}$ with $12 \mathrm{mM} \mathrm{CH}_{3} \mathrm{COOH}$ in $0.1 \mathrm{M} \mathrm{Bu}_{4} \mathrm{NPF}_{6}$ methanol solution. (B) Plot of peak current versus $\left[\mathrm{ZnL}^{1}\right]^{2}$. 


\subsection{3. $\mathrm{H}_{2} \mathrm{~L}^{1}$ Cyclic Voltammetry Hydrogen Evolution and Hydrogen}

\section{Oxidation Studies}

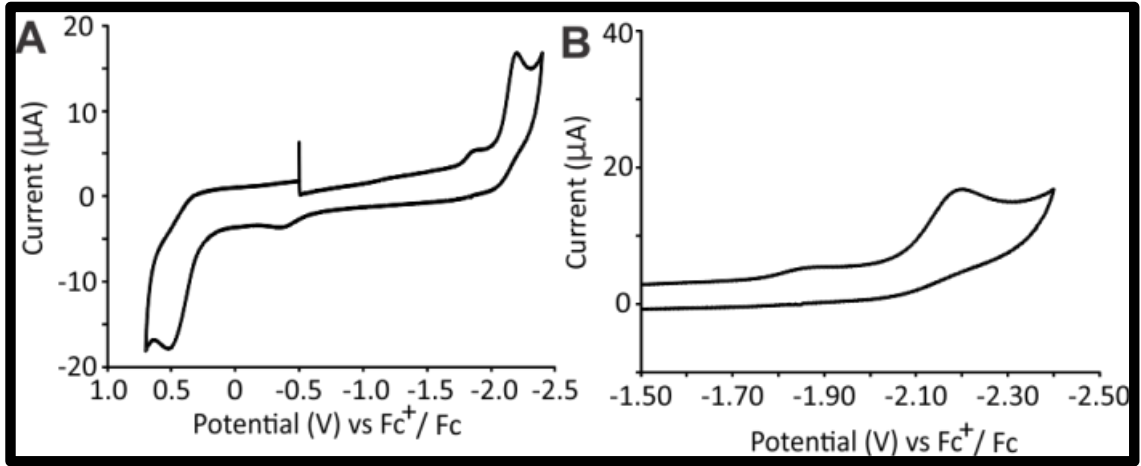

Figure 29. (A) Cyclic Voltammogram of $\mathrm{H}_{2} \mathrm{~L}^{1}$ in $0.1 \mathrm{M} \mathrm{Bu}_{4} \mathrm{NPF}_{6}$ solution collected at $0.5 \mathrm{~V} / \mathrm{s}$. (B) Blow up showing cathodic scan only of $\mathrm{H}_{2} \mathrm{~L}^{1}$.

The metal-free $\mathrm{H}_{2} \mathrm{~L}^{1}$ ligand was subsequently evaluated as a proton reduction and hydrogen oxidation electrocatalyst. In the absence of acid, $\mathrm{H}_{2} \mathrm{~L}^{1}$ displays an irreversible reduction at $-2.1 \mathrm{~V}$ and an irreversible oxidation at $+0.5 \mathrm{~V}_{\mathrm{vs} \mathrm{Fc}}^{+} / \mathrm{Fc}$ in $0.1 \mathrm{M} \mathrm{Bu}_{4} \mathrm{NPF}_{6}$ methanol solutions (Figure 29AB). Upon addition of acetic acid, the cathodic current at $-2.1 \mathrm{~V}$ increases steadily (Figure 30A), reaching a maximum at concentrations of 9.8 $\mathrm{mM}$ (Figure 30B). Under acid-saturated conditions, $\mathrm{H}_{2} \mathrm{~L}^{1}$ displays a TOF of $1320 \mathrm{~s}^{-1}$ with an overpotential of $1430 \mathrm{mV}$ (see appendix for more information). To our knowledge, this is the only reported metal free, homogeneous, electrocatalyst for HER. 


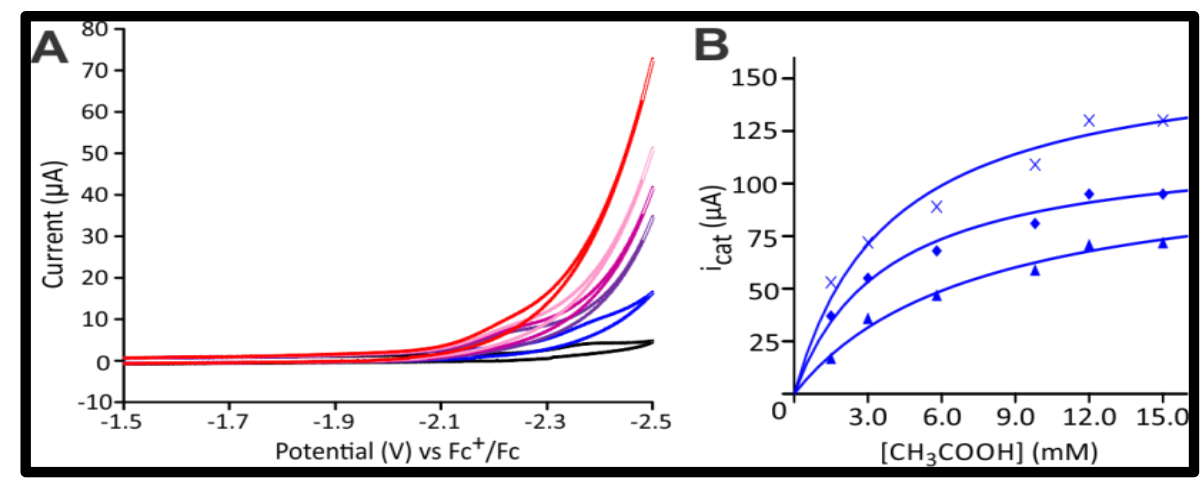

Figure 30. (A) Cyclic voltammograms of $3 \mathrm{mM} \mathrm{H}_{2} \mathrm{~L}^{1}$ with no added acid (black), $3 \mathrm{mM}$ $\mathrm{CH}_{3} \mathrm{COOH}$ (blue), $5.8 \mathrm{mM} \mathrm{CH} \mathrm{CH}_{3} \mathrm{COOH}$ (purple), and $7 \mathrm{mM} \mathrm{CH}_{3} \mathrm{COOH}$ (light purple), $8.2 \mathrm{mM}$ $\mathrm{CH}_{3} \mathrm{COOH}$ (pink) and, $9.8 \mathrm{mM} \mathrm{CH}_{3} \mathrm{COOH}$ (red). Data collected at a scan rate of $0.5 \mathrm{~V} / \mathrm{s}$ in the presence of $0.1 \mathrm{M} \mathrm{Bu}_{4} \mathrm{NPF}_{6}$ as supporting electrolyte. (B) Plot of $\mathrm{i}_{\text {cat }} \mathrm{vs}\left[\mathrm{CH}_{3} \mathrm{COOH}\right]$ for $3 \mathrm{mM}$ $\mathrm{H}_{2} \mathrm{~L}^{1}$ (blue) at scan rates of $0.2(\boldsymbol{\Delta}), 0.5(\diamond)$, and $1.0(\times) \mathrm{V} / \mathrm{s}$.

Given the bi-functional nature of the $\mathrm{Zn}$ based system we decided to investigate $\mathrm{H}_{2} \mathrm{~L}^{1}$ as an electrocatalyst for hydrogen oxidation. Introduction of triethylamine to methanol solutions of $\mathrm{H}_{2} \mathrm{~L}^{1}$ under 1 atmosphere of $\mathrm{H}_{2}$ results in an increase in anodic current near the irreversible oxidation wave of $\mathrm{H}_{2} \mathrm{~L}^{1}$ (Figures $31 \mathrm{~A}$ ). The catalytic current intensity shows saturation behavior (Figure 31B) with near saturation at a base concentration of $21 \mathrm{mM}$, indicating that catalysis is no longer limited by diffusion of the substrate to the electrode surface, yielding a TOF of $32 \mathrm{~s}^{-1}$ with an overpotential of 0.33 $\mathrm{V}$ (see appendix for more information). Again, to our knowledge this is the only reported metal-free homogeneous electrocatalyst for the oxidation of $\mathrm{H}_{2}$. 


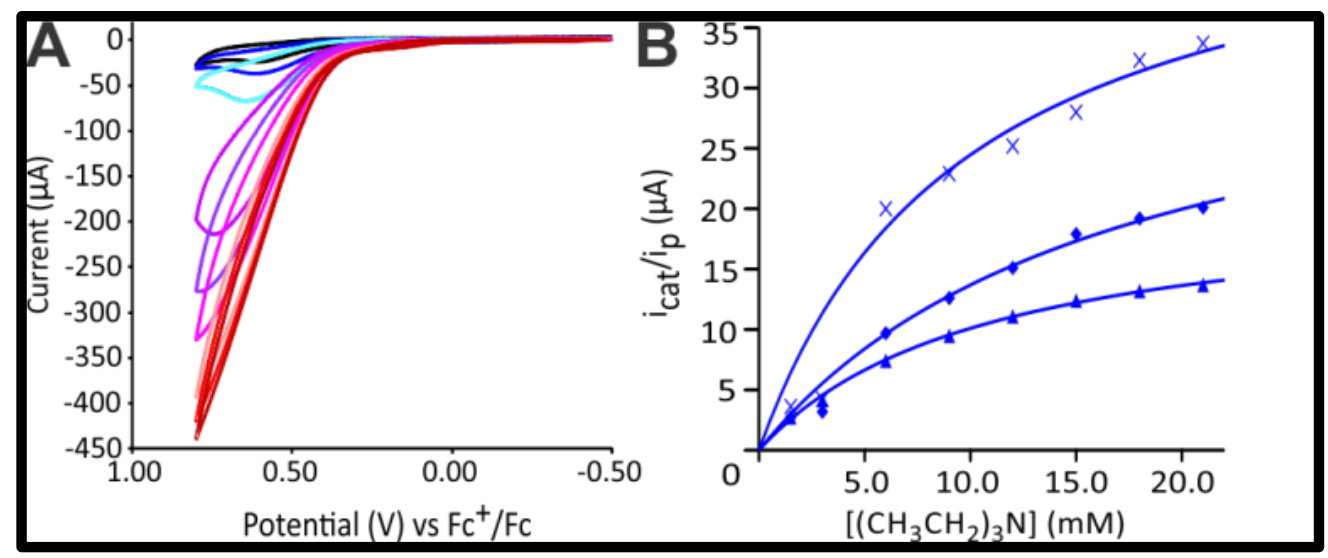

Figure 31. (A) Cyclic voltammograms of $0.3 \mathrm{mM} \mathrm{H} \mathrm{H}_{2} \mathrm{~L}$ in methanol under 1 atm. $\mathrm{H}_{2}$ with no added base (black), $0.75 \mathrm{mM}\left(\mathrm{CH}_{3} \mathrm{CH}_{2}\right)_{3} \mathrm{~N}$ (blue), $1.5 \mathrm{mM}\left(\mathrm{CH}_{3} \mathrm{CH}_{2}\right)_{3} \mathrm{~N}$ (cyan), $3 \mathrm{mM}$ $\left(\mathrm{CH}_{3} \mathrm{CH}_{2}\right)_{3} \mathrm{~N}$ (light blue), $6 \mathrm{mM}\left(\mathrm{CH}_{3} \mathrm{CH}_{2}\right)_{3} \mathrm{~N}$ (light purple), $9 \mathrm{mM}\left(\mathrm{CH}_{3} \mathrm{CH}_{2}\right)_{3} \mathrm{~N}$ (purple), $12 \mathrm{mM}$ $\left(\mathrm{CH}_{3} \mathrm{CH}_{2}\right)_{3} \mathrm{~N}$ (pink), $15 \mathrm{mM}\left(\mathrm{CH}_{3} \mathrm{CH}_{2}\right)_{3} \mathrm{~N}$ (rose), $18 \mathrm{mM}\left(\mathrm{CH}_{3} \mathrm{CH}_{2}\right)_{3} \mathrm{~N}$ (red) and, $21 \mathrm{mM}$ $\left(\mathrm{CH}_{3} \mathrm{CH}_{2}\right)_{3} \mathrm{~N}$ (dark red). (B) Plot of $\mathrm{i}_{\text {cat }} / \mathrm{i}_{\mathrm{p}}$ vs $\left[\left(\mathrm{CH}_{3} \mathrm{CH}_{2}\right)_{3} \mathrm{~N}\right]$ for $0.3 \mathrm{mM} \mathrm{ZnL}$ under $1 \mathrm{~atm} . \mathrm{H}_{2}$ (blue) at scan rates of $0.2(\boldsymbol{\Delta}), 0.5(\diamond)$, and $1.0(\times) \mathrm{V} / \mathrm{s}$.

\subsection{4. $\mathrm{ZnL}^{1}$ Extended Stability and Gas Identification: Controlled Potential}

\section{Coulometry Studies}

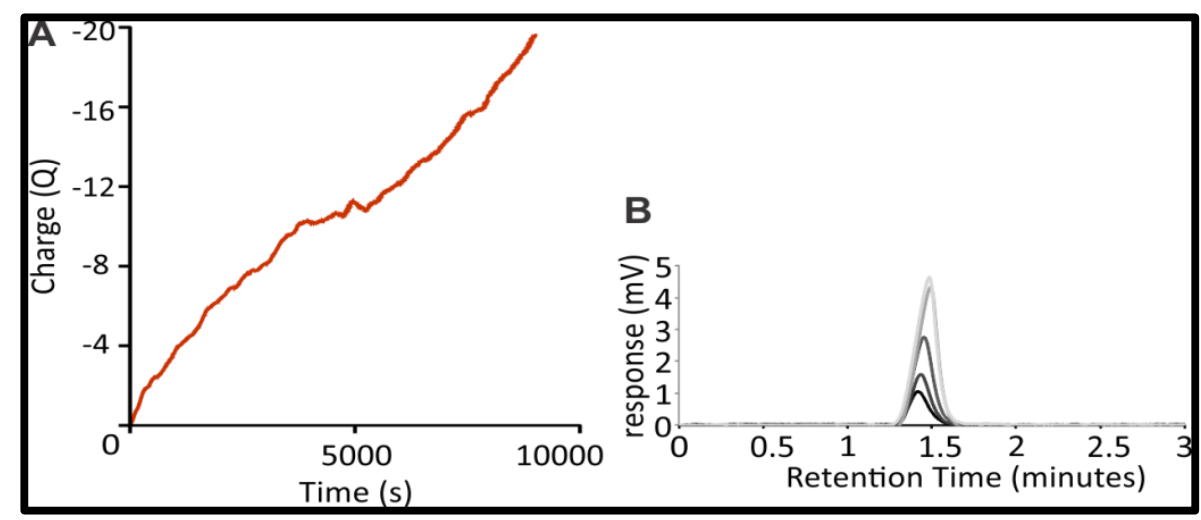

Figure 32. (A) Plot of charge vs time recorded during bulk electrolysis of $0.1 \mathrm{mM} \mathrm{ZnL}^{1}$ and 12 $\mathrm{mM} \mathrm{CH} \mathrm{CH}_{3} \mathrm{COOH}$ in methanol with $0.1 \mathrm{M} \mathrm{Bu}_{4} \mathrm{NPF}_{6}$ as supporting electrolyte. (B) Headspace readout of GC-TCD showing $\mathrm{H}_{2}$ as gaseous product at times $30,60,90,120$, and 150 minutes during electrolysis.

The stability of $\mathrm{ZnL}^{1}$ as a HER electrocatalyst was further examined by controlled potential coulometry. At an applied potential of $-1.7 \mathrm{~V} \mathrm{vs} \mathrm{Fc}^{+} / \mathrm{Fc}, \mathrm{ZnL}^{1}$ evolves $\mathrm{H}_{2}$ from $12 \mathrm{mM}$ acetic acid solutions in methanol with a turnover number of 37 after $2.5 \mathrm{~h}$ (Figure 
32A) based on a total charge of $19.8 \mathrm{C}$. The identity of the gaseous product was confirmed as $\mathrm{H}_{2}$ by gas chromatography thermal conductivity (Figure 32B). The integrated peak areas of headspace samples collected during electrolysis indicate a minimum Faradaic efficiency of $85 \%$ (see Chapter II for more information) throughout the electrolysis; the TOF remained consistent at $15 \mathrm{~h}^{-1}$ with no signs of decreasing activity.

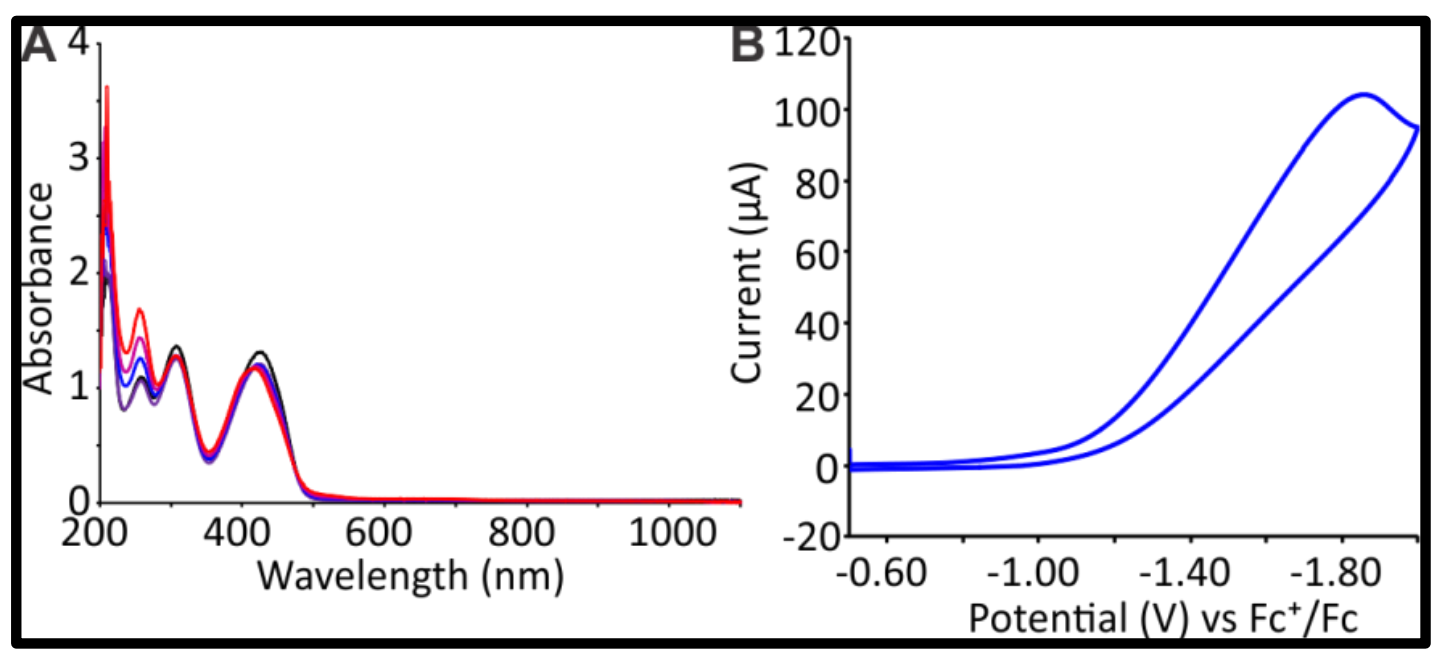

Figure 33. (A) UV spectra recorded every 15 minutes during the electrolysis of $1 \mathrm{mM} \mathrm{ZnL}$ under applied potential of $-1.7 \mathrm{~V}$ in $0.1 \mathrm{M} \mathrm{Bu}_{4} \mathrm{NPF}_{6}$ methanol solution. (B) $\mathrm{CV}$ of $\mathrm{ZnL}$ after electrolysis in $0.1 \mathrm{M} \mathrm{Bu}_{4} \mathrm{NPF}_{6}$ methanol solution with $12 \mathrm{mM}$ acetic acid added. $v=0.2 \mathrm{~V} / \mathrm{s}$ vs $\mathrm{Fc}^{+} / \mathrm{Fc}$.

Spectroelectrochemical experiments were performed on $0.1 \mathrm{M} \mathrm{Bu}_{4} \mathrm{NPF}_{6}$ methanol solutions of $\mathrm{ZnL}^{1}$ with an applied potential of $-1.7 \mathrm{~V}$ in order to identify the absorption characteristics of the one-electron reduced electrocatalyst, $[\mathrm{ZnL}]^{-}$. UV-vis spectra were recorded before electrolysis and then measured every 15 min during electrolysis showing the growth of the absorption band near $250 \mathrm{~nm}$ and a decrease in the absorption band near $430 \mathrm{~nm}$ (Figure 33A). A cyclic voltammogram was then recorded with addition of 12 
$\mathrm{mM}$ acetic acid (Figure 33B). An additional control was performed after prolonged reduction in order to rule out ligand decomposition onto electrode surface as a possible source of catalysis. After reduction, the working electrode was removed, washed with DI water, and then placed in fresh solution containing no catalyst, upon which no current was observed.

\subsection{5. $\mathrm{ZnL}^{1}$ Mechanism Evaluation: Digital Simulations, Isotope Effect Studies}

To evaluate the HER mechanism of $\mathrm{ZnL}$, we first determined the rate law and measured the H/D kinetic isotope effect (KIE). As shown earlier in Chapter 4.2, under nonsaturating acid conditions $i_{\text {cat }}$ is directly proportional to $\left[\mathrm{H}^{+}\right]$indicating a first-order dependence on acid concentration. ${ }^{10}$ Varying the $\left[\mathrm{ZnL}^{1}\right]$ at fixed acid concentrations confirm first-order dependence at catalyst concentrations above $2 \mathrm{mM}$ (Figure 28B). Using the deuterated acid $\mathrm{CD}_{3} \mathrm{CO}_{2} \mathrm{D}$, the $\mathrm{ZnL}^{1}$ catalyst displays a small $\mathrm{KIE}$ of 1.2 , which is distinct from the inverse KIEs reported for several metal-hydride HER catalysts and from the large KIEs associated with electrocatalysts thought to be proceeding through tunneling. 


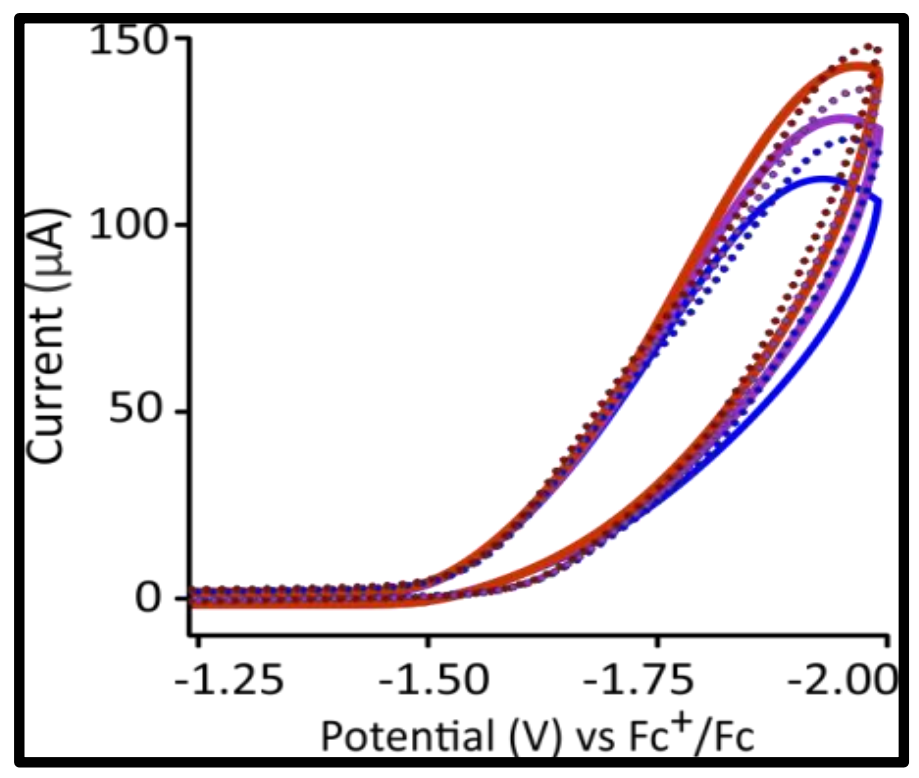

Figure 34. Comparisons of experimental (solid) and simulated (dotted) cyclic voltammograms for $3 \mathrm{mM} \mathrm{ZnL}^{1}$ and $12 \mathrm{mM} \mathrm{CH}_{3} \mathrm{COOH}$ in methanol with $0.1 \mathrm{M} \mathrm{Bu}_{4} \mathrm{NPF}_{6}$ as supporting electrolyte at scan rates of 0.3 (blue), 0.4 (purple), and 0.5 (red) V/s.

Digital simulations of the cyclic voltammograms (Figure 34) reveal parallel routes to proton reduction involving homocoupling of two, neutral $\mathrm{Zn}(\mathrm{HL} \bullet)$ radicals and heterocoupling of a neutral $\mathrm{Zn}(\mathrm{HL} \bullet)$ radical with the cationic radical $\left[\mathrm{Zn}\left(\mathrm{H}_{2} \mathrm{~L} \bullet\right)\right]^{+}$. The proposed mechanism (Figure 35) begins with protonation of $\mathrm{ZnL}^{1}, \mathrm{~K}=2.4 \times 10^{5}$, followed by reduction to $\mathrm{Zn}(\mathrm{HL} \cdot), \mathrm{E}^{\circ}=-1.81 \mathrm{~V}$ vs $\mathrm{Fc}^{+} / \mathrm{Fc}$. In the homocoupling pathway, two $\mathrm{Zn}(\mathrm{HL} \bullet)$ rapidly combine, $k_{f}=3 \times 10^{9} \mathrm{M}^{-1} \mathrm{~s}^{-1}$, to evolve $\mathrm{H}_{2}$ and regenerate 2 equivalents of $\mathrm{ZnL}^{1}$. In the alternate pathway, 1 equivalent of $\mathrm{Zn}(\mathrm{HL} \bullet)$ is further protonated, $\mathrm{K}=8.8$, prior to heterocoupling. Combination of $\left[\mathrm{Zn}\left(\mathrm{H}_{2} \mathrm{~L} \bullet\right]^{+}\right.$with the second equivalent of $\mathrm{Zn}(\mathrm{HL} \cdot), k_{f}=2 \times 10^{10} \mathrm{M}^{-1} \mathrm{~s}^{-1}$, yields $\mathrm{H}_{2}$ completing the catalytic cycle. The simulated kinetic and thermodynamic parameters reveal that both routes to $\mathrm{H}_{2}$ evolution are operational across a range of experimental conditions (see Appendix for more information). 


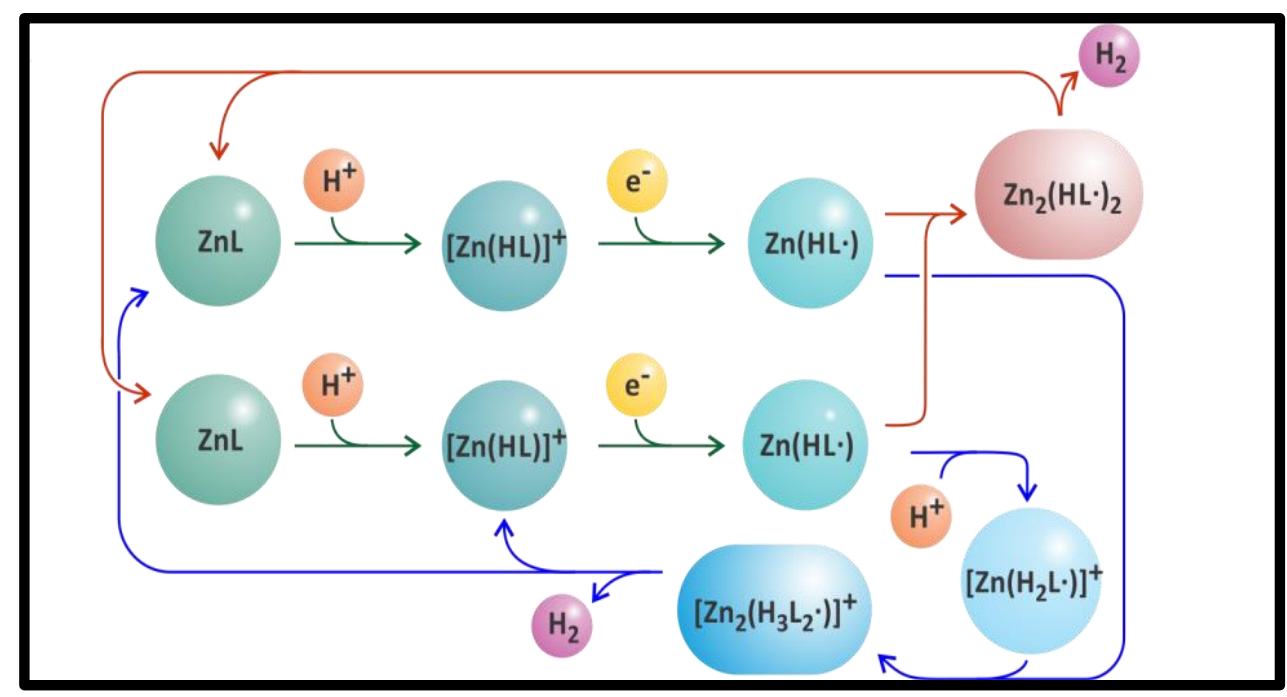

Figure 35. Concurrent catalytic pathways for hydrogen evolution through homocoupling of neutral $\mathrm{Zn}(\mathrm{HL} \bullet$ ) radicals (red arrows) and heterocoupling of a neutral $\mathrm{Zn}(\mathrm{HL} \bullet$ ) and cationic $\left[\mathrm{Zn}\left(\mathrm{H}_{2} \mathrm{~L} \cdot\right)\right]^{+}$radicals (blue arrows).

\subsection{6. $\mathrm{ZnL}^{1}$ Density Functional Theory Study}

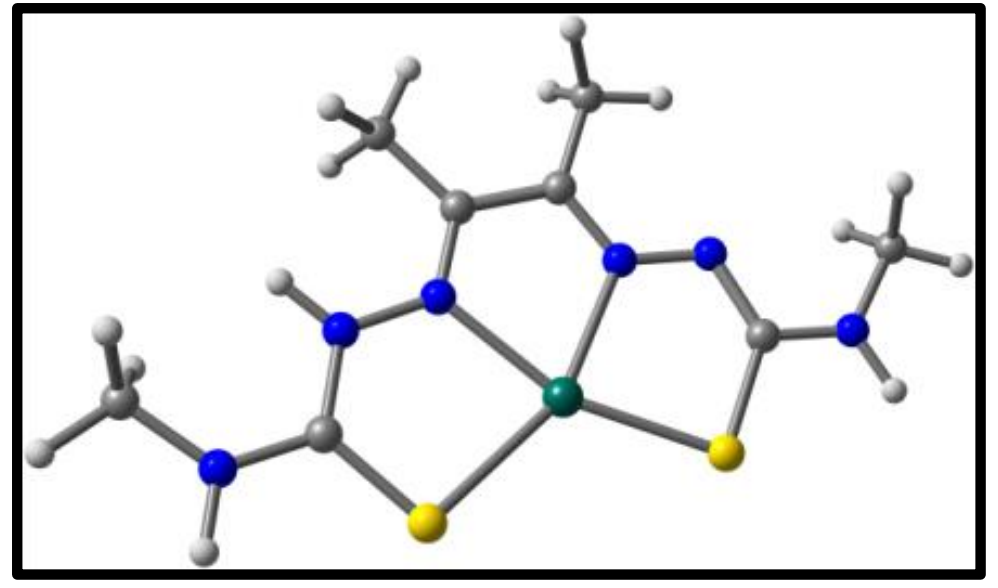

Figure 36. Optimized Structure of $[\mathrm{ZnLH}]^{+}$with protonation on the hydrazino nitrogen, B97$\mathrm{D} / 6-311 \mathrm{G}(\mathrm{d})$

Density functional theory calculations using the B97-D functional and the 6-311G(d) basis set support the proposed catalytic cycle and elucidate the hydrazino nitrogen as the site of protonation. Each of the metal complexes in Figure 35 was successfully optimized. 
Energies reveal that protonation at the hydrazino nitrogen (Figure 36) is favored by at least $13.0 \mathrm{kcal} / \mathrm{mol}$ relative to other potential basic sites within $\mathrm{ZnL}^{1}$ (Figure 37).

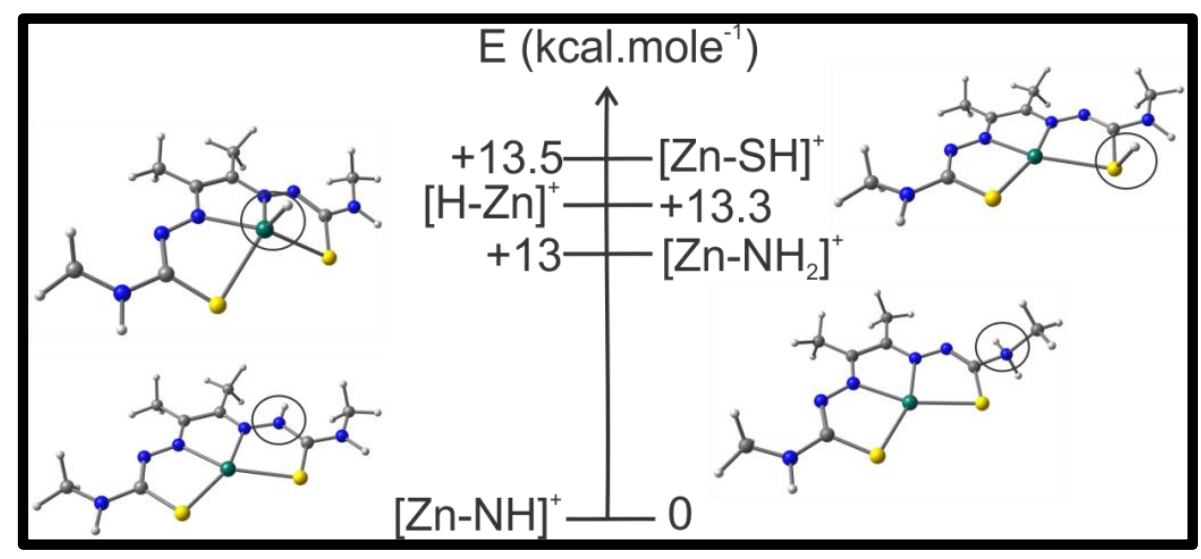

Figure 37. DFT optimized structures showing energetic stability of protonated species, $\left[\mathrm{ZnL}{ }^{1} \mathrm{H}\right]^{+}$.

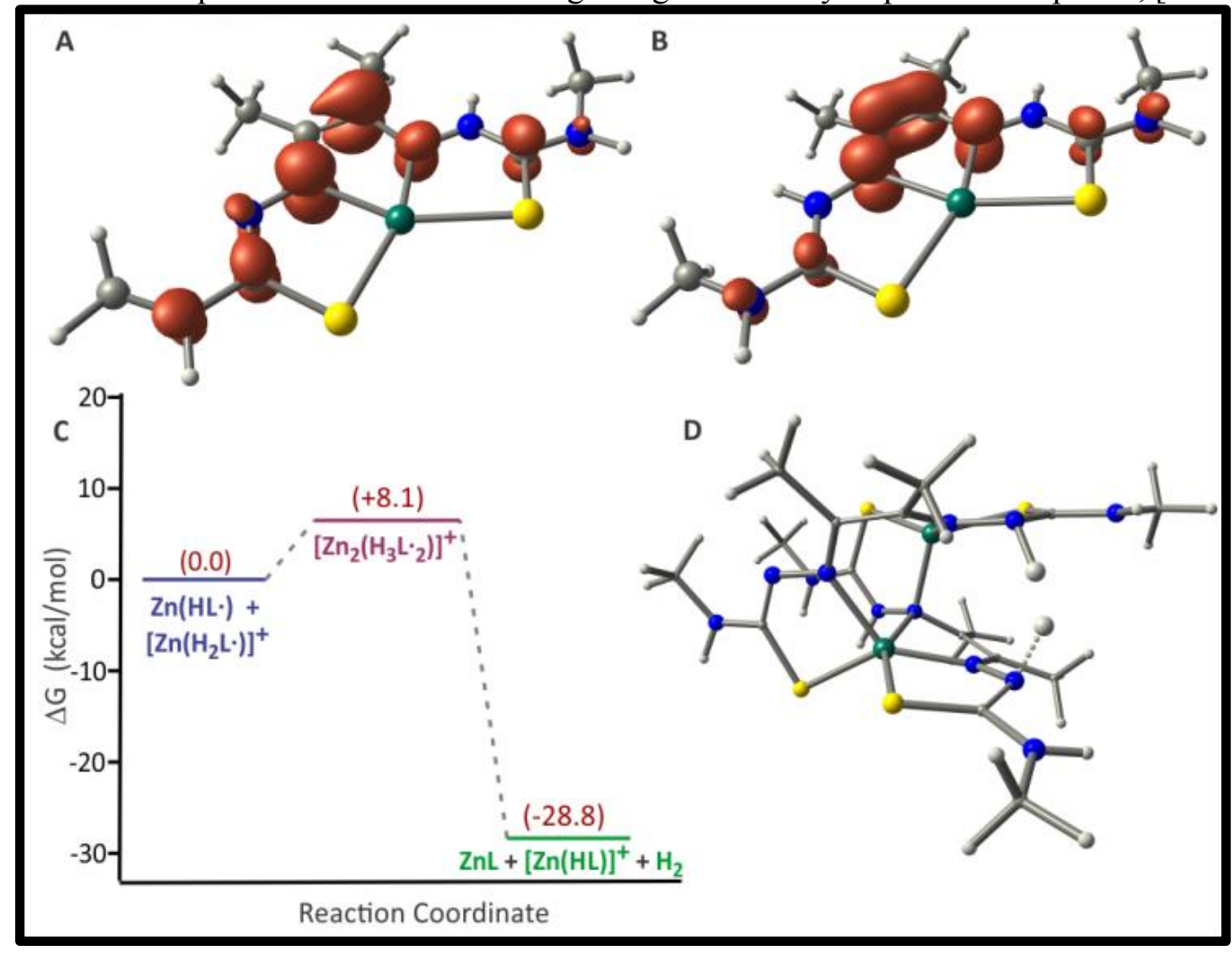

Figure 38. Energy profile along with spin densities of species involved in catalyzed $\mathrm{H}_{2}$ evolution. Spin-density profiles for (A) $\mathrm{Zn}(\mathrm{HL} \bullet)$ and (B) $\left[\mathrm{Zn}(\mathrm{H} 2 \mathrm{~L} \bullet)^{+}\right.$. (C) Relative energies (ZPE corrected) for $\mathrm{H}_{2}$ evolution through the heterocoupling of $\mathrm{Zn}(\mathrm{HL} \bullet)$ and $\left[\mathrm{Zn}(\mathrm{H} 2 \mathrm{~L} \bullet]^{+}\right.$using the B97-D/6-311G(d) level of theory. (D) Structure of the singlet $\left[\mathrm{Zn}_{2}\left(\mathrm{H}_{3} \mathrm{~L}_{2}\right)\right]^{+}$transition state through the heterocoupling pathway. Analysis of the eigenvector associated with the imaginary 
frequency $i 1572 \mathrm{~cm}^{-1}$, and the charge densities of atoms for $\mathrm{H}_{2}$ evolution with respect to intrinsic reaction coordinate.

Evolution of $\mathrm{H}_{2}$ through homocoupling of two $\mathrm{Zn}(\mathrm{HL} \bullet)$ radicals is exergonic by $42.6 \mathrm{kcal} / \mathrm{mol}$, while the parallel pathway involving heterocoupling of $\mathrm{Zn}(\mathrm{HL} \bullet)$ and $[\mathrm{Zn}(\mathrm{H} 2 \mathrm{~L} \bullet)]^{+}$releases $28.8 \mathrm{kcal} / \mathrm{mol}$. Analyses of the $\mathrm{Zn}(\mathrm{HL} \bullet)$ and $\left[\mathrm{Zn}\left(\mathrm{H}_{2} \mathrm{~L} \bullet\right]^{+}\right.$spin density profiles (Figure 38A,B) show radical character delocalized on both protonated ligand frameworks. $\mathrm{H}_{2}$ is evolved by radical heterocoupling, overcoming an $8.1 \mathrm{kcal} / \mathrm{mol}$ barrier (Figure 38C,D). The absence of spin density on $\mathrm{Zn}$ for all species involved in the HER is in unequivocal support of ligand based reduction.

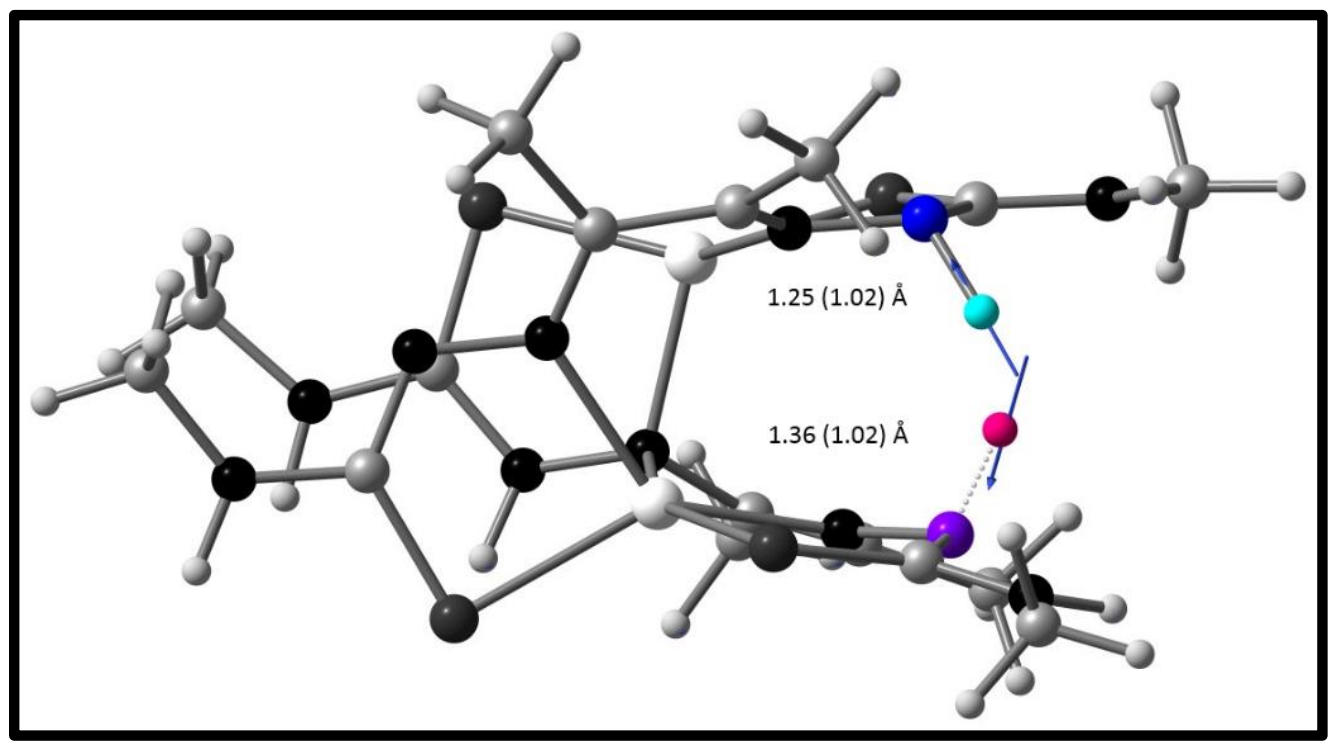




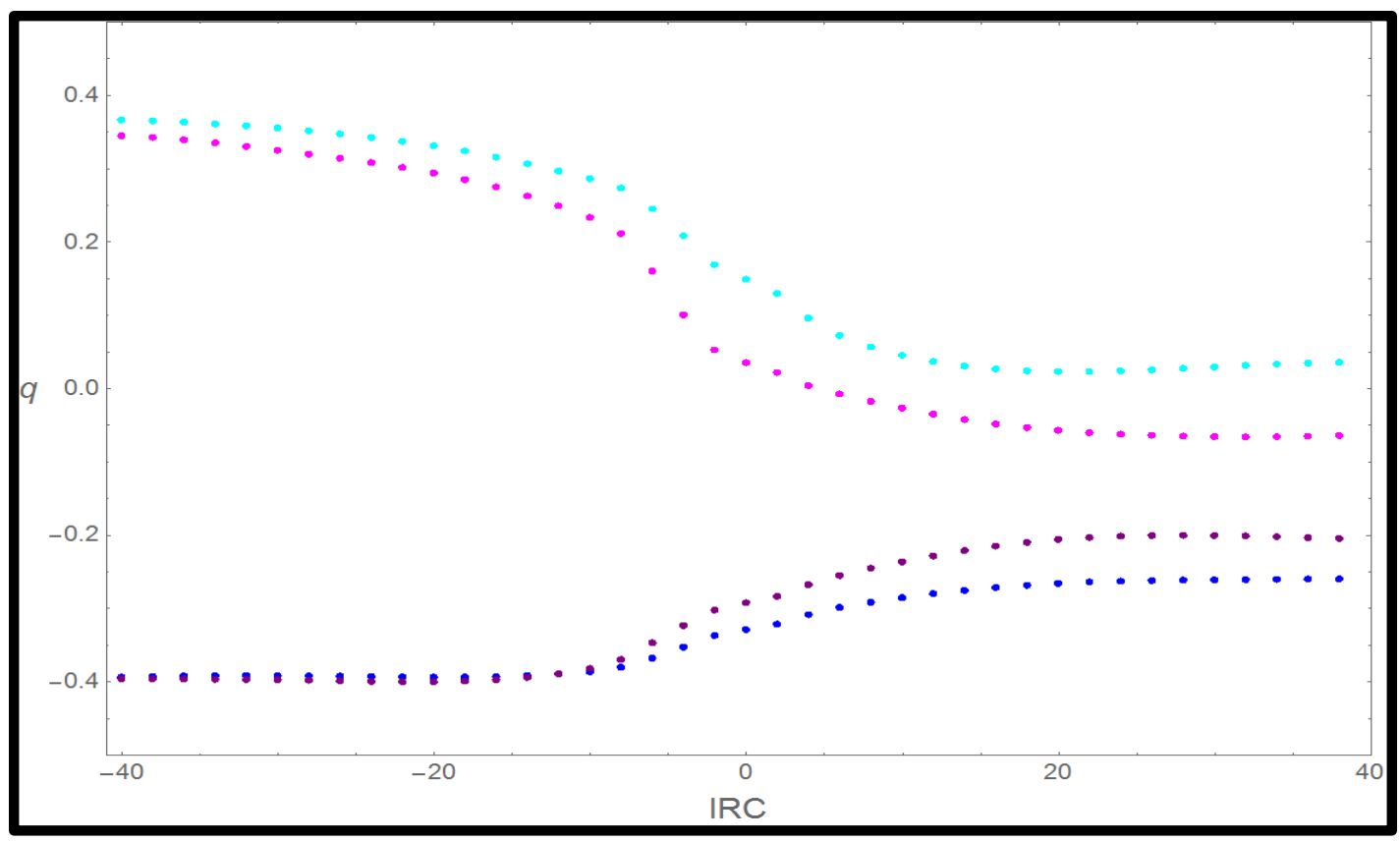

Figure 39. (Upper) Transition state geometry of $\left[\mathrm{Zn}_{2} \mathrm{H}_{3} \mathrm{~L}_{2}{ }_{2}^{+}\right.$along the HER pathway, shown with active $\mathrm{N}-\mathrm{H}$ bond lengths associated with the imaginary frequency $i 1572 \mathrm{~cm}^{-1}$, and equilibrium bond lengths in parentheses. (Lower) Charge densities of atoms near $\mathrm{H}_{2}$ evolution with respect to IRC; N-H of $\left[\mathrm{Zn}\left(\mathrm{HL}^{\bullet}\right)\right]^{+}$(blue, and cyan), and $\mathrm{N}-\mathrm{H}$ of $\mathrm{Zn}\left(\mathrm{H}_{2} \mathrm{~L}^{\bullet}\right.$ ) (magenta, purple).

The transition state (TS) can be described as a dimer with $\mathrm{H}$ dissociations from each monomer fragment, along their respective $\mathrm{N}-\mathrm{H}$ coordinates to form $\mathrm{H}_{2}$ (39 Upper). This is consistent with $\mathrm{N}-\mathrm{H}$ bond lengths in the TS of $1.25 \AA$ for $\mathrm{Zn}(\mathrm{HL} \bullet)$ and $1.36 \AA$ for $\left[\mathrm{Zn}\left(\mathrm{H}_{2} \mathrm{~L} \bullet\right)\right]^{+}$compared to respective equilibrium $\mathrm{N}-\mathrm{H}$ distances, both of $1.02 \AA$. The longer $\mathrm{N}-\mathrm{H}$ bond in the TS associated with $\left[\mathrm{Zn}\left(\mathrm{H}_{2} \mathrm{~L} \bullet\right]^{+}\right.$may also be attributed to an increased charge density along the forward IRC for both $\mathrm{N}$ and $\mathrm{H}$, compared to $\mathrm{Zn}(\mathrm{HL} \bullet)$ (Figure 39 Lower). The HER from $\left[\mathrm{Zn}_{2} \mathrm{H}_{3} \mathrm{~L}_{2}\right]^{+}$is thus interpreted as dimeric, where the now charge-reorganized $\mathrm{Zn}\left(\mathrm{H}_{2} \mathrm{~L} \bullet\right)$ fragment promotes early electron transfer and is coupled to proton transfer from $\left[\mathrm{Zn}(\mathrm{HL} \bullet]^{+}\right.$to form $\mathrm{H}_{2}$. 
Table 2. Bond length comparison of calculated HER intermediates

\begin{tabular}{|c|c|c|c|c|c|}
\hline \multicolumn{2}{|l|}{ Structures } & ZnL & {$\left[\mathrm{ZnHL}^{+}\right.$} & $\operatorname{Zn}\left(\mathrm{HL}^{\bullet}\right)$ & {$\left[\mathrm{ZnH}_{2} \mathbf{L}^{\bullet}\right]^{+}$} \\
\hline Bond Lengths ( § ) & $\mathrm{Zn}-\mathrm{S} 1$ & 2.368 & 2.423 & 2.458 & 2.386 \\
\hline & $\mathrm{Zn}-\mathrm{S} 2$ & 2.368 & 2.318 & 2.341 & 2.386 \\
\hline & Zn-N2 & 2.116 & 2.118 & 2.059 & 2.061 \\
\hline & Zn-N3 & 2.116 & 2.125 & 2.045 & 2.061 \\
\hline & $\mathrm{S} 1-\mathrm{C} 1$ & 1.774 & 1.719 & 1.728 & 1.732 \\
\hline & C1-N5 & 1.356 & 1.343 & 1.373 & 1.349 \\
\hline & N5-C5 & 1.460 & 1.467 & 1.459 & 1.463 \\
\hline & C1-N1 & 1.339 & 1.373 & 1.351 & 1.361 \\
\hline & N1-N2 & 1.344 & 1.357 & 1.368 & 1.362 \\
\hline & $\mathrm{N} 1-\mathrm{H} 15$ & - & 1.015 & 1.016 & 1.015 \\
\hline & $\mathrm{N} 2-\mathrm{C} 2$ & 1.312 & 1.313 & 1.368 & 1.348 \\
\hline & $\mathrm{C} 2-\mathrm{C} 3$ & 1.478 & 1.470 & 1.427 & 1.436 \\
\hline & C3-N3 & 1.312 & 1.322 & 1.345 & 1.348 \\
\hline & N3-N4 & 1.344 & 1.321 & 1.349 & 1.362 \\
\hline & $\mathrm{N} 4-\mathrm{C} 4$ & 1.339 & 1.361 & 1.329 & 1.361 \\
\hline & C4-S2 & 1.774 & 1.767 & 1.792 & 1.732 \\
\hline & C4-N6 & 1.356 & 1.341 & 1.367 & 1.349 \\
\hline & N6-C8 & 1.460 & 1.469 & 1.458 & 1.463 \\
\hline
\end{tabular}

Examination of the change in bond lengths and bond angles amongst $\mathrm{ZnL}$, $[\mathrm{Zn}(\mathrm{HL})]^{+}, \mathrm{Zn}(\mathrm{HL} \bullet)$, and $[\mathrm{Zn}(\mathrm{H} 2 \mathrm{~L} \bullet)]^{+}($Tables $2-3)$ assist to explain structural and electronic changes over the course of the $\mathrm{ZnL}^{1}$ catalyzed HER mechanism. Initial protonation of $\mathrm{ZnL}^{1}$ to give $\left[\mathrm{Zn}(\mathrm{HL})^{+}\right]$results in a slight puckering of the ligand framework around the $\mathrm{Zn}$ center shown by the lengthening of the Zn-S1, Zn-N2, Zn-N3 bonds and a decrease in the $\mathrm{Zn}-\mathrm{S} 2$ bond as well as an increase in the S1-Zn-S2, N3-ZnS2 bond angles and decrease of the S1-Zn-N2, N2-Zn-N3 bond angles. Subsequent reduction to the neutral radical species, $\mathrm{Zn}(\mathrm{HL} \bullet)$, is accompanied by significant contraction of the Zn-N2 and Zn-N3 bonds, $2.118 \AA$ and $2.125 \AA$ to $2.059 \AA$ and 2.045 $\AA$, respectively. Furthermore, moving across the mechanism from protonation to reduction, the $\mathrm{C} 2-\mathrm{C} 3$ bond length always decreases in length moving from an initial 
length of $1.478 \AA$ to $1.470 \AA$ after protonation, and then decreasing further to $1.427 \AA$ after reduction, in agreement with the spin-density map of $\mathrm{Zn}(\mathrm{HL} \bullet)$.

Table 3. Bond angle comparison of calculated HER intermediates.

\begin{tabular}{|c|c|c|c|c|c|}
\hline \multicolumn{2}{|c|}{ Structures } & $\mathbf{Z n L}$ & ZnHL] $^{+}$ & $\mathbf{Z n}\left(\mathbf{H L}^{\bullet}\right)$ & {$\left[\mathbf{Z n H}_{2} \mathbf{L}^{\bullet}\right]^{+}$} \\
\hline Bond Angles $\left(^{\circ}\right)$ & S1-Zn-S2 & 118.02 & 119.08 & 116.68 & 117.56 \\
\hline & S1-Zn-N2 & 82.78 & 81.57 & 82.39 & 83.80 \\
\hline & N2-Zn-N3 & 76.43 & 74.94 & 77.40 & 73.34 \\
\hline & N3-Zn-S2 & 82.78 & 84.41 & 85.07 & 83.30 \\
\hline & C1-S1-Zn & 93.70 & 96.92 & 95.10 & 95.54 \\
\hline & N1-N2-C2 & 121.88 & 122.99 & 120.43 & 122.41 \\
\hline & N1-N2-Zn & 122.08 & 119.62 & 119.13 & 118.45 \\
\hline & C2-N2-Zn & 116.04 & 117.39 & 115.19 & 118.59 \\
\hline & C3-N3-Zn & 116.04 & 117.76 & 117.15 & 118.59 \\
\hline & C3-N3-N4 & 121.88 & 122.01 & 121.05 & 122.41 \\
\hline & N4-N3-Zn & 122.08 & 120.23 & 121.44 & 118.45 \\
\hline
\end{tabular}

\subsection{Conclusion}

In summary, the non-transition-metal complex $\mathrm{ZnL}^{1}$ and the metal-free ligand $\mathrm{H}_{2} \mathrm{~L}^{1}$ represent a fundamentally new class of homogeneous HER and HOR electrocatalysts. Unlike traditional catalysts that employ a metal-hydride as the key intermediate, this new approach facilitates $\mathrm{H}_{2}$ evolution through ligand-centered radical coupling. The combination of the redox active ligand $\mathrm{H}_{2} \mathrm{~L}^{1}$ with the non-transition-metal $\mathrm{Zn}$ constrains redox activity to the ligand, in contrast to transition-metal complexes where spincoupling between the ligand radical and unpaired electrons on the metal may reduce reactivity. The confinement of radical character to the ligand is further evidenced by the catalytic activity of $\mathrm{H}_{2} \mathrm{~L}^{1}$; albeit with higher overpotential than $\mathrm{ZnL}^{1}$. The enhanced activity with $\mathrm{Zn}$ is attributed in part to the Lewis acidity of $\mathrm{Zn}(\mathrm{II})$, which balances the charge of the anionic ligand, promotes protonation, and lowers the reduction potential. Further, $\mathrm{Zn}(\mathrm{II})$ provides a structural framework for the $\mathrm{N}_{2} \mathrm{~S}_{2}$ chelate that pre-organizes 
the radical complexes for $\mathrm{H}_{2}$ evolution. We can envision the strategies introduced in this study being tailored in future works to improve TOF and lower overpotential and for the development of other catalysts for small molecule activation.

\subsection{Acknowledgement}

The work described in Chapter Four was supported in part by the National Science Foundation (CHE-1361728) and a grant from the Kentucky Science and Engineering Foundation as per grant agreement no. KSEF-148-502-15-350 with the Kentucky Science and Technology Corporation. The authors are thankful to Cardinal Research Cluster at the University of Louisville for providing the computational facilities. A.Z.H, R.M.B., and C.A.G. are inventors on a U.S. provisional patent application no. 62/348,420, filed by the University of Louisville Research Foundation, Inc., and related to this work. 


\section{CHAPTER V: \\ TRANSITION METAL ASSISTED \\ LIGAND-CENTERED $\mathrm{H}_{2}$ \\ EVOLUTION}




\subsection{Introduction}

Rising international energy demands, coupled with growing concerns of repercussion from global climate change, have ignited considerable interest in the development of carbon-free and carbon neutral energy systems. ${ }^{5,15,16}$ Hydrogen is a promising component of these systems as a light weight, energy dense carrier. Hydrogen evolution reactions (HERs), which involve a two-electron reduction of protons, can be used to store energy in $\mathrm{H}_{2}$, with subsequent energy release through hydrogen oxidation reactions (HORs). ${ }^{1,181,182}$ Consequently, there has been significant research into the development of inexpensive, abundant homogeneous and heterogeneous materials that serve as electrocatalysts for the production of $\mathrm{H}_{2}$. Platinum is an excellent catalyst for HER and HOR, ${ }^{183}$ yet its scarcity and high costs limit practical large scale application, leading to the pursuit of sustainable alternates that employ abundant first-row transition metals. ${ }^{80,89,90,184-191}$ Not surprisingly, much of these works have taken an approach to generate HER catalysts which operate via mechanisms invoking metal-hydrides. While this approach has led to substantial advances, sustainable candidates are limited to economically viable first-row transition metals complexes capable of stabilizing metal-hydrides. The recent development of HER catalysts that function via ligand-centered processes or employ redox-active ligands, ${ }^{192}$ has expanded the realm of HER electrocatalysts beyond traditional transition metalhydrides to include non-transition metal, ${ }^{76,99}$ and metal-free catalysts ${ }^{76}$ for HER invoking ligand-directed radical coupling of $\mathrm{H}$-atoms ${ }^{77,193}$ or protonation of ligand-centered hydrides. $^{71,76}$

As discussed previously in Chapter Four, we reported the first examples of HER/HOR activity with the non-innocent bis(thiosemicarbazone) ligand framework. ${ }^{76}$ 
The zinc complex of diacetyl-bis(N-4-methyl-3-thiosemicarbazone), $\mathrm{ZnL}^{1}$, catalyzes HER with a maximum TOF of $1170 \mathrm{~s}^{-1}$ and the HOR in the presence of triethylamine with a maximum TOF of $72 \mathrm{~s}^{-1}$. The HER mechanism was established through a rigorous protocol involving kinetic studies, including digital simulations of electrochemical data, DFT computations of catalytic intermediates, and location of the transition state. Results indicate a ligand-centered process involving a binuclear transition state with evolution of $\mathrm{H}_{2}$ via ligand hydride-proton coupling. Notably, the free ligand $\mathrm{H}_{2} \mathrm{~L}^{1}$ also demonstrates similar HER activity. Very recently, Straistari et al. reported HER activity with a related bis(thiosemicarbazonato)Ni(II) complex with an enhanced TOF of 3080 $\mathrm{s}^{-1}$, proposed to involve initial ligand-centered reduction and protonation followed by metal-centered reduction. ${ }^{88}$ The compound studied in this chapter, $\mathrm{CuL}^{1}$, was previously investigated by Holland et al. in 2008 as a radiopharmaceutical agent for the treatment of hypoxic cells. ${ }^{194}$ In their studies, electrochemical characterizations were performed in an array of conditions, including under slightly acidic reducing conditions $(22 \mathrm{mM}$ maximum). In that report, the authors state that they observe the production of hydrogen, however, no complete analysis of these observations was provided. In this study, we reexamine these findings while continuing our pursuit of alternate HER strategies which avoid metal-hydride intermediates, and provide a more complete report of ligandcentered HER activity observed with the bis(thiosemicarbazonato) $\mathrm{Cu}(\mathrm{II})$ complex, $\mathrm{CuL}^{1}$, Scheme 7. 


\subsection{Results and Discussion}

\subsection{1. $\mathrm{CuL}^{1}$ Cyclic Voltammetry HER Studies}

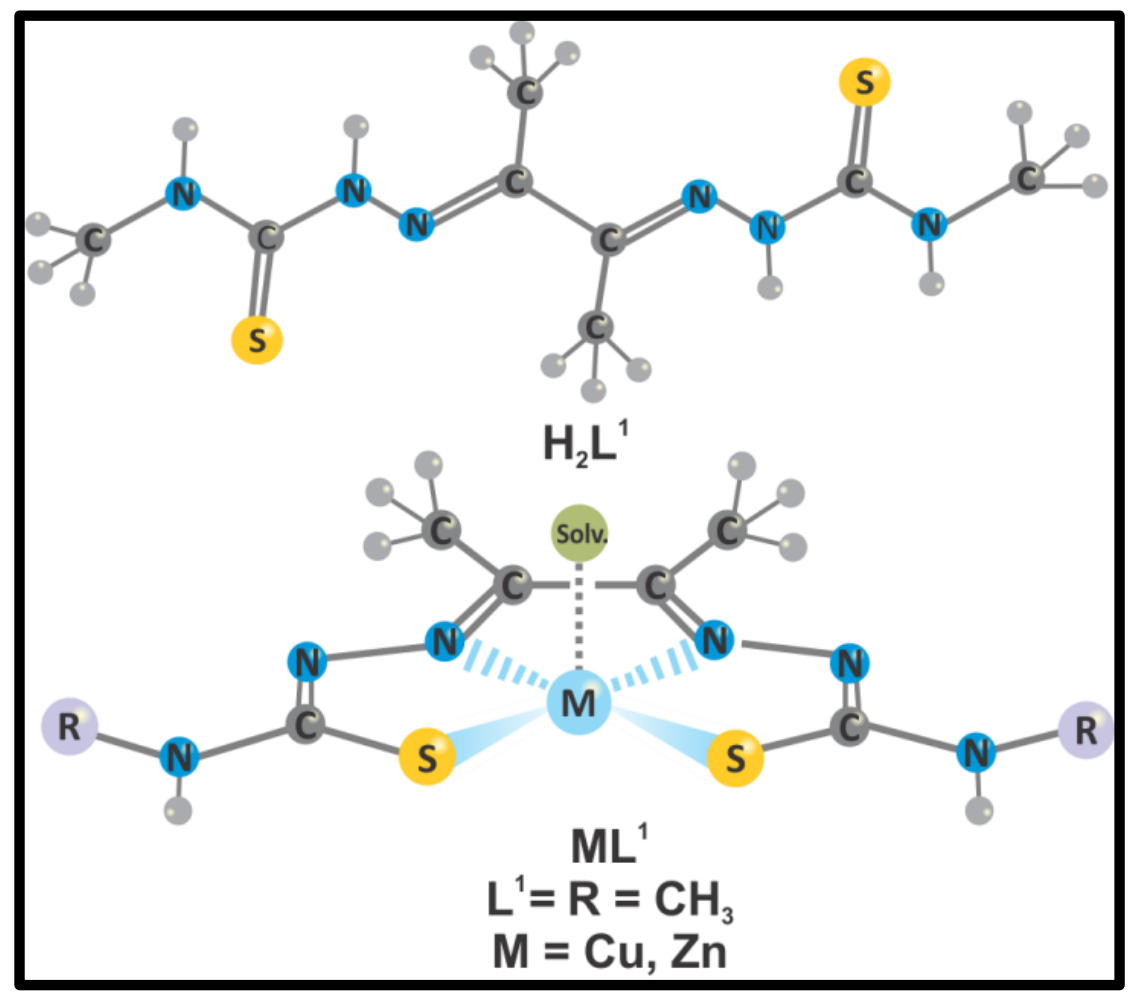

Scheme 7. Representation of thiosemicarbazone based electrocatalysts.

Building upon our previous work, the neutral, monomeric complex diacetyl-bis(N-4methyl-3-thiosemicarbazonato) $\mathrm{Cu}(\mathrm{II}), \mathrm{CuL}^{1}$, was evaluated as $\mathrm{HER}$ electrocatalyst, Scheme 7. The synthesis and single crystal $\mathrm{x}$-ray structure of $\mathrm{CuL}^{1}$ was originally reported by Dilworth et al. ${ }^{195,196}$ The $\mathrm{CuL}^{1}$ compound was isolated as air-stable burgundy solid from $\mathrm{H}_{2} \mathrm{~L}^{1}$ and copper(II) acetate per prior methods (described in Chapter II). 


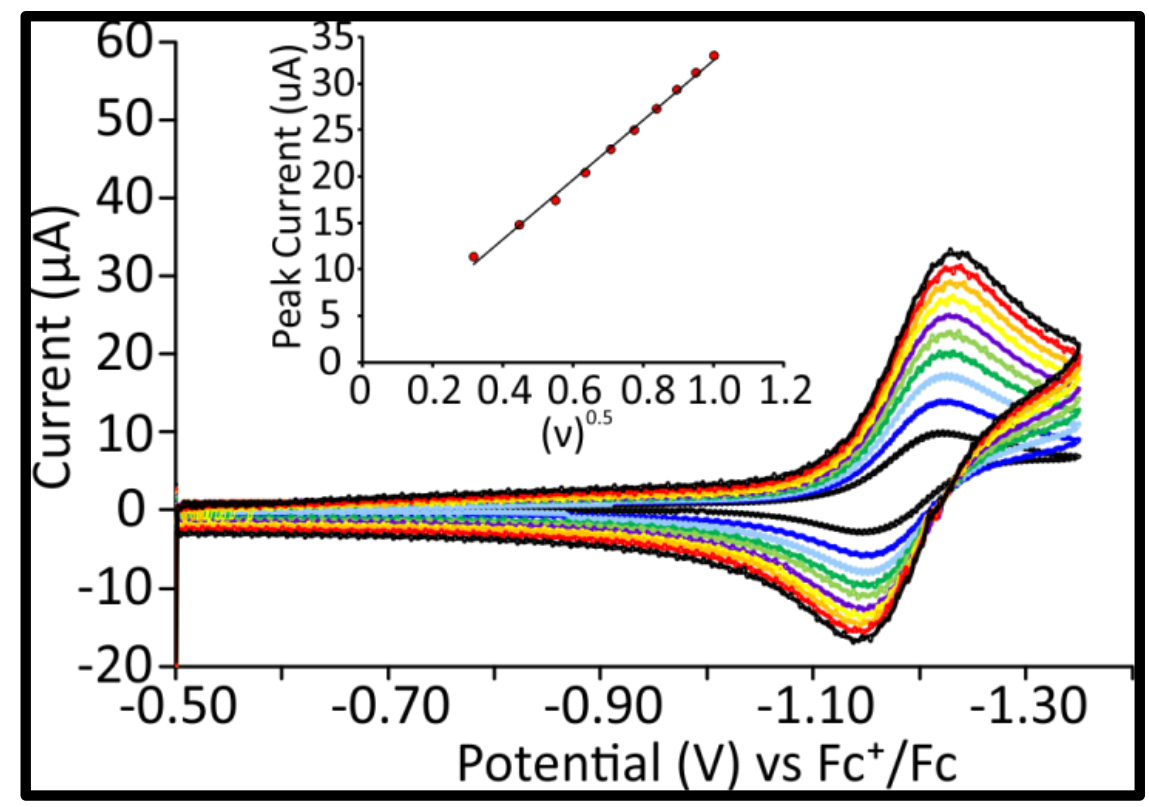

Figure 40. $\mathrm{CVs}$ of $\mathrm{CuL}^{1}$ in $0.1 \mathrm{M} \mathrm{Bu}_{4} \mathrm{NPF}_{6}$ acetonitrile solution at scan rates of 0.1 (black), 0.2 (blue), 0.3 (light blue), 0.4 (green), 0.5 (light green), 0.6 (purple), 0.7 (yellow), 0.8 (orange), 0.9 (red) and 1.0 (black) V/s. CuL ${ }^{1}$. Inset: Cottrell plot of peak current vs square root of scan rate.

The cyclic voltammogram $(\mathrm{CV})$ of $\mathrm{CuL}^{1}$ in acetonitrile containing $0.1 \mathrm{M}$ $\mathrm{Bu}_{4} \mathrm{NPF}_{6}$ as supporting electrolyte displays a reversible $\mathrm{Cu}^{\mathrm{I} / \mathrm{I}}$ event at $-1.20 \mathrm{~V}$ vs. $\mathrm{Fc}^{+} / \mathrm{Fc}$ consistent with prior reports. Additional $\mathrm{CV}$ data collected at multiple scan rates from 0.1 to $1.0 \mathrm{~V} / \mathrm{s}$ (Figure 40) were used to construct Cottrell plots (Figure 40, inset) establishing that the $\mathrm{Cu}^{\mathrm{II} / \mathrm{I}}$ reduction is diffusion limited and demonstrating the potential of $\mathrm{CuL}^{1}$ as a homogeneous electrocatalyst. The slope of the plot yields a diffusion coefficient of $7.9 \times$ $10^{-6} \mathrm{~cm}^{2} / \mathrm{s}$. The catalytic activities for hydrogen evolution were then evaluated in two solvents, acetonitrile and dimethylformamide (DMF). 


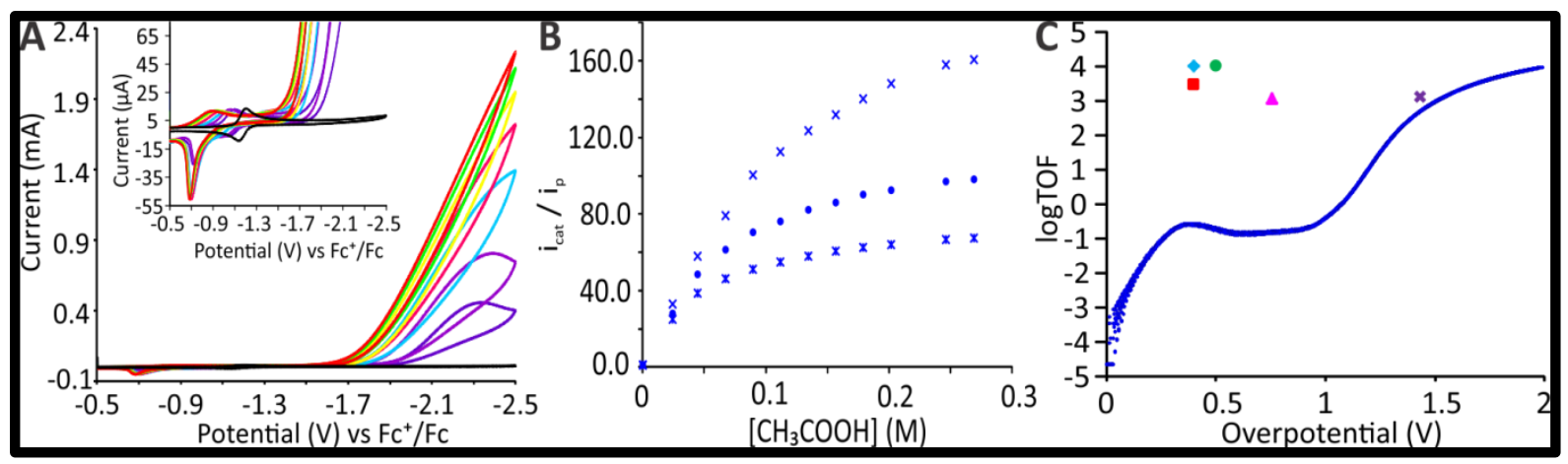

Figure 41. (A) $\mathrm{CVs}$ of $0.6 \mathrm{mM} \mathrm{CuL}^{1}$ (black) in $0.1 \mathrm{M} \mathrm{Bu}_{4} \mathrm{NPF}_{6}$ acetonitrile with 0.0244 (purple), 0.0448 (light purple), 0.0896 (light blue), 0.134 (pink), 0.179 (yellow), 0.244 (light green) and 0.269 (red) $\mathrm{M} \mathrm{CH}_{3} \mathrm{COOH}$, Inset. Blow up of $\mathrm{CV}$ showing shift of $\mathrm{Cu}^{\mathrm{II} / \mathrm{I}}$ reduction event. (B) Plot of $i_{c a} / i_{p}$ vs $\left[\mathrm{CH}_{3} \mathrm{COOH}\right]$ for $0.60 \mathrm{mM} \mathrm{CuL}^{1}$ (blue) at scan rates of $0.20(\mathrm{X}), 0.50(\bullet)$ and $1.00(*)$ $\mathrm{V} / \mathrm{s}$ (C) Catalytic Tafel Plot of $\mathrm{CuL}^{1}$ (blue) with comparison of performance for hydrogen evolution with those of others reported in literature. Blue $\diamond$ : $\mathrm{Co}^{\mathrm{II}}(\mathrm{dmgH})_{2} \mathrm{py}$; green $\bullet$ : $\left[\mathrm{Ni}\left(\mathrm{P}_{2}{ }^{\mathrm{Ph}} \mathrm{N}^{\mathrm{Ph}}\right)_{2}\right]^{2+}$; red $\mathbf{\mathbf { c }}: \mathrm{NiL}^{2}$; magenta $\boldsymbol{\Delta}: \mathrm{ZnL}^{1}$; purple $\mathrm{X}: \mathrm{H}_{2} \mathrm{~L}^{1} .{ }^{197}$

Addition of acetic acid to $0.6 \mathrm{mM}$ acetonitrile solutions of $\mathrm{CuL}^{1}$ shifts the $\mathrm{Cu}^{\mathrm{II} / \mathrm{I}}$ potential from $-1.20 \mathrm{~V}$ to $-0.95 \mathrm{~V}$ and introduces a catalytic cathodic current at $-1.70 \mathrm{~V}$ vs $\mathrm{Fc}^{+} / \mathrm{Fc}$ (Figure $41 \mathrm{~A}$ ). The $+0.25 \mathrm{~V}$ shift is consistent with a single protonation event prior to the initial electrochemical reduction (Figure $41 \mathrm{~A}$, inset). ${ }^{77}$ The catalytic current intensity at $-1.70 \mathrm{~V}$ displays linear dependence on the concentration of acid, indicating diffusion control to the electrode and confirming a first-order dependence on acid concentration. ${ }^{10}$ At concentrations greater than $0.269 \mathrm{M}$, catalytic current saturates at a maximum value of $2.25 \mathrm{~mA}$ (Figure 41B). The $i_{p}$ of $\mathrm{Cu}^{\mathrm{II} / \mathrm{I}}$ reduction event, $14.0 \mu \mathrm{A}$, and the $i_{c a t}$ max of $2.25 \mathrm{~mA}$ correspond with a maximum $i_{c a t} / i_{p}$ value of 161 , affording a TOF of $9,900 \mathrm{~s}^{-1} \cdot{ }^{120-123}$

Catalytic activity was also assessed in DMF. CVs of $0.6 \mathrm{mM} \mathrm{CuL}^{1}$ in $0.1 \mathrm{M}$ $\mathrm{Bu}_{4} \mathrm{NPF}_{6}$ DMF solutions exhibit an increase in current at $-1.9 \mathrm{~V}$ vs $\mathrm{Fc}^{+} / \mathrm{Fc}$ upon increasing additions of acetic acid (Figure 42A). At concentrations of acid greater than 
$0.292 \mathrm{M}$, the current saturates reaching a maximum $i_{\text {cat }}$ of $1.49 \mathrm{~mA}$ (Figure 42B). Acid addition results in the same shift of the $\mathrm{Cu}^{\mathrm{II} / \mathrm{I}}$ potential from $-1.20 \mathrm{~V}$ to $-0.95 \mathrm{~V}$, as observed in acetonitrile, which is consistent with previous reports suggesting a single protonation event prior to reduction. ${ }^{194}$ Catalytic current becomes independent of scan rate above $1.0 \mathrm{~V} / \mathrm{s}$. Under these conditions when $i_{\text {cat }}$ is $1490 \mu \mathrm{A}$ and $i_{\mathrm{p}}$ is $29 \mu \mathrm{A}$, the TOF is estimated to be $5140 \mathrm{~s}^{-1}$, significantly lower than values observed when performed in acetonitrile.

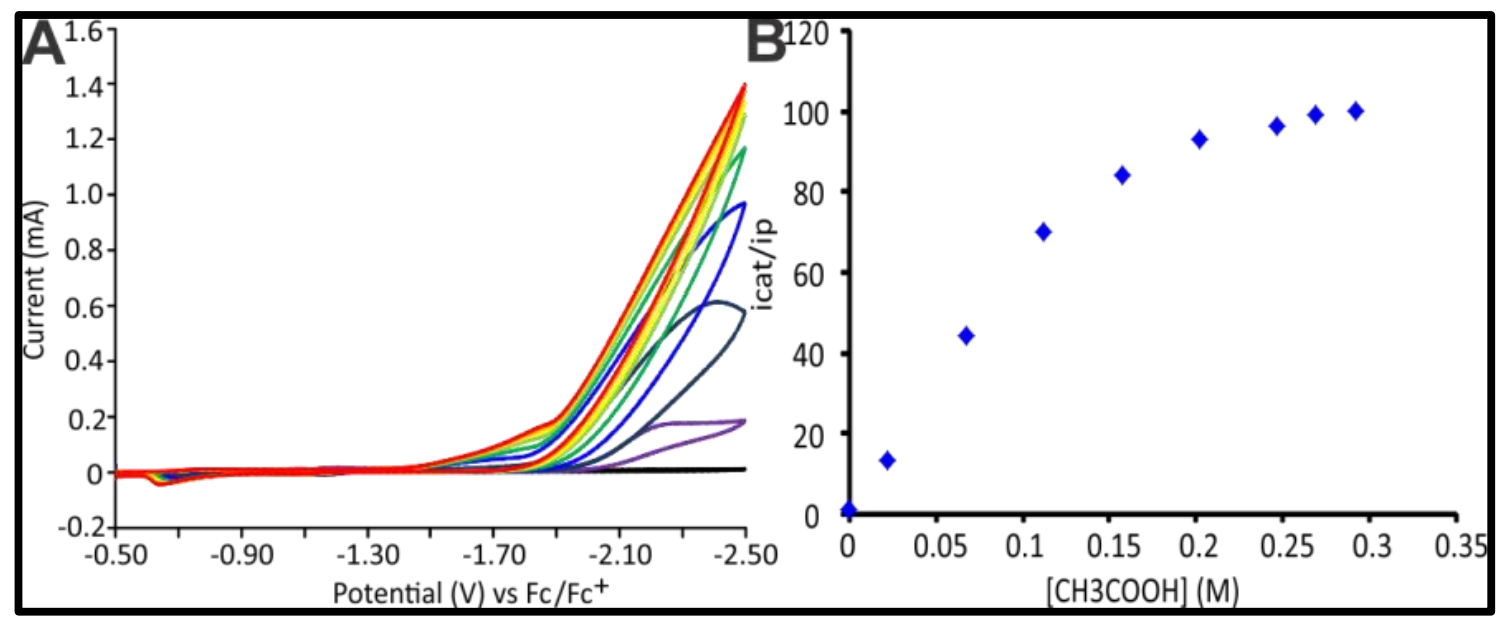

Figure 42. (A) $\mathrm{CVs}$ of $0.6 \mathrm{mM} \mathrm{CuL}^{1}$ (black) in $0.1 \mathrm{M} \mathrm{Bu}_{4} \mathrm{NPF}_{6} \mathrm{DMF}$ with 0.0244 (light purple), 0.0448 (purple), 0.0896 (blue), 0.157 (green), 0.202 (light green), 0.246 (yellow), 0.269 (orange). And 0.292 (red) $\mathrm{M} \mathrm{CH}_{3} \mathrm{COOH}$. (B) Plot of $i_{c a t} / i_{p}$ vs $\left[\mathrm{CH}_{3} \mathrm{COOH}\right]$ concentration.

Control CVs containing only acetic acid were run in acetonitrile and DMF. Addition of $67.2 \mathrm{mM}$ acetic acid to of $0.1 \mathrm{M} \mathrm{Bu}_{4} \mathrm{NPF}_{6}$ acetonitrile solutions resulted in an observable current of $300 \mu \mathrm{A}$. However after $2 \mathrm{CV}$ cycles the current drops to a stable value near $100 \mu \mathrm{A}$. Upon addition of $0.6 \mathrm{mM} \mathrm{CuL}^{1}$, the current increases to $900 \mu \mathrm{A}$ (see appendix). In DMF addition of $22.4 \mathrm{mM}$ acetic acid results in almost no current increase, giving current values of roughly $5 \mu \mathrm{A}$. Addition of $0.6 \mathrm{mM} \mathrm{CuL}^{1}$ to this solution resulted in an 
increase, giving a value of $200 \mu \mathrm{A}$ (see appendix)Higher concentrations of acetic acid were also performed as controls. Addition of $0.292 \mathrm{M}$ acetic acid to $0.1 \mathrm{M} \mathrm{Bu}_{4} \mathrm{NPF}_{6}$ DMF solutions results in a current value of $50 \mu \mathrm{A}$. Upon addition of $0.6 \mathrm{mM} \mathrm{CuL}^{1}$ results in an increase of current to $650 \mu \mathrm{A}$ (see appendix).

The Tafel plot of the log TOF versus overpotential for $\mathrm{CuL}^{1}$ (Figure 41C) represents the TOF activity as a function of the applied overpotential. ${ }^{197} \mathrm{CuL}^{1}$ displays the highest maximum $\log \mathrm{TOF}$ values reported to date of any homogeneous ligandcentered electrocatalyst, reaching a maximum of 3.99. The $\mathrm{CuL}^{1}$ electrocatalyst maintains a $\log$ TOF value greater than one, with applied overpotentials greater than 1.2 $\mathrm{V}$. Overpotentials less than $1.2 \mathrm{~V}$ result in significantly decreased TOF values, correlating with negative or near zero logTOF values. The local maxima observed near $0.4 \mathrm{~V}$ is indicative of the pre-catalytic $\mathrm{Cu}^{\mathrm{II} / \mathrm{I}}$ reduction, which has an anodic shift of 0.25 V during catalysis.

The maximum $\log \mathrm{TOF}$ for $\mathrm{CuL}^{1}$ of 3.99 requires a large overpotential of $2.0 \mathrm{~V}$. Comparatively, state of the art metal-hydride HER electrocatalysts, such as nickelbis(diphosphine) and cobaloxime exhibit logTOF values of 4.00 at overpotentials of 0.50 and $0.40 \mathrm{~V}$, respectively. ${ }^{197}$ Our previously reported ligand-centered electrocatalysts $\mathrm{ZnL}^{1}$ and $\mathrm{H}_{2} \mathrm{~L}^{1}$ have lower maximum $\log \mathrm{TOF}$ values than $\mathrm{CuL}^{1}$, but they achieve $\log \mathrm{TOF}$ values of 3.06 and 3.12 at lower overpotentials of 0.75 and $1.4 \mathrm{~V}$, respectively. ${ }^{76}$ Artero's related $\mathrm{NiL}^{2}$ electrocatalyst achieves a maximum logTOF of 3.50 at an overpotential of $0.4 \mathrm{~V}$, similar to the state of the art metal-hydride HER catalysts. ${ }^{88}$ 


\subsection{2. $\mathrm{CuL}^{1}$ Extended Stability: Controlled Potential Coulometry and Gas}

\section{Identification}

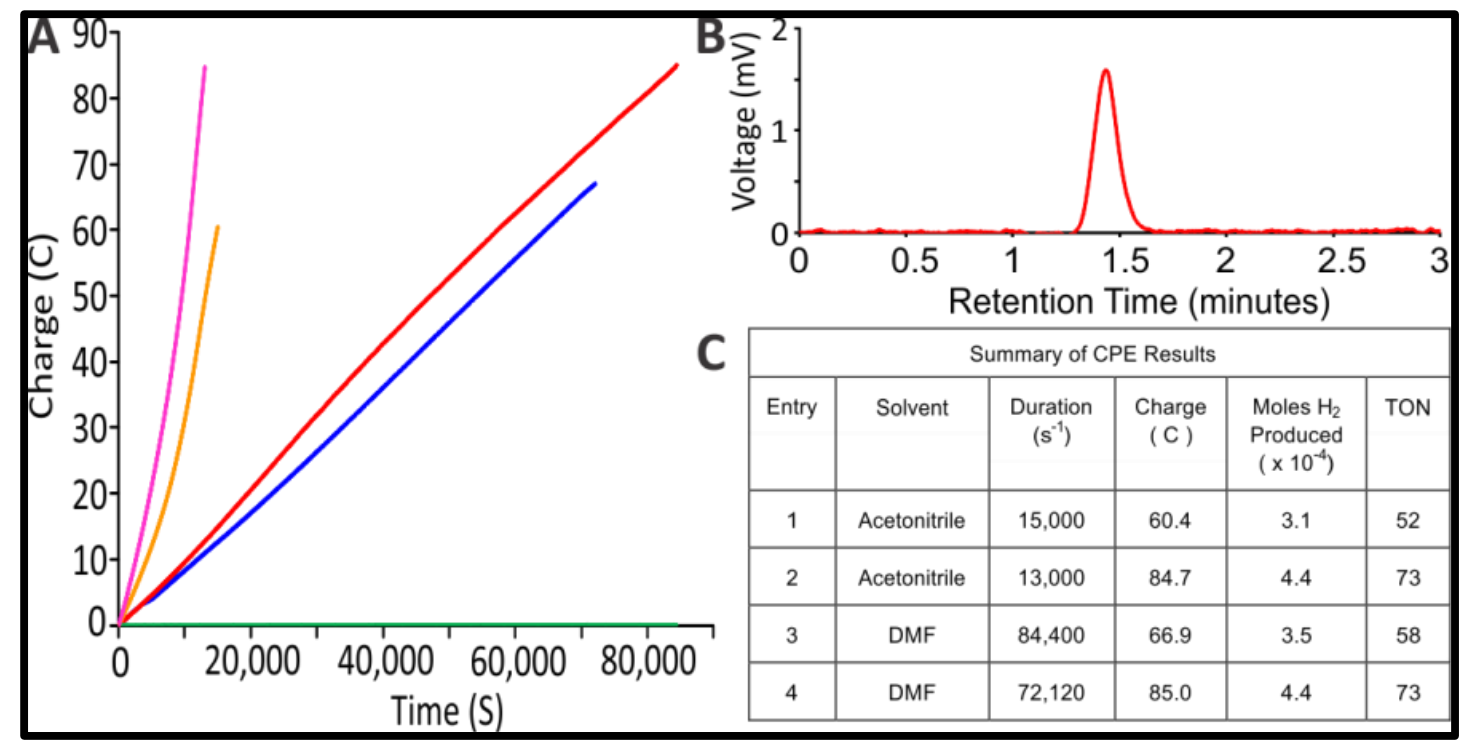

Figure 43. (A) Bulk electrolysis showing plot of charge versus time of $0.6 \mathrm{mM} \mathrm{CuL}^{1}$ in $0.1 \mathrm{M}$ $\mathrm{Bu}_{4} \mathrm{NPF}_{6}$ acetonitrile (pink and orange) and in $0.1 \mathrm{M} \mathrm{Bu}_{4} \mathrm{NPF}_{6}$ DMF (red and blue) with $0.292 \mathrm{M}$ $\mathrm{CH}_{3} \mathrm{COOH}$ added. Blank acetonitrile (green). (B) GC-TCD headspace readout of $\mathrm{H}_{2}$ from electrolysis. (C) Summary of CPE results.

A series of controlled potential electrolysis (CPE) experiments were performed using 0.6

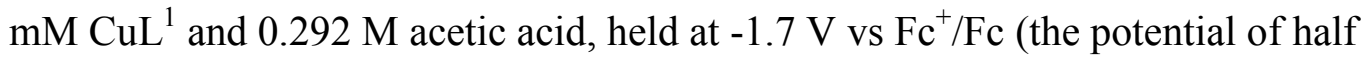
maximum catalytic current), in both DMF and acetonitrile (Figure 43A). Electrolysis in 0.1 $\mathrm{M} \mathrm{Bu}_{4} \mathrm{NPF}_{6}$ DMF solutions was as allowed to run for 84,400 seconds (23.4 hours) resulting in a total charge passed of $85 \mathrm{C}$, corresponding to $4.4 \times 10^{-4}$ moles of $\mathrm{H}_{2}$ produced with a turnover number (TON) of 73.3. Gas analysis of the headspace was analyzed using gas chromatography thermal conductivity (GC-TCD) (Figure 43B), confirming $\mathrm{H}_{2}$ as the gaseous product. The growth of charge during the electrolysis remained linear over the course of the experiments and showed no signs of degradation or decrease in activity over 23 hours. A second CPE in DMF over 72,120 seconds (20 hours) yielded similar results giving a slightly lower charge of $66.96 \mathrm{C}$, producing $3.5 \mathrm{x}$ 
$10^{-4}$ moles of $\mathrm{H}_{2}$ corresponding with a TON of 58.3. CPE's performed in $0.1 \mathrm{M} \mathrm{Bu}_{4} \mathrm{NPF}_{6}$ passed similar charge, giving values of 60.43 and $84.74 \mathrm{C}$ corresponding to TON values of 51.7 and 73.3 over electrolysis times of 15,000 and 13,000 respectively. In contrast to CPE's performed in DMF, the growth of the charge with respect to time is much steeper, possibly indicating that the HER reaction proceeds faster in acetonitrile, which is consistent with CV studies which indicate that the HER TOF in acetonitrile is approximately twice as fast than when performed in DMF. After 15,000 of electrolysis in acetonitrile solutions, the auxiliary compartment began to become discolored, changing from the clear solution which initially is just $0.1 \mathrm{M} \mathrm{Bu}_{4} \mathrm{NPF}_{6}$, to a cloudy brown color, suggesting diffusion of some species across the frit from the working compartment. Around the same time when this happens, the charge begins to plateau reaching a maximum value. All CPE trials in acetonitrile resulted in diffusion across the frit, thus only shorter electrolysis's were able to be performed.

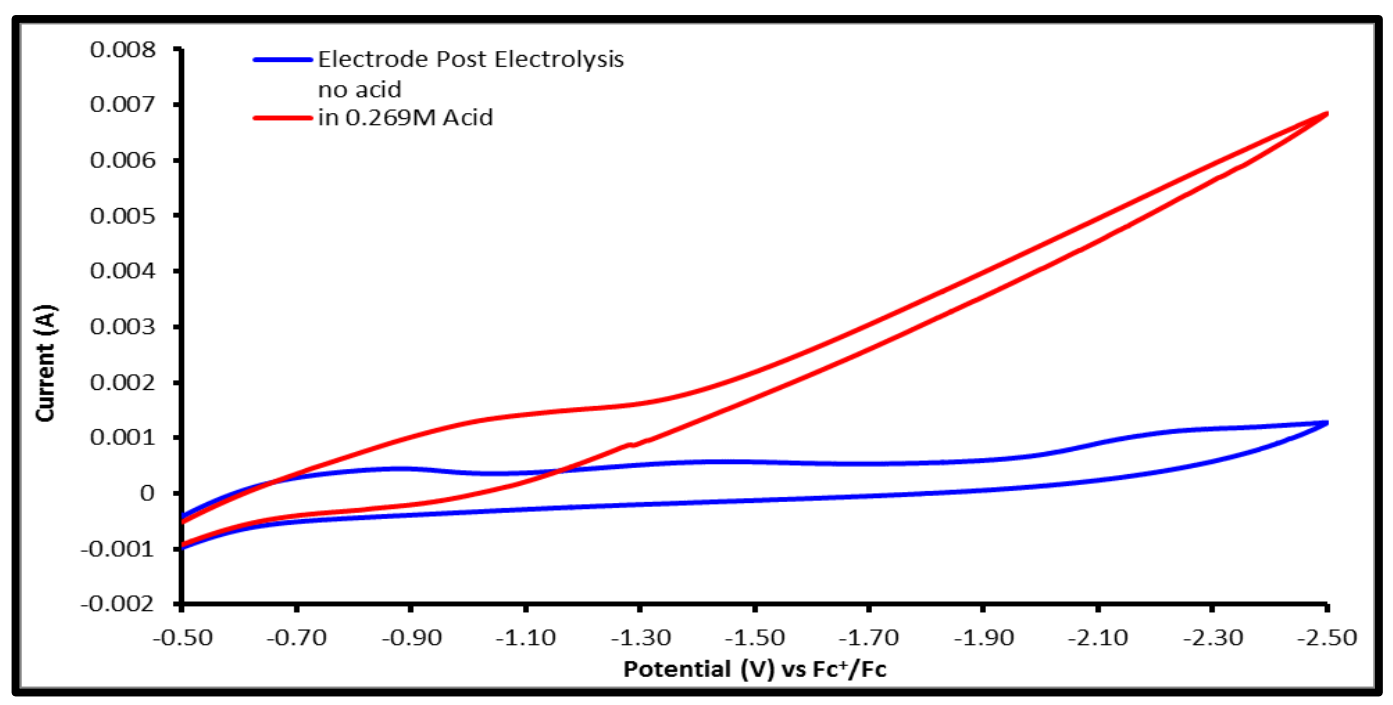

Figure 44. Dip test post electrolysis in acetonitrile: After electrolysis working electrode was rinsed with water and immersed in a fresh solution of $0.1 \mathrm{M} \mathrm{Bu}_{4} \mathrm{NPF}_{6}$ acetonitrile 
solution and a CV was recorded (blue). $0.269 \mathrm{M}$ acetic acid was then added and a CV was obtained (red)

After electrolysis, dip-tests were performed on the working glassy carbon electrode to identify any potential electrode adsorbed species. In both DMF and acetonitrile, the electrode was removed and washed with D.I water and then immersed into a fresh $0.1 \mathrm{M} \mathrm{Bu}_{4} \mathrm{NPF}_{6} \mathrm{DMF} /$ acetonitrile solution and a $\mathrm{CV}$ was run. In both cases the electrode the electrode displays a reduction event near $-0.9 \mathrm{~V}$, the same potential at which $\left[\mathrm{CuL}{ }^{1} \mathrm{H}\right]^{+}$is observed during $\mathrm{CV}$ studies, suggesting that the adsorbed species may be $\left[\mathrm{CuL}^{1} \mathrm{H}\right]^{+}$. Upon addition of acetic acid to these new solutions current increases and catalysis is observed (Figure 44). Recently, Dempsey and co-workers reported that protonation of the unreduced cobalt dithiolene HER catalyst results in an electrode adsorbed intermediate which regenerates the homogeneous cobalt complex upon reduction. ${ }^{198}$ Using the methods of Dempsey and co-workers we then performed a "soak test", in which the working electrode was left to sit in a $0.1 \mathrm{M} \mathrm{Bu}_{4} \mathrm{NPF}_{6}$ acetonitrile solution with $0.6 \mathrm{mM} \mathrm{CuL}^{1}$ and $0.292 \mathrm{M}$ acetic acid. The electrode was left immersed in the solution overnight. The electrode was then removed and put into a fresh solution of $0.1 \mathrm{M} \mathrm{Bu}_{4} \mathrm{NPF}_{6}$ acetonitrile solution with no added acid or catalyst. A CV was run, and no redox events were observed, suggesting that electrode adsorption occurs only under reducing conditions, contrary to what is observed by Dempsey and co-workers. The electrode adsorbed films that resulted post electrolysis in DMF and acetonitrile were then scraped off of the electrode and collected for analysis by x-ray photoelectron spectroscopy, in order to gain insight into its composition. We are currently awaiting these results. 


\subsubsection{Mechanistic Insights}

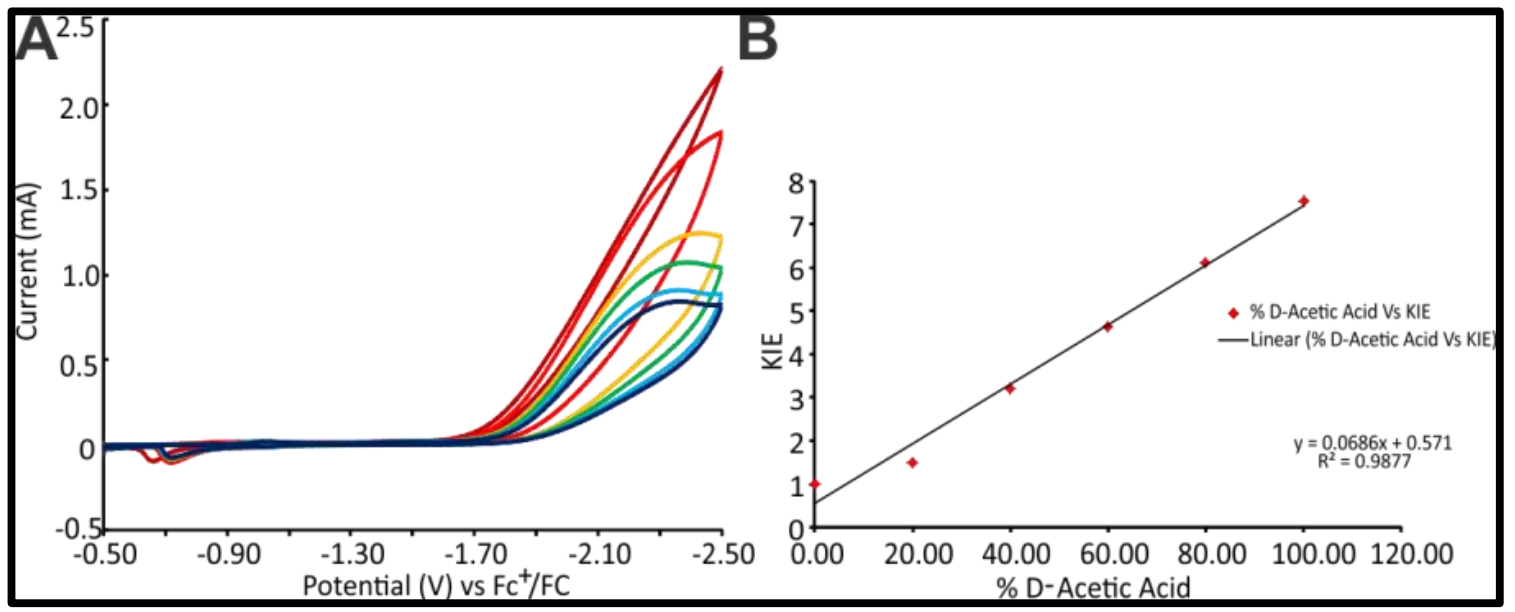

Figure 45. (A) $\mathrm{CVs}_{\mathrm{s}}$ of $0.6 \mathrm{mM} \mathrm{CuL}^{1}$ in $0.1 \mathrm{M} \mathrm{Bu}_{4} \mathrm{NPF}_{6}$ acetonitrile solution with $0.269 \mathrm{M}$ acetic acid, from 0-100\% D-acetic acid use. (B) Plot of \%D-Acetic acid use vs KIE.

To further evaluate the HER mechanism of $\mathrm{CuL}^{1}$, we examined the $\mathrm{H} / \mathrm{D}$ kinetic isotope effect (KIE). Using deuterated acetic acid $\mathrm{CD}_{3} \mathrm{CO}_{2} \mathrm{D}$, the $\mathrm{CuL}^{1}$ catalyst displays a large KIE of 7.54, suggesting that the rate-determining step involves the breaking/making of labeled acid substrate. In order to gain more insight into the nature of this transition, CVs were run in $0.1 \mathrm{M} \mathrm{Bu}_{4} \mathrm{NPF}_{6}$ acetonitrile solution with $0.269 \mathrm{M}$ acetic acid added. The percent fraction of $\mathrm{CD}_{3} \mathrm{CO}_{2} \mathrm{D}$ was increased from 0 to $100 \%$ in increments of $20 \%$.(Figure $45 \mathrm{~A})$. The ratio of the observed reaction rates relative to the rates obtained when not using $\mathrm{CD}_{3} \mathrm{CO}_{2} \mathrm{D}$ were interpreted in order to obtain KIE values. These were then plotted against their respective percent $\mathrm{CD}_{3} \mathrm{CO}_{2} \mathrm{D}$ concentrations yielding a linear fit, with KIE values ranging from 1 at $0 \% \mathrm{CD}_{3} \mathrm{CO}_{2} \mathrm{D}$, to 7.54 when using $100 \%$ $\mathrm{CD}_{3} \mathrm{CO}_{2} \mathrm{D}$ (Figure 45B). The linear response of the KIE with respect to the percent $\mathrm{CD}_{3} \mathrm{CO}_{2} \mathrm{D}$ used suggests a $\mathrm{RDS}$ with a concerted bond making/breaking process, in which both hydrogen atoms are equivalent. The high KIE value observed when using 
$100 \% \mathrm{CD}_{3} \mathrm{CO}_{2} \mathrm{D}$ are distinct from the inverse KIEs reported for some HER catalysts proceeding through metal-hydrides, ${ }^{167}$ but similar to that observed for a ligand-centered Re-thiolate HER catalyst. ${ }^{77}$ It has been reported previously that KIE values exceeding seven, may implicate some semblance of quantum tunneling. ${ }^{168,169,199,200}$

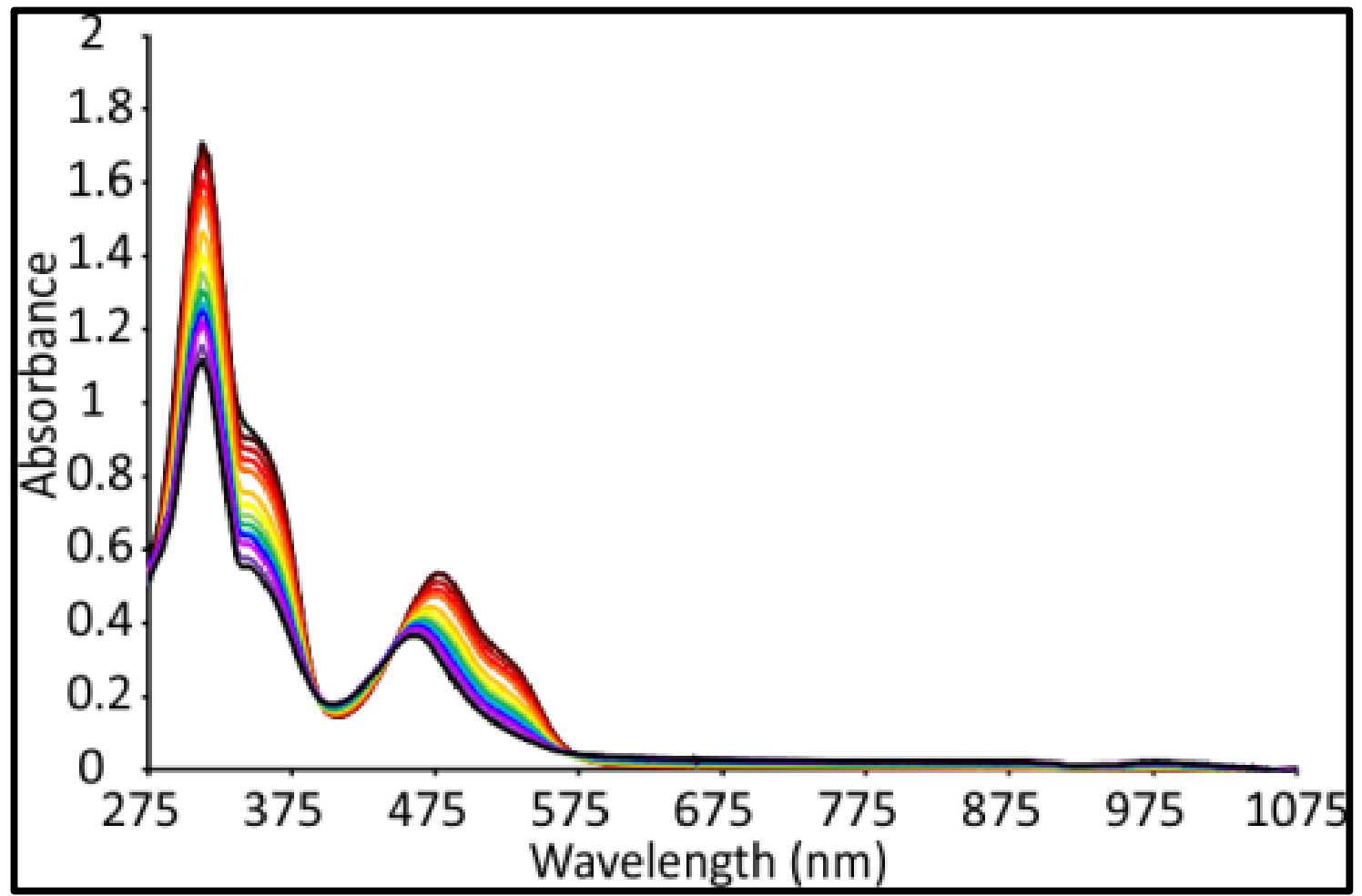

Figure 46. UV-Visible spectrum of $\mathrm{CuL}^{1}$ titrated with acetic acid; 0.022 (dark red), 0.044 (red), 0.056 (light red), 0.067 (orange), 0.089 (light orange), 0.112 (yellow), 0.134 (light green), 0.157 (green), 0.202 (sky blue), 0.244 (blue), 0.269 (magenta), 0.292 (light blue), 0.337 (purple), and 0.382 (black) M.

In order to confirm that protonation of $\mathrm{CuL}^{1}$ occurs before electrochemical reduction, $\mathrm{UV}-\mathrm{Visible}$ spectroscopy acid titrations were performed. $0.6 \mathrm{mM} \mathrm{CuL}^{1}$ was dissolved into deoxygenated DMF and the UV spectrum was recorded showing an absorbance bands at $310,375,475$ and $520 \mathrm{~nm}$. The solution was then titrated with acetic acid increasing in concentration from $0.022 \mathrm{M}$ to $0.382 \mathrm{M}$. Upon increasing additions, the 
absorbance bands at $310,375,475$, and 520 decrease in intensity concurrent with an increase in intensity of new bands at 405 and $460 \mathrm{~nm}$, yielding isosbestic points near 380 and $450 \mathrm{~nm}$, consistent with the formation of the protonated intermediate, $\left[\mathrm{CuL}^{1} \mathrm{H}\right]^{+}$ (Figure 46).

${ }^{1} \mathrm{H}$ NMR further confirms the hydrazino nitrogen as the site of protonation. In the glove box, $6 \times 10^{-6}$ moles of $\mathrm{CuL}^{1}$ was dissolved in DMSO- $\mathrm{d}_{6}$, to which one equivalent of cobaltocene was added and stirred for 15 minutes in order to achieve the reduced anionic copper(I) complex $\left[\mathrm{CuL}^{1}\right]^{-}$. Upon addition and stirring with cobaltocence, the solution changed color from red to light purple. An aliquot was syringed out and injected into an NMR tube for analysis. The spectrum of $\left[\mathrm{CuL}^{1}\right]^{-}$displays the expected peaks values with chemical shifts at 2.726, 2.886, and 7.948 ppm, integrated 3:3:1, consistent with methyl backbone $\mathrm{CH}_{3}, \mathrm{NH}\left(\mathrm{CH}_{3}\right)$, and $\mathrm{NH}$, respectively. Upon addition of one equivalent of $\mathrm{HBF}_{4}$, the solution changes color from light purple to orange. An aliquot was taken and analyzed by ${ }^{1} \mathrm{H}$ NMR. All the previously identified peaks observed in $\left[\mathrm{CuL}^{1}\right]^{-}$are present, along with a new peak at $8.266 \mathrm{ppm}$, which integrates to 1 . We assign this as the protonation of the hydrazino nitrogen. If protonation were to occur on the copper center to generate a copper hydride, a negative chemical shift would have been observed in the ${ }^{1} \mathrm{H}$ NMR spectrum; however, this region of the spectrum is void of any peaks. 


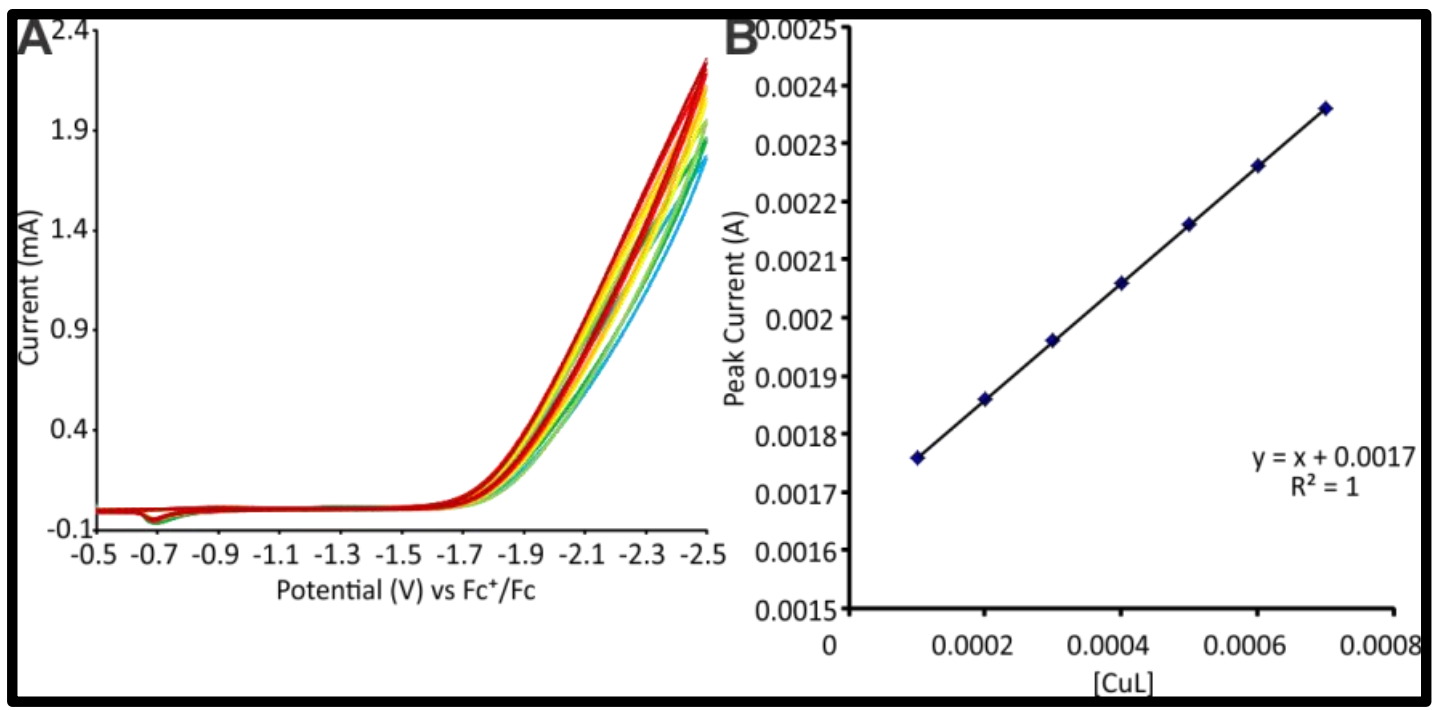

Figure 47. (A) Cyclic Voltammograms run in $0.1 \mathrm{M} \mathrm{Bu}_{4} \mathrm{NPF}_{6}$ acetonitrile solution with $0.269 \mathrm{M}$ acetic acid added run with 0.1 (light blue), 0.2 (green), 0.3 (light green), 0.4 (yellow), 0.5 (orange), 0.6 (red), and 0.7 (dark red) $\mathrm{mM} \mathrm{CuL}^{1}$. (B) Plot of peak current versus catalyst concentration showing linear dependence and $1^{\text {st }}$ order relationship.

Further insight into the mechanism was gained by examining the order of the reaction with respect to the concentration of the catalyst. The concentration of $\mathrm{CuL}^{1}$ was varied from low to high at fixed acid concentrations, and peak currents from CVs were measured at each catalyst concentration. A plot of catalyst concentration versus peak current resulted in a linear relationship, confirming a first-order dependence on the concentration of the catalyst (Figures 43A and 43B).

\subsection{4. $\mathrm{CuL}^{1}$ Density Functional Theory Study}

Density functional theory (DFT) calculations using the B97-D functional ${ }^{147}$ and the 6$31 \lg (\mathrm{d}, \mathrm{p})$ basis set support the proposed mechanism in Figure 45 and help to elucidate the favored protonation and reduction sites. For $\left[\mathrm{CuL}^{1} \mathrm{H}\right]^{+}(\mathrm{S}=1 / 2)$, the $\mathrm{Cu}, \mathrm{S}$, and each $\mathrm{N}$ were evaluated as possible $\mathrm{H}^{+}$locations. For each structure, the geometry and frequencies were optimized and energy minimizations were performed. The hydrizino 
protonated $\left[\mathrm{CuL}^{1} \mathrm{H}\right]^{+}$species is energetically preferred, lying $10 \mathrm{kcal} / \mathrm{mol}$ lower than the metal-hydride (Figure 46A and Figure 47). Protonation at $\mathrm{S}$ is less favored by 12 $\mathrm{kcal} / \mathrm{mol}$. Attempts to optimize structures with protonation of the pendant amine nitrogen or coordinated imine nitrogen resulted in migration of the hydrogen onto the hydrazino nitrogen.

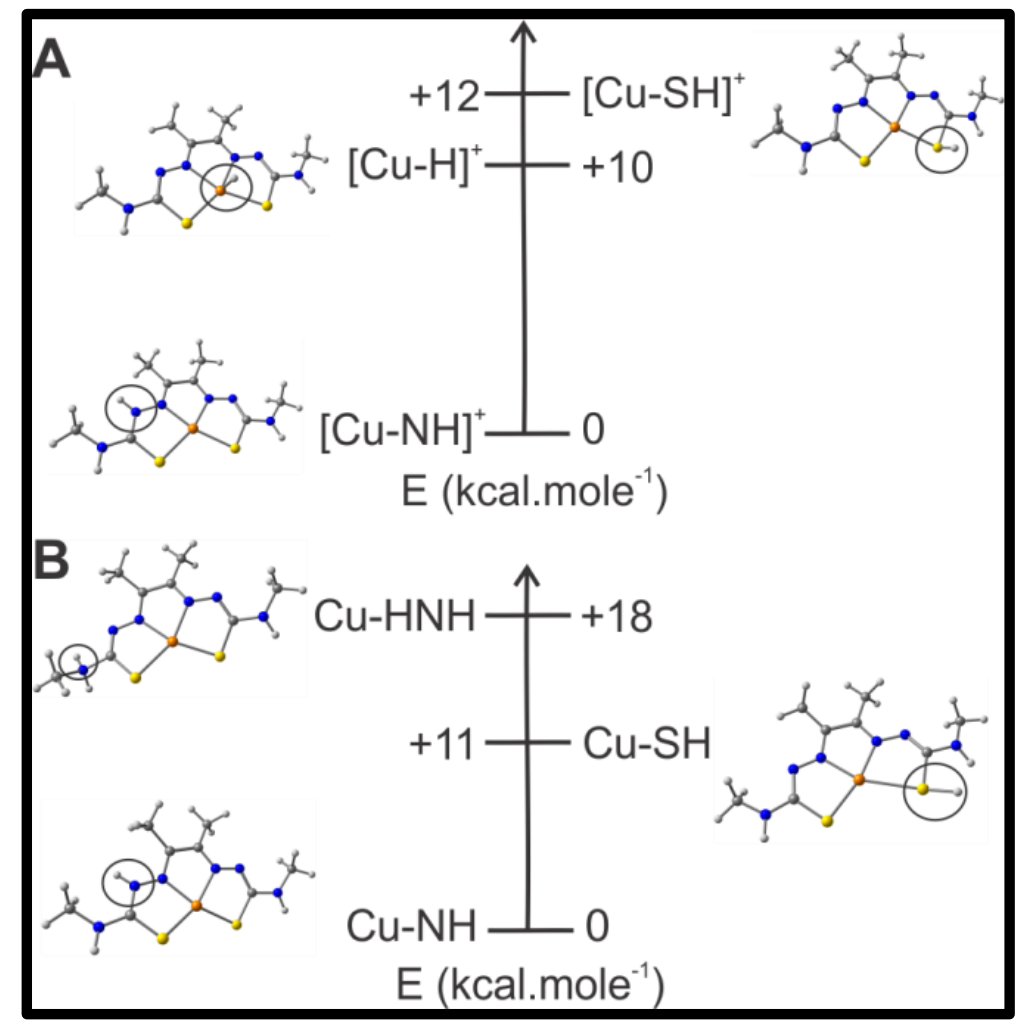

Figure 48. (A) Energetic stability of protonated species, $\left[\mathrm{CuL}^{1} \mathrm{H}\right]^{+}$. (B) Energetic Stability of protonated and reduced species, $\mathrm{CuL}^{1} \mathrm{H}$.

We also examined the site of protonation in the one-electron reduced protonated species, $\mathrm{CuL}^{1} \mathrm{H}(\mathrm{S}=0)$ (Figure $46 \mathrm{~B}$ and Figure 48). Computed free energies for structures with protonation at $\mathrm{Cu}, \mathrm{S}$, and each $\mathrm{N}$, clearly indicate that protonation on the hydrazino $\mathrm{N}$ is favored, lying $11 \mathrm{kcal} / \mathrm{mol}$ lower than protonation at $\mathrm{S}$. Protonation at the 
pendant amine is less favored by $18 \mathrm{kcal} / \mathrm{mole}$. Attempts to optimize $\mathrm{CuL}^{1} \mathrm{H}$ with protonation at the coordinated nitrogen again resulted in migration of hydrogen onto the hydrazino nitrogen. Calculations performed using B3LYP gave similar results. This is in contrast to recent calculations on $\mathrm{NiL}^{2} \mathrm{H}$, which indicated the coordinated nitrogen is the site of protonation. ${ }^{88}$

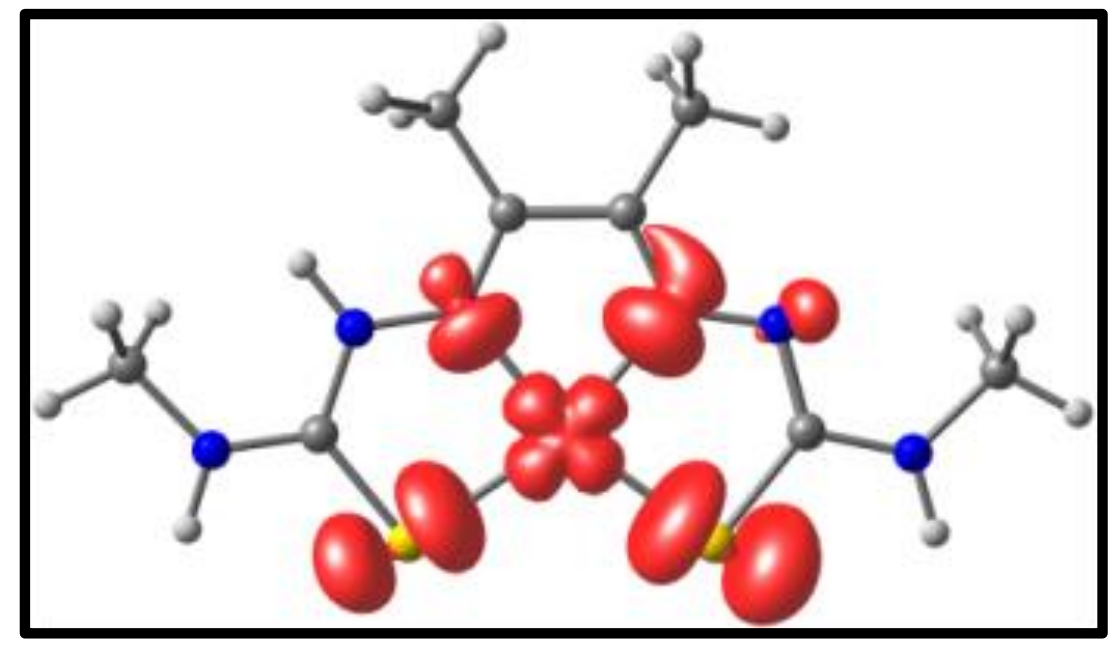

Figure 49. Spin-density map of $\left[\mathrm{CuL}^{1} \mathrm{H}\right]^{+}$.

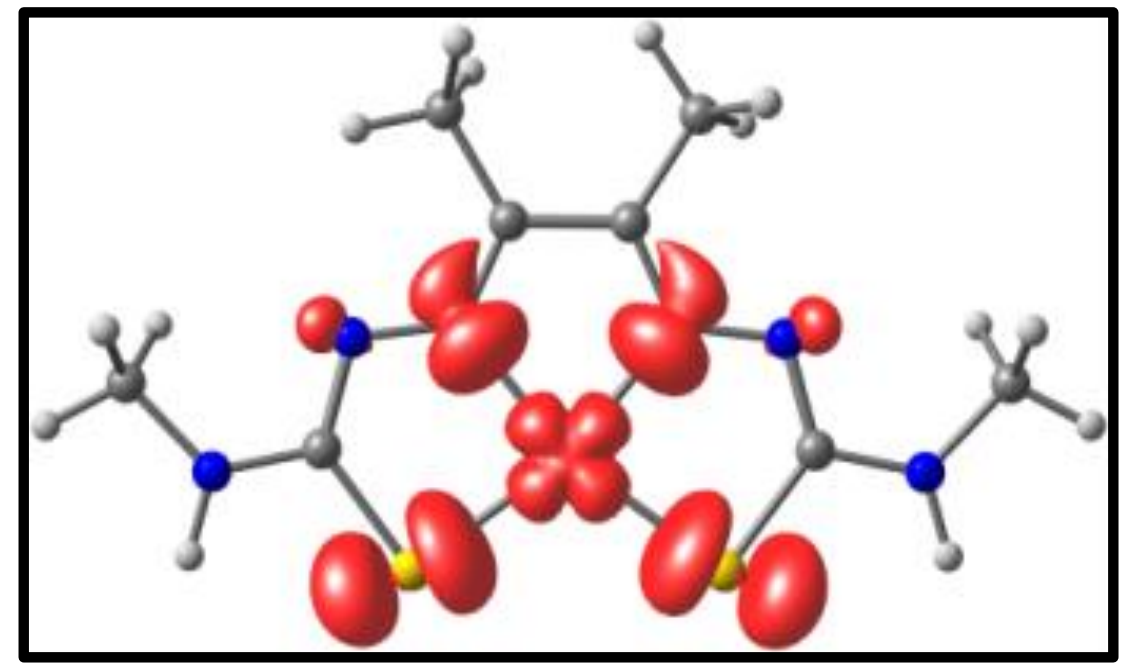

Figure 50. Spin-density map of $\mathrm{CuL}^{1}(\mathrm{~S}=1 / 2)$. 


\subsubsection{Overview of $\mathrm{CuL}^{1}$ and Comparison with $\mathrm{ZnL}^{1}, \mathrm{H}_{2} \mathrm{~L}^{1}$ and Other HER Electrocatalysts.}

Thiosemicarbazone ligands and their metal complexes are relatively new to the field of electrochemical proton reduction, but are emerging as an important class of HER catalysts. The current work represents the $5^{\text {th }}$ thiosemicarbazone motif to be reported as an active HER catalyst since the first report at the end of $2015 .^{76,88,201}$ These complexes present intriguing reactivity as the thiosemicarbazone ligand can participate in electron transfer events, either with or without a transition metal—rendering it "non-innocent". However, a long held question, which often arises in the field of redox-active ligand chemistry, is whether the radical character of the ligand can be used to promote reaction chemistry at the ligand. ${ }^{202}$

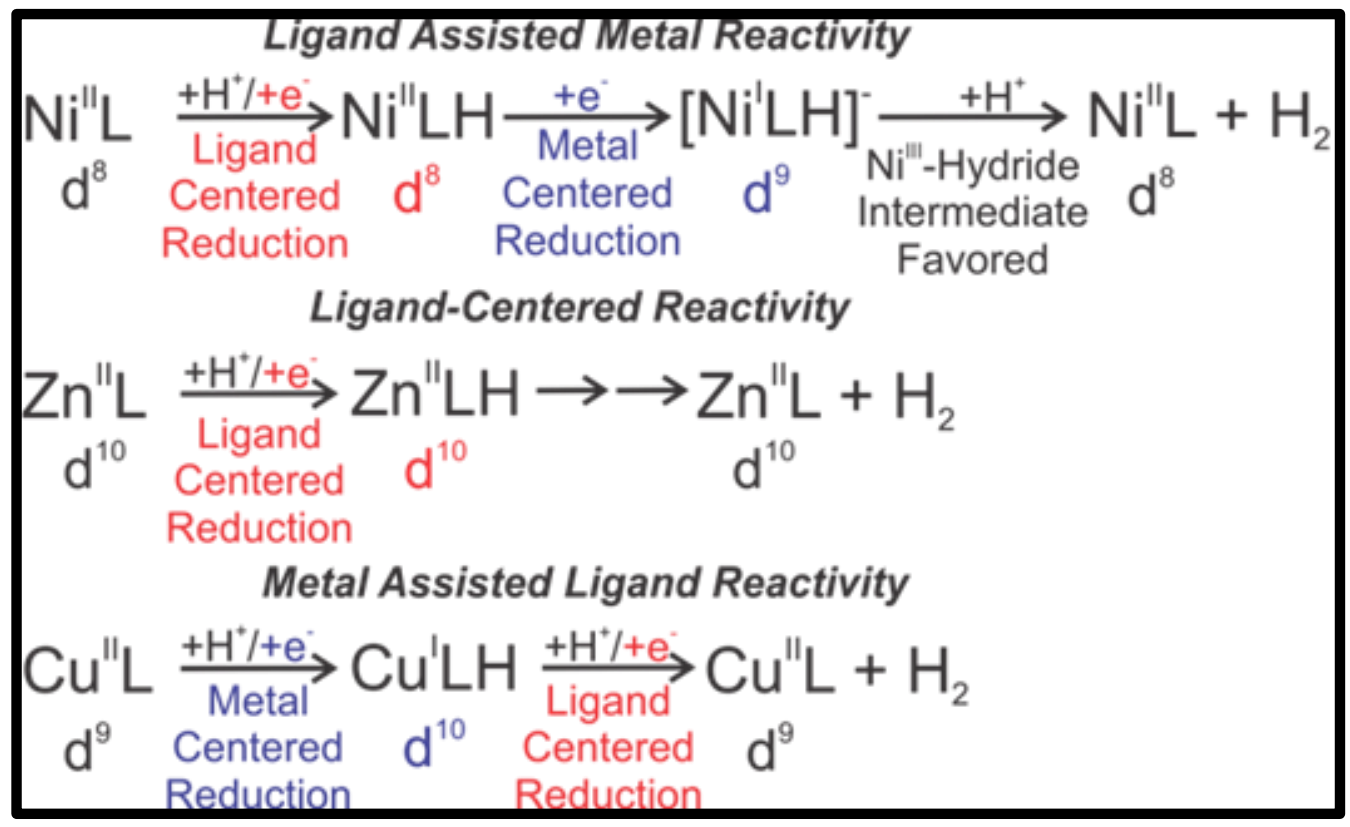

Scheme 8. Comparison of thiosemicarbazone HER electrocatalysts. 
Thiosemicarbazone HER catalysts have shed light onto this question. The impact of the ligand non-innocence is dependent on the metal ion, Scheme 8 , which can result in ligand-assisted metal reactivity, purely ligand-centered activity, or metal-assisted ligand reactivity. The $\mathrm{NiL}^{2}$ catalyst demonstrates ligand-assisted metal reactivity that is proposed to involve initial ligand-centered reduction and protonation followed by metalcentered reduction. ${ }^{88}$ The initial ligand reactivity allows the second reduction to occur at the $\mathrm{d}^{8} \mathrm{Ni}(\mathrm{II})$ generating a nucleophilic $\mathrm{d}^{9} \mathrm{Ni}(\mathrm{I})$. Straistari et al. posit that given the nature of the second reduction as metal-based, the site of the second protonation is likely on the $\mathrm{Ni}$, generating a $\mathrm{Ni}^{\mathrm{III}}$-hydride as the catalytically active species for $\mathrm{H}_{2}$ evolution. In this context, $\mathrm{NiL}^{2}$ can be viewed in the traditional sense of ligand non-innocence, in which the ligand serves as an auxiliary redox site to facilitate two-electron chemistry at the metal site.

The HER chemistry of $\mathrm{ZnL}^{1}$ demonstrates a strictly ligand-centered mechanism with all chemical and electrochemical reactivity being localized on the ligand, with the metal providing structural support. As in the case of $\mathrm{NiL}^{2}$, initial protonation and reduction is ligand-centered, however, the $\mathrm{d}^{10} \mathrm{Zn}(\mathrm{II})$ metal center is incapable of undergoing reduction and HER proceeds via a purely ligand-centered, bimolecular process. $^{76}$

For $\mathrm{CuL}^{1}$, the $\mathrm{d}^{9}$ electron configuration of $\mathrm{Cu}(\mathrm{II})$ favors metal-assisted ligand reactivity. $\mathrm{CuL}^{1}$ undergoes an initial protonation at the energetically preferred hydrazino nitrogen, followed by a metal based reduction. The resulting $\mathrm{CuL}^{1} \mathrm{H}, \mathrm{d}^{10} \mathrm{Cu}(\mathrm{I})$, is isoelectronic with $\mathrm{ZnL}^{1}$. As such, $\mathrm{CuL}^{1} \mathrm{H}$ favors ligand-based protonation and reduction similar to $\mathrm{ZnL}^{1}$, as opposed to metal-hydride formation as proposed for $\left[\mathrm{NiL}^{2} \mathrm{H}\right]^{-}$. This 
results in $\mathrm{H}_{2}$ evolution at the protonated hydrazino nitrogen to regenerate $\mathrm{CuL}^{1}$. In this context, $\mathrm{CuL}^{1}$ can be viewed as atypical ligand non-innocence, where the metal serves as the auxiliary redox site to facilitate two-electron chemistry at the ligand.

The metal-assisted ligand reactivity of $\mathrm{CuL}^{1}$ for $\mathrm{H}_{2}$ evolution involves an initial protonation before electrochemical reduction to produce $\left[\mathrm{CuL}^{1} \mathrm{H}\right]^{+}$. This species is then reduced by one electron to generate the neutral intermediate, $\mathrm{CuL}^{1} \mathrm{H}$. This intermediate can then be reduced in order to generate the anion, $\left[\mathrm{CuL}^{1} \mathrm{H}\right]^{-}$, which then reacts with a free proton in solution to evolve $\mathrm{H}_{2}$. However, due to adsorption onto the electrode surface during prolonged electrolysis when held at cathodic potentials, we cannot discount the possibility that the catalytically active species for $\mathrm{H}_{2}$ evolution is this adsorbed film. We are currently investigating this in order to determine if all observed catalysis is due to the electrode adsorbed film, or if adsorption generates some alternate species, which also catalyses HER in a heterogeneous fashion, in addition to the observed homogeneous catalysis via $\mathrm{CuL}^{1}$.Nonetheless, the identification of this third type of reaction mechanism employing redox-active ligands represents an important step in the development of further redox-active based catalysts for HER and the activation of small molecules.

\subsection{Conclusions}

In summary, the $\mathrm{CuL}^{1}$ electrocatalyst demonstrates that $\mathrm{Cu}^{\mathrm{II}}$ metals, when paired with robust redox-active ligands can demonstrate high activity as HER catalysts. This further confirms that organic redox-active ligands have the ability to store and transfer electrons in the ligand and work in unison with late transition metals in order to carry out catalysis.

To the best of our knowledge, the $\mathrm{CuL}^{1}$ electrocatalyst exhibits the highest reported TOF 
of any ligand-centered homogeneous HER catalysts to date, however, its high activity coincides with substantially large overpotentials. This signifies the need for the development of new thiosemicarbazone ligands that employ more electron-donating auxiliary R group's which should greatly increase proton binding affinity, as well as drastically lower overpotentials. Thiosemicarbazones and thiosemicarbazonato frameworks display significant potential for hydrogen evolution, and demonstrate that incorporation of redox-active ligands into HER systems could potentially lead to a new class of HER electrocatalysts.

\subsection{Acknowledgement}

This research shown in Chapter Five was funded in part by the National Science Foundation (CHE-1361728) and a grant from the Kentucky Science and Engineering Foundation as per grant agreement no. KSEF 148-502-15-350 with the Kentucky Science and Technology Corporation. The authors are thankful to Cardinal Research Cluster at the University of Louisville for providing the computational facilities. A provisional patent has been filed on the work described in chapter 5. 


\section{CHAPTER VI: CONCLUSIONS}




\subsection{Ligand-Centered Electrocatalytic Hydrogen Evolution and Hydrogen Oxidation}

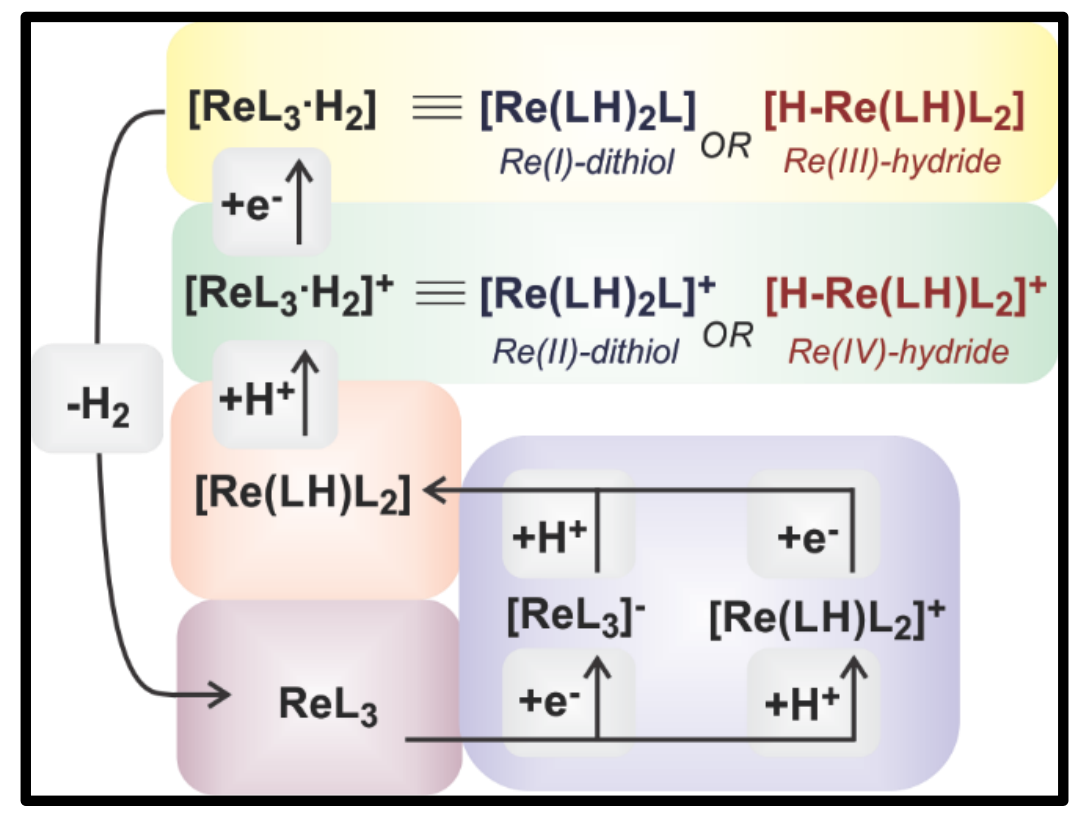

Scheme 9. $\operatorname{ReL}_{3}$ HER mechanism

Homogeneous electrochemical studies were performed to assess $\mathrm{ReL}_{3}$ as an electrocatalyst for $\mathrm{H}_{2}$ evolution and oxidation. ${ }^{9}$ Homogeneous studies show that $\mathrm{ReL}_{3}$ reduces acid in $\mathrm{CH}_{2} \mathrm{Cl}_{2}$ to $\mathrm{H}_{2}$ with an overpotential of $0.708 \mathrm{~V}$ and a turnover frequency of $32 \pm 3 \mathrm{~s}^{-1}$ via a unimolecular mechanism. Additionally, $\operatorname{ReL}_{3}$ oxidizes $\mathrm{H}_{2}$ in the presence of base at an overpotential of $0.970 \mathrm{~V}$ with a turnover frequency of $4 \pm 1 \mathrm{~s}^{-1}$. To our knowledge, this is one of four published electrocatalysts which can perform both the HER and HOR reaction. ${ }^{76,77,203}$ Furthermore, it was the first ligand-centered HER/HOR electrocatalyst reported. The HER mechanism, Scheme 9, is consistent with experimental results and further supported by density functional theory. Further, computational studies, including location of the transition state and intrinsic reaction coordinate analysis, identified the $\mathrm{H}_{2}$ evolving complex as a Re-dithiol that generates $\mathrm{H}_{2}$ through a radical 
coupling mechanism. The process involves homolytic S-H bond cleavage with no formation of metal-hydride intermediates, Scheme 10. The results represent the first example of a ligand-centered HER mechanism to be validated through a rigorous combination of study.

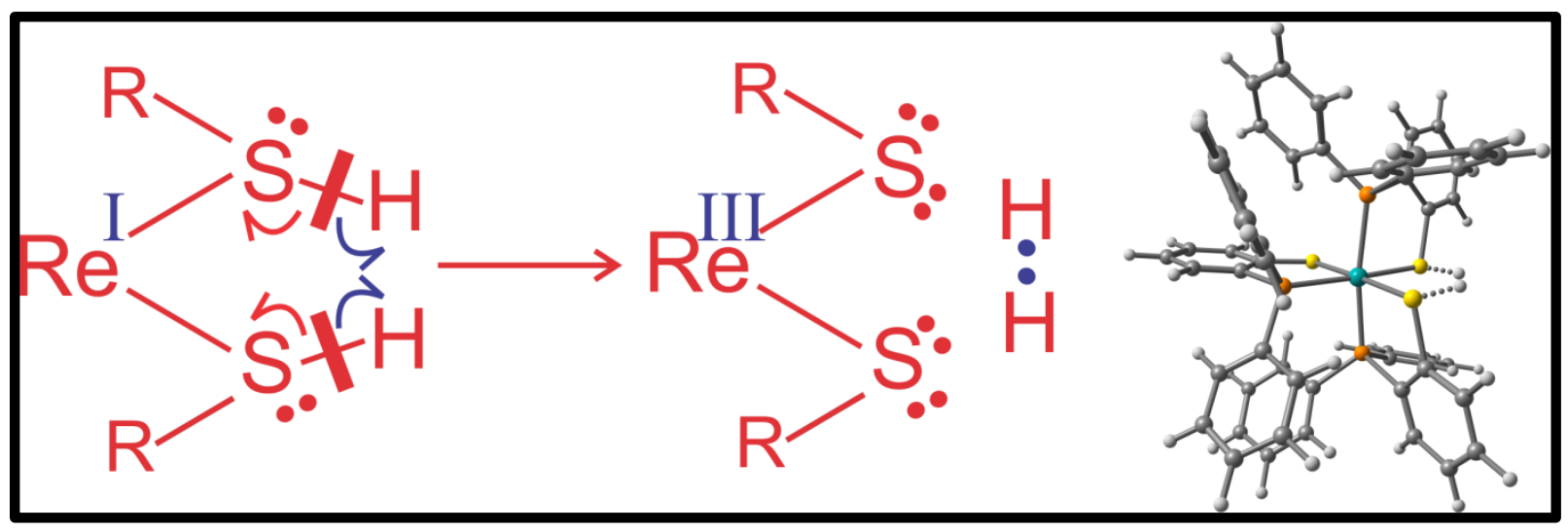

Scheme 10. Representation of homolytic S-H bond cleavage leading to $\mathrm{H}_{2}$ evolution via radical coupling and calculated transition state for $\mathrm{H}_{2}$ evolution.

While unprecedented in homogeneous mononuclear systems, there have been numerous reports of heterogeneous $\mathrm{H}_{2}$ production electrocatalysis that are believed to proceed without the formation of metal-hydrides. ${ }^{100,101,172,204-206}$ The unique reactivity observed with $\mathrm{ReL}_{3}$ could be attributed to a sterically crowded, kinetically inert, and coordinativley saturated metal center that prevents facile formation of metal hydride, rather favoring dithiol formation and $\mathrm{H}_{2}$ evolution via homolytic S-H bond cleavage. This type of reactivity is not unusual for these complexes, as the non-innocent ligands in $\mathrm{ReL}_{3}$ are known to react with small molecule substrates in a ligand-centered process. ${ }^{98,152,153}$ This could explain the unusual KIE and bifunctional $\left(\mathrm{H}_{2}\right.$ evolution and $\mathrm{H}_{2}$ oxidation) activity of $\mathrm{ReL}_{3}$. Nonetheless, this work represents a valuable jumping off point into the 
field of strictly ligand-centered catalysis, and the lessons learned will undoubtedly be pivotal in the future design of other small molecule activation catalysts.

A significant disadvantage of the $\mathrm{ReL}_{3}$ catalyst is the inclusion of the precious metal Re. As noted previously, our mechanistic studies indicate the metal is not directly involved in the HER/HOR, rather serving as an auxiliary source of electrons. This suggests similar first-row transition metal $(\mathrm{Ni})$ or even non-transition metal $(\mathrm{Zn})$ complexes employing the diphenylphosphinebenzenethiolate ligand may catalyze HER/HOR. Currently efforts in our lab are underway to investigate the $\mathrm{NiL}_{2}$ and the $\mathrm{ZnL}_{2}$ complexes for electrocatalytic small molecule activation.

\subsection{Sustainable Metal Alternatives for Ligand-Centered $\mathbf{H}_{2}$ Evolution Oxidation}

The $\mathrm{ReL}_{3}$ system opens the door to novel pathways and alternative strategies for catalytic HER development. However, the system suffers from significant limitations including: 1) incorporation of a non-sustainable precious metal; 2) the ligand synthesis requires multiple steps that are air, moisture, and/or light sensitive performed under inert conditions; 3) catalysis is limited to halogenated organic solvents; 4) modification of the ligand structure requires an individualized approach for each new derivative; and 5) large complex size $/ 3^{\text {rd }}$ row transition metal complicates computational studies of the mechanism.

In lieu of this, we developed new catalysts based on the non-innocent bisthiosemicarbazone ligand $\mathrm{H}_{2} \mathrm{~L}^{1}$ ( $\mathrm{L}^{1}=$ diacetyl-bis(N-4-methyl-3-thiosemicarbazide). $\mathrm{H}_{2} \mathrm{~L}^{1}$ represents the first homogeneous metal-free HER catalyst, $\mathrm{ZnL}^{1}$ is the most active

transition metal free HER catalyst. ${ }^{76}$ Further, these systems overcome the limitations 
noted above as they: 1) incorporate sustainable first-row metals; 2) the ligand syntheses require no specialized skills and can be performed on the benchtop in water and/or alcohol using inexpensive synthons; 3) catalysis occurs in water/alcohol or acetonitrile; 4) the framework is easily derivatized and very stable to hydrolysis; 5) the structures are small with metals that are well calibrated from a computational perspective.

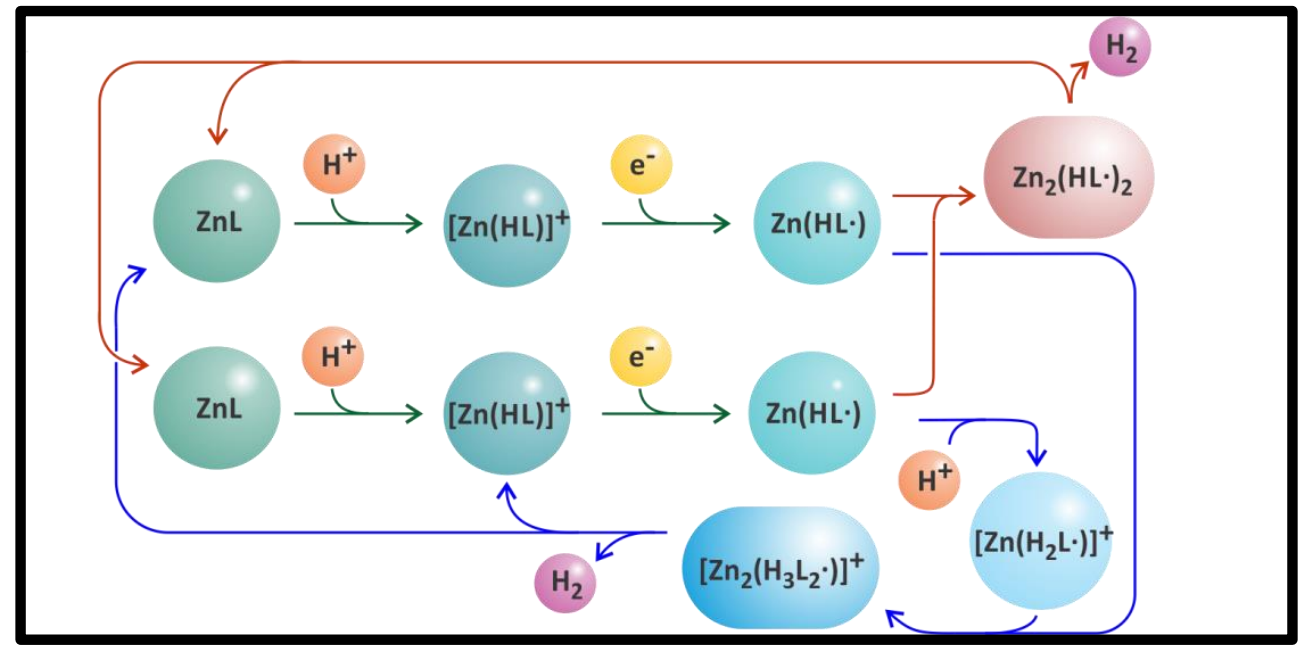

Scheme 11. Proposed mechanism for $\mathrm{H}_{2}$ evolution by $\mathrm{ZnL}^{1}$.

As previously discussed, the ligand diacetyl-bis(N-4-methyl-3-thiosemicarbazone) $\left(\mathrm{H}_{2} \mathrm{~L}^{1}\right)$ and its $\mathrm{Zn}$ complex $\left(\mathrm{ZnL}^{1}\right)$ display the highest reported TOFs of any homogeneous ligand-centered $\mathrm{H}_{2}$ evolution catalyst, $1320 \mathrm{~s}^{-1}$ and $1170 \mathrm{~s}^{-1}$ respectively, while the zinc complex also displays one of the highest reported TOF values for $\mathrm{H}_{2}$ oxidation, $72 \mathrm{~s}^{-1}$, of any homogeneous catalyst. Controlled potential coulometry experiments show a Faradaic efficiency of $85 \%$ and a turnover number of 36.7 . The reaction proceeds through a bi-molecular mechanism, supported by digital simulations of voltammetric data and DFT, and culminates in $\mathrm{H}_{2}$ release through parallel routes, Scheme 11. In both pathways, catalysis proceeds via ligand-centered proton-transfer and electron- 
transfer events while avoiding traditional metal-hydride intermediates. The calculated transition state reveals a binuclear core comprised of two protonated and reduced equivalents of $\mathrm{ZnL}^{1}$. Analysis of the intrinsic reaction coordinates indicates heterolytic cleavage of one hydrazino $\mathrm{N}-\mathrm{H}$ bond to release $\mathrm{H}^{-}$, which deprotonates the neighboring hydrazino $\mathrm{N}-\mathrm{H}$ to evolve $\mathrm{H}_{2}$, Scheme 12 , and regenerate the mononuclear $\mathrm{ZnL}^{1}$ complexes. The results represent the second example from our research team of a validated ligand-centered HER mechanism. To our knowledge, the HER mechanisms presented in this dissertation for $\mathrm{ReL}_{3}$ and $\mathrm{ZnL}^{1}$ are the only two ligand-centered processes in the literature examined by a combined experimental simulations and computational investigations.

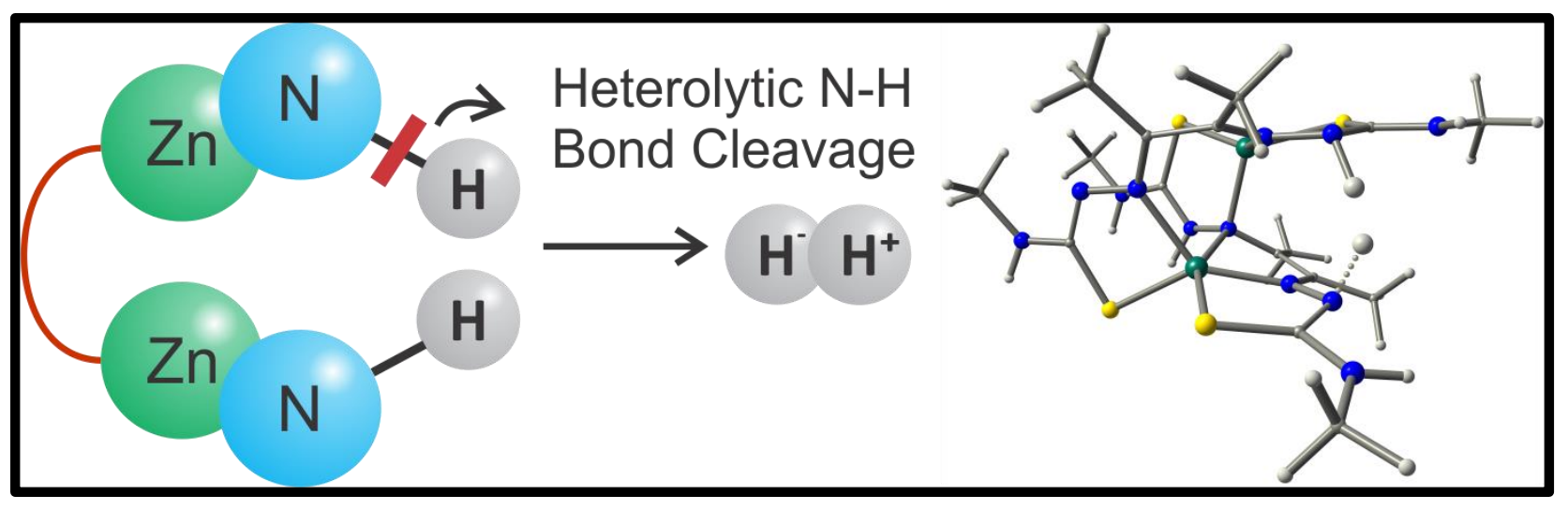

Scheme 12. Mechanism for $\mathrm{H}_{2}$ evolution for $\mathrm{ZnL}^{1}$ showing evolution through heterolytic N-H bond cleavage resulting in deprotonation of neighboring hydrogen and (right) the calculated transition state for $\mathrm{H}_{2}$ evolution.

Other ligand-centered processes for HER/HOR are emerging. Initial work focused on heterogeneous systems including a metal-free HER catalyst based on N-doped graphene with graphitic-carbon nitride ${ }^{100}$ and metal-free and zincphthalocyanines. ${ }^{101,105,106}$ Notable heterogeneous HOR electrocatalysts include a metal- 
free frustrated Lewis pair ${ }^{107}$ that is proposed to operate through a hydride intermediate similar to homogeneous $\mathrm{Ni}$ and $\mathrm{Fe}$ HOR catalysts. As previously discussed, an aluminum-bis(imino)pyridine complex was reported as a homogeneous, non-transition metal HER electrocatalyst with a TOF of $3.3 \mathrm{hr}^{-1} .^{99}$ Activity was attributed to a radical process involving homolytic C-H bond cleavage. A similar mechanism was proposed for a nickel "hangman"-porphyrin complex via a Ni phorlin intermediate, although no TOF

was reported. ${ }^{173}$ Recently, a heterobimetallic W-Ni complex employing a redox-active ligand was reported as a HER catalyst in acidic aqueous solutions with a cis-thiolate core proposed as the active site. ${ }^{174}$

The recent development of ligand-centered HER/HOR catalysts underscores the need for alternate approaches to the traditional metal-hydride systems. From our own studies, it is clear the redox non-innocence and propensity of the framework to tautomerize hydrogen atoms makes the thiosemicarbazone ligand class an ideal choice for further examination of ligand-center HER/HOR electrocatalysis.

\subsection{Transition Metal Assisted Ligand-Centered $\mathrm{H}_{2}$ Evolution}

Building off of the work using the non-innocent bis-thiosemicarbazone ligand $\mathrm{H}_{2} \mathrm{~L}^{1}$ ( $\mathrm{L}^{1}=$ diacetyl-bis(N-4-methyl-3-thiosemicarbazide), we then investigated its copper complex, $\mathrm{CuL}^{1}$ as an electrocatalyst for hydrogen evolution. $\mathrm{CuL}^{1}$ displays a turnover frequency (TOF) of $10,000 \mathrm{~s}^{-1}$, the highest reported TOF values of any homogeneous ligand-centered $\mathrm{H}_{2}$ evolution electrocatalyst. Gas analysis from controlled potential coulometry confirms $\mathrm{CuL}^{1}$ as an electrocatalyst to produce $\mathrm{H}_{2}$, with Faradaic efficiency of $86 \%$. The $\mathrm{H}_{2}$ evolution reaction (HER) was probed using deuterated acid, demonstrating a kinetic isotope effect of 7.54 . The mechanism is proposed to involve 
ligand centered protonation, metal-centered reduction and ligand-centered reduction in which hydrogen is evolved via solution proton and nitrogen-hydride coupling. The $\mathrm{d}^{9}$ electron configuration of $\mathrm{Cu}(\mathrm{II})$ in $\mathrm{CuL}^{1}$ favors metal-assisted ligand reactivity. $\mathrm{CuL}^{1}$ undergoes an initial protonation at the energetically preferred hydrazino nitrogen, followed by a metal based reduction. The resulting $\mathrm{CuL}^{1} \mathrm{H}, \mathrm{d}^{10} \mathrm{Cu}(\mathrm{I})$, is isoelectronic with the previously described $\mathrm{ZnL}^{1}$. As such, $\mathrm{CuL}^{1} \mathrm{H}$ favors ligand-based protonation and reduction similar to $\mathrm{ZnL}^{1}$. This results in $\mathrm{H}_{2}$ evolution at the protonated hydrazino nitrogen to regenerate $\mathrm{CuL}^{1}$. In this context, $\mathrm{CuL}^{1}$ can be viewed as atypical ligand noninnocence, where the metal serves as the auxiliary redox site to facilitate two-electron chemistry at the ligand. The proposed homogeneous mechanism is further supported by density functional theory (DFT) calculations. However, due to the presence of an adsorbed film on the electrode post electrolysis, we cannot discount a heterogeneous electrode adsorbed film as the active species for hydrogen evolution.

We are currently trying to identify if adsorption generates some alternate species which also catalyses HER in a heterogeneous fashion, or if the observed catalysis is due solely to homogeneous activity from $\mathrm{CuL}^{1}$. Nonetheless, the identification of this third type of reaction mechanism employing redox-active ligands represents a key step in the development of further redox-active based catalysts for HER and the activation of small molecules. $\mathrm{CuL}^{1}$ demonstrates that $\mathrm{Cu}^{\mathrm{II}}$ metals, when paired with robust redox-active ligands can demonstrate high activity as HER electrocatalysts, and further confirms that organic redox-active ligands have the ability to store and transfer electrons in the ligand and work in unison with late transition metals in order to carry out catalysis. 
To the best of our knowledge, the $\mathrm{CuL}^{1}$ electrocatalyst exhibits the highest reported TOF of any ligand-centered homogeneous HER catalysts to date. However, their high activities coincide with substantially large overpotentials. This signifies the need for the development of new thiosemicarbazone ligands that employ more electron-donating auxiliary R groups which should greatly increase proton binding affinity, as well as drastically lower overpotentials. Still, thiosemicarbazones and thiosemicarbazonato frameworks display significant potential for hydrogen evolution, and demonstrate that incorporation of redox-active ligands into HER systems could potentially lead to a new class of HER electrocatalysts. 


\section{REFERENCES}

1. D. G. Nocera, Acc. Chem. Res., 2012, 45, 767-776.

2. M. I. Hoffert, K. Caldeira, A. K. Jain, E. F. Haites, L. D. D. Harvey, S. D. Potter, M. E. Schlesinger, S. H. Schneider, R. G. Watts, T. M. L. Wigley and D. J. Wuebbles, Nature, 1998, 395, 881-884.

3. D. A. LaVan and J. N. Cha, Proc. Natl. Acad. Sci., 2006, 103, 5251-5255.

4. S. Shafiee and E. Topal, Energy Policy, 2009, 37, 181-189.

5. N. S. Lewis and D. G. Nocera, Proc. Natl. Acad. Sci., 2006, 103, 15729-15735.

6. J. A. Turner, Science, 2004, 305, 972-974.

7. A. Das, Z. Han, W. W. Brennessel, P. L. Holland and R. Eisenberg, ACS Catal., 2015, 5, 1397-1406.

8. M. R. Dubois and D. L. Dubois, Acc. Chem. Res., 2009, 42, 1974-1982.

9. A. Z. Haddad, D. Kumar, K. O. Sampson, A. M. Matzner, M. S. Mashuta and C. A. Grapperhaus, J. Am. Chem. Soc., 2015, 137, 9238-9241.

10. X. L. Hu, B. S. Brunschwig and J. C. Peters, J. Am. Chem. Soc., 2007, 129, 8988-8998.

11. W. R. McNamara, Z. J. Han, P. J. Alperin, W. W. Brennessel, P. L. Holland and R. Eisenberg, J. Am. Chem. Soc., 2011, 133, 15368-15371.

12. W. R. McNamara, Z. J. Han, C. J. Yin, W. W. Brennessel, P. L. Holland and R. Eisenberg, Proc. Natl. Acad. Sci. U. S. A., 2012, 109, 15594-15599.

13. S. E. Smith, J. Y. Yang, D. L. DuBois and R. M. Bullock, Angew. Chem. Int. Ed., 2012, 51, 3152-3155.

14. S. Wiese, U. J. Kilgore, D. L. DuBois and R. M. Bullock, ACS Catal., 2012, 2, 720-727.

15. T. R. Cook, D. K. Dogutan, S. Y. Reece, Y. Surendranath, T. S. Teets and D. G. Nocera, Chem. Rev., 2010, 110, 6474-6502.

16. H. B. Gray, Nat. Chem., 2009, 1, 7-7.

17. R. Chaubey, S. Sahu, O. O. James and S. Maity, Renewable and Sustainable Energy Reviews, 2013, 23, 443-462.

18. P. M. Vignais, B. Billoud and J. Meyer, FEMS Microbiology Reviews, 2001, 25, 455-501.

19. P. M. Vignais and B. Billoud, Chem. Rev., 2007, 107, 4206-4272.

20. M. Stephenson and L. H. Stickland, The properties of the enzyme, 1931, 25, 205-214.

21. D. E. Green and L. H. Stickland, <span class="subtitle" $>$ The reversibility of the hydrogenase system of <em>Bact. coli</em>.</span>, 1934, 28, 898-900.

22. H. Ogata, S. Hirota, A. Nakahara, H. Komori, N. Shibata, T. Kato, K. Kano and Y. Higuchi, Structure, 2005, 13, 1635-1642.

23. Y. Nicolet, C. Piras, P. Legrand, C. E. Hatchikian and J. C. Fontecilla-Camps, Structure, 1999, 7, 13-23.

24. P. Tamagnini, R. Axelsson, P. Lindberg, F. Oxelfelt, R. Wünschiers and P. Lindblad, Microbiology and Molecular Biology Reviews, 2002, 66, 1-20. 
25. P. Tamagnini, E. Leitão, P. Oliveira, D. Ferreira, F. Pinto, D. J. Harris, T. Heidorn and P. Lindblad, FEMS Microbiology Reviews, 2007, 31, 692-720.

26. M. Y. Darensbourg, E. J. Lyon, X. Zhao and I. P. Georgakaki, Proceedings of the National Academy of Sciences of the United States of America, 2003, 100, 3683-3688.

27. J. C. Fontecilla-Camps, A. Volbeda, C. Cavazza and Y. Nicolet, Chem. Rev., 2007, 107, 4273-4303.

28. S. Shima, O. Pilak, S. Vogt, M. Schick, M. S. Stagni, W. Meyer-Klaucke, E. Warkentin, R. K. Thauer and U. Ermler, Science, 2008, 321, 572-575.

29. J. C. Fontecilla-Camps, A. Volbeda, C. Cavazza and Y. Nicolet, Chem. Rev., 2007, 107, 4273-4303.

30. J. C. Fontecilla-Camps, P. Amara, C. Cavazza, Y. Nicolet and A. Volbeda, Nature, 2009, 460, 814-822.

31. R. P. Happe, W. Roseboom, A. J. Pierik, S. P. J. Albracht and K. A. Bagley, Nature, 1997, 385, 126-126.

32. A. J. Pierik, M. Hulstein, W. R. Hagen and S. P. J. Albracht, Eur. J. Biochem., 1998, 258, 572-578.

33. A. Volbeda, E. Garcin, C. Piras, A. L. de Lacey, V. M. Fernandez, E. C. Hatchikian, M. Frey and J. C. Fontecilla-Camps, J. Am. Chem. Soc., 1996, 118, 12989-12996.

34. E. J. Lyon, S. Shima, R. Boecher, R. K. Thauer, F.-W. Grevels, E. Bill, W. Roseboom and S. P. J. Albracht, J. Am. Chem. Soc., 2004, 126, 14239-14248.

35. S. Shima, E. J. Lyon, M. Sordel-Klippert, M. Kauß, J. Kahnt, R. K. Thauer, K. Steinbach, X. Xie, L. Verdier and C. Griesinger, Angew. Chem. Int. Ed., 2004, 43, 2547-2551.

36. E. J. Lyon, S. Shima, G. Buurman, S. Chowdhuri, A. Batschauer, K. Steinbach and R. K. Thauer, Eur. J. Biochem., 2004, 271, 195-204.

37. S. Shima, E. J. Lyon, R. K. Thauer, B. Mienert and E. Bill, J. Am. Chem. Soc., 2005, 127, 10430-10435.

38. K. A. Vincent, A. Parkin and F. A. Armstrong, Chem. Rev., 2007, 107, 4366-4413.

39. C. Tard and C. J. Pickett, Chem. Rev., 2009, 109, 2245-2274.

40. A. Adamska, A. Silakov, C. Lambertz, O. Rüdiger, T. Happe, E. Reijerse and W. Lubitz, Angew. Chem. Int. Ed., 2012, 51, 11458-11462.

41. D. W. Mulder, M. W. Ratzloff, E. M. Shepard, A. S. Byer, S. M. Noone, J. W. Peters, J. B. Broderick and P. W. King, J. Am. Chem. Soc., 2013, 135, 6921-6929.

42. A. Volbeda, M.-H. Charon, C. Piras, E. C. Hatchikian, M. Frey and J. C. Fontecilla-Camps, Nature, 1995, 373, 580-587.

43. S. Canaguier, V. Artero and M. Fontecave, Dalton Trans, 2008, DOI: 10.1039/B713567J, 315-325.

44. H. Reihlen, A. Gruhl and G. v. Hessling, Justus Liebigs Annalen der Chemie, 1929, 472, 268-287.

45. A. Le Cloirec, S. C. Davies, D. J. Evans, D. L. Hughes, C. J. Pickett, S. P. Best and S. Borg, Chem. Commun., 1999, DOI: 10.1039/A906391I, 2285-2286.

46. M. Schmidt, S. M. Contakes and T. B. Rauchfuss, J. Am. Chem. Soc., 1999, 121, 97369737.

47. E. J. Lyon, I. P. Georgakaki, J. H. Reibenspies and M. Y. Darensbourg, Angew. Chem. Int. Ed., 1999, 38, 3178-3180.

48. J. W. Peters, W. N. Lanzilotta, B. J. Lemon and L. C. Seefeldt, Science, 1998, 282, 18531858.

49. J.-F. Capon, F. Gloaguen, F. Y. Pétillon, P. Schollhammer and J. Talarmin, Coord. Chem. Rev., 2009, 253, 1476-1494. 
50. C. Sommer, A. Adamska-Venkatesh, K. Pawlak, J. A. Birrell, O. Rüdiger, E. J. Reijerse and W. Lubitz, J. Am. Chem. Soc., 2017, 139, 1440-1443.

51. P. A. Eckert and K. J. Kubarych, The Journal of Physical Chemistry A, 2017, 121, 608-615.

52. D. W. Mulder, Y. Guo, M. W. Ratzloff and P. W. King, J. Am. Chem. Soc., 2017, 139, 8386.

53. Y. Li and T. B. Rauchfuss, Chem. Rev., 2016, 116, 7043-7077.

54. Y.-C. Liu, K.-T. Chu, Y.-L. Huang, C.-H. Hsu, G.-H. Lee, M.-C. Tseng and M.-H. Chiang, ACS Catal., 2016, 6, 2559-2576.

55. D. Yang, Y. Li, B. Wang, X. Zhao, L. Su, S. Chen, P. Tong, Y. Luo and J. Qu, Inorg. Chem., 2015, 54, 10243-10249.

56. D. Zheng, N. Wang, M. Wang, S. Ding, C. Ma, M. Y. Darensbourg, M. B. Hall and L. Sun, J. Am. Chem. Soc., 2014, 136, 16817-16823.

57. B. Li, T. Liu, C. V. Popescu, A. Bilko and M. Y. Darensbourg, Inorg. Chem., 2009, 48, 11283-11289.

58. J. C. Lansing, J. M. Camara, D. E. Gray and T. B. Rauchfuss, Organometallics, 2014, 33, 5897-5906.

59. S. Gao, J. Fan, S. Sun, X. Peng, X. Zhao and J. Hou, Dalton Trans, 2008, DOI: 10.1039/B717497G, 2128-2135.

60. E. S. Donovan, J. J. McCormick, G. S. Nichol and G. A. N. Felton, Organometallics, 2012, 31, 8067-8070.

61. L. Schwartz, P. S. Singh, L. Eriksson, R. Lomoth and S. Ott, Comptes Rendus Chimie, 2008, 11, 875-889.

62. J. P. Collman, P. S. Wagenknecht and N. S. Lewis, J. Am. Chem. Soc., 1992, 114, 56655673.

63. J. P. Collman, Y. Ha, P. S. Wagenknecht, M. A. Lopez and R. Guilard, J. Am. Chem. Soc., 1993, 115, 9080-9088.

64. J. L. Dempsey, J. R. Winkler and H. B. Gray, J. Am. Chem. Soc., 2010, 132, 1060-1065.

65. J. L. Dempsey, J. R. Winkler and H. B. Gray, J. Am. Chem. Soc., 2010, 132, 16774-16776.

66. C. N. Valdez, J. L. Dempsey, B. S. Brunschwig, J. R. Winkler and H. B. Gray, Proc. Natl. Acad. Sci., 2012, 109, 15589-15593.

67. C. H. Lee, D. K. Dogutan and D. G. Nocera, J. Am. Chem. Soc., 2011, 133, 8775-8777.

68. M. M. Roubelakis, D. K. Bediako, D. K. Dogutan and D. G. Nocera, Energy Environ Sci, 2012, 5, 7737-7740.

69. B. H. Solis and S. Hammes-Schiffer, Inorg. Chem., 2011, 50, 11252-11262.

70. B. H. Solis and S. Hammes-Schiffer, J. Am. Chem. Soc., 2011, 133, 19036-19039.

71. B. H. Solis, A. G. Maher, D. K. Dogutan, D. G. Nocera and S. Hammes-Schiffer, Proc. Natl. Acad. Sci., 2016, 113, 485-492.

72. J. T. Muckerman and E. Fujita, Chem. Commun., 2011, 47, 12456-12458.

73. M. Razavet, V. Artero and M. Fontecave, Inorg. Chem., 2005, 44, 4786-4795.

74. C. Baffert, V. Artero and M. Fontecave, Inorg. Chem., 2007, 46, 1817-1824.

75. B. D. Stubbert, J. C. Peters and H. B. Gray, J. Am. Chem. Soc., 2011, 133, 18070-18073.

76. A. Z. Haddad, B. D. Garabato, P. M. Kozlowski, R. M. Buchanan and C. A. Grapperhaus, J. Am. Chem. Soc., 2016, 138, 7844-7847.

77. A. Z. Haddad, D. Kumar, K. Ouch Sampson, A. M. Matzner, M. S. Mashuta and C. A. Grapperhaus, J. Am. Chem. Soc., 2015, 137, 9238-9241.

78. W. Zhang, A. Z. Haddad, B. D. Garabato, P. M. Kozlowski, R. M. Buchanan and C. A. Grapperhaus, Inorg. Chem., 2017, 56, 2177-2187.

79. A. M. Appel, D. L. DuBois and M. R. DuBois, J. Am. Chem. Soc., 2005, 127, 12717-12726. 
80. N. Coutard, N. Kaeffer and V. Artero, Chem. Commun., 2016, 52, 13728-13748.

81. D. L. DuBois, Inorg. Chem., 2014, 53, 3935-3960.

82. G. M. Jacobsen, J. Y. Yang, B. Twamley, A. D. Wilson, R. M. Bullock, M. R. DuBois and D. L. DuBois, Energy Environ Sci, 2008, 1, 167-174.

83. T. Liu, Q. Liao, M. O'Hagan, E. B. Hulley, D. L. DuBois and R. M. Bullock, Organometallics, 2015, 34, 2747-2764.

84. A. D. Wilson, R. H. Newell, M. J. McNevin, J. T. Muckerman, M. R. DuBois and D. L. DuBois, J. Am. Chem. Soc., 2006, 128, 358-366.

85. J. M. Darmon, N. Kumar, E. B. Hulley, C. J. Weiss, S. Raugei, R. M. Bullock and M. L. Helm, Chem. Sci., 2015, 6, 2737-2745.

86. J. M. Darmon, S. Raugei, T. Liu, E. B. Hulley, C. J. Weiss, R. M. Bullock and M. L. Helm, ACS Catal., 2014, 4, 1246-1260.

87. W. A. Hoffert, J. A. S. Roberts, R. Morris Bullock and M. L. Helm, Chem. Commun., 2013, 49, 7767-7769.

88. T. Straistari, J. Fize, S. Shova, M. Réglier, V. Artero and M. Orio, ChemCatChem, 2016, DOI: 10.1002/cctc.201600967.

89. A. Zarkadoulas, M. J. Field, C. Papatriantafyllopoulou, J. Fize, V. Artero and C. A. Mitsopoulou, Inorg. Chem., 2016, 55, 432-444.

90. C. Tsay and J. Y. Yang, J. Am. Chem. Soc., 2016, 138, 14174-14177.

91. J. L. Dempsey, B. S. Brunschwig, J. R. Winkler and H. B. Gray, Acc. Chem. Res., 2009, 42, 1995-2004.

92. A. Bhattacharjee, E. S. Andreiadis, M. Chavarot-Kerlidou, M. Fontecave, M. J. Field and V. Artero, Chemistry - A European Journal, 2013, 19, 15166-15174.

93. N. Kaeffer, A. Morozan, J. Fize, E. Martinez, L. Guetaz and V. Artero, ACS Catal., 2016, 6, 3727-3737.

94. M. Rakowski Dubois and D. L. Dubois, Acc. Chem. Res., 2009, 42, 1974-1982.

95. W. R. McNamara, Z. J. Han, C. J. Yin, W. W. Brennessel, P. L. Holland and R. Eisenberg, Proc. Natl. Acad. Sci., 2012, 109, 15594-15599.

96. W. Kaim and B. Schwederski, Coord. Chem. Rev., 2010, 254, 1580-1588.

97. W. Kaim, Coord. Chem. Rev., 1987, 76, 187-235.

98. C. A. Grapperhaus, K. Ouch and M. S. Mashuta, J. Am. Chem. Soc., 2009, 131, 64-65.

99. E. J. Thompson and L. A. Berben, Angew. Chem. Int. Ed., 2015, 54, 11642-11646.

100. Y. Zheng, Y. Jiao, Y. Zhu, L. H. Li, Y. Han, Y. Chen, A. Du, M. Jaroniec and S. Z. Qiao, Nature Communications, 2014, 5.

101. N. Chebotareva and T. Nyokong, Electrochim. Acta, 1997, 42, 3519-3524.

102. A. Koca, Electrochem. Commun., 2009, 11, 838-841.

103. A. Koca, Ş. Bayar, H. A. Dinçer and E. Gonca, Electrochim. Acta, 2009, 54, 2684-2692.

104. A. Koca, A. Kalkan and Z. Altuntaş Bayır, Electroanalysis, 2010, 22, 310-319.

105. A. Koca, A. Kalkan and Z. A. Bayır, Electrochim. Acta, 2011, 56, 5513-5525.

106. Ö. A. Osmanbaş, A. Koca, M. Kandaz and F. Karaca, Int. J. Hydrogen Energy, 2008, 33, 3281-3288.

107. E. J. Lawrence, R. J. Blagg, D. L. Hughes, A. E. Ashley and G. G. Wildgoose, Chemistry - A European Journal, 2015, 21, 900-906.

108. J. Y. Yang, S. Chen, W. G. Dougherty, W. S. Kassel, R. M. Bullock, D. L. DuBois, S. Raugei, R. Rousseau, M. Dupuis and M. R. DuBois, Chem. Commun., 2010, 46, 8618-8620.

109. B. E. Barton, M. T. Olsen and T. B. Rauchfuss, Curr. Opin. Biotechnol., 2010, 21, 292-297.

110. E. Block, V. Eswarakrishnan, M. Gernon, G. Ofori-Okai, C. Saha, K. Tang and J. Zubieta, J. Am. Chem. Soc., 1989, 111, 658-665. 
111. H. M. Betts, P. J. Barnard, S. R. Bayly, J. R. Dilworth, A. D. Gee and J. P. Holland, Angew. Chem. Int. Ed., 2008, 47, 8416-8419.

112. J. P. Holland, F. I. Aigbirhio, H. M. Betts, P. D. Bonnitcha, P. Burke, M. Christlieb, G. C. Churchill, A. R. Cowley, J. R. Dilworth, P. S. Donnelly, J. C. Green, J. M. Peach, S. R. Vasudevan and J. E. Warren, Inorg. Chem., 2007, 46, 465-485.

113. A. J. Gordon, The Chemistry Companion, John Wiley \& Sons Inc., Canada 1972.

114. J. A. Bard, Faulkner, R. L., Electrochemical Methods: Fundamentals and Applications, Wiley, Somerset, New Jersey, 2nd edn., 2001.

115. S. L. R. D.T., Heinman; J.M. Beebe, Chemistry Experiments for Insturmental Methods, J. Wiley \& Sons, 1984.

116. C. A. Grapperhaus and S. Poturovic, Inorg. Chem., 2004, 43, 3292-3298.

117. A. M. Appel and M. L. Helm, ACS Catal., 2014, 4, 630-633.

118. D. H. Pool, M. P. Stewart, M. O'Hagan, W. J. Shaw, J. A. S. Roberts, R. M. Bullock and D. L. DuBois, Proc. Natl. Acad. Sci., 2012, 109, 15634-15639.

119. M. P. Stewart, M.-H. Ho, S. Wiese, M. L. Lindstrom, C. E. Thogerson, S. Raugei, R. M. Bullock and M. L. Helm, J. Am. Chem. Soc., 2013, 135, 6033-6046.

120. C. P. Andrieux, C. Blocman, J. M. Dumasbouchiat, F. Mhalla and Savéant, J. M., J. Electroanal. Chem., 1980, 113, 19-40.

121. V. Fourmond, P. A. Jacques, M. Fontecave and V. Artero, Inorg. Chem., 2010, 49, 1033810347.

122. Savéant, J. M. and K. B. Su, J. Electroanal. Chem., 1984, 171, 341-349.

123. C. Costentin, G. Passard and J.-M. Savéant, J. Am. Chem. Soc., 2015, 137, 5461-5467.

124. ElchSoft, ElchSoft - Simulation Software, http://www.elchsoft.com/digielch/DigiElch7/Default.aspx, (accessed December 2015, 2015).

125. P. J. Stephens, F. J. Devlin, C. F. Chabalowski and M. J. Frisch, J Phys Chem, 1994, 98, 11623-11627.

126. Y. Zhao and D. G. Truhlar, Theor. Chem. Acc., 2008, 120, 215-241.

127. C. Adamo and V. Barone, J Chem Phys, 1998, 108, 664-675.

128. A. D. Becke, J Chem Phys, 2000, 112, 4020-4026.

129. E. J. Baerends, D. E. Ellis and P. Ros, Chem. Phys., 1973, 2, 41-51.

130. B. I. Dunlap and I. V. Schweigert, J Chem Phys, 2011, 134, 044122.

131. O. Vahtras, J. Almlöf and M. W. Feyereisen, Chem. Phys. Lett., 1993, 213, 514-518.

132. S. Lim and N. Park, Appl. Phys. Lett., 2009, 95, 243110.

133. G. te Velde, F. M. Bickelhaupt, E. J. Baerends, C. Fonseca Guerra, S. J. A. van Gisbergen, J. G. Snijders and T. Ziegler, J. Comput. Chem., 2001, 22, 931-967.

134. V. Weber, M. Iannuzzi, S. Giani, J. Hutter, R. Declerck and M. Waroquier, J Chem Phys, 2009, 131, 014106.

135. Y. Jung, A. Sodt, P. M. W. Gill and M. Head-Gordon, Proceedings of the National Academy of Sciences of the United States of America, 2005, 102, 6692-6697.

136. K. Eichkorn, O. Treutler, H. Öhm, M. Häser and R. Ahlrichs, Chem. Phys. Lett., 1995, 242, 652-660.

137. L. Füsti-Molnár and P. Pulay, Journal of Molecular Structure: THEOCHEM, 2003, 666667, 25-30.

138. S. Chris-Kriton, D. H. Peter, A. M. Arash and C. P. Mike, J. Phys.: Condens. Matter, 2008, 20, 064209.

139. M. J. Frisch and e. al., Journal, 2009.

140. A. D. Becke, J Chem Phys, 1993, 98, 5648-5652. 
141. C. Lee, W. Yang and R. G. Parr, Phys. Rev. B, 1988, 37, 785-789.

142. S. H. Vosko, L. Wilk and M. Nusair, Can. J. Phys., 1980, 58, 1200-1211.

143. C. A. Grapperhaus, P. M. Kozlowski, D. Kumar, H. N. Frye, K. B. Venna and S. Poturovic, Angew. Chem. Int. Ed., 2007, 46, 4085-4088.

144. G. Andrienko, ChemCraft Graphics Vishualization Software, http://www.chemcraftprog.com, (accessed November 2015, 2015).

145. M. J. Frisch, G. W. Trucks, H. B. Schlegel, G. E. Scuseria, M. A. Robb, J. R. Cheeseman, G. Scalmani, V. Barone, B. Mennucci, G. A. Petersson, H. Nakatsuji, M. Caricato, X. Li, H. P. Hratchian, A. F. Izmaylov, J. Bloino, G. Zheng, J. L. Sonnenberg, M. Hada, M. Ehara, K. Toyota, R. Fukuda, J. Hasegawa, M. Ishida, T. Nakajima, Y. Honda, O. Kitao, H. Nakai, T. Vreven, J. A. Montgomery Jr., J. E. Peralta, F. Ogliaro, M. J. Bearpark, J. Heyd, E. N. Brothers, K. N. Kudin, V. N. Staroverov, R. Kobayashi, J. Normand, K. Raghavachari, A. P. Rendell, J. C. Burant, S. S. Iyengar, J. Tomasi, M. Cossi, N. Rega, N. J. Millam, M. Klene, J. E. Knox, J. B. Cross, V. Bakken, C. Adamo, J. Jaramillo, R. Gomperts, R. E. Stratmann, O. Yazyev, A. J. Austin, R. Cammi, C. Pomelli, J. W. Ochterski, R. L. Martin, K. Morokuma, V. G. Zakrzewski, G. A. Voth, P. Salvador, J. J. Dannenberg, S. Dapprich, A. D. Daniels, Ö. Farkas, J. B. Foresman, J. V. Ortiz, J. Cioslowski and D. J. Fox, Journal, 2009.

146. A. R. Cowley, J. R. Dilworth, P. S. Donnelly, E. Labisbal and A. Sousa, J. Am. Chem. Soc., 2002, 124, 5270-5271.

147. S. Grimme, J. Comput. Chem., 2006, 27, 1787-1799.

148. L. A. Berben and J. C. Peters, Chem. Commun., 2010, 46, 398-400.

149. N. Kaeffer, M. Chavarot-Kerlidou and V. Artero, Acc. Chem. Res., 2015, 48, 1286-1295.

150. N. Kaeffer, A. Morozan, J. Fize, E. Martinez, L. Guetaz and V. Artero, ACS Catal., 2016, 6, 3727-3737.

151. S. Poturovic, C. A. Grapperhaus and M. S. Mashuta, Angew. Chem. Int. Ed., 2005, 44, 1883-1887.

152. C. A. Grapperhaus, K. B. Venna and M. S. Mashuta, Inorg. Chem., 2007, 46, 8044-8050.

153. K. Ouch, M. S. Mashuta and C. A. Grapperhaus, Inorg. Chem., 2011, DOI: 10.1021/ic200416y, 9904 - 9914.

154. R. Chauhan, M. S. Mashuta and C. A. Grapperhaus, Inorg. Chem., 2012, 51, 7913-7920.

155. K. Ouch, M. S. Mashuta and C. A. Grapperhaus, Eur. J. Inorg. Chem., 2012, 2012, 475478.

156. K. O. Sampson, D. Kumar, M. S. Mashuta and C. A. Grapperhaus, Inorg. Chim. Acta, 2013, 408, 1-8.

157. J. R. Dilworth, A. J. Hutson, S. Morton, M. Harman, M. B. Hursthouse, J. Zubieta, C. M. Archer and J. D. Kelly, Polyhedron, 1992, 11, 2151-2155.

158. C. A. Grapperhaus, S. Poturovic and M. S. Mashuta, Inorg. Chem., 2005, 44, 8185-8187.

159. R. Chauhan, M. S. Mashuta and C. A. Grapperhaus, Inorg. Chem. Commun., 2013, 37, 186-188.

160. C. A. Grapperhaus and S. Poturovic, Inorganic Chemistry, 2004, 43, 3292-3298.

161. H. I. Karunadasa, C. J. Chang and J. R. Long, Nature, 2010, 464, 1329-1333.

162. L. Farrugia, J. Appl. Crystallogr., 1997, 30, 565.

163. C. P. Andrieux, C. Blocman, J. M. Dumasbouchiat, F. Mhalla and J. M. Saveant, Journal of Electroanalytical Chemistry, 1980, 113, 19-40.

164. G. A. N. Felton, A. K. Vannucci, J. Z. Chen, L. T. Lockett, N. Okumura, B. J. Petro, U. I. Zakai, D. H. Evans, R. S. Glass and D. L. Lichtenberger, J. Am. Chem. Soc., 2007, 129, 12521-12530.

165. J. M. Saveant and K. B. Su, Journal of Electroanalytical Chemistry, 1984, 171, 341-349. 
166. J. A. S. Roberts and R. M. Bullock, Inorg. Chem., 2013, 52, 3823-3835.

167. S. C. Marinescu, J. R. Winkler and H. B. Gray, Proc. Natl. Acad. Sci., 2012, 109, $15127-$ 15131.

168. H. Kotani, R. Hanazaki, K. Ohkubo, Y. Yamada and S. Fukuzumi, Chem. Eur. J., 2011, 17, 2777-2785.

169. S. Fukuzumi, T. Kobayashi and T. Suenobu, J. Am. Chem. Soc., 2010, 132, 1496-1497.

170. D. Sellmann, G. Mahr, F. Knoch and M. Moll, Inorg. Chim. Acta, 1994, 224, 45-59.

171. F. Zhong, G. P. Lisi, D. P. Collins, J. H. Dawson and E. V. Pletneva, Proc. Natl. Acad. Sci., 2014, DOI: 10.1073/pnas.1317173111, ASAP.

172. Y. Yan, B. Xia, Z. Xu and X. Wang, ACS Catal., 2014, 4, 1693-1705.

173. B. H. Solis, A. G. Maher, D. K. Dogutan, D. G. Nocera and S. Hammes-Schiffer, Proc. Natl. Acad. Sci. U. S. A., 2016, 113, 485-492.

174. A. F. Heyduk, R. A. Zarkesh and A. I. Nguyen, Inorg. Chem., 2011, 50, 9849-9863.

175. Y. R. de Miguel, N. Bampos, K. M. Nalin de Silva, J. K. M. Sanders and S. A. Richards, Chem. Commun., 1998, DOI: 10.1039/A806034G, 2267-2268.

176. C. P. Andrieux, C. Blocman, J. M. Dumasbouchiat, F. Mhalla and J. M. Saveant, J. Electroanal. Chem., 1980, 113, 19-40.

177. J. M. Saveant and K. B. Su, J. Electroanal. Chem., 1984, 171, 341-349.

178. D. X. West, A. E. Liberta, S. B. Padhye, R. C. Chikate, P. B. Sonawane, A. S. Kumbhar and R. G. Yerande, Coord. Chem. Rev., 1993, 123, 49-71.

179. R. Vuilleumier and D. Borgis, Nat. Chem., 2012, 4, 432-433.

180. X. Jing, P. Wu, X. Liu, L. Yang, C. He and C. Duan, New J. Chem., 2015, 39, 1051-1059.

181. P. C. K. Vesborg, B. Seger and I. Chorkendorff, J. Phys. Chem. Lett., 2015, 6, 951-957.

182. T. S. Teets and D. G. Nocera, Chem. Commun., 2011, 47, 9268-9274.

183. J. W. S. O.T. Holton, Platinum Met. Rev., 2013, 57, 259-271.

184. J. R. McKone, S. C. Marinescu, B. S. Brunschwig, J. R. Winkler and H. B. Gray, Chem. Sci., 2014, 5, 865-878.

185. T. R. Simmons, G. Berggren, M. Bacchi, M. Fontecave and V. Artero, Coord. Chem. Rev., 2014, 270-271, 127-150.

186. V. S. Thoi, Y. Sun, J. R. Long and C. J. Chang, Chem. Soc. Rev., 2013, 42, 2388-2400.

187. D. Brazzolotto, M. Gennari, N. Queyriaux, T. R. Simmons, J. Pécaut, S. Demeshko, F. Meyer, M. Orio, V. Artero and C. Duboc, Nat. Chem., 2016, 8, 1054-1060.

188. N. Kaeffer, M. Chavarot-Kerlidou and V. Artero, Acc. Chem. Res., 2015, 48, 1286-1295.

189. H. Lei, H. Fang, Y. Han, W. Lai, X. Fu and R. Cao, ACS Catal., 2015, 5, 5145-5153.

190. M. Bacchi, E. Veinberg, M. J. Field, J. Niklas, T. Matsui, D. M. Tiede, O. G. Poluektov, M. Ikeda-Saito, M. Fontecave and V. Artero, ChemPlusChem, 2016, 81, 1083-1089.

191. J. E. Armstrong, P. M. Crossland, M. A. Frank, M. J. Van Dongen and W. R. McNamara, Dalton Trans, 2016, 45, 5430-5433.

192. J. W. Jurss, R. S. Khnayzer, J. A. Panetier, K. A. El Roz, E. M. Nichols, M. Head-Gordon, J. R. Long, F. N. Castellano and C. J. Chang, Chem. Sci., 2015, 6, 4954-4972.

193. J. A. Panetier, C. S. Letko, T. D. Tilley and M. Head-Gordon, J Chem Theory Comput, 2016, 12, 223-230.

194. J. P. Holland, P. J. Barnard, D. Collison, J. R. Dilworth, R. Edge, J. C. Green and E. J. L. McInnes, Chemistry - A European Journal, 2008, 14, 5890-5907.

195. H. M. Acta Crystallographica Section CBetts, P. J. Barnard, S. R. Bayly, J. R. Dilworth, A. D. Gee and J. P. Holland, Angew. Chem. Int. Ed., 2008, 47, 8416-8419.

196. M. Christlieb, H. S. R. Struthers, P. D. Bonnitcha, A. R. Cowley and J. R. Dilworth, Dalton Trans, 2007, 5043-5054. 
197. V. Artero and Savéant, Jean-Michel, Energy Environ Sci, 2014, 7, 3808-3814.

198. K. J. Lee, B. D. McCarthy, E. S. Rountree and J. L. Dempsey, Inorg. Chem., 2017, 56, 19881998.

199. J. P. Layfield and S. Hammes-Schiffer, Chem. Rev., 2014, 114, 3466-3494.

200. A. R. Zeradjanin, J.-P. Grote, G. Polymeros and K. J. J. Mayrhofer, Electroanalysis, 2016, 28, 2256-2269.

201. X. Jing, P. Wu, X. Liu, L. Yang, C. He and C. Duan, New J. Chem., 2015, 39, 1051-1059.

202. P. J. Chirik, Inorg. Chem., 2011, 50, 9737-9740.

203. A. D. Wilson, R. H. Newell, M. J. McNevin, J. T. Muckerman, M. Rakowski DuBois and D. L. DuBois, J. Am. Chem. Soc., 2006, 128, 358-366.

204. E. J. Lawrence, V. S. Oganesyan, D. L. Hughes, A. E. Ashley and G. G. Wildgoose, J. Am. Chem. Soc., 2014, 136, 6031-6036.

205. D. W. Stephan and G. Erker, Angew. Chem. Int. Ed., 2010, 49, 46-76.

206. F. Zhao, J. Zhang, D. Wohrle and M. Kaneko, J. Porphyrins Phthalocyanines, 2000, 04, $31-$ 36. 


\section{APPENDIX A: CYCLIC VOLTAMMETRY SIMULATION PARAMETER TABLES AND DIGIELCH GUIDE}


Table A4. $\mathrm{ZnL}^{1}$ Optimized parameters of data fitting, $12 \mathrm{mM}[\mathrm{acid}] ; v=0.2-0.5 \mathrm{~V} / \mathrm{s} \mathrm{vs} \mathrm{Fc}^{+} / \mathrm{Fc}$

\begin{tabular}{|c|c|c|c|c|}
\hline Charge-transfer Steps & $\begin{array}{l}99 \% \\
\text { Confidence }\end{array}$ & $\mathbf{E}^{\mathbf{0}}$ & $\boldsymbol{\alpha}$ & $\mathbf{k}_{\mathbf{s}}$ \\
\hline \multirow[t]{3}{*}[\mathrm{ZnHL}]{$^{+}+\mathrm{e}^{-}=\mathrm{Zn}\left(\mathrm{HL}^{\bullet}\right)$} & Optimized & -1.8110 & 0.3166 & 0.0070 \\
\hline & Upper Limit & -1.8113 & 0.3166 & 0.0070 \\
\hline & Lower Limit & -1.8107 & 0.3166 & 0.0070 \\
\hline \multirow[t]{3}{*}[\mathrm{ZnH}_{2}\mathbf{L}]{$^{2+}+\mathrm{e}^{-}=\left[\mathbf{Z n}\left(\mathbf{H}_{2} \mathbf{L}^{\bullet}\right)\right]^{+}$} & Optimized & -1.5872 & 0.3166 & 0.0070 \\
\hline & Upper Limit & -1.5874 & 0.3166 & 0.0070 \\
\hline & Lower Limit & -1.5870 & 0.3166 & 0.0070 \\
\hline Chemical Steps & $\begin{array}{l}99 \% \\
\text { Confidence }\end{array}$ & $\mathbf{K}_{\mathrm{eq}}$ & $\mathbf{k}_{\mathbf{f}}$ & \\
\hline \multirow[t]{3}{*}{$\mathbf{Z n L}+\mathbf{H}^{+}=[\mathbf{Z n H L}]^{+}$} & Optimized & $2.42 \mathrm{E}+05$ & $1.28 \mathrm{E}+13$ & \\
\hline & Upper Limit & $3.42 \mathrm{E}+06$ & $6.40 \mathrm{E}+13$ & \\
\hline & Lower Limit & $1.91 \mathrm{E}+05$ & $1.94 \mathrm{E}+12$ & \\
\hline \multirow[t]{3}{*}[\mathrm{ZnHL}]{$^{+}+\mathbf{H}^{+}=\left[\mathrm{ZnH}_{2} \mathbf{L}\right]^{2+}$} & Optimized & $8.80 \mathrm{E}+00$ & $4.06 \mathrm{E}+06$ & \\
\hline & Upper Limit & $8.93 \mathrm{E}+00$ & $6.92 \mathrm{E}+06$ & \\
\hline & Lower Limit & $8.68 \mathrm{E}+00$ & $1.20 \mathrm{E}+06$ & \\
\hline \multirow[t]{3}{*}{$\mathbf{Z n}\left(\mathbf{H L}^{\bullet}\right)+\mathbf{Z n}\left(\mathbf{H L}^{\bullet}\right)=\mathbf{H}_{2}$} & Optimized & $4.89 \mathrm{E}+10$ & $3.09 \mathrm{E}+09$ & \\
\hline & Upper Limit & $4.96 \mathrm{E}+10$ & $6.51 \mathrm{E}+09$ & \\
\hline & Lower Limit & $4.80 \mathrm{E}+10$ & $6.45 \mathrm{E}+08$ & \\
\hline \multirow[t]{3}{*}{$\mathbf{Z n}\left(\mathrm{HL}^{\bullet}\right)+\left[\mathrm{Zn}\left(\mathbf{H}_{2} \mathbf{L}^{\bullet}\right)\right]^{+}=\mathbf{H}_{2}$} & Optimized & $9.07 \mathrm{E}+07$ & $2.47 \mathrm{E}+10$ & \\
\hline & Upper Limit & $9.19 \mathrm{E}+07$ & $3.95 \mathrm{E}+10$ & \\
\hline & Lower Limit & $8.90 \mathrm{E}+07$ & $9.94 \mathrm{E}+09$ & \\
\hline \multirow[t]{3}{*}[\mathbf{Zn}(\mathbf{H}_{2}\mathbf{L}^{\bullet})]{$^{+}=\mathbf{Z n}\left(\mathbf{H L}^{\bullet}\right)+\mathbf{H}^{+}$} & Calculated & $1.87 \mathrm{E}-05$ & $8.14 \mathrm{E}+04$ & \\
\hline & Upper Limit & $1.87 \mathrm{E}-05$ & $1.07 \mathrm{E}+05$ & \\
\hline & Lower Limit & $1.87 \mathrm{E}-05$ & $2.82 \mathrm{E}+04$ & \\
\hline
\end{tabular}


Table A5. $\mathrm{Znl}^{1}$ Optimized parameters of data fitting, $12 \mathrm{mM}$ [acid]; $v=1.0-5.0 \mathrm{~V} / \mathrm{s} \mathrm{vs} \mathrm{Fc}^{+} / \mathrm{Fc}$

\begin{tabular}{|c|c|c|c|c|}
\hline Charge-transfer Steps & $\begin{array}{l}99 \% \\
\text { Confidence }\end{array}$ & $\mathbf{E}^{\mathbf{0}}$ & $\alpha$ & $\mathbf{k}_{\mathbf{s}}$ \\
\hline \multirow[t]{3}{*}[\mathrm{ZnHL}]{$^{+}+\mathrm{e}^{-}=\mathbf{Z n}\left(\mathrm{HL}^{\bullet}\right)$} & Optimized & -1.8004 & 0.3166 & 0.007 \\
\hline & Upper Limit & -1.8010 & 0.3166 & 0.007 \\
\hline & Lower Limit & -1.8000 & 0.3166 & 0.007 \\
\hline \multirow{3}{*}[\mathbf{ZnH}_{2}\mathbf{L}]{$^{2+}+\mathrm{e}^{-}=\left[\mathbf{Z n}\left(\mathbf{H}_{2} \mathbf{L}^{\bullet}\right)\right]^{+}$} & Optimized & -1.5264 & 0.3166 & 0.007 \\
\hline & Upper Limit & -1.5274 & 0.3166 & 0.007 \\
\hline & Lower Limit & -1.5254 & 0.3166 & 0.007 \\
\hline Chemical Steps & $\begin{array}{l}99 \% \\
\text { Confidence }\end{array}$ & $\mathbf{K}_{\mathrm{eq}}$ & $\mathbf{k}_{\mathbf{f}}$ & \\
\hline \multirow[t]{3}{*}{$\mathbf{Z n L}+\mathbf{H}^{+}=[\mathbf{Z n H L}]^{+}$} & Optimized & 1364 & $3.20 \mathrm{E}+13$ & \\
\hline & Upper Limit & 1442.8 & $8.72 \mathrm{E}+15$ & \\
\hline & Lower Limit & 1285.2 & $8.65 \mathrm{E}+12$ & \\
\hline \multirow[t]{3}{*}[\mathrm{ZnHL}]{$^{+}+\mathbf{H}^{+}=\left[\mathrm{ZnH}_{2} \mathrm{~L}\right]^{2+}$} & Optimized & 13.438 & $3.06 \mathrm{E}+09$ & \\
\hline & Upper Limit & 13.6 & $9.83 \mathrm{E}+10$ & \\
\hline & Lower Limit & 13.276 & $9.22 \mathrm{E}+08$ & \\
\hline \multirow[t]{3}{*}{$\mathrm{Zn}\left(\mathrm{HL}^{\bullet}\right)+\mathrm{Zn}\left(\mathrm{HL}^{\bullet}\right)=\mathrm{H}_{2}$} & Optimized & $3.69 \mathrm{E}+11$ & $4.57 \mathrm{E}+08$ & \\
\hline & Upper Limit & $3.69 \mathrm{E}+11$ & $5.57 \mathrm{E}+08$ & \\
\hline & Lower Limit & $3.68 \mathrm{E}+11$ & $3.57 \mathrm{E}+08$ & \\
\hline \multirow[t]{3}{*}{$\mathbf{Z n}\left(\mathrm{HL}^{\bullet}\right)+\left[\mathbf{Z n}\left(\mathbf{H}_{2} \mathbf{L}^{\bullet}\right)\right]^{+}=\mathbf{H}_{2}$} & Optimized & $4.44 \mathrm{E}+08$ & $2.72 \mathrm{E}+11$ & \\
\hline & Upper Limit & $4.46 \mathrm{E}+08$ & $3.84 \mathrm{E}+11$ & \\
\hline & Lower Limit & $4.42 \mathrm{E}+08$ & $1.61 \mathrm{E}+11$ & \\
\hline \multirow[t]{3}{*}[\mathbf{Zn}(\mathbf{H}_{2}\mathbf{L}^{\bullet})]{$^{+}=\mathbf{Z n}\left(\mathbf{H L}^{\bullet}\right)+\mathbf{H}^{+}$} & Calculated & $1.74 \mathrm{E}-06$ & 2414 & \\
\hline & Upper Limit & $1.74 \mathrm{E}-06$ & 2414 & \\
\hline & Lower Limit & $1.74 \mathrm{E}-06$ & 2414 & \\
\hline
\end{tabular}


Table A6. $\mathrm{ZnL}^{1}$ Optimized parameters of data fitting, $6 \mathrm{mM}[\mathrm{acid}] ; v=0.2-0.5 \mathrm{~V} / \mathrm{s} \mathrm{vs} \mathrm{Fc}^{+} / \mathrm{Fc}$

\begin{tabular}{|c|c|c|c|c|}
\hline \multirow[b]{2}{*}{ Charge-transfer Steps } & \multicolumn{4}{|l|}{$99 \%$} \\
\hline & Confidence & $\mathbf{E}^{0}$ & $\alpha$ & $\mathbf{k}_{\mathrm{s}}$ \\
\hline \multirow[t]{4}{*}[\mathrm{ZnHL}]{$^{+}+\mathrm{e}^{-}=\mathbf{Z n}\left(\mathrm{HL}^{\bullet}\right)$} & Optimized & -1.8431 & 0.3166 & 0.007 \\
\hline & Upper Limit & -1.8562 & 0.3166 & 0.007 \\
\hline & Lower & & & \\
\hline & Limit & -1.8333 & 0.3166 & 0.007 \\
\hline \multirow{4}{*}[\mathrm{ZnH}_{2}\mathbf{L}]{$^{2+}+\mathrm{e}^{-}=\left[\mathrm{Zn}\left(\mathbf{H}_{2} \mathbf{L}^{\bullet}\right)\right]^{+}$} & Optimized & -1.6958 & 0.3166 & 0.007 \\
\hline & Upper Limit & -1.7939 & 0.3166 & 0.007 \\
\hline & Lower & & & \\
\hline & Limit & -1.5977 & 0.3166 & 0.007 \\
\hline \multirow{2}{*}{ Chemical Steps } & $99 \%$ & & & \\
\hline & Confidence & $\mathbf{K}_{\mathrm{eq}}$ & $\mathbf{k}_{\mathbf{f}}$ & \\
\hline \multirow[t]{4}{*}{$\mathbf{Z n L}+\mathbf{H}^{+}=[\mathbf{Z n H L}]^{+}$} & Optimized & 32000 & $5.00 \mathrm{E}+11$ & \\
\hline & Upper Limit & $6.68 \mathrm{E}+05$ & $1.43 \mathrm{E}+12$ & \\
\hline & Lower & & & \\
\hline & Limit & $6.04 \mathrm{E}+03$ & $1.04 \mathrm{E}+10$ & \\
\hline \multirow[t]{4}{*}[\mathrm{ZnHL}]{$^{+}+\mathrm{H}^{+}=\left[\mathrm{ZnH}_{2} \mathrm{~L}\right]^{2+}$} & Optimized & 19.942 & $2.86 \mathrm{E}+02$ & \\
\hline & Upper Limit & 95.717 & $2.86 \mathrm{E}+03$ & \\
\hline & Lower & & & \\
\hline & Limit & 0.55833 & $2.23 \mathrm{E}+01$ & \\
\hline \multirow[t]{4}{*}{$\mathrm{Zn}\left(\mathrm{HL}^{\bullet}\right)+\mathrm{Zn}\left(\mathrm{HL}^{\bullet}\right)=\mathrm{H}_{2}$} & Optimized & $7.28 \mathrm{E}+09$ & $2.00 \mathrm{E}+08$ & \\
\hline & Upper Limit & $1.05 \mathrm{E}+11$ & $1.35 \mathrm{E}+12$ & \\
\hline & Lower & & & \\
\hline & Limit & $9.08 \mathrm{E}+08$ & $1.35 \mathrm{E}+06$ & \\
\hline \multirow[t]{3}{*}{$\mathbf{Z n}\left(\mathbf{H L}^{\bullet}\right)+\left[\mathbf{Z n}\left(\mathbf{H}_{2} \mathbf{L}^{\bullet}\right)\right]^{+}=\mathbf{H}_{2}$} & Optimized & $8.58 \mathrm{E}+07$ & $2.00 \mathrm{E}+12$ & \\
\hline & Upper Limit & $1.28 \mathrm{E}+09$ & $1.49 \mathrm{E}+13$ & \\
\hline & Lower & $1.11 \mathrm{E}+06$ & $1.09 \mathrm{E}+10$ & \\
\hline
\end{tabular}




\begin{tabular}{llll}
{$\left[\mathbf{Z n}\left(\mathbf{H}_{2} \mathbf{L}^{\bullet}\right)\right]^{+}=\mathbf{Z n}\left(\mathbf{H L}^{\bullet}\right)+\mathbf{H}^{+}$} & Limit & & \\
& Calculated & $1.55 \mathrm{E}-04$ & 4000 \\
& Upper Limit & $1.55 \mathrm{E}-04$ & 4754.6 \\
& Lower & & \\
& Limit & $1.55 \mathrm{E}-04$ & 3245.4 \\
\hline
\end{tabular}

\section{DigiElch Guide}

Obtain the $\mathrm{CV}$ of your complex at several scan rates, starting at different potentials, going from high to low and vice-versa, as well at different concentrations. In any event you will most likely need to go back and redo the experiment at some point. Generally, a concentration of $1 \mathrm{mM}$ catalyst with $0.1 \mathrm{M}$ supporting electrolyte will be sufficient to obtain a good CV.

Once you have a series of CVs that you wish to model, the first thing that you must do is export the potential and current values from the Gamry Analyst software. To do this, first click on the cyclic voltammetry tab, this will give a drop down menu. Then, click on "Export to DigiElch". Doing this will prompt you to save the data file, save as a .use file. Repeat for every individual voltammogram you wish to model. For example, if you were modeling catalytic reactions at a certain concentration of analyte, it would be a good idea to export CVs run over a range of scan rates, so that you have multiple data points to fit your model. 


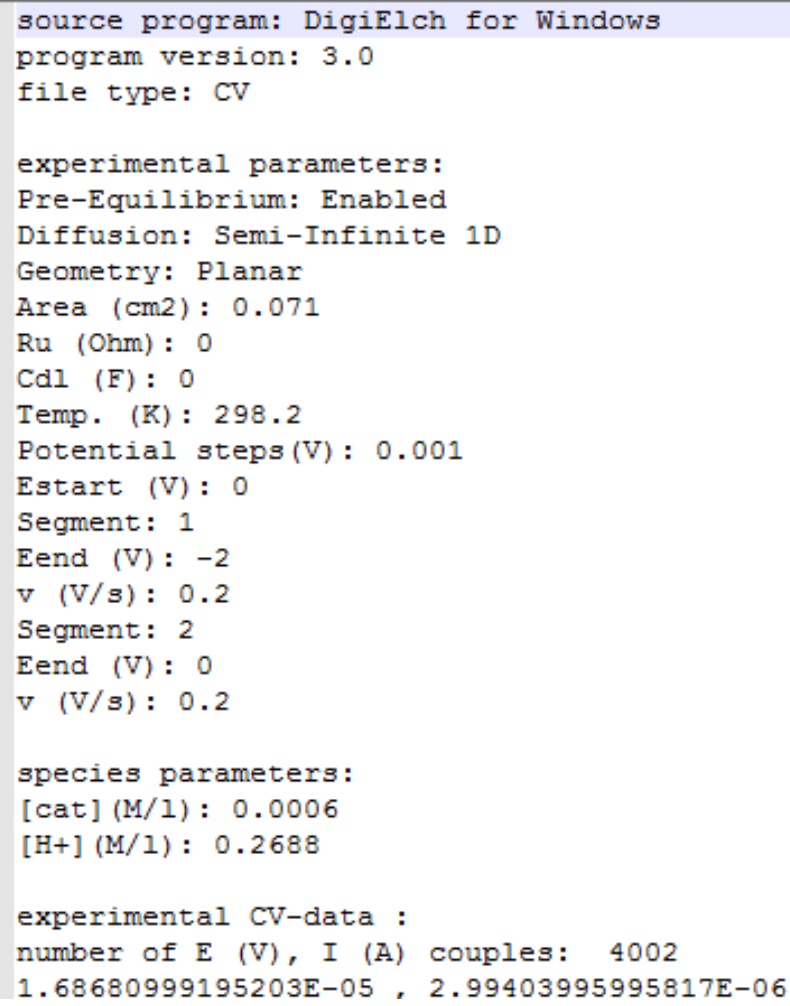

Figure A51. Screenshot of a .use file used for import into DigiElch.

After successfully exporting your data and converting it to a .use file, it is a good idea to make sure that all parameters have been exported correctly. To do this, open the .use file using notepad ++ and confirm that values of electrode area, species concentrations, potential step values, and CV segment descriptions are all correct and as intended (Figure A49). If they are not formatted correctly, the files will not import. In order to import to DigiElch, open DigiElch, click on the experiments tab, and click on the import icon at the top of the page. Doing so prompts the selection of files; select the appropriate .use files that you have previously prepared (Figure A50). 


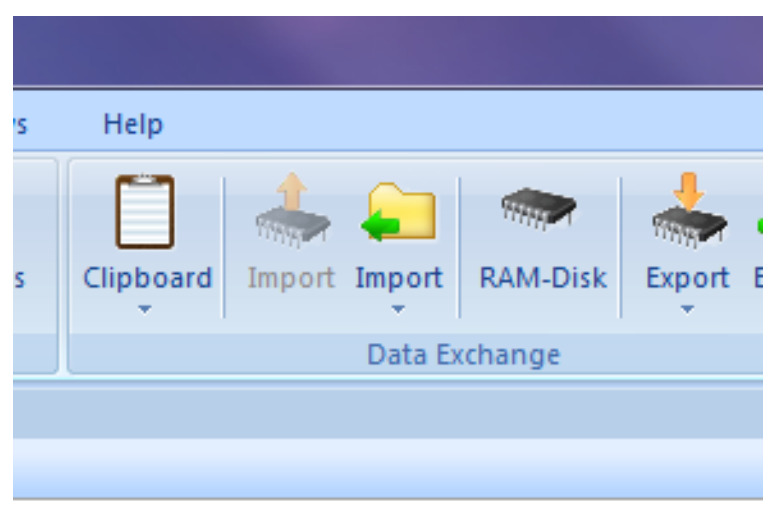

its

\section{A + exp for fitting}

\begin{tabular}{|c|c|c|c|}
\hline ce Concentrations & Experiments & Data Fitting & $\mathrm{Cl}$ \\
\hline
\end{tabular}

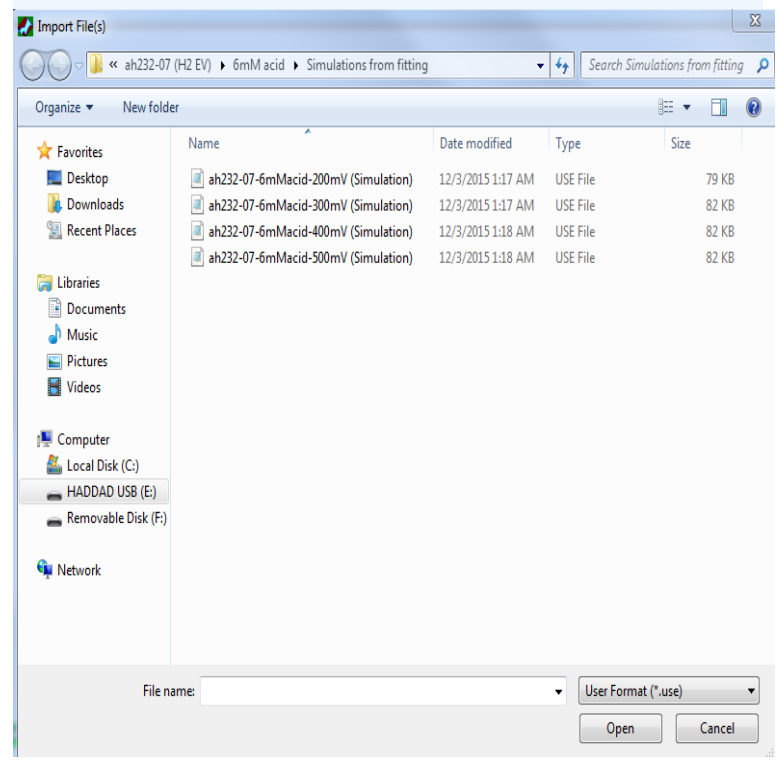

Figure A52. (Left) Screenshot showing how to import files to DigiElch using import icon. (Right) Sample .use files to import.

Next you will want to build a model to fit your experimental data. In DigiElch, click on the data fitting tab and click edit mechanism. This will prompt a new screen to appear reading, define mechanism and starting parameters. This window will contain three tabs: chemical reactions, surface reactions and simulation parameters. Within this there are a number of parameters to consider (Figure A51 and A52): $\alpha=$ the symmetry 
factor and 0.5 is initial programmed approximation. This variable affects the symmetry of the electron transfer reaction, a reasonable value will be between 0.2 and 0.7 . The variable, $\mathrm{k}_{\mathrm{s}}=$ heterogeneous reaction constant, changes overall peak shape, smaller value $\rightarrow$ wider the current peak will be. $E_{0}(V)$ : potential at which the electron transfer reaction is observed, this is often experimentally measured. $\mathrm{Ru}(\mathrm{Ohm})=$ changing this variable results in the slanted response in the current response of the $\mathrm{CV}$, it can be approximated by taking the first derivative of CV curve (Gamry Data Analysis). CdI(F) = capacitance how much the cell needs be charged before current begins to flow through the cell and results in making the current response wider. Changing results in either increase or decrease of separation between anodic and cathodic current values (thickness of CV essentially). Usually $1 \times 10^{-6}$ is a good starting place. Change by moving value up until simulation overlays well with experimental data. It is important to note that values of $\mathrm{k}_{\mathrm{s}}$ and $\alpha$ can be obtained by fitting CVs of a $1 \mathrm{e}^{-}$reduction/oxidation with just your complex and supporting electrolyte from data over a large range of scan rates.

Under the chemical reactions tab there will be three boxes reading charge-transfer reactions, chemical reactions, and species (Figure A52.) All charge transfer reactions are read as reductions by DigiElch (keep in mind if trying to model oxidations). You can adjust species concentrations and diffusion coefficents for all species. Values of $\mathrm{E}^{0}, \alpha$, and $\mathrm{k}_{\mathrm{s}}$ can be entered for each charge transfer step. Clicking on the charge transfer box prompts a new window to appear (Figure A53) which allows you to specify the type of reduction 1-9 electrons, enable absroption to the elctrode, or make charge-transfer events irreversible. For chemical reaction steps, you can enter and adjust the equilibrium constants and forward reaction rates. You can also make reactions irreversible by double 
clicking on the chemical reaction box and specifying this by changing the $=$ sign in the electron transfer equation to the $=>$ sign.

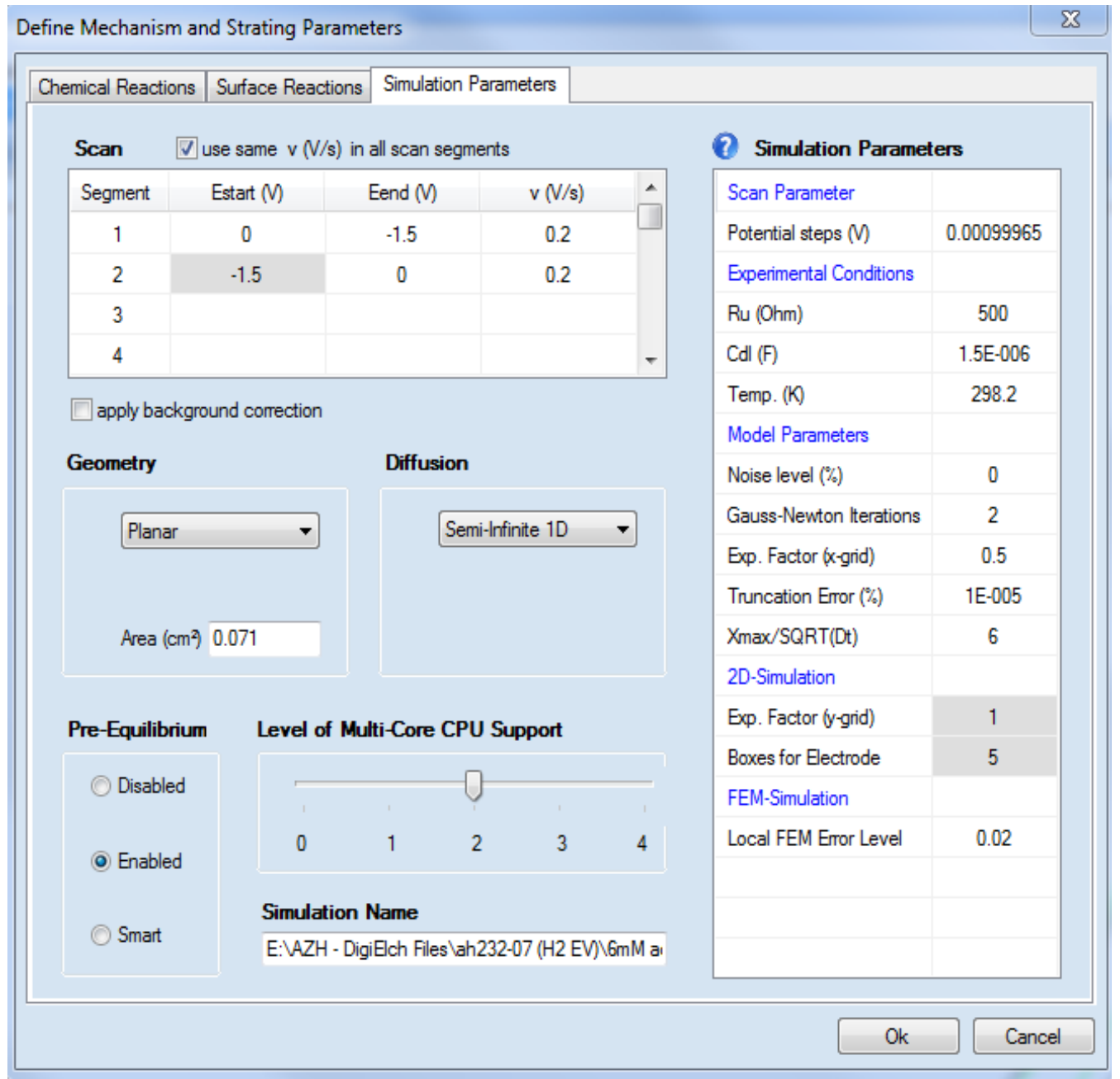

Figure A53. Screenshot of simulation parameters. Setting under Model parameters, 2D Simulation and FEM-Simulation do not need to be changed at all. 


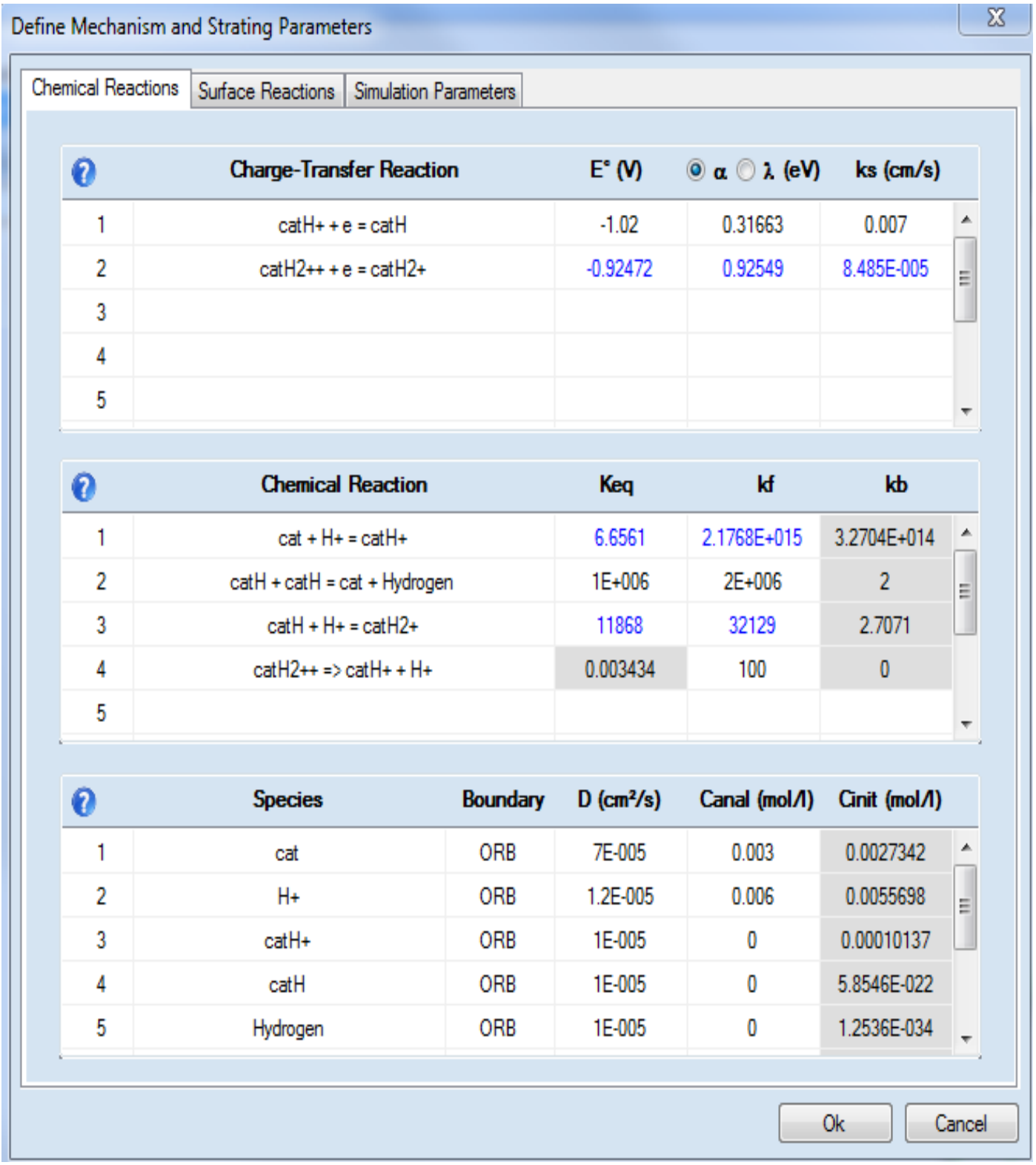

Figure A54. Screenshot of the chemical reactions tab. 


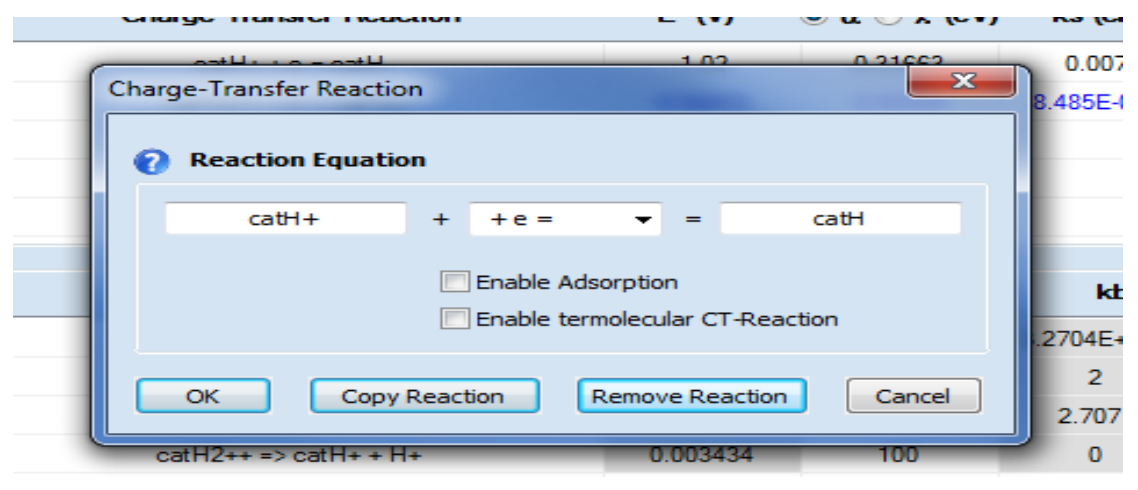

Figure A55. Screenshot of popup window obtained by double clicking on charge transfer reaction box.

After you have entered all parameters correctly, perform data fitting by clicking the fit data icon. Keep doing this and making small changes to mechanism or entered parameters until you get a good fit of experimental data. This sometimes takes weeks, so don't be discouraged if you do not succeed initially.

Once you have obtained a good fit of your experimental data, you must now export the simulated CVs. For example, if you fit your data over a scan rate range of $0.2-0.5 \mathrm{~V} / \mathrm{s}$, you will actually have 4 different simulated CVs—at each scan rate. You can scroll through by clicking the arrow reading next file. For each scan rate (performing one by one) click compare curves. The compare curve tab will be located at the top of the screen. Two new CVs will be present on this screen, one of your experimental and one of your simulated. Highlight the simulated CV and click export file. It will export and save as a .use file. Delete both curves from the compare curves section and go back to the data fitting section. Scroll to the next scan rate and repeat process by clicking compare curves. Once you have successfully exported all simulated files you can open them with 
notepad ++ and resave them as.$c s v$ files. This allows you to open the files in excel and then proceed to generate publication quality plots of $\mathrm{CV}$ data. 


\section{APPENDIX B: \\ EXPERIMENTAL AND SIMULATED CYCLIC VOLTAMMOGRAMS}




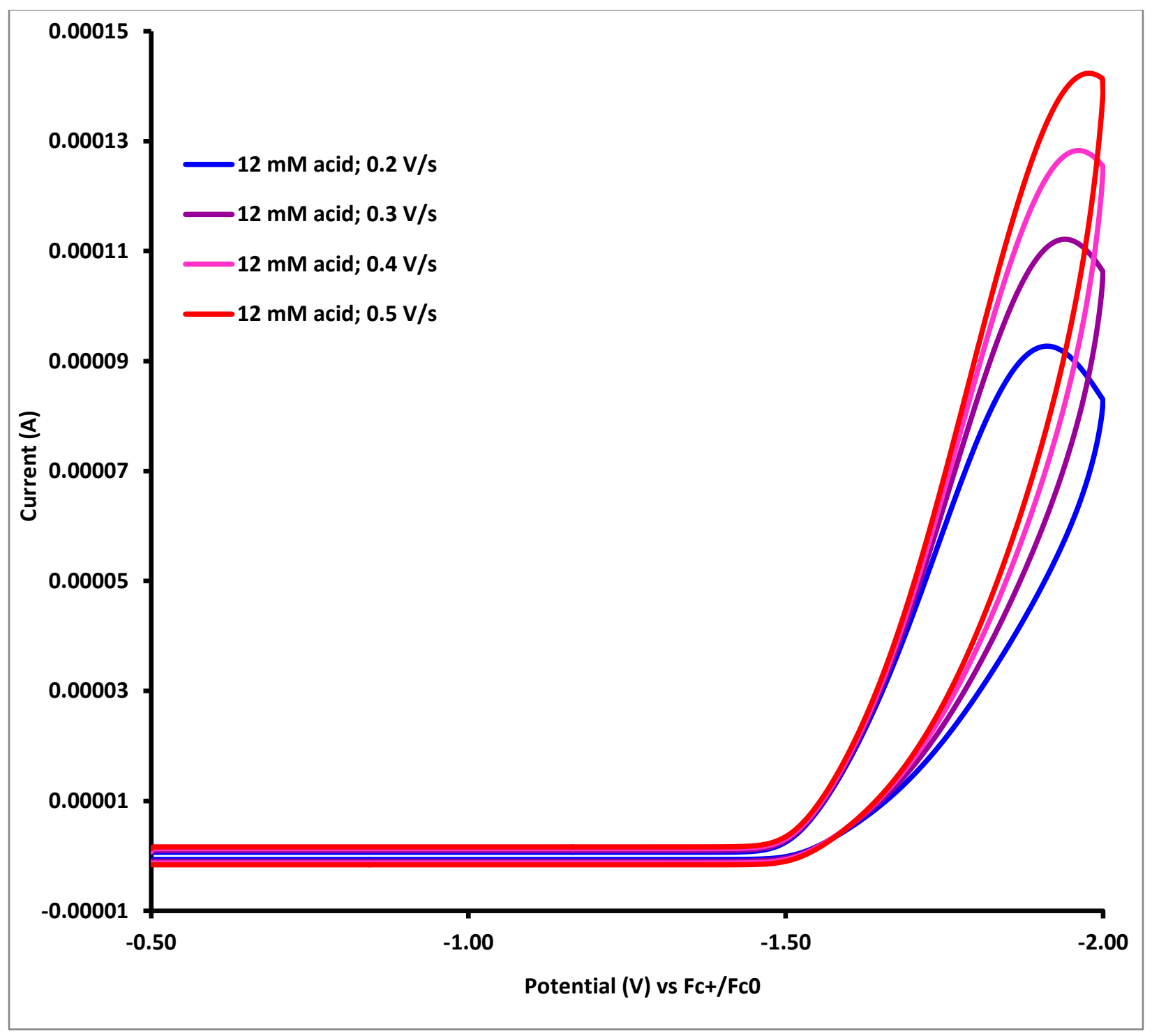

Figure B56. ZnL HER CV Simulations of experimental data; $12 \mathrm{mM}$ [acid]; $\mathrm{v}=0.2-0.5 \mathrm{~V} / \mathrm{s}$ vs $\mathrm{Fc}^{+} / \mathrm{Fc}$. Fit with mechanism parameters from Table A4. 


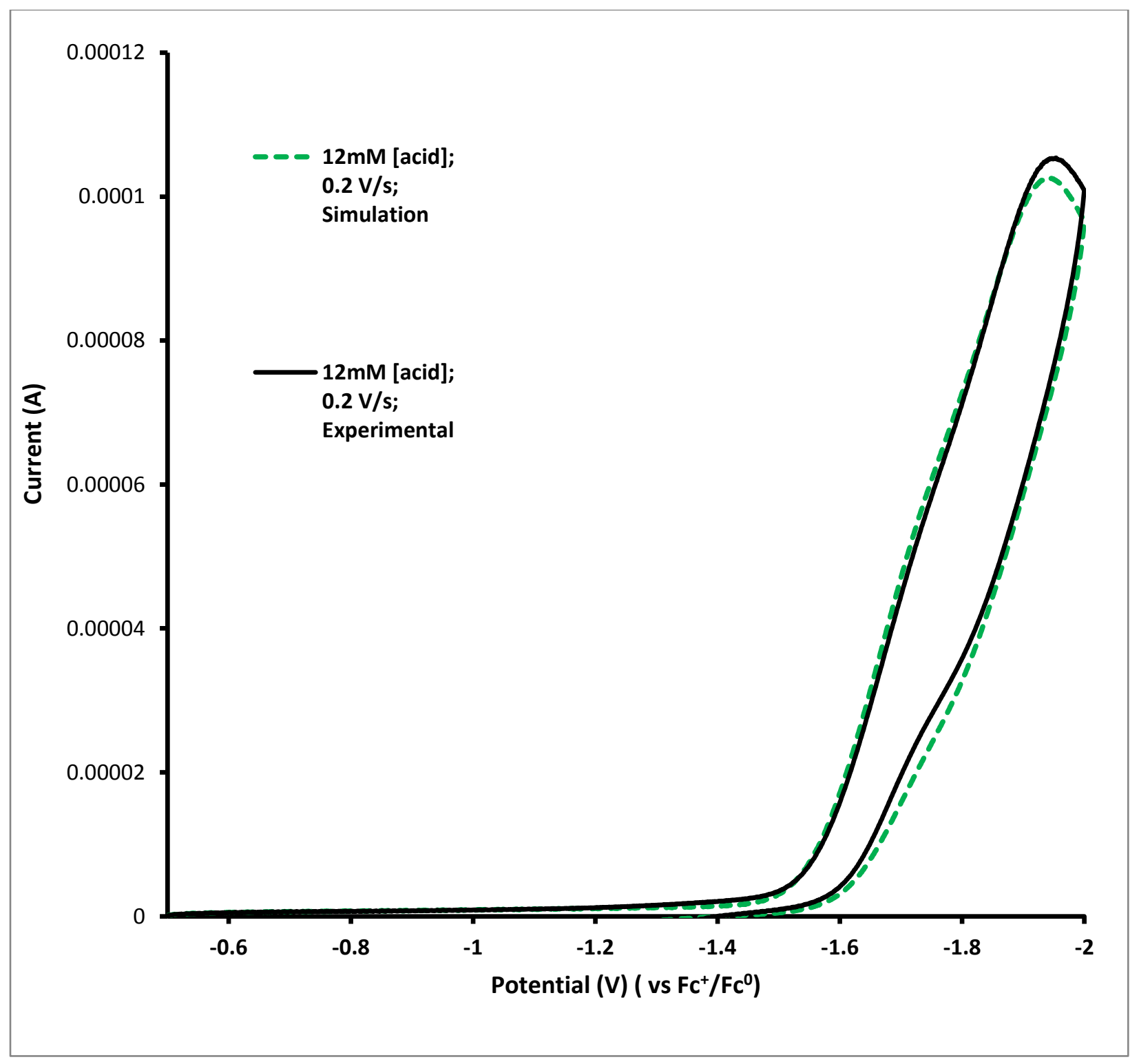

Figure B57. Comparison of experimental (black solid) and simulated (green dotted) cyclic voltammograms; $\mathrm{ZnL}^{1}$ HER. $12 \mathrm{mM}$ [acid]; $\mathrm{v}=0.2 \mathrm{~V} / \mathrm{s}$ vs $\mathrm{Fc}^{+} / \mathrm{Fc}$. Fit with mechanism parameters from Table A4. 


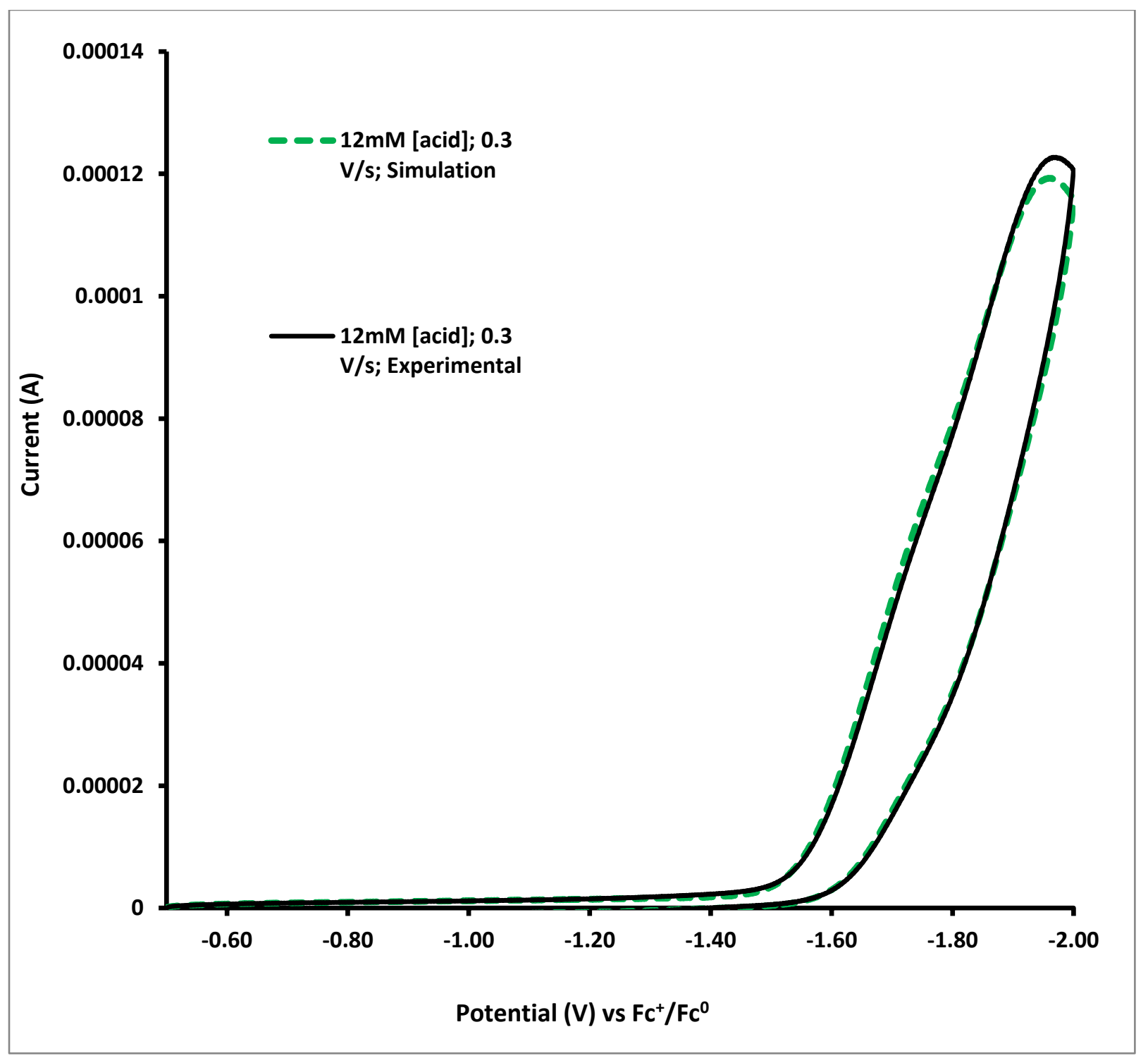

Figure B58. Comparison of experimental (black solid) and simulated (green dotted) cyclic voltammograms; $\mathrm{ZnL}^{1}$ HER. $12 \mathrm{mM}$ [acid]; $\mathrm{v}=0.3 \mathrm{~V} / \mathrm{s} \mathrm{vs}^{\mathrm{Fc}^{+}} / \mathrm{Fc}$. Fit with mechanism parameters from Table A4. 


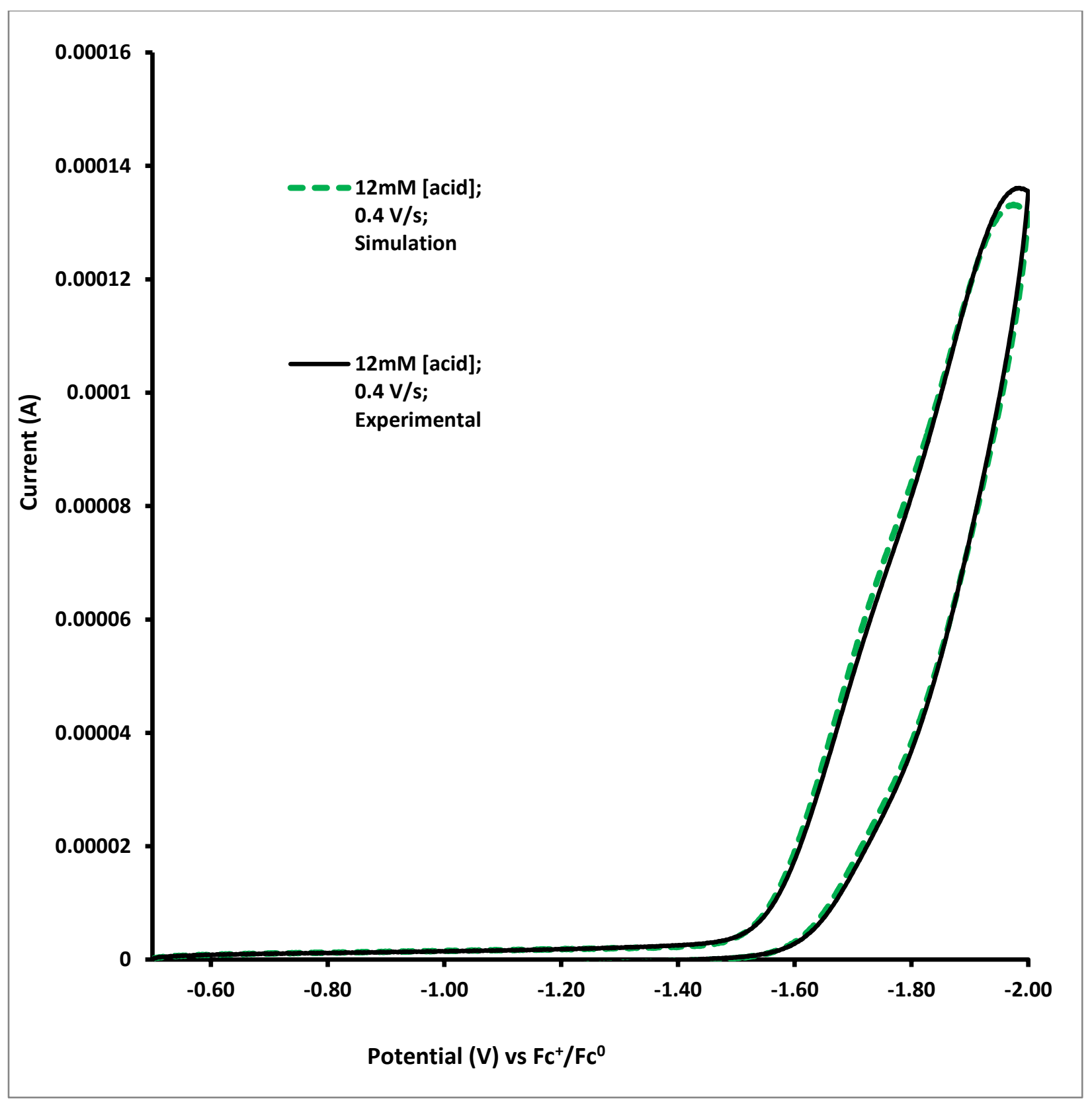

Figure B59. Comparison of experimental (black solid) and simulated (green dotted) cyclic voltammograms; $\mathrm{ZnL}^{1}$ HER. $12 \mathrm{mM}$ [acid]; $\mathrm{v}=0.4 \mathrm{~V} / \mathrm{s}$ vs $\mathrm{Fc}^{+} / \mathrm{Fc}$. Fit with mechanism parameters from Table A4. 


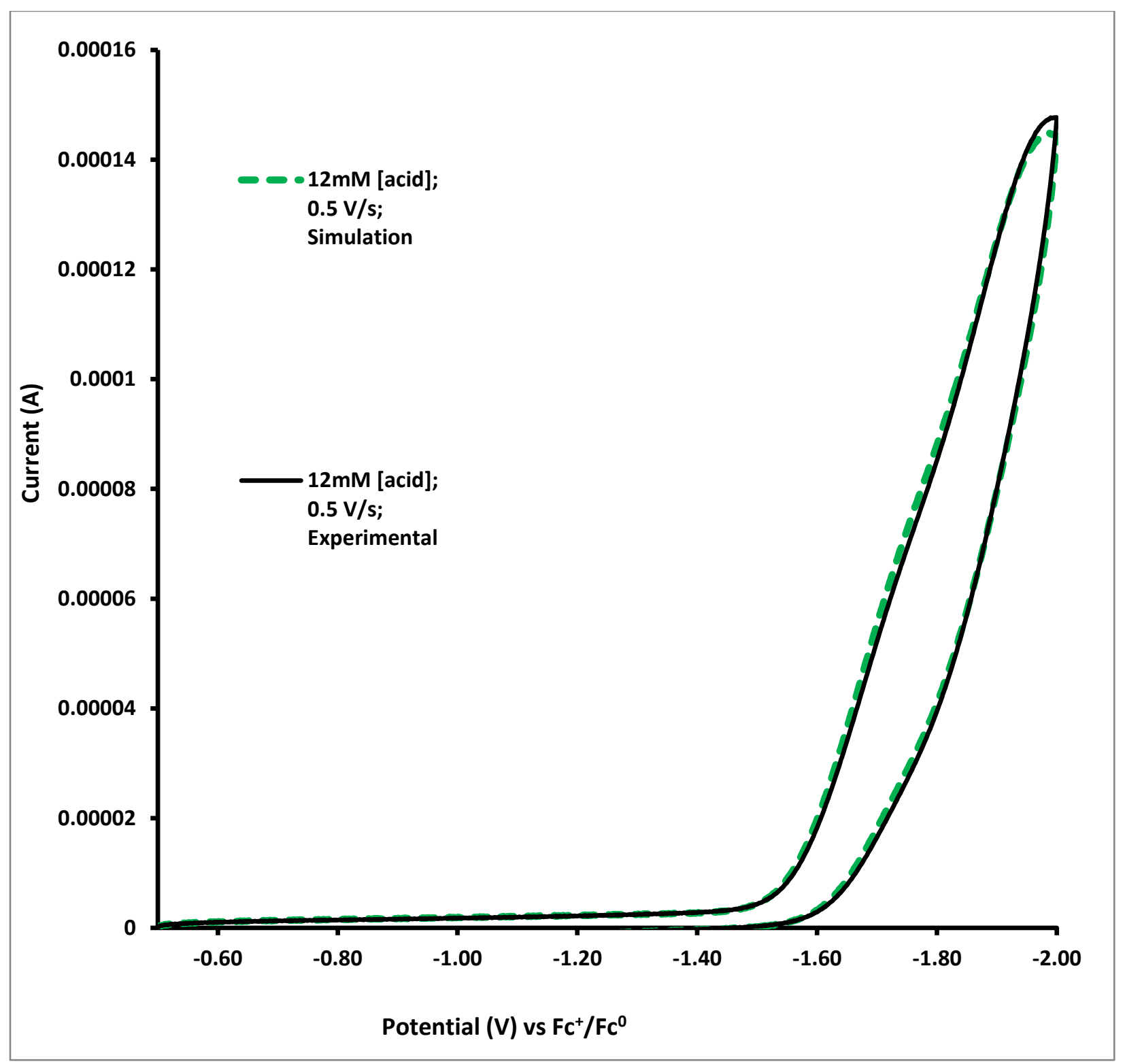

Figure B60. Comparison of experimental (black solid) and simulated (green dotted) cyclic voltammograms; $\mathrm{ZnL}^{1}$ HER. $12 \mathrm{mM}$ [acid]; $\mathrm{v}=0.5 \mathrm{~V} / \mathrm{s}$ vs $\mathrm{Fc}^{+} / \mathrm{Fc}$. Fit with mechanism parameters from Table A4. 


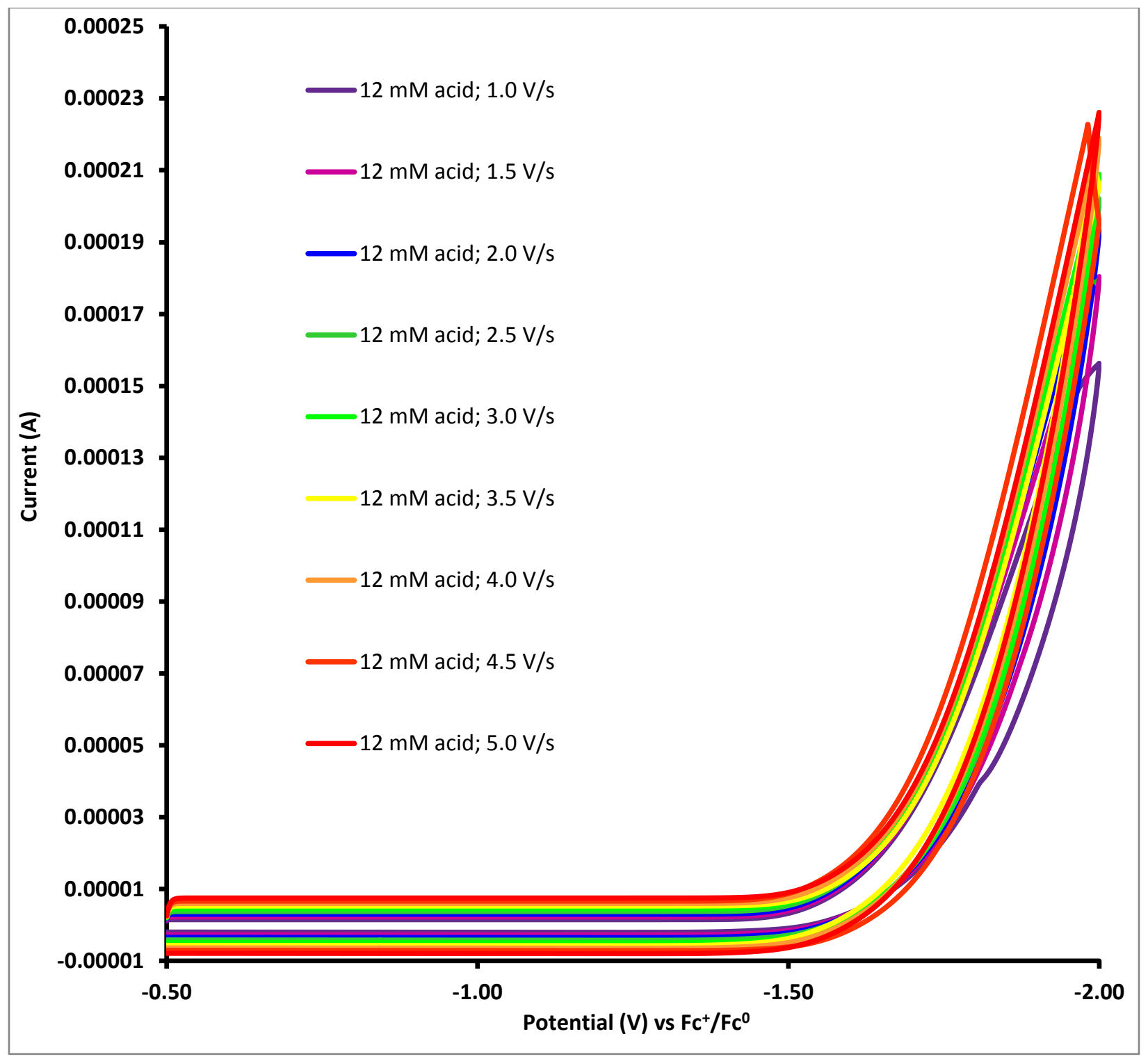

Figure B61. ZnL HER CV Simulations of experimental data; $12 \mathrm{mM}$ [acid]; v $=1.0-5.0 \mathrm{~V} / \mathrm{s}$ vs $\mathrm{Fc}^{+} / \mathrm{Fc}$. Fit with mechanism parameters from Table A5. 


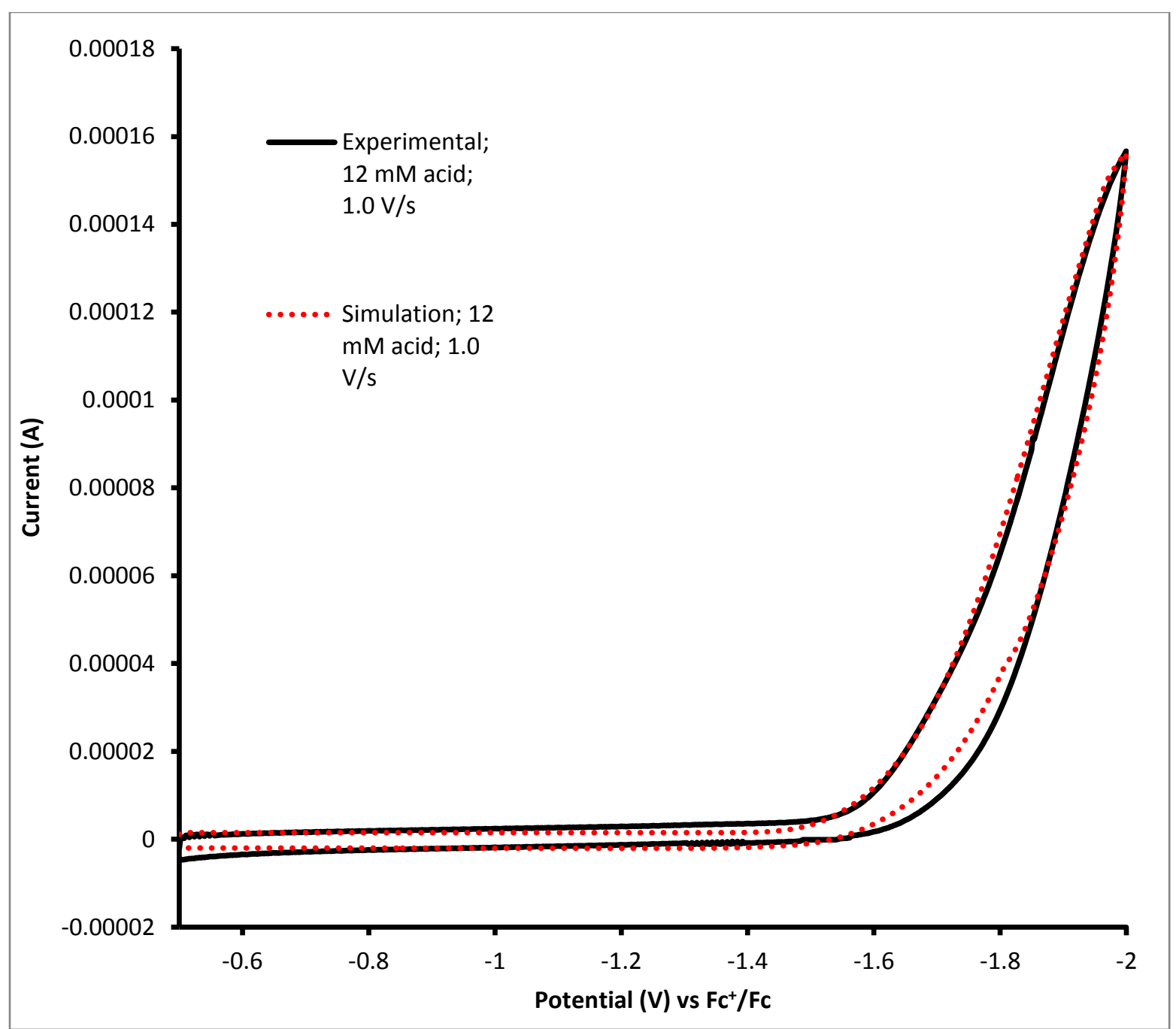

Figure B62. Comparison of experimental (black solid) and simulated (red dotted) cyclic voltammograms; $\mathrm{ZnL}^{1}$ HER. $12 \mathrm{mM}$ [acid]; $\mathrm{v}=1.0 \mathrm{~V} / \mathrm{s} \mathrm{vs} \mathrm{Fc}^{+} / \mathrm{Fc}$. Fit with mechanism parameters from Table A5. 


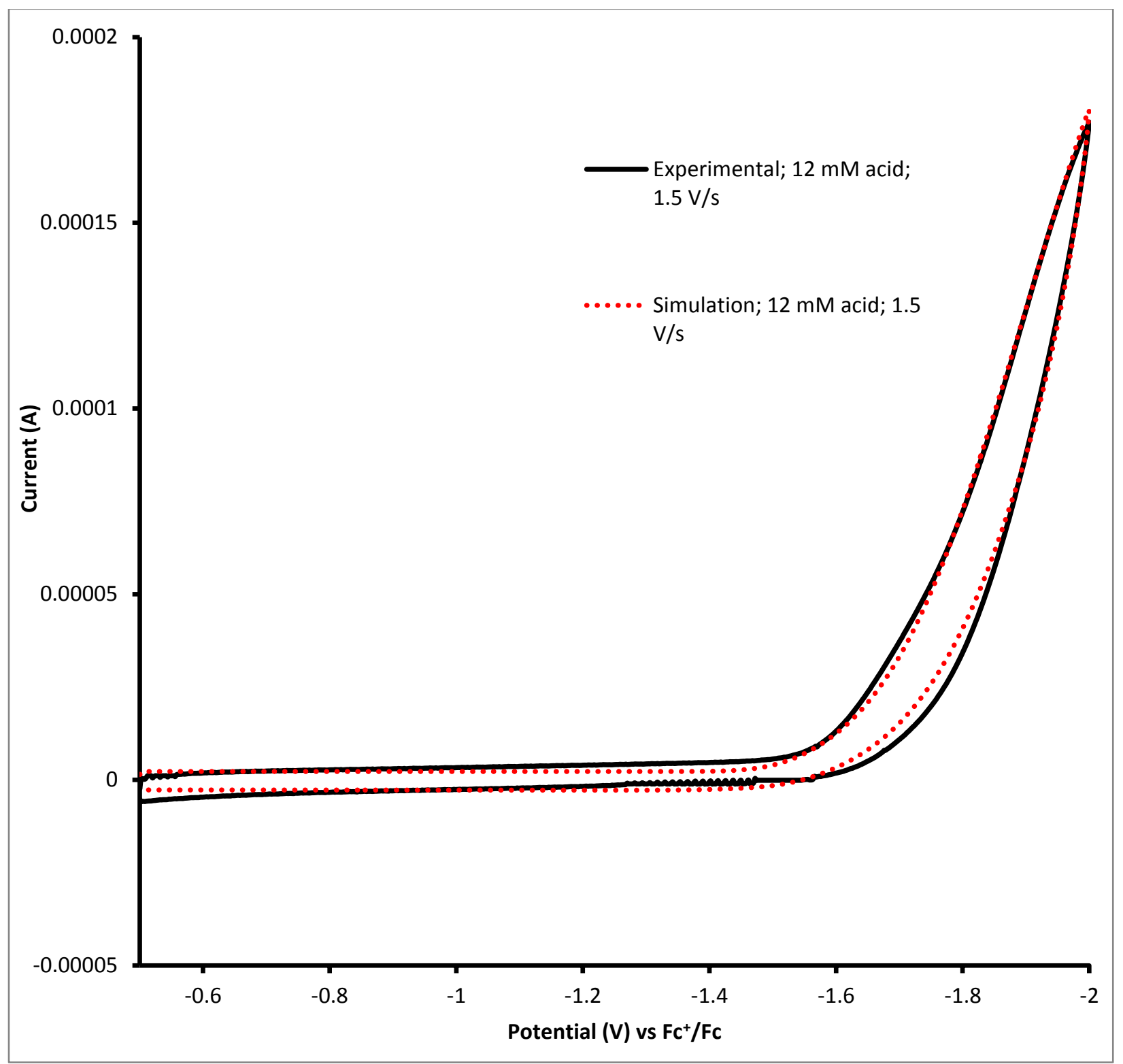

Figure B63. Comparison of experimental (black solid) and simulated (red dotted) cyclic voltammograms; $\mathrm{ZnL}^{1}$ HER. $12 \mathrm{mM}$ [acid]; $v=1.5 \mathrm{~V} / \mathrm{s} \mathrm{vs}^{2} \mathrm{Fc}^{+} / \mathrm{Fc}$. Fit with mechanism parameters from Table A5. 


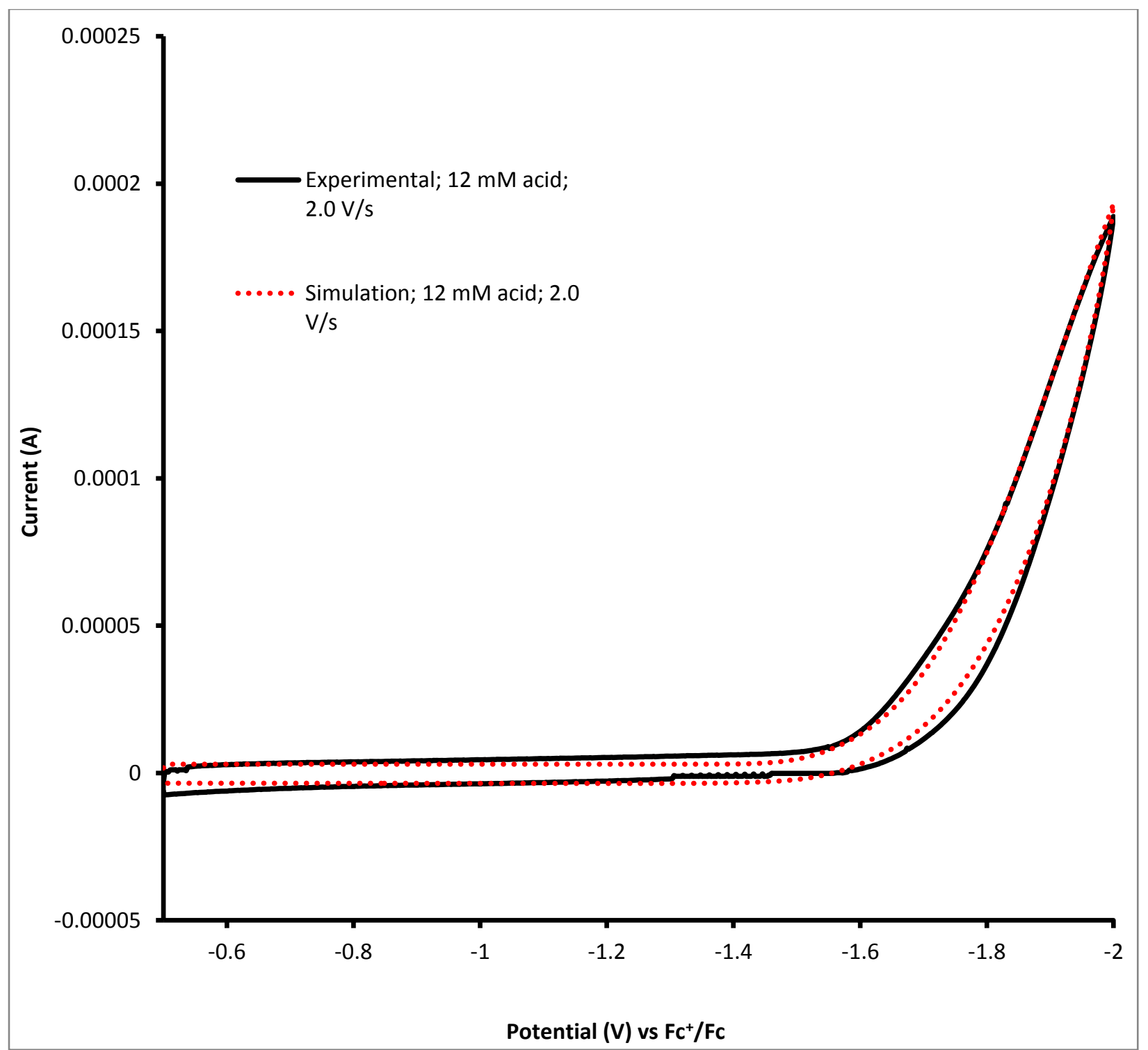

Figure B64. Comparison of experimental (black solid) and simulated (red dotted) cyclic voltammograms; $\mathrm{ZnL}^{1}$ HER. $12 \mathrm{mM}$ [acid]; $v=2.0 \mathrm{~V} / \mathrm{s} \mathrm{vs} \mathrm{Fc}^{+} / \mathrm{Fc}$. Fit with mechanism parameters from Table A5. 


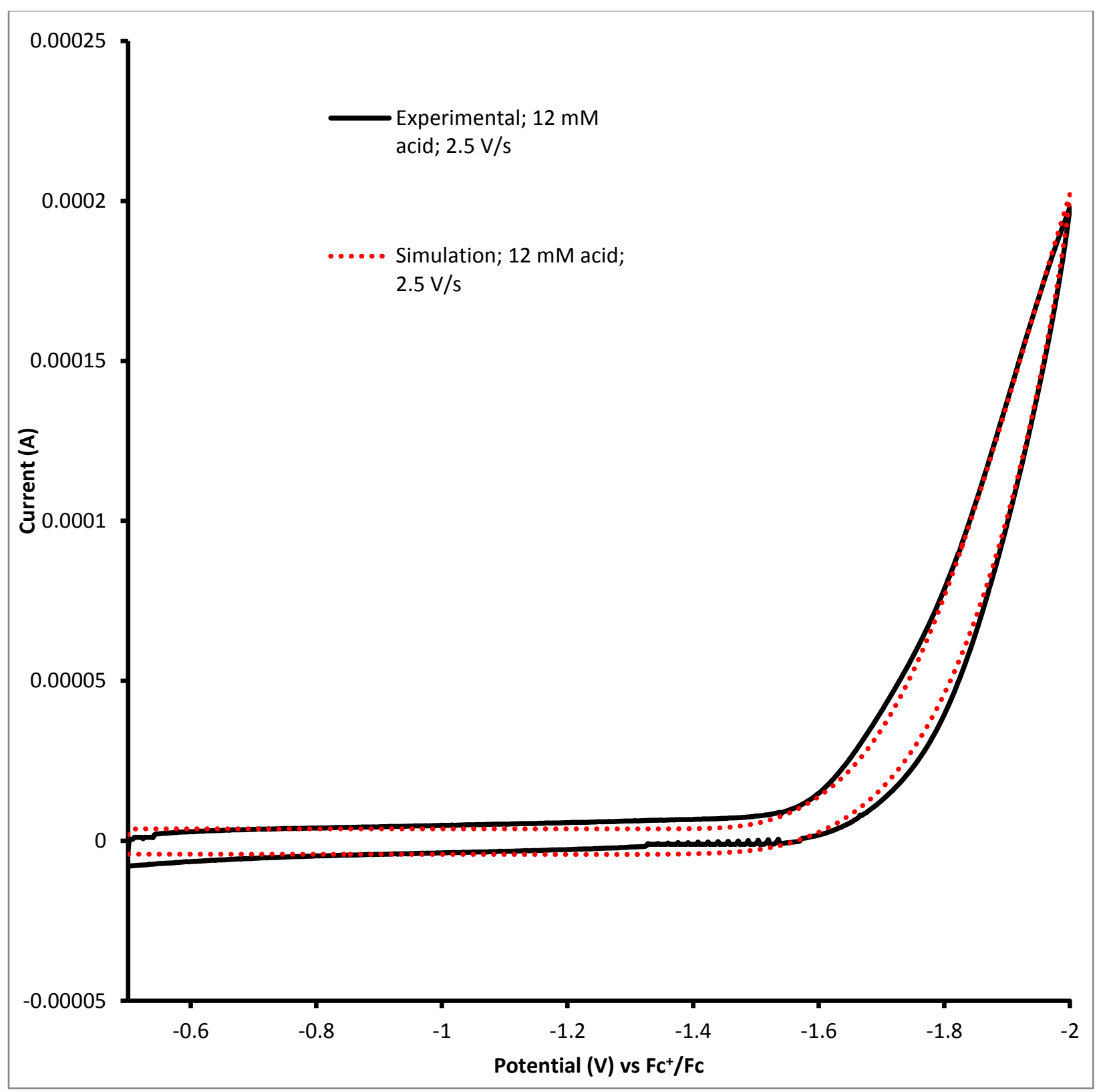

Figure B65. Comparison of experimental (black solid) and simulated (red dotted) cyclic voltammograms; $\mathrm{ZnL}^{1}$ HER. $12 \mathrm{mM}$ [acid]; $\mathrm{v}=2.5 \mathrm{~V} / \mathrm{s} \mathrm{vs} \mathrm{Fc}^{+} / \mathrm{Fc}$. Fit with mechanism parameters from Table A5. 


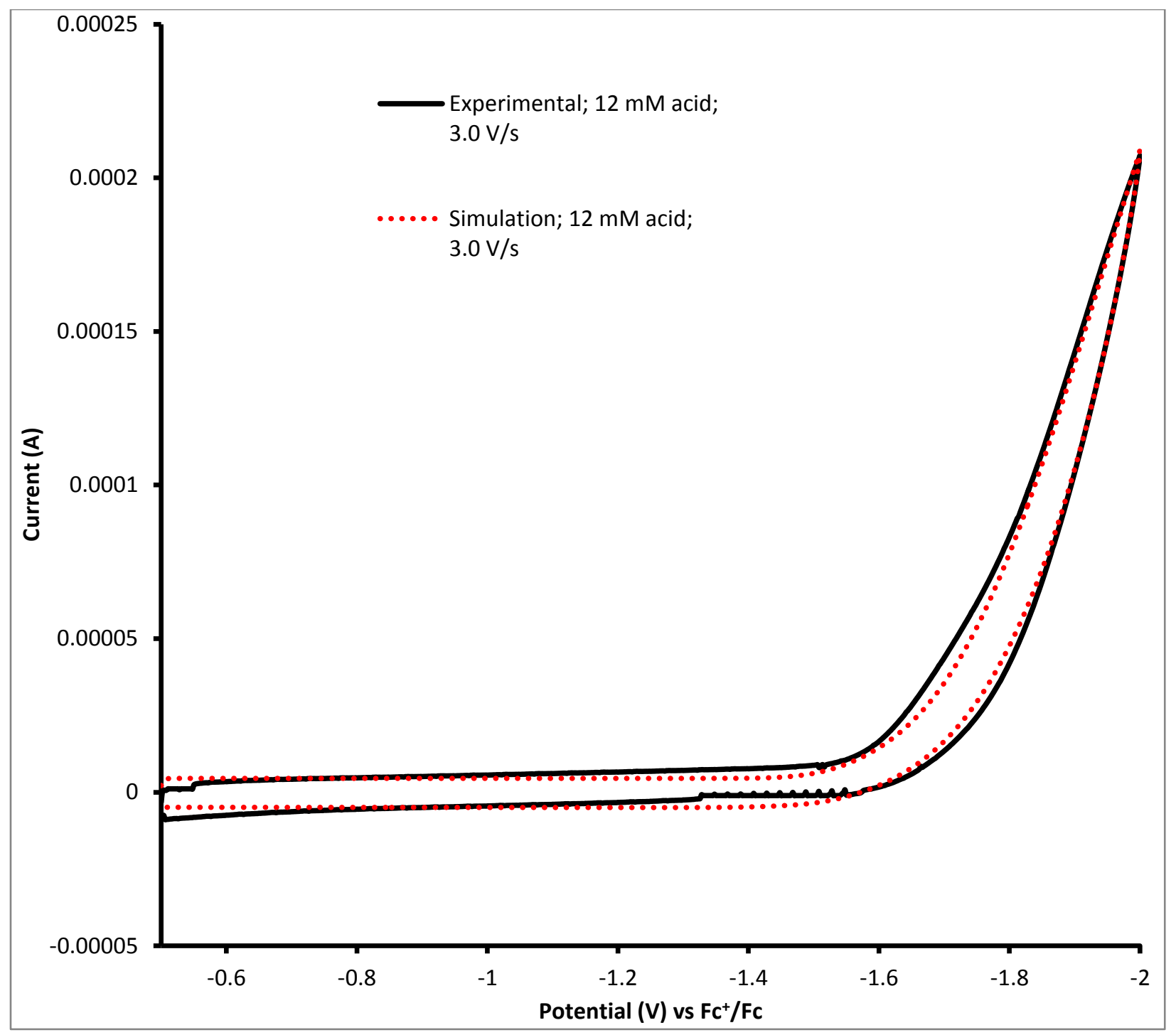

Figure B66. Comparison of experimental (black solid) and simulated (red dotted) cyclic voltammograms; $\mathrm{ZnL}^{1}$ HER. $12 \mathrm{mM}$ [acid]; $v=3.0 \mathrm{~V} / \mathrm{s} \mathrm{vs} \mathrm{Fc}^{+} / \mathrm{Fc}$. Fit with mechanism parameters from Table A5. 


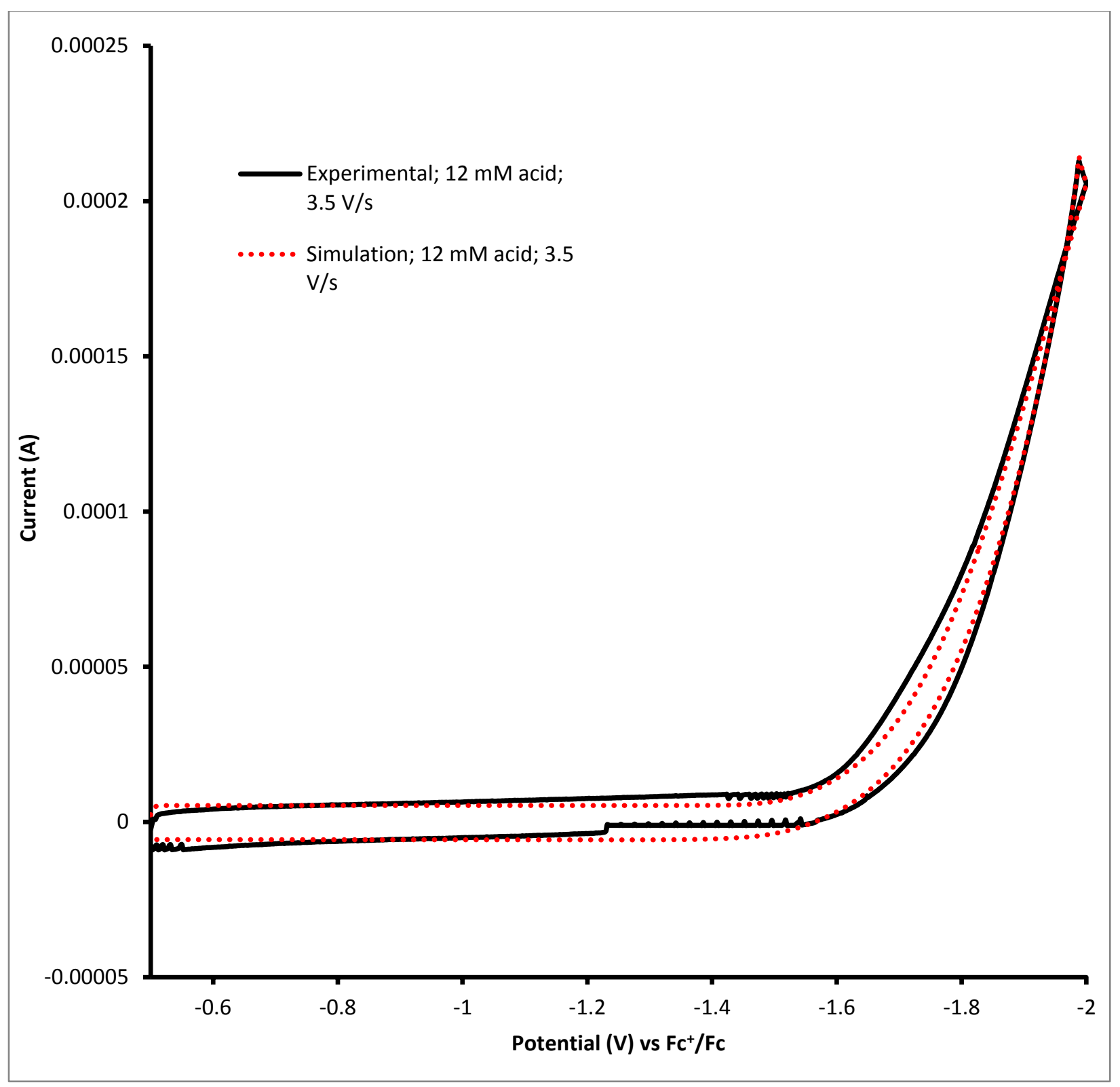

Figure B67. Comparison of experimental (black solid) and simulated (red dotted) cyclic voltammograms; $\mathrm{ZnL}^{1}$ HER. $12 \mathrm{mM}$ [acid]; $\mathrm{v}=3.5 \mathrm{~V} / \mathrm{s} \mathrm{vs} \mathrm{Fc}^{+} / \mathrm{Fc}$. Fit with mechanism parameters from Table A5. 


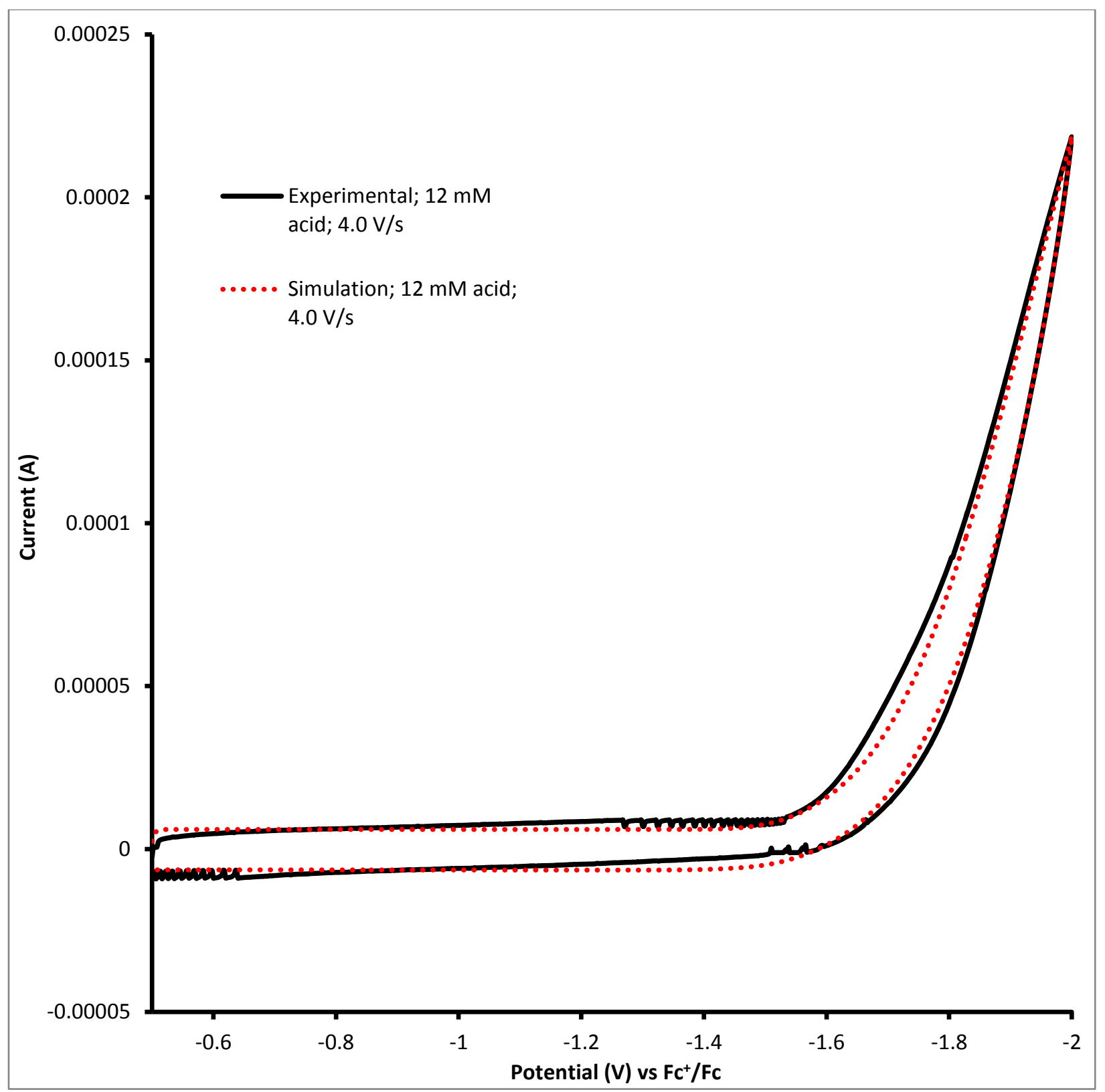

Figure B68. Comparison of experimental (black solid) and simulated (red dotted) cyclic voltammograms; $\mathrm{ZnL}^{1}$ HER. $12 \mathrm{mM}$ [acid]; $v=4.0 \mathrm{~V} / \mathrm{s} \mathrm{vs} \mathrm{Fc}^{+} / \mathrm{Fc}$. Fit with mechanism parameters from Table A5. 


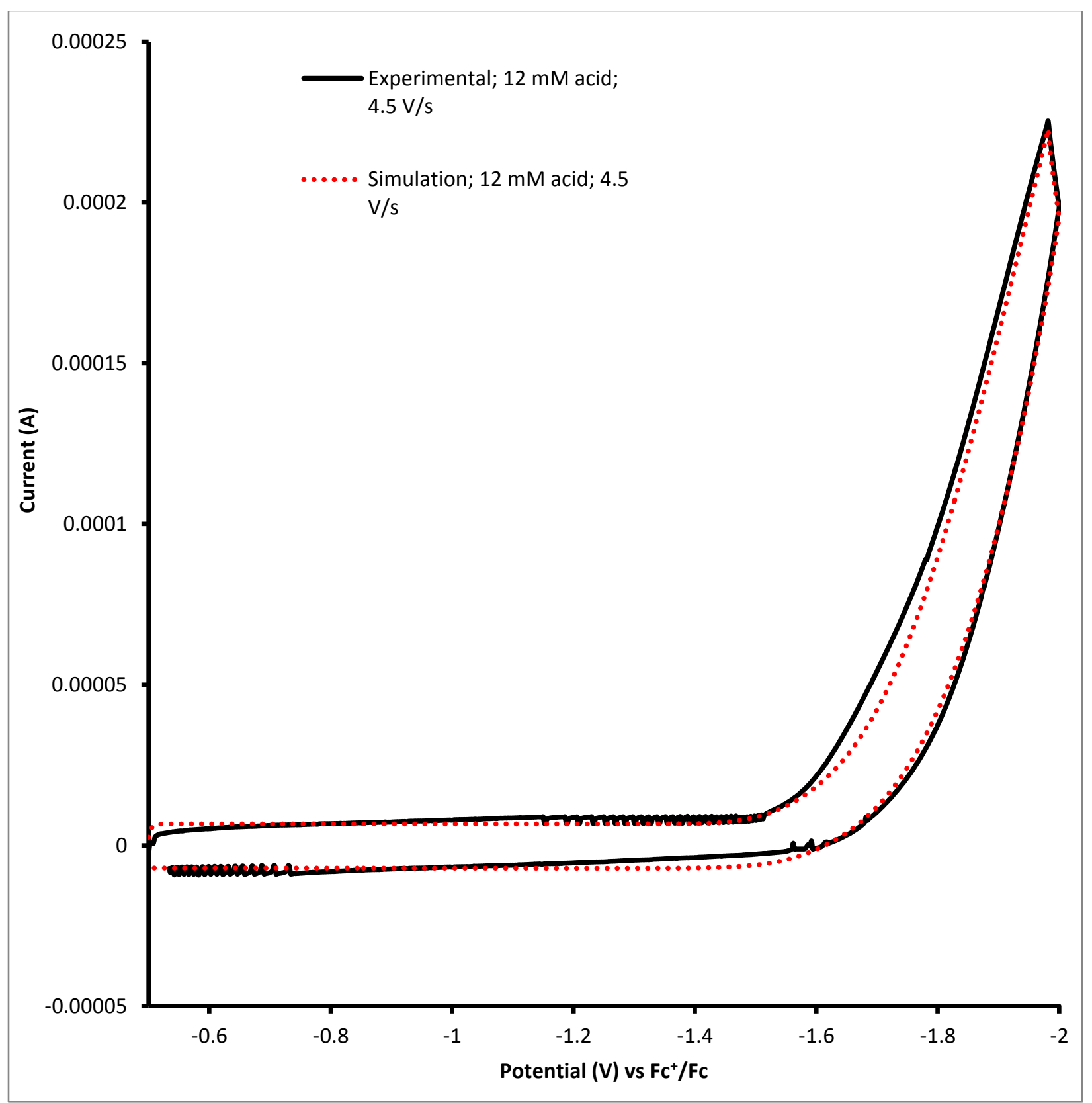

Figure B69. Comparison of experimental (black solid) and simulated (red dotted) cyclic voltammograms; $\mathrm{ZnL}^{1}$ HER. $12 \mathrm{mM}$ [acid]; $\mathrm{v}=4.5 \mathrm{~V} / \mathrm{s} \mathrm{vs} \mathrm{Fc}^{+} / \mathrm{Fc}$. Fit with mechanism parameters from Table A5. 


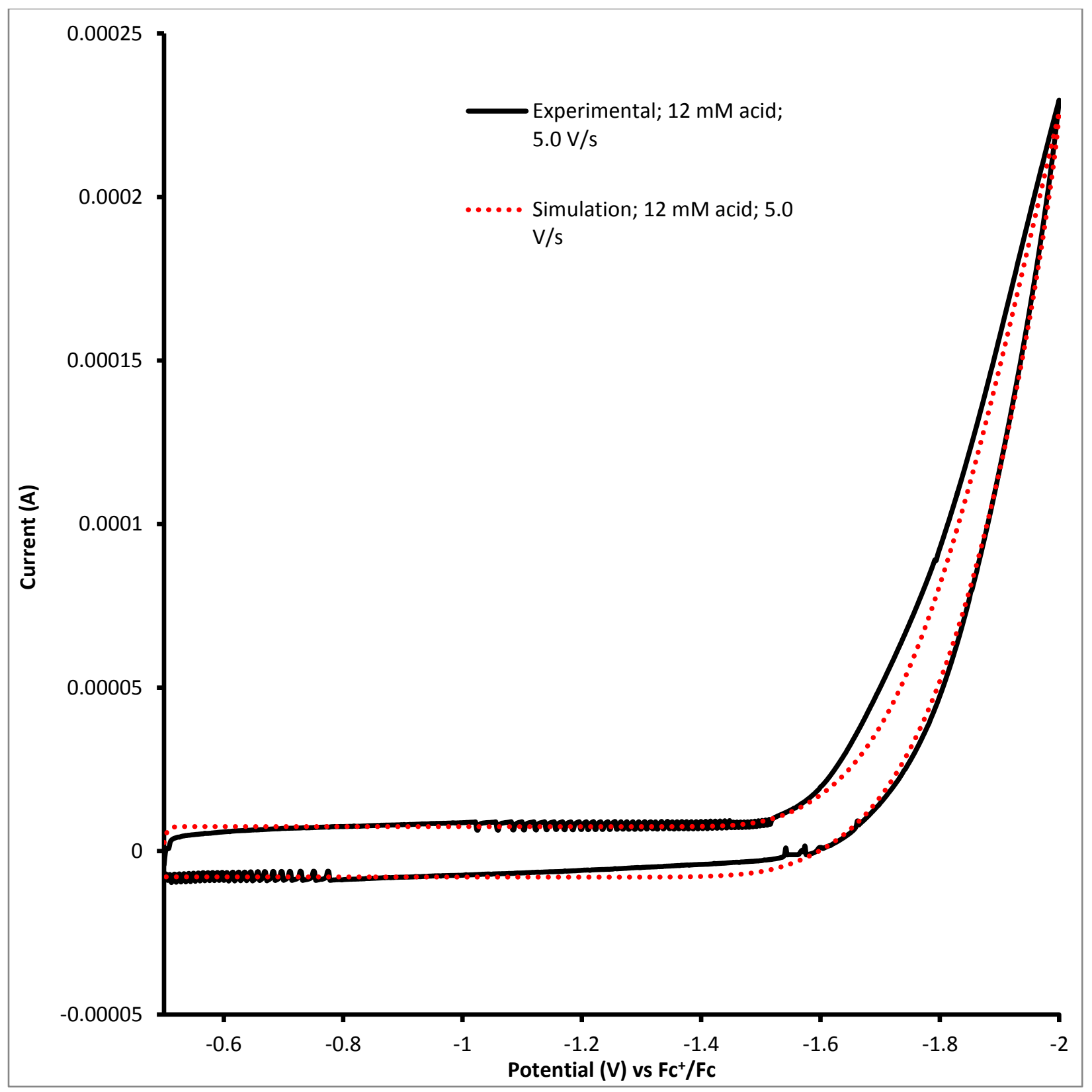

Figure B70. Comparison of experimental (black solid) and simulated (red dotted) cyclic voltammograms; $\mathrm{ZnL}^{1}$ HER. $12 \mathrm{mM}$ [acid]; $v=5.0 \mathrm{~V} / \mathrm{s} \mathrm{vs} \mathrm{Fc}^{+} / \mathrm{Fc}$. Fit with mechanism parameters from Table A5. 


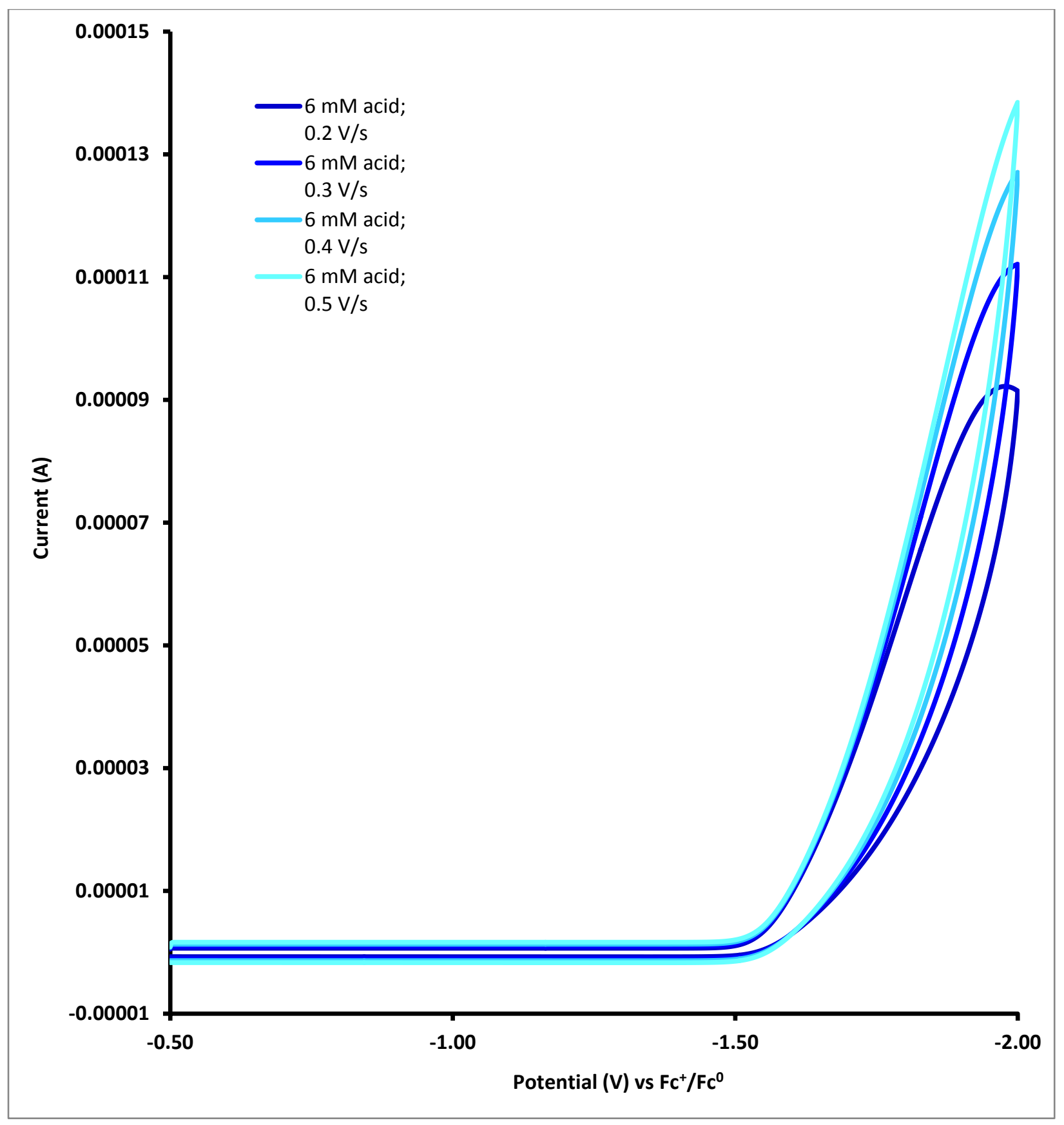

Figure B71. $\mathrm{ZnL}^{1}$ HER. ZnL HER CV Simulations of experimental data; $6 \mathrm{mM}$ [acid]; v = 0.2$0.5 \mathrm{~V} / \mathrm{s}$ vs $\mathrm{Fc}^{+} / \mathrm{Fc}$. Fit with mechanism parameters from Table A6. 


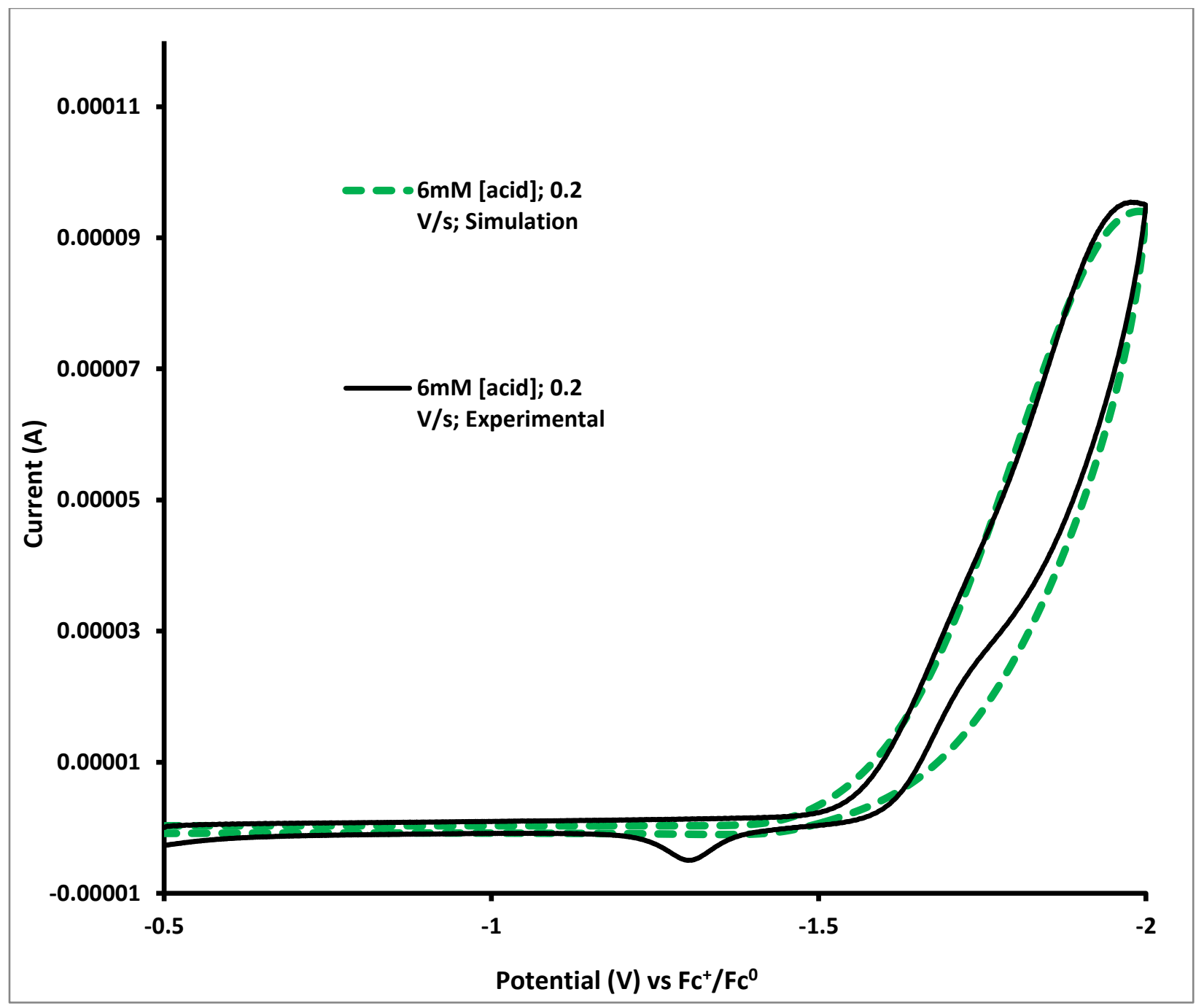

Figure B72. Comparison of experimental (black solid) and simulated (green dotted) cyclic voltammograms; $\mathrm{ZnL}^{1}$ HER. $6 \mathrm{mM}$ [acid]; v $=0.2 \mathrm{~V} / \mathrm{s}$ vs $\mathrm{Fc}^{+} / \mathrm{Fc}$. Fit with mechanism parameters from Table A6. 


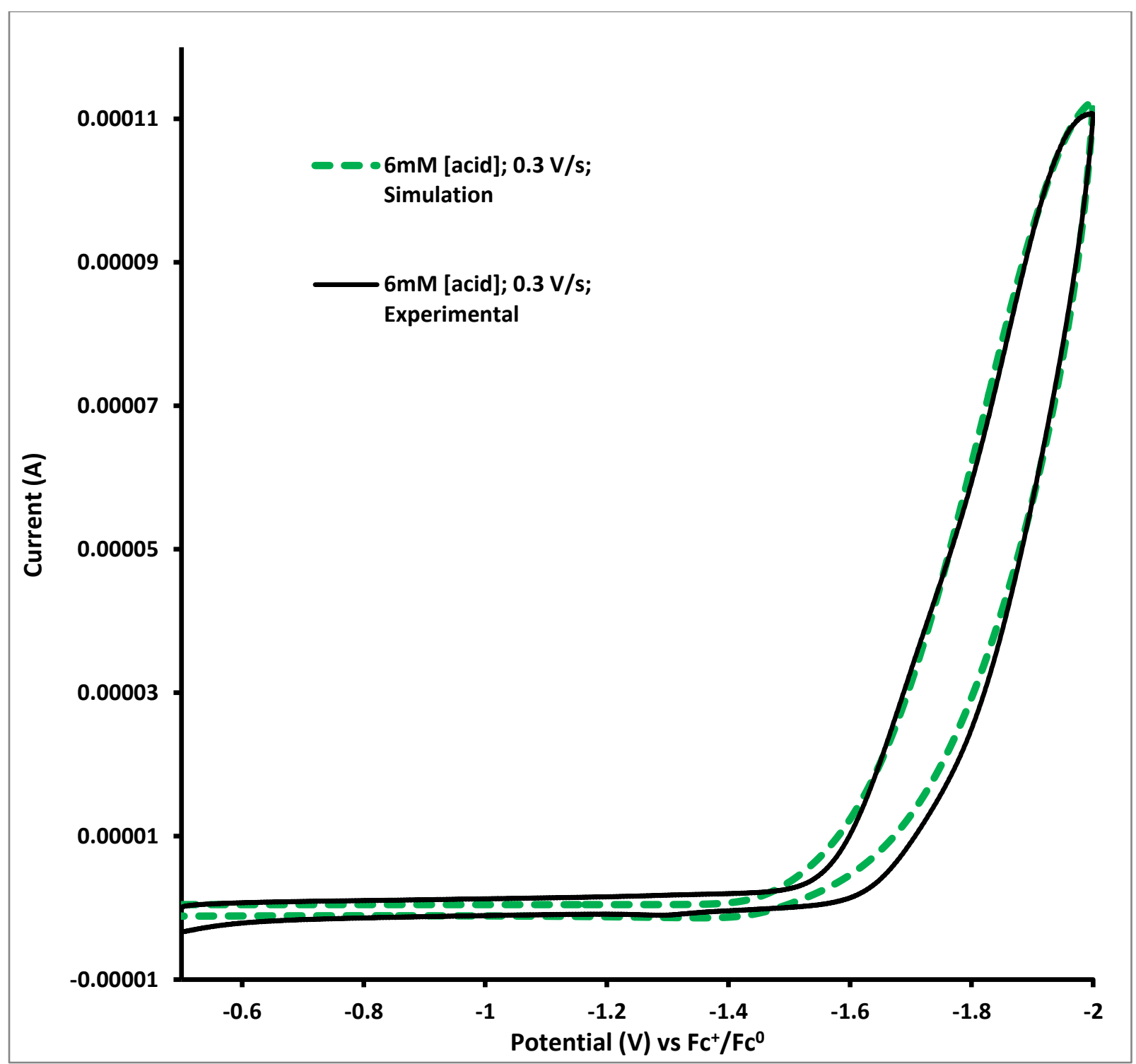

Figure B73. Comparison of experimental (black solid) and simulated (green dotted) cyclic voltammograms; $\mathrm{ZnL}^{1}$ HER. $6 \mathrm{mM}$ [acid]; v $=0.3 \mathrm{~V} / \mathrm{s} \mathrm{vs} \mathrm{Fc}^{+} / \mathrm{Fc}$. Fit with mechanism parameters from Table A6. 


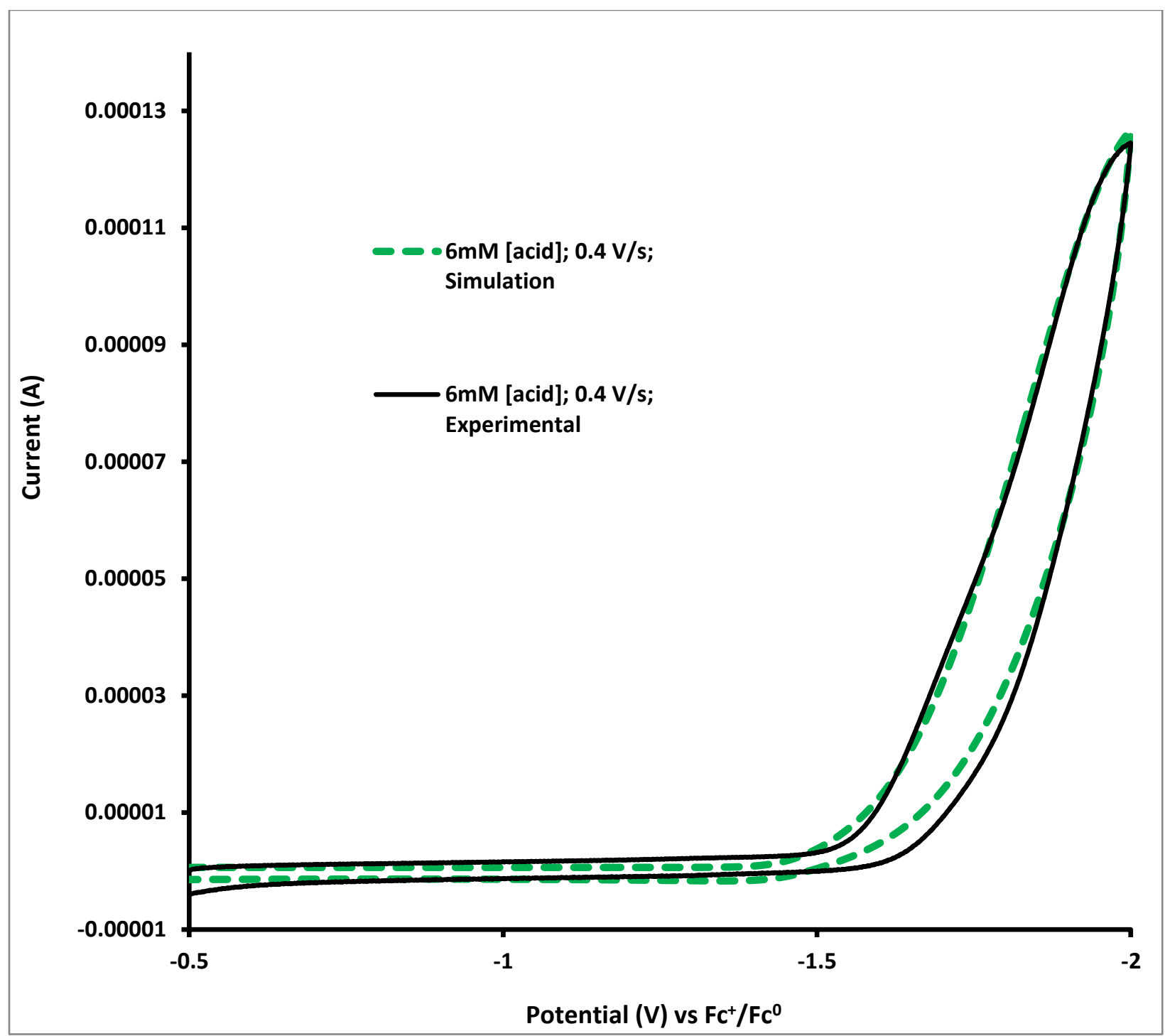

Figure B74. Comparison of experimental (black solid) and simulated (green dotted) cyclic voltammograms; $\mathrm{ZnL}^{1}$ HER. $6 \mathrm{mM}$ [acid]; v $=0.4 \mathrm{~V} / \mathrm{s}$ vs $\mathrm{Fc}^{+} / \mathrm{Fc}$. Fit with mechanism parameters from Table A6. 


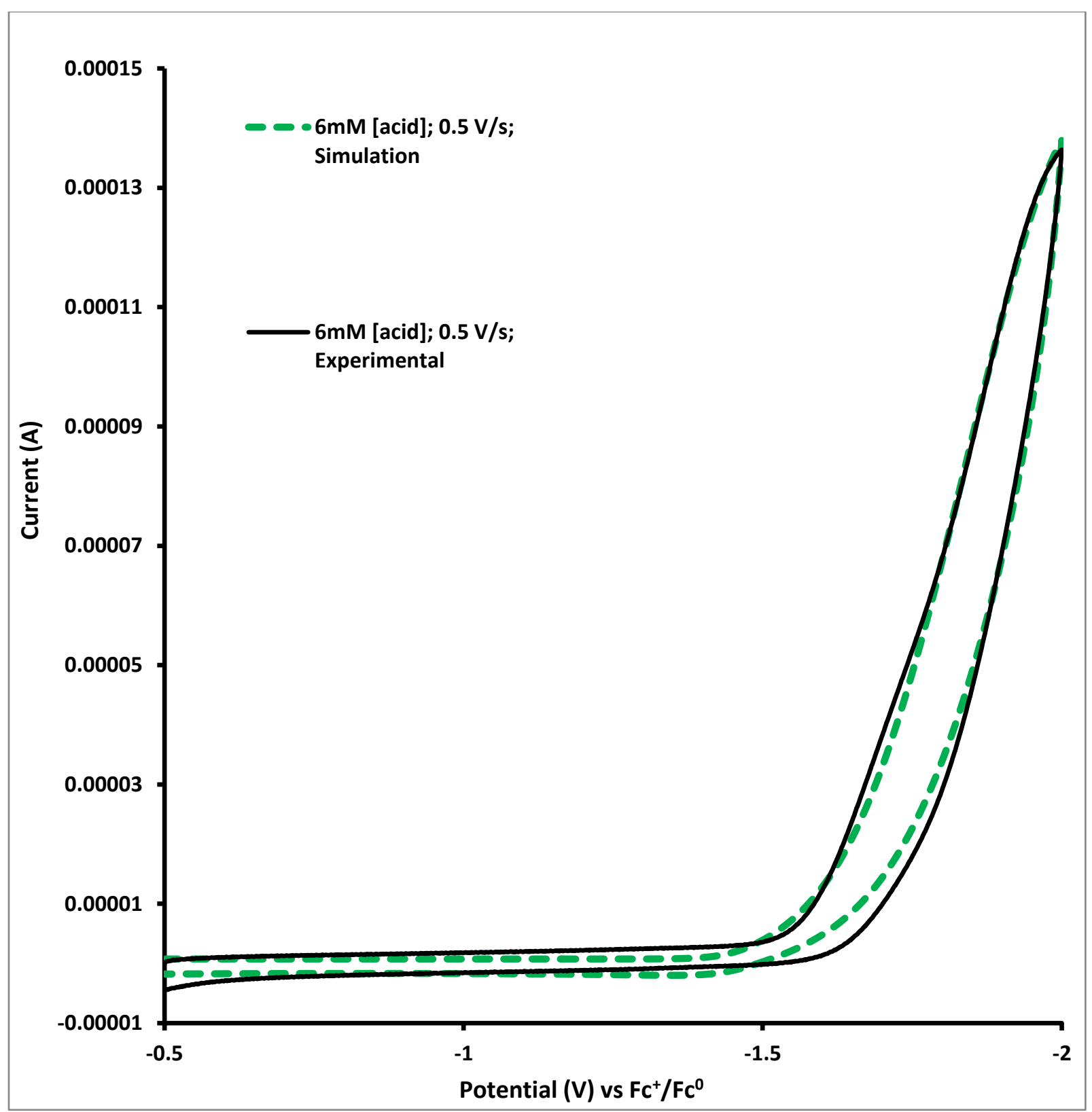

Figure B75. Comparison of experimental (black solid) and simulated (green dotted) cyclic voltammograms; $\mathrm{ZnL}^{1}$ HER. $6 \mathrm{mM}$ [acid]; v $=0.5 \mathrm{~V} / \mathrm{s}$ vs Fc ${ }^{+} / \mathrm{Fc}$. Fit with mechanism parameters from Table A6. 


\section{APPENDIX C: \\ ADDITIONAL ELECTROCHEMICAL \\ AND UV-VIS DATA}




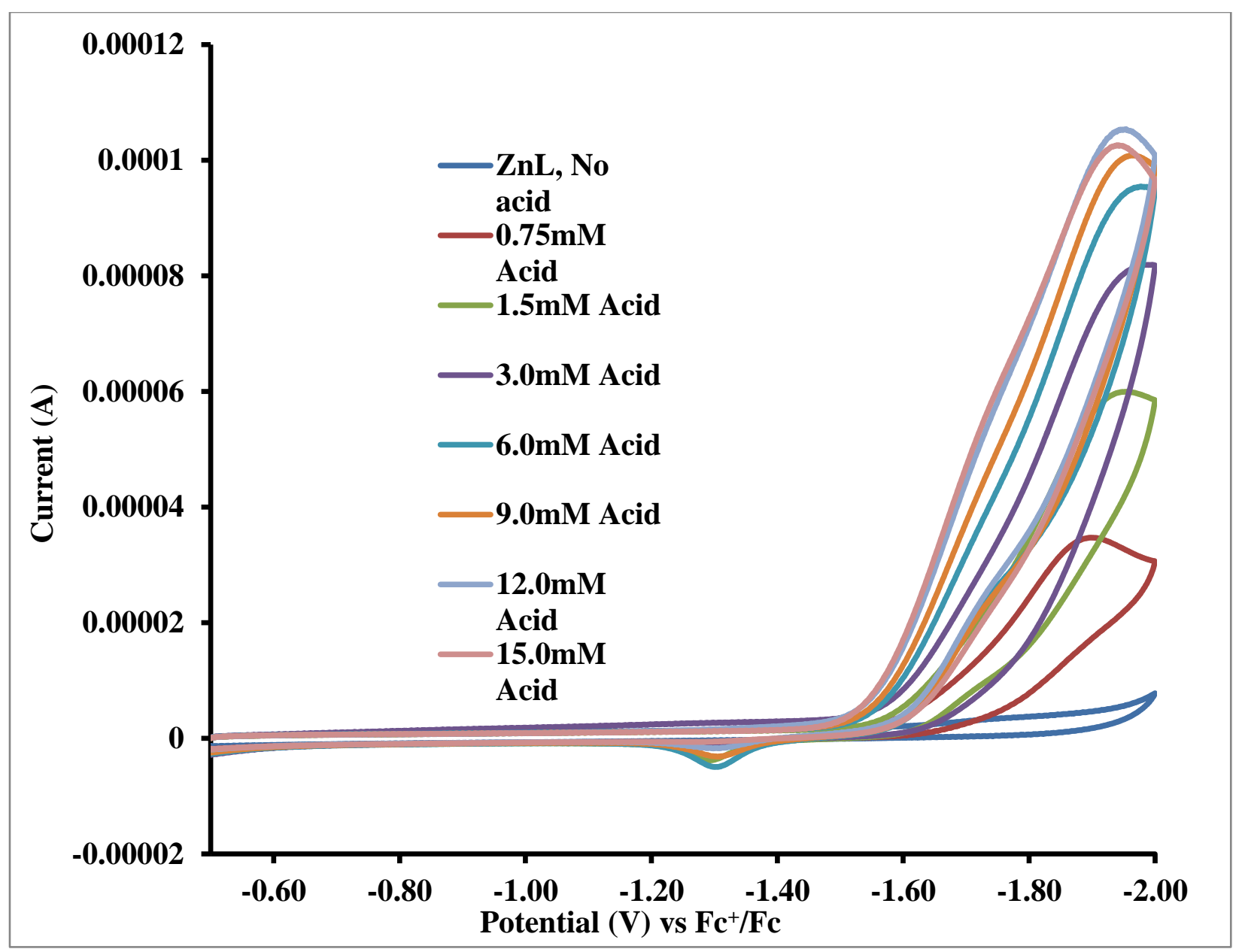

Figure C76. $\mathrm{ZnL}^{1} \mathrm{HER}$ cyclic voltammograms in $0.1 \mathrm{M} \mathrm{Bu}_{4} \mathrm{NPF}_{6}$ methanol solution with increasing concentrations of $\mathrm{CH}_{3} \mathrm{COOH}$ added; $v=0.2 \mathrm{~V} / \mathrm{s}$. 


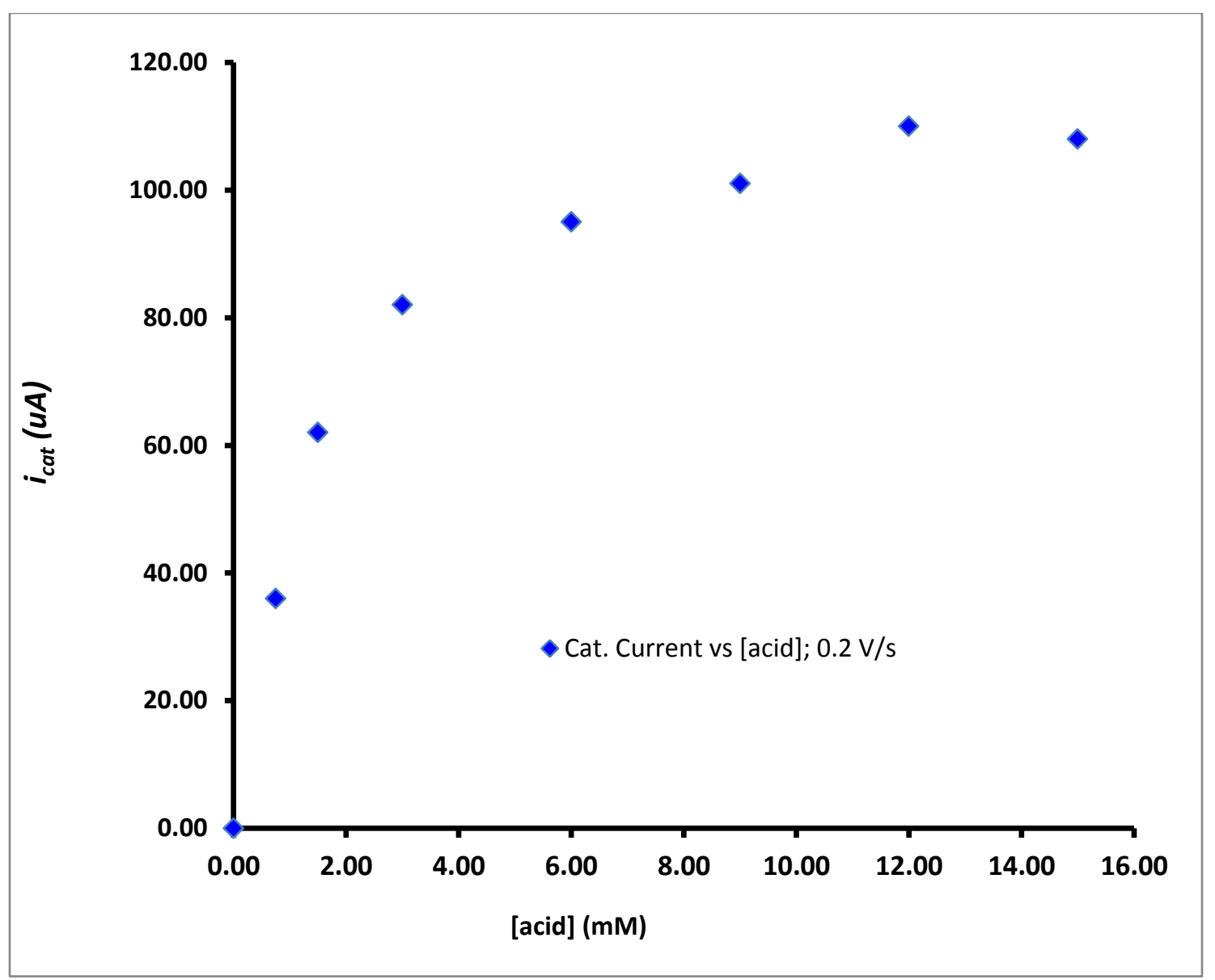

Figure C77. Plot of $\mathrm{CH}_{3} \mathrm{COOH}$ concentration versus catalytic current for $\mathrm{ZnL}^{1}$ in $0.1 \mathrm{M} \mathrm{Bu}_{4} \mathrm{NPF}_{6}$ methanol solution; $v=0.2 \mathrm{~V} / \mathrm{s}$. 


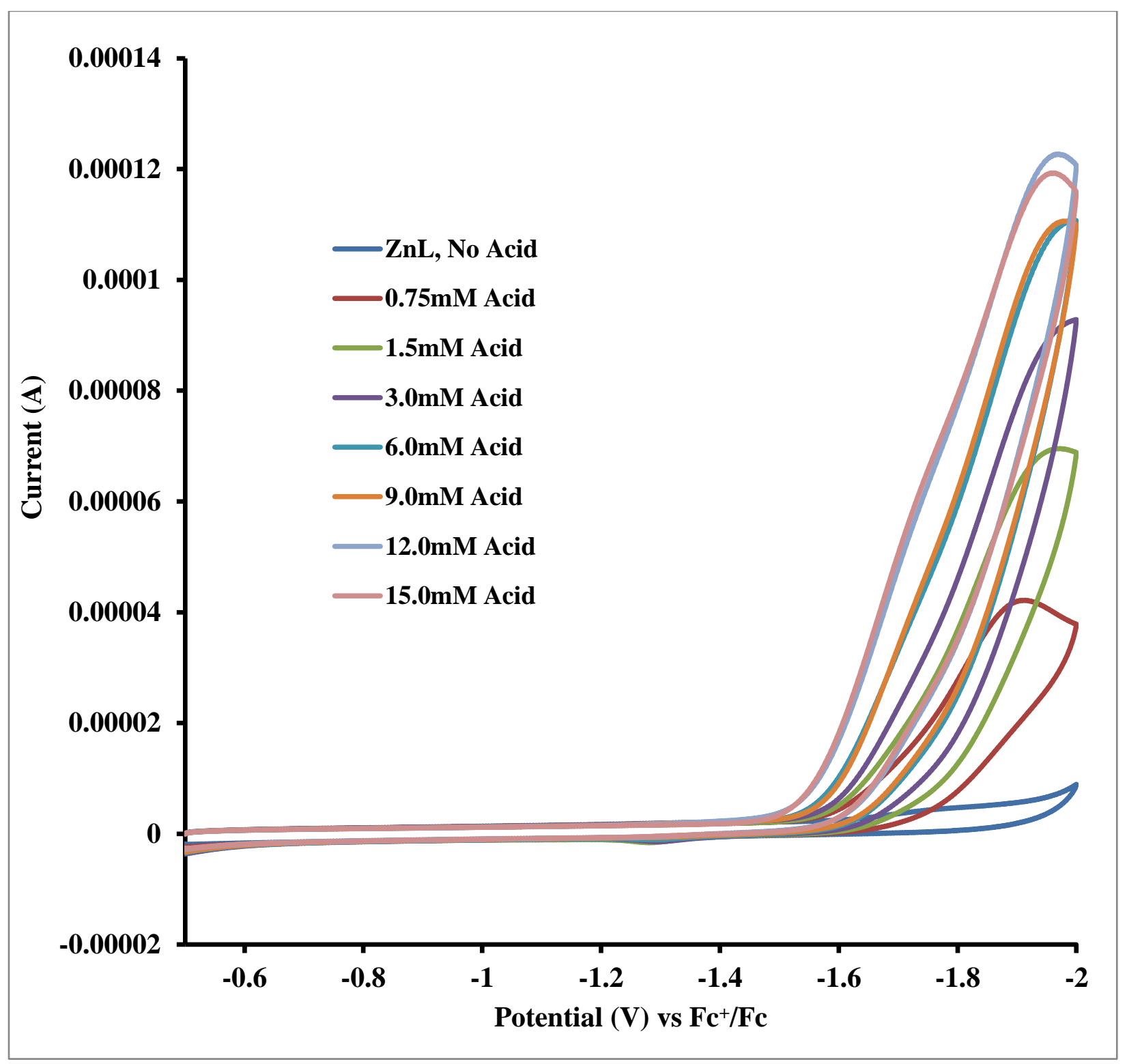

Figure C78. $\mathrm{ZnL}^{1} \mathrm{HER}$ cyclic voltammograms in $0.1 \mathrm{M} \mathrm{Bu}_{4} \mathrm{NPF}_{6}$ methanol solution with increasing concentrations of $\mathrm{CH}_{3} \mathrm{COOH}$ added; $v=0.3 \mathrm{~V} / \mathrm{s}$. 


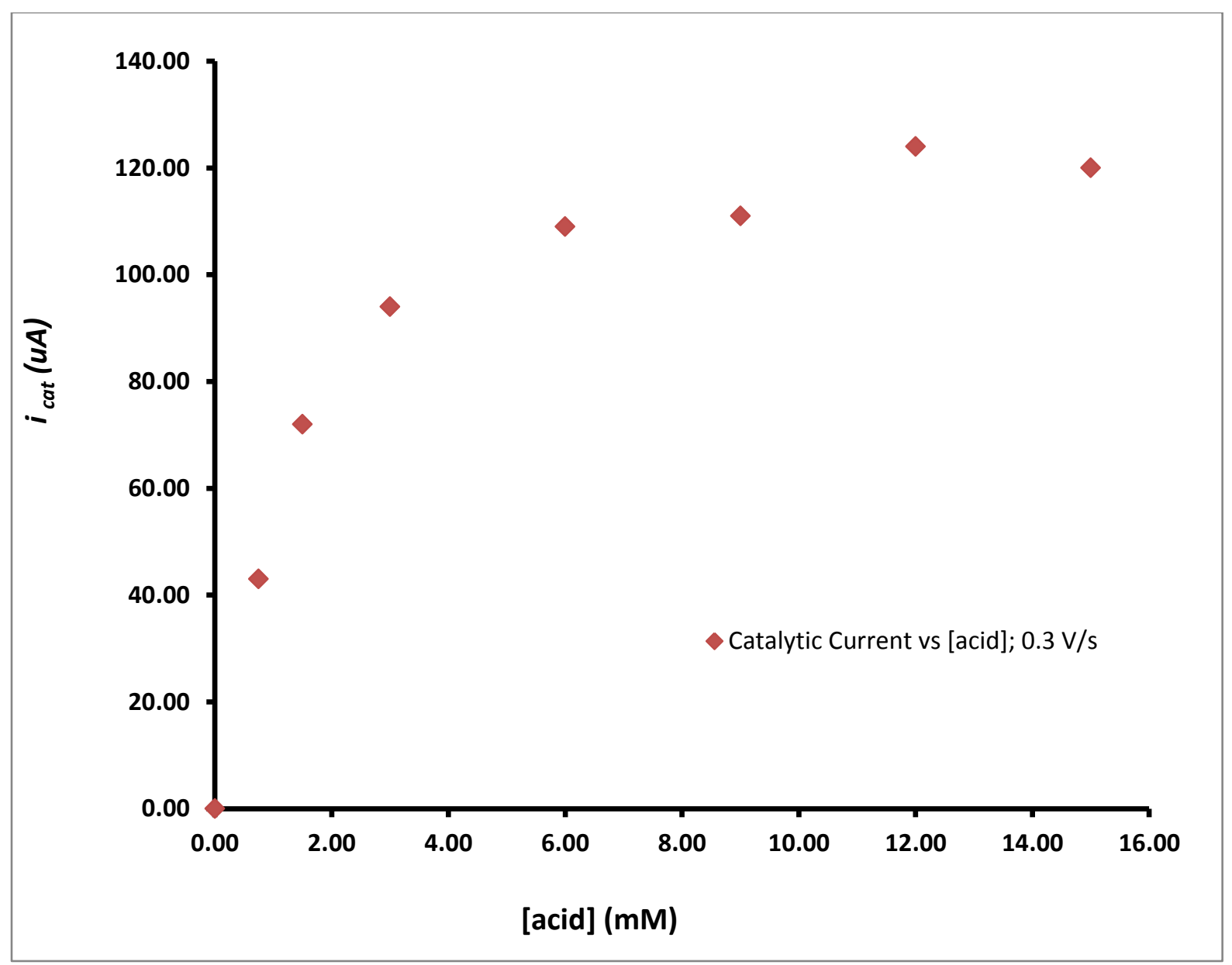

Figure C79. Plot of $\mathrm{CH}_{3} \mathrm{COOH}$ concentration versus catalytic current for $\mathrm{ZnL}^{1}$ in $0.1 \mathrm{M} \mathrm{Bu}_{4} \mathrm{NPF}_{6}$ methanol solution; $v=0.3 \mathrm{~V} / \mathrm{s}$. 


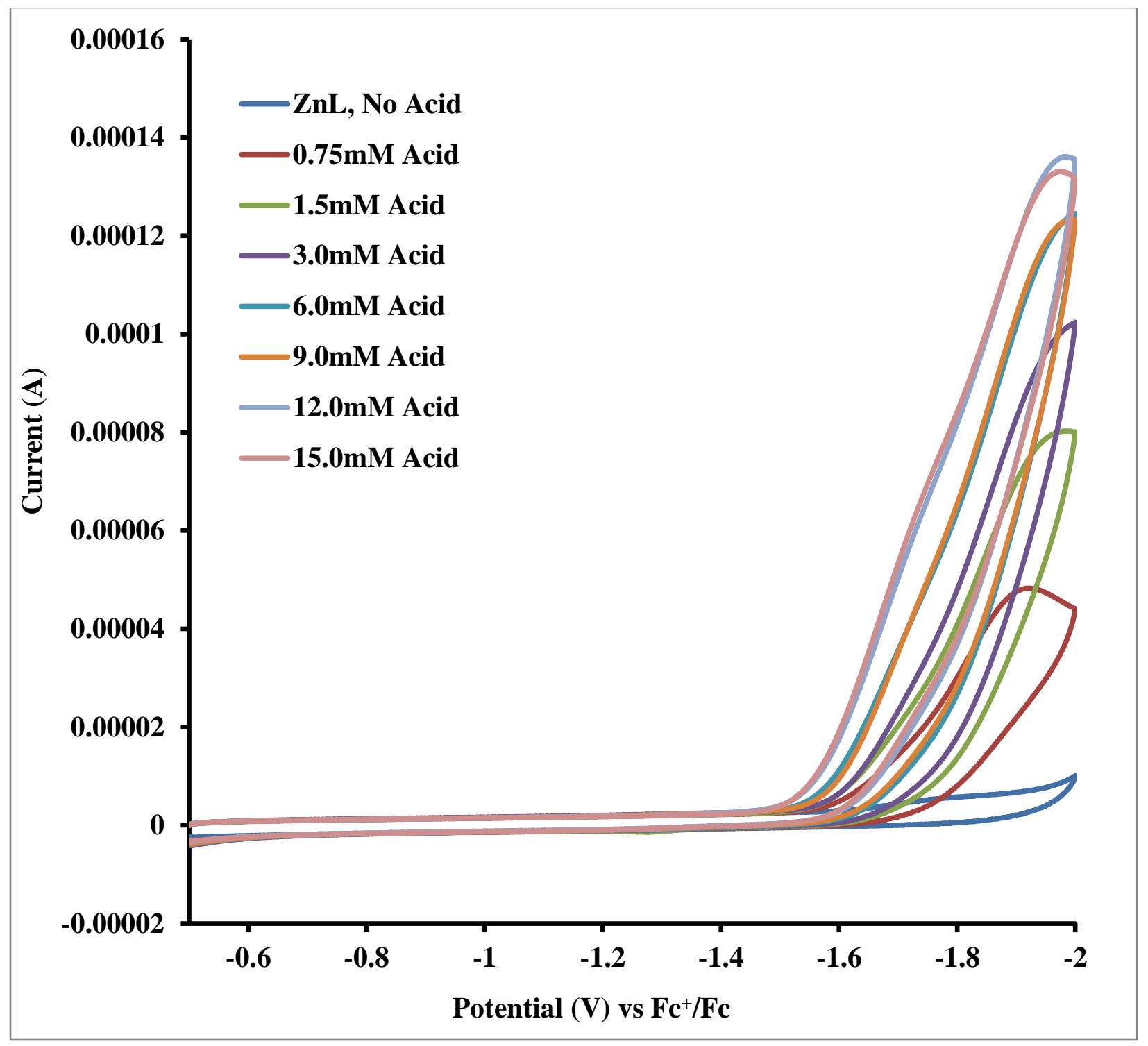

Figure C80. $\mathrm{ZnL}^{1}$ HER cyclic voltammograms in $0.1 \mathrm{M} \mathrm{Bu}_{4} \mathrm{NPF}_{6}$ methanol solution with increasing concentrations of $\mathrm{CH}_{3} \mathrm{COOH}$ added; $v=0.4 \mathrm{~V} / \mathrm{s}$. 


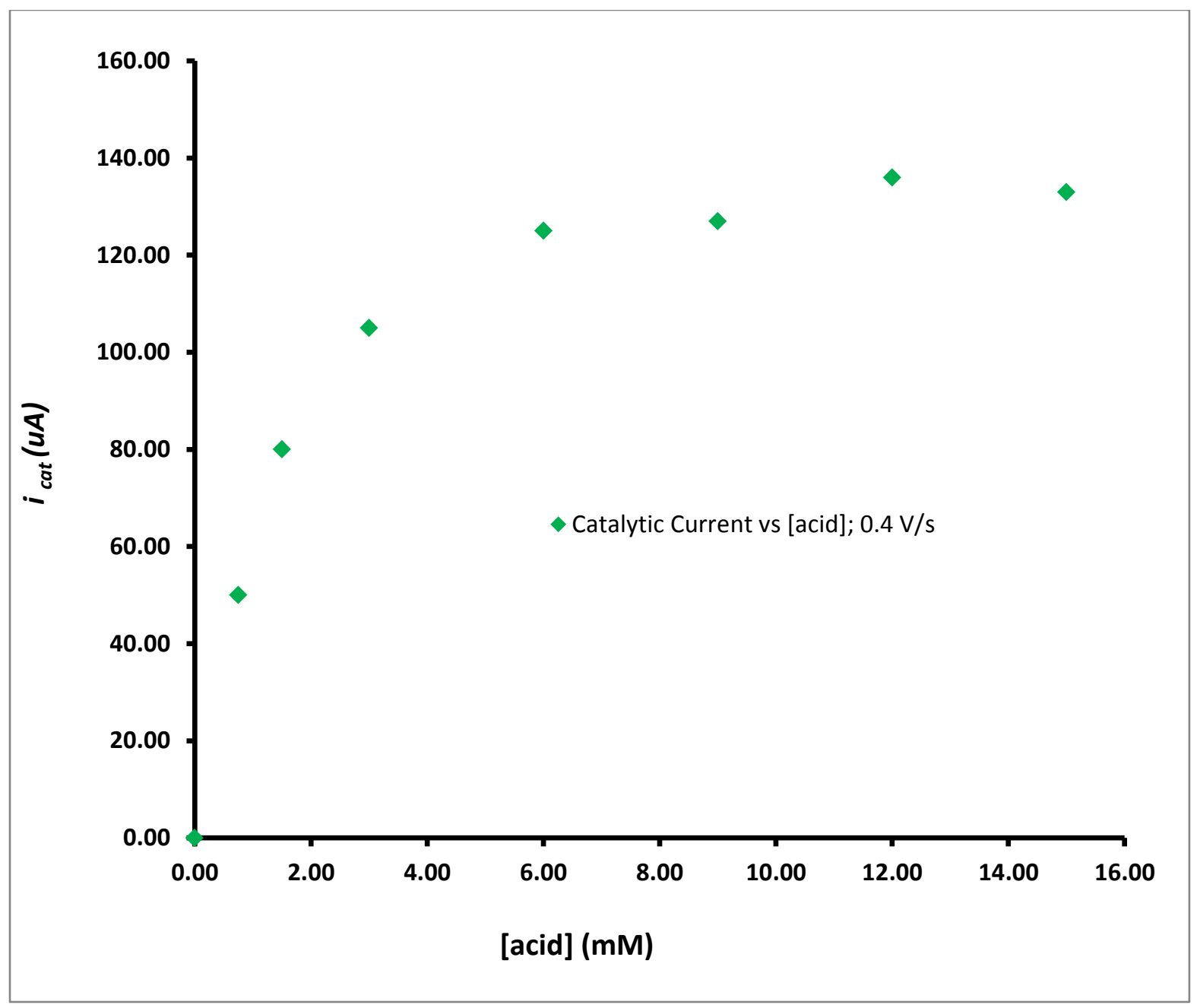

Figure C81. Plot of $\mathrm{CH}_{3} \mathrm{COOH}$ concentration versus catalytic current for $\mathrm{ZnL}^{1}$ in $0.1 \mathrm{M} \mathrm{Bu}_{4} \mathrm{NPF}_{6}$ methanol solution; $v=0.4 \mathrm{~V} / \mathrm{s}$. 


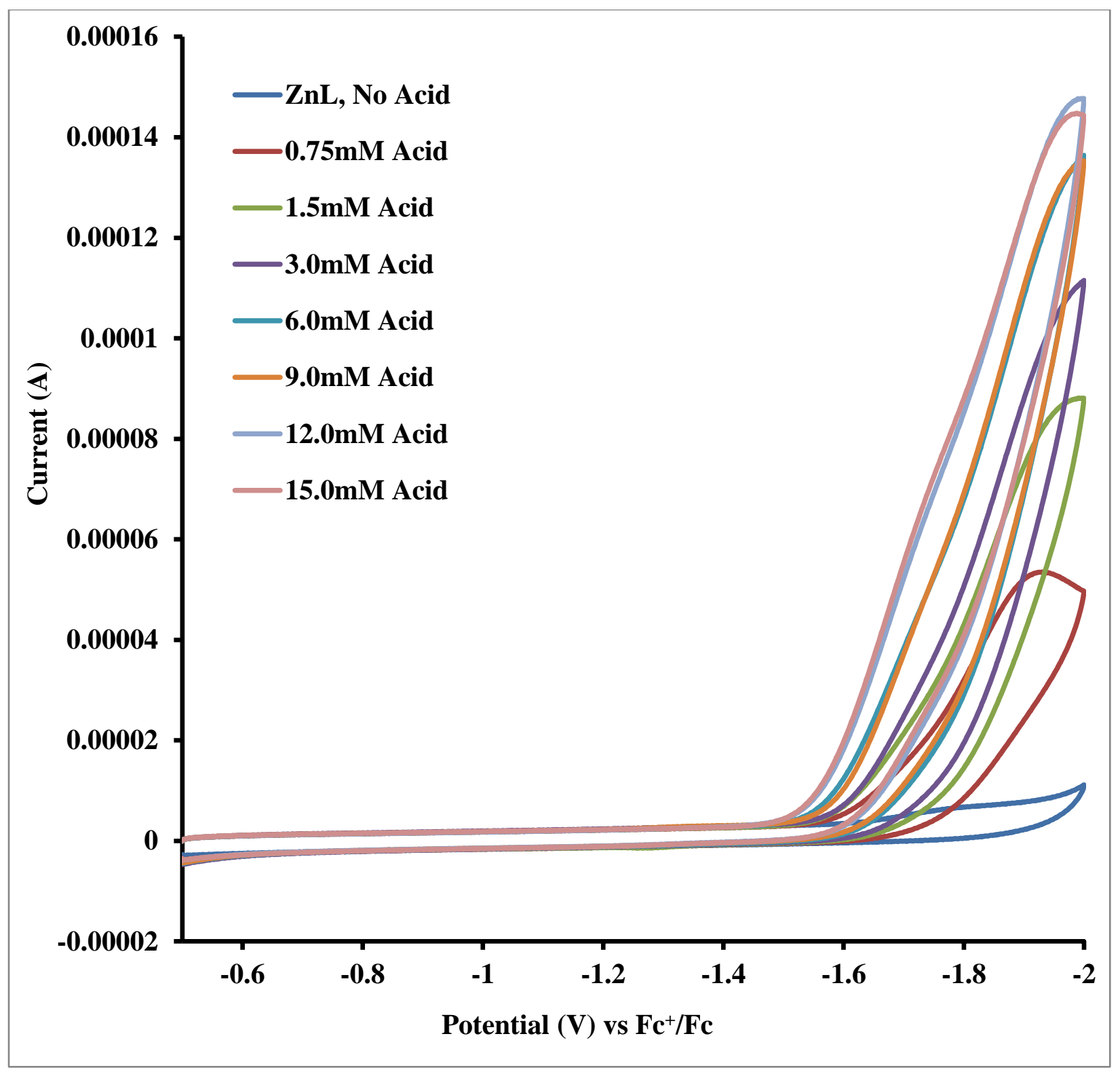

Figure C82. $\mathrm{ZnL}^{1} \mathrm{HER}$ cyclic voltammograms in $0.1 \mathrm{M} \mathrm{Bu}_{4} \mathrm{NPF}_{6}$ methanol solution with increasing concentrations of $\mathrm{CH}_{3} \mathrm{COOH}$ added; $v=0.5 \mathrm{~V} / \mathrm{s}$. 


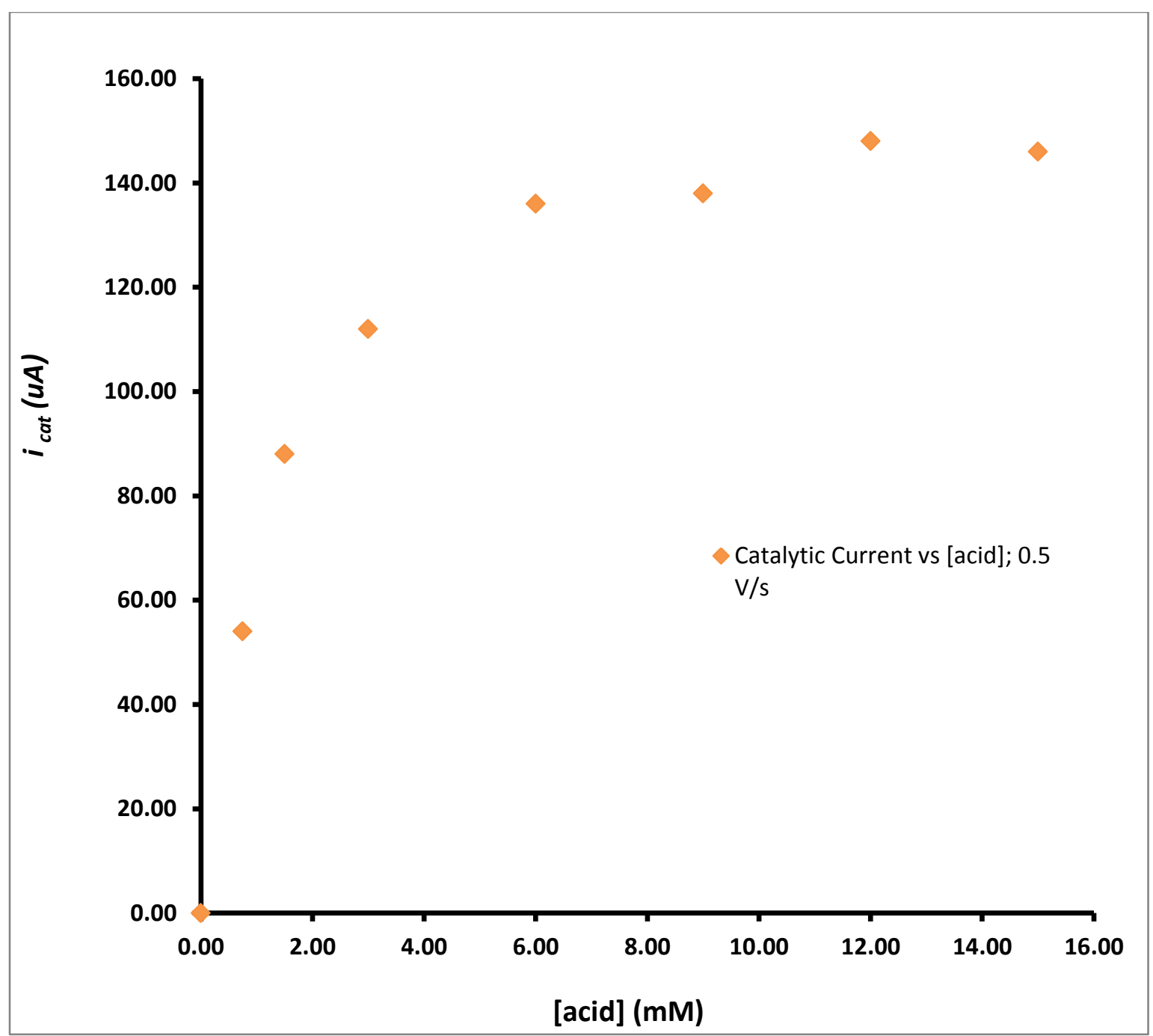

Figure C83. Plot of $\mathrm{CH}_{3} \mathrm{COOH}$ concentration versus catalytic current for $\mathrm{ZnL}^{1}$ in $0.1 \mathrm{M} \mathrm{Bu}_{4} \mathrm{NPF}_{6}$ methanol solution; $v=0.5 \mathrm{~V} / \mathrm{s}$. 


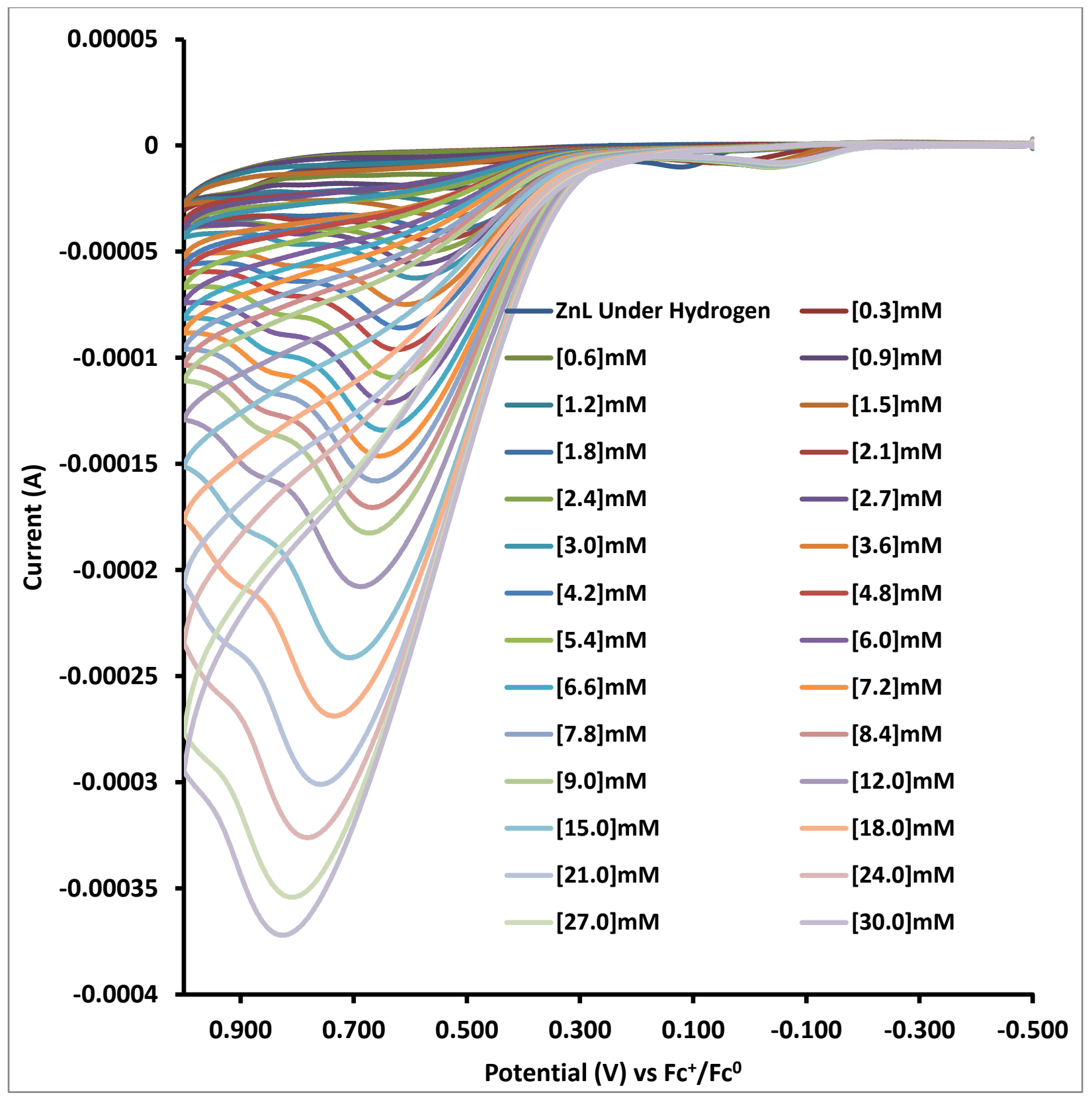

Figure C84. $\mathrm{ZnL}^{1} \mathrm{HOR}$ cyclic voltammograms in $0.1 \mathrm{M} \mathrm{Bu}_{4} \mathrm{NPF}_{6}$ methanol solution, under an $\mathrm{H}_{2}$ atmosphere, with increasing concentrations of $\left(\mathrm{CH}_{2} \mathrm{CH}_{3}\right)_{3} \mathrm{~N}$ added; $v=0.2 \mathrm{~V} / \mathrm{s}$. 


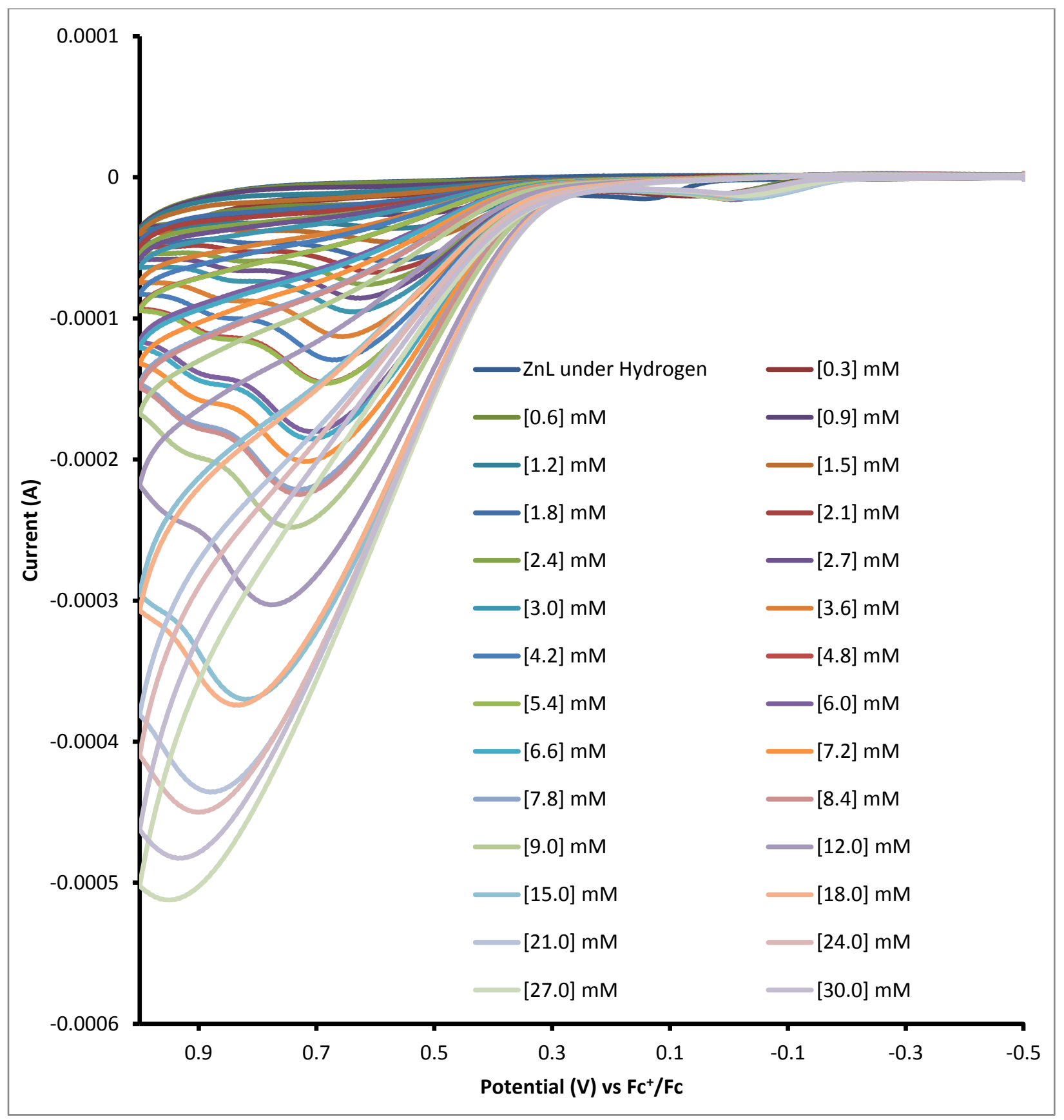

Figure C85. $\mathrm{ZnL}^{1} \mathrm{HOR}$ cyclic voltammograms in $0.1 \mathrm{M} \mathrm{Bu}_{4} \mathrm{NPF}_{6}$ methanol solution, under an $\mathrm{H}_{2}$ atmosphere, with increasing concentrations of $\left(\mathrm{CH}_{2} \mathrm{CH}_{3}\right)_{3} \mathrm{~N}$ added; $v=0.5 \mathrm{~V} / \mathrm{s}$. 


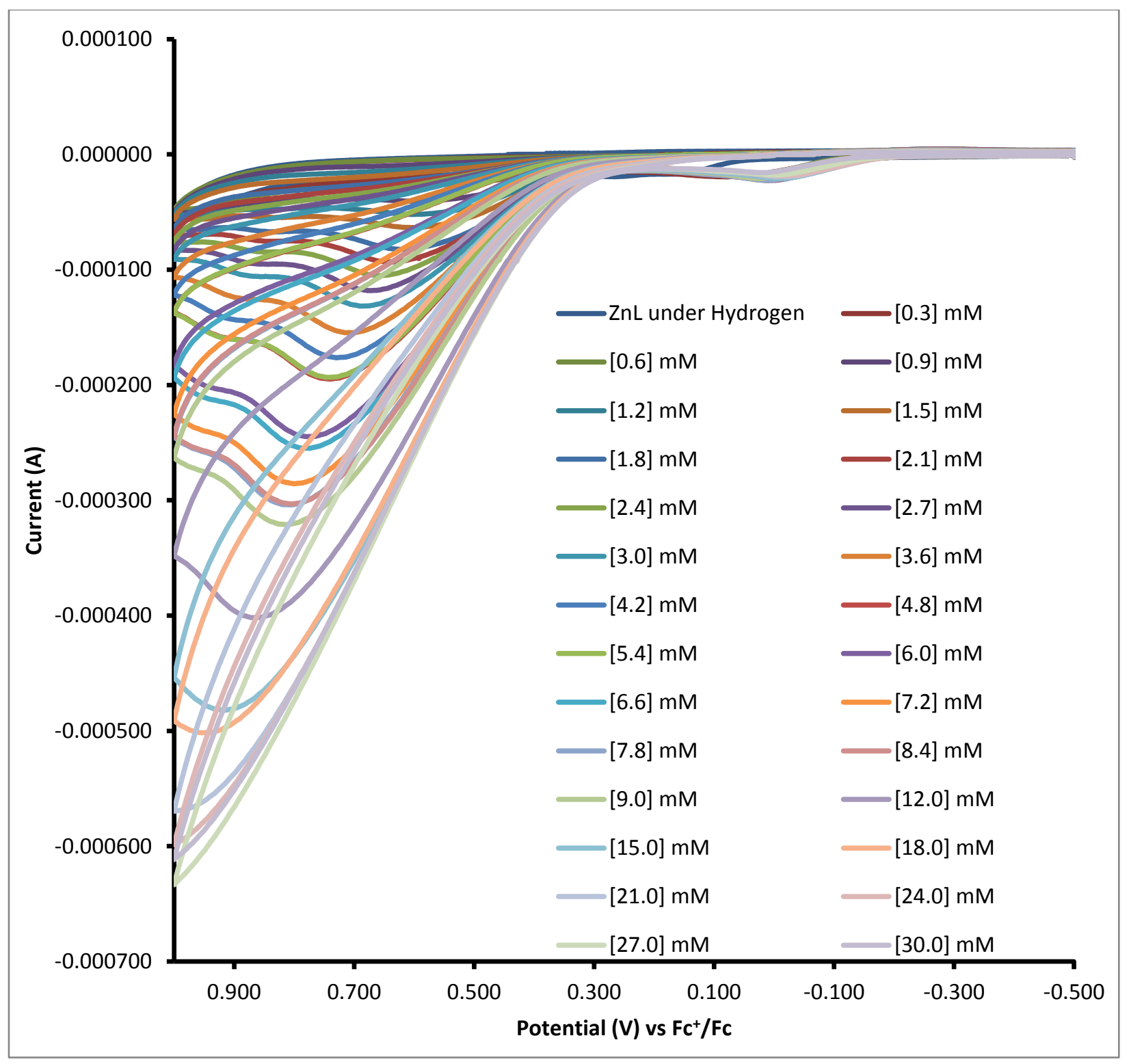

Figure C86. $\mathrm{ZnL}^{1} \mathrm{HOR}$ cyclic voltammograms in $0.1 \mathrm{M} \mathrm{Bu}_{4} \mathrm{NPF}_{6}$ methanol solution, under an $\mathrm{H}_{2}$ atmosphere, with increasing concentrations of $\left(\mathrm{CH}_{2} \mathrm{CH}_{3}\right)_{3} \mathrm{~N}$ added; $v=1.0 \mathrm{~V} / \mathrm{s}$. 


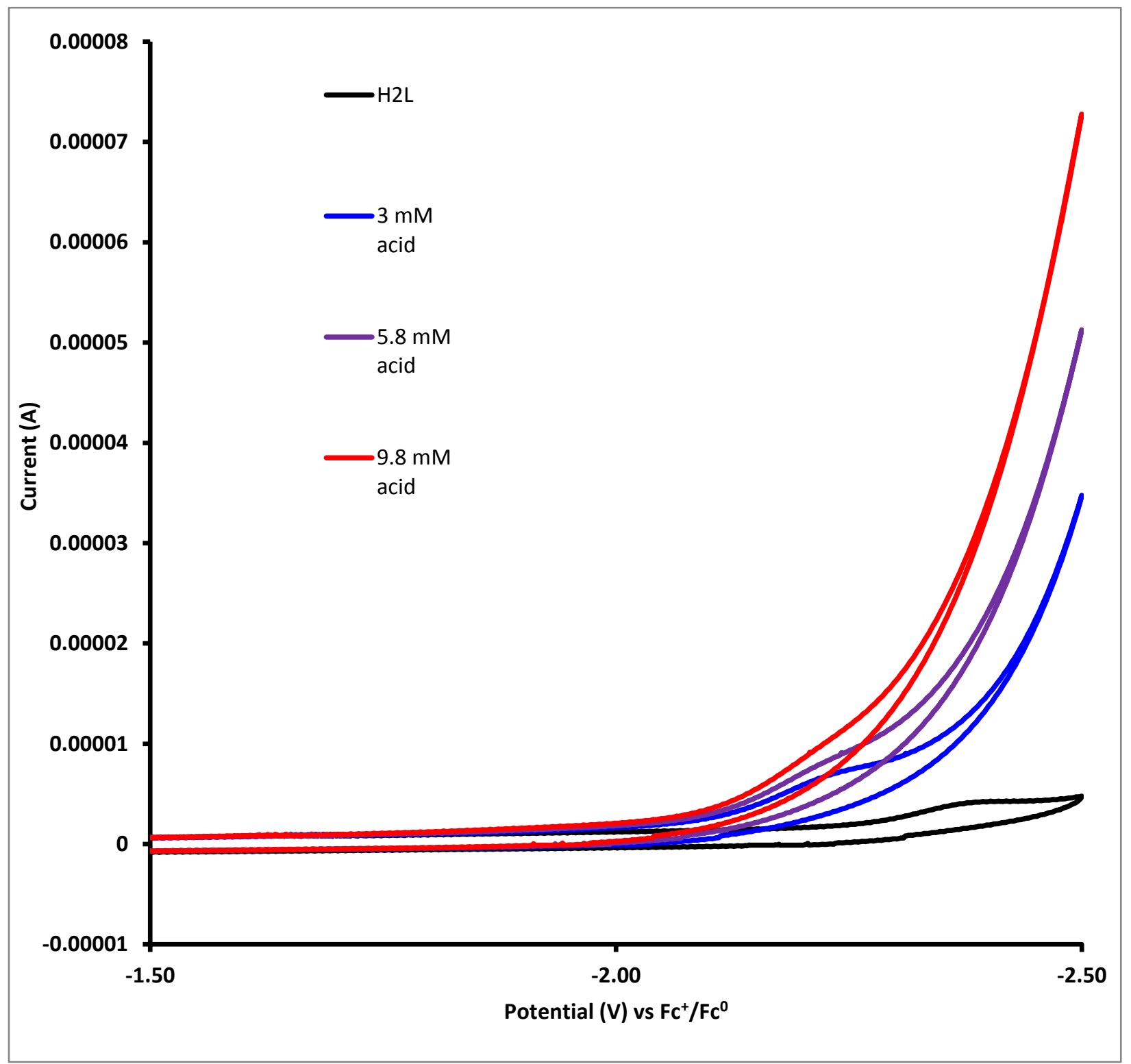

Figure C87. $\mathrm{H}_{2} \mathrm{~L}^{1}$ HER cyclic voltammograms in $0.1 \mathrm{M} \mathrm{Bu}_{4} \mathrm{NPF}_{6}$ methanol solution with increasing concentrations of $\mathrm{CH}_{3} \mathrm{COOH}$ added ; $v=0.5 \mathrm{~V} / \mathrm{s}$. 


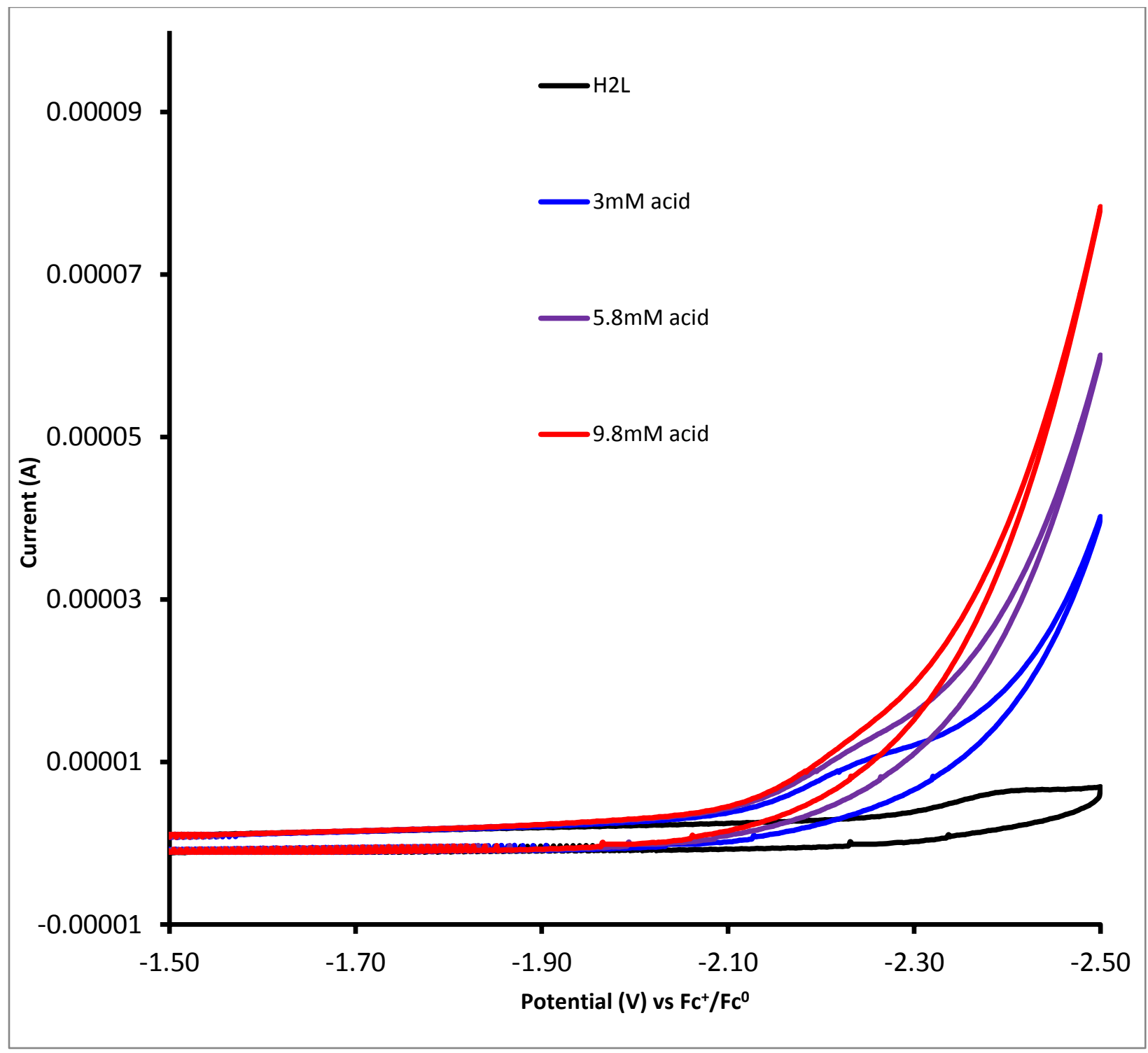

Figure C88. $\mathrm{H}_{2} \mathrm{~L}^{1}$ HER cyclic voltammograms in $0.1 \mathrm{M} \mathrm{Bu}_{4} \mathrm{NPF}_{6}$ methanol solution with increasing concentrations of $\mathrm{CH}_{3} \mathrm{COOH}$ added; $\mathrm{v}=1.0 \mathrm{~V} / \mathrm{s}$. 


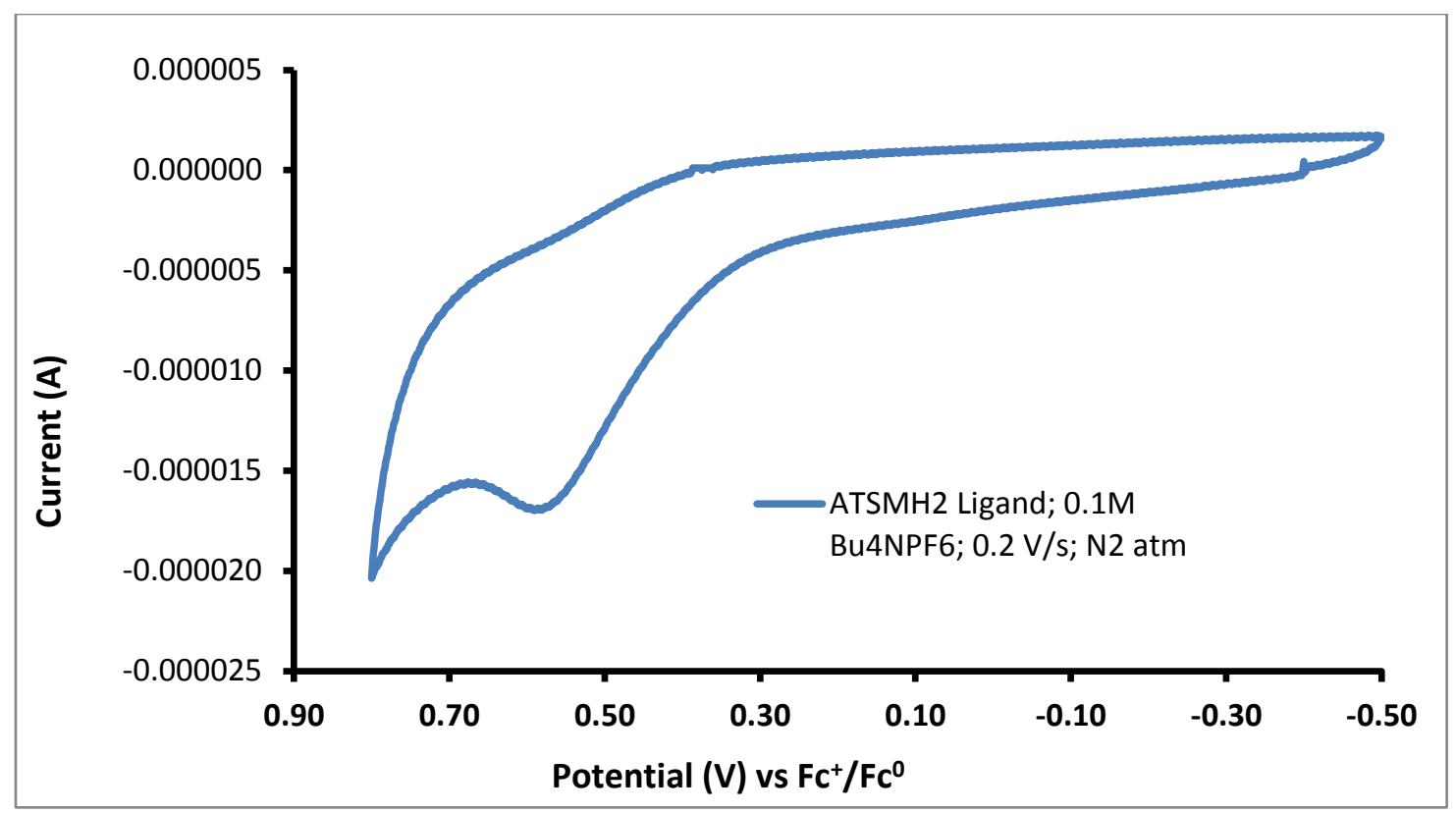

Figure C89. Cyclic Voltammogram of $\mathrm{H}_{2} \mathrm{~L}^{1}$ in $0.1 \mathrm{M} \mathrm{Bu}_{4} \mathrm{NPF}_{6}$ methanol solution; $v=0.2 \mathrm{~V} / \mathrm{s}$.

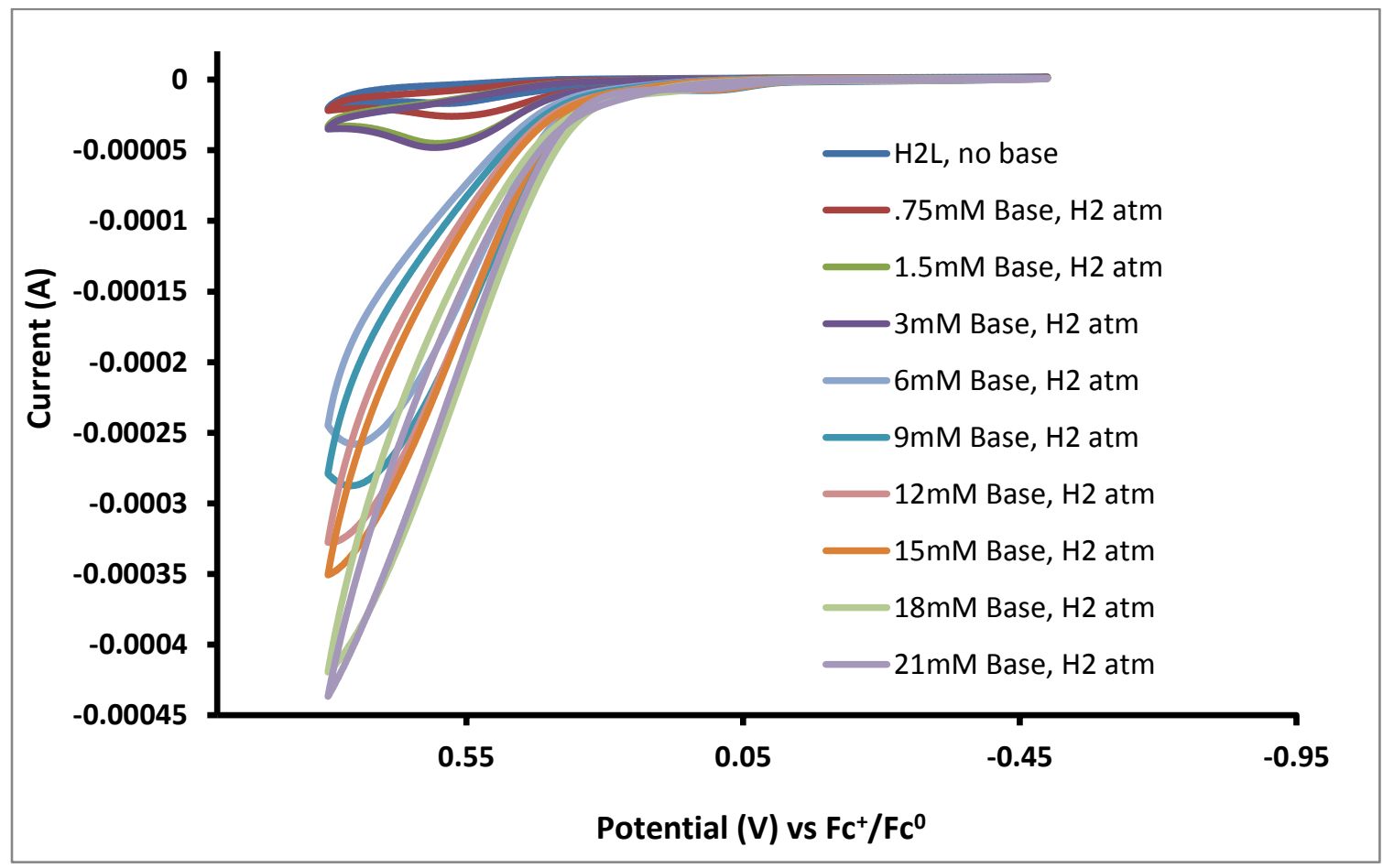

Figure C90. $\mathrm{H}_{2} \mathrm{~L}^{1} \mathrm{HOR}$ cyclic voltammograms in $0.1 \mathrm{M} \mathrm{Bu}_{4} \mathrm{NPF}_{6}$ methanol solution, under an $\mathrm{H}_{2}$ atmosphere, with increasing concentrations of $\left(\mathrm{CH}_{2} \mathrm{CH}_{3}\right)_{3} \mathrm{~N}$ added; $v=0.2 \mathrm{~V} / \mathrm{s}$. 


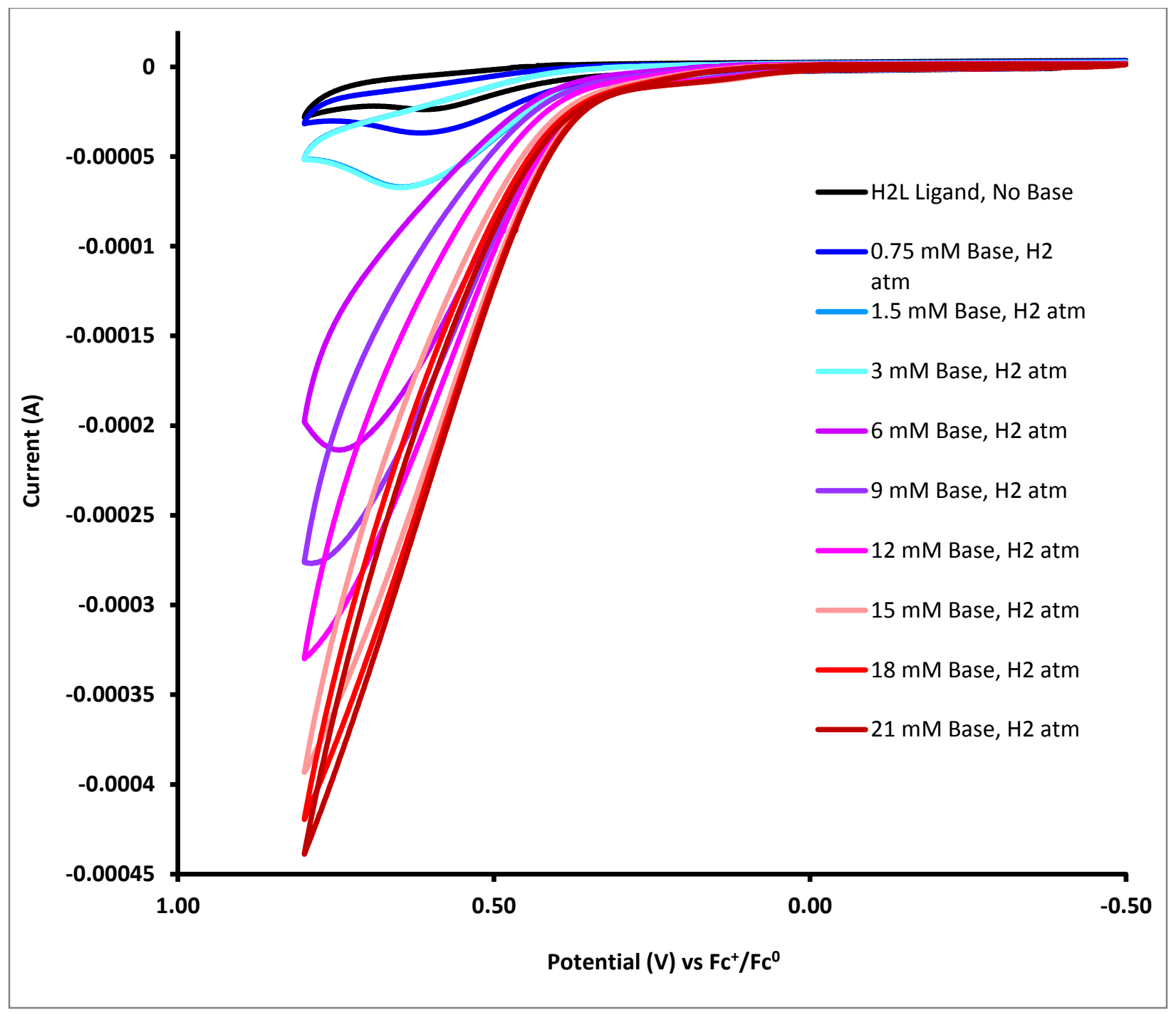

Figure C91. $\mathrm{H}_{2} \mathrm{~L}^{1} \mathrm{HOR}$ cyclic voltammograms in $0.1 \mathrm{M} \mathrm{Bu}_{4} \mathrm{NPF}_{6}$ methanol solution, under an $\mathrm{H}_{2}$ atmosphere, with increasing concentrations of $\left(\mathrm{CH}_{2} \mathrm{CH}_{3}\right)_{3} \mathrm{~N}$ added; $v=0.5 \mathrm{~V} / \mathrm{s}$. 


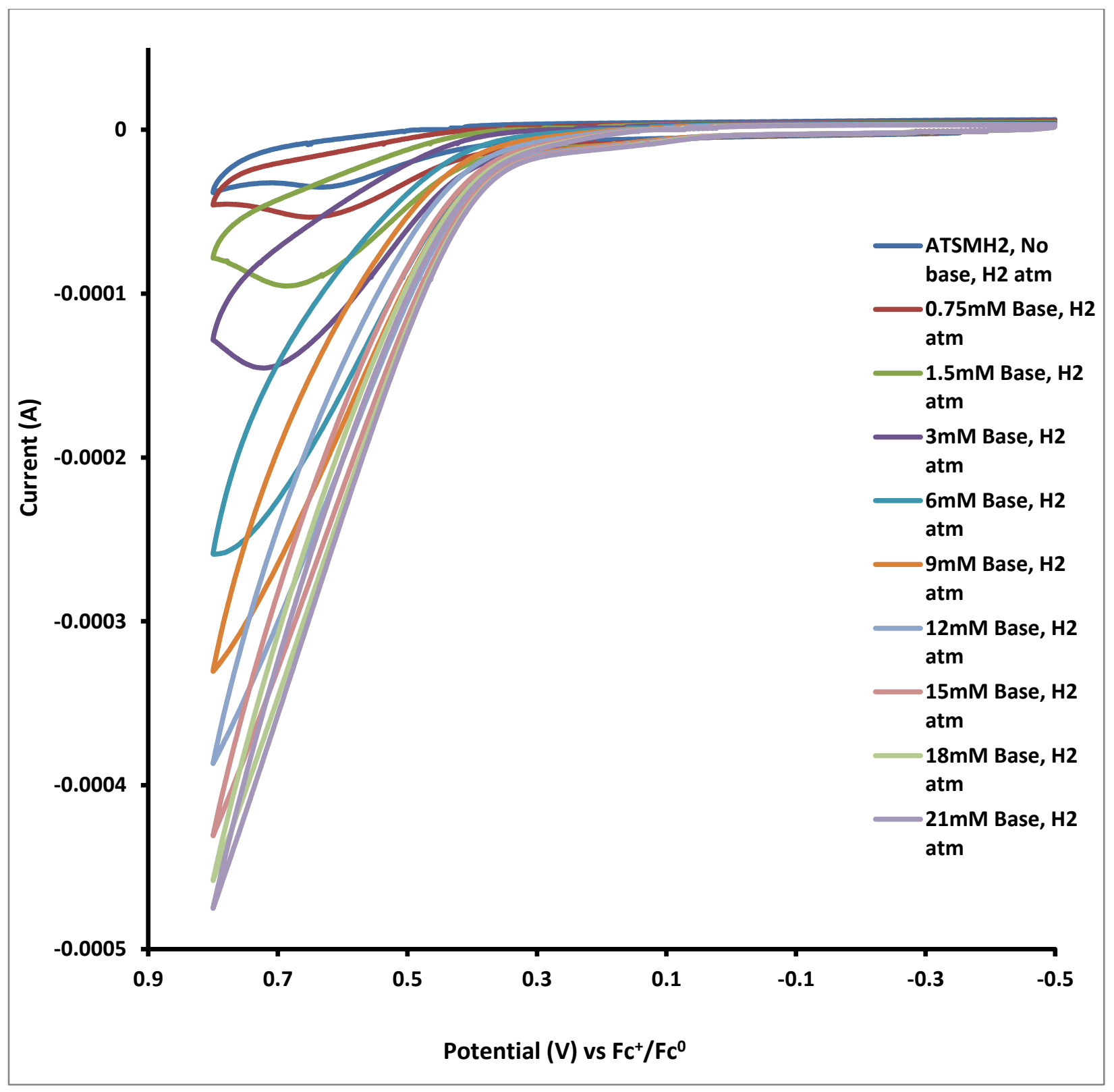

Figure C92. $\mathrm{H}_{2} \mathrm{~L}^{1} \mathrm{HOR}$ cyclic voltammograms in $0.1 \mathrm{M} \mathrm{Bu}_{4} \mathrm{NPF}_{6}$ methanol solution, under an $\mathrm{H}_{2}$ atmosphere, with increasing concentrations of $\left(\mathrm{CH}_{2} \mathrm{CH}_{3}\right)_{3} \mathrm{~N}$ added; $v=1.0 \mathrm{~V} / \mathrm{s}$. 


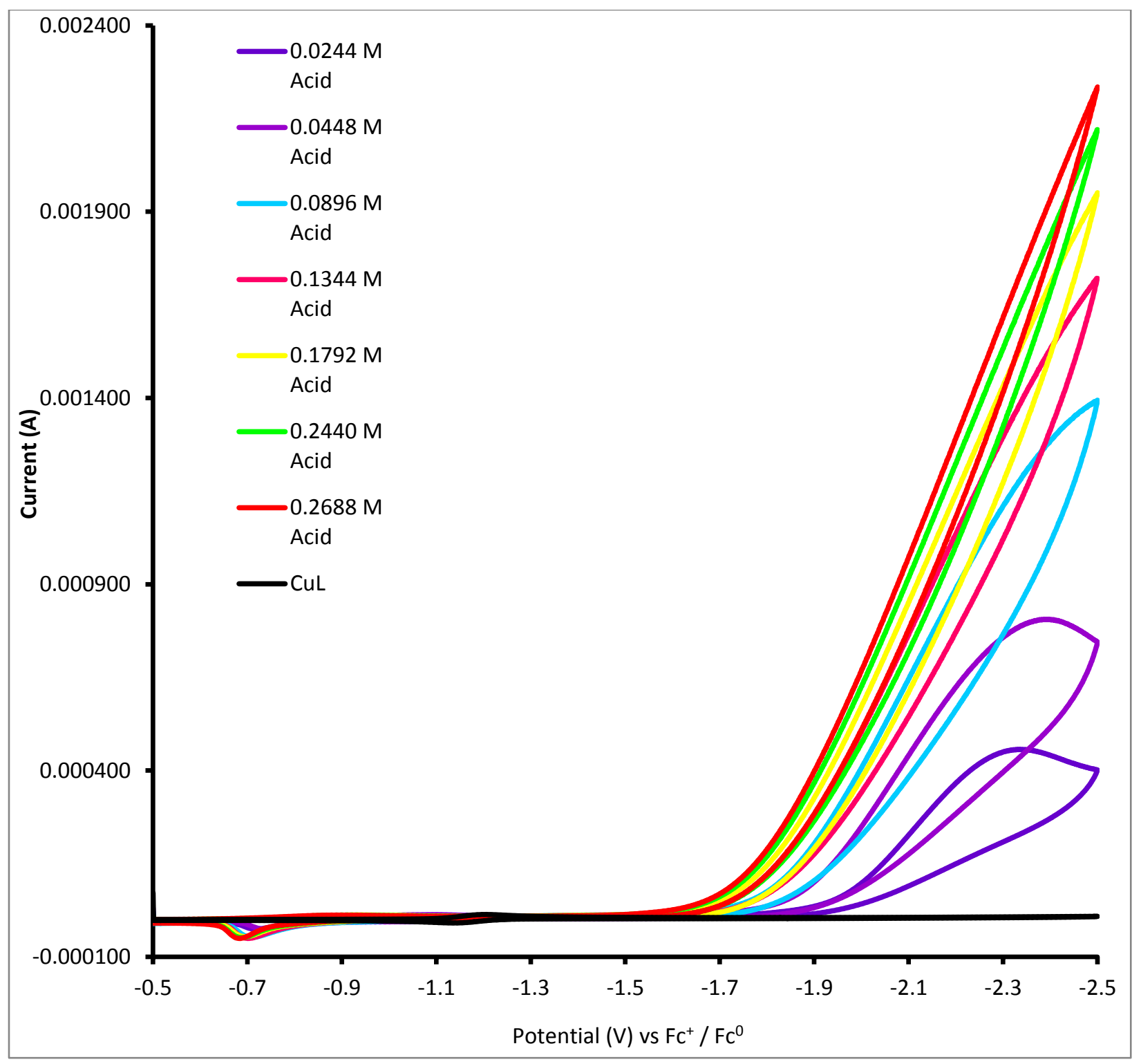

Figure C93. $\mathrm{CuL}^{1} \mathrm{HER}$ cyclic voltammograms in $0.1 \mathrm{M} \mathrm{Bu}_{4} \mathrm{NPF}_{6}$ acetonitrile solution with increasing concentrations of $\mathrm{CH}_{3} \mathrm{COOH}$ added; $v=0.2 \mathrm{~V} / \mathrm{s}$. 


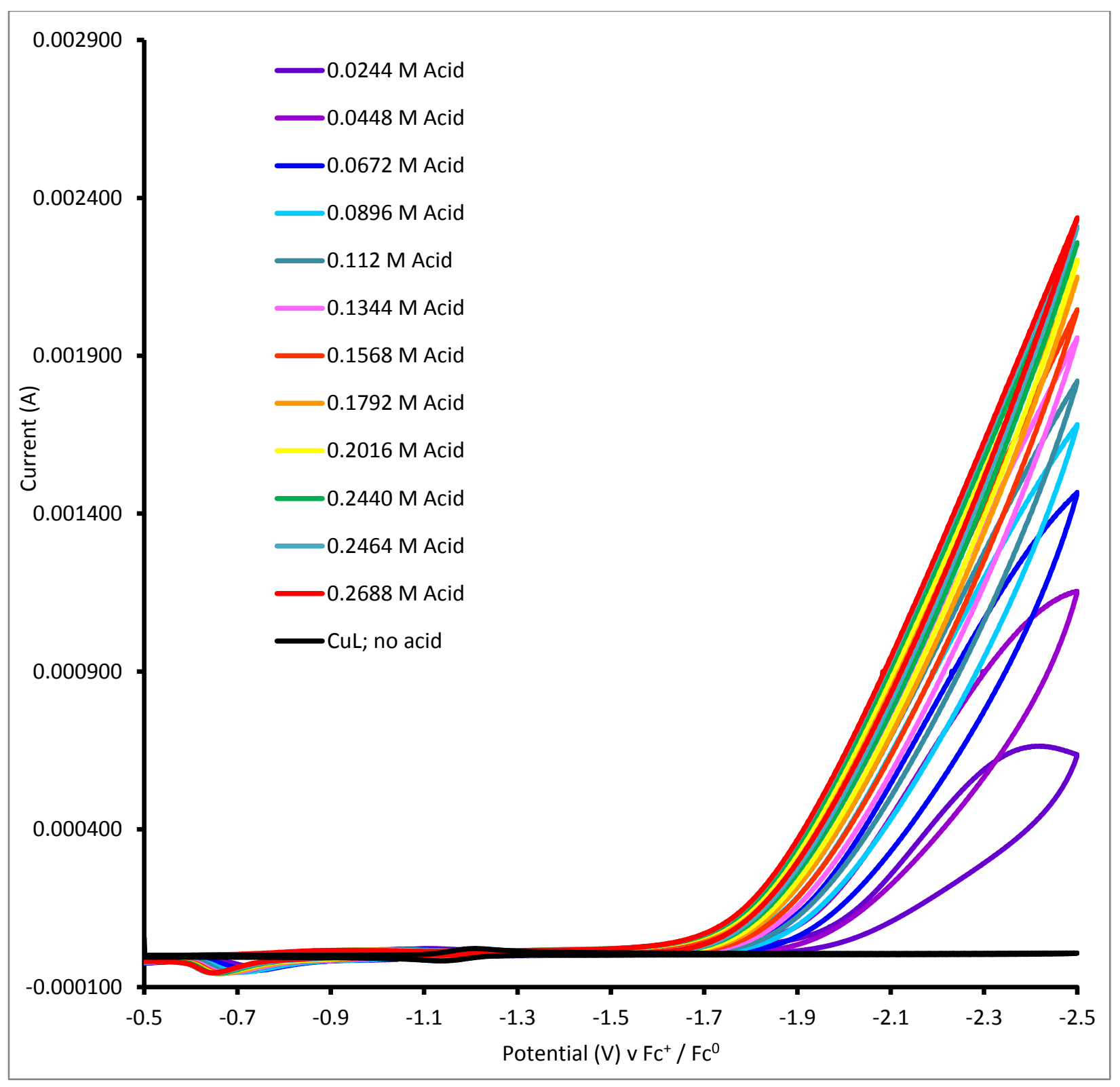

Figure C94. $\mathrm{CuL}^{1} \mathrm{HER}$ cyclic voltammograms in $0.1 \mathrm{M} \mathrm{Bu}_{4} \mathrm{NPF}_{6}$ acetonitrile solution with increasing concentrations of $\mathrm{CH}_{3} \mathrm{COOH}$ added; $v=0.5 \mathrm{~V} / \mathrm{s}$. 


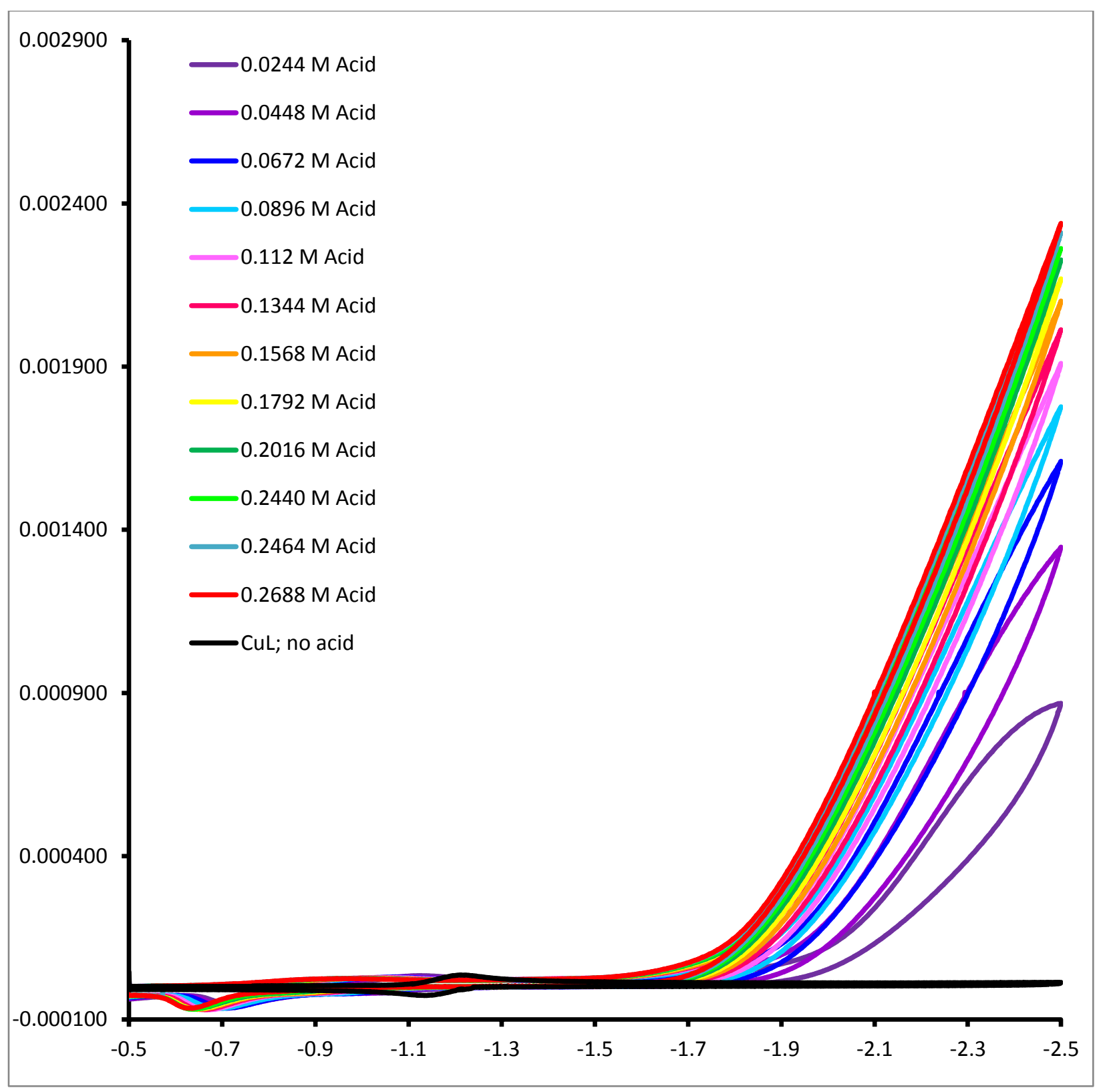

Figure C95. $\mathrm{CuL}^{1} \mathrm{HER}$ cyclic voltammograms in $0.1 \mathrm{M} \mathrm{Bu}_{4} \mathrm{NPF}_{6}$ acetonitrile solution with increasing concentrations of $\mathrm{CH}_{3} \mathrm{COOH}$ added; $v=1.0 \mathrm{~V} / \mathrm{s}$. 


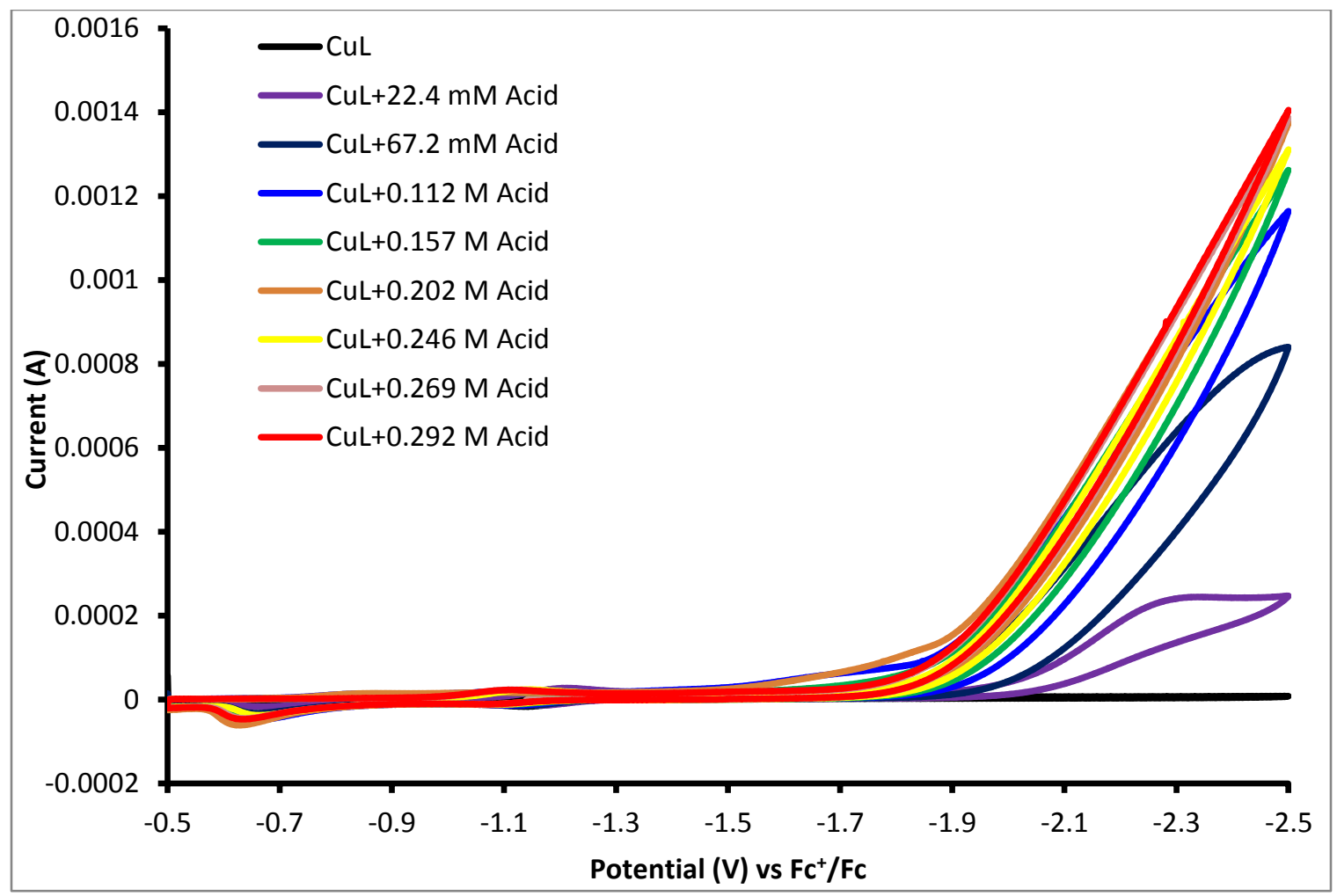

Figure C96. $0.6 \mathrm{mM} \mathrm{CuL}^{1}$ in $0.1 \mathrm{M} \mathrm{Bu}_{4} \mathrm{NPF}_{6}$ DMF; HER CVs scanned at $0.5 \mathrm{~V} / \mathrm{s}$.

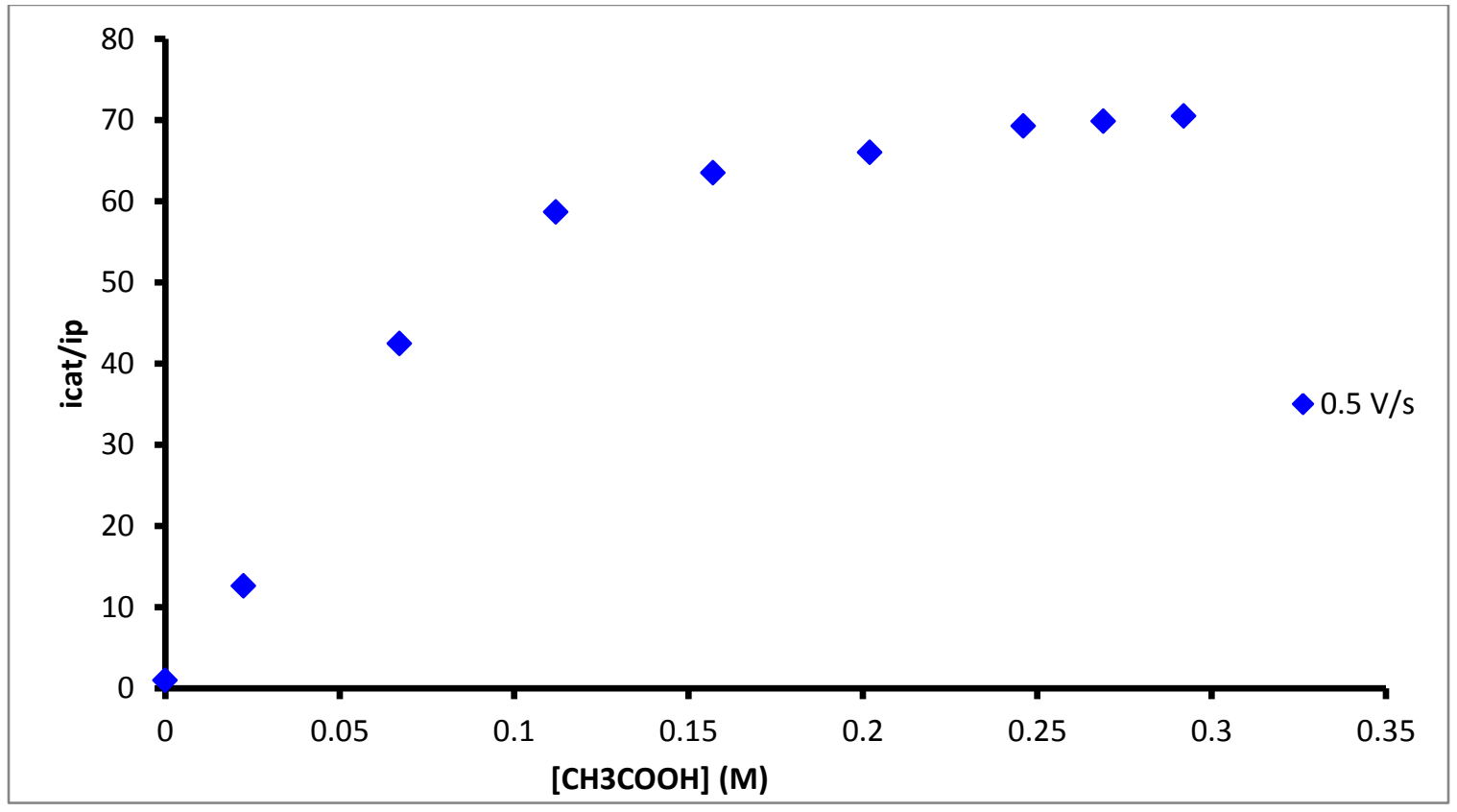

Figure C97. Plot of $i_{c a t} / i_{p}$ vs $\left[\mathrm{CH}_{3} \mathrm{COOH}\right] ; v=0.5 \mathrm{~V} / \mathrm{s}$ 


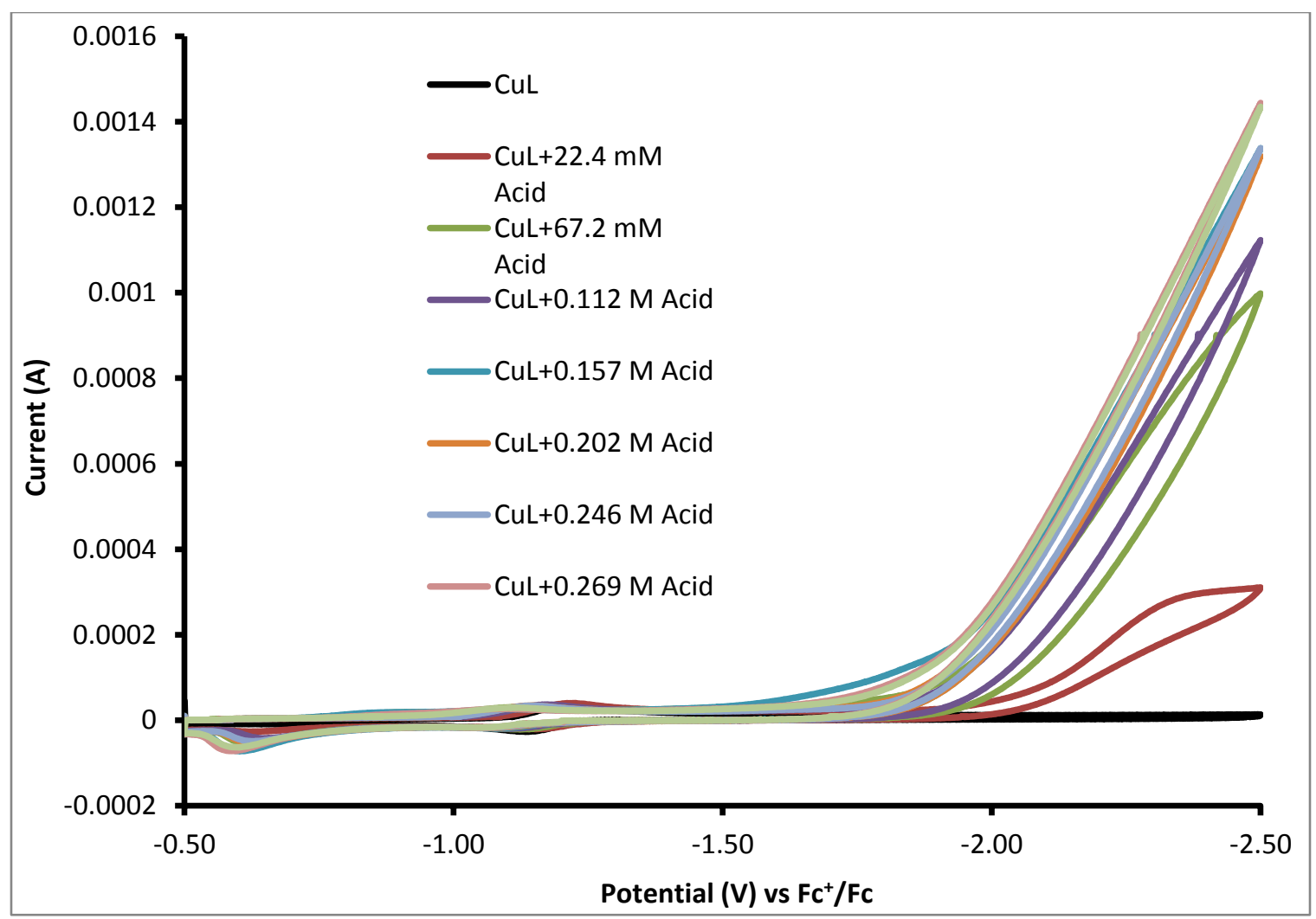

Figure C98. $0.6 \mathrm{mM} \mathrm{CuL}^{1}$ in $0.1 \mathrm{M} \mathrm{Bu}_{4} \mathrm{NPF}_{6}$ DMF; HER CVs scanned at $1.0 \mathrm{~V} / \mathrm{s}$.

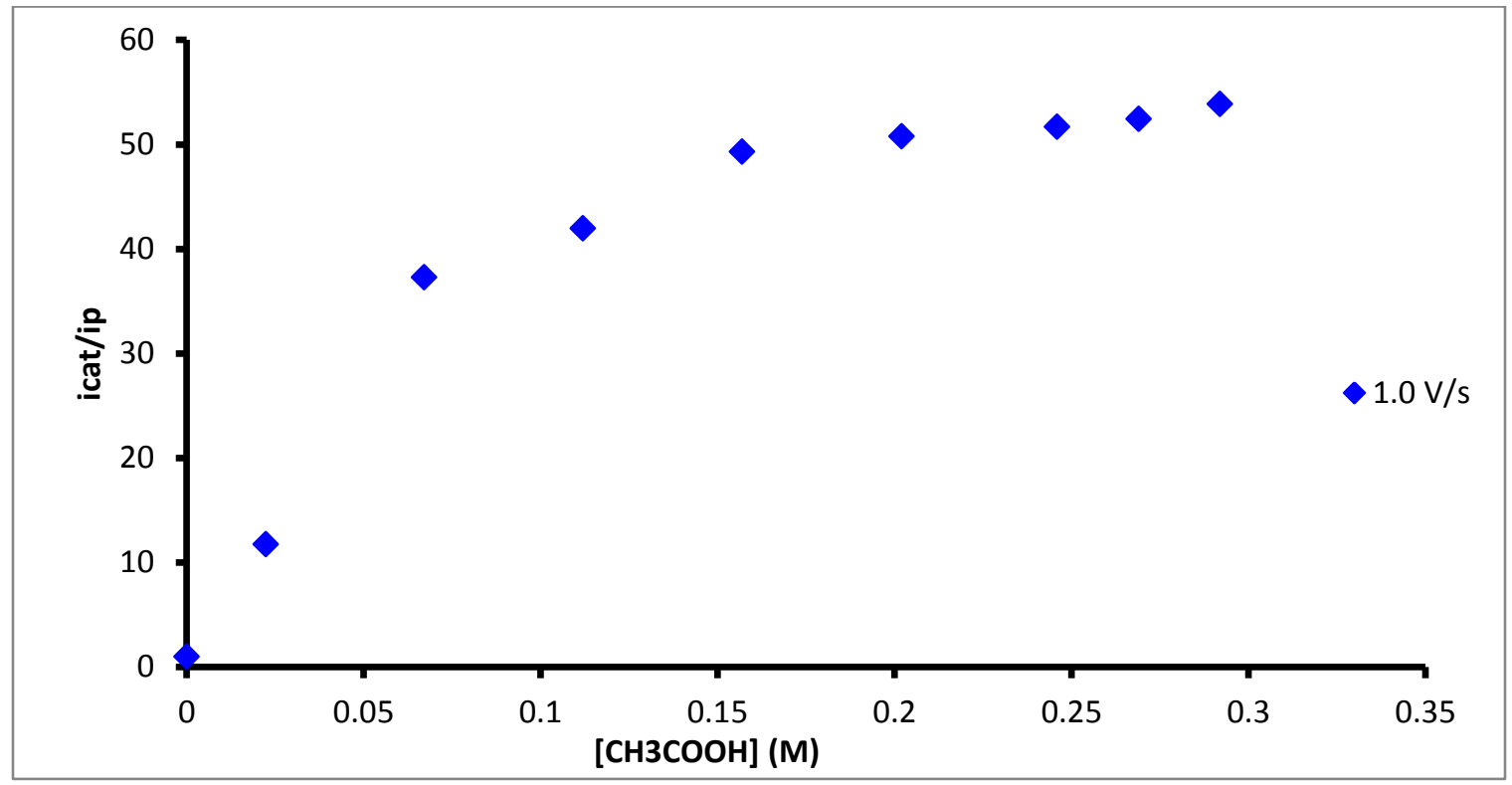

Figure C99. Plot of $i_{c a t} / i_{p}$ vs $\left[\mathrm{CH}_{3} \mathrm{COOH}\right] ; v=1.0 \mathrm{~V} / \mathrm{s}$ 


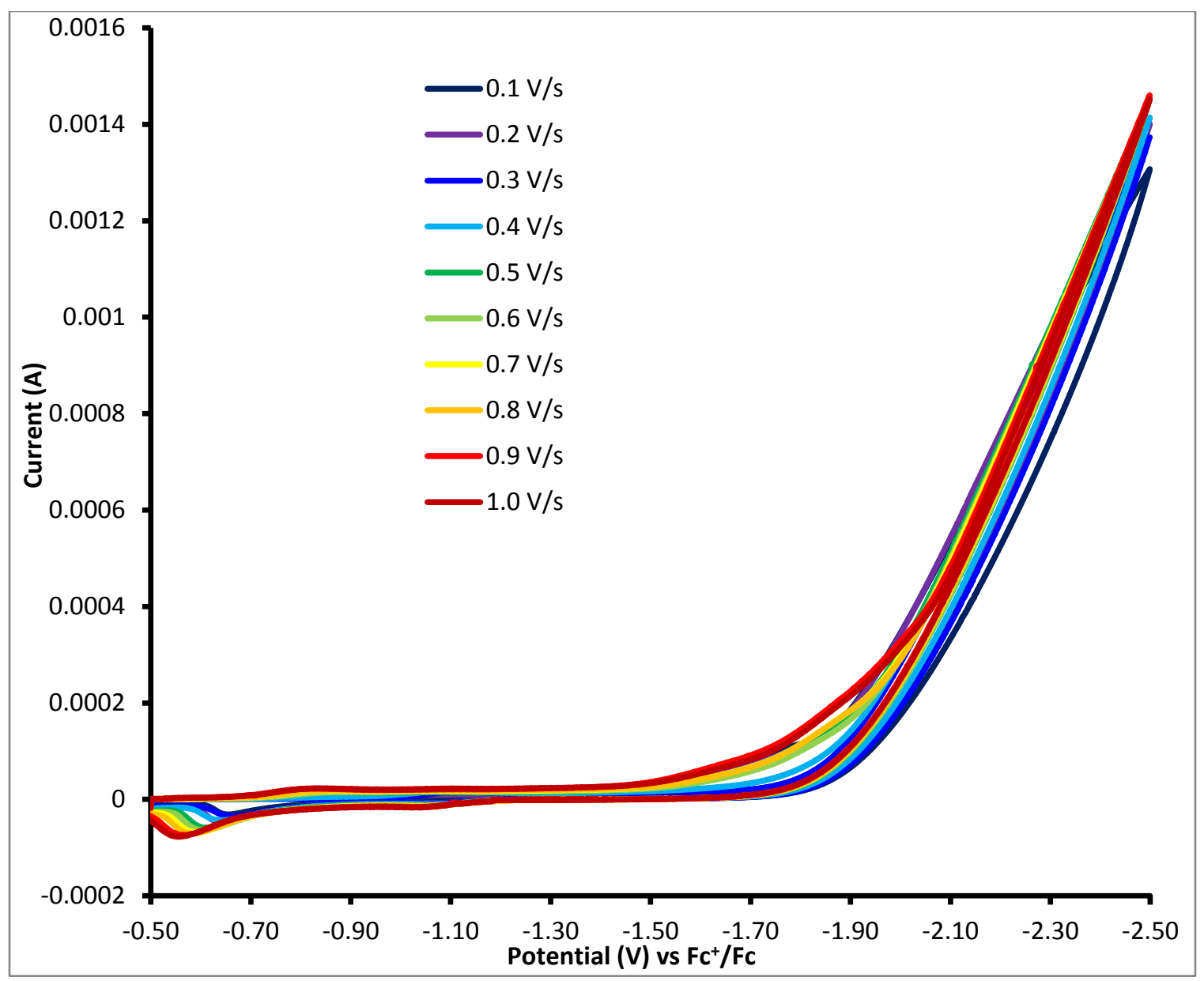

Figure C100. Scan Rate Dependence: $\mathrm{CVs}$ of $0.6 \mathrm{mM} \mathrm{CuL}^{1}$ in $0.1 \mathrm{M} \mathrm{Bu}_{4} \mathrm{NPF}_{6} \mathrm{DMF}$ solution with $0.292 \mathrm{M}$ acetic acid added scanned from $0.1-1.0 \mathrm{~V} / \mathrm{s}$.

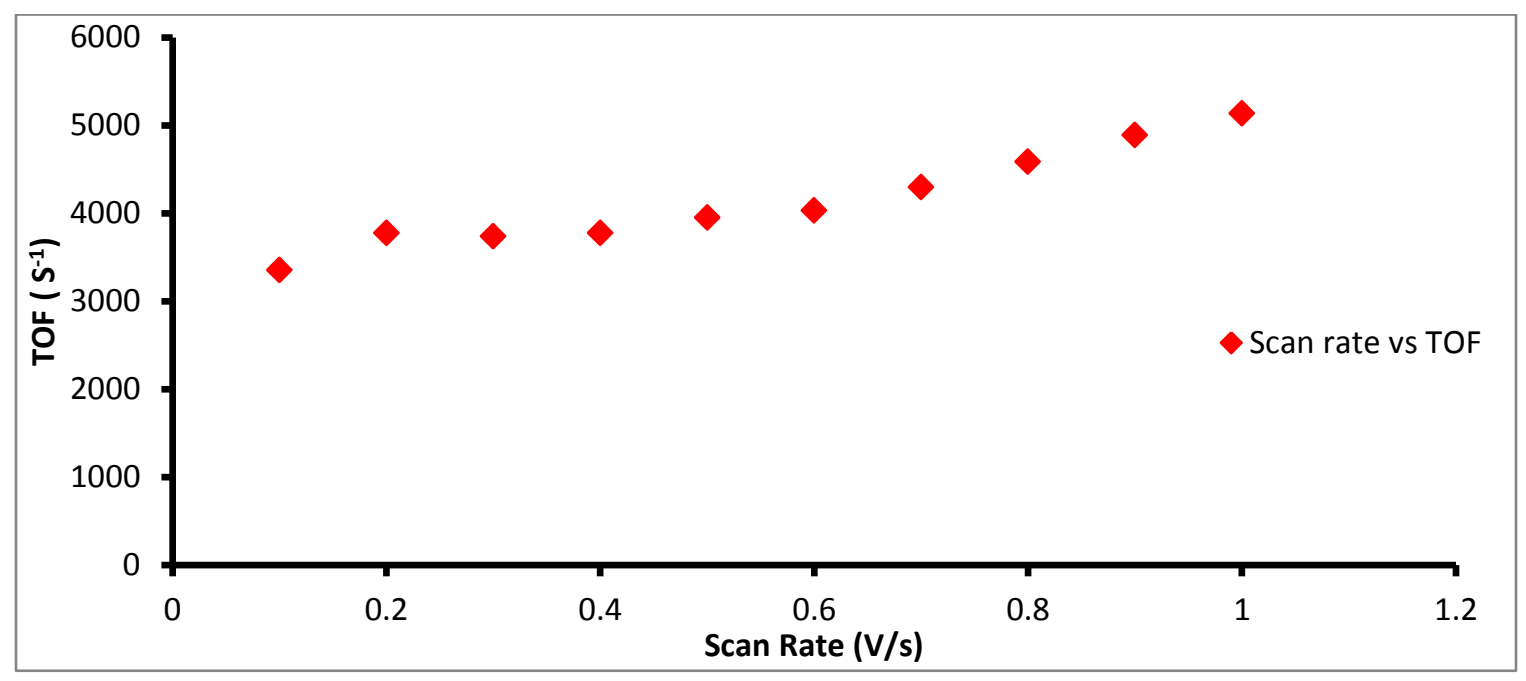

Figure C101. Plot of scan rate vs TOF for $\mathrm{CuL}^{1}$ in DMF. 


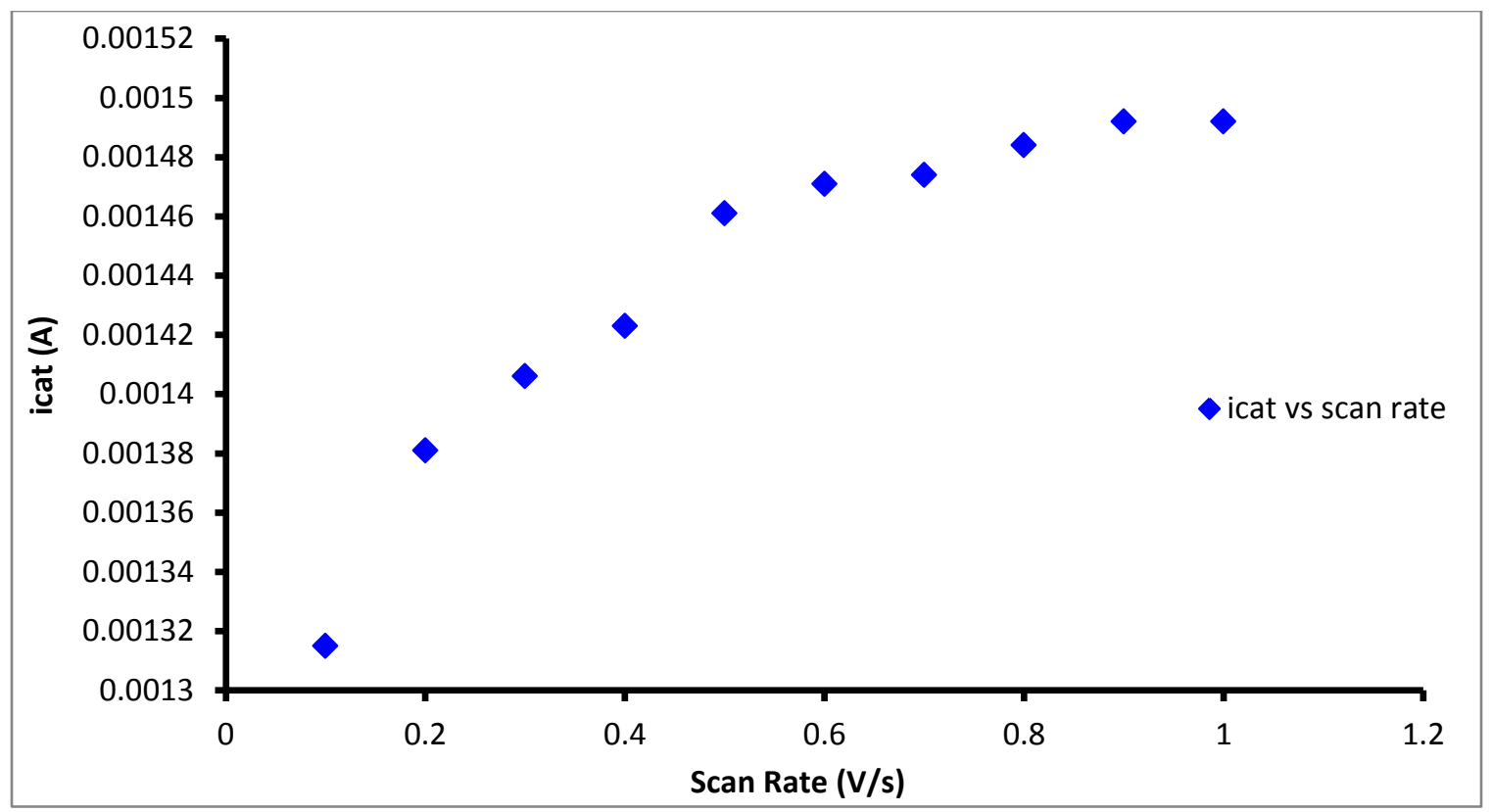

Figure C102. Plot of scan rate vs catalytic current for $\mathrm{CuL}^{1}$ in $\mathrm{DMF}$.

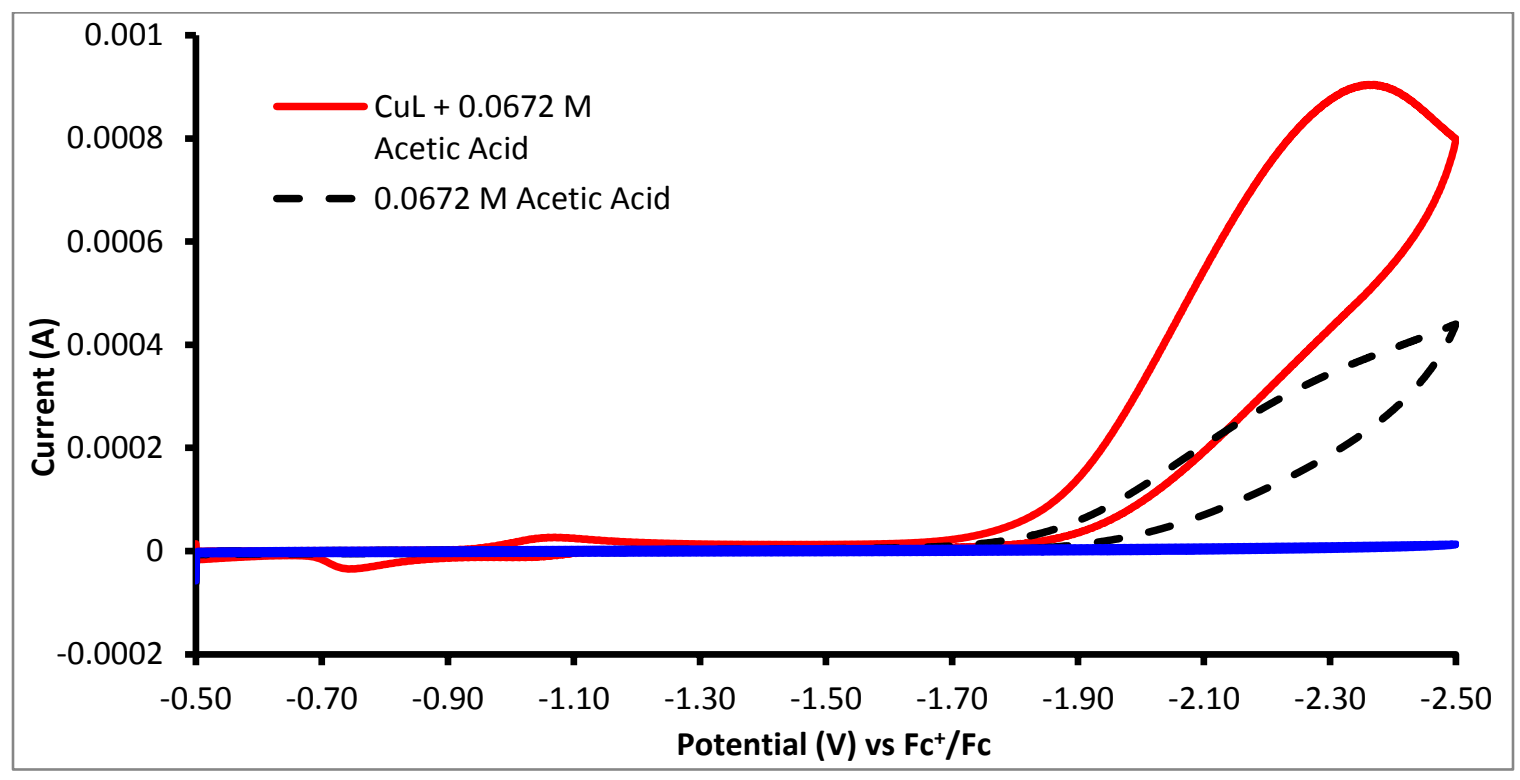

Figure C103. $\mathrm{CV}$ s run in $0.1 \mathrm{M} \mathrm{Bu}_{4} \mathrm{NPF}_{6}$ acetonitrile solutions, showing blank acetonitrile (blue), with $0.0672 \mathrm{M}$ acetic acid added (black dashed), and with $0.0672 \mathrm{M}$ acetic acid and $0.6 \mathrm{mM} \mathrm{CuL}^{1}$ (red). 


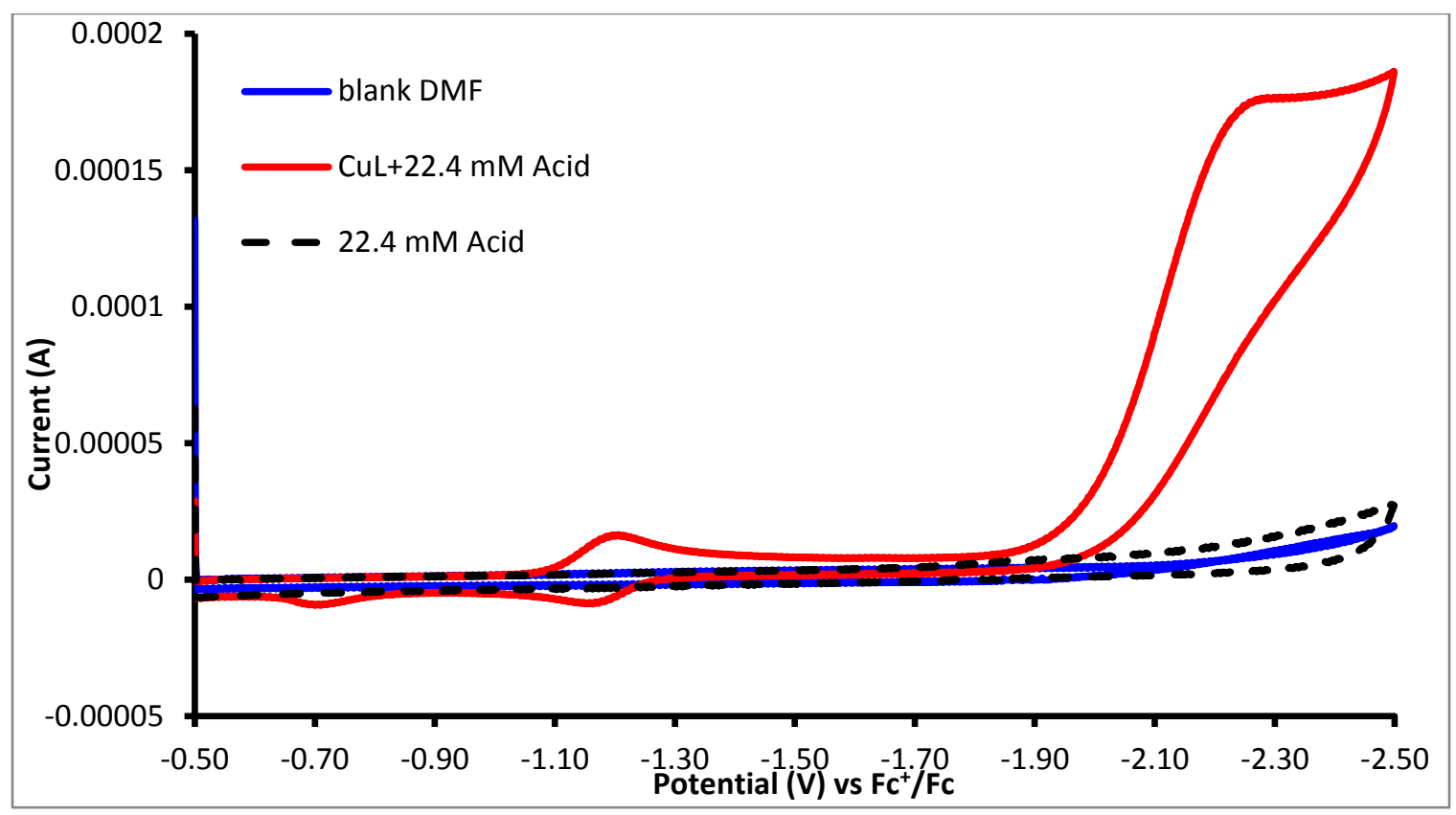

Figure 104. CVs run in $0.1 \mathrm{M} \mathrm{Bu}_{4} \mathrm{NPF}_{6} \mathrm{DMF}$ solutions, showing blank DMF (blue), with $0.0224 \mathrm{M}$ acetic acid added (black dashed), and with $0.0224 \mathrm{M}$ acetic acid and $0.6 \mathrm{mM}$ $\mathrm{CuL}^{1}$ (red).

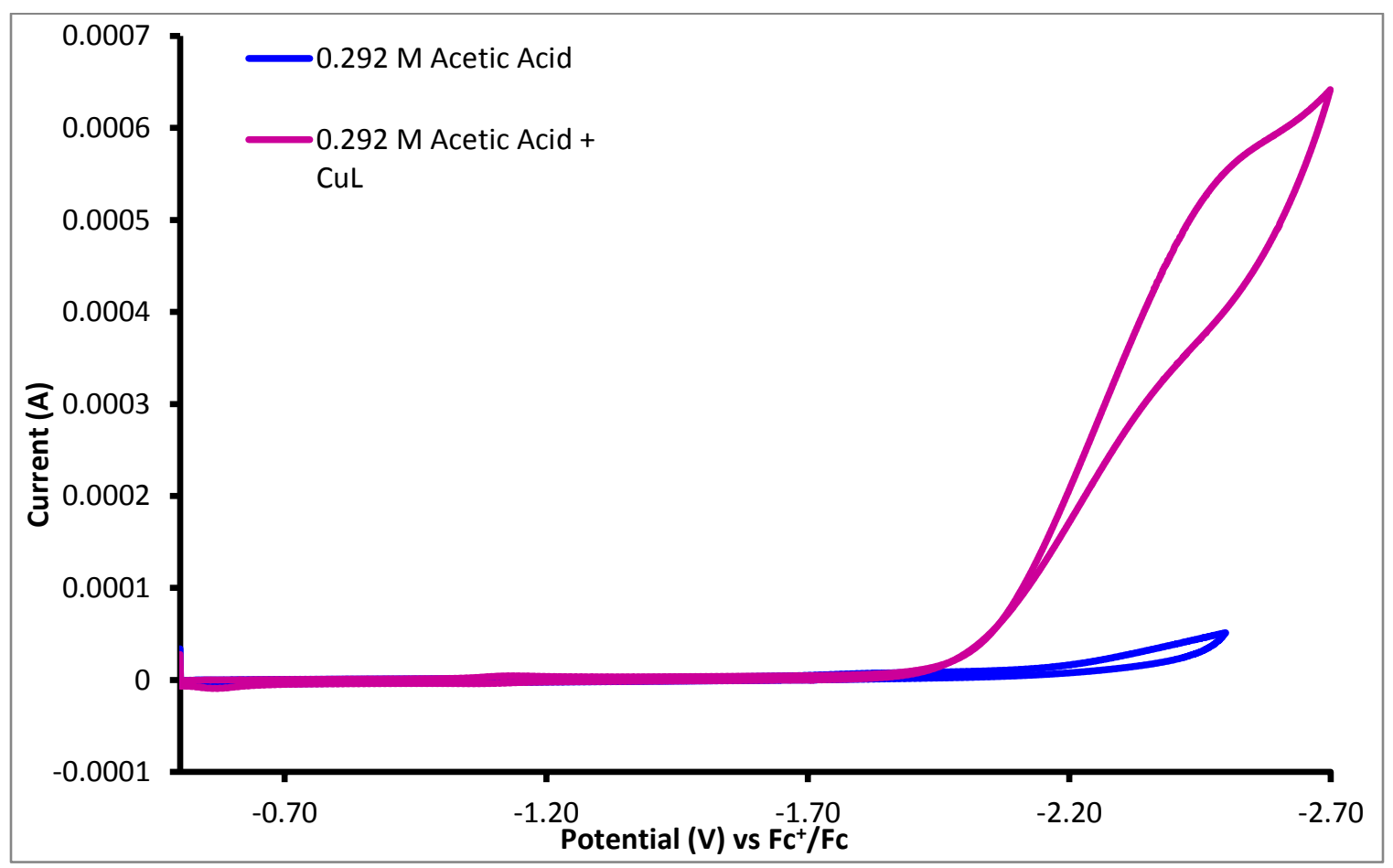

Figure C105. CVs run in $0.1 \mathrm{M} \mathrm{Bu}_{4} \mathrm{NPF}_{6} \mathrm{DMF}$ solutions with $0.292 \mathrm{M}$ acetic acid (blue) and upon addition of $0.6 \mathrm{mM} \mathrm{CuL}^{1}$ (purple). 


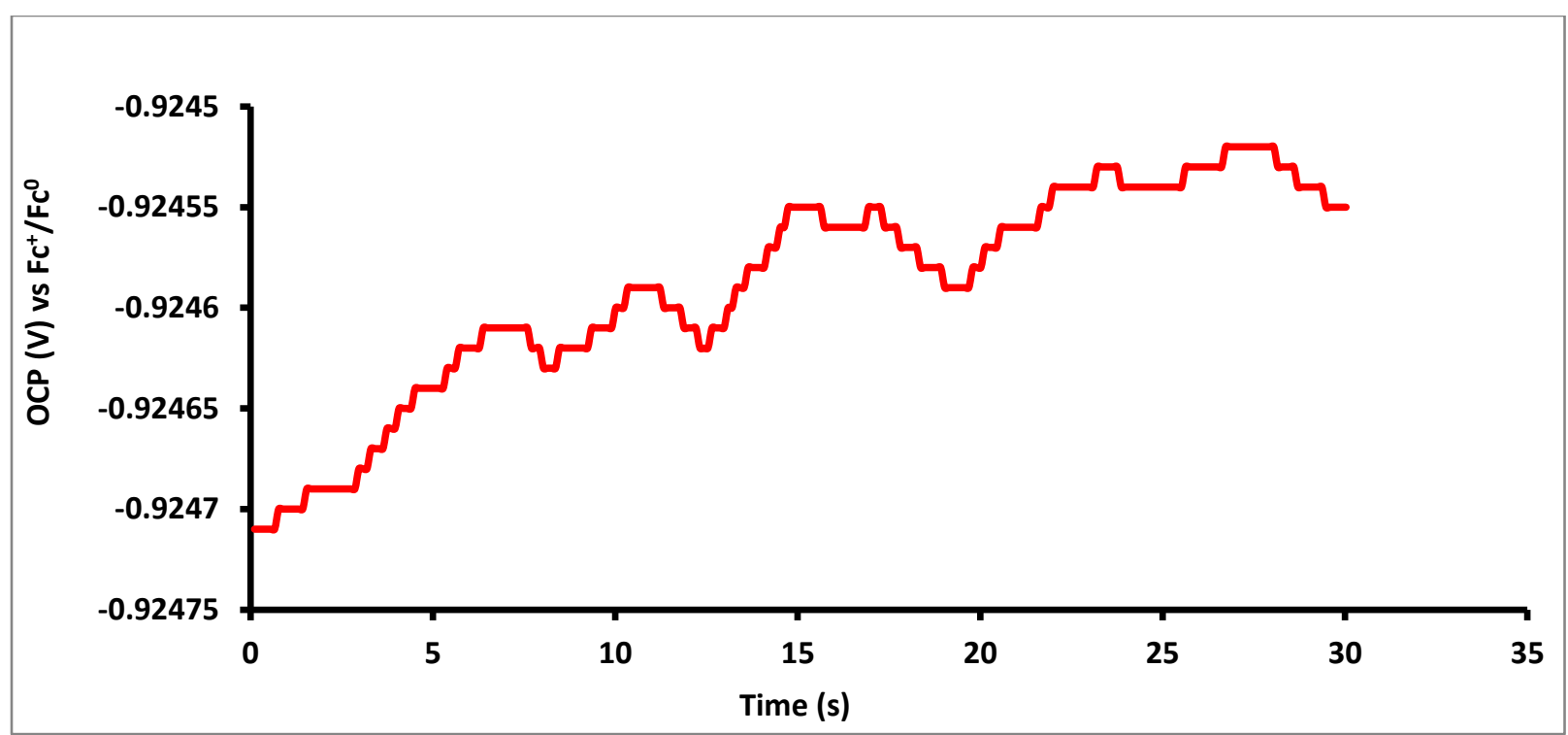

Figure C106. OCP measurement for $\mathrm{ZnL}^{1} \mathrm{HER}$

$0.1 \mathrm{M} \mathrm{Bu}_{4} \mathrm{NPF}_{6}$ methanol solution with $12 \mathrm{mM}$ acetic acid added.

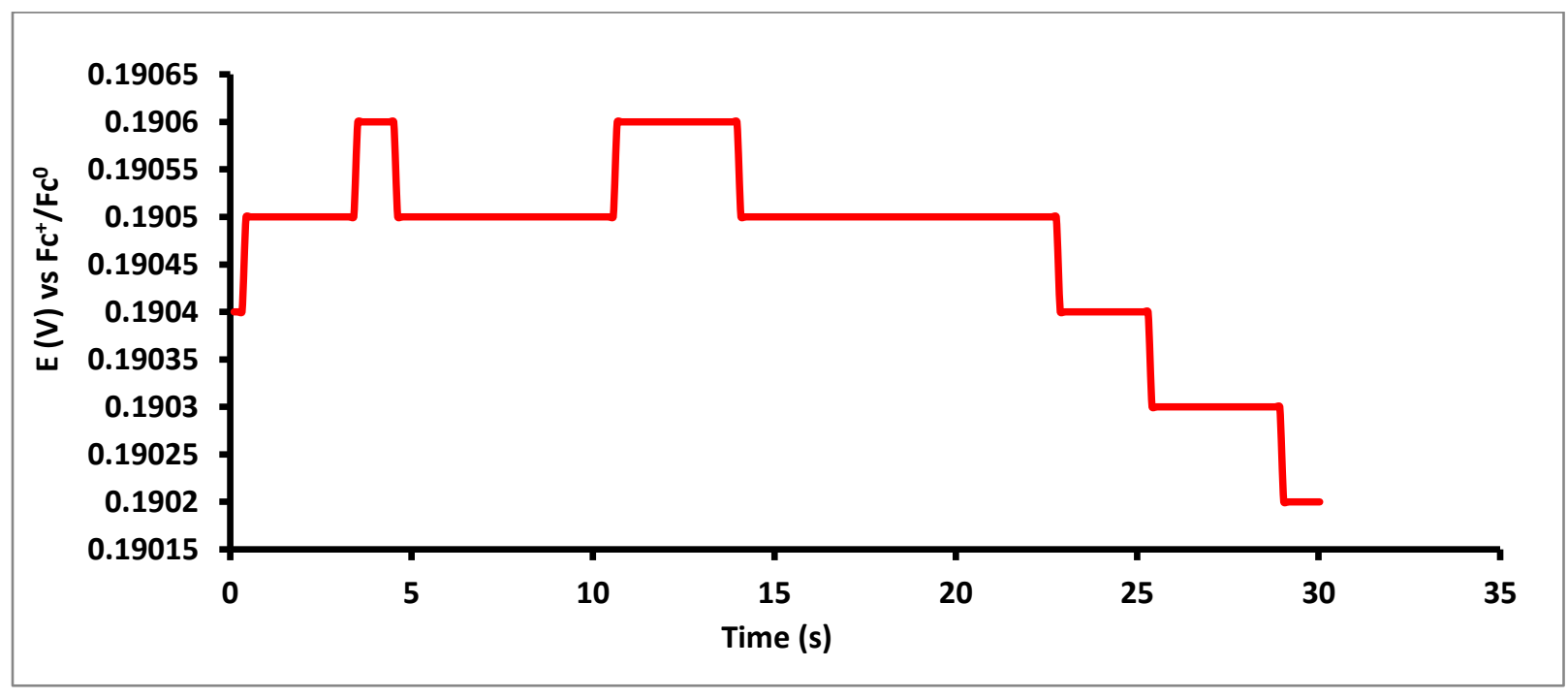

Figure C107. OCP measurement for $\mathrm{ZnL}^{1} \mathrm{HOR}$

$0.1 \mathrm{M} \mathrm{Bu}_{4} \mathrm{NPF}_{6}$ methanol solution with $30 \mathrm{mM}$ triethylamine added. 


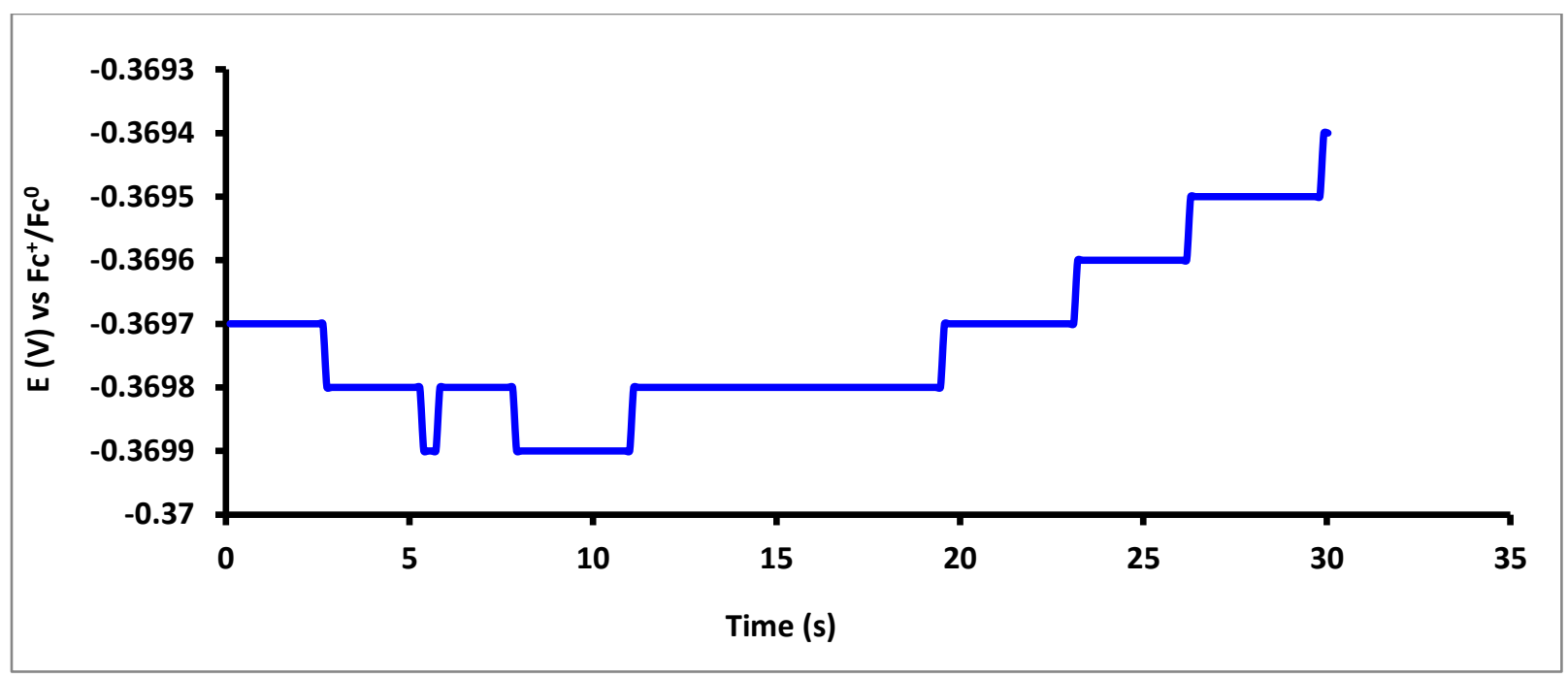

Figure C108. OCP measurement for $\mathrm{H}_{2} \mathrm{~L}^{1} \mathrm{HER}$

$0.1 \mathrm{M} \mathrm{Bu}_{4} \mathrm{NPF}_{6}$ methanol solution with $10 \mathrm{mM}$ acetic acid added.

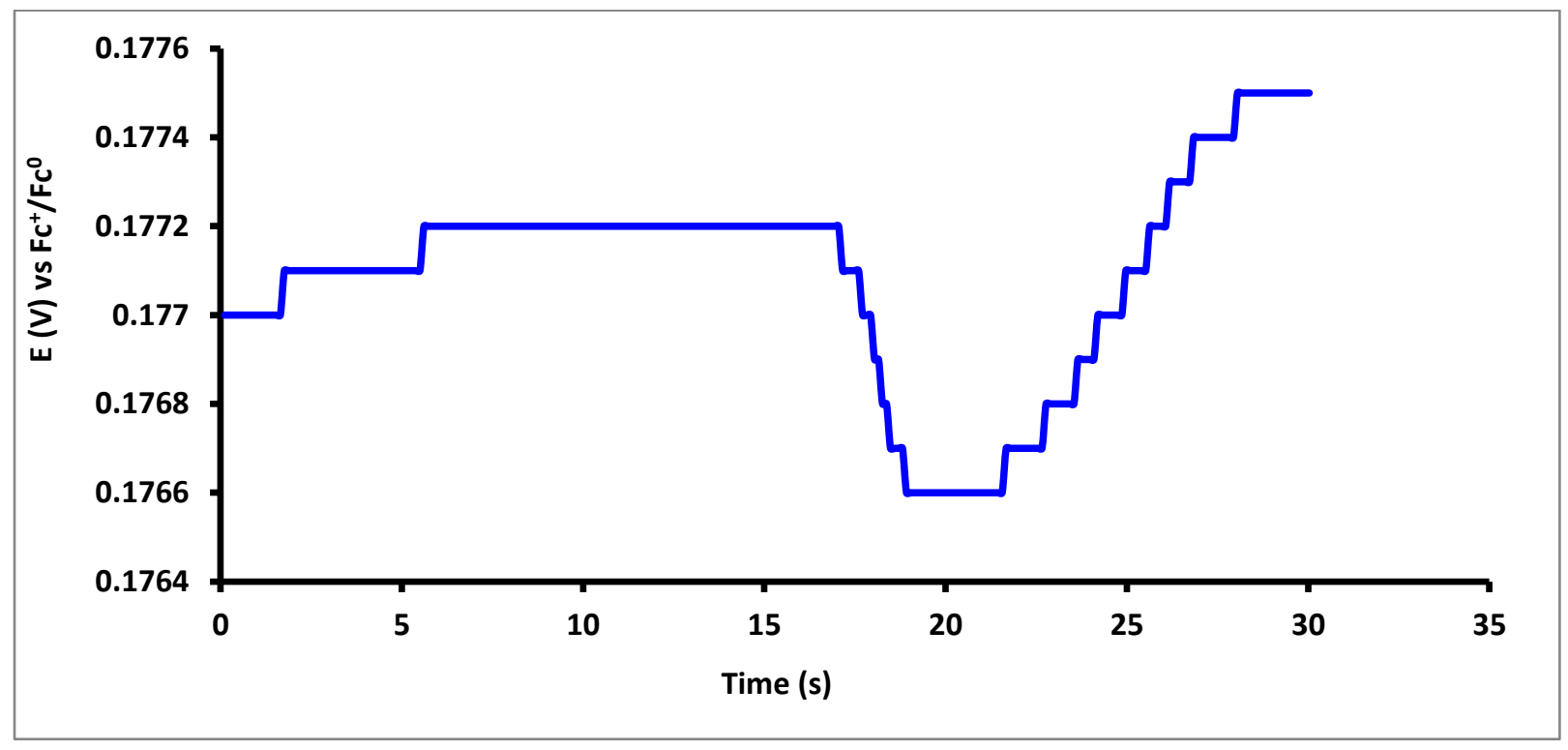

Figure C109. OCP measurement for $\mathrm{H}_{2} \mathrm{~L}^{1} \mathrm{HOR}$

$0.1 \mathrm{M} \mathrm{Bu}_{4} \mathrm{NPF}_{6}$ methanol solution with $10 \mathrm{mM}$ acetic acid added. 


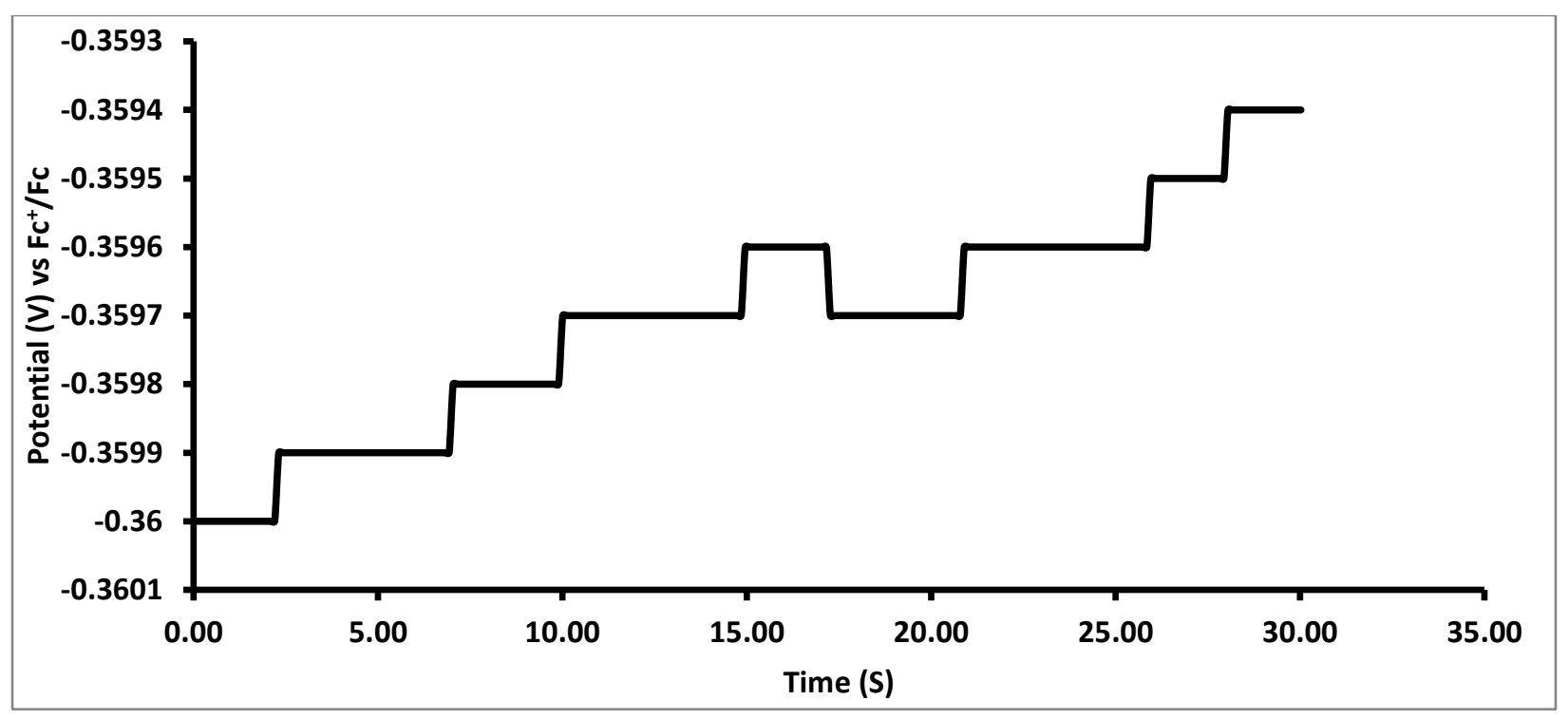

Figure C110. OCP measurement for $\mathrm{ZnL}^{1} \mathrm{HER}$ in Acetonitrile

$0.1 \mathrm{M} \mathrm{Bu}_{4} \mathrm{NPF}_{6}$ acetonitrile solution with $21 \mathrm{mM}$ acetic acid added.

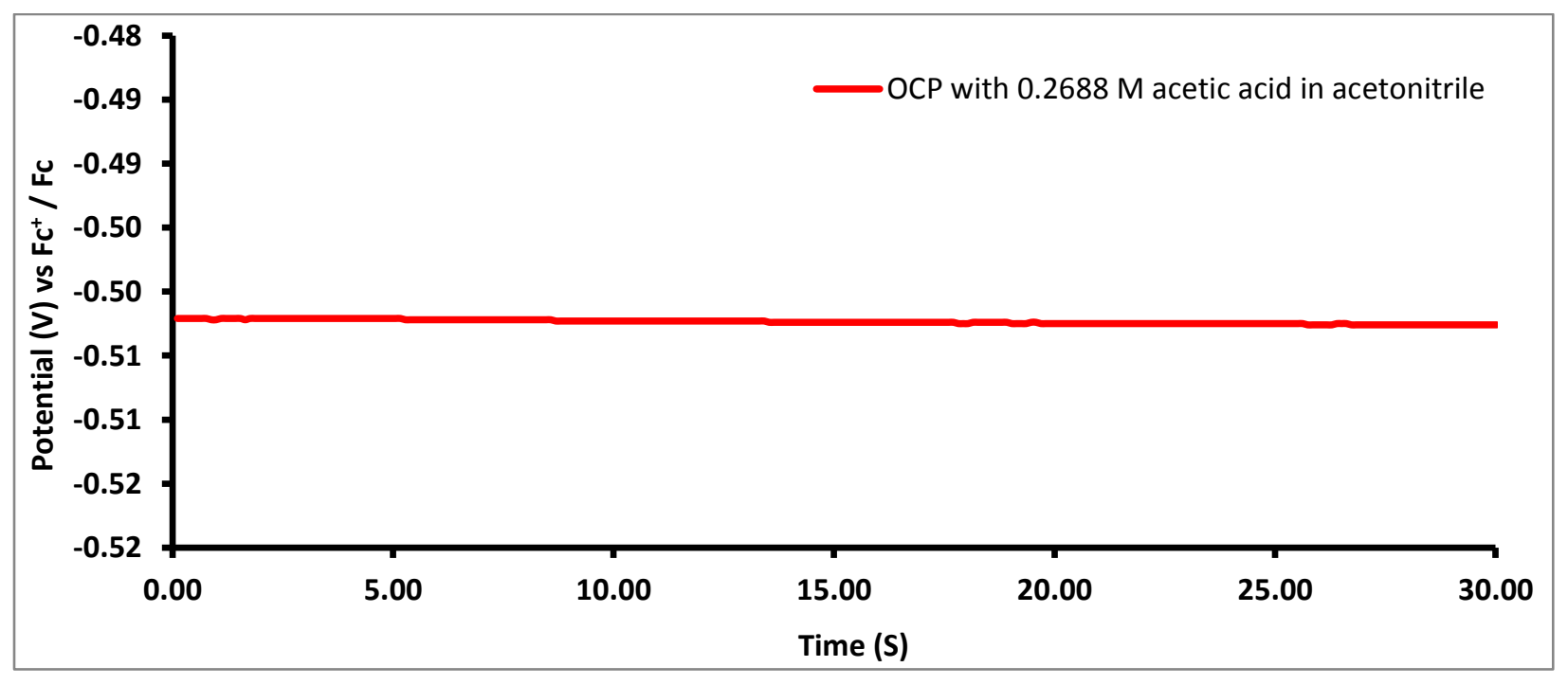

Figure C111. OCP measurement for $\mathrm{CuL}^{1} \mathrm{HER}$

$0.1 \mathrm{M} \mathrm{Bu}_{4} \mathrm{NPF}_{6}$ acetonitrile solution with $0.269 \mathrm{M}$ acetic acid added 


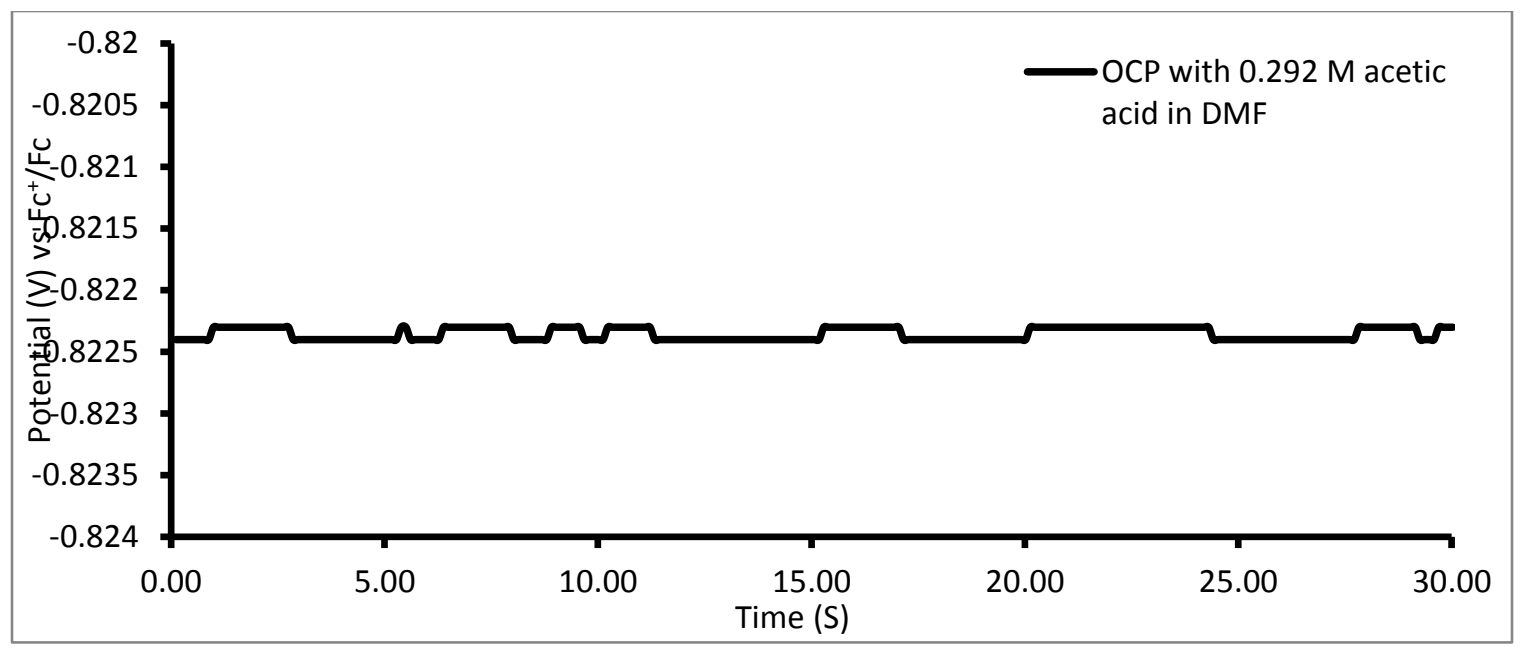

Figure C112. OCP measurement for $\mathrm{CuL}^{1} \mathrm{HER}$

$0.1 \mathrm{M} \mathrm{Bu}_{4} \mathrm{NPF}_{6}$ DMF solution with $0.292 \mathrm{M}$ acetic acid added.

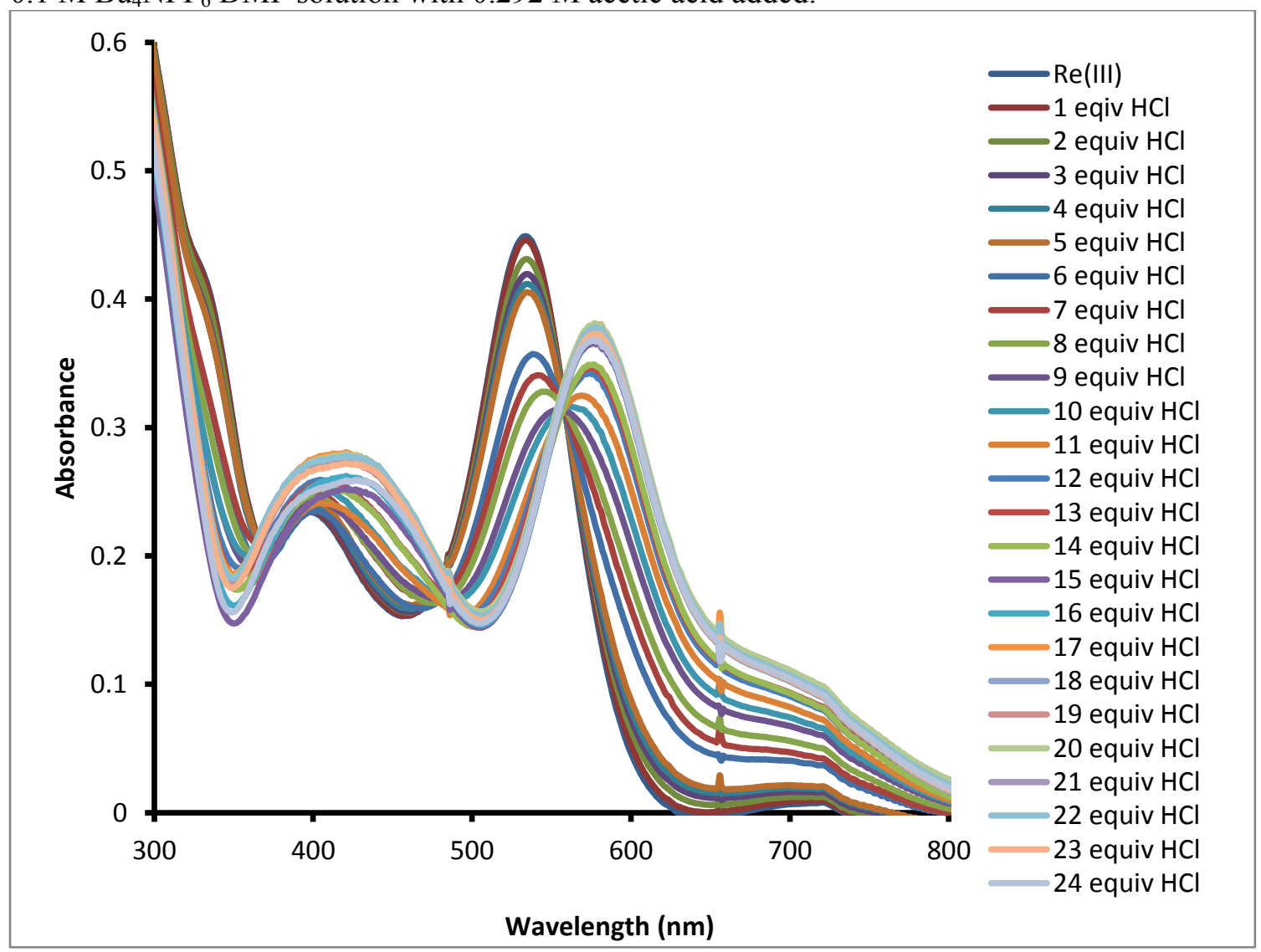

Figure C113. UV-Vis absorbance's measured during titration of $\mathrm{ReL}_{3}$ with increasing equivalents of $\mathrm{HCl}$. 


\section{APPENDIX D: ADDITIONAL DFT STRUCTURES AND ALL COMPUTATIONAL INPUT COORDINATES}




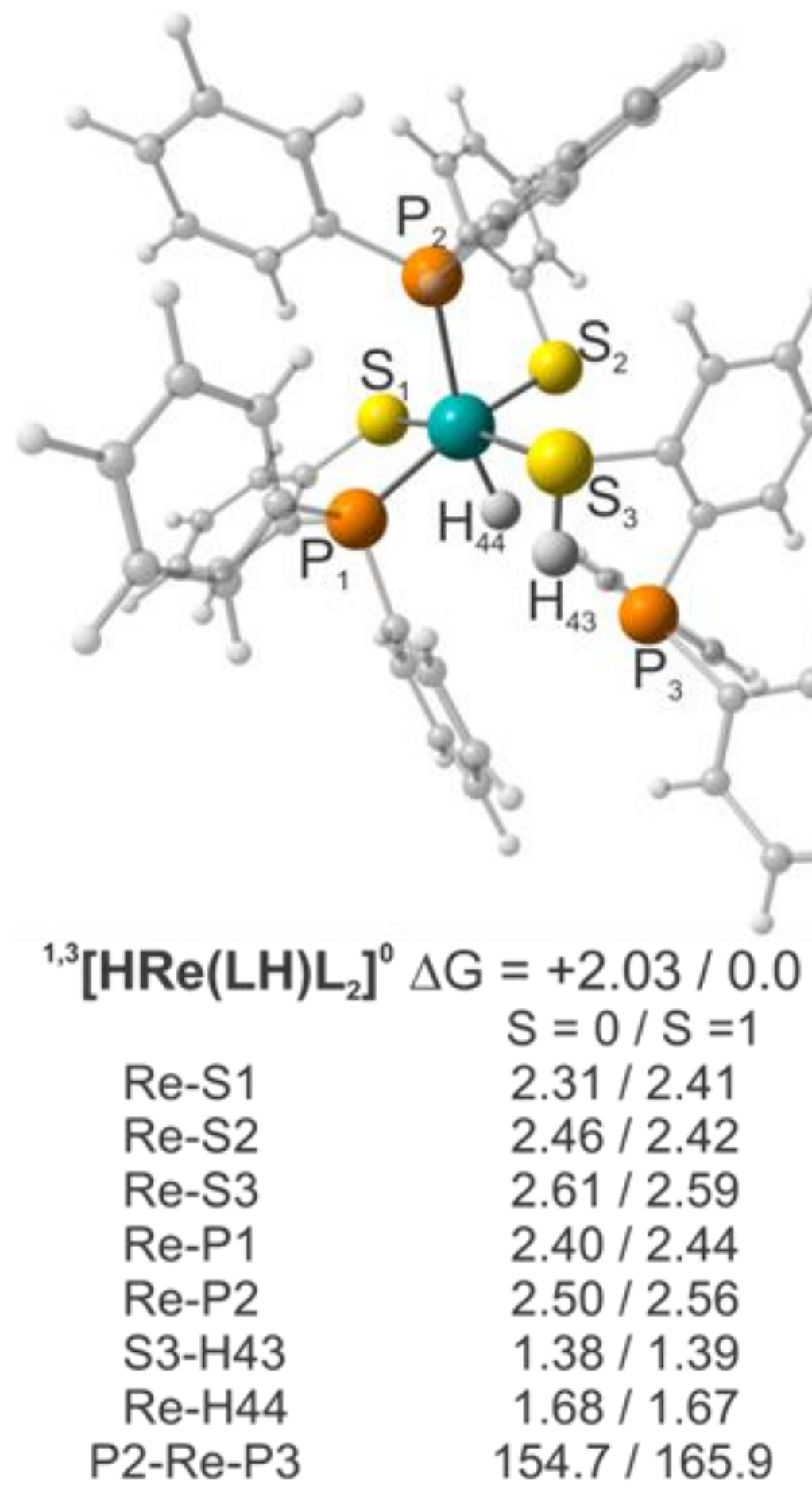

Figure D114. DFT (M06 / LANL2DZ) optimized geometric parameters with bond lengths $(\AA)$ and angles $\left(^{\circ}\right)$ for $\left[\mathrm{HRe}(\mathrm{LH}) \mathrm{L}_{2}\right]^{0}$ with free energy energies (kcal / mole) of singlet $(\mathrm{S}=0)$ and triplet $(\mathrm{S}=1)$ electronic states. 
Table D7. Computational input coordinates for $\mathrm{ZnL}^{1}$ and related compounds. $\underline{\mathrm{ZnL}}$

01

$\mathrm{Zn} \quad 0.00003000 \quad-0.87035000 \quad-0.00021000$

S $\quad 1.99717800 \quad-1.98187000 \quad 0.39859600$

C $\quad 3.02385700 \quad-0.57568000 \quad 0.06312600$

$\mathrm{N} \quad 2.64126500 \quad 0.68182000 \quad-0.11295000$

$\mathrm{N} \quad 1.29611500 \quad 0.83221600 \quad-0.13343000$

$\begin{array}{llll}\text { C } & 0.74221000 & 2.00306700 & -0.01927000\end{array}$

$\begin{array}{llll}\text { C } & -0.74227000 & 2.00309000 & 0.01908300\end{array}$

$\mathrm{N} \quad-1.29622000 \quad 0.83222900 \quad 0.13305300$

$\mathrm{N} \quad-2.64133000 \quad 0.68180300 \quad 0.11294100$

C $\quad-3.02384000 \quad-0.57582000 \quad-0.06295000$

S $\quad-1.99721000 \quad-1.98199000 \quad-0.39809000$

$\mathrm{N} \quad 4.35570700 \quad-0.82176000 \quad 0.01195100$

C $\quad 5.36070300 \quad 0.19708100 \quad-0.24871000$

$\begin{array}{llll}\text { C } & 1.51592800 & 3.28691200 & 0.08674400\end{array}$

C $\quad-1.51582000 \quad 3.28710900 \quad-0.08627000$

$\mathrm{N} \quad-4.35572000 \quad-0.82183000 \quad-0.01172000$

$\begin{array}{llll}\text { C } & -5.36071000 & 0.19724100 & 0.24805300\end{array}$

$\mathrm{H} \quad 4.64910400 \quad-1.76944000 \quad 0.19775300$

$\mathrm{H} \quad-4.64921000 \quad-1.76953000 \quad-0.19732000$

$\mathrm{H} \quad 6.34217200 \quad-0.28345000 \quad-0.24323000$

$\begin{array}{llll}\mathrm{H} & 5.33720300 & 0.97919000 & 0.51882200\end{array}$ 


$\begin{array}{llll}\mathrm{H} & 5.19661500 & 0.66931400 & -1.22332000 \\ \mathrm{H} & 2.57356100 & 3.10001400 & -0.10327000 \\ \mathrm{H} & 1.41553600 & 3.72317600 & 1.09013800 \\ \mathrm{H} & 1.14601100 & 4.03184200 & -0.62751000 \\ \mathrm{H} & -2.57412000 & 3.09947900 & 0.09927500 \\ \mathrm{H} & -1.14881000 & 4.02987600 & 0.63178900 \\ \mathrm{H} & -1.41150000 & 3.72652300 & -1.08785000 \\ \mathrm{H} & -6.34227000 & -0.28309000 & 0.24188600 \\ \mathrm{H} & -5.19732000 & 0.66960500 & 1.22273300 \\ \mathrm{H} & -5.33643000 & 0.97923600 & -0.51956000\end{array}$

\section{$\underline{\mathrm{ZnHL}]^{+}}$}

11

$\begin{array}{llll}\mathrm{Zn} & 0.000030000 & -0.870350000 & -0.000210000\end{array}$

S $\quad 1.997178000 \quad-1.981870000 \quad 0.398596000$

$\begin{array}{llll}\text { C } & 3.023857000 & -0.575680000 & 0.063126000\end{array}$

$\mathrm{N} \quad 2.641265000 \quad 0.681820000 \quad-0.112950000$

$\mathrm{N} \quad 1.296115000 \quad 0.832216000 \quad-0.133430000$

C $\quad 0.742210000 \quad 2.003067000 \quad-0.019270000$

C $\quad-0.742270000 \quad 2.003090000 \quad 0.019083000$

$\mathrm{N} \quad-1.296220000 \quad 0.832229000 \quad 0.133053000$

$\mathrm{N} \quad-2.641330000 \quad 0.681803000 \quad 0.112941000$

$\begin{array}{llll}\text { C } & -3.023840000 & -0.575820000 & -0.062950000\end{array}$ 


\begin{tabular}{|c|c|c|c|}
\hline $\mathrm{S}$ & -1.997210000 & -1.981990000 & -0.398090000 \\
\hline $\mathrm{N}$ & 4.355707000 & -0.821760000 & 0.011951000 \\
\hline $\mathrm{C}$ & 5.360703000 & 0.197081000 & -0.248710000 \\
\hline $\mathrm{C}$ & 1.515928000 & 3.286912000 & 0.086744000 \\
\hline $\mathrm{C}$ & -1.515820000 & 3.287109000 & -0.086270000 \\
\hline $\mathrm{N}$ & -4.355720000 & -0.821830000 & -0.011720000 \\
\hline $\mathrm{C}$ & -5.360710000 & 0.197241000 & 0.248053000 \\
\hline $\mathrm{H}$ & 4.649104000 & -1.769440000 & 0.197753000 \\
\hline $\mathrm{H}$ & -4.649210000 & -1.769530000 & -0.197320000 \\
\hline $\mathrm{H}$ & 6.342172000 & -0.283450000 & -0.243230000 \\
\hline $\mathrm{H}$ & 5.337203000 & 0.979190000 & 0.518822000 \\
\hline $\mathrm{H}$ & 5.196615000 & 0.669314000 & -1.223320000 \\
\hline $\mathrm{H}$ & 2.573561000 & 3.100014000 & -0.103270000 \\
\hline $\mathrm{H}$ & 1.415536000 & 3.723176000 & 1.090138000 \\
\hline $\mathrm{H}$ & 1.146011000 & 4.031842000 & -0.627510000 \\
\hline $\mathrm{H}$ & -2.574120000 & 3.099479000 & 0.099275000 \\
\hline $\mathrm{H}$ & -1.148810000 & 4.029876000 & 0.631789000 \\
\hline $\mathrm{H}$ & -1.411500000 & 3.726523000 & -1.087850000 \\
\hline $\mathrm{H}$ & -6.342270000 & -0.283090000 & 0.241886000 \\
\hline $\mathrm{H}$ & -5.197320000 & 0.669605000 & 1.222733000 \\
\hline $\mathrm{H}$ & -5.336430000 & 0.979236000 & -0.519560000 \\
\hline $\mathrm{H}$ & 3.281842792 & 1.442241206 & -0.219812917 \\
\hline
\end{tabular}




$\begin{array}{llll}\mathrm{Zn}(\mathrm{HL} \cdot) & & & \\ \mathrm{N} 2 & & & \\ \mathrm{Zn} & 0.000030000 & -0.870350000 & -0.000210000 \\ \mathrm{~S} & 1.997178000 & -1.981870000 & 0.398596000 \\ \mathrm{C} & 3.023857000 & -0.575680000 & 0.063126000 \\ \mathrm{~N} & 2.641265000 & 0.681820000 & -0.112950000 \\ \mathrm{~N} & 1.296115000 & 0.832216000 & -0.133430000 \\ \mathrm{C} & 0.742210000 & 2.003067000 & -0.019270000 \\ \mathrm{C} & -0.742270000 & 2.003090000 & 0.019083000 \\ \mathrm{~N} & -1.296220000 & 0.832229000 & 0.133053000 \\ \mathrm{~N} & -2.641330000 & 0.681803000 & 0.112941000 \\ \mathrm{C} & -3.023840000 & -0.575820000 & -0.062950000 \\ \mathrm{~S} & -1.997210000 & -1.981990000 & -0.398090000 \\ \mathrm{~N} & 4.355707000 & -0.821760000 & 0.011951000 \\ \mathrm{C} & 5.360703000 & 0.197081000 & -0.248710000 \\ \mathrm{C} & 1.515928000 & 3.286912000 & 0.086744000 \\ \mathrm{C} & -1.515820000 & 3.287109000 & -0.086270000 \\ \mathrm{~N} & -4.355720000 & -0.821830000 & -0.011720000 \\ \mathrm{C} & -5.360710000 & 0.197241000 & 0.248053000 \\ \mathrm{H} & 4.649104000 & -1.769440000 & 0.197753000 \\ \mathrm{H} & -4.649210000 & -1.769530000 & -0.197320000 \\ \mathrm{H} & 6.342172000 & -0.283450000 & -0.243230000 \\ \mathrm{H} & 5.337203000 & 0.979190000 & 0.518822000\end{array}$




$\begin{array}{llll}\text { H } & 5.196615000 & 0.669314000 & -1.223320000 \\ \mathrm{H} & 2.573561000 & 3.100014000 & -0.103270000 \\ \mathrm{H} & 1.415536000 & 3.723176000 & 1.090138000 \\ \mathrm{H} & 1.146011000 & 4.031842000 & -0.627510000 \\ \mathrm{H} & -2.574120000 & 3.099479000 & 0.099275000 \\ \mathrm{H} & -1.148810000 & 4.029876000 & 0.631789000 \\ \mathrm{H} & -1.411500000 & 3.726523000 & -1.087850000 \\ \mathrm{H} & -6.342270000 & -0.283090000 & 0.241886000 \\ \mathrm{H} & -5.197320000 & 0.669605000 & 1.222733000 \\ \mathrm{H} & -5.336430000 & 0.979236000 & -0.519560000 \\ \mathrm{H} & 3.281842792 & 1.442241206 & -0.219812917\end{array}$

\section{$\left[\mathrm{ZnH}_{2} \underline{\underline{L}} \underline{1}^{+}\right.$}

12

Zn $\quad 0.000030000 \quad-0.870350000 \quad-0.000210000$

S $\quad 1.997178000 \quad-1.981870000 \quad 0.398596000$

$\begin{array}{llll}\text { C } & 3.023857000 & -0.575680000 & 0.063126000\end{array}$

$\mathrm{N} \quad 2.641265000 \quad 0.681820000 \quad-0.112950000$

$\mathrm{N} \quad 1.296115000 \quad 0.832216000 \quad-0.133430000$

$\begin{array}{llll}\text { C } & 0.742210000 & 2.003067000 & -0.019270000\end{array}$

$\begin{array}{llll}\text { C } & -0.742270000 & 2.003090000 & 0.019083000\end{array}$

$\mathrm{N} \quad-1.296220000 \quad 0.832229000 \quad 0.133053000$

$\mathrm{N} \quad-2.641330000 \quad 0.681803000 \quad 0.112941000$ 


\begin{tabular}{|c|c|c|c|}
\hline & -3.023840000 & -0.575820000 & -0.062950000 \\
\hline & -1.997210000 & -1.981990000 & -0.398090000 \\
\hline & 4.355707000 & -0.821760000 & 0.011951000 \\
\hline & 5.360703000 & 0.197081000 & -0.248710000 \\
\hline & 1.515928000 & 3.286912000 & 0.086744000 \\
\hline & -1.515820000 & 3.287109000 & -0.086270000 \\
\hline & -4.355720000 & -0.821830000 & -0.011720000 \\
\hline & -5.360710000 & 0.197241000 & 0.248053000 \\
\hline & 4.649104000 & -1.769440000 & 0.197753000 \\
\hline F & -4.649210000 & -1.769530000 & -0.197320000 \\
\hline & 6.342172000 & -0.283450000 & -0.243230000 \\
\hline & 5.337203000 & 0.979190000 & 0.518822000 \\
\hline & 5.196615000 & 0.669314000 & -1.223320000 \\
\hline & 2.573561000 & 3.100014000 & -0.103270000 \\
\hline & 1.415536000 & 3.723176000 & 1.090138000 \\
\hline & 1.146011000 & 4.031842000 & -0.627510000 \\
\hline $\mathrm{H}$ & -2.574120000 & 3.099479000 & 0.099275000 \\
\hline & -1.148810000 & 4.029876000 & 0.631789000 \\
\hline $\mathrm{H}$ & -1.411500000 & 3.726523000 & -1.087850000 \\
\hline F & -6.342270000 & -0.283090000 & 0.241886000 \\
\hline H & -5.197320000 & 0.669605000 & 1.222733000 \\
\hline & -5.336430000 & 0.979236000 & -0.51956000 \\
\hline
\end{tabular}




$\begin{array}{llll}\mathrm{H} & 3.281842792 & 1.442241206 & -0.219812917 \\ \mathrm{H} & -3.281933702 & 1.442187461 & 0.219910007\end{array}$

Protonation of $\underline{\mathrm{ZnL}^{1}}$ at $\underline{\text { sulfur }}$

\begin{tabular}{|c|c|c|c|}
\hline 30 & 0.000030000 & -0.870350000 & -0.000210000 \\
\hline 6 & 1.997178000 & -1.981870000 & 0.398596000 \\
\hline & 3.023857000 & -0.575680000 & 0.063126000 \\
\hline & 2.641265000 & 0.681820000 & -0.112950000 \\
\hline & 1.296115000 & 0.832216000 & -0.133430000 \\
\hline & 0.742210000 & 2.003067000 & -0.019270000 \\
\hline 6 & -0.742270000 & 2.003090000 & 0.019083000 \\
\hline 7 & -1.296220000 & 0.832229000 & 0.133053000 \\
\hline & -2.641330000 & 0.681803000 & 0.112941000 \\
\hline 6 & -3.023840000 & -0.575820000 & -0.062950000 \\
\hline 6 & -1.997210000 & -1.981990000 & -0.398090000 \\
\hline 7 & 4.355707000 & -0.821760000 & 0.011951000 \\
\hline 6 & 5.360703000 & 0.197081000 & -0.248710000 \\
\hline 6 & 1.515928000 & 3.286912000 & 0.086744000 \\
\hline 6 & -1.515820000 & 3.287109000 & -0.086270000 \\
\hline 7 & -4.355720000 & -0.821830000 & -0.011720000 \\
\hline & -5.360710000 & 0.197241000 & 0.248053000 \\
\hline & 4.649104000 & -1.769440000 & 0.197753000 \\
\hline
\end{tabular}




$\begin{array}{llll}1 & -4.649210000 & -1.769530000 & -0.197320000 \\ 1 & 6.342172000 & -0.283450000 & -0.243230000 \\ 1 & 5.337203000 & 0.979190000 & 0.518822000 \\ 1 & 5.196615000 & 0.669314000 & -1.223320000 \\ 1 & 2.573561000 & 3.100014000 & -0.103270000 \\ 1 & 1.415536000 & 3.723176000 & 1.090138000 \\ 1 & 1.146011000 & 4.031842000 & -0.627510000 \\ 1 & -2.574120000 & 3.099479000 & 0.099275000 \\ 1 & -1.148810000 & 4.029876000 & 0.631789000 \\ 1 & -1.411500000 & 3.726523000 & -1.087850000 \\ 1 & -6.342270000 & -0.283090000 & 0.241886000 \\ 1 & -5.197320000 & 0.669605000 & 1.222733000 \\ 1 & -5.336430000 & 0.979236000 & -0.519560000 \\ 1 & 2.274340046 & -3.233237278 & 0.753787688\end{array}$

$\underline{\text { Protonation at }} \underline{\text { Amine Nitrogen }}$

$\begin{array}{llll}11 & & & \\ \text { Zn } & 0.000030000 & -0.870350000 & -0.000210000 \\ \text { S } & 1.997178000 & -1.981870000 & 0.398596000 \\ \text { C } & 3.023857000 & -0.575680000 & 0.063126000 \\ \text { N } & 2.641265000 & 0.681820000 & -0.112950000 \\ \text { N } & 1.296115000 & 0.832216000 & -0.133430000 \\ \text { C } & 0.742210000 & 2.003067000 & -0.019270000\end{array}$




\begin{tabular}{|c|c|c|c|}
\hline & -0.742270000 & 2.003090000 & 0.019083000 \\
\hline & 0000 & 0.832229000 & 0.13305300 \\
\hline & 0000 & 3000 & .112941000 \\
\hline & .023840000 & -0.575 & 5000 \\
\hline & .997210000 & -1.981 & .398090000 \\
\hline & 4.355707000 & -0.821760000 & 1000 \\
\hline & 5.360703000 & 0.197081000 & 10000 \\
\hline & 1.515928000 & 3.286 & 4000 \\
\hline & 1.515820000 & 09000 & -0.08 \\
\hline & -4.355720000 & 30000 & -0.01172000 \\
\hline & 000 & 1000 & 53000 \\
\hline & 4.649104000 & -1.769440000 & 0.197753000 \\
\hline & -4.649210000 & -1.769530000 & 32000 \\
\hline & 6.34217 & -0.283 & -0.2 \\
\hline & 5.337203000 & 0.979190000 & 0.518822000 \\
\hline & 5.196615000 & 0.669314000 & -1.22 \\
\hline & 000 & 3.100014000 & -0.103270000 \\
\hline & 415536000 & 3.723176000 & 1.09013800 \\
\hline $\mathrm{H}$ & 146011000 & 4.031842000 & -0.627510000 \\
\hline & .574120000 & 3.099479000 & 0.09927500 \\
\hline 11 & -1.148810000 & 4.029876000 & 0.631789000 \\
\hline & -1.411500000 & 3.726523000 & -1.08785000 \\
\hline & 000 & 000 & 0.241886 \\
\hline
\end{tabular}




$\begin{array}{llll}\mathrm{H} & -5.197320000 & 0.669605000 & 1.222733000 \\ \mathrm{H} & -5.336430000 & 0.979236000 & -0.519560000 \\ \mathrm{H} & 4.370833470 & -0.021327902 & -0.587281548\end{array}$

Protonation on Zinc

11

Zn $\quad 0.000030000 \quad-0.870350000 \quad-0.000210000$

S $\quad 1.997178000 \quad-1.981870000 \quad 0.398596000$

$\begin{array}{llll}\text { C } & 3.023857000 & -0.575680000 & 0.063126000\end{array}$

$\mathrm{N} \quad 2.641265000 \quad 0.681820000 \quad-0.112950000$

$\mathrm{N} \quad 1.296115000 \quad 0.832216000 \quad-0.133430000$

$\begin{array}{llll}\text { C } & 0.742210000 & 2.003067000 & -0.019270000\end{array}$

$\begin{array}{llll}\text { C } & -0.742270000 & 2.003090000 & 0.019083000\end{array}$

$\mathrm{N} \quad-1.296220000 \quad 0.832229000 \quad 0.133053000$

$\mathrm{N} \quad-2.641330000 \quad 0.681803000 \quad 0.112941000$

$\begin{array}{llll}\text { C } & -3.023840000 & -0.575820000 & -0.062950000\end{array}$

S $\quad-1.997210000 \quad-1.981990000 \quad-0.398090000$

$\mathrm{N} \quad 4.355707000 \quad-0.821760000 \quad 0.011951000$

$\begin{array}{llll}\text { C } & 5.360703000 & 0.197081000 & -0.248710000\end{array}$

C $\quad 1.515928000 \quad 3.286912000 \quad 0.086744000$

$\begin{array}{llll}\text { C } & -1.515820000 & 3.287109000 & -0.086270000\end{array}$

$\mathrm{N} \quad-4.355720000 \quad-0.821830000 \quad-0.011720000$

C $\quad-5.360710000 \quad 0.197241000 \quad 0.248053000$ 


\begin{tabular}{|c|c|c|c|}
\hline $\mathrm{H}$ & 4.649104000 & -1.769440000 & 0.197753000 \\
\hline $\mathrm{H}$ & -4.649210000 & -1.769530000 & -0.197320000 \\
\hline $\mathrm{H}$ & 6.342172000 & -0.283450000 & -0.243230000 \\
\hline & 5.337203000 & 0.979190000 & 0.518822000 \\
\hline $\mathrm{F}$ & 5.196615000 & 0.669314000 & -1.223320000 \\
\hline $\mathrm{H}$ & 2.573561000 & 3.100014000 & -0.103270000 \\
\hline $\mathrm{H}$ & 1.415536000 & 3.723176000 & 1.090138000 \\
\hline $\mathrm{F}$ & 1.146011000 & 4.031842000 & -0.627510000 \\
\hline $\mathrm{H}$ & -2.574120000 & 3.099479000 & 0.099275000 \\
\hline $\mathrm{H}$ & -1.148810000 & 4.029876000 & 0.631789000 \\
\hline $\mathrm{H}$ & -1.411500000 & 3.726523000 & -1.087850000 \\
\hline $\mathrm{H}$ & -6.342270000 & -0.283090000 & 0.241886000 \\
\hline $\mathrm{H}$ & -5.197320000 & 0.669605000 & 1.222733000 \\
\hline $\mathrm{H}$ & -5.336430000 & 0.979236000 & -0.519560000 \\
\hline & 0.000293000 & -2.650349596 & -0.001380325 \\
\hline
\end{tabular}

Hydrogen

01

H $\quad 3.259348439 \quad 4.169555780 \quad-0.124845483$

H $\quad 3.259348439 \quad 4.169555780 \quad-0.864845483$ 
Table D8. Computational input coordinates for $\mathrm{ReL}_{3}$ and related compounds.

\section{$\underline{\mathrm{ReL}}_{3}$}

01

Re $\quad 0.001887000 \quad 0.522349000 \quad-0.151905000$

S $\quad-0.053024000 \quad 0.170602000 \quad-2.464628000$

S $\quad-0.168218000 \quad 2.947928000 \quad-0.676510000$

S $\quad 0.235228000 \quad 0.982632000 \quad 2.249003000$

P $\quad 0.064739000 \quad-1.839301000 \quad 0.025067000$

$\mathrm{P} \quad-2.439968000 \quad 0.764165000 \quad 0.031527000$

$\begin{array}{llll}\mathrm{P} & 2.429160000 & 0.825934000 & -0.104875000\end{array}$

C $\quad-0.301468000 \quad-1.577539000 \quad-2.716189000$

C $\quad-0.556521000 \quad-2.025037000 \quad-4.018084000$

$\mathrm{H} \quad-0.575283000 \quad-1.302804000 \quad-4.834265000$

C $\quad-0.803553000 \quad-3.369352000 \quad-4.258760000$

$\mathrm{H} \quad-1.010875000 \quad-3.707084000 \quad-5.272736000$

C $\quad-0.795043000 \quad-4.284222000 \quad-3.206110000$

H $\quad-0.995787000 \quad-5.337287000 \quad-3.392194000$

C $\quad-0.526709000 \quad-3.844709000 \quad-1.915438000$

$\mathrm{H} \quad-0.526242000 \quad-4.559284000 \quad-1.091063000$

C $\quad-0.270658000 \quad-2.494077000 \quad-1.656259000$

C $\quad 1.613029000 \quad-2.687870000 \quad 0.573505000$

$\begin{array}{llll}\text { C } & 2.238949000 & -3.691270000 & -0.169394000\end{array}$

$\mathrm{H} \quad 1.855648000 \quad-3.967596000 \quad-1.150047000$

C $\quad 3.367705000 \quad-4.339723000 \quad 0.324353000$

H $\quad 3.841212000 \quad-5.117524000 \quad-0.272559000$

C $\quad 3.893235000 \quad-3.997206000 \quad 1.565189000$ 


\begin{tabular}{lrrr}
$\mathrm{H}$ & 4.771049000 & -4.513236000 & 1.950104000 \\
$\mathrm{C}$ & 3.298881000 & -2.977879000 & 2.302993000 \\
$\mathrm{H}$ & 3.711237000 & -2.678761000 & 3.266054000 \\
$\mathrm{C}$ & 2.176162000 & -2.327649000 & 1.805212000 \\
$\mathrm{H}$ & 1.745128000 & -1.514887000 & 2.389742000 \\
$\mathrm{C}$ & -1.179490000 & -2.731939000 & 1.074363000 \\
$\mathrm{C}$ & -0.932203000 & -2.986628000 & 2.430355000 \\
$\mathrm{H}$ & 0.039883000 & -2.762528000 & 2.865459000 \\
$\mathrm{C}$ & -1.899778000 & -3.577639000 & 3.236756000 \\
$\mathrm{H}$ & -1.677885000 & -3.777433000 & 4.283962000 \\
$\mathrm{C}$ & -3.134379000 & -3.934001000 & 2.702217000 \\
$\mathrm{H}$ & -3.887891000 & -4.407141000 & 3.329047000 \\
$\mathrm{C}$ & -3.389557000 & -3.696825000 & 1.356096000 \\
$\mathrm{H}$ & -4.346479000 & -3.978451000 & 0.919431000 \\
$\mathrm{C}$ & -2.425280000 & -3.096296000 & 0.550612000 \\
$\mathrm{H}$ & -2.650255000 & -2.922079000 & -0.500889000 \\
$\mathrm{C}$ & -1.904631000 & 3.298883000 & -1.047041000 \\
$\mathrm{C}$ & -2.211759000 & 4.526884000 & -1.627125000 \\
$\mathrm{H}$ & -1.415910000 & 5.237700000 & -1.845356000 \\
$\mathrm{C}$ & -3.535280000 & 4.826753000 & -1.928924000 \\
$\mathrm{H}$ & -3.782502000 & 5.784282000 & -2.382684000 \\
$\mathrm{C}$ & -4.537204000 & 3.897085000 & -1.663032000 \\
$\mathrm{H}$ & -5.572722000 & 4.127569000 & -1.905125000 \\
\hline & -4.217527000 & 2.667565000 & -1.099171000 \\
$\mathrm{H}$ & -5.004051000 & 1.939035000 & -0.901592000
\end{tabular}




\begin{tabular}{lrrr}
$\mathrm{C}$ & -2.892279000 & 2.352936000 & -0.784987000 \\
$\mathrm{C}$ & -2.971189000 & 1.040659000 & 1.764975000 \\
$\mathrm{C}$ & -3.173051000 & 2.327691000 & 2.270983000 \\
$\mathrm{H}$ & -3.152166000 & 3.190254000 & 1.604393000 \\
$\mathrm{C}$ & -3.406147000 & 2.517360000 & 3.630416000 \\
$\mathrm{H}$ & -3.562726000 & 3.523518000 & 4.014881000 \\
$\mathrm{C}$ & -3.444556000 & 1.428211000 & 4.494972000 \\
$\mathrm{H}$ & -3.629630000 & 1.581746000 & 5.556491000 \\
$\mathrm{C}$ & -3.251644000 & 0.141593000 & 3.997067000 \\
$\mathrm{H}$ & -3.288099000 & -0.721392000 & 4.660717000 \\
$\mathrm{C}$ & -3.008874000 & -0.050896000 & 2.642408000 \\
$\mathrm{H}$ & -2.847951000 & -1.058285000 & 2.260735000 \\
$\mathrm{C}$ & -3.693431000 & -0.360336000 & -0.694248000 \\
$\mathrm{C}$ & -4.824866000 & -0.790762000 & 0.001785000 \\
$\mathrm{H}$ & -4.993143000 & -0.471241000 & 1.029348000 \\
$\mathrm{C}$ & -5.741539000 & -1.641759000 & -0.610803000 \\
$\mathrm{H}$ & -6.620419000 & -1.971006000 & -0.058855000 \\
$\mathrm{C}$ & -5.535450000 & -2.069420000 & -1.918199000 \\
$\mathrm{H}$ & -6.249257000 & -2.741712000 & -2.390573000 \\
$\mathrm{C}$ & -4.422751000 & -1.621240000 & -2.627136000 \\
$\mathrm{H}$ & -4.266030000 & -1.935452000 & -3.657435000 \\
$\mathrm{C}$ & -3.511869000 & -0.764223000 & -2.022597000 \\
$\mathrm{H}$ & -2.650858000 & -0.406584000 & -2.586327000 \\
\hline & 1.993805000 & 1.035542000 & 2.661036000 \\
\hline
\end{tabular}




\begin{tabular}{|c|c|c|c|}
\hline I & 1.582001000 & 1.184349000 & 4.773014000 \\
\hline & 3.689518000 & 1.328199000 & 4.340708000 \\
\hline & .974222000 & 1.426527000 & 5.386205000 \\
\hline & 655948000 & 1.402548000 & 3.339346000 \\
\hline & .698742000 & 1.573337000 & 3.598264000 \\
\hline & 286999000 & 1.276995000 & 2.006891000 \\
\hline 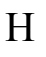 & 041755000 & 1.376832000 & 1.227325000 \\
\hline & 953554000 & 1.038507000 & 1.647089000 \\
\hline $\mathrm{C}$ & 3.554628000 & -0.421 & -0.863119000 \\
\hline 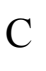 & .297504000 & -0.804 & -2.187684000 \\
\hline I & 2.422550000 & -0.416356000 & -2.70841200 \\
\hline C & 4.135443000 & -1.695966000 & -2.847752000 \\
\hline $\mathrm{H}$ & 3.917255000 & -1.971348000 & -3.87807600 \\
\hline $\mathrm{C}$ & 5.238018000 & -2.234946000 & -2.193887000 \\
\hline $\mathrm{J}$ & 5.896651000 & -2.930855000 & -2.710072000 \\
\hline $\mathrm{C}$ & 5.480417000 & -1.892276000 & -0.868921000 \\
\hline $\mathrm{H}$ & 6.321967000 & -2.331009000 & -0.334982000 \\
\hline $\mathrm{C}$ & 4.647080000 & -0.995926000 & -0.207248000 \\
\hline $\mathrm{H}$ & 4.846659000 & -0.778804000 & 0.838883000 \\
\hline$C$ & 2.995063000 & 2.420758000 & -0.832613000 \\
\hline $\mathrm{C}$ & 3.238245000 & 2.536798000 & -2.204155000 \\
\hline $\mathrm{H}$ & 3.237226000 & 1.653785000 & -2.84076700 \\
\hline $\mathrm{C}$ & 3.492878000 & 3.780314000 & -2.771394000 \\
\hline $\mathrm{H}$ & 3.684891000 & 3.853136000 & -3.8401840 \\
\hline & 3.507567000 & 4.924266000 & -1.980002 \\
\hline
\end{tabular}




$\begin{array}{llll}\mathrm{H} & 3.707829000 & 5.895897000 & -2.427456000 \\ \mathrm{C} & 3.270966000 & 4.819435000 & -0.613479000 \\ \mathrm{H} & 3.290951000 & 5.707730000 & 0.015613000 \\ \mathrm{C} & 3.012520000 & 3.577085000 & -0.043616000 \\ \mathrm{H} & 2.824596000 & 3.513512000 & 1.029318000\end{array}$

\section{$\left[\mathrm{ReL}_{3}\right]^{-}$}

$-12$

Re $\quad 0.001887000 \quad 0.522349000 \quad-0.151905000$

S $\quad-0.053024000 \quad 0.170602000 \quad-2.464628000$

S $\quad-0.168218000 \quad 2.947928000 \quad-0.676510000$

S $\quad 0.235228000 \quad 0.982632000 \quad 2.249003000$

P $\quad 0.064739000 \quad-1.839301000 \quad 0.025067000$

$\begin{array}{llll}\mathrm{P} & -2.439968000 & 0.764165000 & 0.031527000\end{array}$

$\mathrm{P} \quad 2.429160000 \quad 0.825934000 \quad-0.104875000$

$\begin{array}{llll}\text { C } & -0.301468000 & -1.577539000 & -2.716189000\end{array}$

C $\quad-0.556521000 \quad-2.025037000 \quad-4.018084000$

H $\quad-0.575283000 \quad-1.302804000 \quad-4.834265000$

C $\quad-0.803553000 \quad-3.369352000 \quad-4.258760000$

H $\quad-1.010875000 \quad-3.707084000 \quad-5.272736000$

C $\quad-0.795043000 \quad-4.284222000 \quad-3.206110000$

H $\quad-0.995787000 \quad-5.337287000 \quad-3.392194000$

C $\quad-0.526709000 \quad-3.844709000 \quad-1.915438000$

$\mathrm{H} \quad-0.526242000 \quad-4.559284000 \quad-1.091063000$

$\begin{array}{llll}\text { C } & -0.270658000 & -2.494077000 & -1.656259000\end{array}$ 


\begin{tabular}{lrrr}
$\mathrm{C}$ & 1.613029000 & -2.687870000 & 0.573505000 \\
$\mathrm{C}$ & 2.238949000 & -3.691270000 & -0.169394000 \\
$\mathrm{H}$ & 1.855648000 & -3.967596000 & -1.150047000 \\
$\mathrm{C}$ & 3.367705000 & -4.339723000 & 0.324353000 \\
$\mathrm{H}$ & 3.841212000 & -5.117524000 & -0.272559000 \\
$\mathrm{C}$ & 3.893235000 & -3.997206000 & 1.565189000 \\
$\mathrm{H}$ & 4.771049000 & -4.513236000 & 1.950104000 \\
$\mathrm{C}$ & 3.298881000 & -2.977879000 & 2.302993000 \\
$\mathrm{H}$ & 3.711237000 & -2.678761000 & 3.266054000 \\
$\mathrm{C}$ & 2.176162000 & -2.327649000 & 1.805212000 \\
$\mathrm{H}$ & 1.745128000 & -1.514887000 & 2.389742000 \\
$\mathrm{C}$ & -1.179490000 & -2.731939000 & 1.074363000 \\
$\mathrm{C}$ & -0.932203000 & -2.986628000 & 2.430355000 \\
$\mathrm{H}$ & 0.039883000 & -2.762528000 & 2.865459000 \\
$\mathrm{C}$ & -1.899778000 & -3.577639000 & 3.236756000 \\
$\mathrm{H}$ & -1.677885000 & -3.777433000 & 4.283962000 \\
$\mathrm{C}$ & -3.134379000 & -3.934001000 & 2.702217000 \\
$\mathrm{H}$ & -3.887891000 & -4.407141000 & 3.329047000 \\
$\mathrm{C}$ & -3.389557000 & -3.696825000 & 1.356096000 \\
$\mathrm{H}$ & -4.346479000 & -3.978451000 & 0.919431000 \\
$\mathrm{C}$ & -2.425280000 & -3.096296000 & 0.550612000 \\
$\mathrm{H}$ & -2.650255000 & -2.922079000 & -0.500889000 \\
$\mathrm{C}$ & -1.904631000 & 3.298883000 & -1.047041000 \\
\hline & -2.211759000 & 4.526884000 & -1.627125000 \\
$\mathrm{H}$ & -1.415910000 & 5.237700000 & -1.845356000
\end{tabular}




\begin{tabular}{lrrr}
$\mathrm{C}$ & -3.535280000 & 4.826753000 & -1.928924000 \\
$\mathrm{H}$ & -3.782502000 & 5.784282000 & -2.382684000 \\
$\mathrm{C}$ & -4.537204000 & 3.897085000 & -1.663032000 \\
$\mathrm{H}$ & -5.572722000 & 4.127569000 & -1.905125000 \\
$\mathrm{C}$ & -4.217527000 & 2.667565000 & -1.099171000 \\
$\mathrm{H}$ & -5.004051000 & 1.939035000 & -0.901592000 \\
$\mathrm{C}$ & -2.892279000 & 2.352936000 & -0.784987000 \\
$\mathrm{C}$ & -2.971189000 & 1.040659000 & 1.764975000 \\
$\mathrm{C}$ & -3.173051000 & 2.327691000 & 2.270983000 \\
$\mathrm{H}$ & -3.152166000 & 3.190254000 & 1.604393000 \\
$\mathrm{C}$ & -3.406147000 & 2.517360000 & 3.630416000 \\
$\mathrm{H}$ & -3.562726000 & 3.523518000 & 4.014881000 \\
$\mathrm{C}$ & -3.444556000 & 1.428211000 & 4.494972000 \\
$\mathrm{H}$ & -3.629630000 & 1.581746000 & 5.556491000 \\
$\mathrm{C}$ & -3.251644000 & 0.141593000 & 3.997067000 \\
$\mathrm{H}$ & -3.288099000 & -0.721392000 & 4.660717000 \\
$\mathrm{C}$ & -3.008874000 & -0.050896000 & 2.642408000 \\
$\mathrm{H}$ & -2.847951000 & -1.058285000 & 2.260735000 \\
$\mathrm{C}$ & -3.693431000 & -0.360336000 & -0.694248000 \\
$\mathrm{C}$ & -4.8248660000 & -0.790762000 & 0.001785000 \\
$\mathrm{H}$ & -4.993143000 & -0.471241000 & 1.029348000 \\
$\mathrm{C}$ & -5.741539000 & -1.641759000 & -0.610803000 \\
$\mathrm{H}$ & -6.620419000 & -1.971006000 & -0.058855000 \\
\hline & -5.535450000 & -2.069420000 & -1.918199000 \\
$\mathrm{H}$ & -6.249257000 & -2.741712000 & -2.390573000
\end{tabular}




\begin{tabular}{|c|c|c|c|}
\hline $\mathrm{C}$ & -4.422751000 & -1.621240000 & -2.627136000 \\
\hline & -4.266030000 & -1.935452000 & -3.65743500 \\
\hline & -3.511869000 & -0.764223000 & -2.022597000 \\
\hline & -2.650858000 & -0.406584000 & -2.58632700 \\
\hline & 1.993805000 & 1.035542000 & 2.661036000 \\
\hline & 2.351666000 & 1.1763 & 4.001720000 \\
\hline & 1.582001000 & 1.184349000 & 4.773014000 \\
\hline & 3.689518000 & 1.328199000 & 4.340 \\
\hline & 3.974222000 & 1.426527000 & 5.386205000 \\
\hline & 4.655948000 & 1.402 & 3.33 \\
\hline & 5.698742000 & 1.573337000 & 3.598264000 \\
\hline & 4.286999000 & 1.276 & 2.006 \\
\hline & 5.041755000 & 1.376832000 & 1.227325000 \\
\hline & 2.953554000 & 1.038507000 & 1.647089000 \\
\hline & 3.554628000 & -0.421 & -0.863 \\
\hline C & 3.297504000 & -0.804214000 & -2.187684000 \\
\hline $\mathrm{H}$ & 2.422550000 & -0.416356000 & -2.708412000 \\
\hline $\mathrm{C}$ & 4.135443000 & -1.695966000 & -2.847752000 \\
\hline $\mathrm{H}$ & 3.917255000 & -1.971348000 & -3.878076000 \\
\hline $\mathrm{C}$ & 5.238018000 & -2.234946000 & -2.193887000 \\
\hline $\mathrm{H}$ & 5.896651000 & -2.930855000 & -2.710072000 \\
\hline $\mathrm{C}$ & 5.480417000 & -1.892276000 & -0.86892100 \\
\hline $\mathrm{H}$ & 6.321967000 & -2.331009000 & -0.334982000 \\
\hline $\mathrm{C}$ & 4.647080000 & -0.995926000 & -0.20724800 \\
\hline & 4.846659000 & -0.778804000 & 388830 \\
\hline
\end{tabular}




$\begin{array}{llll}\text { C } & 2.995063000 & 2.420758000 & -0.832613000 \\ \text { C } & 3.238245000 & 2.536798000 & -2.204155000 \\ \text { H } & 3.237226000 & 1.653785000 & -2.840767000 \\ \text { C } & 3.492878000 & 3.780314000 & -2.771394000 \\ \text { H } & 3.684891000 & 3.853136000 & -3.840184000 \\ \text { C } & 3.507567000 & 4.924266000 & -1.980002000 \\ \text { H } & 3.707829000 & 5.895897000 & -2.427456000 \\ \text { C } & 3.270966000 & 4.819435000 & -0.613479000 \\ \text { H } & 3.290951000 & 5.707730000 & 0.015613000 \\ \text { C } & 3.012520000 & 3.577085000 & -0.043616000 \\ \text { H } & 2.824596000 & 3.513512000 & 1.029318000\end{array}$

\section{$\left[\operatorname{Re}(\mathrm{LH}) \mathrm{L}_{2}\right]^{+}$}

11

Re $\quad 0.001887000 \quad 0.522349000 \quad-0.151905000$

S $\quad-0.053024000 \quad 0.170602000 \quad-2.464628000$

S $\quad-0.168218000 \quad 2.947928000 \quad-0.676510000$

S $\quad 0.235228000 \quad 0.982632000 \quad 2.249003000$

$\begin{array}{llll}\mathrm{P} & 0.064739000 & -1.839301000 & 0.025067000\end{array}$

$\begin{array}{llll}\mathrm{P} & -2.439968000 & 0.764165000 & 0.031527000\end{array}$

$\begin{array}{llll}\mathrm{P} & 2.429160000 & 0.825934000 & -0.104875000\end{array}$

C $\quad-0.301468000 \quad-1.577539000 \quad-2.716189000$

C $\quad-0.556521000 \quad-2.025037000 \quad-4.018084000$

$\mathrm{H} \quad-0.575283000 \quad-1.302804000 \quad-4.834265000$

C $\quad-0.803553000 \quad-3.369352000 \quad-4.258760000$ 


\begin{tabular}{|c|c|c|c|}
\hline & -1.010875000 & -3.707084000 & -5.27273600 \\
\hline & -0.795043000 & -4.284222000 & -3.206110000 \\
\hline & 0.995787000 & -5.337287000 & .39219400 \\
\hline & .526709000 & -3.844709000 & -1.915438000 \\
\hline & -0.526242000 & -4.559284000 & -1.091063000 \\
\hline & -0.270658000 & -2.494077000 & -1.656259000 \\
\hline & 1.613029000 & -2.687870000 & 0.573505000 \\
\hline & 2.238949000 & -3.691270000 & -0.169394000 \\
\hline & 1.855648000 & -3.967596000 & -1.150047000 \\
\hline & 3.367705000 & -4.339723000 & 0.324353000 \\
\hline & 3.841212000 & -5.117524000 & -0.272559000 \\
\hline & 3.893235000 & -3.997206000 & 1.565189000 \\
\hline & 4.771049000 & -4.513 & 1.950 \\
\hline & 3.298881000 & -2.977879000 & 2.302993000 \\
\hline & 3.711237000 & -2.678761000 & 3.266054000 \\
\hline & 2.176162000 & -2.327649000 & 1.805212000 \\
\hline & 1.745128000 & -1.514887000 & 2.389 \\
\hline & -1.179490000 & -2.731939000 & 1.074363000 \\
\hline & -0.932203000 & -2.986628000 & 2.430355000 \\
\hline & 0.039883000 & -2.762528000 & 2.865459000 \\
\hline & -1.899 & -3.577 & 3.236756000 \\
\hline & -1.677885000 & -3.777433000 & 4.283962000 \\
\hline & -3.134379000 & -3.934001000 & 2.702217000 \\
\hline & -3.887891000 & -4.407141000 & 3.3290470 \\
\hline & .389557000 & -3.696825000 & 35609 \\
\hline
\end{tabular}




\begin{tabular}{lrrr}
$\mathrm{H}$ & -4.346479000 & -3.978451000 & 0.919431000 \\
$\mathrm{C}$ & -2.425280000 & -3.096296000 & 0.550612000 \\
$\mathrm{H}$ & -2.650255000 & -2.922079000 & -0.500889000 \\
$\mathrm{C}$ & -1.904631000 & 3.298883000 & -1.047041000 \\
$\mathrm{C}$ & -2.211759000 & 4.526884000 & -1.627125000 \\
$\mathrm{H}$ & -1.415910000 & 5.237700000 & -1.845356000 \\
$\mathrm{C}$ & -3.535280000 & 4.826753000 & -1.928924000 \\
$\mathrm{H}$ & -3.782502000 & 5.784282000 & -2.382684000 \\
$\mathrm{C}$ & -4.537204000 & 3.897085000 & -1.663032000 \\
$\mathrm{H}$ & -5.572722000 & 4.127569000 & -1.905125000 \\
$\mathrm{C}$ & -4.217527000 & 2.667565000 & -1.099171000 \\
$\mathrm{H}$ & -5.004051000 & 1.939035000 & -0.901592000 \\
$\mathrm{C}$ & -2.892279000 & 2.352936000 & -0.784987000 \\
$\mathrm{C}$ & -2.971189000 & 1.040659000 & 1.764975000 \\
$\mathrm{C}$ & -3.173051000 & 2.327691000 & 2.270983000 \\
$\mathrm{H}$ & -3.152166000 & 3.190254000 & 1.604393000 \\
$\mathrm{C}$ & -3.406147000 & 2.517360000 & 3.630416000 \\
$\mathrm{H}$ & -3.562726000 & 3.523518000 & 4.014881000 \\
$\mathrm{C}$ & -3.444556000 & 1.428211000 & 4.494972000 \\
$\mathrm{H}$ & -3.629630000 & 1.581746000 & 5.556491000 \\
$\mathrm{C}$ & -3.251644000 & 0.141593000 & 3.997067000 \\
$\mathrm{H}$ & -3.288099000 & -0.721392000 & 4.660717000 \\
$\mathrm{C}$ & -3.008874000 & -0.050896000 & 2.642408000 \\
\hline & -2.847951000 & -1.058285000 & 2.260735000 \\
$\mathrm{H}$ & -3.693431000 & -0.360336000 & -0.694248000
\end{tabular}




\begin{tabular}{lrrr}
$\mathrm{C}$ & -4.824866000 & -0.790762000 & 0.001785000 \\
$\mathrm{H}$ & -4.993143000 & -0.471241000 & 1.029348000 \\
$\mathrm{C}$ & -5.741539000 & -1.641759000 & -0.610803000 \\
$\mathrm{H}$ & -6.620419000 & -1.971006000 & -0.058855000 \\
$\mathrm{C}$ & -5.535450000 & -2.069420000 & -1.918199000 \\
$\mathrm{H}$ & -6.249257000 & -2.741712000 & -2.390573000 \\
$\mathrm{C}$ & -4.422751000 & -1.621240000 & -2.627136000 \\
$\mathrm{H}$ & -4.266030000 & -1.935452000 & -3.657435000 \\
$\mathrm{C}$ & -3.511869000 & -0.764223000 & -2.022597000 \\
$\mathrm{H}$ & -2.650858000 & -0.406584000 & -2.586327000 \\
$\mathrm{C}$ & 1.993805000 & 1.035542000 & 2.661036000 \\
$\mathrm{C}$ & 2.351666000 & 1.176395000 & 4.001720000 \\
$\mathrm{H}$ & 1.582001000 & 1.184349000 & 4.773014000 \\
$\mathrm{C}$ & 3.689518000 & 1.328199000 & 4.340708000 \\
$\mathrm{H}$ & 3.974222000 & 1.426527000 & 5.386205000 \\
$\mathrm{C}$ & 4.655948000 & 1.402548000 & 3.339346000 \\
$\mathrm{H}$ & 5.698742000 & 1.573337000 & 3.598264000 \\
$\mathrm{C}$ & 4.286999000 & 1.276995000 & 2.006891000 \\
$\mathrm{H}$ & 5.041755000 & 1.376832000 & 1.227325000 \\
$\mathrm{C}$ & 2.953554000 & 1.038507000 & 1.647089000 \\
$\mathrm{C}$ & 3.554628000 & -0.421858000 & -0.863119000 \\
$\mathrm{C}$ & 3.297504000 & -0.804214000 & -2.187684000 \\
$\mathrm{H}$ & 2.422550000 & -0.416356000 & -2.708412000 \\
$\mathrm{H}$ & 4.135443000 & -1.695966000 & -2.847752000 \\
\hline & 3.917255000 & -1.971348000 & -3.878076000
\end{tabular}




$\begin{array}{llll}\mathrm{C} & 5.238018000 & -2.234946000 & -2.193887000 \\ \mathrm{H} & 5.896651000 & -2.930855000 & -2.710072000 \\ \mathrm{C} & 5.480417000 & -1.892276000 & -0.868921000 \\ \mathrm{H} & 6.321967000 & -2.331009000 & -0.334982000 \\ \mathrm{C} & 4.647080000 & -0.995926000 & -0.207248000 \\ \mathrm{H} & 4.846659000 & -0.778804000 & 0.838883000 \\ \mathrm{C} & 2.995063000 & 2.420758000 & -0.832613000 \\ \mathrm{C} & 3.238245000 & 2.536798000 & -2.204155000 \\ \mathrm{H} & 3.237226000 & 1.653785000 & -2.840767000 \\ \mathrm{C} & 3.492878000 & 3.780314000 & -2.771394000 \\ \mathrm{H} & 3.684891000 & 3.853136000 & -3.840184000 \\ \mathrm{C} & 3.507567000 & 4.924266000 & -1.980002000 \\ \mathrm{H} & 3.707829000 & 5.895897000 & -2.427456000 \\ \mathrm{H} & 3.270966000 & 4.819435000 & -0.613479000 \\ \mathrm{H} & 3.290951000 & 5.707730000 & 0.015613000 \\ \mathrm{H} & 3.012520000 & 3.577085000 & -0.043616000 \\ \mathrm{H} & 2.824596000 & 3.513512000 & 1.029318000 \\ & -0.076380480 & 0.368482252 & 3.100003943\end{array}$

\section{$\left[\operatorname{Re}(\mathrm{LH}) \mathrm{L}_{2}\right]$}

02

Re $\quad 0.001887000 \quad 0.522349000 \quad-0.151905000$

S $\quad-0.053024000 \quad 0.170602000 \quad-2.464628000$

S $\quad-0.168218000 \quad 2.947928000 \quad-0.676510000$

S $\quad 0.235228000 \quad 0.982632000 \quad 2.249003000$ 


\begin{tabular}{llll}
$\mathrm{P}$ & 0.064739000 & -1.839301000 & 0.025067000 \\
$\mathrm{P}$ & -2.439968000 & 0.764165000 & 0.031527000 \\
$\mathrm{P}$ & 2.429160000 & 0.825934000 & -0.104875000 \\
$\mathrm{C}$ & -0.301468000 & -1.577539000 & -2.716189000 \\
$\mathrm{C}$ & -0.556521000 & -2.025037000 & -4.018084000 \\
$\mathrm{H}$ & -0.575283000 & -1.302804000 & -4.834265000 \\
$\mathrm{C}$ & -0.803553000 & -3.369352000 & -4.258760000 \\
$\mathrm{H}$ & -1.010875000 & -3.707084000 & -5.272736000 \\
$\mathrm{C}$ & -0.795043000 & -4.284222000 & -3.206110000 \\
$\mathrm{H}$ & -0.995787000 & -5.337287000 & -3.392194000 \\
$\mathrm{C}$ & -0.526709000 & -3.844709000 & -1.915438000 \\
$\mathrm{H}$ & -0.526242000 & -4.559284000 & -1.091063000 \\
$\mathrm{C}$ & -0.270658000 & -2.494077000 & -1.656259000 \\
$\mathrm{C}$ & 1.613029000 & -2.687870000 & 0.573505000 \\
$\mathrm{C}$ & 2.238949000 & -3.691270000 & -0.169394000 \\
$\mathrm{H}$ & 1.855648000 & -3.967596000 & -1.150047000 \\
$\mathrm{C}$ & 3.367705000 & -4.339723000 & 0.324353000 \\
$\mathrm{H}$ & 3.841212000 & -5.117524000 & -0.272559000 \\
$\mathrm{C}$ & 3.893235000 & -3.997206000 & 1.565189000 \\
$\mathrm{H}$ & 4.771049000 & -4.513236000 & 1.950104000 \\
$\mathrm{C}$ & 3.298881000 & -2.977879000 & 2.302993000 \\
$\mathrm{H}$ & 3.711237000 & -2.678761000 & 3.266054000 \\
$\mathrm{C}$ & 2.176162000 & -2.327649000 & 1.805212000 \\
\hline & -1.1745128000 & -1.514887000 & 2.389742000 \\
$\mathrm{H}$ & -2.731939000 & 1.074363000
\end{tabular}




\begin{tabular}{lrrr}
$\mathrm{C}$ & -0.932203000 & -2.986628000 & 2.430355000 \\
$\mathrm{H}$ & 0.039883000 & -2.762528000 & 2.865459000 \\
$\mathrm{C}$ & -1.899778000 & -3.577639000 & 3.236756000 \\
$\mathrm{H}$ & -1.677885000 & -3.777433000 & 4.283962000 \\
$\mathrm{C}$ & -3.134379000 & -3.934001000 & 2.702217000 \\
$\mathrm{H}$ & -3.887891000 & -4.407141000 & 3.329047000 \\
$\mathrm{C}$ & -3.389557000 & -3.696825000 & 1.356096000 \\
$\mathrm{H}$ & -4.346479000 & -3.978451000 & 0.919431000 \\
$\mathrm{C}$ & -2.425280000 & -3.096296000 & 0.550612000 \\
$\mathrm{H}$ & -2.650255000 & -2.922079000 & -0.500889000 \\
$\mathrm{C}$ & -1.904631000 & 3.298883000 & -1.047041000 \\
$\mathrm{C}$ & -2.211759000 & 4.526884000 & -1.627125000 \\
$\mathrm{H}$ & -1.415910000 & 5.237700000 & -1.845356000 \\
$\mathrm{C}$ & -3.535280000 & 4.826753000 & -1.928924000 \\
$\mathrm{H}$ & -3.782502000 & 5.784282000 & -2.382684000 \\
$\mathrm{C}$ & -4.537204000 & 3.897085000 & -1.663032000 \\
$\mathrm{H}$ & -5.572722000 & 4.127569000 & -1.905125000 \\
$\mathrm{C}$ & -4.217527000 & 2.667565000 & -1.099171000 \\
$\mathrm{H}$ & -5.004051000 & 1.939035000 & -0.901592000 \\
$\mathrm{C}$ & -2.892279000 & 2.352936000 & -0.784987000 \\
$\mathrm{C}$ & -2.971189000 & 1.040659000 & 1.764975000 \\
$\mathrm{C}$ & -3.173051000 & 2.327691000 & 2.270983000 \\
$\mathrm{H}$ & -3.152166000 & 3.190254000 & 1.604393000 \\
\hline & -3.406147000 & 2.517360000 & 3.630416000 \\
$\mathrm{H}$ & -3.562726000 & 3.523518000 & 4.014881000
\end{tabular}




\begin{tabular}{|c|c|c|c|}
\hline C & -3.444556000 & 1.428211000 & 4.494972000 \\
\hline & -3.629630000 & 1.581746000 & 5.556491000 \\
\hline & 3.251644000 & .141593000 & .997067000 \\
\hline & -3.288099000 & -0.721392000 & .660717000 \\
\hline & -3.008874000 & -0.050896000 & 2.642408000 \\
\hline & -2.847951000 & -1.05 & 5000 \\
\hline & -3.693431000 & -0.360 & 248000 \\
\hline & -4.824866000 & -0.790762000 & 0.001785000 \\
\hline $\mathrm{I}$ & -4.993143000 & -0.471241000 & 1.029348000 \\
\hline & -5.741539000 & -1.641759000 & -0.610803000 \\
\hline $\mathrm{H}$ & -6.620419000 & -1.971006000 & -0.05 \\
\hline C & -5.535450000 & -2.069420000 & -1.918199000 \\
\hline $\mathrm{H}$ & -6.249257000 & -2.741712000 & -2.3 \\
\hline C & -4.422751000 & -1.621240000 & -2.62713600 \\
\hline $\mathrm{H}$ & -4.266030000 & -1.935452000 & -3.657435000 \\
\hline & -3.511869000 & -0.764223000 & -2.02259700 \\
\hline $\mathrm{H}$ & -2.650858000 & -0.406584000 & -2.586327000 \\
\hline & 1.993805000 & 2000 & 2.661036000 \\
\hline C & 2.351666000 & 1.176395000 & 4.001720000 \\
\hline $\mathrm{H}$ & 1.582001000 & 1.184349000 & 4.773014000 \\
\hline $\mathrm{C}$ & 3.689518000 & 1.328199000 & 4.340708000 \\
\hline $\mathrm{H}$ & 3.974222000 & 1.426527000 & 5.386205000 \\
\hline C & 4.655948000 & 1.402548000 & 3.339346000 \\
\hline $\mathrm{H}$ & 5.698742000 & 1.573337000 & 3.598264000 \\
\hline & 4.286999000 & 1.276995000 & 2.006891000 \\
\hline
\end{tabular}




\begin{tabular}{|c|c|c|c|}
\hline I & 5.041755000 & 1.376832000 & 1.227325000 \\
\hline & .953554000 & 1.038507000 & 1.647089000 \\
\hline & 3.554628000 & -0.421858000 & -0.863119000 \\
\hline ( & 3.297504000 & -0.804214000 & -2.187684000 \\
\hline $\mathrm{F}$ & 2.422550000 & -0.416356000 & -2.70841200 \\
\hline C & 4.135443000 & -1.695966000 & -2.847752000 \\
\hline I & 3.917255000 & -1.971348000 & -3.87807600 \\
\hline & 5.238018000 & -2.234946000 & -2.193887000 \\
\hline I & 5.896651000 & -2.930855000 & -2.71007200 \\
\hline & 5.480417000 & -1.892276000 & -0.868921000 \\
\hline $\mathrm{F}$ & 6.321967000 & -2.331009000 & -0.334982000 \\
\hline C & 4.647080000 & -0.995926000 & -0.207248000 \\
\hline $\mathrm{I}$ & 4.846659000 & -0.77 & 0.8388 \\
\hline C & 2.995063000 & 2.420758000 & -0.832613000 \\
\hline $\mathrm{C}$ & 3.238245000 & 2.536798000 & -2.204155000 \\
\hline [ & 3.237226000 & 1.653785000 & -2.840767000 \\
\hline $\mathrm{C}$ & 3.492878000 & 3.780314000 & -2.771394000 \\
\hline $\mathrm{H}$ & 3.684891000 & 3.853136000 & -3.840184000 \\
\hline$r$ & 3.507567000 & 4.924266000 & -1.980002000 \\
\hline $\mathrm{H}$ & 3.707829000 & 5.895897000 & -2.427456000 \\
\hline C & 3.270966000 & 4.819435000 & -0.613479000 \\
\hline $\mathrm{H}$ & 3.290951000 & 5.707730000 & 0.015613000 \\
\hline $\mathrm{C}$ & 3.012520000 & 3.577085000 & -0.04361600 \\
\hline $\mathrm{H}$ & 2.824596000 & 3.513512000 & 1.02931800 \\
\hline & -0.076380480 & 0.368482252 & 3.1000039 \\
\hline
\end{tabular}




\section{$\left[\operatorname{Re}(\mathrm{LH})_{2} \underline{\underline{L}} \underline{]^{+}}\right.$}

12

$\begin{array}{llll}75 & 0.001887000 & 0.522349000 & -0.151905000\end{array}$

$\begin{array}{llll}16 & -0.053024000 & 0.170602000 & -2.464628000\end{array}$

$\begin{array}{llll}16 & -0.168218000 & 2.947928000 & -0.676510000\end{array}$

$\begin{array}{llll}16 & 0.235228000 & 0.982632000 & 2.249003000\end{array}$

$\begin{array}{llll}1 & -0.078752000 & -0.110550000 & 2.999021000\end{array}$

$\begin{array}{llll}15 & 0.064739000 & -1.839301000 & 0.025067000\end{array}$

$\begin{array}{llll}15 & -2.439968000 & 0.764165000 & 0.031527000\end{array}$

$\begin{array}{llll}15 & 2.429160000 & 0.825934000 & -0.104875000\end{array}$

$6 \quad-0.301468000 \quad-1.577539000 \quad-2.716189000$

$6 \quad-0.556521000 \quad-2.025037000 \quad-4.018084000$

$1 \quad-0.575283000 \quad-1.302804000 \quad-4.834265000$

$6 \quad-0.803553000 \quad-3.369352000 \quad-4.258760000$

$1 \quad-1.010875000 \quad-3.707084000 \quad-5.272736000$

$6 \quad-0.795043000 \quad-4.284222000 \quad-3.206110000$

$\begin{array}{llll}1 & -0.995787000 & -5.337287000 & -3.392194000\end{array}$

$6 \quad-0.526709000 \quad-3.844709000 \quad-1.915438000$

$1 \quad-0.526242000 \quad-4.559284000 \quad-1.091063000$

$6 \quad-0.270658000 \quad-2.494077000 \quad-1.656259000$

$6 \quad 1.613029000 \quad-2.687870000 \quad 0.573505000$

$\begin{array}{llll}6 & 2.238949000 & -3.691270000 & -0.169394000\end{array}$

$1 \quad 1.855648000 \quad-3.967596000 \quad-1.150047000$

$\begin{array}{llll}6 & 3.367705000 & -4.339723000 & 0.324353000\end{array}$

$1 \quad 3.841212000 \quad-5.117524000 \quad-0.272559000$ 


\begin{tabular}{|c|c|c|c|}
\hline & 3.893235000 & -3.997206000 & 1.56 \\
\hline 1 & 9000 & -4.513236000 & 1.950104000 \\
\hline ( & .298881000 & -2.977879000 & 302993000 \\
\hline 1 & 3.711237000 & -2.678761000 & 1000 \\
\hline 6 & 2.176162000 & -2.327649000 & 1.805212000 \\
\hline & .745128000 & -1.514887000 & 42000 \\
\hline ( & -1.179490000 & -2.7 & 363000 \\
\hline 6 & -0.932203000 & -2.986 & 5000 \\
\hline 1 & .039883000 & -2.762 & 2.86 \\
\hline 6 & -1.899778000 & -3.577639000 & 756000 \\
\hline 1 & -1.677885000 & -3.77 & 2000 \\
\hline 6 & -3.134379000 & -3.934001000 & 7000 \\
\hline 1 & -3.887891000 & -4.40 & 7000 \\
\hline 6 & -3.389557000 & -3.696825000 & 1.356096000 \\
\hline 1 & -4.346479000 & -3.9 & 1000 \\
\hline 6 & -2.425280000 & -3.096296000 & 0.550612000 \\
\hline 1 & -2.650255000 & -2.9 & -0.500889000 \\
\hline 6 & -1.904631000 & 883000 & 041000 \\
\hline 6 & -2.211759000 & 4.526884000 & -1.627125000 \\
\hline 1 & -1.415910000 & 700000 & -1.845356000 \\
\hline 6 & -3.535280000 & 4.826753000 & -1.928924000 \\
\hline 1 & -3.782502000 & 5.784282000 & -2.382684000 \\
\hline 6 & -4.537204000 & 3.897085000 & -1.663032000 \\
\hline 1 & -5.572722000 & 4.127569000 & -1.905125000 \\
\hline & -4.217527000 & 2.667565000 & -1.099171000 \\
\hline
\end{tabular}




\begin{tabular}{|c|c|c|c|}
\hline 1 & -5.004051000 & 1.939035000 & -0.9 \\
\hline 6 & -2.892279000 & 2.352936000 & -0.784987000 \\
\hline & -2.971189000 & 1.040659000 & 1.764975000 \\
\hline & -3.173051000 & 2.327691000 & 3000 \\
\hline & -3.152166000 & 3.190254000 & 1.604393000 \\
\hline & -3.406147000 & 2.517360000 & 6000 \\
\hline & -3.562726000 & 8000 & 4.01 \\
\hline & -3.44 & 1000 & 2000 \\
\hline & -3.62 & 6000 & 000 \\
\hline ( & -3.251644000 & 3000 & 7000 \\
\hline & -3.28 & 2000 & 7000 \\
\hline 6 & -3.008874000 & -0.050896000 & 2.642408000 \\
\hline 1 & -2.847951000 & -1.058285000 & 2.26 \\
\hline 6 & -3.693431000 & -0.360336000 & -0.694248000 \\
\hline 6 & 66000 & 2000 & 5000 \\
\hline & -4.993143000 & -0.471241000 & 1.029348000 \\
\hline 6 & -5.741539000 & -1.641759000 & -0.61 \\
\hline 1 & -6.620419000 & -1.971006000 & -0.05 \\
\hline 6 & -5.535450000 & -2.069420000 & -1.918199000 \\
\hline 1 & -6.249257000 & -2.741712000 & -2.390573000 \\
\hline 6 & -4.422751000 & -1.621240000 & -2.627136000 \\
\hline 1 & -4.266030000 & -1.935452000 & -3.657435000 \\
\hline 6 & -3.511869000 & -0.764223000 & -2.022597000 \\
\hline 1 & -2.650858000 & -0.406584000 & -2.586327000 \\
\hline & 1.993805000 & 1.035542000 & 2.661036000 \\
\hline
\end{tabular}




\begin{tabular}{|c|c|c|c|}
\hline & 2.351666000 & 1.176395000 & 4.001720000 \\
\hline 1 & 1.582001000 & 1.184349000 & 4.773014000 \\
\hline ( & 689518000 & 1.328 & 4.340708000 \\
\hline 1 & 974222000 & 1.426527000 & 5.386205000 \\
\hline ( & 655948000 & 1.402548000 & 3.339346000 \\
\hline 1 & 698742000 & 1.573337000 & 3.598264000 \\
\hline 6 & 4.286999000 & 1.276995000 & 2.006891000 \\
\hline 1 & .041755000 & 1.376832000 & 25000 \\
\hline ( & 2.953554000 & 1.038507000 & 1.647089000 \\
\hline 6 & .554628000 & 858000 & 19000 \\
\hline ( & 3.297504000 & -0.804214000 & -2.187684000 \\
\hline 1 & 2.422550000 & -0.416356000 & -2.708412000 \\
\hline ( & 4.135443000 & -1.695966000 & -2.847752000 \\
\hline 1 & 3.917255000 & -1.971348000 & -3.878076000 \\
\hline 6 & 5.238018000 & -2.234946000 & -2.193887000 \\
\hline 1 & 5.896651000 & -2.930855000 & -2.710072000 \\
\hline 6 & 5.480417000 & -1.892276000 & -0.868921000 \\
\hline 1 & 6.321967000 & -2.331009000 & -0.334982000 \\
\hline 6 & 4.647080000 & -0.995926000 & -0.207248000 \\
\hline 1 & 4.846659000 & -0.778804000 & 0.838883000 \\
\hline 6 & 2.995063000 & 2.420758000 & -0.832613000 \\
\hline 6 & 3.238245000 & 2.536798000 & -2.204155000 \\
\hline 1 & 3.237226000 & 1.653785000 & -2.840767000 \\
\hline 6 & 3.492878000 & 3.780314000 & -2.771394000 \\
\hline & 3.684891000 & 3.853136000 & -3.840184000 \\
\hline
\end{tabular}




$\begin{array}{llll}6 & 3.507567000 & 4.924266000 & -1.980002000 \\ 1 & 3.707829000 & 5.895897000 & -2.427456000 \\ 6 & 3.270966000 & 4.819435000 & -0.613479000 \\ 1 & 3.290951000 & 5.707730000 & 0.015613000 \\ 6 & 3.012520000 & 3.577085000 & -0.043616000 \\ 1 & 2.824596000 & 3.513512000 & 1.029318000 \\ 1 & -0.147353000 & 3.612050000 & 0.512809000\end{array}$

\section{$\left[\mathrm{HRe}(\mathrm{LH}) \mathrm{L}_{2}\right]$}

03

$\begin{array}{lrrr}75 & 0.613046000 & -0.028143000 & -0.554165000 \\ 16 & 1.509376000 & 0.802675000 & -2.566135000 \\ 16 & 0.147988000 & -2.071776000 & -1.710397000 \\ 16 & -0.724780000 & -0.508924000 & 1.563418000 \\ 1 & -1.712239000 & 0.390656000 & 1.246216000 \\ 15 & 0.560111000 & 2.372512000 & 0.087389000 \\ 15 & 2.648465000 & -1.385303000 & 0.127155000 \\ 15 & -3.661665000 & -0.171656000 & 0.060986000 \\ 6 & 1.857257000 & 2.532408000 & -2.349503000 \\ 6 & 2.547475000 & 3.191817000 & -3.373981000 \\ 1 & 2.865696000 & 2.629250000 & -4.250753000 \\ 6 & 2.815328000 & 4.549608000 & -3.271696000 \\ 1 & 3.352904000 & 5.051353000 & -4.074181000 \\ 6 & 2.400166000 & 5.274207000 & -2.153916000 \\ 1 & 2.610662000 & 6.338755000 & -2.080621000\end{array}$




\begin{tabular}{|c|c|c|c|}
\hline & 1.716334000 & 4.627726000 & -1.133806000 \\
\hline 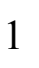 & 1.393934000 & 186111000 & -0.253934000 \\
\hline ( & .443197000 & 3.260470000 & -1.225362000 \\
\hline & .137220000 & .029009000 & 0.140161000 \\
\hline ( & 1.745276000 & 3.429659000 & -1.053411000 \\
\hline & -1.170935000 & 3.447951000 & -1.980277000 \\
\hline ( & -3.085609000 & 3.799088000 & -1.061159000 \\
\hline & -3.550008000 & 4.120690000 & 1260000 \\
\hline ( & -3.829211000 & 3.760795000 & 0.115215000 \\
\hline & -4.876874000 & 4.056810000 & 128000 \\
\hline ( & -3.236253000 & 3.341001000 & 1.302176000 \\
\hline 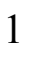 & -3.821816000 & 3.293 & 2.218672000 \\
\hline ( & -1.894222000 & 2.974866000 & 1.316673000 \\
\hline 1 & -1.436337000 & 2.658936000 & 2.255435000 \\
\hline ( & 1.378647000 & 2.867858000 & 1.640912000 \\
\hline 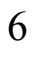 & 0.988296000 & 3.986068000 & 2.384923000 \\
\hline 1 & 0.118894000 & 4.570911000 & 2.085233000 \\
\hline 0 & 1.708437000 & 4.352939000 & 3.517465000 \\
\hline 1 & 1.398211000 & 5.221927000 & 4.094499000 \\
\hline 6 & 2.822477000 & 3.616653000 & 3.910959000 \\
\hline 1 & 3.380641000 & 3.908624000 & 4.798396000 \\
\hline 6 & 3.225787000 & 2.512273000 & 3.165457000 \\
\hline 1 & 4.103363000 & 1.936302000 & 3.456274000 \\
\hline 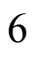 & 2.506551000 & 2.141660000 & 2.035946000 \\
\hline & 2.840800000 & 1.292421000 & 1.4389840 \\
\hline
\end{tabular}




\begin{tabular}{|c|c|c|c|}
\hline 6 & 1.697304000 & -2.911634000 & -1.941599000 \\
\hline 6 & 1.767715000 & -3.917176000 & -2.911609000 \\
\hline & .880382000 & -4.161338000 & -3.493597000 \\
\hline 6 & 967233000 & -4.579994000 & -3.141694000 \\
\hline & 3.014145000 & -5.350792000 & -3.908592000 \\
\hline 6 & 109770000 & -4.258939000 & -2.410792000 \\
\hline & 5.047469000 & -4.775736000 & -2.602730000 \\
\hline & 4.045983000 & -3.270893000 & -1.434006000 \\
\hline & 4.930008000 & -3.016204000 & -0.847520000 \\
\hline & 2.846148000 & -2.600429000 & -1.197511000 \\
\hline C & 2.397460000 & 1000 & 1.647628000 \\
\hline & 2.379728000 & -3.761344000 & 1.628476000 \\
\hline & 2.559103000 & 595000 & 0.696858000 \\
\hline 6 & 2.128201000 & -4.472060000 & 2.799948000 \\
\hline & 2.119488000 & -5.560114000 & 2.777815000 \\
\hline 6 & 1.894112000 & -3.795264000 & 3.992731000 \\
\hline 1 & 1.697891000 & -4.352811000 & 4.906492000 \\
\hline 6 & 1.907641000 & -2.401730000 & 4.017779000 \\
\hline 1 & 1.721901000 & -1.869684000 & 4.948701000 \\
\hline 6 & 2.151154000 & -1.688472000 & 2.850545000 \\
\hline 1 & 2.150705000 & -0.596396000 & 2.875573000 \\
\hline 6 & 4.252438000 & -0.542053000 & 0.338302000 \\
\hline 6 & 5.082839000 & -0.779982000 & 1.437997000 \\
\hline 1 & 4.806360000 & -1.522503000 & 2.185506000 \\
\hline & 6.271019000 & -0.067560000 & 1.578731000 \\
\hline
\end{tabular}




\begin{tabular}{|c|c|c|c|}
\hline 1 & 6.916764000 & -0.261996000 & 1000 \\
\hline & .632654000 & 0.883823000 & 0.630478000 \\
\hline & 7.559312000 & 1.442471000 & 0.746871000 \\
\hline & 5.812037000 & 1.117691000 & -0.470883000 \\
\hline & 6.094388000 & 1.858407000 & -1.216508000 \\
\hline & 4.625519000 & 0.411730000 & 470000 \\
\hline & 3.979571000 & 0.603643000 & -1.476649000 \\
\hline & 1.743669000 & -1.946869000 & 1.165949000 \\
\hline 6 & -1.219526000 & -3.180703000 & 0000 \\
\hline & -0.277429000 & 221000 & 6000 \\
\hline 6 & -1.905864000 & -4.340958000 & 1.209768000 \\
\hline & -1.495431000 & -5.30 & 3000 \\
\hline ( & -3.112180000 & -4.262130000 & 0.519532000 \\
\hline & -3.652879000 & -5.168581000 & 947000 \\
\hline 6 & -3.633373000 & -3.021031000 & 79000 \\
\hline & -4.582435000 & -2.964989000 & -0.358777000 \\
\hline 6 & -2.966386000 & -1.832084000 & 0.490458000 \\
\hline 6 & -5.090069000 & -0.049804000 & 1.204254000 \\
\hline 6 & -6.035621000 & 0.958116000 & 29000 \\
\hline 1 & -5.972808000 & 1.555234000 & 0.055654000 \\
\hline 6 & -7.068017000 & 1.187476000 & 1.867399000 \\
\hline 1 & -7.804854000 & 1.962087000 & 1.661112000 \\
\hline 6 & -7.161907000 & 0.427322000 & 3.031287000 \\
\hline & -7.968100000 & 0.608737000 & 3.739498000 \\
\hline & -6.222238000 & -0.565675000 & 3.28232600 \\
\hline
\end{tabular}




\begin{tabular}{llll}
1 & -6.291074000 & -1.166264000 & 4.187774000 \\
6 & -5.192722000 & -0.805119000 & 2.375510000 \\
1 & -4.469643000 & -1.593733000 & 2.583130000 \\
6 & -4.415928000 & -0.482302000 & -1.580422000 \\
6 & -5.719756000 & -0.955838000 & -1.764471000 \\
1 & -6.360007000 & -1.140413000 & -0.901583000 \\
6 & -6.207567000 & -1.185034000 & -3.046784000 \\
1 & -7.223706000 & -1.552334000 & -3.180285000 \\
6 & -5.399229000 & -0.949469000 & -4.155350000 \\
1 & -5.784947000 & -1.128779000 & -5.157341000 \\
6 & -4.101703000 & -0.477663000 & -3.981584000 \\
\hline 1 & -3.468495000 & -0.285935000 & -4.845931000 \\
6 & -3.614747000 & -0.236858000 & -2.701574000 \\
1 & -2.601680000 & 0.149116000 & -2.569878000 \\
\hline & -0.968072000 & 0.163467000 & -1.121573000
\end{tabular}

\section{$\left[\operatorname{Re}(\mathrm{LH})_{2} \underline{\mathrm{L}}\right]$}

$\begin{array}{llll}01 & & & \\ 75 & 0.001887000 & 0.522349000 & -0.151905000 \\ 16 & -0.053024000 & 0.170602000 & -2.464628000 \\ 16 & -0.168218000 & 2.947928000 & -0.676510000 \\ 16 & 0.235228000 & 0.982632000 & 2.249003000 \\ 1 & -0.078752000 & -0.110550000 & 2.999021000 \\ 15 & 0.064739000 & -1.839301000 & 0.025067000 \\ 15 & -2.439968000 & 0.764165000 & 0.031527000\end{array}$




\begin{tabular}{|c|c|c|c|}
\hline 5 & 2.429160000 & 0.825934000 & -0.104875000 \\
\hline & -0.301468000 & -1.577539000 & -2.716189000 \\
\hline & -0.556521000 & -2.025037000 & -4.018084000 \\
\hline & -0.575283000 & -1.302804000 & -4.834265000 \\
\hline & -0.803553000 & -3.369352000 & -4.258760000 \\
\hline & -1.010875000 & -3.707084000 & -5.272736000 \\
\hline & -0.795043000 & -4.284222000 & 110000 \\
\hline & -0.995787000 & -5.337287000 & -3.3 \\
\hline & -0.526709000 & -3.844709000 & -1.915438000 \\
\hline & -0.526242000 & -4.55 & -1.0 \\
\hline & -0.270658000 & -2.494077000 & -1.656259000 \\
\hline & 1.613029000 & -2.68 & 505000 \\
\hline & 2.238949000 & -3.691270000 & -0.169394000 \\
\hline & 1.855648000 & -3.967596000 & -1.150047000 \\
\hline & 3.367705000 & -4.339723000 & 0.324353000 \\
\hline & 3.841212000 & -5.117524000 & -0.272559000 \\
\hline & 3.893235000 & -3.997206000 & 1.565189000 \\
\hline & 4.771049000 & -4.513236000 & 1.950104000 \\
\hline & 3.298881000 & -2.977879000 & 2.302993000 \\
\hline & 3.711237000 & -2.678761000 & 3.266054000 \\
\hline & 2.176162000 & -2.327649000 & 1.805212000 \\
\hline & 1.745128000 & -1.514887000 & 2.389742000 \\
\hline & -1.179490000 & -2.731939000 & 1.07436300 \\
\hline & -0.932203000 & -2.986628000 & 2.43035500 \\
\hline & 0.039883000 & -2.762528000 & 2.86545900 \\
\hline
\end{tabular}




\begin{tabular}{|c|c|c|c|}
\hline 6 & -1.899778000 & -3.577639000 & 3.236756000 \\
\hline & -1.677885000 & -3.777433000 & 4.283962000 \\
\hline & -3.134379000 & -3.934001000 & 2.702217000 \\
\hline & -3.887891000 & -4.407141000 & 3.329047000 \\
\hline & -3.389557000 & -3.696825000 & 1.356096000 \\
\hline & -4.346479000 & -3.978451000 & 0.919431000 \\
\hline & -2.425280000 & -3.096296000 & 0.550612000 \\
\hline & -2.650255000 & -2.9220 & -0.500889000 \\
\hline & -1.904631000 & 3.298883000 & 41000 \\
\hline & 59000 & 4.5268 & -1.6 \\
\hline & -1.415910000 & 5.237700000 & -1.845356000 \\
\hline & 280000 & 4.826 & -1.92 \\
\hline & -3.782502000 & 5.784282000 & -2.382684000 \\
\hline & -4.537204000 & 3.897085000 & -1.663 \\
\hline & -5.572722000 & 4.1275 & -1.905125000 \\
\hline & -4.217527000 & 2.6675 & 71000 \\
\hline & -5.004051000 & 1.935 & -0.901592000 \\
\hline & -2.892279000 & 2.352936000 & -0.784987000 \\
\hline & -2.971189000 & 1.040659000 & 1.764975000 \\
\hline 6 & -3.173051000 & 2.327691000 & 2.270983000 \\
\hline 1 & -3.152166000 & 3.190254000 & 1.604393000 \\
\hline 6 & -3.406147000 & 2.517360000 & 3.630416000 \\
\hline 1 & -3.562726000 & 3.523518000 & 4.014881000 \\
\hline 6 & -3.444556000 & 1.428211000 & 4.494972000 \\
\hline & -3.629630000 & 1.581746000 & 6491 \\
\hline
\end{tabular}




\begin{tabular}{|c|c|c|c|}
\hline 6 & -3.251644000 & 0.141593000 & 3.997067000 \\
\hline & -3.288099000 & -0.721392000 & 4.660717000 \\
\hline & -3.008874000 & -0.050896000 & 2.642408000 \\
\hline & -2.847951000 & -1.058285000 & 2.260735000 \\
\hline & -3.693431000 & -0.360336000 & -0.694248000 \\
\hline & -4.824866000 & -0.790762000 & 0.001785000 \\
\hline & -4.993143000 & 41000 & 8000 \\
\hline & -5.741539000 & 59000 & -0.610 \\
\hline & -6.620419000 & 06000 & -0.05 \\
\hline & 450000 & 20000 & 000 \\
\hline & -6.249257000 & -2.741712000 & -2.39 \\
\hline & $-4.422^{\prime}$ & 240000 & -2.6 \\
\hline & -4.266030000 & 2000 & -3.65 \\
\hline & -3.511869000 & -0.764223000 & -2.02259700 \\
\hline & -2.650858000 & -0.406584000 & -2.5863 \\
\hline & 1.993805000 & 1.035542000 & 2.661036000 \\
\hline 6 & 2.351666000 & 1.176395000 & 4.001720000 \\
\hline & 1.582001000 & 1.184349000 & 4.773014000 \\
\hline 6 & 3.689518000 & 1.328199000 & 4.340708000 \\
\hline 1 & 3.974222000 & 1.426527000 & 5.386205000 \\
\hline 6 & 4.655948000 & 1.402548000 & 3.339346000 \\
\hline 1 & 5.698742000 & 1.573337000 & 3.598264000 \\
\hline 6 & 4.286999000 & 1.276995000 & 2.006891000 \\
\hline 1 & 5.041755000 & 1.376832000 & 1.22732500 \\
\hline & 953554000 & 1.038507000 & 1.64708900 \\
\hline
\end{tabular}




\begin{tabular}{|c|c|c|c|}
\hline 0 & 3.554628000 & -0.421858000 & -0.863119000 \\
\hline & 3.297504000 & -0.804214000 & -2.187684000 \\
\hline & 422550000 & -0.416356000 & -2.708412000 \\
\hline & .135443000 & -1.695966000 & -2.847752000 \\
\hline & 3.917255000 & -1.971348000 & -3.878076000 \\
\hline & 5.238018000 & -2.234946000 & -2.193887000 \\
\hline & 5.896651000 & -2.930855000 & -2.710072000 \\
\hline & 5.480417000 & -1.89 & 21000 \\
\hline & 6.321967000 & -2.331009000 & -0.334982000 \\
\hline & 4.647080000 & -0.995926000 & -0.207248000 \\
\hline & 4.846659000 & -0.778804000 & 0.838883000 \\
\hline & 2.995063000 & 2.420758000 & -0.832613000 \\
\hline & 3.238245000 & 2.536798000 & -2.204155000 \\
\hline & 3.237226000 & 1.653785000 & -2.840767000 \\
\hline & 3.492878000 & 3.780314000 & -2.771394000 \\
\hline & 3.684891000 & 3.853136000 & -3.840184000 \\
\hline & 3.507567000 & 4.924266000 & -1.980002000 \\
\hline & 3.707829000 & 5.895897000 & -2.427456000 \\
\hline & 3.270966000 & 4.819435000 & -0.613479000 \\
\hline 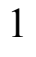 & 3.290951000 & 5.707730000 & 0.015613000 \\
\hline & 3.012520000 & 3.577085000 & -0.043616000 \\
\hline & 2.824596000 & 3.513512000 & 1.029318000 \\
\hline & -0.147353000 & 3.612050000 & 0.512809000 \\
\hline
\end{tabular}


Table D9. Computational input coordinates for $\mathrm{CuL}^{1}$ and related compounds. $\underline{\mathrm{CuL}^{1}}$

02

$\begin{array}{llll}\mathrm{Cu} & 1.431847450 & -0.488032580 & 0.446112510\end{array}$

S $\quad 2.332615610 \quad-0.119942340 \quad 2.552696700$

S $\quad 2.858402730 \quad-1.722415690 \quad-0.909505780$

$\mathrm{N} \quad-0.257435500 \quad 0.971116720 \quad 2.468152050$

$\mathrm{N} \quad-0.172027540 \quad 0.534274340 \quad 1.177021620$

$\mathrm{N} \quad 0.574079220 \quad-1.034389140 \quad-2.391256330$

$\mathrm{N} \quad 0.223704470 \quad-0.461096440 \quad-1.204115870$

C $\quad 0.866804360 \quad 0.696900310 \quad 3.160702940$

$\begin{array}{llll}\text { C } & -1.156654600 & 0.726779040 & 0.313291070\end{array}$

$\begin{array}{llll}\text { C } & 1.780157800 & -1.630949380 & -2.329823970\end{array}$

C $\quad-0.928456430 \quad 0.172470660 \quad-1.041194200$

$\begin{array}{llll}\text { C } & -2.430852170 & 1.445672040 & 0.707410510\end{array}$

$\begin{array}{llll}\text { C } & -1.949721220 & 0.325466600 & -2.151313540\end{array}$

$\mathrm{N} \quad 0.905903760 \quad 1.099112750 \quad 4.470338340$

$\begin{array}{llll}\mathrm{N} & 2.249331710 & -2.229486700 & -3.469048500\end{array}$

C $\quad 1.542073250 \quad-2.300940750 \quad-4.757663730$

C $\quad-0.256906930 \quad 1.621968390 \quad 5.210058210$

$\begin{array}{llll}\mathrm{H} & -0.736089590 & 2.427871470 & 4.633939270\end{array}$

$\begin{array}{llll}\mathrm{H} & 0.095862870 & 2.020878310 & 6.174487110\end{array}$

$\mathrm{H} \quad-1.009760380 \quad 0.833110030 \quad 5.396764760$

$\mathrm{H} \quad-3.052880760 \quad 1.693994160 \quad-0.164430810$

H $\quad-2.187359810 \quad 2.369822740 \quad 1.257044200$

$\begin{array}{llll}\mathrm{H} & -3.027972700 & 0.817502200 & 1.394048690\end{array}$ 


$\begin{array}{lrrr}\mathrm{H} & 2.232241150 & -2.034661770 & -5.577035900 \\ \mathrm{H} & 0.709065320 & -1.588742850 & -4.742827890 \\ \mathrm{H} & 1.143750430 & -3.316026930 & -4.940576080 \\ \mathrm{H} & -1.595749020 & -0.186808630 & -3.055724620 \\ \mathrm{H} & -2.117801900 & 1.390722990 & -2.392856600 \\ \mathrm{H} & -2.924379830 & -0.103170090 & -1.856998090 \\ \mathrm{H} & 1.714229460 & 0.779113230 & 5.003296850 \\ \mathrm{H} & 3.143979070 & -2.710111620 & -3.380991940\end{array}$

$\left[\mathrm{CuL}^{1} \mathrm{H}\right]^{+}$

$\begin{array}{lrrr}12 & & & \\ \mathrm{Cu} & 1.431847450 & -0.488032580 & 0.446112510 \\ \mathrm{~S} & 2.332615610 & -0.119942340 & 2.552696700 \\ \mathrm{~S} & 2.858402730 & -1.722415690 & -0.909505780 \\ \mathrm{~N} & -0.257435500 & 0.971116720 & 2.468152050 \\ \mathrm{~N} & -0.172027540 & 0.534274340 & 1.177021620 \\ \mathrm{~N} & 0.574079220 & -1.034389140 & -2.391256330 \\ \mathrm{~N} & 0.223704470 & -0.461096440 & -1.204115870 \\ \mathrm{C} & 0.866804360 & 0.696900310 & 3.160702940 \\ \mathrm{C} & -1.156654600 & 0.726779040 & 0.313291070 \\ \mathrm{C} & 1.780157800 & -1.630949380 & -2.329823970 \\ \mathrm{C} & -0.928456430 & 0.172470660 & -1.041194200 \\ \mathrm{C} & -2.430852170 & 1.445672040 & 0.707410510 \\ \mathrm{C} & -1.949721220 & 0.325466600 & -2.151313540 \\ \mathrm{~N} & 0.905903760 & 1.099112750 & 4.470338340\end{array}$




\begin{tabular}{|c|c|c|c|}
\hline & 2.249331710 & -2.229486700 & -3.469048500 \\
\hline & .542073250 & -2.300940750 & -4.757663730 \\
\hline & .256906930 & 1.621968390 & 5.210058210 \\
\hline & .736089590 & 2.427871470 & 9270 \\
\hline & 0.095862870 & 2.020878310 & 87110 \\
\hline & -1.009 & 0.833110030 & 64760 \\
\hline & -3.052880760 & 1.693 & -0.16 \\
\hline & -2.187359810 & 2.36 & 1.257044200 \\
\hline & -3.027972700 & 0.817502200 & 1.394048690 \\
\hline & 2.232241150 & -2.034661770 & 7035900 \\
\hline $\mathrm{H}$ & 0.709065320 & -1.588742850 & -4.742827890 \\
\hline $\mathrm{H}$ & 1.143750430 & -3.316026930 & -4.940576080 \\
\hline $\mathrm{I}$ & -1.595749020 & -0.186 & 5724620 \\
\hline $\mathrm{H}$ & -2.117801900 & 1.390722990 & -2.392856600 \\
\hline $\mathrm{H}$ & -2.924379830 & -0.103170090 & -1.856998090 \\
\hline $\mathrm{H}$ & 1.714229460 & 0.779113230 & 5.003296850 \\
\hline $\mathrm{H}$ & 3.143979070 & -2.710111620 & -3.380991940 \\
\hline & 0.002279216 & -1.014134076 & 113992 \\
\hline
\end{tabular}

\section{$\underline{\mathrm{CuL}^{1} \mathrm{H}}$}

01

$\mathrm{Cu} \quad 1.431847450 \quad-0.488032580 \quad 0.446112510$

S $\quad 2.332615610 \quad-0.119942340 \quad 2.552696700$

S $\quad 2.858402730 \quad-1.722415690 \quad-0.909505780$

$\mathrm{N} \quad-0.257435500 \quad 0.971116720 \quad 2.468152050$ 


\begin{tabular}{llll}
$\mathrm{N}$ & -0.172027540 & 0.534274340 & 1.177021620 \\
$\mathrm{~N}$ & 0.574079220 & -1.034389140 & -2.391256330 \\
$\mathrm{~N}$ & 0.223704470 & -0.461096440 & -1.204115870 \\
$\mathrm{C}$ & 0.866804360 & 0.696900310 & 3.160702940 \\
$\mathrm{C}$ & -1.156654600 & 0.726779040 & 0.313291070 \\
$\mathrm{C}$ & 1.780157800 & -1.630949380 & -2.329823970 \\
$\mathrm{C}$ & -0.928456430 & 0.172470660 & -1.041194200 \\
$\mathrm{C}$ & -2.430852170 & 1.445672040 & 0.707410510 \\
$\mathrm{C}$ & -1.949721220 & 0.325466600 & -2.151313540 \\
$\mathrm{~N}$ & 0.905903760 & 1.099112750 & 4.470338340 \\
$\mathrm{~N}$ & 2.249331710 & -2.229486700 & -3.469048500 \\
$\mathrm{C}$ & 1.542073250 & -2.300940750 & -4.757663730 \\
$\mathrm{C}$ & -0.256906930 & 1.621968390 & 5.210058210 \\
$\mathrm{H}$ & -0.736089590 & 2.427871470 & 4.633939270 \\
$\mathrm{H}$ & 0.095862870 & 2.020878310 & 6.174487110 \\
$\mathrm{H}$ & -1.009760380 & 0.833110030 & 5.396764760 \\
$\mathrm{H}$ & -3.052880760 & 1.693994160 & -0.164430810 \\
$\mathrm{H}$ & -2.187359810 & 2.369822740 & 1.257044200 \\
$\mathrm{H}$ & -3.027972700 & 0.817502200 & 1.394048690 \\
$\mathrm{H}$ & 2.232241150 & -2.034661770 & -5.577035900 \\
$\mathrm{H}$ & 0.709065320 & -1.588742850 & -4.742827890 \\
$\mathrm{H}$ & 1.143750430 & -3.316026930 & -4.940576080 \\
$\mathrm{H}$ & -1.595749020 & -0.186808630 & -3.055724620 \\
\hline & -2.117801900 & 1.390722990 & -2.392856600 \\
\hline
\end{tabular}


$\mathrm{H} \quad 1.714229460 \quad 0.779113230 \quad 5.003296850$

H $\quad 3.143979070 \quad-2.710111620 \quad-3.380991940$

H $\quad 0.002279216 \quad-1.014134076 \quad-3.211399298$ 


\section{CURRICULUM VITA}

Andrew Z. Haddad

University of Louisville I Department of Chemistry

2320 South Brook Street, Louisville, KY 40202

Tel. (502) 370-8358

DOB. 03/19/1990; Citizenship: United States

azhaddad1@gmail.com | andrew.haddad@,louisville.edu

\section{Education}

B.A., Chemistry

University of Louisville

2008-2012

M.S., Chemistry

University of Louisville

2012-2015

Ph.D., Chemistry

University of Louisville

2012-2017

\section{Honors and Awards}

- 2017: John Richard Binford Memorial Award

- 2017: Graduate Deans Citation Award

- 2017: Awarded ITRI-Rosenfeld Postdoctoral Fellowship at Lawrence Berkeley National Laboratory: research proposal on new technologies for desalination of brackish water using capacitive deionization.

- 2016: Awarded first place in the graduate student oral presentation category at the Kentucky Academy of Sciences Annual Meeting

- 2016: Awarded Council on Postsecondary Education Fellowship Award

- 2016: School Of Interdisciplinary Studies Tuition Award 
- 2016: Intellectual Property and Preliminary Patent's filed through the University of Louisville Patent Office, Co-Inventor. http://www.flintbox.com/public/project/29807/

- 2015: Winner of the Merck International Student Research Poster Presentation (Inorganic Division) Competition at the International Chemical Congress of Pacific Basin Societies (Pacifi-Chem) Conference. Honolulu, HI. December 2015

- 2014: Kentucky Science \& Engineering Research Grant \#148-502-15-350; Research (student) and Co-Author

- 2013: National Science Foundation Research Grant Funding Grant \#1361728; Research (student) and Co-Author

- 2011: Summer Research Opportunity Program (SROP), Selected Applicant, University of Louisville

- 2010: Univ. of Louisville STEM-UTA-Program: Undergraduate Teaching Assistantship Appointment (Instructed three classes per week or two labs per week each semester until graduation)

- 2008: University of Louisville Trustees Scholar (4yrs tuition and fees)

- 2007: Kentucky Governor's Scholars Program, participant and alum Major in International Relations; Minor in Integrated Mathematical Relationships

\section{Publications and Presentations}

1. Proposed Ligand-Centered Electrocatalytic Hydrogen Evolution and Hydrogen Oxidation at a Noninnocent Mononuclear Metal-Thiolate Andrew Z. Haddad, Davinder Kumar, Kagna Ouch Sampson, Anna M. Matzner, Mark S. Mashuta, and Craig A. Grapperhaus. Journal of the American Chemical Society 2015137 (29), 92389241.

DOI: $\underline{10.1021 / j a c s .5 b 05561}$

2. Beyond Metal-Hydrides: Non-Transition Metal and MetalFree Ligand-Centered Electrocatalytic Hydrogen Evolution and Hydrogen Oxidation

Andrew Z. Haddad, Brady D. Garabato, Pawel M. Kozlowski, Robert M. Buchanan, Craig A. Grapperhaus

Journal of the American Chemical Society 2016 138, 7844

DOI: $\underline{10.1021 / \mathrm{jacs} .6 \mathrm{~b} 04441}$

3. Compounds, Their Preparation, Related Compositions, Catalysts, Electrochemical Cells, Fuel Cells, and Uses Thereof Andrew Z. Haddad, Robert M. Buchanan, Craig A. Grapperhaus U.S. Provisional Patent Application No. 62/348,420. Filed: June 10,2016

ULRF 16082-02, http://www.flintbox.com/public/project/29807/ 
4. Materials, Compounds, Their Preparation, Related Compositions, Catalysts, Electrochemical Cells, Fuel Cells, and Uses Thereof Andrew Z. Haddad, Robert M. Buchanan, Craig A. Grapperhaus U.S. Provisional Patent Application No. 62/348,490. Filed: June 10,2016 ULRF 16082-02(P2), http://www.flintbox.com/public/project/29807/

5. Translation of Ligand-Centered HER Activity and Mechanism of a Rhenium-Thiolate from Solution to Modified Electrodes: A Combined Experimental and DFT Study

Andrew Z. Haddad, Wuyu Zhang, Brady D. Garabato, Pawel M. Kozlowski, Robert M. Buchanan, Craig A. Grapperhaus Inorganic Chemistry 201756 (4), pp 2177-2187

DOI: http://dx.doi.org/10.1021/acs.inorgchem.6b02829

6. Ligand-Centered Hydrogen Evolution upon Reduction of a Bis(thiosemicarbazonato) Cu(II) Complex Andrew Z. Haddad, Robert M. Buchanan, Craig A. Grapperhaus Journal of the American Chemical Society 2017 Submitted

1. American Chemical Society International Conference September 2013 Indianapolis, Indiana

- Presentation 1: Inorganic Chemistry: Homogeneous Ligand-Centered Proton Reduction (Presenter)

- Presentation 2: Invited Sci-Mixer: Homogeneous LigandCentered Proton Reduction (Presenter)

2. Gordon Research Conference: Inorganic Reaction Mechanisms

March 1-6, 2015 Galveston, Texas.

- Presentation: Homogeneous Ligand-Centered Hydrogen Evolution and Oxidation at a Mono-Nuclear Metal Thiolate. (Presenter)

3. Pacifi-Chem Research Conference

December 14-22, 2015 Honolulu Hawaii. 
- Presentation 1: Redox Active Ligands: Ligand-Centered Electrocatalytic Proton Reduction and Hydrogen Oxidation (Presenter; Winner Inorganic Division)

- Presentation 2: Synthesis, Characterization and Electrochemical Properties of New Tetra Coordinated $\mathrm{Ni}(\mathrm{ii})$ and $\mathrm{Zn}$ (ii) Complexes with New $\mathrm{P}_{2} \mathrm{~S}_{2}$ type Ligand Framework (Co-Author)

- Symposium Talk: Redox-active metal-thiolates: Ligandcentered Electrocatalytic Proton Reduction/Hydrogen Oxidation (Co-Author)

\section{Kentucky Academy of Sciences Annual Meeting}

November 4-5, 2016 Louisville, KY (University of Louisville)

- Talk: Homogeneous Ligand-Centered Electrocatalytic Hydrogen Evolution and Oxidation: Exploiting Redox NonInnocence to Drive Catalysis (Presenter; $1^{\text {st }}$ Place)

5. Lawrence Berkeley National Laboratory: Energy and Technology Area Guest Lecturer January 5, 2017 Berkeley, CA

- Talk: Ligand-Centered Electrocatalytic Hydrogen Evolution and Oxidation: Applying Water-Splitting for $L B N L$ 's Advanced CDI Technology (Presenter)

6. University of Louisville Graduate Research Conference: Three Minute Thesis Competition March 24, 2017 Louisville, KY

- Talk: Transition metal and Metal Free Hydrogen Production and Oxidation: A viable Path for the Future 